\title{
Festschrift
}

RUFUS H. GOUWS

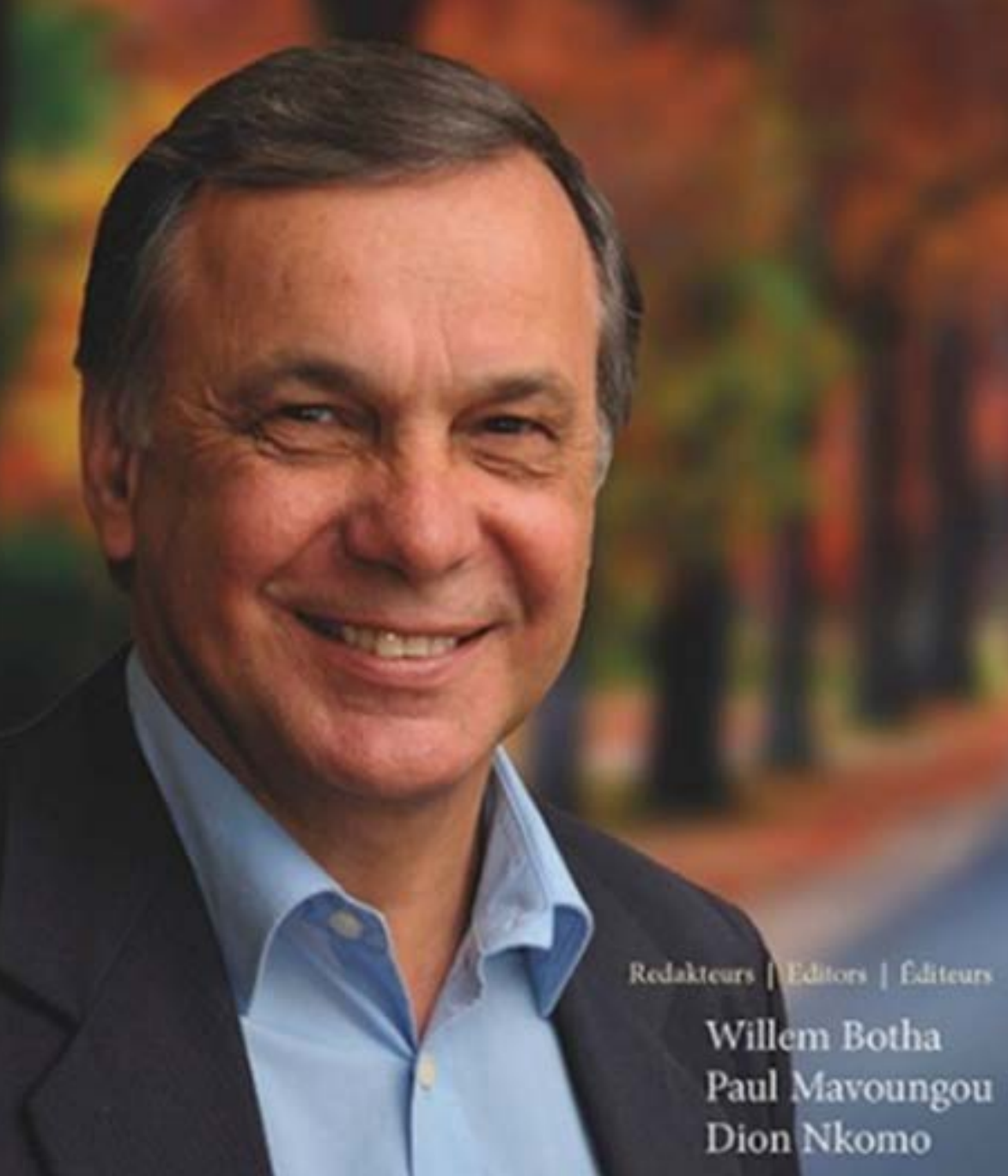




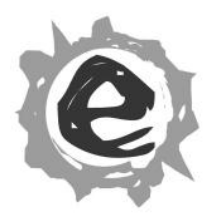





\section{Festschrift RUFUS H. GOUWS}

Redakteurs / Editors / Éditeurs

Willem Botha

Paul Mavoungou

Dion Nkomo 
Festschrift RUFUS H. GOUWS

Uitgewer / Publisher / Éditeur

SUN PReSS, SUN MeDIA Stellenbosch

Kopiereg @ 2013 deur die uitgewer

Copyright $\odot 2013$ by the publisher

Droits d'auteur (c) 2013 par l'éditeur

Alle regte streng voorbehou

All rights strictly reserved

Tous droits réservés strictement

ISBN: 978-1-920338-95-4

e-ISBN: 978-1-920338-97-8

DOI: $10.18820 / 9781920338978$

Eerste uitgawe / First edition / Première édition 2013

Geen gedeelte van hierdie publikasie mag sonder skriftelike verlof van die uitgewer gereproduseer of in enige vorm of deur enige elektroniese of meganiese middel weergegee word nie, hetsy deur fotokopiëring, plaat- of bandopname, mikroverfilming of enige ander stelsel van inligtingsbewaring

No part of this publication may be reproduced, stored in a retrieval system, or transmitted, in any form or by any means, including electronic, mechanical, photographic, magnetic or other means, without the prior written permission of the publisher

Aucune partie de cette publication ne peut être reproduite, stockée dans un système électronique d'extraction, ni transmise, sous quelque forme que ce soit ni par aucun autre moyen, y compris électronique, mécanique, photographique, magnétique ou autre, sans l'autorisation préalable écrite de l'éditeur

Menings wat in artikels uitgespreek word, is nie noodwendig dié van SUN PReSS nie Opinions expressed in the articles are not necessarily those of SUN PReSS

Les opinions exprimées dans les articles ne sont pas nécessairement celles de SUN PreSS

Fotograaf / Photographer / Photographe: Anton Jordaan

Omslag deur / Cover by / Couverture par Liezel Meintjes, SUN MeDIA Stellenbosch

Tipografie en uitleg deur / Typography and layout by / Typographie et mise en page par Tanja Harteveld \& Hermien van der Westhuizen, WAT

Geset in 10 op 12 pt Palatino

Typeset in 10 on 12 pt Palatino

Saisi en 10 sur 12 pt Palatino

Gedruk en gebind deur / Printed and bound by / Imprimé et relié par

SUN MeDIA Stellenbosch, Office 5, The Woodmill, Vredenburg Road, Stellenbosch

www.africansunmedia.co.za

www.sun-e-shop.co.za 


\section{Peer review}

The publisher wishes to acknowledge the peer reviewers and thank them for their valuable contribution to this publication:

- $\quad$ Prof. Elsabé Taljard, University of Pretoria

- Prof. Danie J. Prinsloo, University of Pretoria

- Prof. Justus C. Roux, North-West University, Potchefstroom Campus

- Prof. Piet H. Swanepoel, University of South Africa 



\section{Inhoudsopgawe / Table of Contents / Table des matières}

Voorwoord

Preface

ix

Préface

xi

xiii

Willem Botha

\section{Artikels / Articles}

Les dictionnaires hybrides: Le futur de la lexicographie?

Thierry Afane-Otsaga

Glosse en vertaalkomplemente in tweetalige woordeboeke

Herman L. Beyer

Die gebruik van ANNA in 'n Nederlandse taalverwerwings-

kursus - toegangsgemak en inligtingkoste

Nerina Bosman

Orthography in the Planning of a Fang Dictionary

Guy-Modeste Ekwa Ebanéga

Plaidoyer pour des dictionnaires de langues locales adaptés

à différents niveaux et groupes d'âge au Gabon

Edgard Maillard Ella

Différentiation systématique des homonymes et des polysèmes en yilumbu (B44) du Gabon

P.A. Mavoungou

LSP Lexicography in the Academic Discourse

Guy-Roger Mihindou

Bilingual Dictionaries in the South African Context 
What Cultural Information can be taken from Example Sentences

in Bilingual Dictionaries, and is it Useful?

Lorna Morris

The Lemmatisation of Dialectal Forms in a Northern Sotho General

Monolingual Dictionary: Is the Language Developed or Polluted?

M.C. Mphahlele

Towards Internally-motivated English School Dictionaries for

Zimbabwe

Dion Nkomo

'n Kritiese waardering van die hantering van kollokasies en

idiome in die HAT (2005)

Anna N. Otto

Leksikografiese seleksie as deel van die samestellingsproses van

'n vakwoordeboek vir vertalers

Liezl Potgieter

The Role and Function of Illustrative Material in the Planning of an Encyclopaedic Dictionary of Yilumbu

Gilles Saphou-Bivigat

Troeteltaal in taalkundige en leksikografiese verband

Gerda Simpson

Rufus Gouws se rol in die bekendstelling van H.E. Wiegand se

metaleksikografie en terminologie in die Suider-Afrikaanse konteks Maria Smit

Aperçu critique sur Petit Dictionnaire Français-Gisira-Ngosi

et éléments de verbes de Sœur Gabriel-Marie Lemoine

Fatima Tomba Moussavou

Kriteria vir woordeboekwerkboeke in Afrikaans

Michele F. van der Merwe

Magister- en doktorale studente van / Master's and Doctoral

Students of Rufus H. Gouws 1986 tot / to 2012 


\section{Voorwoord}

Prof. Paul Mavoungou en dr. Dion Nkomo het vroeg in 2012 met die gedagte van ' $n$ huldigingsbundel vir prof. Rufus Gouws in sy sestigste jaar na vore gekom. Ek is gevra om as redakteur op te tree van 'n bundel met artikels deur sy oudstudente en toe dr. Johan du Plessis my hierin ondersteun, is die bal aan die rol gesit.

Die gevoel was dat hierdie bundel aan oudstudente van Rufus Gouws die geleentheid sal gee om op gepaste wyse hul dank en waardering teenoor hom te betoon. Magister- en doktorale studente van 1986 tot Desember 2012 was almal geesdriftig oor ' $n$ huldigingsbundel vir iemand wat veel meer as hul dosent en studieleier is. Vir baie is hy 'n mentor en ' $n$ bron van inspirasie met wie hulle steeds op ' $n$ gereelde basis kontak het. Sy geesdrif vir woordeboeke en die leksikografie, gerugsteun deur 'n buitengewone leksikografiese kennis en insig, sy aansteeklike positiewe ingesteldheid, sy besondere formuleringsvermoë, sy seldsame slag om die humor in 'n situasie te snap en te verwoord, sy goeie voorbereiding en stiptelike nakoming van spertye, sy parate kennis van en ingeligtheid oor beskikbare tersaaklike bronne, 'n algemene presiesheid sonder om klinies te wees, sy simpatieke en geduldige leiding, onkreukbare integriteit en belangstelling in die persoonlike welsyn van sy studente maak van hom 'n persoon aan wie sy oudstudente met die grootste oortuiging 'n huldigingsbundel opdra.

Rufus Gouws se loopbaan begin in 1977 as junior lektor by die Departement Afrikaans en Nederlands aan die Universiteit van Suid-Afrika (Unisa). Binne dieselfde jaar word hy tot lektor bevorder. In Januarie 1980 verskuif hy na die Departement Afrikaans en Nederlands aan die Universiteit Stellenbosch waar hy in 1999 tot professor bevorder word. Reeds in 1980 bied hy die eerste honneurskursus in Leksikografie by die Universiteit Stellenbosch aan. Sy produktiewe doseer- en navorsingsloopbaan in die Afrikaanse taalkunde en meer spesifiek die leksikografie strek dus reeds oor 36 jaar.

Afgesien van sy doseerloopbaan in Stellenbosch, vestig hy ook sedert die middeltagtigerjare ' $n$ loopbaan as besoekende dosent, plaaslik veral aan die Universiteit van Pretoria. Internasionaal doseer hy of is hy navorsingsgenoot in onder andere Duitsland, Engeland, Denemarke, België, Nederland, Slowakye, Slowenië en Rusland.

My opregte dank aan die Viserektoraat: Navorsing, Universiteit Stellenbosch, die Fakulteit Lettere en Sosiale Wetenskappe, Universiteit Stellenbosch, die Navorsingstigting, Rhodes Universiteit en die Woordeboek van die Afrikaanse Taal (WAT) wat die koste van die bundel gedra het. 'n Groot dankie gaan aan prof. Ilse Feinauer vir haar ondersteuning met die konseptualisering van hierdie festschrift ter ere van prof. Rufus Gouws, asook Liana Roos, albei 
van die Departement Afrikaans en Nederlands aan die Universiteit Stellenbosch. ' $n$ Spesiale woord van dank moet gerig word aan dr. Johan du Plessis, wat 'n leeueaandeel in hierdie publikasie gehad het. Die volgende persone het as keurders opgetree: me. A.E. Cloete, Buro van die WAT, Stellenbosch, prof. C.J. Conradie, Universiteit van Johannesburg, prof. A.E. Feinauer, Universiteit Stellenbosch, prof. I.M. Kosch, Universiteit van Suid-Afrika (Unisa), Pretoria, Jana Luther, redakteur Handwoordeboek van die Afrikaanse Taal, Pearson, Kaapstad, prof. P.A. Mavoungou, Omar Bongo Universiteit, Libreville, dr. Firmin Moussounda Ibouanga, Omar Bongo Universiteit, Libreville, dr. Dion Nkomo, Rhodes Universiteit, Grahamstad, dr. Jean-Aimé Pambou, École Normale Supérieure, Libreville, Fred Pheiffer, redakteur Handwoordeboek van die Afrikaanse Taal, Pearson, Kaapstad en dr. Liezl Potgieter, Paarl.

Dr. Willem Botha

Hoofredakteur en Uitvoerende Direkteur, Woordeboek van die Afrikaanse Taal 


\section{Preface}

Early in 2012 Prof. Paul Mavoungou and Dr Dion Nkomo put forward the idea of a celebratory volume for Prof. Rufus Gouws in his sixtieth year. I was asked to act as editor for a compilation of articles by his former students and when Dr Johan du Plessis offered me his support the process was set in motion.

The intention was that this compilation might provide former students of Rufus Gouws with the opportunity to express their appreciation towards him. Masters and doctoral students from 1986 to December 2012 were all enthusiastic about a celebratory volume for someone who had been much more than their lecturer and supervisor. To many he had been a mentor and a source of inspiration, with whom they still communicated on a regular basis. His fervour for dictionaries and lexicography, underpinned by an extraordinary lexicographic knowledge and insight, his infectious positive attitude, his remarkable ability to turn a phrase, his rare knack for grasping and verbalising the humour in a situation, his excellent preparation and unfailing compliance with deadlines, his ready knowledge and familiarity with available, relevant sources, a general precision without being distant, his patient and sympathetic guidance, infallible integrity and interest in the personal wellbeing of his students, have made him someone to whom his former students have the greatest conviction in dedicating a celebratory volume.

Rufus Gouws began his career in 1977 as a junior lecturer in the Department of Afrikaans and Dutch at the University of South Africa (Unisa). Within the same year he was promoted to lecturer. In January 1980 he transferred to the Department of Afrikaans and Dutch at Stellenbosch University, where he was promoted to professor in 1999. As early as 1980 he taught the first Honours course in lexicography at Stellenbosch University. His prolific lecturing and research career in Afrikaans language studies and specifically in lexicography therefore already spans 36 years.

Besides his career as lecturer at Stellenbosch he has also established a career as a guest lecturer since the mid-eighties, locally particularly at the University of Pretoria. He lectures internationally or acts as a research partner in Germany, England, Denmark, Belgium, the Netherlands, Slovakia, Slovenia and Russia.

My sincere thanks to the Vice-Rectorship: Research from Stellenbosch University; the Faculty of Arts and Social Sciences, Stellenbosch University; the Research Foundation, Rhodes University; and the Woordeboek van die Afrikaanse Taal (WAT) who have borne the cost of the publication. Many thanks are due to Prof. Ilse Feinauer for her support in conceptualising this festschrift in honour of Prof. Rufus Gouws, as well as Liana Roos, both from the Depart- 
ment of Afrikaans and Dutch at Stellenbosch University. I would like to offer a special word of thanks to Dr Johan du Plessis, who had the lion's share of participation in this publication. The following people acted as reviewers: Ms A.E. Cloete, Bureau of the WAT, Stellenbosch, Prof. C.J. Conradie, University of Johannesburg, Prof. A.E. Feinauer, Stellenbosch University, Prof. I.M. Kosch, University of South Africa (Unisa), Pretoria, Jana Luther, editor Handwoordeboek van die Afrikaanse Taal, Pearson, Cape Town, Prof. P.A. Mavoungou, University Omar Bongo, Libreville, Dr Firmin Moussounda Ibouanga, University Omar Bongo, Libreville, Dr Dion Nkomo, Rhodes University, Grahamstown, Dr JeanAimé Pambou, École Normale Supérieure, Libreville, Fred Pheiffer, editor Handwoordeboek van die Afrikaanse Taal, Pearson, Cape Town and Dr Liezl Potgieter, Paarl.

Dr Willem Botha

Chief Editor and Executive Director, Woordeboek van die Afrikaanse Taal 


\section{Préface}

Au début de l'année 2012, le Professeur Paul Mavoungou et le Dr Dion Nkomo ont eu l'idée d'organiser des mélanges en l'honneur du Professeur Rufus Gouws à l'occasion de son soixantième anniversaire. On m'a demandé d'agir en tant que rédacteur en chef pour regrouper les articles de ses anciens étudiants et, lorsque le Dr Johan du Plessis m'a offert son soutien le processus a été lancé.

L'intention était qu'à travers cette publication, les anciens étudiants de Rufus Gouws aient la possibilité de lui exprimer leur gratitude. Les étudiants de Master et de Doctorat de 1986 à décembre 2012 étaient tous enthousiastes à l'idée d'un mélange en l'honneur de quelqu'un qui a été beaucoup plus que leur enseignant et superviseur. Pour beaucoup, il a été un mentor et une source d'inspiration, avec qui ils continuent de communiquer régulièrement. Sa ferveur pour les dictionnaires et la lexicographie, sous-tendue par une extraordinaire connaissance lexicographique et sa perspicacité, sa contagieuse attitude positive, sa remarquable capacité à tourner une phrase, son talent rare pour saisir et verbaliser l'humour dans une situation donnée, son excellente préparation et son respect sans faille des délais, sa connaissance et sa familiarité doublée d'une grande disponibilité, ses sources pertinentes, d'une grande précision générale sans être pour autant lointaines, son encadrement patient et sympathique, son intégrité infaillible et sa préoccupation pour le bien-être personnel de ses étudiants, ont fait de lui quelqu'un pour qui ses anciens étudiants ont la plus grande conviction en offrant ces mélanges en son honneur.

Rufus Gouws a commencé sa carrière en 1977 comme assistant au Département d'afrikaans et de néerlandais à l'Université de l'Afrique du Sud (Unisa). Dans la même année, il a été promu maître de conférences. En janvier 1980, il a été transféré au Département d'afrikaans et de néerlandais à l'Université de Stellenbosch, où il a été promu professeur titulaire en 1999. Dès 1980, il a donné son premier cours de licence en lexicographie à l'Université de Stellenbosch. Sa carrière prolifique d'enseignant et de chercheur dans les études linguistiques afrikaans en général et en particulier en matière de lexicographie s'étale donc déjà sur 36 ans.

En sus de sa carrière comme enseignant à Stellenbosch, il a également établi une carrière en tant que professeur missionnaire depuis le milieu des années 80 , localement à l'Université de Pretoria notamment. Il donne des conférences au niveau international ou il a le statut de partenaire de recherche en Allemagne, en Angleterre, au Danemark, en Belgique, aux Pays-Bas, en Slovaquie, en Slovénie et en Russie.

Mes sincères remerciements vont à l'endroit du vice-rectorat en charge de la recherche à l'Université de Stellenbosch; la Faculté des arts et des sciences sociales, Université de Stellenbosch; la Fondation de recherche, Université 
Rhodes; et le Woordeboek van die Afrikaanse Taal (WAT) qui ont supporté le coût de la publication. Je dis également un grand merci au Professeur Ilse Feinauer pour son soutien dans la conceptualisation de ces mélanges en l'honneur du Professeur Rufus Gouws, ainsi que Liana Roos, tous deux appartenant au Département d'afrikaans et de néerlandais à l'Université de Stellenbosch. Je voudrais adresser un mot de remerciement spécial au Dr Johan du Plessis, qui a eu la part du lion de la participation dans cette publication. Les personnes suivantes ont participé comme évaluateurs: Mme A.E. Cloete, Bureau du WAT, Stellenbosch, Prof. C.J. Conradie, Université de Johannesburg, Prof. A.E. Feinauer, Université de Stellenbosch, Prof. I.M. Kosch, Université de l'Afrique du Sud (Unisa), Pretoria, Jana Luther, rédacteur Handwoordeboek van die Afrikaanse Taal, Pearson, Le Cap, Prof. P.A. Mavoungou, Université Omar Bongo, Libreville, Dr Firmin Moussounda Ibouanga, Université Omar Bongo, Libreville, Dr Dion Nkomo, Université Rhodes, Grahamstown, Dr Jean-Aimé Pambou, École Normale Supérieure, Libreville, Fred Pheiffer, rédacteur Handwoordeboek van die Afrikaanse Taal, Pearson, Le Cap, Dr Liezl Potgieter, Paarl.

Dr Willem Botha

Rédacteur en chef et Directeur exécutif, Woordeboek van die Afrikaanse Taal 


\title{
Les dictionnaires hybrides: Le futur de la lexicographie?
}

\author{
Thierry Afane-Otsaga, Chaire UNESCO Interculturalité, \\ Université Omar Bongo, Libreville, Gabon (afanotsaga@gmail.com)
}

\begin{abstract}
Résumé: Les dictionnaires diffèrent non seulement par rapport à leur typologie, mais aussi par rapport à leur fonction. Cette fonction dépend du contenu que lui donne le lexicographe. En lexicographie, la compilation d'un dictionnaire ne se fait donc pas de manière hasardeuse; elle tient compte des besoins du public-cible. Son contenu et sa forme ont donc pour fonction de permettre à l'usager-cible de combler ses besoins linguistiques. Avec la mondialisation et la transformation accélérée du monde, l'acquisition de nouvelles connaissances dans des domaines diversifiés est devenue une impérieuse nécessité pour tout individu qui veut rester moderne et ne pas se laisser dépasser par l'évolution. Aujourd'hui par exemple, il ne suffit plus d'être compétent et performant dans son domaine de prédilection, mais il est aussi indispensable d'avoir des connaissances et des notions dans d'autres domaines. Il ne s'agit donc plus pour les lexicographes de compiler des dictionnaires ayant simplement une seule fonction lexicographique, mais de réaliser des dictionnaires qui peuvent avoir plusieurs fonctions à la fois, et qui vont donc s'adresser à plusieurs types d'usagers en même temps. C'est ce que nous appelons les dictionnaires hybrides. Le but de cet article est de montrer que la compilation des dictionnaires hybrides va devenir de plus indispensable dans le monde moderne et que l'utilisation de ce type de dictionnaires pourrait supplanter celle des autres modèles.
\end{abstract}

Mots-clés: DICTIONNAIRE HYBRIDE, LEXICOGRAPHIE, FONCTION DU DICTIONNAIRE, USAGER-CIBLE, LANGUE-SOURCE, LANGUE-CIBLE, BESOINS DES USAGERS

\begin{abstract}
Hybrid Dictionaries: The Future of Lexicography? Dictionaries differ not only according to their typology, but also according to their function. This function depends on the content that the lexicographer gives to it. In lexicography, the compilation of a dictionary is not done haphazardly; it takes into account the needs of the target users. Its content and its form have therefore as function to allow the target users to meet their linguistic needs. With the globalization and rapid transformation of the world, the acquisition of new knowledge in diversified domains has become an imperious necessity for everyone who wants to stay modern and not be overtaken by the evolution. Nowadays, for instance, it is no longer enough to be competent and efficient in one's own domain, but it is also important to have knowledge and understanding of other domains. For lexicographers, it is therefore no longer a question of compiling dictionaries with one single lexicographical function, but of realizing dictionaries having several functions at once, and therefore addressing several types of users at the same time. These are what we call hybrid dictionaries. The purpose of this article is to show that the compilation of hybrid dictionaries will become more essential in the modern world and that the use of this type of dictionaries could replace that of the other models.
\end{abstract}


Keywords: HYBRID DICTIONARY, LEXICOGRAPHY, DICTIONARY FUNCTION, TARGETUSER, SOURCE-LANGUAGE, TARGET-LANGUAGE, USER NEED

\section{Introduction}

Les dictionnaires diffèrent non seulement par rapport à leur typologie, mais aussi par rapport à leur fonction. Cette fonction dépend du contenu que lui donne le lexicographe. En effet, ce dernier donne un certain contenu au dictionnaire selon les objectifs qu'il souhaite atteindre, mais aussi selon les besoins des usagers-cibles. Ainsi, par exemple, un dictionnaire qui présente la forme normalisée ou le dialecte de référence d'une langue aura pour fonction de favoriser l'harmonisation de l'utilisation d'une langue et par conséquent sa standardisation. Dans un tel dictionnaire les données seront présentées de sorte que celuici puisse servir de référence aux usages de langue. Ce dictionnaire, qui sera qualifié de standard, sera donc normatif dans son approche.

En lexicographie, la compilation d'un dictionnaire ne se fait donc pas de manière hasardeuse, elle tient compte des besoins du public-cible. Son contenu et sa forme ont donc pour fonction de permettre à l'usager-cible de combler ses besoins aussi bien au plan de la maîtrise de la langue (rôle des dictionnaires de langue) qu'à celui de l'acquisition des connaissances extralinguistiques (rôle des dictionnaires encyclopédiques).

Cependant, avec la mondialisation et la transformation accélérée du monde, l'acquisition de nouvelles connaissances dans des domaines diversifiés est devenue une impérieuse nécessité pour tout individu qui veut rester moderne et ne pas se laisser dépasser par l'évolution. Aujourd'hui par exemple, il ne suffit plus d'être compétent et performant dans son domaine de prédilection, mais il est aussi indispensable d'avoir des connaissances et des notions dans d'autres domaines. Par exemple lors d'entretiens d'embauche entre plusieurs individus ayant les mêmes diplômes, ce sont ces connaissances en plus qui font généralement la différence.

Depuis l'antiquité, le dictionnaire a toujours joué un rôle important auprès des populations pour l'acquisition des connaissances. De nos jours, les besoins des usagers étant multidimensionnels et multisectoriels, le dictionnaire se doit d'adapter sa présentation et son contenu en fonction de la donne actuelle. Il ne s'agit donc plus pour les lexicographes de compiler des dictionnaires ayant simplement une seule fonction lexicographique, mais de réaliser des dictionnaires qui peuvent avoir plusieurs fonctions à la fois, qui vont donc s'adresser à plusieurs types d'usagers en même temps. C'est ce que nous appelons les dictionnaires hybrides.

Le but de cet article est de montrer que la compilation des dictionnaires hybrides va devenir de plus indispensable dans le monde moderne et que l'utilisation de ce type de dictionnaires pourrait supplanter celle des autres modèles. Pour réaliser notre démonstration, nous commencerons par présenter les différents types de fonctions que peuvent avoir les dictionnaires. Nous 
proposerons ensuite des exemples d'organisation macro- et microstructurales que pourront avoir les dictionnaires hybrides. Et nous proposerons, in fine, une typologie de potentiels dictionnaires hybrides.

\section{Fonctions du dictionnaire}

Avant de parler des dictionnaires hybrides, il est nécessaire de comprendre ce à quoi renvoi la fonction d'un dictionnaire. Pour cela, nous allons nous intéresser au rôle spécifique que doit jouer chaque type de dictionnaire par rapport à une langue et/ou à son public-cible lors de sa compilation. De manière générale, il existe deux types de fonctions dictionnairiques: une fonction orientée vers la communication et une fonction orientée vers la connaissance. On dit d'un dictionnaire qu'il a une fonction orientée vers la communication lorsque le dictionnaire en question permet à un usager d'améliorer ses compétences dans l'utilisation de la langue traitée: permettre la compréhension et/ou la production des textes dans une langue première ou dans une langue étrangère. Alors qu'un dictionnaire qui une fonction orientée vers la connaissance permet à l'usager d'acquérir des compétences extralinguistiques ou encyclopédiques et culturelles dans des domaines spécifiques. La fonction assignée à un dictionnaire est donc intimement liée à sa typologie. À chaque type de dictionnaire va correspondre une fonction spécifique. C'est pour cela qu'il existe plusieurs types de dictionnaires tels que: les dictionnaires de langue, les dictionnaires de traduction, les dictionnaires standards, les dictionnaires de définition, les dictionnaires synchroniques, les dictionnaires diachroniques.

L'objectif des dictionnaires standards est de présenter la forme normalisée ou le dialecte de référence d'une langue. Sa fonction est donc de favoriser l'harmonisation de l'utilisation d'une langue et par conséquent sa standardisation. Dans un dictionnaire standard les données sont présentées de sorte que ce dictionnaire puisse servir de référence aux usagers de la langue. Un dictionnaire standard est donc normatif dans son approche, il peut avoir trois fonctions principales: (1) une fonction unificatrice en favorisant l'utilisation d'un seul dialecte; (2) une fonction identitaire en permettant aux membres d'une communauté linguistique de se distinguer des autres communautés linguistiques; et (3) une fonction honorifique en permettant aux locuteurs de revendiquer leur maîtrise de la langue standard (Zgusta 1971: 185).

Le rôle des dictionnaires explicatifs est de présenter des explications et des définitions sur les mots d'une langue. C'est pour cela que ce type de dictionnaire est toujours monolingue, puisque tout le traitement lexicographique est fait dans la même langue. Il s'oppose donc au dictionnaire de traduction et appartient à la catégorie des dictionnaires de langue. Dans les dictionnaires de langue le traitement lexicographique est présenté dans une ou plusieurs langue(s). Un dictionnaire de langue peut être synchronique ou diachronique. L'objectif d'un dictionnaire synchronique est de traiter le stock lexical d'une langue à une période précise de son développement (Al-Kasimi 1977: 202), 
alors que celui d'un dictionnaire diachronique est de s'occuper de l'histoire et du développement des mots d'une langue, aussi bien au niveau sémantique (sens) que morphologique (forme).

La fonction des dictionnaires synchroniques est orientée vers la communication, puisqu'ils permettent aux usagers de mieux maîtriser la langue telle qu'elle est parlée à une période précise, alors que la fonction des dictionnaires diachroniques est orientée vers la connaissance, puisqu'elle permet de connaître les différents changements intervenus dans l'évolution d'une langue, même si ces changements ne vont pas nécessairement servir à la pratique contemporaine de la langue.

Les dictionnaires de traduction qui présentent les mots d'une langue source (langue de départ) avec leurs traductions dans une ou plusieurs autres langues cibles (langue d'arrivée) ont pour fonction de permettre aux usagers de transférer leurs connaissances d'une langue vers une autre ou simplement d'acquérir une nouvelle langue. Un dictionnaire de traduction peut être soit bilingue lorsqu'il présente deux langues, soit multilingue lorsqu'il présente plus de deux langues (Al-Kasimi 1977).

Pour mieux appréhender la fonction de chaque type de dictionnaire, nous allons nous intéresser à la typologie de ces derniers. En effet, il existe plusieurs propositions de classification des dictionnaires selon un certain nombre de critères. Ces critères nous permettent de saisir les objectifs visés par les lexicographes lors de la compilation de leurs dictionnaires et par conséquent d'identifier leurs fonctions.

La première classification des dictionnaires est celle du Ščerba qui réalisa une typologie des dictionnaires publiés en 1940 (Al-Kasimi 1977: 12). Cette classification se base sur les caractéristiques structurales des différents types possibles de dictionnaires. Dans cette classification, Ščerba distingue les dictionnaires en six principales oppositions contrastives. Nous ne retiendrons ici que celles qui nous paraissent les plus pertinentes par rapport à notre démonstration:

1. La première distinction oppose les dictionnaires normatifs aux dictionnaires de référence. Les dictionnaires normatifs dictent la norme de la langue, leur fonction est donc d'amener les usagers à respecter les règles d'usage de la langue. Ces dictionnaires ont donc pour rôle principale de veiller au bon usage de la langue. Leur fonction est plus orientée vers la communication qu'autre chose. Pour ce qui est des dictionnaires de référence, ils adoptent beaucoup plus une approche descriptive que prescriptive. En d'autres termes, ces dictionnaires se donnent pour rôle de décrire la langue telle qu'elle est sans se préoccuper des aspects réglementaires ou normatifs. La fonction principale de ces dictionnaires est d'offrir aux usagers un maximum d'informations sur les différentes unités lexicales qui composent la langue.

2. La deuxième distinction oppose les dictionnaires ordinaires aux dictionnaires de concordances. Un dictionnaire ordinaire adopte un traitement 
standard en proposant des définitions ou des traductions, alors qu'un dictionnaire de concordances propose simplement une liste de mots ayant pour unique traitement des citations des auteurs. Si la fonction des dictionnaires ordinaires dépend de leur contenu, celle des dictionnaires de concordances consiste à établir un lien entre les unités lexicales traitées et des citations des auteurs. L'objectif ici est de permettre aux usagers d'utiliser les mots dans des citations. Cela donne aux locuteurs la faculté de dire beaucoup de choses en peu de mots. Ce type de dictionnaire a donc une fonction orientée vers la communication.

3. La troisième distinction oppose les dictionnaires usuels aux dictionnaires idéologiques. Les dictionnaires usuels sont les dictionnaires les plus courants, ceux qui sont les plus utilisés, alors que les dictionnaires idéologiques traitent des idées, des sujets ou des idéologies particulières (les religions ou les philosophies par exemple).

4. La quatrième distinction oppose les dictionnaires historiques aux dictionnaires non-historiques. Si la fonction de la plupart des dictionnaires nonhistoriques est orientée vers la communication, celle des dictionnaires historiques est plus orientée vers la connaissance. En effet, le rôle de ce type de dictionnaires est de mettre en lumière les différentes étapes de l'évolution d'une langue et permettre ainsi à l'usager de connaître l'origine des mots et des sens.

Une autre classification nous permet de comprendre la fonction des dictionnaires. Il s'agit de celle proposée par Malkiel (1980) qui met en évidence trois caractéristiques principales permettant de distinguer les dictionnaires entre eux. En effet, Malkiel classe les dictionnaires selon trois critères: l'ordre de rangement, la perspective et la présentation. Pour lui, les dictionnaires sont rangés en fonction de (a) la densité des entrées; (b) le nombre de langues impliquées et (c) le degré de concentration des données strictement lexicales.

On peut ainsi comprendre que lorsqu'un dictionnaire inclut un grand nombre d'entrées, sa principale fonction est d'offrir le maximum de connaissances sur la langue aux usagers. Ce type de dictionnaire s'adresse généralement à un public très large. De même, lorsque le dictionnaire inclut une seule langue, il ne s'adresse qu'à une seule catégorie d'usagers: les locuteurs natifs de la langue décrite. Par contre, si les données du dictionnaire sont strictement lexicales, c'est-à-dire qu'elles n'abordent pas les aspects extralinguistiques, la fonction de ce type de dictionnaire d'offrir uniquement des connaissances linguistiques aux usagers.

En ce qui concerne la perspective, ce type de classification permet de comprendre que les dictionnaires peuvent être compilés en tenant compte du caractère synchronique ou diachronique des données, en présentant les entrées par ordre alphabétique, sémantique ou de manière arbitraire et aussi selon les objectifs du lexicographe. Un dictionnaire ayant un caractère purement syn- 
chronique a pour fonction de ne proposer aux usagers que des données linguistiques d'une époque précise de la langue, alors que les dictionnaires diachroniques ont pour fonction de mettre à la disposition des usagers des informations sur l'évolution de la langue dans le temps.

Pour ce qui est de la présentation des dictionnaires, il s'agit particulièrement de leur contenu en rapport avec les aspects définitoires, l'exemplification, les illustrations graphiques ou de toutes autres données supplémentaires comme la localisation, la prononciation, etc. Ainsi, un dictionnaire qui met l'accent sur la définition a pour fonction de transmettre aux usagers un maximum de connaissances sur le contenu sémantique des unités lexicales. Lorsque l'accent est mis sur les exemples la fonction de ces dictionnaires est de permettre aux usagers d'être capable de bien utiliser les unités lexicales en contexte. Si ce sont les illustrations graphiques qui occupent une place importante, la fonction de ce type de dictionnaires est de transmettre les connaissances de manière visuelle afin de faire gagner du temps aux usagers et de leur permettre de se faire une idée précise de la forme physique de la réalité décrite. Ce type de dictionnaires peut être particulièrement utile pour les enfants.

On peut donc voir à travers les quelques exemples proposés que chaque type de dictionnaire s'adresse à une catégorie précise d'usagers et que celui-ci (le dictionnaire) a une fonction précise auprès son groupe d'usagers-cible. En résumé, les dictionnaires tels qu'ils sont compilés de nos jours ne sont pas faits pour tous les usagers. N'importe quel usager ne peut pas prendre n'importe quel dictionnaire et être certain d'y trouver les informations qui correspondent à ses besoins. Il ne peut trouver entièrement satisfaction que dans un dictionnaire compilé pour le groupe d'usagers-cible auquel il appartient. On peut alors se poser les questions suivantes: Avec les besoins de plus en plus croissants des usagers, aussi bien au plan de la communication qu'au plan de la connaissance dans des domaines variés, la solution est-elle de continuer à compiler des dictionnaires spécifiques à chaque type de public? La solution n'est-elle pas de donner aux travaux lexicographiques des fonctions plus élargies de sorte qu'un seul dictionnaire soit capable de remplir les besoins de plusieurs groupes-cibles en même temps?

\section{Pourquoi les dictionnaires hybrides?}

Précisons, de prime abord, qu'un dictionnaire hybride est un dictionnaire qui intègre les caractéristiques de plusieurs types de dictionnaires. En effet, le fond et la forme d'un dictionnaire sont largement dépendants de la fonction qu'on assigne à ce dernier par rapport aux besoins d'un public-cible. Ainsi, par exemple un dictionnaire monolingue général qui aura pour fonction de décrire les unités lexicales et qui a pour public-cible les élèves du secondaire, sera nécessairement moins volumineux qu'un autre dictionnaire monolingue général qui s'adresse aux universitaires. Cela pour la simple raison que le deuxième type de dictionnaire vise un public plus averti et qui détient déjà un certain nombre de connaissances importantes sur la langue. Pour que ce public d'universitaires 
trouve son compte dans ce dictionnaire, il faut que les données y soient plus importantes et le traitement lexicographique plus détaillé et mieux affiné. Par contre un dictionnaire monolingue général qui vise les élèves du primaire se contentera de ne présenter que les mots les plus utilisés dans l'environnement immédiat (école et maison) de cette population avec des explications plus concises.

Pour revenir aux dictionnaires hybrides, l'objectif de leur compilation serait de donner un caractère polyvalent et polyfonctionnel aux dictionnaires. Il ne s'agira plus de compiler des dictionnaires spécifiques à un seul groupe d'usagers, mais de réaliser des dictionnaires qui peuvent satisfaire plusieurs groupes d'usagers en même temps. En d'autres termes, il est question de prendre en compte dans un seul dictionnaire, les besoins de plusieurs groupes d'utilisateurs. De plus, il est aujourd'hui important de tenir compte du fait que le monde connaît une évolution rapide et que les individus doivent adopter de nouvelles attitudes, acquérir de nouvelles connaissances tous les jours et dans des domaines variés afin de ne pas se laisser distancer par l'évolution. À notre avis, le monde de demain sera très exigeant pour tous les citoyens du monde (s'il ne l'est pas déjà). Ceux qui ne voudront pas se laisser dépasser par les évènements devront faire preuve de polyvalence et avoir la capacité de s'adapter à toutes les situations, aussi bien au plan professionnel qu'à celui de la vie quotidienne. Pour cela, ils auront besoin de sources de connaissances, telles que les dictionnaires, adaptées à leurs besoins.

En effet, depuis la nuit des temps, le dictionnaire a toujours joué un rôle important, auprès des populations, pour l'acquisition des savoirs et pour l'épanouissement intellectuel des usagers. Les usagers opteront pour un seul produit qui peut leur offrir le maximum d'informations dans des domaines divers, plutôt que de recourir à plusieurs produits spécifiques ou spécialisés pour chaque domaine. Cela risque de leur faire perdre du temps et surtout de l'argent, alors que la tendance est justement à plus de savoirs, en peu de temps et à moindre coût. Par conséquent, pour rester cet outil privilégié d'acquisition des connaissances linguistiques et extralinguistiques, les dictionnaires de demain devront être capables de satisfaire les besoins des usagers de plus en plus exigeants, aussi bien au plan du fond qu'à celui de la forme. Les dictionnaires n'auront pas d'autres choix que celui de tendre ou de migrer vers l'hybridité.

À notre avis, les dictionnaires qui n'auront pas cette caractéristique hybride seront considérés comme mauvais par les utilisateurs. En effet, il est un fait avéré que lorsqu'un usager ne trouve pas ce qu'il cherche dans un dictionnaire, il estime que celui-ci n'est pas de bonne qualité. Les dictionnaires hybrides ayant cette particularité d'intégrer les besoins d'usagers ayant des préoccupations différentes et variées, ils vont nécessairement devenir la référence et obliger, d'une certaine manière, tous les lexicographes à s'approprier cette tendance au risque de perdre toute crédibilité. Pour illustrer notre propos, prenons l'exemple de deux domaines spécifiques et assez éloignés comme la linguistique et la médecine. 
Bien qu'ayant comme principal objet d'étude la langue, la linguistique est un domaine qui englobe un grand nombre de spécialités telles que la phonétique, la phonologie, la morphologie, la sémantique, la syntaxe, la pragmatique, l'informatique, la lexicologie, etc. Chacune de ces spécialités développe et utilise des notions, des théories et des méthodes qui lui sont propres, bien que certaines d'entre elles leur soient communes. Il n'est d'ailleurs pas rare de trouver des dictionnaires spécifiquement dédiés à chacun de ces domaines, en plus de ceux consacrés globalement à la linguistique. Le constat est que la plupart des dictionnaires de linguistique font généralement la part belle à certains domaines, surtout aux cinq principaux niveaux d'analyse linguistique que sont la phonétique, la phonologie, la morphologie, la syntaxe et la sémantique. Les notions liées aux autres domaines comme l'informatique, la lexicographie, la pragmatique, etc. y sont plus rares. Cela est d'autant plus vrai que ces domaines ont été associés à la linguistique seulement récemment. Pour véritablement s'imprégner de l'ensemble des notions qui ont cours dans cette science, un individu qui s'intéresse aux questions de linguistique doit chercher à acquérir une documentation spécifique à chaque domaine. Ce qui est difficile (il faudra déjà les trouver) et très coûteux. L'une des solutions à ce problème serait, à notre avis, la compilation de dictionnaires hybrides qui peuvent permettre à tous ceux qui s'intéressent à la linguistique d'avoir à leur disposition le maximum d'informations sur chacun des domaines qui compose cette science.

En ce qui concerne la médecine, nul n'est sans savoir que tout médecin est d'abord un généraliste. Ce qui signifie qu'il doit être capable de diagnostiquer tout type de maladie et si possible en proposer le traitement approprié. Un tel travail nécessite des connaissances élargies et disponibles. Beaucoup de médecin n'hésitent d'ailleurs pas à se documenter non seulement pour améliorer leurs compétences, mais surtout lorsqu'ils se retrouvent face à des maladies ou des symptômes qu'ils ont du mal à identifier. Cela est aussi valable pour les médecins spécialistes qui non seulement doivent affiner leurs connaissances dans leur spécialité, mais ont aussi besoin de savoir et comprendre ce qui se fait de mieux dans les autres spécialités, surtout celles qui ont des aspects communs avec la leur (ce qui est très fréquent en médecine). De plus, avec les avancés technologiques, la pratique de la médecine se fait de plus en plus avec les outils techniques très sophistiqués. Il est donc important qu'un praticien qui veut rester compétent mette régulièrement à jour ses connaissances. À condition, bien sûr, que les éléments qui peuvent lui permettre de le faire soient à sa portée ou à sa disposition.

Précisons aussi qu'en dehors des spécialistes de la santé, la situation du monde amène aujourd'hui chaque individu à avoir un minimum de connaissances dans le domaine médical. Le dictionnaire hybride peut lui permettre d'avoir cela à sa portée, sans nécessairement avoir recours à un ouvrage spécialisé, qu'il risque d'ailleurs de ne pas comprendre.

Nous ne prétendons pas qu'un dictionnaire, si complet soit-il, puisse remplacer un document de spécialité. Mais les informations de base que peuvent 
proposer les dictionnaires hybrides dans des domaines différents peuvent s'avérer fort utiles pour l'usager moderne.

\section{Quels types de dictionnaires hybrides?}

\subsection{Généralités}

Il est important de préciser que la compilation des dictionnaires hybrides ne doit pas se faire de manière hasardeuse ou anarchique. Dans ce type de dictionnaires, on ne peut mélanger que des domaines proches ou compatibles. Mais, il s'agit surtout de rendre le dictionnaire polyfonctionnel de sorte que celui-ci réponde aux besoins de plusieurs groupes d'usagers-cibles et non plus d'un seul groupe. À titre illustratif, nous pensons qu'un dictionnaire hybride peut par exemple intégrer les caractéristiques et les fonctions d'un dictionnaire de traduction, tout en incorporant celles d'un dictionnaire général monolingue. Ce genre de dictionnaire peut, par la même occasion, jouer le rôle d'un dictionnaire standard (Afane-Otsaga 2002). Nous allons tenter de l'illustrer dans les propos qui suivent.

\subsection{Les caractéristiques compatibles}

De manière générale, nous avons répertorié 14 types de dictionnaires et chacun d'eux à une fonction particulière auprès du groupe d'usagers qu'il vise, même si certains de ces dictionnaires peuvent être polyfonctionnels ${ }^{\dagger}$. Ce recensement est assez proche de la classification faite par Al-Kasimi (1977). Il s'agit des dictionnaires suivants: (1) les dictionnaires pour locuteurs de la langue cible; (2) les dictionnaires pour locuteurs de la langue-cible; (3) les dictionnaires du langage littéraire; (4) les dictionnaires du langage parlé; (5) les dictionnaires de production; (6) les dictionnaires de compréhension; (7) les dictionnaires pour hommes; (8) les dictionnaires les usagers humains; (8) les dictionnaires pour traducteurs automatiques; (9) les dictionnaires historiques; (10) les dictionnaires de description; (11) les dictionnaires lexicaux; (12) les dictionnaires encyclopédiques; (13) les dictionnaires généraux et (14) les dictionnaires spécialisés.

À notre avis, il est possible de combiner dans un même dictionnaire les fonctions de plusieurs de ces dictionnaires. Nous proposons ici une typologie de dictionnaires hybrides possibles:

Le dictionnaire bilingue biscopal et bidirectionnel. Ce type de dictionnaire hybride peut viser aussi bien les locuteurs de la langue-source que ceux de la langue-cible. C'est donc un dictionnaire qui traite de deux langues: une langue-source $X$ et une langue-cible $Y$. Ce type de dictionnaire doit comporter normalement deux sections. Dans la première section la langue $X$ fait office de langue-source $(X$ vers $Y)$, alors que dans la deuxième section, c'est la langue $\mathrm{Y}$ qui fait office de langue-source $(\mathrm{Y}$ 
vers X). En d'autres termes, dans la première section les lemmes sont présentés dans la langue $X$ et les traductions équivalentes dans la langue $Y$, alors que dans la deuxième section les lemmes sont présentés dans la langue $Y$ et les traductions équivalentes dans la langue $X$. Ce type de dictionnaire vise ainsi deux catégories d'usagers: les locuteurs de la langue $X$ et ceux de la langue $Y$. Ce dictionnaire est bilingue parce qu'il inclut deux langues. Il est biscopal parce qu'il comporte deux sections. Et il est bidirectionnel parce qu'il vise aussi bien les locuteurs de la languesource que ceux de la langue-cible.

- Le dictionnaire monolingue poly-source. Ce type de dictionnaire présente aussi bien les données du langage littéraire que celles du langage parlé. En effet, la plupart des dictionnaires sont compilés soit sur la base de données écrites, soit sur la base de données orales. La plupart des linguistes estiment que le langage oral est la forme la plus représentative de l'activité langagière, alors que la forme écrite n'est que la représentation de cette dernière. Il ne faut cependant pas oublier que dans sa forme littéraire, la langue présente un certain nombre de tournures et de formulations particulières qu'on trouve rarement dans le langage oral. De plus, l'utilisation orale de la langue est souvent moins rigoureuse, moins respectueuse des règles, contrairement à la forme écrite qui reste plus conforme à la structure orthographique et grammaticale de la langue, puisque mieux pensée et moins spontanée. Compiler un dictionnaire poly-source qui prend en compte aussi bien la forme écrite que la forme orale de langue permet de lui donner une double fonction. La première fonction consiste à mettre en évidence la distance qui existe entre le langage écrit et le langage oral et la deuxième fonction consiste à attirer l'attention des usagers sur ce qui est conforme ou pas dans l'utilisation de la langue.

- Le dictionnaire bi-cognitif. Ce type de dictionnaires hybrides doit présenter des données qui permettent aux usagers d'améliorer leurs compétences aussi bien dans l'expression que dans la compréhension de la langue. En d'autres termes, le dictionnaire bi-cognitif a deux fonctions essentielles. La première fonction consiste à aider l'usager dans la production langagière et la seconde consiste à l'aider à mieux comprendre la langue. La première fonction est particulièrement intéressante pour les locuteurs natifs qui souhaitent améliorer leur performance dans la langue, alors que la deuxième fonction peut être plus utile pour les locuteurs étrangers qui souhaitent améliorer leur compréhension de la langue. L'aspect lié à la production consiste pour le lexicographe à intégrer un grand nombre de données illustratives qui présentent de nombreux exemples d'utilisation des unités lexicales en contexte. Alors que l'aspect lié à la compréhension consiste à fournir un grand nombre de données sur le contenu sémantique des unités lexicales. On peut donc com- 
prendre ici qu'un dictionnaire bi-cognitif est l'association d'un dictionnaire de compréhension et d'un dictionnaire de production. D'où d'ailleurs son caractère hybride.

- Le dictionnaire bilingue multitâche. Il existe une différence essentielle entre un dictionnaire bilingue compilé pour des utilisateurs humains et celui compilé pour les traductions automatiques par la machine. En effet, un dictionnaire pour utilisateurs humains présente seulement les informations essentielles qui correspondent aux besoins linguistiques des usagers-cibles. Alors qu'un dictionnaire bilingue pour traductions automatiques par la machine doit contenir des informations grammaticales plus détaillées sur les deux langues. La compilation de dictionnaires bilingues multitâches permet d'inclure dans un même dictionnaire, d'une part des données essentiellement linguistiques pour tout utilisateur qui veut transférer ses connaissances d'une langue A vers une langue $B$, et d'autre part des données grammaticales très détaillées qui peuvent permettre à un ordinateur de réaliser des traductions automatiques de qualité. On peut donc comprendre ici qu'un dictionnaire bilingue multitâche sera essentiellement électronique.

- Le dictionnaire historico-descriptif. Un dictionnaire hybride historicodescriptif est, comme son nom l'indique, l'association des caractéristiques d'un dictionnaire historique et à celles d'un dictionnaire descriptif. En d'autres termes, ce dictionnaire inclura les données sur le passé de la langue à l'instar des expressions obsolètes, les origines étymologiques des unités lexicales, les citations du passé, etc. Ce type de dictionnaire ne se contentera pas simplement de présenter ces données historiques, comme c'est souvent le cas des dictionnaires ordinaires. Il fera aussi la description détaillée de chaque unité lexicale.

- Le dictionnaire lexico-encyclopédique. Ce type de dictionnaire est le mélange d'un dictionnaire lexical et d'un dictionnaire encyclopédique. Habituellement on trouve d'un côté les dictionnaires lexicaux qui se consacrent uniquement à la description du lexique et les dictionnaires encyclopédiques qui accordent une place importante à la description des réalités extralinguistiques. Un dictionnaire lexico-encyclopédique aura pour fonction de satisfaire aussi bien les utilisateurs qui s'intéressent à la description du lexique que ceux qui souhaitent en connaître plus sur les réalités extralinguistiques.

- Le dictionnaire semi-spécialisé. Ce type de dictionnaire intègre les caractéristiques d'un dictionnaire général et celles d'un dictionnaire spécialisé. Dans un dictionnaire semi-spécialisé, il est question décrire les notions d'un domaine de spécialité comme s'il s'agissait de termes du langage quotidien. La fonction d'un tel dictionnaire est non seulement de décrire les termes issus d'un domaine de spécialité, mais surtout de faire en 
sorte que ces descriptions soient à la portée du plus grand. L'objectif étant que même les profanes du domaine soient capables de comprendre les notions décrites.

Bien que la typologie que nous venons de proposer ait mis l'accent uniquement sur des modèles visant seulement deux groupes d'usagers, il n'est pas exclu que certains dictionnaires hybrides aient trois ou quatre groupes d'usagerscibles. D'autres combinaisons sont donc possibles. Dans sa thèse de doctorat, publiée en 2010, Afane-Otsaga en donne un exemple à travers la proposition méta-lexicographique d'un dictionnaire bilingue standard qui intègre, à la fois, les caractéristiques d'un dictionnaire bilingue, d'un dictionnaire standard, d'un dictionnaire biscopal, d'un dictionnaire bidirectionnel, d'un dictionnaire encyclopédique, d'un dictionnaire diachronique, d'un dictionnaire général et d'un dictionnaire descriptif.

\subsection{Macrostructure des dictionnaires hybrides}

\subsubsection{Présentation de la macrostructure}

Dans un dictionnaire hybride la macrostructure devrait être organisée dans un ordre alphabétique strict, ce que Svensén (1993) appelle la méthode du mot à mot. Cette présentation a des avantages considérables:

- Les usagers peuvent exploiter leur connaissance de l'alphabet pour trouver plus rapidement le signe-lemme recherché.

- L'ordre alphabétique strict place les lemmes dans un système conventionnel qui permet de vérifier plus facilement la présence ou l'absence d'un terme dans la macrostructure à partir du moment où son orthographe est connue. De plus, les dictionnaires conceptuels qui organisent la macrostructure en fonction de l'ordre sémantique ne permettent pas d'assurer le traitement complet de toutes unités lexicales. L'ordre alphabétique reste donc la présentation qui sied le mieux pour les dictionnaires hybrides (Afane-Otsaga 2010).

Cette présentation demande aussi moins d'effort pour l'utilisateur du dictionnaire et permet au lexicographe de gagner du temps dans son travail. En effet, ce dernier peut rédiger ses articles dans n'importe quel ordre et les réorganiser automatiquement une fois la rédaction terminée.

\subsubsection{Sélection des lemmes}

Comme pour tous les dictionnaires, une fois la conceptualisation faite et les critères de sélection des lemmes établis, l'étape suivante consiste pour le lexicographe à sélectionner les unités lexicales qui doivent faire office de lemmes 
dans le dictionnaire. La sélection des lemmes pour un dictionnaire hybride est beaucoup plus difficile que celle qui est fait pour un dictionnaire ordinaire. Car un dictionnaire hybride doit non seulement être polyfonctionnel, mais aussi cibler plusieurs groupes d'usager. Ce qu'il faut retenir c'est que la macrostructure d'un dictionnaire hybride doit être sélectionnée à partir d'un corpus qui prend en compte l'ensemble des besoins des groupes d'usagers-cibles. La sélection d'un lemme ne doit donc pas se faire de manière arbitraire, mais doit répondre aux critères lexicographiques fixés dès le départ. Cependant, les critères fixés doivent tenir compte de la nature typologique du dictionnaire, mais aussi de la fréquence d'usage, par les groupes-cibles, des termes sélectionnés. Pour un dictionnaire hybride bilingue par exemple, les principes suivants doivent être respectés:

- $\quad$ Si le dictionnaire en préparation doit être de volume moyen, il est conseillé d'omettre les synonymes les moins connus ou les moins utilisés de la langue-source à condition, bien sur, que les plus connus ou les plus utilisés soient inclus. Cependant, si le dictionnaire vise aussi bien ceux qui maîtrisent la langue-cible que ceux qui la maîtrisent un peu moins, le mieux est d'inclure le maximum de synonymes possibles.

- Si le dictionnaire hybride en préparation doit aussi avoir pour fonction de favoriser la standardisation d'une des langues présentées et s'il vise un public jeune, il est conseillé d'y inclure les termes argotiques, vulgaires ou même des jargons, à condition d'attirer l'attention de l'usager sur le côté vulgaire ou insultant de ces expressions.

- Si la langue-cible du dictionnaire hybride est parlée dans un environnement culturel ou géographique différent de celui de la langue-source, il est important de prendre en compte la réalité sociologique de la languecible dans la sélection de la macrostructure. En d'autres termes, la sélection d'un item lexical comme lemme dans la langue-source peut être dictée par la nécessité de présenter son équivalent dans la langue-cible. Cette méthode est surtout applicable lorsqu'il y a un important écart culturel entre la langue-source et la langue-cible.

- Pour la compilation de dictionnaires hybrides bilingues qui incluent une langue-cible qui n'est pas encore assez développée, le lexicographe peut se retrouver confronté à l'absence d'un grand nombre de traductions équivalentes dans cette dernière. Dans ce cas, la préparation de la macrostructure dans la langue-source doit prendre en compte le plus de lemmes possibles pouvant se retrouver dans cette situation, afin d'amener le lexicographe à introduire des néologismes dans la langue-cible et de permettre à cette dernière de combler certaines lacunes lexicales et se mettre ainsi au même niveau que la langue-source. 
Certains critères peuvent aussi guider le lexicographe dans la sélection des lemmes dans un dictionnaire hybride bilingue. Il s'agit de:

- La fréquence d'utilisation des mots: l'analyse automatique des corpus au moyen de certains outils informatiques permet aujourd'hui d'avoir facilement ce type de données;

- $\quad$ La fonction des mots: le rôle que joue certains mots dans l'acquisition des connaissances dans la langue-cible aussi bien au plan académique que dans la vie de tous les jours;

- Les critères sémantiques: les mots ayant plusieurs sens ou plusieurs synonymes doivent faire l'objet d'une attention particulière. En effet, le dictionnaire doit donner l'opportunité aux usagers de devenir le plus compétent possible dans la langue-cible. Si un mot contient plusieurs sens ou plusieurs synonymes, l'utilisateur doit être capable de les distinguer lorsqu'ils sont utilisés.

Tout en appliquant ces critères, le lexicographe doit observer les règles suivantes:

- $\quad$ Regarder attentivement dans la base de données le sens des unités lexicales;

- Indiquer le contexte d'utilisation des termes les moins connus;

- Lorsqu'un terme est nouveau dans la langue et pas encore complètement établi dans celle-ci, cela doit être clairement indiqué dans son traitement.

\subsection{Microstructure des dictionnaires hybrides}

Pour être plus complet dans notre démonstration, nous présentons, dans les lignes qui suivent l'exemple d'une microstructure d'un dictionnaire hybride telle que nous l'avons proposé en 2010. Dans un dictionnaire, il y a plusieurs types de données proposées pour le traitement des signes-lemmes. Bien que ces données ne soient pas d'égale importance, la microstructure garde toujours plus ou moins la même organisation, puisque les catégories de données présentées dans un article sont plus ou moins les mêmes dans chaque article. Si le lexicographe décide que le programme de traitement doit contenir quatre catégories d'information (par exemple les parties du discours, les définitions, les synonymes et les homonymes), ces quatre types d'informations doivent apparaître dans chaque article (Rey-Debove 1971: 151).

Il faut cependant spécifier que certaines catégories de données peuvent être absentes ou omises dans certains articles, au cas où elles n'existeraient pas pour certains mots. Même lorsque ces données existent, le lexicographe peut juger nécessaire de ne pas les inclure dans certains articles. Par conséquent, le lexicographe doit identifier, à l'avance la microstructure obligatoire, c'est-à-dire la catégorie d'informations qui doit être commune à tous les articles. Dans les dictionnaires généraux monolingues, chaque article de dictionnaire devrait 
contenir des indications sur les parties du discours et une certaine forme de description sémantique, c'est-à-dire une paraphrase du sens ou un synonyme. Lorsque le lexicographe décide d'inclure d'autres données en dehors de celles qui sont obligatoires, on parle alors de microstructure obligatoire élargie (Gouws 1999: 45).

Une microstructure dans un dictionnaire hybride va nécessairement inclure des données élargies ou supplémentaires qui peuvent être utiles pour l'ensemble des groupes d'usagers-cibles. Cette microstructure sera principalement intégrée avec une dimension semi-intégrée. Cela signifie que les entrées co-textuelles seront directement présentées à la suite des paraphrases du sens et/ou des traductions équivalentes. Quelques données co-textuelles peuvent aussi être ajoutées à la fin de chaque article, en fonction du lemme traité. Le lexicographe doit simplement veiller à ne pas rendre l'article inutilement complexe (Gouws 2002).

De manière pratique, nous présentons l'exemple d'une microstructure d'un dictionnaire standard de traduction ayant des caractéristiques hybrides. Il s'agit précisément d'un dictionnaire bilingue ayant pour langue-source le français et pour langue-cible le fang. La particularité de ce dictionnaire réside dans le contenu hybride de sa microstructure qui présente à la fois les caractéristiques d'un dictionnaire bilingue et celle d'un dictionnaire monolingue. Cette microstructure se divise en trois principales composantes; les deux premières étant obligatoires et la dernière optionnelle (Afane-Otsaga 2010).

- La première composante obligatoire présente essentiellement le commentaire sur la forme et certains aspects du commentaire sur le sens du lemme. Le commentaire sur la forme présente ce que Hausmann et Wiegand (1989) appellent l'identification synchronique du lemme (prononciation phonétique, parties du discours, etc.), alors que le commentaire sur le sens présente les données explicatives sur le lemme (définition du lemme en français). Cependant, le commentaire sur le sens en français n'est pas proposé pour tous les lemmes. Il concerne seulement les signes-lemmes qui sont rarement utilisées par les groupes-cibles et pour ceux qui ont un sens culturel spécifique dans le contexte gabonais.

- $\quad$ La seconde composante obligatoire de la microstructure proposée est la plus importante aussi bien au niveau de la densité des données fournies qu'au niveau de la qualité de ces dernières. Cette composante, entière rédigée dans la langue-cible (le fang en l'occurrence), propose la traduction équivalente du lemme, suivie par le commentaire sur la forme et du commentaire sur le sens de cette traduction équivalente. Celle signifie que chaque traduction équivalente en fang est traitée comme s'il s'agissait du lemme principal d'un dictionnaire monolingue: identification synchronique de la traduction équivalente (prononciation phonétique, partie du discours, forme du pluriel, etc.), données explications (définition ou paraphrase du sens) de la traduction équivalente. Cette 
composante propose aussi des illustrations et des exemples sur la traduction équivalente, ainsi que quelques données optionnelles sur les antonymes, les synonymes ou les homonymes de cette traduction équivalente en fang lorsqu'elles existent. Cette partie peut aussi à proposer des renvois lorsqu'un item important de cet article est traité à un autre endroit du dictionnaire.

- La troisième et dernière composante de la microstructure est faite en français et dépendra de la traduction équivalente traitée. Cette composante constitue la microstructure élargie, parce qu'elle vient ajouter plus de données au traitement lexicographique que le minimum exigé. Cette composante présente des informations explicatives additionnelles ou des données culturelles en rapport avec la traduction équivalente. Il s'agit précisément de données encyclopédiques ou ethnologiques sur la traduction équivalente.

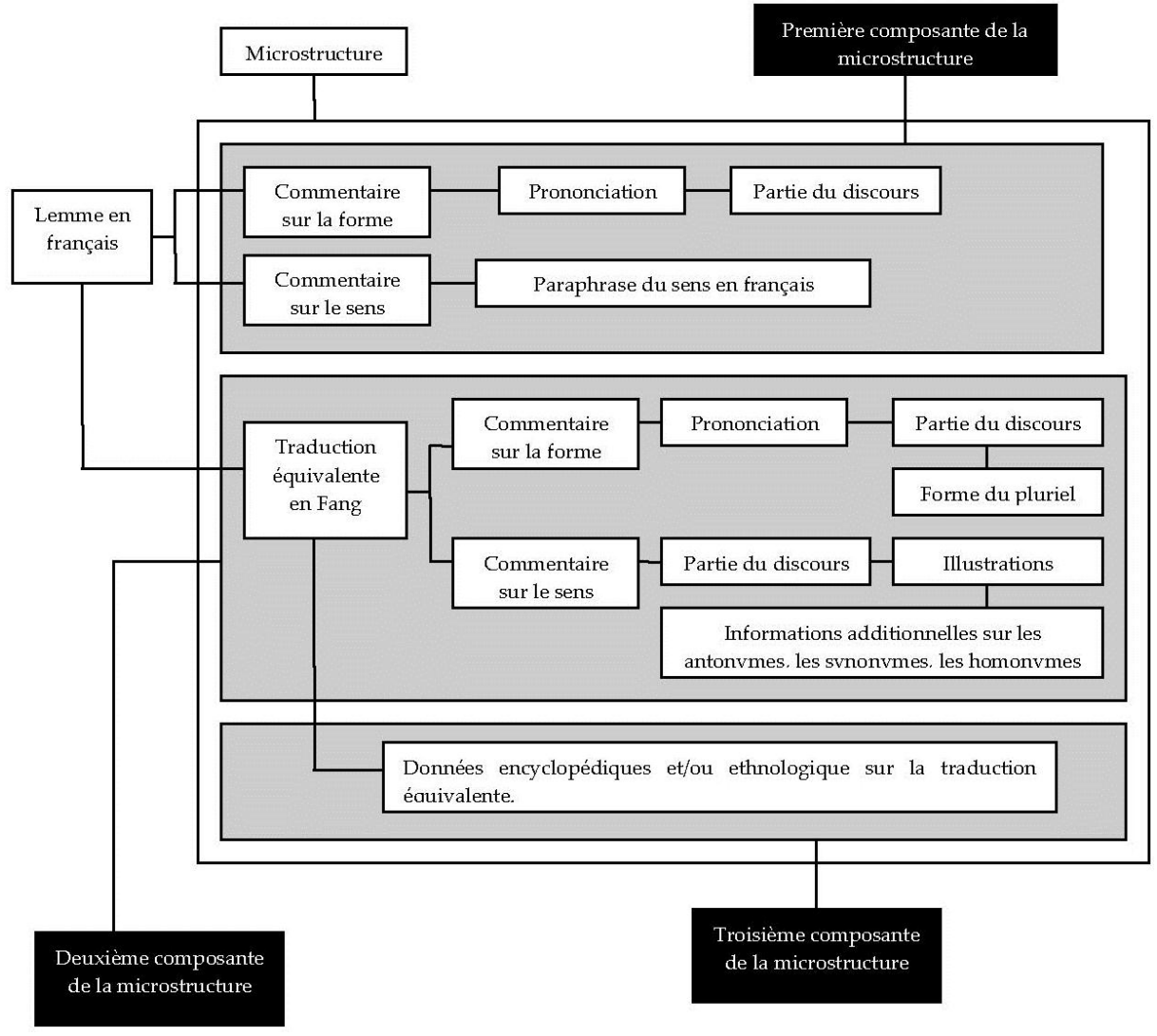

Il faut préciser que la microstructure proposée a pour objectif, non seulement de permettre aux usagers de transférer leurs connaissances du français vers le 
fang, de fournir aux locuteurs de la langue fang une description assez détaillée des unités lexicales et de favoriser la standardisation de cette langue. Une telle microstructure vise deux principaux groupes d'usagers-cibles: les locuteurs de la langue française qui souhaitent apprendre le fang et les locuteurs fang qui souhaitent améliorer leurs connaissances dans la langue fang, puisque le modèle proposé a une dimension bilingue, une dimension monolingue et une dimension encyclopédique.

La microstructure proposée peut être schématisée de la manière indiquée dans le diagramme. Deux exemples concrets de microstructure d'un dictionnaire bilingue standard hybride, avec les mots danse et dot, sont présentés ciaprès.

danse [dãs] n.f. Suite de mouvement rythmique du corps, évolution à pas réglés, le plus souvent à la cadence de la musique ou de la voix.

abok [abok] e.d. Ab. mebok. Ngura aval ya nfog nyol eyong azik ngëki dzya dalot. Ku e këlë anë abok binëga.

$\operatorname{dot}[\mathrm{d} \jmath t]$ n.f. Biens donnés par un tiers dans le contrat de mariage.

nsua [nswa] e.d. Ab. misua. Mibeng fam da kë bëkya mibeng eyong avëk minëga. Nsua Ndong a nga mvëk ngal obë mintët mëwom mëtan. $\Leftrightarrow$ bili bi kama.

+ Dans la tradition Africaine en général, et Fang en particulier, la dot est un ensemble de biens matériels et financiers qu'un homme apporte à la famille de sa fiancée pour sceller traditionnellement leur mariage. La cérémonie a souvent lieu dans le village de la femme en présence des deux familles. Elle se déroule en termes de négociations, chaque camp usant de stratégies verbales: la famille de l'homme voulant donner le moins possible, et celle de la femme voulant gagner le plus possible. Les deux fiancés n'interviennent généralement pas (mais ils peuvent être consultés en privé), toute la procédure est laissée aux parents, jusqu'au moment où les parents de la fiancée demandent à cette dernière de prendre l'argent proposé par les parents de l'homme. Si cette dernière rend l'argent aux parents de son prétendant, cela veut dire qu'elle ne veut pas épouser l'homme qui demande sa main. Mais si elle donne l'argent à ses parents, cela veut dire qu'elle accepte le mariage.

Explications sur les abréviations et symboles utilisés dans les articles

n.f.: Indication sur les parties discours en français

e.d.: Indication sur les parties du discours en fang

Ab.: Introduit la forme pluriel en fang

$\Leftrightarrow$ : Introduit un renvoi

+: Introduit des données culturelles

On peut ainsi voir, dans les exemples proposés, que les articles des dictionnaires hybrides peuvent se révéler plus complexes et plus fournis que ceux des 
dictionnaires ordinaires. Ces articles ont deux fonctions principales: (1) aider les utilisateurs à transférer leurs connaissance en français vers le fang; et (2) aider les locuteurs fang à améliorer leurs connaissances dans cette langue. C'est pour cela que le traitement lexicographique présente les lemmes en français avec leurs traductions équivalentes en fang et ces dernières sont aussi entièrement traitées comme s'il s'agissait de lemme à part entière. Un tel dictionnaire présente aussi bien une dimension bilingue et une dimension monolingue. Ce qui signifie que plusieurs groupes d'utilisateurs peuvent trouver leur compte dans ce type de dictionnaire.

\section{Conclusion}

Le présent article avait pour but premier de montrer, qu'avec l'évolution actuelle du monde, la lexicographie ne va véritablement continuer à jouer son rôle de concepteur d'ouvrages de référence que si s'adapte à cette évolution. Ce qui signifie qu'elle va devoir améliorer la qualité de ses produits, aussi bien au plan du fond qu'à celui de la forme. L'utilisateur moderne du dictionnaire a des besoins variés. Il faut donc aux usagers des dictionnaires polyvalents, c'est-àdire susceptibles de satisfaire plusieurs groupes d'usagers à la fois. Les usagers souhaitent avoir des produits qui soient aussi élargis que leurs besoins de connaissance et de communication. À notre avis, les seuls produits qui soient capables de satisfaire leurs besoins, ce sont les dictionnaires hybrides. Pour satisfaire les besoins des usagers futurs il deviendra difficile de ne pas compiler des dictionnaires polyfonctionnels et poly-usagers. D'où notre question: les dictionnaires hybrides ne sont-ils pas le futur de la lexicographie?

\section{Note}

$\dagger \quad$ Ils peuvent avoir plusieurs fonctions.

\section{Bibliographie}

Afane-Otsaga, T. 2002. Le rôle du dictionnaire dans le développement des langues gabonaises. Emejulu, J.D. (Éd). 2002. Éléments de lexicographie gabonaise, Tome II: 206-229. New York: Jimacs-Hillman Publishers.

Afane-Otsaga, T. 2010. Dictionary and Standardization of Fang: The Standard Translation Dictionary as an Instrument in the Standardization of Fang. VDM Verlag Dr. Müller.

Al-Kasimi, A.M. 1977. Linguistics and Bilingual Dictionaries. Leyde: E.J. Brill.

Gouws, R.H. 1999. Mediostructural Presentation, Textual Condensation and User-Orientation in the WAT X. Lexicographica 15: 4-37.

Gouws, R.H. 2002. Using a Frame Structure to Accommodate Cultural Data. Emejulu, J.D. (Éd). 2002. Éléments de lexicographie gabonaise, Tome II: 54-69. New York: Jimacs-Hillman Publishers. 
Hausmann, F.J. et H.E. Wiegand. 1989. Component Parts and Structures of General Monolingual Dictionaries: A Survey. Hausmann, F. J. et al. (Éds.). 1989-1991. Wörterbücher. Ein internationales Handbuch zur Lexicographie/Dictionaries. An International Encyclopedia of Lexicography/Dictionnaires. Encyclopédie internationale de lexicographie: 328-360. Berlin/New York: Walter de Gruyter.

Malkiel, Y. 1980. The Lexicographer as a Mediator between Linguistics and Society. Zgusta, L. (Éd). 1980. Theory and Method in Lexicography: Western and Non-Western Perspectives: 43-58. Columbia: Hornbeam Press.

Rey-Debove, J. 1971. Étude linguistique et sémiotique des dictionnaires français contemporains. La Haye: Mouton.

Ščerba, L.V. 1940. Towards a General Theory of Lexicography. International Journal of Lexicography 8(4): 315-350, 1995.

Svensén, B. 1993. Practical Lexicography. Principles and Methods of Dictionary-making. Oxford/New York: Oxford University Press.

Zgusta, L. 1971. Manual of Lexicography. La Haye: Mouton. 


\title{
Glosse en vertaalkomplemente in tweetalige woordeboeke
}

\author{
Herman L. Beyer, Departement Taal- en Literatuurstudie, \\ Universiteit van Namibië, Windhoek, Namibië (hbeyer@unam.na)
}

Opsomming: Hierdie artikel ondersoek twee tipes kontekstualiserende inskrywings in tweetalige woordeboeke, naamlik glosse en vertaalkomplemente. Glosse is 'n element van die klas diskriminators, wat in tweetalige woordeboeke ter wille van ekwivalentdiskriminasie aangewend word om kommunikatiewe ekwivalensie te bewerkstellig. Die verband tussen die konsepte glos en vertaalkomplement, wat oor die afgelope drie dekades gewissel het, word uiteengesit. Vertaalkomplement het blykbaar met verloop van tyd uiteindelik ten gunste van glos verdwyn. Glosse word vervolgens onderskei van die ander tipes diskriminators, naamlik betekenisverklarings en etikette. Die mikrostrukturele plasing en gepaardgaande adresseringstruktuur van glosse word binne die raamwerk van 'n kommunikatiewe metaleksikografie ondersoek. Binne hierdie raamwerk word 'n alternatiewe denotasie aan die term leksikografiese funksie toegeken as wat byvoorbeeld binne die funksieteorie geld. Die vasstelling van die funksie van hierdie tipe inskrywing lei tot die gevolgtrekking dat glosse aan lemmata geadresseer moet word en dat vertaalekwivalente in prosedures van nielemmatiese adressering aan glosse geadresseer behoort te wees, anders as wat tans in die Afrikaanse tweetalige leksikografie van toepassing is. Ten slotte word die herwinning van die inskrywingstipe vertaalkomplement en sy klassifikasie as diskriminator, wat in die lig van die herwaardering van glosse klaarblyklik steeds 'n belangrike leksikografiese funksie vervul, voorgestel.

Sleutelwoorde: ADRESSERINGSTRUKTUUR, BETEKENISVERKLARING, DISKRIMINATOR, DOEL, ETIKET, FUNKSIE, GLOS, KOMMUNIKATIEWE METALEKSIKOGRAFIE, KONTEKS, KONTEKSTUALISERENDE INSKRYWING, LEKSIKOGRAFIE, MIKROSTRUKTUUR, TWEETALIGE WOORDEBOEK, VERTAALEKWIVALENT, VERTAALKOMPLEMENT

Abstract: Glosses and Translation Complements in Bilingual Dictionaries.
This article investigates two types of contextualising entries in bilingual dictionaries, i.e. glosses
and translation complements. Glosses represent an element of the class of discriminators, which is
employed to facilitate equivalent discrimination in order to ensure communicative equivalence.
The relationship between the concepts gloss and translation complement, which has varied over the
last three decades, is outlined. It seems that translation equivalent eventually disappeared in favour
of gloss. Glosses are distinguished from the other types of discriminators, i.e. meaning explanations
and labels. The microstructural position and addressing structure of glosses are investigated within
the framework of a communicative metalexicography, which proposes an alternative denotation to
the term lexicographic function than applies in for example the function theory. The establishment of
the function of glosses results in the conclusion that glosses should be addressed to lemmata and
that glosses should themselves be the addresses of translation equivalents through procedures of
non-lemmatic addressing. These proposed procedures differ from the status quo in the Afrikaans
bilingual lexicography. Ultimately the recovery of the entry type translation complement and its 
classification as a discriminator is proposed, as it still fulfils an important function in the light of the re-appreciation of glosses.

Keywords: ADDRESSING STRUCTURE, BILINGUAL DICTIONARY, COMMUNICATIVE METALEXICOGRAPHY, CONTEXT, CONTEXTUALISING ENTRY, DISCRIMINATOR, FUNCTION, GLOSS, LABEL, LEXICOGRAPHY, MEANING EXPLANATION, MICROSTRUCTURE, PURPOSE, TRANSLATION COMPLEMENT, TRANSLATION EQUIVALENT

\section{Inleiding}

Dit is hoofsaaklik aan die substansiële omvang en verskeidenheid van wetenskaplike publikasies deur Rufus H. Gouws te danke dat daar vandag 'n teoretiese fundering van die Afrikaanse leksikografie bestaan. In die tweetalige leksikografie met Afrikaans het Gouws van fundamentele tot hoogs gevorderde werk gedoen - vergelyk in hierdie verband onder vele meer Gouws (1988, 1989, 1990, 1994, 1996, 1996a, 1996b, 1999, 2000, 2001, 2002, 2002a, 2003, 2004, 2004a, 2005, 2007, 2007a), Louw en Gouws (1996), Prinsloo en Gouws (2000), Gouws, Prinsloo en De Schryver (2004), Gouws en Prinsloo (2005) en Wiegand en Gouws (2011).

Hierdie bydrae wil in die gees van die wetenskap op Gouws se grondlegging voortbou deur 'n herwaardering van leksikografiese glosse as 'n tipe diskriminator, dit wil sê 'n tipe ekwivalentdiskriminerende inskrywing, in tweetalige woordeboeke te bied. Die konsepte glos en vertaalkomplement, soos wat dit in die relevante literatuur aangebied word, word krities binne die raamwerk van 'n kommunikatiewe metaleksikografie en aan die hand van bestaande woordeboekdata sowel as 'n woordeboekprojek wat tans onderneem word, ondersoek. 'n Alternatiewe denotasie vir die term leksikografiese funksie word ook binne die kommunikatiewe benadering aangebied en toegepas. Die resultaat van dié ondersoek is 'n herkarakterisering van glosse en 'n voorstel vir die herwinning van die term vertaalkomplement en sy klassifikasie as 'n diskriminator.

\section{Kontekstualisering en diskriminators}

Gouws (1996) vereis dat tweetalige woordeboeke moet bydra tot kommunikatiewe ekwivalensie. Ter wille hiervan moet die leksikograaf die teikengebruiker van 'n tweetalige woordeboek in staat stel om die gepaste vertaalekwivalent uit 'n aangebode vertaalekwivalentparadigma te selekteer vir onder meer suksesvolle teksresepsie, teksproduksie of vertaling in 'n bepaalde gebruikersituasie. Die teikengebruiker moet dus suksesvolle ekwivalentdiskriminasie kan toepas, en die leksikograaf kan die gebruiker hierin bystaan deur die aanbod van ekwivalentdiskriminerende inskrywings naas vertaalekwivalente in woordeboekartikels. Ekwivalentdiskriminerende inskrywings het ten doel om hulle adresse 
te kontekstualiseer, waar met konteks bedoel word beide die linguistiese omgewing (d.w.s. die semantiese en kotekstuele omgewings) én buitetalige (oftewel pragmatiese) omgewing waarbinne die koördinering van die lemma met vertaalekwivalente plaasvind. Ekwivalentdiskriminerende inskrywings is dus gewoonlik per definisie ook kontekstualiserende inskrywings. ${ }^{1}$

Beyer (2009) bied 'n teoretiese basis vir kontekstualisering in tweetalige woordeboeke en klassifiseer kontekstualiserende inskrywings soos volg:

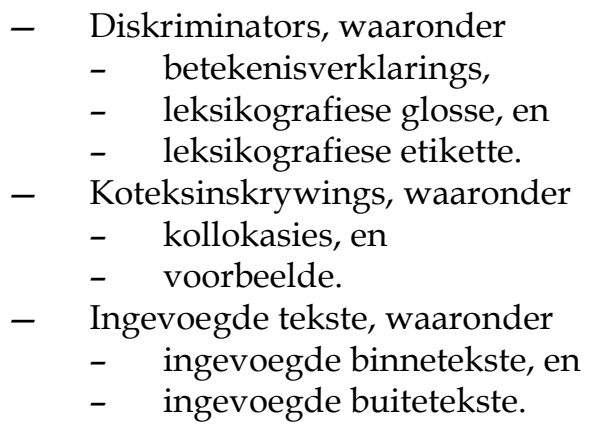

Vir die doel van hierdie artikel word op die klas diskriminators gefokus. Aanvanklik word die tipes diskriminators van mekaar onderskei ooreenkomstig die stand van die teorie, waarna glosse van nader beskou word.

\section{Vertaalkomplemente, glosse, betekenisverklarings en etikette}

\subsection{Van vertaalkomplemente tot glosse}

Die term vertaalkomplement is aanvanklik deur Iannucci (1985) voorgestel as 'n tipe inskrywing wat gebruik word om 'n vertaalekwivalent semanties-pragmaties te voltooi indien die lemma 'n spesifieker of beperkter betekenis as die vertaalekwivalent verteenwoordig. Vergelyk Iannucci (1985: 61) se voorbeelde in hierdie verband:

(1) (a) Duits essen: Engels eat (said of a human)

(b) Duits fressen: Engels eat (said of an animal)

Die inskrywings said of a human in (1)(a) en said of an animal in (1)(b) geld dan as vertaalkomplemente. Die behoefte aan hierdie tipe semanties-pragmatiese bepalers van vertaalekwivalente "arises very infrequently in bilingual dictionaries" (Iannucci 1985: 62). Vertaalkomplemente behoort in die doeltaal aangebied te word en mikrostruktureel ná hulle adresse (d.w.s. die vertaalekwivalente) te verskyn (Iannucci 1985).

'n Inskrywingstipe wat volgens Iannucci baie gereelder as vertaalkomplemente in tweetalige woordeboeke behoort te figureer, is betekenisdiskrimina- 
tors van lemmata. Die volgende voorbeeld uit The New College Spanish E English Dictionary (Williams 1968) word onder meer voorgehou (Iannucci 1985: 59):

(2) spring [...] (season of the year) primavera; (issue of water from earth) fuente; (of a watch) resorte; (of a mattress) muelle; (of an automobile) ballesta; (leap) brinco, salto; (springiness) elasticidad.

Die volgende inskrywings in (2) geld as betekenisdiskriminators:

(3) (a) season of the year en issue of water from the earth

(b) of a watch, of a mattress en of an automobile

(c) leap en springiness

Volgens Iannucci (1967) kan die volgende inskrywings as betekenisdiskriminators geld:

(4) (a) leksikografiese betekenisparafrases (ook definisies genoem) (soos in (3)(a));

(b) woordsinonieme (soos in (3)(c));

(c) kontekswoorde of -frases (soos in (3)(b));

(d) die (tipe) onderwerp(e) waarmee 'n werkwoordlemma tipies verbind;

(e) die (tipe) voorwerp(e) waarmee 'n werkwoordlemma tipies verbind;

(f) die selfstandige naamwoord(e) waarmee 'n adjektieflemma tipies verbind;

(g) etikette;

(h) aanduiders van (sub)woordsoort; en

(i) voorbeelde.

Betekenisdiskriminators behoort in die doeltaal aangebied te word en mikrostruktureel voor hulle adresse (d.w.s. die vertaalekwivalente) te verskyn,

simply because it is a lexicographical convention that explanatory or descriptive matter of any kind refers to what precedes rather than to what follows, and sense discriminations refer to the different senses of the preceding entry word (Iannucci 1985: 58-59).

Vergelyk ook Al-Kasimi (1977).

Die beginsel van betekenisdiskriminasie geld ook by Iannucci (1967: 205) se voorstel vir die koördinering van die tweetalige woordeboek met die eentalig verklarende woordeboek, "thus making the definitions in the monolingual dictionary serve as meaning discriminators for the bilingual dictionary". Een van die praktiese probleme wat Iannucci (1967: 205) self met hierdie voorstel voorsien, is dat die leksikograaf aan die semantiese ontleding van die verkla- 
rende woordeboek gebonde sou wees: "The discrimination there may be too fine at some point and not fine enough at some point." Hoewel oplossings aan die hand gedoen word, illustreer hierdie probleem 'n fundamentele tekortkoming in die benadering van betekenisdiskriminasie wanneer die bedoelde gebruik(e) van 'n tweetalige woordeboek ter sprake is.

Die gebruiker van ' $n$ tweetalige woordeboek is naamlik nie op soek na die betekenis van 'n lemma nie, maar na die vertaalekwivalent(e) waarmee die brontaalbetekenis van die lemma in die doeltaal uitgedruk kan word (vergelyk Zgusta 1971, Gouws 1989). Die werk van die vertalende leksikograaf moet dus nie diskriminasie tussen betekeniswaardes fasiliteer nie, maar diskriminasie tussen vertaalekwivalente, en hiervoor moet tweetalige woordeboeke nie betekenisgestruktureerd wees nie, maar ekwivalensiegestruktureerd (Manley et al. 1988). Die beginsel van betekenisdiskriminasie wat in verklarende woordeboeke toegepas word, moet in tweetalige woordeboeke vervang word deur die beginsel van ekwivalentdiskriminasie (Gouws 1996: 27-28).

Die term glos word aanvanklik deur Zgusta (1971: 329) voorgestel en soos volg beskryf:

[A] gloss is not an explanation: whereas the latter [d.i. ' $n$ betekenisverklaring HLB] approaches the lexicographic definition, the gloss does not attempt more than to indicate as succinctly as possible the relevant difference, the critical features, the sphere of application, etc.

Later onderskei Zgusta (1987) tussen verklarende glosse en beperkende glosse. Eersgenoemde tipe vervul die funksie ${ }^{2}$ van betekenisbeskrywing, dit wil sê inskrywings soos (4)(a) en (b); laasgenoemde is minstens die ekwivalent van inskrywingstipes soos (4)(c) tot (f). In Beyer (2009) se klassifikasie van kontekstualiserende inskrywings word aanduiders van woordsoort $((4)(\mathrm{h}))$ en voorbeelde ((4)(i)) nie as kontekstualiserende inskrywings en diskriminators onderskeidelik erken nie; gevolglik word in hierdie artikel nie verdere aandag aan dié inskrywingstipes gegee nie. Die belangrike onderskeid tussen glosse en betekenisverklaring enersyds en tussen glosse en etikette andersyds word in afdeling 3.2 en 3.3 onderskeidelik behandel. Vir die doel van hierdie bespreking verwys die term glos dus uitsluitlik na Zgusta se beperkende glosse.

In sy bydrae tot die tweetalige metaleksikografie neem Gouws (1989: 171) die term vertaalkomplement by Iannucci oor, maar gebruik dit "effens anders [...] as wat Iannucci voorstel deurdat dit eerder verwys na semantiese konteksleiding" (oftewel: kontekstualisering - vergelyk Beyer 2009), wat aansluit by Zgusta se konsep van beperkende glosse. Hierdeur verkry die term vertaalkomplement op die oog af twee potensiële lesings in die algemene tweetalige metaleksikografie: dié van Zgusta se beperkende glosse enersyds, soos inskrywingstipes (4)(c) tot (f), en andersyds dié van Iannucci se inskrywings wat in spesiale gevalle gebruik word om die mate waarin die lemma 'n spesifieker of beperkter betekenis as die vertaalekwivalent verteenwoordig aan te dui, soos die inskrywings in (1). Maar die twee lesings is nie wedersyds uitsluitend nie; 
trouens, as die beginsel van ekwivalentdiskriminasie in plaas van betekenisdiskriminasie in tweetalige woordeboeke toegepas word, wil dit voorkom of Iannucci se konsep uitgedien is en in 'n groot mate deur Zgusta se glos en Gouws se sinonimiese vertaalkomplement geënkapsuleer word.

Die term vertaalkomplement met Gouws se denotasie word in studies soos Louw en Gouws (1996), Louw (1998) en De Wet (1999) gebruik, maar blykbaar verdwyn dié term dan. Uit studies in die Afrikaanse tweetalige leksikografie ná 1998, soos Kotzé (1999), Gouws (2002a en 2003), Potgieter (2008) en Beyer (2009), wil dit voorkom asof die term glos (in gedeeltelike navolging van Zgusta (1971) en Manley et al. (1988)) voorkeur geniet.

Die gekursiveerde inskrywings tussen hakies in elk van die volgende artikels uit Pharos word dus in die hedendaagse Afrikaanse metaleksikografie as glosse beskou ${ }^{3}$ :

(5) (a) skitterend =rende sparkling, glittering, glittery (eyes, diamonds, etc.); brilliant, splendid, scintillating (performance etc.); shining (example etc.); superb (idea etc.); superlative (display, specimen, etc.); outstanding (plan, success, etc.); magnificent (reception etc.); glorious (victory, weather, etc.); spectacular (show etc.); vivid (colours); effulgent (poet.); 'n $\sim e$... wees excel as a ... (cook etc.).

(b) aanbreek $=g e=, v b$. , (day) break, dawn; (night) fall, close in; (age) dawn; (autumn, winter) set in; (spring, summer) begin; (time) come, be at hand $[\ldots]$

Volgens Gouws (1989) word glosse aan vertaalekwivalente geadresseer, wat 'n prosedure van nielemmatiese adressering (vergelyk Louw en Gouws 1996) verteenwoordig. Uit die twee woordeboekartikels in (5) blyk dit dat die mikrostrukturele plasing van glosse in dieselfde woordeboek kan wissel: In die artikel in (5)(a) volg glosse op hulle adresse, en in die artikel in (5)(b) gaan glosse hulle adresse vooraf (indien die voorgenoemde adresseringsbeginsel geld). Volgens die "Gebruiksriglyne" in Pharos word glosse slegs voor hulle adresse geplaas om aan te dui dat die tersaaklike werkwoord onoorganklik gebruik word (p. xiii). 'n Soortgelyke prosedure kom in sommige internasionale tweetalige woordeboeke voor. Vergelyk die volgende artikels uit die Duits-Engelsdeel van Oxford:

(6) (a) konzipieren tr. V. draft <speech, essay>; draw up, draft <plan, policy, etc. $>$; design $<$ device, car, etc. $>$

(b) klein Adj. little; small <format, letter $>$; little <finger, toe $>$; small, short <steps>

(c) komplett adv. 1 fully <furnished, equipped> 2 (ugs.: ganz und gar) completely; totally 
(d) klirren itr. V. <glasses, ice cubes> clink; <weapons in fight> clash; <window pane $>$ rattle; <chains, spurs $>$ clank, rattle; <harness $>$ jingle

(e) Schar die crowd; horde; (von Vögeln) flock

(f) Bescherung die $\mathbf{1}$ (zu Weihnachten) giving out of the Christmas presents $2[\ldots]$

$\mathrm{Na}$ aanleiding van die woordeboekdata in (6) kan die volgende tipes glosse onderskei word:

(7) (a) aanduiders van die tipiese voorwerpe van 'n oorganklike werkwoord, soos die gekursiveerde inskrywings tussen punthakies in (6)(a);

(b) aanduiders van tipiese selfstandige naamwoorde wat deur 'n adjektief bepaal word, soos die gekursiveerde inskrywings tussen punthakies in (6)(b);

(c) aanduiders van tipiese werkwoorde of adjektiewe wat deur 'n bywoord bepaal word, soos die gekursiveerde inskrywings tussen punthakies in $(6)(\mathrm{c})$;

(d) aanduiders van tipiese onderwerpe van 'n werkwoord, soos die gekursiveerde inskrywings tussen punthakies in (6)(d);

(e) aanduiders van tipiese komplemente van selfstandige naamwoorde, soos von Vögeln in (6)(e);

(f) aanduiders van buitetalige konteks, soos zu Weihnachten in (6)(f).

Al vertoon die glosse in (7)(a) tot (e) grammatiese eienskappe, bly die doel om pragmatiese konteks te spesifiseer. In die lig van Zgusta (1971: 330) se standpunt dat dit nie baie belangrik is om (in die metaleksikografiese gesprek) uitgebreid aandag aan die vorm van glosse te gee nie, is dit nie duidelik of die verskillende artikelgleuwe waarin verskillende tipes glosse ten opsigte van hulle adresse in een woordeboek geplaas word en die verskillende tipes tipografiese en nietipografiese struktuurmerkers werklik funksioneel is nie. Die resultate van gerigte gebruikersnavorsing sou uitsluitsel kon gee, maar so ver vasgestel kon word, is geen verslae van sodanige navorsing gepubliseer nie.

In teenstelling tot Pharos, Oxford, Hachette en Van Dale word glosse in hulle verskillende vorme in die Engels-Duits-aanlynwoordeboek Collins blykbaar altyd voor hulle adresse geplaas. Die plasing van glosse wissel dus van woordeboek tot woordeboek, en kan ook in 'n enkele woordeboek na gelang van beleid wissel, soos deur die data in (6) bewys is.

In navolging van Gouws (1989) word glosse in Pharos in die doeltaal aangebied aangesien hulle aan doeltaalinskrywings geadresseer is. Ook ten opsigte hiervan kan nie van 'n universele beleid sprake wees nie. In Collins, Hachette, 
Oxford en Van Dale word glosse byvoorbeeld in die brontaal aangebied. In afdeling 4 word op die bostaande aspekte teruggekeer.

\subsection{Glosse en betekenisverklarings}

Die klas betekenisverklarings bestaan enersyds uit betekenisparafrases, wat die denotatiewe betekenisse van brontaalinskrywings deur 'n semasiologiese aanbod van betekenisinligting verskaf, en andersyds uit woordsinonieme, wat die denotatiewe betekenisse van brontaalinskrywings deur 'n onomasiologiese aanbod van betekenisinligting verskaf (vergelyk Louw 2000). In tweetalige woordeboeke is die funksie van betekenisverklaring nie om die betekeniswaarde van die lemma weer te gee sodat die gebruiker die betekenis van die lemma kan verstaan nie, maar eerder om slegs daardie onderskeidende semantiese kenmerke van die lemma weer te gee wat nodig is om funksionele ekwivalentdiskriminasie te fasiliteer. As sodanig verteenwoordig betekenisverklaring die eksplisering van die semantiese konteks waarbinne vertaalekwivalente met die lemma gekoördineer word. Hierdie doel word in die meeste gevalle effektief deur woordsinonieme (in plaas van betekenisparafrases) vervul. Iannucci (1967) vind ook dat lang, formele betekenisparafrases soos wat in verklarende woordeboeke aangewend word onvanpas en (veral in gedrukte woordeboeke) 'n vermorsing van waardevolle ruimte is. Hier geld Bergenholtz en Gouws (2007) se eis van korrektheid, volledigheid en relevansie aan betekenisparafrases ewenwel.

In Zgusta (1971) se funksiebeskrywing van glosse is dit duidelik dat glosse nie betekenisverklaring ten doel het nie, aangesien hulle nie die semantiese konteks aandui waarbinne vertaalekwivalente met die lemma gekoördineer word nie, maar eerder die pragmatiese konteks. Derhalwe kan 'n glos nie die vorm van ' $n$ betekenisparafrase of ' $n$ woordsinoniem aanneem nie. Dit beteken egter nie dat betekenisverklarings én glosse nie ten opsigte van dieselfde betekeniswaarde van 'n lemma mag optree nie; trouens Gouws (1989: 172) verklaar dat dit die ideaal is dat albei tipes inskrywings in een artikel gebruik moet kan word, soos wat die geval is in die artikel van break in Collins (sien figuur 1).

Met betrekking tot die eerste betekeniswaarde van die lemma break as selfstandige naamwoord word die inskrywing fracture as betekenisverklaring in die vorm van 'n woordsinoniem aangebied en gevolg deur die glos in bone, pipe, relations, wat die vertaalekwivalent Bruch voorafgaan. Die hantering van die tweede betekeniswaarde vertoon dieselfde strategie.

'n Verdere verskil tussen betekenisverklarings en glosse wat minstens in die literatuur getref word, is dat eersgenoemde uitsluitlik aan brontaalinskrywings geadresseer is, terwyl laasgenoemde uitsluitlik aan doeltaalinskrywings geadresseer is (vergelyk byvoorbeeld Gouws 1989: 172). Betekenisverklarings en glosse word derhalwe as twee verskillende tipes diskriminators beskou, soos wat die verskillende nietipografiese struktuurmerkers illustreer wat in Collins (en Pharos) op hulle van toepassing is. 


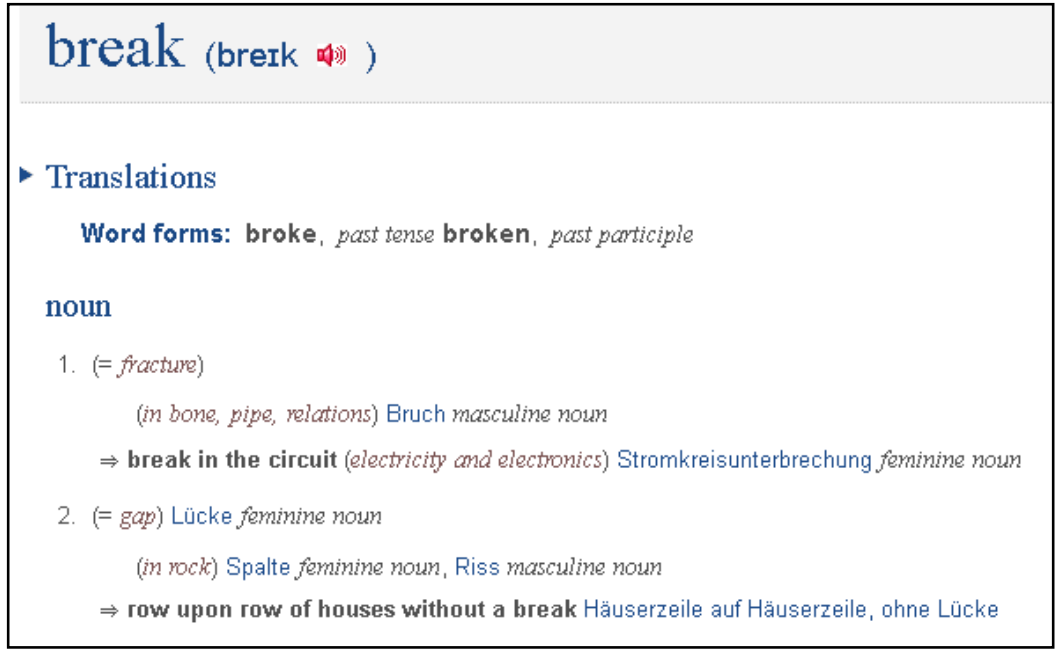

Figuur 1: Uittreksel van die artikel van break uit Collins

\subsection{Glosse en etikette}

Gouws $(1988,1989)$ lê die grondslag vir die beskrywing van leksikografiese etikette in die Afrikaanse leksikografie. Op hierdie basis ontwikkel Beyer (2011) aan die hand van tweetalige woordeboeke 'n algemene etikettipologie. 'n Etiket kan beskryf word as

'n bepaalde tipe meta-inskrywing in 'n woordeboekartikel met die funksie om 'n brontaal- of doeltaalinskrywing se uitsonderlikheid in terme van (i) die woordeboektipe, (ii) die relevante linguistiese kriteria en (iii) die woordeboekspesifieke konteks te ekspliseer ten einde kommunikatiewe sukses vir die teikengebruiker te bewerkstellig. (Vergelyk Beyer 2011: 443.)

Beyer (2011) se tipologie van etikette onderskei drie hoofklasse, naamlik domeinetikette (waaronder geografiese, temporele, frekwensie-, tegniese en kultuuretikette ressorteer), linguistiese etikette en stilistiese etikette (waaronder registeretikette, sosiostilistiese etikette en stilisties-funksionele etikette ressorteer).

Soos blyk uit die bostaande beskrywing en tipologie van leksikografiese etikette, is hulle primêre doel om op bepaalde gebruiksbeperkinge van bron- of doeltaalinskrywings binne 'n bepaalde gebruikersituasie te wys. As sodanig is hulle verplig by brontaal- of doeltaalinskrywings wat leksikografies gemerk is, en hulle vorme word presies voorgeskryf in die woordeboekplan. Hulle ekwivalentdiskriminerende funksie kan gevolglik as sekondêr beskryf word, wat hulle tewens voldoende vervul. Die aanduiding van gebruiksbeperkinge wat vir lemmata of vertaalekwivalente geld, kan nie deur glosse uitgedruk word 
nie. Indien 'n glos wel gebruik word om 'n bron- of doeltaalinskrywing se gebruiksfeer aan te dui, is sodanige gebruiksfeer nie leksikografies gemerk nie. Leksikografiese etikette geniet voorrang bo glosse. Die aanwending van 'n etiket moet egter nie die gebruik van glosse in 'n woordeboekartikel uitsluit nie. Ten spyte van die leksikografiese gemerktheid van 'n bron- of doeltaalinskrywing kan 'n glos steeds bykomend aangewend word om ekwivalentdiskriminasie te help bewerkstellig.

\section{Glosse en vertaalkomplemente: 'n herwaardering}

Na Gouws (1989) se oorname en aanpassing van Iannucci (1985) se term vertaalkomplement is die aangepaste identiteit en funksie van dié term vir ongeveer 'n dekade lank in die Afrikaanse metaleksikografie gebruik voordat dit in die literatuur deur die term glos vervang is. Dit blyk gevolglik dat die term vertaalkomplement in al sy potensiële lesings uitgedien is. In hierdie afdeling sal egter aangetoon word dat Iannucci (1985) se konsep van vertaalkomplement in die moderne tweetalige leksikografie steeds kan geld en dat 'n formele onderskeid tussen die begrippe glos en vertaalkomplement nodig is. Hierdie formele onderskeid word op grond van die funksies en die gepaardgaande adresseringstrukture van dié twee tipes inskrywings getref.

Op hierdie stadium is dit nodig om die gebruik van die term funksie te verduidelik, veral in die lig van die gebruik daarvan in die sogenaamde moderne teorie van leksikografiese funksies (ook die "funksieteorie" genoem) om te verwys na die bevrediging van spesifieke tipes inligtingsbehoeftes by 'n spesifieke tipe teikengebruiker in 'n spesifieke tipe gebruikersituasie (vergelyk byvoorbeeld Tarp 2008). Vir die doel van hierdie artikel kan die funksieteorie se konsep van funksie deur die term gebruik uitgedruk word: 'n Woordeboek word deur 'n spesifieke tipe teikengebruiker gebruik om spesifieke tipes inligtingsbehoeftes in 'n spesifieke tipe gebruikersituasie te bevredig; die woordeboek het dus bepaalde tipes gebruike. ${ }^{4}$

Wanneer 'n kommunikatiewe benadering tot die leksikografie gevolg word (vergelyk Beyer 2006), word aanvaar dat die leksikograaf tydens die leksikografiese proses bepaalde tipes leksikografiese data in bepaalde tipes leksikografiese boodskappe (tekste) enkodeer, wat tydens die woordeboekgebruiksproses deur die teikengebruiker gedekodeer word om sekere tipes inligting te onttrek vir interpretasie en toepassing in die gebruikersituasie (vergelyk Beyer 2009). Die leksikografiese proses enersyds en die gebruiksproses andersyds vorm die primêre komponente van die oorkoepelende proses van leksikografiese kommunikasie. Binne hierdie proses het elke tekselement in die woordeboek ' $n$ bepaalde bydraende doel en funksie. Die doel van 'n tekselement is altyd om die doel van die teks waartoe dit behoort en daardeur die suksesvolle bedoelde gebruik (en die bedoelde nut) van die woordeboek te ondersteun deurdat daarin 'n bepaalde tipe of tipes leksikografiese data geënkodeer is. In die kommunikasieteorie word die funksie van kommunikasie geassosieer met die 
doel en effek daarvan (Steinberg 1994), en die effek kan intensioneel of nieintensioneel wees (Steinberg 2007). Toegepas op leksikografiese kommunikasie kan die funksie van 'n leksikografiese tekselement dan beskryf word as die produk van die doel en die intensionele effek daarvan by die teikengebruiker:

DOEL (v.d. tekselement) + INTENSIONELE EFFEK (by die teikengebruiker) = FUNKSIE

Hiervolgens kan die funksie van 'n vertaalekwivalentaanduider (as tekselement) in 'n vertalende woordeboek vir gebruik in 'n vertaalsituasie in tabel 1 voorgestel word:

Tabel 1: Die funksie van ' $n$ bepaalde tipe tekselement in die leksikografiese kommunikasieproses

\begin{tabular}{|l|l|}
\hline \multicolumn{2}{|c|}{ Die funksie van 'n vertaalekwivalentaanduider } \\
\hline Doel (van die tekselement) & $\begin{array}{l}\text { Intensionele effek (by die teiken- } \\
\text { gebruiker) }\end{array}$ \\
\hline $\begin{array}{l}\text { Die doel van 'n vertaalekwivalent- } \\
\text { aanduider is om die vertaalekwiva- } \\
\text { lent wat in 'n bepaalde semanties- } \\
\text { pragmatiese konteks met die lemma } \\
\text { gekoördineer word, weer te gee, }\end{array}$ & $\begin{array}{l}\text { vertaling van die brontaalitem in } \\
\text { daardie semanties-pragmatiese kon- } \\
\text { teks kan lewer. }\end{array}$ \\
\hline
\end{tabular}

Die funksie van 'n vertaalekwivalentaanduider kan derhalwe soos volg geformuleer word:

(8) Die funksie van 'n vertaalekwivalentaanduider is om die vertaalekwivalent wat in 'n bepaalde semanties-pragmatiese konteks met die lemma gekoördineer word, weer te gee, sodat die teikengebruiker 'n gepaste vertaling van die brontaalitem in daardie semanties-pragmatiese konteks kan lewer.

Soos uit tabel 1 blyk, kan die intensionele effek na aanleiding van Steinberg (2007) beskryf word as die direkte en voorspelbare gedrag, opinie, houding of gevoel wat die leksikograaf by die teikengebruiker wil bewerkstellig wanneer laasgenoemde die leksikografiese tekselement in die gebruik(er)situasie dekodeer en interpreteer.

Die bepaling intensioneel veronderstel dat alternatiewe effekte ook kan voorkom. Die tipes effekte kan in terme van die leksikografiese funksionaliteit van die betrokke tekselemente in die gebruik(er)situasie beskryf word. Drie sodanige tipes effekte kan onderskei word:

(9) (a) 'n Leksikografies funksionele effek vind plaas wanneer die werklike effek by die teikengebruiker identies is aan die intensionele effek van die 
leksikograaf en die woordeboek gevolglik in daardie instansie nuttig in sy bedoelde gebruik is.

(b) 'n Leksikografies disfunksionele effek vind plaas wanneer die werklike effek by die teikengebruiker sodanig van die intensionele effek van die leksikograaf verskil dat die woordeboek in daardie instansie nie nuttig is nie. Die teikengebruiker kan bewus of onbewus van die disfunksionele effek wees na gelang van sy/haar individuele woordeboekkultuur.

(c) 'n Leksikografies niefunksionele effek vind plaas wanneer die werklike effek by die teikengebruiker van die intensionele effek van die leksikograaf verskil, maar die woordeboek steeds in daardie instansie nuttig is, hoewel nie noodwendig in sy bedoelde gebruik nie. Die teikengebruiker kan bewus of onbewus van die niefunksionele effek wees na gelang van sy/haar individuele woordeboekkultuur.

'n Voorbeeld van 'n leksikografies funksionele effek sou wees wanneer die intensionele effek in tabel 1 identies aan die werklike effek is. Die woordeboek was dan nuttig in sy bedoelde gebruik. 'n Leksikografies disfunksionele effek sou plaasvind indien die teikengebruiker byvoorbeeld na aanleiding van die gebruik van 'n vertalende woordeboek die Engelse item father pragmaties onvanpas met die Afrikaanse item outoppie vir die geldende konteks vertaal, of indien die teikengebruiker om watter rede ook al nie die relevante inligting in die woordeboek kan vind nie. ${ }^{5}$ Die woordeboek was dan nienuttig in sy bedoelde gebruik. 'n Leksikografies niefunksionele effek sou plaasvind indien 'n woordeboekgebruiker byvoorbeeld 'n tweetalige woordeboek gebruik om die betekenis van 'n bepaalde leksikale item na te slaan en deur die interpretasie van die aangebode vertaalekwivalent suksesvol die gepaste betekenis van die lemma aflei. Die woordeboek was dan nuttig, maar nie in sy bedoelde gebruik nie.

\section{1 'n Herkarakterisering van die konsep glos}

Binne die raamwerk van 'n kommunikatiewe metaleksikografie, soos hierbo uiteengesit, kan die funksie van 'n glos in tabel 2 voorgestel en na aanleiding daarvan in (10) geformuleer word:

(10) Die funksie van 'n glos is om die (tipe) ongemerkte pragmatiese konteks waarbinne 'n bepaalde vertaalekwivalent met die lemma gekoördineer word, weer te gee, sodat die teikengebruiker kan vasstel of daardie vertaalekwivalent ' $n$ pragmaties gepaste vertaling van die lemma in die geldende konteks verteenwoordig. 
Tabel 2: Die funksie van 'n glos

\begin{tabular}{|l|l|}
\hline \multicolumn{2}{|c|}{ Die funksie van 'n glos } \\
\hline Doel (van die tekselement) & $\begin{array}{l}\text { Intensionele effek (by die teiken- } \\
\text { gebruiker) }\end{array}$ \\
\hline $\begin{array}{l}\text { Die doel van 'n glos is om die } \\
\text { (tipe) ongemerkte pragmatiese } \\
\text { konteks waarbinne 'n bepaalde } \\
\text { vertaalekwivalent met die lemma } \\
\text { gekoördineer word, weer te gee, }\end{array}$ & $\begin{array}{l}\text { sodat die teikengebruiker kan vas- } \\
\text { stel of daardie vertaalekwivalent 'n } \\
\text { pragmaties gepaste vertaling van die } \\
\text { lemma in die geldende konteks ver- } \\
\text { teenwoordig. }\end{array}$ \\
\hline
\end{tabular}

Bostaande uiteensetting en formulering van die funksie van 'n glos bied die geleentheid tot sistematiese analise, wat soos volg uiteengesit kan word:

(11) (a) Vertaalekwivalent $x$ word met lemma $y$ gekoördineer.

(b) Die koördinering vind binne konteks $z$ plaas (soos deur 'n glos aangedui kan word).

(c) Dus: Indien konteks $z$ op lemma $y$ van toepassing is, kan vertaalekwivalent $x$ daarmee gekoördineer word.

(d) Nié: Indien konteks $z$ op vertaalekwivalent $x$ van toepassing is, kan dit met lemma y gekoördineer word.

Vergelyk ook Louw en Gouws (1996: 94) se beskrywing van die ekwivalentverhouding tussen 'n lemma desavoueer en 'n vertaalekwivalent deny: "Deny is slegs 'n vertaalekwivalent vir desavoueer indien dit gebruik word in die konteks van iemand wat iemand anders verloën."

Die implikasie van die redenasie in (11) vir die mikrostrukturele ordening van die betrokke inskrywings is duidelik: Die lemma behoort gespesifiseer te word, daarna 'n bepaalde konteks, en daarna die vertaalekwivalent (en sy sinonieme) wat binne daardie konteks met die lemma gekoördineer word. Daarna volg die spesifikasie van die volgende konteks, en so meer.

Hierdie gevolgtrekking bevraagteken die siening dat 'n glos "die vertaalekwivalent en nie die lemma nie as adres het" (Louw en Gouws 1996: 94) en mikrostruktureel ná die betrokke vertaalekwivalent geplaas behoort te word.

Vergelyk die funksie van 'n betekenisparafrase by 'n lemma in 'n tweetalige woordeboek, wat na aanleiding van die beskrywing daarvan in 3.2 soos volg geformuleer kan word:

(12) Die funksie van 'n betekenisparafrase is om die semantiese konteks waarbinne 'n bepaalde vertaalekwivalent met die lemma gekoördineer word, deur 'n semasiologiese aanbod van betekenisdata weer te gee, sodat die teikengebruiker kan vasstel of daardie vertaalekwivalent 'n semanties gepaste vertaling van die lemma in die geldende konteks verteenwoordig. 
In die woordeboekdata word woordsinonieme en betekenisparafrases sonder uitsondering voor die vertaalekwivalente geplaas, omdat die betekeniswaarde van die lemma wat geld eerstens vir die teikengebruiker duidelik moet wees voordat hy/sy die tersaaklike vertaalekwivalent kan selekteer. Dieselfde beginsel behoort vir glosse te geld: Die pragmatiese konteks waarin die lemma gebruik word, moet eers duidelik wees voordat die teikengebruiker die tersaaklike vertaalekwivalent kan selekteer.

In sy bespreking van diskriminasie tussen doeltaalsinonieme in vertalende woordeboeke stel Louw (1998) 'n adresseringstruktuur voor waarin die diskriminator die lemma as primêre adres het, en nie die vertaalekwivalent(e) nie. Die diskriminator self

is the primary address of the translation equivalent, which is then connected to the lemma only by means of a secondary lemmatic addressing procedure. Though primarily addressed to the lemma the discriminator, because of its interposition, provides valuable equivalent discrimination.

Vir glosse is hierdie adresseringsprosedure die mees funksionele een. Dit is die prosedure wat in Collins geld (vergelyk figuur 1), sowel as in 'n nuwe biskopale Afrikaans-Duits-woordeboek wat tans saamgestel word. Vergelyk die volgende konsepartikel uit laasgenoemde woordeboek:

stillen og.ww. [...] 1 \{baba\} borsvoed, borsvoeding gee 2 \{iem.\} tot stilte/ rus bring, laat bedaar, stilmaak 3 \{honger\} stil; $\{$ dors $\}$ les $\mathbf{4}$ \{bloeding\} stop

In die artikel in (13) word die glosse tussen krulhakies geplaas (nietipografiese struktuurmerker) en gekursiveer (tipografiese struktuurmerker), en gaan telkens die vertaalekwivalente vooraf wat in die aangeduide kontekste gepaste vertalings verteenwoordig. Hierdie prosedure word vir ekwivalentdiskriminasie by semantiese divergensie (soos tussen betekenisonderskeiding 1 en 2) sowel as leksikale divergensie (soos oorspronklik deur Louw (1998) voorgestel, by betekenisonderskeiding 3) toegepas.

Die taal waarin glosse aangebied word, word bepaal deur die tipe teikengebruiker en die bedoelde gebruik van die woordeboek. Die glosse in (13) word in Afrikaans aangebied omdat die teikengebruiker in die meeste gevalle 'n moedertaalspreker van Afrikaans is wat die woordeboek gebruik vir teksresepsie van Duitse tekste of vertaling van Duitse tekste in Afrikaans. Vergelyk ook Al-Kasimi (1977) wat aanvoer dat glosse in die moedertaal van die teikengebruiker aangebied behoort te word. 'n Verdere bedoelde gebruik van die konsepwoordeboek is as hulpmiddel by die aanleer van Duits deur Afrikaanssprekendes. Duitssprekendes is sekondêre teikengebruikers binne 'n konteks waarin Afrikaans die dominante taal is en waarmee selfs die Duitssprekende teikengebruiker in 'n mate vertroud is. Vertaling van Afrikaanse tekste in Duits is ook 'n sekondêre bedoelde gebruik. 


\subsection{Vertaalkomplemente herwin}

In die lig van die herkarakterisering van glosse het vertaalkomplemente, soos deur Iannucci (1985) voorgestel en in afdeling 3.1 bespreek, steeds ' $n$ plek in die tweetalige leksikografie. Iannucci se voorbeelde in (1) kan egter funksioneel deur glosse hanteer word. Vergelyk hiervoor die teksweergawe sonder mikroargitektuur van die volgende artikel uit Collins:

(14) eat verb a. [person] essen; b. [animal] fressen

Die inskrywings person en animal tree as glosse op en nie as vertaalkomplemente nie.

Die funksie van 'n vertaalkomplement word deur die volgende artikel uit Pharos geïllustreer:

sarcophagus [...] sarkofaag, lykkis (v. klip)

Die vertaalkomplement $v$. klip is aan die doeltaalsinoniem lykkis geadresseer. Dié doeltaalsinoniem is deur ' $n$ prosedure van nielemmatiese adressering aan die primêre vertaalekwivalent sarkofagg geadresseer. Die vertaalkomplement dui dus daarop dat die doeltaalsinoniem lykkis semanties meer beperk is as die vertaalekwivalent sarkofaag en dat die semantiese pluswaarde "van klip" by lykkis moet geld indien die twee vertaalekwivalente as doeltaalsinonieme aangebied word. Die inskrywing word tereg in die doeltaal aangebied.

Die funksie van 'n vertaalkomplement kan soos volg geformuleer word:

Die funksie van 'n vertaalkomplement is om die semanties spesifieker of beperkter aard van 'n bepaalde vertaalekwivalent relatief tot die lemma of 'n doeltaalsinoniem in ' $\mathrm{n}$ bepaalde semanties-pragmatiese konteks weer te gee, sodat die teikengebruiker kennis sal neem dat daardie vertaalekwivalent nie sonder meer die presiese semantiese lading van die lemma of die doeltaalsinoniem in daardie konteks dra nie en gevolglik kan vasstel of daardie vertaalekwivalent 'n semanties-pragmaties gepaste vertaling van die lemma verteenwoordig.

Dit is dus duidelik dat glosse en vertaalkomplemente verskillende funksies vervul. Daarom verskil hulle adresse en gevolglik hulle mikrostrukturele plasing, hoewel beide tipes inskrywings ter wille van ekwivalentdiskriminering aangewend word, dit wil sê beide tipes inskrywings wil dieselfde tipe uiteindelike intensionele effek by die teikengebruiker bewerkstellig. Daarom kan 'n vertaalkomplement ook as 'n tipe diskriminator beskou word. Iannucci (1985) se standpunt dat die behoefte aan vertaalkomplemente baie min in tweetalige woordeboeke voorkom, geld egter steeds. 


\section{Perspektief en slot}

Hierdie artikel het ten doel gehad om tot die ontwikkeling van die Afrikaanse tweetalige leksikografie by te dra deur die inskrywingstipe glos krities te beskou en aan te toon dat Iannucci se vertaalkomplement steeds 'n (beperkte) funksie in vertalende woordeboeke vervul. Tot die klas kontekstualiserende inskrywings wat as diskriminators bekend staan, moet vertaalkomplemente dus toegevoeg word, sodat die subtipologie soos volg daar uitsien:

- Diskriminators, waaronder
- $\quad$ betekenisverklarings,
- $\quad$ leksikografiese glosse,
- $\quad$ vertaalkomplemente, en
- $\quad$ leksikografiese etikette.

Die artikel probeer ook om tot die teoretiese gesprek by te dra deur 'n alternatiewe konsep van leksikografiese funksies vanuit die oogpunt van 'n kommunikatiewe metaleksikografie te bied. Dit is 'n relatief nuwe benadering tot die teoretiese leksikografie wat nog om veel verfyning vra, maar wat opwindende navorsingsmoontlikhede bied. Die benadering is 'n eklektiese een wat in die kommunikasieteorie gegrond is en insigte betrek uit onder meer die teksteorie van Wiegand (1996, ensovoorts) en die funksieteorie - twee teoretiese raamwerke waarin Gouws beduidende bydraes gemaak het en steeds maak. Sy aktiewe betrokkenheid by die uitbou van hierdie teorieë, wat deur sommiges in die metaleksikografiegemeenskap as opponerende paradigmas beskou word (vergelyk Bergenholtz en Tarp 2003), getuig van Gouws se akademiese veelsydigheid, wetenskaplike integriteit en toewyding aan die vak.

Hiérdie artikel en die enigsins alternatiewe teoretiese benadering wat dit onder meer voorstel, is 'n direkte uitvloeisel van Gouws se standpunt in gesprekke met die outeur dat enige teoretiese paradigma wat potensiaal toon om teorieontwikkeling in die leksikografie te bevorder, ondersoek behoort te word. Dus, selfs al onderskryf hierdie artikel nie noodwendig direk die teoretiese raamwerke waarmee hy hom tans vereenselwig nie, is dit 'n indirekte en hopelik produktiewe gevolg van Gouws se internasionaal gerekende akademiese leierskap.

\section{Notas}

1. Daar is (potensiële) uitsonderings op hierdie oënskynlik voor die hand liggende verband; vergelyk Beyer (2009: 7-10).

2. Die term funksie, soos hier gebruik, moenie met die identiese term in die sogenaamde moderne teorie van leksikografiese fuksies verwar word nie. Vergelyk afdeling 4 vir 'n verduideliking van die gebruik van dié term in hierdie artikel.

3. Pharos geld tans as verteenwoordiger van die stand van die Afrikaanse tweetalige leksikografie. 
4. Die term gebruik sluit logies aan by die funksieteorie se gebruiker, gebruikersituasie en gebruiksituasie, waar laasgenoemde term verwys na die aktiwiteit van woordeboekgebruik. ('n Potensiële sinoniem sou makrofunksie kon wees.)

5. Hierdeur word verskillende tipes leksikografies disfunksionele effekte gesuggereer, waarop nie nou uitgebrei word nie.

\section{Bronnelys}

\section{A. Primêre literatuur (woordeboekdata)}

Collins = Collins English-German Dictionary. http://www.collinsdictionary.com/english-german [Intyds besoek op 30 Oktober 2012].

Hachette = Corréard, M., V. Grundy, J. Ormal-Grenon en N. Rolin (Reds.). 20074. Oxford Hachette French Dictionary. New York: Oxford University Press.

Oxford = Clark, M. en O. Thyen (Reds.). 20053. Concise Oxford German Dictionary. Oxford: Oxford University Press.

Pharos $=$ Pheiffer, F. (Red.). 2007. Pharos Afrikaans-Engels/English-Afrikaans Kernwoordeboek/Concise Dictionary. Kaapstad: Pharos.

Van Dale = Martin, W. en G.A.J. Tops (Hoofreds.). 1999³. Van Dale Groot Woordenboek NederlandsEngels. Utrecht/ Antwerpen: Van Dale.

Williams, E.B. 1968. The New College Spanish \& English Dictionary. New York: Bantam.

\section{B. Sekondêre literatuur}

Al-Kasimi, A.M. 1977. Linguistics and Bilingual Dictionaries. Leiden: E.J. Brill.

Bergenholtz, H. en R.H. Gouws. 2007. Korrek, volledig en relevant. Dít is die vraag aan leksikografiese definisies. Tydskrif vir Geesteswetenskappe 47(4): 568-586.

Bergenholtz, H. en S. Tarp. 2003. Two Opposing Theories: On H.E. Wiegand's Recent Discovery of Lexicographic Functions. Hermes, Journal of Linguistics 31: 171-196.

Beyer, H.L. 2006. 'n Voorlopige model vir die sistematiese beskrywing van gebruikersvriendelikheid in woordeboeke. Lexikos 16: 46-66.

Beyer, H.L. 2009. 'n Teoretiese basis vir konteksleiding in tweetalige woordeboeke. Lexikos 19: 1-22.

Beyer, H.L. 2011. ' $n$ Algemene tipologie van leksikografiese etikette. Tydskrif vir Geesteswetenskappe 51(3): 419-445.

De Wet, G. 1999. Die mikrostrukturele bewerking van affikse in Afrikaanse vertalende woordeboeke. Lexikos 9: 36-53.

Gouws, R.H. 1988. Die gebruik van etikette as leksikografiese hulpmiddel. Suid-Afrikaanse Tydskrif vir Taalkunde, Geleentheidsuitgawe 6.

Gouws, R.H. 1989. Leksikografie. Pretoria/Kaapstad: Academica.

Gouws, R.H. 1990. Information Categories in Dictionaries, with Special Reference to Southern Africa. Hartmann, R.R.K. (Red.). 1990. Lexicography in Africa. Progress Reports from the Dictionary Research Centre Workshop at Exeter, 24-25 March 1989: 52-65. Exeter: University of Exeter Press. 
Gouws, R.H. 1994. Ostensiewe adressering in vertalende woordeboeke. Lexikos 4: 61-85.

Gouws, R.H. 1996. Bilingual Dictionaries and Communicative Equivalence for a Multilingual Society. Lexikos 6: 14-31.

Gouws, R.H. 1996a. Leksikografiese behoeftevervulling. Lexikos 6: 171-183.

Gouws, R.H. 1996b. Idioms and Collocations in Bilingual Dictionaries and their Afrikaans Translation Equivalents. Lexicographica 12: 54-88.

Gouws, R.H. 1999. Die maatskaplike gerigtheid van die metaleksikografie in 'n meertalige samelewing. Intreerede. Stellenbosch: Universiteit van Stellenbosch.

Gouws, R.H. 2000. Doeltaalgerigtheid teenoor lemmagerigtheid in vertalende woordeboeke. Tydskrif vir Geesteswetenskappe 40(1): 39-47.

Gouws, R.H. 2001. The Use of an Improved Access Structure in Dictionaries. Lexikos 11: 101-111.

Gouws, R.H. 2002. Niching as Marcostructural Procedure. Lexikos 12: 133-158.

Gouws, R.H. 2002a. Equivalent Relations, Context and Cotext in Bilingual Dictionaries. Hermes, Journal of Linguistics 28: 195-209.

Gouws, R.H. 2003. Aspekte van mikrostrukturele verskeidenheid en inkonsekwentheid in woordeboeke. Lexikos 13: 92-110.

Gouws, R.H. 2004. Outer Texts in Bilingual Dictionaries. Lexikos 14: 1-23.

Gouws, R.H. 2004a. Monolingual and Bilingual Learners' Dictionaries. Lexikos 14: 264-274.

Gouws, R.H. 2005. Oor die verhouding tussen woordeboekstrukture, woordeboekinhoud en leksikografiese funksies. Lexikos 15: 52-69.

Gouws, R.H. 2007. On the Development of Bilingual Dictionaries in South Africa: Aspects of Dictionary Culture and Government Policy. International Journal of Lexicography 20(3): 313-327.

Gouws, R.H. 2007a. The Selection, Presentation and Treatment of Cultural Phrases in a Multicultural Dictionary. Lexicographica 22: 24-36.

Gouws, R.H. en D.J. Prinsloo. 2005. Principles and Practice of South African Lexicography. Stellenbosch: SUN PReSS.

Gouws, R.H., D.J. Prinsloo en G.-M. de Schryver. 2004. Friends will be Friends - True or False. Lexicographic Approaches to the Treatment of False Friends. Williams, G. et al. (Reds.). 2004. Proceedings of the Eleventh EURALEX International Congress, EURALEX 2004, Lorient, France, July 6-10, 2004: 797-806. Lorient: Faculté des Lettres et des Sciences Humaines, Université de Bretagne-Sud.

Iannucci, J.E. 1967. Meaning Discrimination in Bilingual Dictionaries. Householder, F.W. en S. Saporta (Reds.). 1967. Problems in Lexicography: 201-216. Den Haag: Mouton.

Iannucci, J.E. 1985. Sense Discriminations and Translation Complements in Bilingual Dictionaries. Dictionaries 7: 57-65.

Kotzé, E. 1999. Translating Culture in Bilingual Dictionaries. Lexikos 9: 89-107.

Louw, P. 2000. An Integrated Semasiological and Onomasiological Presentation of Semantic Information in General Monolingual Dictionaries as Proposed in H.E. Wiegand's Semantics and Lexicography. Lexikos 10: 119-137.

Louw, P.A. 1998. Synonymy in the Translation Equivalent Paradigms of a Standard Translation Dictionary. Lexikos 8: 173-182.

Louw, P.A. en R.H. Gouws. 1996. Lemmatiese en nielemmatiese adressering in Afrikaanse vertalende woordeboeke. Suid-Afrikaanse Tydskrif vir Taalkunde 14(3): 92-100. 
Manley, J., J. Jacobsen en V.H. Pedersen. 1988. Telling Lies Efficiently: Terminology and the Microstructure in the Bilingual Dictionary. Hyldgaard-Jensen, K. en A. Zettersten (Reds.) 1988. Symposium on Lexicography III. Proceedings of the Third International Symposium on Lexicography, May 14-16, 1986, at the University of Copenhagen: 281-302. Tübingen: Max Niemeyer.

Potgieter, L. 2008. ' $n$ Moontlike model vir die bewerking van idiome in tweetalige woordeboeke. Lexikos 18: 190-206.

Prinsloo, D.J. en R.H. Gouws. 2000. The Use of Examples in Polyfunctional Dictionaries. Lexikos 10: 138-156.

Steinberg, S. 1994. Introduction to Communication. The Basics. Kaapstad: Juta.

Steinberg, S. 2007. An Introduction to Communication Studies. Kaapstad: Juta.

Tarp, S. 2008. Lexicography in the Borderland between Knowledge and Non-Knowledge. General Lexicographical Theory with Particular Focus on Learner's Lexicography. Tübingen: Max Niemeyer.

Wiegand, H.E. 1996. A Theory of Lexicographic Texts: An Overview. South African Journal of Linguistics 14(4): 134-149.

Wiegand, H.E. en R.H. Gouws. 2011. Theoriebedingte Wörterbuchformprobleme und wörterbuchformbedingte Benutzerprobleme I. Ein Beitrag zur Wörterbuchkritik und zur Erweiterung der Theorie der Wörterbuchform. Lexikos 21: 232-297.

Zgusta, L. 1971. Manual of Lexicography. Den Haag: Mouton.

Zgusta, L. 1987. Translational Equivalence in a Bilingual Dictionary. Dictionaries 9: 1-47. 


\title{
Die gebruik van ANNA in 'n Nederlandse taalverwerwingskursus - toegangsgemak en inligtingkoste
}

\author{
Nerina Bosman, Departement Afrikaans, Universiteit van Pretoria, \\ Pretoria, Suid-Afrika (nerina.bosman@up.ac.za)
}

Opsomming: In 2011 verskyn die tweetalige Groot Woordeboek Afrikaans en Nederlands (GWAN), ook bekend as ANNA. Die woordeboek is opvallend anders veral vanweë sy innoverende makrostruktuur - dit het een geamalgameerde lemmalys. Omdat dit 'n kontrastiewe woordeboek is wat sowel die verskille as die ooreenkomste tussen die Afrikaanse en Nederlandse leksikons aantoon, het die mikrostruktuur ook eiesoortige eienskappe. Die woordeboek verskyn op 'n tydstip wanneer die leksikografiediskoers tot 'n groot mate oorheers word deur die moderne funksieteorie. Hierdie artikel lewer verslag oor 'n gevallestudie uitgevoer met sewe Afrikaanssprekende respondente in die T2- Nederlandse aanleerderkursus. In 'n kommunikatiewe situasie moes die respondente vyf Nederlandse leksikale items met behulp van ANNA produseer. Die hoofnavorsingsvraag was: verleen ANNA vinnige en maklike toegang tot die inligting wat die navorsinggroep moes vind? Uit die data blyk dit dat die inligting nie vinnig en maklik gevind kon word nie en dat die inligtingkoste nogal hoog was. Indien ANNA met vrug in die T2-klaskamer gebruik wil word, sal studente vooraf ' $n$ volledige demonstrasie moet kry oor hoe inligting in hierdie woordeboek die beste opgespoor kan word. Vanweë die digte artikelstruktuur sal dit beklemtoon moet word hoe belangrik dit is om die (baie volledige en nogal lang) voorteks goed deur te lees.

Sleutelwoorde: FUNKSIE, GEBRUIKER, GEBRUIKSITUASIE, TOEGANGSTRUKTUUR, TOEGANGSGEMAK, INLIGTINGKOSTE

\begin{abstract}
The Use of ANNA in a Dutch Language Acquisition Course Ease of Access and Information Cost. In 2011 a new bilingual Dutch-Afrikaans dictionary, popularly known by the acronym ANNA, was published. The dictionary is markedly different mainly on account of its innovative macrostructure - it has one amalgamated lemma list. Because it is a contrastive dictionary which pays particular attention to the differences and similarities between the Afrikaans and Dutch lexicons, the microstructure also displays unique characteristics. The dictionary arrived at a time when the lexicographic discourse is dominated to some extent by the modern function theory. This article reports on a case study conducted with seven Afrikaansspeaking respondents in the L2 Dutch learners' course. In a communicative situation, the respondents had to produce five Dutch lexical items with the help of ANNA. The main research question was: Does ANNA provide quick and easy access to the information that the respondents had to find? The data shows that the information could not be quickly and easily found and that the information costs were rather high. If ANNA is to be used meaningfully in the L2 classroom, stu-
\end{abstract}


dents will have to be given a full demonstration on how information in this dictionary can best be accessed. Because of the dense article structure, the importance of reading well through the (quite detailed and rather long) front matter with close attention will have to be stressed.

Keywords: FUNCTION, USER, USAGE SITUATION, ACCESS STRUCTURE, EASE OF ACCESS, INFORMATION COST

\section{Inleiding}

Die inspirasie vir hierdie artikel was tweeledig. In 2011 verskyn naamlik die tweetalige Groot Woordeboek Afrikaans en Nederlands (GWAN), ook bekend as ANNA. Opvallend anders veral vanweë sy unieke makrostruktuur (die "eerste geamalgameerde woordeboek" soos wat dit op die stofomslag gestel word), is die woordeboek wyd en syd entoesiasties ontvang. Prinsloo (2012) merk byvoorbeeld op:

Groot Woordeboek Afrikaans en Nederlands is a dictionary of high lexicographic achievement and a recommended option/alternative for Afrikaans and Dutch lexicography. It succeeds in its systematic and consistent presentation of especially similarities and differences.

In die tweede plek was 'n artikel deur Bergenholtz en Gouws (2010) oor twee gevallestudies betreffende die toegangsproses in woordeboeke en ander naslaanwerke in besonder die aanleiding tot die ondersoek waaroor hier verslag gedoen word. In 'n gekontroleerde gevallestudie wat onderneem is met Afrikaanse studente in 'n Nederlandse aanleerderskursus is daar gekyk na die manier waarop ANNA in 'n spesifieke gebruiksituasie geraadpleeg is. Die studente kan getipeer word as eerste gebruikers van die bepaalde woordeboek en daar word ook rekening gehou met hierdie feit wanneer die resultate bespreek word. Met hierdie ondersoek word daar gehoop om 'n bydrae te lewer tot die huidige leksikografiese ondersoek na die toegangsproses in woordeboekgebruik as 'n fokusarea. Tot dusver (2012) is nog geen navorsing gedoen oor die gebruik van ANNA deur Afrikaanssprekendes as óf passiewe óf aktiewe gebruikers van Nederlands nie.

\section{Kontekstualisering}

\subsection{Gebruikers, inligtingbehoeftes en die moderne funksieteorie}

Binne die metaleksikografie vorm navorsing rakende woordeboekgebruik 'n belangrike onderafdeling. Die gebruiksgedrewe aanpak en die ontwikkeling van 'n nuwe rigting in die teoretiese leksikografie, te wete die sogenaamde "funksieteorie", is nie van mekaar te skei nie. 
Die belangstelling in woordeboekgebruik en die gedrag van woordeboekgebruikers kan volgens Tarp (2009: 276) teruggevoer word na die 1960-konferensie by die Indiana University met as tema "Problems in lexicography". Die fokus op die woordeboekgebruiker lei mettertyd tot die kristallisering van die "moderne funksieteorie", soos ontwikkel deur die Aarhusskool sedert die negentigerjare van die vorige eeu (vergelyk Bergenholtz en Tarp 2003 vir 'n deeglike oorsig oor dié teorie). Onderliggend aan die funksieteorie is die uitgangspunt dat woordeboekgebruikers, hulle behoeftes en die situasies waarin hulle woordeboeke gebruik, sentraal staan en as wegspringplek behoort te dien vir die leksikografieteorie en -praktyk. Gouws (2001: 110) stel dit so: "Modernday lexicography is dominated by the user-perspective and the access structure of any new dictionary has to be user-driven."

Die ondersoek waaroor hier berig word, word dan ook gekontekstualiseer binne die breër funksieteorie met ' $n$ baie sterk fokus op die toegangstruktuur van ANNA.

Volgens Bergenholtz en Tarp (2003: 172) berus die funksieteorie op twee veronderstellings:

(a) die leksikografie is 'n onafhanklike wetenskaplike dissipline en nie 'n subdissipline van die linguistiek nie; en

(b) woordeboeke is nutsprodukte wat in bepaalde behoeftes moet voorsien.

Tarp (2007: 171) stel dit so: "A dictionary is a utility tool whose essential characteristic is its capacity to provide quickly accessible data from which information can be retrieved."

Bergenholtz en Tarp (2003: 176) definieer leksikografiese funksie, een van die hoekstene van die moderne funksieteorie, soos volg: "A lexicographic function (...) is to provide assistance to a specific user group with specific characteristics in order to cover the complex of needs that arise in a specific type of user situation."

Werklike gebruikers en hulle behoeftes moet dus deur die leksikograaf voortdurend voor oë gehou word en navorsing moet gedoen word oor die tipes gebruikers, die gebruiksituasies, die gebruik van die woordeboek en die mate waarin hulle tevrede is met die woordeboek wat hulle geraadpleeg het (Tarp 2009: 279). In hierdie ondersoek was dit dan ook belangrik om die situasie waarin die gebruikers bepaalde leksikografiese behoeftes gehad het, duidelik te omskryf - vergelyk hieroor paragraaf 4.

\section{$2.2 \quad$ Toegangsgemak en inligtingkoste}

'n Tweetalige woordeboek soos ANNA kan beskou word as 'n nuttige instrument om inligting te verkry oor die taal wat aangeleer word en daar kan verwag word dat dit die T2-leerder sal voorsien van antwoorde op spesifieke vrae in 'n werklike situasie van woordeboekgebruik. Hierdie leerders behoort ideaal 
gesproke vinnige en onverhinderde toegang te verkry tot data wat aan hulle die inligting sal verskaf waarna hulle op soek is (Gouws 2001: 102) en hierby is die toegangstruktuur van die woordeboek van die allergrootste belang. Met toegangstruktuur word bedoel die soekroete wat die woordeboekgebruiker volg tydens 'n datakonsultasieprosedure (Gouws 2001: 102) en die ideaal is dat hierdie toegangstruktuur só sal wees dat dit sal sorg vir optimale toegangsgemak.

Die begrippe toegang, toegangstruktuur en toegangsgemak is sonder twyfel kernbegrippe in die huidge leksikografiediskoers. Toegang ("access") word soos volg deur Hartmann en James (1998) gedefinieer: "the relative ease with which information can be located in a reference work" en in hierdie definisie word die begrip reeds in verband gebring met 'n eis dat toegang maklik en met so min hindernisse moontlik moet geskied.

'n Begrip wat verwant is aan toegangsgemak is dié van leksikografiese inligtingkoste. Hierdie konsep, wat sy oorsprong in die ekonomiese wetenskappe het, word deur Nielsen (2008) ook op die leksikografie toegepas. In 'n verwysing na sy 1999-artikel definieer Nielsen (2008: 173) leksikografiese inligtingkoste soos volg: "The effort that a user believes or feels is associated with consulting a dictionary, an article or any other text part of a dictionary."

Nielsen (2008: 173-174) onderskei twee soorte inligtingkoste, te wete soekverwante koste en begripsverwante koste. Eersgenoemde het betrekking op die soektog en die opsoekaktiwiteit self, en aspekte soos die toegangsroete, dataverspreiding, artikelstruktuur en kruisverwysings is ter sake. Hierdie aspekte kan die soekproses nadelig of positief beïnvloed - dit is met ander woorde direk in verband te bring met toegangsgemak. Begripsverwante koste hou verband met die inspanning wat van die gebruiker geverg word om die data wat in die woordeboek aangetref word, te verstaan en te interpreteer. Vir die doel van hierdie ondersoek was beide begrippe ter sake.

\section{ANNA: 'n tweetalige woordeboek vir twee naverwante tale}

Die graad van ooreenkoms tussen die onderskeie leksikons van die twee naverwante tale Afrikaans en Nederlands is allermins onproblematies. In samehang met uitsprake soos die volgende: "Die grootste gedeelte van die Afrikaanse woordvoorraad is van 17de-eeuse Nederlands afkomstig" (Raidt 1991: 156) en "Daar word soms gereken dat 90 tot 95 persent van die Afrikaanse woordeskat tot die Nederlandse erfbron teruggevoer kan word" (Carstens 2011: 129) geld De Villiers (1983) se waarskuwing dat die groot ooreenkoms in woordeskat versigtig geformuleer moet word, as belangrike korrektief: "Die woordmateriaal van Afrikaans is vir diep in die negentig persent van Nederlandse herkoms, al is daar belangrike verskille in die woorde self" (my kursivering) (De Villiers 1983: 29).

Ná 1994 is daar 'n nuwe toenadering tussen die twee tale - onder andere te sien in vertalings na en uit Nederlands. Daar is ' $n$ toenemende bewuswording dat die tale nie wedersyds honderd persent toeganklik is nie. Dit het tyd geword vir 'n vertaalwoordeboek - een met 'n nuwe en innoverende leksiko- 
grafiese aanpak wat vir sowel die ooreenkomste as die verskille tussen die twee tale voorsiening kon maak sonder om bekende inligting te herhaal. Soos wat Martin en Gouws (2000: 788) opmerk, skep die een geamalgameerde lemmalys - met woorde wat slegs in Afrikaans voorkom (baie, verkeersdrempel), woorde wat slegs in Nederlands voorkom (auto, rotonde) en woorde wat identies is in Nederlands en Afrikaans (tafel) - 'n "dictionary consultation environment where both differences and similarities become apparent in an efficient and contrastive way". Hiervoor laat 'n tradisionele vertaalwoordeboekstruktuur nie toe nie - daar sou 'n te groot mate van redundante inligting wees. As gevolg van 'n groter aanbod aan semantiese inligting en voorbeeldmateriaal as in tradisionele vertaalwoordeboeke, asook ekstra inligting wat deur nietipografiese tekens aan die gebruiker gebied word, kan ANNA dan ook beskryf word as 'n tweetalige kontrastiewe woordeboek met hibridiese eienskappe (Martin en Gouws 2000: 789). Vertaalekwivalente is nie die enigste, of selfs die belangrikste inligting wat die gebruiker in hierdie woordeboek kry nie.

In die loop van die groot leksikografiese projek wat tot ANNA gelei het, het dit ook duidelik geword dat die dikwels aangehaalde "diep in die $90 \%$ ooreenkoms" tussen die leksikons van die twee tale aangepas moes word. Die woordeboek het 60,000 trefwoorde waarvan slegs 29,500 kognate is (GWAN: 22). Kognate is dié woorde wat 'n vormlike ooreenkoms deel (soos tafel/tafel, dink/denken, bloempot/blompot) en ook semanties verwant is omdat hulle een of meer betekenisonderskeidings deel, soos robot/robot. Niekognate is woorde soos kuiergas/logé of valse vriende soos amper of mus.

Dit is hoogs onwaarskynlik dat Afrikaanse woordeboekgebruikers tevore al met 'n soortgelyke woordeboek kennis sou gemaak het. Volgens die gebruiksaanwysings (GWAN: 22) is dit 'n unikum in die leksikografie.

Vanuit die funksieteorie gesien, is die waarskynlikste kommunikasiebehoeftes van die gebruikers van ANNA die volgende:

(a) die verstaan van 'n teks in die T2 - met ander woorde 'n reseptiewe behoefte,

(b) teksproduksie in die tweede taal - 'n produktiewe behoefte, en

(c) vertaling uit die T2 in die T1.

In Bergenholtz en Tarp (2003) se terminologie kan ANNA dus omskryf word as 'n multifunksionele woordeboek.

Alhoewel ANNA nie 'n aanleerderswoordeboek is nie, kan dit wel 'n belangrike bron van inligting wees in die T2-klaskamer. Veral in 'n kontrastiewe kursus is daar 'n behoefte om studente enersyds bewus te maak van die ooreenkomste tussen die Nederlandse en Afrikaanse leksikons maar om leerders andersyds te lei na fynere nuanses van betekenisverskil, die verskille in kollokasies en natuurlik ook grammatikale verskille. Die soort behoeftes wat 'n gebruiker van ANNA in die T2-klas mag hê, mag dus veral wees om inligting te kry oor aspekte van die T2 en ooreenkomste en verskille tussen die T1 en die 
T2. Daar kan aangeneem word dat bogenoemde behoeftes die struktuur (sowel die makro- as die mikrostruktuur) van ANNA bepaal het. Wat die makrostruktuur betref, het die een geamalgameerde woordelys verskeie voordele: dit vergemaklik die kontrastiewe aanpak (wat van die begin af 'n vertrekpunt was vir die woordeboek), betekenisuitbreidings en -verskille word duidelik aangetoon en oortolligheid word vermy.

\section{Die ondersoek}

Vir die doel van die ondersoek was die gebruiksituasie (vergelyk byvoorbeeld Tarp 2008 en 2009) 'n kommunikatiewe situasie waar veral produksiebehoeftes sentraal gestaan het. Die studente in die ondersoekgroep (hier dus werklike gebruikers in 'n werklike woordeboekgebruiksituasie) moes in die uitvoering van 'n spesifieke taak (vergelyk paragraaf 4.3) vyf Nederlandse leksikale items produseer. Die taak is soos volg geformuleer:

Jy word gevra om die volgende woordeskattoets ${ }^{1}$ te voltooi met behulp van ANNA. Jy moet 5 Nederlandse woorde, met hulle korrekte spelling en in hulle korrekte grammatikale vorm, invul. Gebruik jou kennis van Afrikaans om jou te help, raai watter woorde ingevul moet word en gebruik ANNA om jou raaiskoot te bevestig, byvoorbeeld. Terwyl jy die taak voltooi, moet jy deurgaans hardop dink en sê wat jy doen.

Alhoewel reseptiewe vaardighede nie eksplisiet getoets is nie, was dit wel belangrik. Ten einde die taak te kon voltooi, moes studente ook die Nederlandse kontekssinne goed genoeg verstaan. Hulle het dus inderdaad 'n "complex of needs" (Bergenholtz en Tarp 2003: 176) gehad.

\subsection{Probleemstelling}

Die oorkoepelende vraag wat die navorsing gelei het, was: tot watter mate voldoen ANNA in die inligtingsbehoeftes van spesifieke tipe gebruikers wat hulleself in 'n spesifieke tipe gebruiksituasie (vergelyk Tarp 2007: 171) bevind? Anders gestel: Verleen ANNA vinnige en maklike toegang tot die inligting wat die navorsinggroep moes vind? Sodat daar op die toegangsproses gekonsentreer kon word, is die volgende vrae gestel:

- Wat was the soektyd?

- Wat was die soekroete?

- Hoeveel verskillende stappe (soekstappe) was nodig om die gevraagde inligting te vind?

- Hoe geslaagd of suksesvol was die soektog - met ander woorde, is die gevraagde inligting gevind? 


\subsection{Metodologie}

Daar is besluit om in 'n empiriese ondersoek gebruik te maak van 'n gekontroleerde gevallestudie. Die opsoekgedrag van die respondente wat 'n spesifieke taak een-een voltooi het, is direk waargeneem en gemonitor. 'n Digitale stemopnemer is gebruik tydens elke individuele opsoekproses en die respondente is gevra om deurgaans te praat ("hardop te dink") terwyl hulle die woordeboek gebruik. Tydens die opsoekproses het die navorser ook skriftelike notas gemaak wat onmiddellik ná afloop van elke sessie neergeskryf is.

Vir die ondersoek is die volgende terme soos volg gedefinieer:

Soektyd: die tyd wat dit die student geneem het om die antwoord (d.w.s. die gevraagde inligting) in die woordeboek te vind.

Soekroete: die verskillende soektogte, dikwels met verskillende lemmas in gedagte, wat uitgevoer is om die verlangde inligting in die woordeboek te vind.

Soekstappe: die kere wat 'n student sy fokus of soekplek in die woordeboek verander het.

\subsection{Die ondersoekgroep}

Sewe tweedejaar- Afrikaanssprekende studente in 'n Nederlandse taalverwerwingskursus het vrywillig deelgeneem aan die ondersoek. Nie een van die studente het al voorheen te make gehad met ANNA nie en nie een het op die stadium van die ondersoek voorheen al Nederlandse tekste gelees nie.

Die resultate wat verkry word met so 'n klein ondersoekgroep kan nie as verteenwoordigend beskou word nie, maar sekere gevolgtrekkings betreffende die woordeboekgedrag van hierdie spesifieke groep gebruikers mag wel waardevol wees vir dosente wat die woordeboek in die T2-klaskamer wil gebruik.

Die profiel van die ondersoekgroep (losweg gebaseer op die riglyne wat deur Bergenholtz en Tarp (2003: 173) verskaf word) is soos volg:

Ouderdom: 19-20 jaar

Moedertaal (T1): Afrikaans

Vaardigheid in die T1: tersiêre studente met Afrikaans as vak

Vaardigheid en vlak van taalbeheersing in die T2 (Nederlands): geen

kennis van Nederlands nie

Vertaalervaring tussen die twee tale: geen

Algemene woordeboekgebruikpatrone: volgens eie getuienis gebruik al sewe studente gereeld veral tweetalige woordeboeke (met name Afrikaans-Engels/Engels-Afrikaans).

Kennis van ANNA: geen

Die leksikografiese funksie van ANNA is om hulp te verleen aan 'n spesifieke gebruikersgroep - in die onderhawige geval is die gebruikersgroep 'n deel- 
groep van die meer algemene en noodwendig vaag omskrewe groep gebruikers wat moontlik van die woordeboek gebruik sou wou maak. Die ondersoekgroep kan beskryf word as spesifieke gebruikers in 'n spesifieke gebruiksituasie met bepaalde behoeftes. Soos Tarp (2009: 283) dit stel: "Lexicographic needs (...) are not abstract needs in general, but concrete, specific types of needs related to a specific type of user."

In die geval van die ondersoek was die gebruiksituasie dié van 'n opdrag ('n Nederlandse woordeskattoets ${ }^{2}$ ) wat voltooi moes word. Die keuse om 'n woordeskattoets te gebruik, is gemotiveer deur Tarp (2009: 293) wat voorstel dat toetse gebruik kan word juis om vas te stel watter resepsieprobleme spesifieke woordeboekgebruikers mag ervaar. Aan die deelnemers is gesê dat hulle alle inligting wat hulle moontlik kon nodig kry om die toets te voltooi, in die woordeboek sou vind en dat hulle soveel moontlik gebruik moes maak van ANNA om te help met die voltooiing van die taak. Hulle moes staatmaak op hulle Afrikaanse woordeskatkennis en raaiskote waag. Hierdie raaiskote moes hulle met behulp van ANNA bevestig. Om die korrekte items te kon produseer, moes hulle gebruik maak van die Nederlandse ortografie (wat soms verskil van die Afrikaanse), die korrekte grammatikale vorm van die woord (byvoorbeeld die infinitiefsvorm van 'n werkwoord of die Nederlandse meervoudsvorm) produseer en ook die gepaste betekenis (by homonieme of uit verskillende polisemiese moontlikhede byvoorbeeld) agterhaal.

Die leksikografiese behoeftes het dus te make gehad met sowel resepsie as produksie. Omdat daar bepaalde begripsprobleme was betreffende die Nederlandse kontekssinne, het studente hulle soektog dikwels begin deur onbekende Nederlandse woorde op te soek, soos wc (vraag 1), kunnen (vraag 4), klap en aangeboden (vraag 5). Hierdie soektogte het te make gehad met die primêre behoefte om genoeg data te kry sodat die opdrag - die produksie van 'n Nederlandse woord - voltooi kon word.

\subsection{Resultate}

Die bevindings in tabel 1 hieronder verskaf antwoorde op die navorsingsvrae soos geformuleer in paragraaf 4.1 .

\section{Noteringsleutel}

kursief: Die student soek 'n trefwoord wat nie in dié vorm as lemma in die woordeboek opgeneem is nie (bv. denk).

[ ]: Die student staak die soektog en vind nie die inligting nie.

*: Die student skryf nie die regte Nederlandse grammatikale vorm van die woord neer nie, bv. dink in plaas van denk; geloven in plaas van geloof. 


\section{Tabel 1}

\begin{tabular}{|c|c|c|c|c|}
\hline \begin{tabular}{|l} 
Korrekte \\
antwoord
\end{tabular} & $\begin{array}{l}\text { Soektyd (per } \\
\text { respondent) }\end{array}$ & Soekroete & \begin{tabular}{|l} 
Aantal \\
soekstappe
\end{tabular} & Sukses \\
\hline Bril & $\begin{array}{l}\text { A } 22^{\prime} 34^{\prime \prime} \\
\text { B } 2^{\prime} 47^{\prime \prime} \\
\left.\text { [C hou op ná } 5^{\prime} 35^{\prime \prime}\right] \\
\text { D } 1^{\prime} 58^{\prime \prime} \\
\text { E } 1^{\prime} 50^{\prime \prime} \\
\text { F } 2^{\prime} 42^{\prime \prime} \\
\text { G } 3^{\prime} 11^{\prime \prime} \\
\end{array}$ & $\begin{array}{l}\text { A bril } \\
\text { B bril, zetten, wc, bril } \\
\text { C zetten, wc, sitplek } \\
\text { D wc } \\
\text { E bril } \\
\text { F bril, wc } \\
\text { G wc, zetten } \\
\end{array}$ & $\begin{array}{ll}\text { A } & 2 \\
\text { B } & 7 \\
{[C} & 6 \\
\text { D } & 6 \\
\text { E } & 1 \\
\text { F } & 8 \\
\text { G } & 4 \\
\end{array}$ & $\begin{array}{l}\text { Positief } \\
\text { Positief } \\
\text { Negatief } \\
\text { Positief } \\
\text { Positief } \\
\text { Positief } \\
\text { Positief } \\
\end{array}$ \\
\hline Denk & $\mid \begin{array}{ll}\text { A } & 3^{\prime} 7^{\prime \prime} \\
\text { B } & 3^{\prime} 43^{\prime \prime} \\
\text { C } & 48^{\prime \prime} \\
\text { D } & 2^{\prime} 28^{\prime \prime} \\
\text { E } & 1^{\prime} 22^{\prime \prime} \\
\text { F } & 46^{\prime \prime} \\
\text { G } & 3^{\prime} 23^{\prime \prime}\end{array}$ & $\begin{array}{l}\text { A dink, denk, denken } \\
\text { B is } \\
\text { C dink } \\
\text { D zullen, vaak } \\
\text { E dink } \\
\text { F dink, denken } \\
\text { G denk, denken }\end{array}$ & $\begin{array}{ll}\text { A } & 5 \\
\text { B } & 3 \\
\text { C } & 3 \\
\text { D } & 5 \\
\text { E } & 1 \\
\text { F } & 4 \\
\text { G } & 4\end{array}$ & $\begin{array}{l}\text { Negatief } \\
\text { Negatief } \\
\text { Positief } \\
\text { Negatief } \\
\text { Negatief* } \\
\text { Negatief* } \\
\text { Positief }\end{array}$ \\
\hline Geloof & $\begin{array}{l}\text { A } 7^{\prime} 58^{\prime \prime} \\
\text { B } 3^{\prime} 43^{\prime \prime} \\
\left.\text { [C hou op ná } 2^{\prime} 54^{\prime \prime}\right] \\
\text { D } 37^{\prime \prime} \\
\text { E } 22^{\prime} 10^{\prime \prime} \\
\text { F } 55^{\prime} 51^{\prime \prime} \\
\text { G } 5^{\prime} 40^{\prime \prime}\end{array}$ & $\begin{array}{l}\text { A verstaan, glo, geloven } \\
\text { B zegt, zeg, zeer, sê, glo } \\
\text { C zeer } \\
\text { D zeer } \\
\text { E verstaan, zeer, glo, geloof } \\
\text { F verstaan, begrijpen, teenwoordigheid, } \\
\text { invloed, hoor, geloof } \\
\text { G verstaan, geloof }\end{array}$ & $\begin{array}{ll}\text { A } & 6 \\
\text { B } & 9 \\
\text { C } & 3 \\
\text { D } & 3 \\
\text { E } & 10 \\
\text { F } & 8 \\
\text { G } & 4\end{array}$ & $\begin{array}{l}\text { Negatief* } \\
\text { Negatief* } \\
\text { Negatief } \\
\text { Negatief } \\
\text { Positief } \\
\text { Negatief* } \\
\text { Negatief* }\end{array}$ \\
\hline Vertrekken & $\begin{array}{l}\text { A } 2^{\prime} 59^{\prime \prime} \\
\text { B } 3^{\prime} 38^{\prime \prime} \\
\left.\text { [C hou op ná } 6^{\prime} 10^{\prime \prime}\right] \\
\left.\text { [D hou op ná } 1^{\prime} 30^{\prime \prime}\right] \\
\text { E } 5^{\prime} 26^{\prime \prime} \\
\text { F } 46^{\prime \prime} \\
\text { G } 8^{\prime} 8^{\prime \prime}\end{array}$ & $\begin{array}{l}\text { A vertrek, lokaal } \\
\text { B verwarming, loop, seisoene, tyd } \\
\text { C dat, compendium, kunnen } \\
\text { D verwarming } \\
\text { E kunnen, verwarming, vertrekken, } \\
\text { vertrek } \\
\text { F vertrek } \\
\text { G kamer, loop, gang, gangen, kunnen, } \\
\text { vertrekken }\end{array}$ & $\begin{array}{ll}\text { A } & 4 \\
\text { B } & 13 \\
{\left[\begin{array}{ll}\text { C } & 7\end{array}\right]} \\
{\left[\begin{array}{ll}D & 2\end{array}\right]} \\
\text { E } & 13 \\
\text { F } & 2 \\
\text { G } & 12\end{array}$ & $\begin{array}{l}\text { Positief } \\
\text { Negatief } \\
\text { Negatief } \\
\text { Negatief } \\
\text { Positief } \\
\text { Negatief* } \\
\text { Positief }\end{array}$ \\
\hline Ontslag & 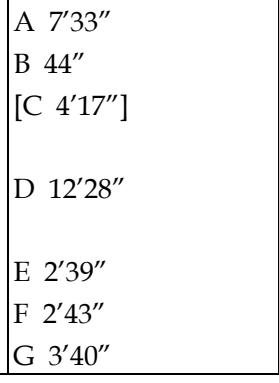 & $\begin{array}{l}\text { A kreeg, afdanking, bedank, afdanking } \\
\text { B werk } \\
\text { C bedanking, bedankings-brief, } \\
\text { kennisgewing, kennis } \\
\text { D kreeg, klap, aange-*, akkoord, krijg, } \\
\text { afdanken } \\
\text { E aangeboden, aanboden, aanbod, bedanking } \\
\text { F bedanking, ontslag } \\
\text { G bedanking }\end{array}$ & $\left.\begin{array}{ll}\text { A } & 8 \\
\text { B } & 8 \\
\text { [C } & 2\end{array}\right]$ & $\begin{array}{l}\text { Negatief } \\
\text { Negatief } \\
\text { Negatief } \\
\text { Negatief } \\
\text { Positief } \\
\text { Negatief } \\
\text { Negatief }\end{array}$ \\
\hline
\end{tabular}


Kortste soektog: ontslag: 44"

Langste soektog: ontslag: 12'28"

Totale aantal mislukte soektogte (student staak die soektog): 5 in totaal (uit 35)

Grootste aantal soekstappe: geloof (6 stappe)

Tabel 2: Totale soektyd per respondent

\begin{tabular}{|l|l|l|}
\hline Respondent & $\begin{array}{l}\text { Totale } \\
\text { soektyd }\end{array}$ & Opmerkings \\
\hline A & $24^{\prime} 11^{\prime \prime}$ & \\
\hline B & $13^{\prime} 19^{\prime \prime}$ & \\
\hline C & $17^{\prime} 44^{\prime \prime}$ & $\begin{array}{l}\left.\text { Hou op soek by vraag } 1 \text { (ná } 5^{\prime} 35^{\prime \prime}\right) \text {, vraag } 4 \text { (ná 6'10') en vraag } 5 \text { (ná } \\
\left.4^{\prime} 17^{\prime \prime}\right) .\end{array}$ \\
\hline D & $19^{\prime} 1^{\prime \prime}$ & Hou op soek by vraag 4 (ná $\left.1^{\prime} 30^{\prime \prime}\right)$. \\
\hline E & $13^{\prime} 27^{\prime \prime}$ & \\
\hline F & $12^{\prime} 48^{\prime \prime}$ & \\
\hline G & $24^{\prime} 2^{\prime \prime}$ & \\
\hline
\end{tabular}

\section{Om op te som}

Totale aantal korrekte antwoorde: 14

Antwoorde waar die korrekte grammatikale vorm nie gegee is nie, alhoewel die regte lemma gevind is: 7

Totale aantal verkeerde antwoorde: 14

Geen student kon al 5 antwoorde vind nie.

\subsection{Analise}

\subsubsection{Algemene waarnemings}

Die waarnemings hieronder betref die algemene opsoekgedrag van die respondente tydens die gebruiksituasie.

Die doelwit van die soektog in die ondersoek was die vind van die regte Nederlandse woord sodat aan die produksie-eis van die woordeskattoets voldoen kon word. Vanweë die artikelstruktuur van ANNA (vergelyk 4.5.4.2), word daar van die respondente vereis dat hulle 'n hele artikel baie sorgvuldig en aandagtig moet deurlees en ook baie spesifiek aandag moet gee aan die nietipografiese merkers. Dit hou weer op sy beurt in dat die voorteks of ten minste die bladsy met die artikeluitleg sorgvuldig gelees moes word voordat daar met die soektog begin is. Nie een student het egter die voor- of agtertekste geraadpleeg nie. Geen student het aanvanklik op die omslag die woorde "geamalgameerde woordeboek" raakgelees of daarop kommentaar gelewer nie. 
Studente soek nie doelgerig nie en vluglees die artikels baie oppervlakkig en vinnig. Belangrike inligting (wat byvoorbeeld in die voorbeeldsinne voorkom) is sodoende nie gevind nie. Dit het selde gebeur dat ' $n$ artikel behoorlik en sorgvuldig van begin tot einde gelees is. Feitlik alle simbole en fonte is geïgnoreer of daar is verkeerde afleidings gemaak oor watter inligting hulle oordra.

Die Nederlandse frase wat 'n kruisverwysing na die agtertekste bevat, zie compendium, is nie deur die studente verstaan nie of bloot geïgnoreer. Respondent B het byvoorbeeld gedink dit is 'n vertaalekwivalent vir die Afrikaanse woord is. Geen student het hierdie kruisverwysing opgevolg nie.

\subsubsection{Voor- en agtertekste}

Benewens die Woord vooraf bevat GWAN 'n afdeling Gebruiksaanwysings wat in beide Afrikaans en Nederlands gelees kan word. Die Afrikaanse gebruiksaanwysings beslaan 12 bladsye waarna eers 'n Nederlandse en dan 'n Afrikaanse lys afkortings en simbole gegee word, gevolg deur voorbeeldbladsye (in Afrikaans en Nederlands) met artikeluitleg. Hierdie gebruiksaanwysings is van die allergrootste belang, aangesien selfs ervare woordeboekgebruikers wat ook vaardig is in albei tale, moeite mag ondervind met die onbekende simbole in ANNA. Die lengte van hierdie gebruiksaanwysings en die feit dat daar miskien 'n ooraanbod aan inligting is (Is dit werklik nodig om vir vier bladsye lank die amalgamasiemodel en die soorte kognate - in GWAN bekend as cognates - uit te lê?) mag bydra tot die grootskaalse ignorering daarvan.

Daar is ook 'n stel agtertekste in die agterste deel van die woordeboek. Dit bestaan onder andere uit 'n grammatikale kompendium met funksiewoorde soos lidwoorde, voorsetsels, telwoorde, voegwoorde en voornaamwoorde. Nog een van die agtertekste is 'n lys onreëlmatige Nederlandse werkwoorde. Die probleem hier is dat Afrikaanse gebruikers nie noodwendig sal weet dat 'n werkwoord onreëlmatig is nie. Dit is ook 'n vraag of gebruikers (indien hulle wel die gebruiksaanwysings lees waarin die agtertekste verduidelik word) sal weet wat funksiewoorde is. 'n Ernstiger probleem is dat die frase zie compendium wat gebruikers na hierdie agterteks verwys, hoegenaamd nie in die gebruiksaanwysings verduidelik word nie. In die artikeluitlegbladsy word daar wel verwys na die grammatikale kompendium maar hier is daar ook nie genoegsame inligting oor waar die grammatikale kompendium gekry kan word nie.

\subsubsection{Die opdrag}

Aangesien die aard van die opdrag die woordeboekgebruiksituasie beïnvloed het, moet die een en ander hieroor gesê word. Die studente het die opdrag as baie moeilik, maar nie onmoontlik nie, ervaar. In die meerderheid gevalle is die gevraagde inligting (d.i. die Nederlandse woord, al is dit nie altyd in die kor- 
rekte grammatikale vorm neergeskryf nie) ook wel gevind (21 uit 'n moontlike 35). Wanneer studente bloot hardop nagedink het oor die moontlike antwoord en (nog) nie die woordeboek gebruik het nie, is hierdie tyd nie gemeet nie. Tydens hierdie aanvanklike nadinkproses moes hulle self besluit wat die data was wat hulle nodig gehad het. Die aard van die opdrag was dus sodanig dat verskillende tipes inligting gevind moes word - nie alleen die gevraagde antwoord nie, maar dikwels ook die betekenis van ander woorde in die sin. Dit het soms gelei tot baie lang soekroetes met baie soekstappe. Die aard van die opdrag en die studente se gebrek aan kennis van Nederlands was belangrike faktore hier.

Wanneer ANNA wel doeltreffend gebruik is, is die nodige inligting relatief vinnig en ondubbelsinning gevind. (Respondent B het die antwoord by vraag 5 binne $44^{\prime \prime}$ gekry - die kortste soektyd. In teenstelling hiermee het korresponent D 12'28" geneem om dieselfde antwoord te kry.)

\subsubsection{Die woordeboekstruktuur}

\subsubsection{Makrostruktuur}

Naslaanpogings misluk dikwels omdat die woordeboekstruktuur die gebruiker van doeltreffende toegang tot die data weerhou (Gouws 2001: 101-111). Dit was natuurlik te wagte dat die nuwe en onbekende makrostruktuur die toegangstruktuur van ANNA sou beïnvloed. Alle studente het die woordeboek verwarrend gevind en heen en weer geblaai op soek na die Afrikaans-Nederlandse of Nederlands-Afrikaanse afdeling van die woordeboek. Veral respondente C, E, F en G het dit besonder hinderlik gevind. Opmerkings hieroor was die volgende:

"Ek is nie seker hoe die woordeboek werk nie."

"Is daar 'n Nederlandse kant?"

"Die v's is baie ver agter."

"Dit bly vir my voel ek gaan van die Nederlandse deel na die Afrikaanse deel toe waar ek nie moet wees nie."

"Ek weet nie waar die Nederlandse deel begin nie."

Een student het tot die gevolgtrekking gekom dat sy nie die Nederlandse deel kan kry nie omdat Nederlands en Afrikaans baie dieselfde gespel word.

Die onbekende makrostruktuur het die soektyd en daarom die soekverwante inligtingkoste sonder twyfel verhoog. Dit is nodig om hier te beklemtoon dat die respondente nuwelinggebruikers van ANNA was. By herhaalde gebruik van die woordeboek sal hierdie aspek later waarskynlik nie meer ter sake wees nie. 


\subsubsection{Mikrostruktuur}

Meer as die makrostruktuur was dit egter die mikrostruktuur wat toegang tot die data belemmer het. ' $n$ Artikel in ANNA is anders as in enige vertaalwoordeboek wat die studente tot dusver teëgekom het en dit stel ' $n$ besondere uitdaging aan die gebruiker wat die woordeboek die heel eerste keer gebruik. Benewens ' $n$ vertaalekwivalent is daar ekstra inligting, met die gevolg dat ' $n$ tipiese artikel in ANNA heelwat langer is as een in ' $n$ tradisionele tweetalige woordeboek. Artikelstruktuur kan die inligtingkoste verhoog of verlaag (Nielsen 2008: 176) en in die geval van dié ondersoek was die soektyd en soekverwante koste inderdaad relatief hoog.

Verskeie niestandaardmerkers soos kursief (vir 'n Afrikaanse woord), !! (vir valse vriende), $<>$ (vir etikette), A/N (vir absolute kognate), en so meer het ten doel om die gebruiker te lei na spesifieke inligting in die artikel, maar dit is onmoontlik om hierdie aanwysers te verstaan indien die voorteks nie gelees is nie. Selfs mét die nodige voorkennis duur dit lank om die artikelstruktuur van ANNA onder die knie te kry. Die gebruik van simbole en fonte is natuurlik ter wille van tekskondensasie en gevolglike ruimtebesparing, maar dit kan die begripverwante koste verhoog (Nielsen 2008: 181). Daar is doodgewoon meer (en as gevolg van die simbole ook soms kriptiese) data in 'n tipiese ANNA-artikel as in 'n tradisionele tweetalige woordeboek. Dit het noodwendig ' $n$ impak gehad op die gemak waarmee die gebruikers by die data kon uitkom. Dat die dekoderingsproses oor die algemeen moeilik was, blyk uit die feit dat sommige studente moed opgegee het, dat geen student al vyf die $100 \%$ korrekte antwoorde (dit wil sê die korrekte Nederlandse vorm van die woord) kon vind nie en dat dit besonder lank geneem het om wel die gevraagde inligting te kry.

\section{Gevolgtrekking}

Gemeet aan Hartmann en James (1998) se definisie ("the relative ease with which information can be located in a reference work") dui die bogenoemde ondersoeksdata en ontleding daarop dat die inligtingontsluitingsproses nóg vinnig nóg maklik was. Die gevraagde informasie is nie vinnig en maklik gevind nie en twee studente het die soektyd hoegenaamd nie aanvaarbaar gevind nie. Sowel soekverwante as begripsverwante koste is aan die hoë kant. By die twee tipes koste wat Nielsen onderskei, kan mens ook emosionele koste byvoeg. Een student, wat by drie vrae opgehou soek het en bloot na die woordeboek sit en staar het, het ten slotte gesê sy het baie dom en ontevrede gevoel omdat sy nie die gevraagde inligting kon kry nie.

Dit is belangrik om daarop te let dat die ondersoek gedoen is met studente wat Nederlands nie ken nie en wat nuwelinggebruikers van ANNA was. 'n Ondersoek met ervare gebruikers wat ook albei tale ken, sal bes moontlik ander resultate oplewer. Dit sal miskien die moeite loon om 'n opvolgreplika- 
studie te onderneem. Die resultate van hierdie ondersoek is egter wel belangrik vir die gebruik van ANNA deur aanleerders. Indien ANNA doeltreffend in 'n Nederlandse taalverwerwingskursus gebruik wil word, sal daar vooraf 'n baie volledige gebruiksdemonstrasie gegee moet word. Omdat daar nêrens in die voorteks gebruiksaanwysings vir die kompendium of die lys onreëlmatige werkwoorde gegee word nie, sal daar, vóórdat die woordeboek gebruik word, baie aandag hieraan bestee moet word om die toegang tot hierdie tipe inligting vir hierdie tipe doelgroep te vergemaklik.

\section{Notas}

1. Vergelyk die addendum.

2. Die vyf leksikale items wat die studente moes vind, is sorgvuldig gekies deur onder andere gebruik te maak van die produktiewe woordeskattoets van Beheydt (2007).

\section{Bibliografie}

Beheydt, L. 2007. De dubbele pregnante contexttoets als productieve woordenschattoets voor Nederlands als vreemde taal. Fenoulhet, J. (Red.). 2007: 411-424.

Bergenholtz, H. en R. Gouws. 2010. A New Perspective on the Access Process. Hermes, Journal of Language and Communication Studies 44: 103-127.

Bergenholtz, H. en S. Tarp. 2003. Two Opposing Theories: On H.E. Wiegand's Recent Discovery of Lexicographic Functions. Hermes, Journal of Linguistics 31: 171-196.

Carstens, W.A.M. 2011. Norme vir Afrikaans. Pretoria: Van Schaik.

De Villiers, M. 1983. Nederlands en Afrikaans. Goodwood: Nasou.

Fenoulhet, J. (Red.). 2007. Neerlandistiek in contrast: Bijdragen aan het Zestiende Colloquium Neerlandicum. Amsterdam: Rozenberg.

Gouws, R.H. 2001. The Use of an Improved Access Structure in Dictionaries. Lexikos 11: 101-111.

Hartmann, R.R.K. en G. James. 1998. Dictionary of Lexicography. Londen/New York: Routledge.

Heid, U et al. (Reds.). 2000. Proceedings of the Ninth EURALEX International Congress, EURALEX 2000, Stuttgart, Germany, August 8th-12th, 2000. Stuttgart: Institut für Maschinelle Sprachverarbeitung, Universität Stuttgart.

Martin, W. (Hoofred.). 2011. Groot Woordeboek Afrikaans en Nederlands. Kaapstad: Pharos.

Martin, W. en R. Gouws. 2000. A New Dictionary Model for Closely Related Languages: The Dutch-Afrikaans Dictionary Project as a Case in Point. Heid, U. et al. (Reds.). 2000: 783-792.

Nielsen, S. 2008. The Effect of Lexicographical Information Costs on Dictionary Making and Use. Lexikos 18: 170-189.

Prinsloo, D. 2012. A Critical Evaluation of Dictionaries with Amalgamated Lemmalists. Ongepubliseerde referaat gelewer by die Sewentiende Internasionale Konferensie van die African Association for Lexicography, gehou by die Universiteit van Pretoria, 3-5 Julie 2012.

Raidt, E.H. 1991. Afrikaans en sy Europese verlede. Kaapstad: Nasou.

Tarp, S. 2007. Lexicography in the Information Age. Lexikos 17: 170-179. 
Tarp, S. 2008. Lexicography in the Borderland between Knowledge and Non-Knowledge. General Lexicographical Theory with Particular Focus on Learner's Lexicography. Tübingen: Niemeyer.

Tarp, S. 2009. Reflections on Lexicographical User Research. Lexikos 19: 275-296. 


\section{Addendum}

Vul 'n woord in wat in beide sinne pas.

Het __ van die zon is mij te sterk vandag. (licht)

De tas is heel __ die kan ik makkelijk dragen. (licht)

$1 \quad$ Ik kan niet meer lezen zonder

Mannen zetten altijd de omhoog in de wc.

$2 \quad \mathrm{Ik}$ nog vaak terug aan die mooie tijd in Indonesië. je dat er veel mensen naar het feest zullen komen?

$3 \quad \mathrm{Ik}$ niet alles wat hij zegt.

Het katholieke is nog altijd zeer sterk in Polen.

4 Als iedereen klaar is kunnen we

In dat oude kasteel brandt niet in alle de verwarming.

5 Gisteren heeft de minister van economische zaken zijn aangeboden omdat hij niet langer akkoord kon gaan met het gevoerde beleid. Toen hij op 57 jaar zijn kreeg bij de firma, was dat een harde klap voor hem. 


\title{
Orthography in the Planning of a Fang Dictionary
}

\author{
Guy-Modeste Ekwa Ebanéga, Département des Sciences du Langage, \\ Université Omar Bongo, Libreville, Gabon (guymodeste_e@yahoo.fr)
}

Summary: Orthographic data can be considered an important part of the microstructure of a dictionary. It will be of great importance in the planned Fang dictionary, as it targets advanced users who want to learn Fang as their second language and those mother tongue speakers who are not fluent in Fang. Therefore the orthographic data will be an important part of the linguistic description of the lexical item that non-native speakers of Fang need to grasp. The planned dictionary will be monodirectional, as it will present only one direction of the relationship between the two languages (from Fang to French). Fang will be the source language, for it will contain the meaning or the description of words. The dictionary will give a complete phonetic description, using the symbols of the International Phonetic Alphabet (IPA). Essential data such as the writing systems, pronunciation variants, orthographic variants, tones and stress in the writing of the Fang language, lemmatisation strategies, letters and punctuation are discussed and treated in this article.

Keywords: ORTHOGRAPHY, FANG, WRITING SYSTEM, TONES, STRESS, VARIANTS, LEMMATISATION STRATEGIES, LETTERS, PUNCTUATION

Résumé: L'orthographe lors de la planification d'un dictionnaire fang. L'orthographe peut être considérée comme une partie importante de la microstructure d'un dictionnaire. Elle sera d'une grande importance pour le dictionnaire planifié en fang, comme il vise des usagers avancés qui veulent apprendre le fang comme leur seconde langue et ceux qui ne maîtrisent pas le fang. Pour cette raison, l'orthographe sera une partie importante de la description linguistique de l'item lexical que les locuteurs non natifs du fang devront saisir. Le dictionnaire planifié sera monodirectionnel, comme il présentera seulement une direction de la relation entre les deux langues (du fang au français). Le fang sera la langue source car il contiendra le sens ou la description des mots. Le dictionnaire donnera une description phonétique complète, utilisant les symboles de l'Alphabet Phonétique International (API). Les données essentielles telles que les systèmes d'écriture, les variantes de prononciation et les variantes orthographiques, les tons et le stress dans l'écriture de la langue fang, les stratégies de lemmatisation, les lettres et la ponctuation sont discutés et traités dans cet article.

Mots-clés: ORTHOGRAPHE, FANG, SYSTÈME D'ÉCRITURE, TONS, STRESS, VARIANTES, STRATÉGIES DE LEMMATISATION, LETTRES, PONCTUATION 


\section{Introduction}

Orthography ${ }^{1}$ is an important part of the microstructure ${ }^{2}$ of a given dictionary. This point is also made in several empirical studies. In 1955, Barnhart (1967: 162-163) circulated 108 questionnaires in 99 American colleges concerning the types of information commonly provided in dictionaries. The results indicated that students considered orthography second in importance (after meaning). Quirk (1973), Béjoint (1981), Greenbaum, Meyer and Taylor (1984), Hartmann (1989), and Beyer and Faul (2010) all obtained results indicating that monolingual dictionaries are first and foremost used for determining or confirming mostly meaning and secondly orthography. Campoy Cubillo (2002), in her study of the needs of students of English for special purposes (ESP), found that $84.7 \%$ of the students demand orthography as a valuable type of data they need in their dictionaries, even though they have no idea how to interpret some unfamiliar symbols that are used to present such data. The need and demand for orthographic data would also be great in the planned Fang dictionary proposed in this article. As far as the needs of Gabonese students are concerned, Ekwa Ebanéga and Tomba Moussavou (2008), in their research, showed that $58 \%$ of the respondents consult a dictionary to look up orthographic data. It could be postulated that the respondents are aware of the importance of orthography in the dictionary.

The orthographic data cannot be described without focusing on the socalled user-perspective, which has emerged as an all significant criterion in the selection and lexicographical treatment of lexical items. Lexicographers such as Hartmann and James (1998) and Gouws (2000) emphasize the importance of the user-perspective in modern dictionary compilation. A dictionary should not reflect the attitude of the lexicographer but it should rather be aimed at specific needs of a well-defined target user. The aim is to present the dictionary text as user-friendly as possible. Gouws and Prinsloo (1998: 18) state in this regard:

The user-perspective, so prevalent in modern-day metalexicography, compels lexicographers to compile their dictionaries according to the needs and research skills of well-defined target user groups. The dominant role of the user has had a definite effect on the compilation of dictionaries as well as on the evaluation of their quality. Good dictionaries do not only display a linguistically sound treatment of a specific selection of lexical items. They are also products that can be used as linguistic instruments by respective target user groups. The better they can be used, the better dictionaries they are.

The planned dictionary is targeted at those advanced users who want to learn Fang as their second language and those mother tongue speakers who do not have a good command of Fang. The planned dictionary will have a communication-orientated function. The expansion of the different data on pronunciation will play a communication-directed function, because the aim is to help users with the production of texts in Fang. In fact, the target users of the 
proposed dictionary need to communicate in Fang among themselves. They must be able to assume the encoding and the decoding task, be capable to read and to write a lexical item and understand it at the same time, although the latter function is not discussed in this paper.

With regard to existing Fang dictionaries, a relevant discussion on the orthography ${ }^{3}$ is lacking. The presentation of orthographic data for users of these dictionaries reveals a number of shortcomings (cf. Mavoungou 2001). One of the problems is that Fang is a language with regional varieties. No variety has yet been chosen as standard variety.

\section{The writing system of Fang}

Attempts at writing the Gabonese languages go back to the arrival of the first colonizers. In his article on this issue, Mayer (1990) identifies three significant periods in the development of Gabonese languages into written form: (a) writing by the first Europeans; (b) writing by the missionaries for pedagogical purposes, and (c) scientific writing on the languages. According to Mayer, the first period lasts from 1500 to 1850 . It begins at the coast, with the arrival of the Portuguese. During this period the writing of the Gabonese languages was based on the alphabets of the former colonizers' native languages (cf. NdingaKoumba-Binza and Roux 2009: 84-88). The writings inherited from this period are, among others, the listings of people's names, and place, person's and common names. The second period begins in 1850 until the inauguration of the works adopting scientific writing, i.e. those by Raponda-Walker (1932). During this period the colonizers' outlook has changed 4 . However, as in the preceding period, the Latin alphabet of the colonizers' languages was still used for writing the Gabonese languages. The examples below are transcriptions of Fang in roman characters:

$\begin{array}{llll}\text { English } & \text { French } & \text { Martrou (1982) } & \text { Galley (1964) } \\ \text { Heart } & \text { Coeur } & \text { Nlẽm } & \text { NLEM } \\ \text { House } & \text { Maison } & \text { Nda } & \text { NDA } \\ \text { Child } & \text { Enfant } & \text { Monœ } & \text { MON } \\ \text { White } & \text { Blanc } & \text { Mfũm } & \text { MFUM }\end{array}$

The orthography of most of the words listed here differs from the current spelling of the same words, because the authors used the phonetic alphabets of their own languages to establish the spelling of Fang words. The third period is characterised by the use of writing systems specific to the Gabonese languages, resulting from linguistic studies (cf. as an example the Scientific alphabet of the Gabonese languages, see Carpentier de Changy and Voltz 1990).

To date, four writing systems of the Gabonese languages ${ }^{5}$ have been recorded: (a) the writing system of Raponda-Walker (1932), (b) the Scientific alphabet of the Gabonese languages, seminar proceedings published by LUTO (1990), (c) the alphabet for the Gabonese languages adopted in April 1999, and 
(d) the Rapidolangue writing system. Only two of these will be discussed: Raponda-Walker's alphabet and the April 1999 alphabet, together with NzangBié's alphabet proposal ${ }^{6}$.

\subsection{Raponda-Walker's system}

Raponda-Walker established a list of phonemes with corresponding graphemes by using the International Phonetic Alphabet (IPA). He proposed a system of 36 alphabetical symbols. This alphabet includes 28 consonants and 8 vowels, and is compiled according to the principle of aphorism, i.e. to each grapheme corresponds only one unique symbol to transcribe it, as can be seen below:

\section{Vowels}

a, e, è, i, o, ö, u, ü

\section{Simple consonants}

b, c, d, f, g, h, j, k, l, m, n, p, q, r, s, t, v, w, x, y, z

\section{Consonants with diacritics}

$\hat{\mathrm{c}}, \epsilon, \bullet \breve{S}, \tilde{\mathrm{n}}, \mathrm{n} ; \mathrm{r} ; \ddot{\mathrm{W}}$

According to Raponda-Walker (1998: 7), this orthographic alphabet, thanks to the specific diacritic signs used with different letters, easily reproduces the pronunciation of native words. It can also be noted that no prosodic phenomenon is mentioned. Raponda-Walker's system is very close to the Latin alphabet (Idiata 2002: 50), as can be seen from the symbols c, $\mathrm{k}$ and $\mathrm{q}$ which all represent the sound [k] (cf. Ndinga-Koumba-Binza and Roux 2009: 89-90).

\subsection{The April 1999 system}

In Gabon, from 8 to 10 April 1999, the Department of Education and the National Commission of UNESCO arranged a session for the consultation of experts with a view to the establishment of a spelling system for the Gabonese languages. During this session, the Gabonese people were advised to bear in mind the following vowels and consonants:

\section{Vowels}

The experts suggested nine vowels: $a, e, \underline{e}, \partial, i, o, \underline{o}, u$ and $\underline{u}$. The length of these vowels is represented by the reduplication of the vowel.

\section{Consonants}

The experts have retained the following monographs and digraphs

\section{Monographs}

b, c, d, $\underline{d}, f, g, h, j, k, 1, m, n, \underline{n}, p, r, s, t, v, w, y$ and $z$. 


\section{Digraphs}

gh, jh, sh, vh and ny.

Mid-nasal consonants and complexes with glides are spelled with the help of two or several letters.

The only criticism that can be brought in against this proposition is the symbol a which is identical to the phonetic symbol. It is important to make a distinction between orthographic and phonetic symbols, particularly for the vowels.

\subsection{Nzang-Bié's system}

In the latest version of Nzang-Bié's (2004) Fang orthographic system, she proposes 33 letters: 10 vowels, 20 consonants and 3 glides. The proposed system is applicable to all Fang dialects.

\section{Vowels}

a, e, $\varepsilon, \partial, \mathrm{i}, \mathrm{o}, \mathrm{o}, \ddot{\mathrm{u}}, \mathfrak{u}, \mathrm{u}$

When long, they are doubled:

aa, ee, $\varepsilon \varepsilon$, əə, ii, oo, эว, üü, uu, uu

\section{Consonants}

b, c, d, f, g, j, k, kp, l, m, n, ny, y, p, r, s, sh, t, v, z

\section{Glides}

$\mathrm{w}, \ddot{\mathrm{w}}, \mathrm{y}$

Nzang-Bié's system can also be criticised for not distinguishing orthographic symbols from phonetic symbols, used particularly for the vowels, e.g. $\varepsilon$, $\partial$ and 0 .

The model of the orthographic system for the planned dictionary will be the April 1999 alphabet, because, in comparison with the other alphabets, it has been agreed on by many experts (among others, linguists, sociologists and anthropologists). In this regard it deserves much consideration, also having the possibility to be accepted by the whole Gabonese community. Furthermore, some ongoing research uses the April 1999 alphabet as basis, among others, that of Nzang-Bié (2004) on the orthography of Fang which is still unpublished. This also has to explain the model for the writing system chosen in the user's guide $^{7}$ of the planned dictionary. 


\subsection{Tones and stress in the writing of Fang}

Writing of the Gabonese languages cannot be discussed without taking into account the matter of tones ${ }^{8}$ and stress ${ }^{9}$. Indeed, the issue of the writing of the Gabonese languages is related not only to the choice of the alphabet system, but also to the dilemma of the transcription or not of the supra-segments (cf. Afane-Otsaga 2004: 243). Lexicographers compiling dictionaries for African languages in general and Fang in particular have been guilty of ignoring these basic components of the phonological analysis of the languages (cf. Mavoungou 2001: 133). Lexicographers sometimes face problems associated with the indication of tones and stress in the transcription of the lemma. This could mislead the user who wants to distinguish between stress and tone.

Given the fact that the target users of the planned dictionary are advanced learners, it will not be problematic to indicate the stress and tone of the lemma, as this will be explained in the user's guide of the dictionary. Stress in Fang can be manifested in vowel length. In the dictionary, the stress indicator will be placed after the syllable that is stressed before the transcription of the lemma. The tone will be indicated between brackets. Consider the modified example of the article of the lemma ako taken from the Dictionnaire Fang-Français et Français-Fang:

$$
\text { ako' [àkóó] }
$$

\section{Orthography and pronunciation variants}

Users often consult a dictionary wanting to learn the exact pronunciation and spelling of a word, only to discover that the word may have several pronunciations and spellings, as in the case of, among others, abe "bad" in Fang-Ntumu and $a b i$ "bad" in Fang-Atsi. The inclusion of variant pronunciations and spellings confuses those who want their dictionary to list one "correct" pronunciation or spelling. However, there can be no objective standard for correct pronunciation other than the usage of attentive and educated speakers of the given language. Among such speakers much variation in pronunciation is heard. The pronunciation and spelling variants cannot be presented without focusing on the varieties of Fang.

Apart from the fact that Fang is widely diffused in Gabon (in four provinces and 17 regions), it is also spoken in neighbouring countries (i.e. Cameroon, Equatorial Guinea, the Republic of the Congo and São Tome). This means that the varieties of Fang spoken in these countries are also counted as varieties of Fang. However, in this article, the focus will primarily be on the five Fang varieties spoken in Gabon. These are:

- $\quad$ Fang-Ntumu: Fang-Ntumu speakers represent the biggest community of Fang in Gabon. This variety, located in Oyem and Bitam, covers the largest Fang area in Gabon. 
- $\quad$ Fang-Okak: This variety is located principally in the Mitzic, Medounou and Cocobeach regions.

- Fang-Mvaii: This sole Fang variety is spoken in only one region of Gabon, namely the Minvoul or Haut Ntem region.

- $\quad$ Fang-Mekè: Fang-Mekè speakers can be located on the other side of the sea, in the Metek ma vii chinchoua zone (on the western side of the Estuaire River) and in the area of Lalala (on the eastern side of the Estuaire River). Fang-Mekè speakers are also called mekè me Nkoma because they are the group of Fang people that decided to leave and cross the Komo River when they reached the Estuaire. The name Mekè comes from the Fang term meke (or mekè), which means "departure". Today this term designates all Fang speakers in the Estuaire area, even those ones who did not cross the Komo River.

- $\quad$ Fang-Atsi: It is spoken by the Betsi population in three regions in Gabon: Lambaréné, Ndjolé and Bifoun (cf. Kwenzi-Mikala (1990 and 1998)).

After discussing the Fang varieties, the choice of the standard variety of Fang in the planned dictionary must be considered. For the choice of the standard variety, a further obstacle faced by lexicographers is the tendency of regional varieties (cf. Zgusta 1989: 71). One of the main problems of existing Fang dictionaries is that they fail to adhere to a standard language. Among the varieties of Fang, no variety has yet been chosen as the standard variety. These dictionaries which may confuse and mislead the users, would be condemned by users and reviewers.

The planned dictionary must be regarded as the authority on the spelling, grammar, meaning and usage of Fang. It must record the standard variety, reflecting the norm, and must include items of other norms or other varieties of Fang, and the social and geographical areas where each is spoken must be marked accordingly.

Many studies have been undertaken regarding the regional varieties of Fang, including those by Ekwa Ebanéga (2000), Nzang-Bié (2004) and AfaneOtsaga (2004). These authors give the following reasons for choosing FangNtumu as the standard variety model.

- $\quad$ Fang-Ntumu is the most vital variety because of its number of speakers.

- $\quad$ Fang-Ntumu is the most homogeneous variety; it is found in the province Woleu-Ntem where Fang is the only language.

- $\quad$ Fang-Ntumu in the province of Woleu-Ntem does not coexist with other foreign languages, as is the case with Fang-Ntumu, which is found in Oyem, while Fang-Ntumu, which is spoken in Bitam, coexist with Hausa, a foreign language spoken in Cameroon and Nigeria. 
- $\quad$ Fang-Ntumu plays an important economic, cultural and social role in the province of Woleu-Ntem. The main activities in this province occur in Oyem and Bitam, which are the original regions of Fang-Ntumu. Many people from other parts of this province and from neighbouring countries (Cameroon and Equatorial Guinea) go there to work, study and do business. Fang-Ntumu is the language of communication between members of the Fang population in this part of Gabon.

- $\quad$ Of all varieties of Fang, works published in Fang-Ntumu are the most accessible to people today. Most of the works in other varieties are not readily available in Gabon. For instance, dictionaries compiled in FangAtsi and Fang-Mekè cannot be found in any Gabonese library.

- $\quad$ Fang-Ntumu is the most used Fang variety in the audiovisual media (radio and television) in Gabon. It is also the first Fang variety in which an entire movie has been made.

The planned dictionary will include pronunciation data and spelling variants. The pronunciation and spelling variants of the words will be shown after the lemma. The pronunciation will be written using Nzang-Bié's alphabet. Lexicographers should be careful when treating these variants. They may be given a microstructural treatment, including the main pronunciation at the frequently used form (cf. Svensén 1993). Such a method of frequency of use may be the ideal way to treat the pronunciation variants, but should be tested empirically. Consider the following modified article of the lemma abi drawn from the Dictionnaire Fang-Français/Français-Fang, showing how the pronunciation and spelling variants will be placed in the planned dictionary:

abe [ábè] Atsi abi [ábì]

In the modified article of the lemma abe, the item of the lemma abe (Ntumu as the standard variety model) is provided, followed by the Atsi spelling variant abi in bold and the pronunciation [ábì]. The label Atsi informs users of the existence of these pronunciation and spelling variants in the Fang dialect Atsi.

Once the orthographic systems and the orthographic variants are known, the lexicographers have to pose the following questions: How are the orthographic principles used to organise the macrostructure ${ }^{10}$ of the planned dictionary? What are the orthographies of the lemmas (nouns, compounds) and which orthographic procedures, strategies and conventions should be used when entering lemmas ${ }^{11}$ (nouns, compounds) in the planned dictionary? 


\section{Lemmatisation ${ }^{12}$}

\subsection{The first or the third letter method}

Entering nouns on the first or the third letter is a method used by Snyman et al. (quoted by Gouws and Prinsloo 2005: 78) in their Dikišinare ya SetswanaEnglish-Afrikaans Dictionary/Woordeboek. In the planned Fang dictionary, irregular forms will be automatically accommodated by being entered under their first letter. The examples below show a few nouns from the Dictionnaire FangFrançais et Français-Fang and the Lexique Fan-Français:

Fang nouns in the Dictionnaire Fang-Français et Français-Fang (Galley 1964)

$\begin{array}{ll}\text { Singular } & \text { Plural } \\ \text { môr } & \text { bôr } \\ \text { tsir } & \text { betsir } \\ \text { afan } & \text { mefan } \\ \text { ékon } & \text { bikon } \\ \text { ésa } & \text { bésa }\end{array}$

Fang nouns in the Lexique Fan-Français (Martrou 1924)

$\begin{array}{ll}\text { Singular } & \text { Plural } \\ \text { môr } & \text { bôr } \\ \text { mbi } & \text { mimbi } \\ \text { ônon } & \text { anon } \\ \text { éli } & \text { bili }\end{array}$

Fang nouns carry different prefixes, as shown in the examples given above. At this level, entering them under their first letter seems to be unproblematic, as they can be easily distributed into different article stretches. The use of such a strategy is motivated by the fact that (a) the compilers of existing Fang dictionaries attach the prefixes to the lemma; and (b) this strategy avoids the problem of the irregularity of the nominal prefixes. However, the use of this procedure could be problematic and users could become frustrated when having to select different forms. Given the fact that the planned dictionary is composed for advanced users, it is expected that they will have sufficient skills to understand this strategy. Nevertheless, an explanation of this procedure will be provided in the front matter of the dictionary.

\subsection{Conjunctivism versus disjunctivism}

Van Wyk (1995) emphasizes that conjunctivism versus disjunctivism is purely a matter of orthography. However, this issue has implications for lexicography. In conjunctively written languages, some lexicographers attach the prefixes to 
the stems. This strategy has the advantage of users seeing the full form of the infinitive. Other lexicographers, in disjunctively written languages, enter the stems according to their forms. The advantage of this strategy is that, (a) unlike nominal prefixes, verbal prefixes are regular in form, and (b) it avoids the inclusion of all the verbs of the language in a single article stretch introduced (in Fang for example) by $a$. Consider the following examples showing the infinitive verbs in Fang:

$\begin{array}{ll}\text { abanə "to press" } & \text { aku "to fall down" } \\ \text { abye "to deliver" } & \text { alom "to send" } \\ \text { adzi "to eat" } & \text { anyu "to drink" } \\ \text { adzighə "to burn down" } & \text { azu "to come" } \\ \text { adzogh "to leave" } & \text { asal "to cut" } \\ \text { akə "to go" } & \text { aswi "to pour" } \\ \text { avə "to give" } & \text { ayo "to bring up" } \\ \text { avilə "to suck" } & \\ \text { awulə "to walk" } & \\ \text { ayələ "to fly" } & \end{array}$

These examples show that listing Fang verbs in alphabetical order according to their basic forms implies entering all verbs under the same letter of the alphabet. Because all Fang verbs will be entered under $a$, this would create an imbalance in the dictionary as such article stretches will be overcrowded.

However, in order to solve the problem of imbalance in listing basic verb forms that have infinitive markers, an alternative convention has to be adopted. The lexicographers chose the practice of listing verbs by stems as illustrated in the examples below:

Fang verb stems, cf. Dictionnaire Fang-Français et Français-Fang (Galley 1964)

$\begin{array}{ll}\text { BOR } & \text { FA } \\ \text { BORA } & \text { FAGHA } \\ \text { DAGHEBE } & \text { FAGHBE } \\ \text { DEP } & \text { FAKH } \\ \text { DIGHE } & \text { FAL } \\ \text { DO } & \text { FANBE } \\ \text { DUMLA } & \text { FANGA } \\ \text { DUP } & \text { FAR } \\ \text { DURA } & \text { FARGA }\end{array}$

Fang verb stems, cf. Lexique Fan-Français (Martrou 1924)

$\begin{array}{ll}\text {-Ba } & \text { Korœ } \\ \text {-Bam } & \text {-Ku } \\ \text {-Bar } & \text {-Le }\end{array}$




$\begin{array}{ll}\text {-Bi } & \text { Ngen } \\ \text { Bur } & \text {-Salœ } \\ \text { Dzur } & \text { Yẽn } \\ \text {-Fè } & \text { Yer } \\ \text { Kilœ } & \end{array}$

Fang verb stems, cf. the project of the revision of the Dictionnaire Fang-Français et Français-Fang of Samuel Galley (2004)

$\begin{array}{ll}\text {-banə } & \text {-ku } \\ \text {-bye } & \text {-lom } \\ \text {-dzi } & \text {-nyu } \\ \text {-dzighə } & \text {-zu } \\ \text {-dzogh } & \text {-sal } \\ \text {-kə } & \text {-swi } \\ \text {-və } & \text {-yir } \\ \text {-vilə } & \text {-yo } \\ \text {-wulə } & \text {-yon } \\ \text {-yələ } & \end{array}$

With regard to the proposed dictionary, the disjunctive method of using verb stems employed by the Dictionnaire Fang-Français et Français-Fang and the Lexique Fan-Français will be followed. By using this method, Fang verbs could be listed under the first letter of the stem.

This method of using verb stems rather than infinitive forms as lemmas solve the problem of imbalance mentioned above. The lexicographers of the planned dictionary are aware of the fact that such a strategy will be unproblematic for users comprising advanced learners, as it demands less effort for them to look up infinitive forms of the full forms minus the verbal prefix $a$-. This has to be explained consistently in the user's guide of the dictionary.

\subsection{The expanded microstructure}

The left-expanded microstructure can be regarded as an orthographic procedure for lemmatizing nouns and verbs in the dictionary. Wiegand (1989, quoted by Gouws and Prinsloo 2005a) has introduced the notion of the leftexpanded microstructure as a procedure where data typically presented in a microstructure slot to the right of the lemma sign can, as an alternative convention, be moved to a position where it precedes the lemma sign but still has the lemma sign as its address. The advantage of the left-expanded microstructure consists of attaching prefixes to the lemma as a guiding element of the article so that users can recognise the orthographic word which they encounter in actual language usage (cf. Gouws and Prinsloo 2005a). Consider the following examples. 

(a-) dzi
"to eat"
(a-) ku
"to fall down"
(a-) lom
"to send"
(a-) nyu
"to drink"

For the users to look up infinitive forms on the full form minus the prefix $a$ - is not expecting too much, even for inexperienced users of the dictionary (cf. Gouws and Prinsloo 2005a).

By employing a left-expanded article structure, the major difficulty regarding stem identification can be simplified substantially. This is beneficial especially for inexperienced users, and the presentation will acknowledge both knowledge-directed and communication-directed functions. The presentation as suggested in the above-mentioned examples will be of value for users consulting the dictionary for text reception and also for text production purposes.

The use of the strategy of the left-expanded microstructure should be retained in the planned dictionary. This orthographic strategy allows lexicographers to attach prefixes to the lemma as a guiding element of the article so that users are able to recognise the orthographic word which they encounter in Fang. The use of such a strategy could be problematic for inexperienced users. Given the fact that the planned dictionary is targeted at advanced learners, it is expected that they will have the necessary knowledge and skills to understand this procedure. However, this has to be explained consistently in the user's guide of the dictionary.

\subsection{The orthography of compounds}

The inclusion of compound lexical items poses a difficult challenge to lexicographers. According to Louw (2004: 44), this challenge is rooted especially in the variation in spelling of these compound lexical items, the appropriateness of sublemmatisation to the target user group and the question of transparency. Compound nouns can be regarded as the category, which best illustrates the variety of problems faced in the treatment of compound lexical items.

As far as English compound nouns are concerned, Béjoint (1999: 81) distinguishes three forms namely XY, X Y and X- Y, which can be applied to compound nouns like paperclip, paper clip and paper-clip respectively. He states that this makes the automatic extraction of compounds particularly difficult in English. The compiler of the dictionary should evidently have problems identifying those compounds of the type $X Y$ or $X-Y$ and considering them for lemmatisation or sublemmatisation, but those of the type $X Y$ can be a more challenging prospect.

The inclusion of compound lexical items also provides a difficult task to the compiler to determine whether the combination dealt with is a compound noun or a collocation. Here the lexicographer's intuition, as an advanced language user, will play an important role, but more scientific criteria can be iden- 
tified to aid in the task. Béjoint (1999) suggests the following criteria to be used to distinguish between compound lexical items and collocations: non-compositionality, position of stress, frequency, and lexical unity.

Once a method of distinguishing between collocations and multi-word compound nouns has been found, the treatment of this type of compound nouns can be considered. These compound nouns should be treated in the same way as single-word or hyphenated compound nouns, because, according to Schnorr (1991: 2815), despite the blank, these compounds will be identified as one concept and therefore as one base form. Sometimes lexicographers do not know whether compounds should be hyphenated or not. The question then arises whether compound nouns should be included as lemmas or sublemmas in the proposed dictionary.

As far as Fang is concerned, three types of compounds can be distinguished. These are as follows:

(a) Compound nouns having the structure: noun + noun. As example: Mbôm fwé (someone who gives the news), taken from Dictionnaire FangFrançais et Français-Fang.

(b) Compound nouns having the structure: derivative + noun

(c) Compound nouns having the structure: noun + connective + noun

In the proposed dictionary, compounds should be presented as lemmas. It will avoid the unusual approach to the treatment of compound nouns employed in both Chambers-Macmillan South African Dictionary Junior Secondary and The South African Oxford School Dictionary, in which compound nouns are usually sublemmatised. Compilers of the proposed dictionary should be aware of how much space such a procedure can take. However, by lemmatising a compound noun as lemma or single-word lemma, the proposed dictionary would better meet the users' expectations and be less confusing. Louw's (2004) suggestion should be considered, i. e. that this conjecture should lead to a decision that must be consistently applied throughout the dictionary. Such a decision should then also apply to all compound lexical items, and not just compound nouns.

\subsection{The orthography of homonyms and polysemes}

According to Catach (1989: 507), the other challenge, which calls into question the lexicographers' desire not to take into account the graphic form of the word, is the presence in the lexicon of words having the same phonic forms, but diverse graphic forms (heterographs, which are selected in alphabetical order) or the opposite (homographs, brought together depending on the dictionaries). This leads to the distinction between homonyms and polysemes.

It is true that homonymy and polysemy can by regarded as two well-known semantic and orthographic issues. A clear and consistent treatment of 
homonymy and polysemy can be an important precursor to the more direct transfer of semantic data. The lexicographers of the planned dictionary should have to use and apply common international systems and principles (superscripts to distinguish homonyms and numeral indicators to separate polysemous senses) in order to make the transfer of dictionary usage skills effective. The users' needs should have to motivate the choice of the system and this has to be explained in the user's guide in the dictionary. Consider the modified article of the lemma EKOA taken from the Dictionnaire Fang-Français et Français-Fang:

EKOA [...] 1. Cimier, partie supérieure d'un casque. 2. Grand bec de toucan. Anon bikôa, oiseaux à grand bec.

EKOA [...] 1. Réunion. 2.

With regard to articles of the lemmas EKOA showing the placement of homonyms and polysemes in the articles of the dictionary, homonyms will be differentiated by the use of superscripts $(1,2, \ldots)$ and polysemes by the use of numeral indicators $(1,2, \ldots)$. The choice is motivated by the fact that the superscripts mark the lemma itself and this will allow users to make a clear distinction between homonyms and polysemous senses.

\subsection{Letters $^{13}$ and punctuation ${ }^{14}$}

It has previously been said that the term orthography is the set of norms or principles on which the writing system is based (e.g. letters). According to Burkhanov (1998: 167), it is used to designate the study of, and/or the instruction in a systematic and uniform representation of speech in writing by means of letters and punctuation marks. This leads to a discussion regarding letters and punctuation marks. In the planned dictionary, the italic letters will indicate the part of speech; the small letters given in bold will be used for the main lemma; the small letters in regular font will indicate the definition and then italics for illustrative examples. Using different fonts, i.e. regular font for definitions and italics for examples, will mark a clear distinction between these two data categories. Although the same type of font can be used for equivalents and the definition, the former may be enclosed in square brackets for easy identification. Capital letters will be used to indicate the idioms. In the proposed dictionary, the entry "IDIOME" will be given in capital letters, which will enhance the rapid access to the text block entrance. Being the only entry given in capital letters, it will become much more noticeable.

As far as the punctuation marks are concerned, in the planned dictionary a semicolon (;) will be used to separate translation equivalents presenting polysemous senses of the lexical items presented by the lemma sign. Compare the following example: 
fam: [...] homme; garçon; courageux; dur.

This presentation implies that the Fang word fam is polysemous and that it has four senses, translated into French by means of the equivalents "homme; garcon; courageux; dur" separated by a semicolon (;). In the proposed dictionary, the different syllables will be separated by means of dots (.) and the syllable with the main stress will immediately be followed by a superscript stress indicator $\left(^{\prime}\right)$.

\section{Conclusion}

In this article, orthographic data was discussed as part of the microstructure of the planned Fang-French dictionary. It can be regarded as an important part of the lexicographical data. The orthographic data will be of great interest in the planned Fang dictionary, as it is targeted at those advanced users who want to learn Fang as their second language and those mother tongue speakers who are not fluent in Fang. In this regard, orthography should be a very important part of a lexical item's linguistic description, which users, particularly non-native speakers of Fang, need to grasp. The planned dictionary will give a comprehensive phonetic transcription, using Nzang Bie's system that has been drawn from the International Phonetic Alphabet (IPA). In this article, different types of data on pronunciation have been discussed in relation to the planned dictionary. It is well attested that the item giving the transcription is addressed at the lemma. This item is traditionally positioned immediately after the lemma, a tradition that will also be followed in the planned dictionary.

As far as the alphabet is concerned, the model for the proposed microstructural programme will be the April 1999 alphabet because, among other alphabets, it is the one that has been considered by many experts. In this regard it deserves much consideration and it also has the possibility of being accepted by the whole of the Gabonese community. Furthermore, some ongoing research, among others, that of Nzang-Bié (2004) on the orthography of Fang which has not been published yet uses the April 1999 alphabet. This also needs to be taken into consideration. The model for the proposed dictionary will be explained in the user's guide. All the vowels, consonants, digraphs and monographs will also be presented and discussed in this functional part of the dictionary.

The writing of the Gabonese languages is not possible without taking into account the matter of tones and stress. In order to avoid the problem associated with the indication of tones and stress in the transcription of the lemma, the lexicographers of the planned dictionary have decided on the following: The stress indicator will be placed before the transcription of the lemma that is stressed. The tone will be indicated between brackets.

The planned dictionary will take into account the orthographic variants and the pronunciation variants. Many studies have been undertaken regarding 
the regional varieties of Fang. Fang-Ntumu has been chosen as the standard variety model, and it will therefore be adopted in the planned dictionary.

Relevant orthographic strategies for lemmatising nouns, verbs, compound nouns, homonyms and polysemes will be used in the planned dictionary. Given the fact that the dictionary is targeted at advanced users, they are expected to have the necessary knowledge and skills to understand these procedures. However, all this has to be explained clearly and consistently in the user's guide of the dictionary.

Orthography certainly affects all aspects of dictionary work such as lemmatisation and treatment of variants and other data categories. The lexicographers of the planned dictionary have to bear Littre's (1959) view in mind. He considers orthography as the second speech form of the language. As recorders and describers of usage, lexicographers should have to intervene all the time in situations where language users experience problems related to it. They should also have to do so in a full knowledge of the facts regarding the language and the skills of the target users.

\section{Endnotes}

1. Hartmann and James (1998: 103-104) define orthography as the set of norms or principles on which the writing system is based (e.g. letters and characters).

2. According to Gouws (2001: 86), the microstructure is the selection of data categories given as part of the treatment of the lemma sign.

3. Idiata (2007: 140-141), in his synthesis of linguistic studies on the Gabonese languages, shows that the incidence of the writing systems of the Gabonese languages in bibliographical data bases is 2\%. Further to Idiata's finding, Ekwa Ebanéga (2010: 228) states: "Malgré son importance et sa valeur, l'orthographe est l'une des données les plus mal utilisées" ("Despite its significance and value, orthography is one of the most misused data").

4. According to Mayer (1990), they stopped communicating with the indigenous peoples, but they started focusing on language learning.

5. The writing systems of the Gabonese languages are not, as the linguists' work, accessible to the public (Ekwa Ebanéga and Tomba Moussavou 2006: 241).

6. Nzang-Bié (2004) proposes this orthographic system for Fang.

7. According to Burkhanov (1998: 258), the main function of the user's guide is to explain the dictionary algorithm to the user, i.e. to show how to get easy access to the lexicographical data contained in particular subdivisions of a dictionary.

8. According to Matthews (1997: 379), a tone is a phonetic or phonological unit belonging to a set of units distinguished or primarily distinguished by levels of or changes in pitch. For Baylon and Fabre (1990: 101), tones are used as distinctive units.

9. According to Anyanwu and Goethe (2001), stress is the accent which is manifested by pitch, intensity and length.

10. According to Gouws and Prinsloo (2005: 63), the macrostructure is the selection of lexical items to be included in the dictionary. They become the primary treatment units of the lexicographical process. 
11. The same as "head words" (see Burkhanov 1998: 116).

12. Lemmatisation can be defined in an over-simplified way as the selection of a specific form from a given paradigm to be used in a dictionary as the starting point for information retrieval (Gouws and Prinsloo 2005: 67).

13. According to Hartmann and James (1998: 83), letters are graphic symbols used in an alphabetical writing system to represent one or more speech sounds.

14. For Hartmann and James (1998: 113), punctuation is a system of graphic marks used to link or separate words and phrases in writing.

\section{References}

Afane-Otsaga, T. 2004. The Standard Translation Dictionary as an Instrument in the Standardization of Fang. Unpublished D.Litt. Thesis. Stellenbosch: University of Stellenbosch.

Anyanwu, R.J. and J.W. Goethe. 2001. On the Manifestation of Stress in African Languages. [Online] Available: http:/www.spectrum.ini-bielefeld.de/TAPS/Anyanwu.pdf.

Barnhart, C.L. 1967. Problems in Editing Commercial Monolingual Dictionaries. Householder, Fred W. and Sol Saporta (Eds.). 1967. Problems in Lexicography: 161-181.

Baylon, C. and P. Fabre. 1990. Initiation à la linguistique. Paris: Nathan.

Béjoint, H. 1981. The Foreign Student's Use of Monolingual English Dictionaries: A Study of Language Needs and Reference Skills. Applied Linguistics 2: 207-222.

Béjoint, H. 1999. Compound Nouns in Learners' Dictionaries. Herbst, T. and K. Popp (Eds.). 1999. The Perfect Learner's Dictionary (?): 81-99. Tübingen: Max Niemeyer.

Beyer, H.L. and A.K. Faul. 2010. Namibian University Entrants' Concepts of a Dictionary. Lexikos 20: 644-679.

Burkhanov, I. 1998. Lexicography: A Dictionary of Basic Terminology. Rzeszów: Wydawnictwo Wyższej Szkoły Pedagogicznej.

Campoy Cubillo, M.C. 2002. Dictionary Use and Dictionary Needs of ESP Students: An Experimental Approach. International Journal of Lexicography 15(3): 206-228.

Carpentier de Changy, H. and M. Voltz. 1990. Alphabet scientifique des langues du Gabon: liste alphabétique. Revue Gabonaise des Sciences de l'Homme 2: 113-115.

Catach, Nina. 1989. L'orthographe dans le dictionnaire monolingue. Hausmann, F.J., O. Reichmann, H.E. Wiegand and L. Zgusta (Eds.). 1989: 501-508.

Chambers-Macmillan. 1996. Chambers-Macmillan South African Dictionary Junior Secondary. Manzini: Macmillan Boleswa Publishers.

Ekwa Ebanéga, G.-M. 2000. L'analyse rhétorique du discours de mariage chez les Fang Ntumu (Oyem). Unpublished M.A. Thesis. Libreville: Université Omar Bongo.

Ekwa Ebanéga, G.-M. 2010. Le dictionnaire comme outil d'enseignement des langues au Gabon. Lexikos 20: 212-233.

Ekwa Ebanéga, G.-M. and F. Tomba Moussavou. 2006. Des considérations sur la lexicographie et la linguistique au Gabon. Lexikos 16: 239-250.

Ekwa Ebanéga, G.-M. and F. Tomba Moussavou. 2008. A Survey of the Dictionary Use of Gabonese Students at Two South African Universities. Lexikos 18: 349-365

Galley, S. 1964. Dictionnaire Fang-Français et Français-Fang, suivi d'une grammaire Fang. Neuchâtel: Henri Messeiller. 
Gouws, R.H. 2000. Towards the Formulation of a Metalexicographic Founded Model for National Lexicographic Units in South Africa. Wiegand, H.E. (Ed.). 2000. Wörterbücher in der Diskussion IV. Vorträge aus dem Heidelberger Lexikographischen Kolloquium: 109-133. Tübingen: Max Niemeyer.

Gouws, R.H. 2001. Lexicographic Training: Approaches and Topics. Emejulu J.D. (Ed.). 2001: Éléments de lexicographie gabonaise. Tome I: 58-94. New York: Jimacs-Hillman Publishers.

Gouws, R.H. and D.J. Prinsloo. 1998. Cross-referencing as a Lexicographic Device. Lexikos 8: 17-36.

Gouws, R.H. and D.J. Prinsloo. 2005. Principles and Practice of South African Lexicography. Stellenbosch: SUN PreSS.

Gouws, R.H. and D.J. Prinsloo. 2005a. Left-expanded Article Structures in Bantu with Special Reference to IsiZulu and Sepedi. International Journal of Lexicography 18(1): 25-46.

Greenbaum, S., C.F. Meyer and J. Taylor. 1984. The Image of the Dictionary for American College Students. Dictionaries 6: 31-52.

Hartmann, R.R.K. 1989. Sociology of the Dictionary User: Hypotheses and Empirical Studies. Hausmann, F.J., O. Reichmann, H.E. Wiegand and L. Zgusta (Eds.). 1989: 102-111.

Hartmann, R.R.K. and G. James. 1998. Dictionary of Lexicography. London/New York: Routledge.

Hausmann, F.J., O. Reichmann, H.E. Wiegand and L. Zgusta (Eds.). 1989-1991. Wörterbücher. Ein internationales Handbuch zur Lexicographie/Dictionaries. An International Encyclopedia of Lexicography/Dictionnaires. Encyclopédie internationale de lexicographie. Berlin: Walter de Gruyter.

Hawkins, J.M. 1996. The South African Oxford School Dictionary. Cape Town: Oxford University Press.

Idiata, D.F. 2002. Il était une fois les langues gabonaises. Libreville: Éditions Raponda-Walker.

Idiata, D.F. 2007. Les langues du Gabon: Données en vue de l'élaboration d'un atlas linguistique. Paris: L'Harmattan.

Kwenzi-Mikala, J.T. 1990. Quel avenir pour les langues gabonaises? Revue Gabonaise des Sciences de l'Homme 2: 121-124.

Kwenzi-Mikala, J.T. 1998. Parlers du Gabon: classification du 11-12-97. Raponda-Walker, A. (Ed.). 1998. Les langues du Gabon. Libreville: Éditions Raponda-Walker.

Littré, E. 1959. Dictionnaire de la langue française. Paris: Gallimard/Hachette.

Louw, P.A. 2004. Criteria for a Multifunctional, Monolingual Dictionary in Junior Secondary Education Unpublished D.Litt. Thesis. Stellenbosch: University of Stellenbosch.

LUTO. 1990. Actes du séminaire des experts sur l'alphabet scientifique des langues du Gabon (tenu à Libreville du 20 au 24 février 1989). Revue Gabonaise des Sciences de l'Homme 2.

Martrou, L. 1924. Lexique fãn-français. Paris: Procure Générale (des Pères du St Esprit)/Abbeville: Imprimerie Paillard.

Matthews, Peter H. 1997. The Concise Oxford Dictionary of Linguistics. Oxford/New York: Oxford University Press.

Mavoungou, P.A. 2001. Macro- and Microstructural Issues in Mazuna Lexicography. Lexikos 11: 122-138.

Mayer, R. 1990. Histoire de l'écriture des langues du Gabon. Revue Gabonaise des Sciences de l'Homme 2: 65-91.

Ndinga-Koumba-Binza, H.S. 2010. Alphabet et écriture: approche historique et cas des langues gabonaises. Hubert, J. et P.A. Mavoungou. 2010. Écriture et Standardisation des Langues Gabonaises: 33-69. Stellenbosch: SUN PReSS. 
Ndinga-Koumba-Binza, H.S. and J.C. Roux. 2009. On Writing Gabonese Languages. Batibo, H.M., R.S. Dikole, S.T.M. Lukusa and R.O.B. Nhlekisana (Eds.). 2009. Language, Literature and Society: Proceedings of the First International Conference of the Department of African Languages and Literature, University of Botswana, 26-28 June 2008: 83-105. Gaborone: Associated Printers.

Nzang-Bié, Y. 2004. La codification du l'orthographe fang. Unpublished paper. Libreville: Université Omar Bongo.

Quirk, R. 1973. The Social Impact of Dictionaries in the UK. McDavid, R.I., Jr. and A.R. Duckert (Eds.). 1973. Lexicography in English: 76-83. New York: New York Academy of Sciences.

Raponda-Walker, A. 1932. L'alphabet des idiomes gabonais. Journal de la Société des Africanistes 3(2): 139-146.

Raponda-Walker, A. (Ed.). 1998. Les langues du Gabon. Libreville: Éditions Raponda-Walker.

Schnorr, V. 1991. Problems of Lemmatization in the Bilingual Dictionary. Hausmann, F.J., O. Reichmann, H.E. Wiegand and L. Zgusta (Eds.). 1991: 2813-2817.

Snyman, J.W., J.S. Shole and J.C. le Roux. 1990. Dikišinare ya Setswana-English-Afrikaans Dictionary/Woordeboek. Pretoria: Via Afrika.

Svensén, B. 1993. Practical Lexicography. Principles and Methods of Dictionary-making. Oxford/New York: Oxford University Press.

Van Wyk, E.B. 1995. Linguistic Assumptions and Lexicographical Traditions in the African Languages. Lexikos 5: 82-96.

Wiegand, H.E. 1989. Arten von Mikrostrukturen im allgemeinen einsprachigen Wörterbuch. Hausmann, F.J., O. Reichmann, H.E. Wiegand and L. Zgusta (Eds.). 1989: 462-501.

Zgusta, L. 1989. The Role of Dictionaries in the Genesis and Development of the Standard. Hausmann, F.J., O. Reichmann, H.E. Wiegand and L. Zgusta (Eds.). 1989: 70-77. 


\title{
Plaidoyer pour des dictionnaires de langues locales adaptés à différents niveaux et groupes d'âge au Gabon
}

\author{
Edgard Maillard Ella, Institut de Recherche en Sciences Humaines \\ (IRSH), Libreville, Gabon (ellamaillard@yahoo.fr)
}

\begin{abstract}
Résumé: Un dictionnaire de langue doit nécessairement être confectionné en plusieurs versions correspondant chacune aux différents niveaux et tranches d'âge des utilisateurs en vue de tous les satisfaire, car leurs compétences varient tout d'abord en fonction de leur âge. Cet article fustige le fait qu'au Gabon, dans un contexte délicat de sauvegarde et de promotion des langues locales, seule une version de dictionnaires destinée aux utilisateurs adultes est souvent disponible dans la majorité des cas, sinon tous. Cela écarte une grande partie des utilisateurs dont les tranches d'âge varient entre 5 et 15 ans. Or, ces tranches d'âge d'utilisateurs sont les plus sensibles, voire peut-être les plus importantes. En les ignorant, plusieurs dictionnaires ne sont pas correctement utilisés et ne sont pas indispensables à tous comme cela l'est actuellement dans presque tous les cas. Cet article est donc un plaidoyer pour que tous les lexicographes gabonais essaient de prévoir des versions de leurs dictionnaires correspondant chacune aux différentes tranches d'âges des utilisateurs, surtout celles des plus jeunes.
\end{abstract}

Mots-clés: COMPÉTENCE, DICTIONNAIRE BILINGUE, DICTIONNAIRE DE LANGUE, DICTIONNAIRE SCOLAIRE, JEUNE UTILISATEUR, GABON, LANGUES LOCALES, NIVEAU, TRANCHE D'AGE, USAGE, UTILISATEUR, UTILISATEUR ADULTE, UTILITÉ, VERSION

\begin{abstract}
Advocacy for Local Language Dictionaries Adapted to Different Levels and Age Groups in Gabon. A linguistic dictionary necessarily has to be compiled in several versions, each corresponding to different levels and age groups in order to satisfy all users because their skills vary in the first place in terms of their age. This article criticizes the fact that in Gabon, within a delicate context of safeguarding and promoting the local languages, only one version of a dictionary aimed at adult users is usually available in most if not all cases. This excludes a large number of users whose age groups vary between the ages of 5 and 15 years. But then, these age groups of users are or can be the most important. By ignoring them, several dictionaries are not properly used and are not needed at all as it currently is in almost all cases. This article then is a plea that from now on all Gabonese lexicographers try to provide for versions of their dictionaries, each corresponding to the different age groups of users, especially the youngest ones.
\end{abstract}

Keywords: ADULT USER, AGE GROUP, GABON, BILINGUAL DICTIONARY, LEVEL, LINGUISTIC DICTIONARY, LOCAL LANGUAGES, SKILLS, USAGE, USER, UTILITY, VERSION, SCHOOL DICTIONARY, YOUNG USER 


\section{Introduction}

La maîtrise par les enfants des langues locales conditionne et constitue le fondement la réussite de la politique de sauvegarde et de la promotion de ces langues dans laquelle s'est lancé notre pays depuis près d'une trentaine d'années maintenant. Raison pour laquelle depuis les États généraux de l'Éducation de 1983 jusqu'à ceux de 2010, le mot d'ordre est l'introduction des langues locales dans le système éducatif.

Avant d'être écrites, les langues sont d'abord parlées. Toutefois, la standardisation des langues gabonaises passe par la production de corpora ou textes écrits ou oraux de provenances variées et de registres divers: livres, journaux, débats échanges informels, conversations téléphoniques, matériaux radiotélévisées, etc. qui peuvent être utilisés pour une variété de buts.

À cet effet, l'un des outils les plus indispensables pour la maîtrise d'une langue est le dictionnaire. De nombreux lexicographes, linguistes et producteurs de dictionnaires gabonais l'ont compris en confectionnant des dictionnaires bilingues de français et de langues locales. Ces ouvrages sont effectivement adaptés au contexte de notre pays dans lequel le français est langue officielle, alors que les langues locales demeurent des langues de communication orale intraethnique. En effet, comme le signale Dubois (1983: 236), le dictionnaire monolingue repose sur l'hypothèse que l'usager a déjà une certaine connaissance de sa langue. Des lexicographes gabonais tels que Nyangone Assam (2001) et Mabika Mbokou (2001) avaient déjà soulevé cet aspect important.

Les articles de Nyangone Assam (2001) et Mabika Mbokou (2001) ont le mérite qu'accorder une place importante à la confection de dictionnaires pédagogiques, à savoir: les dictionnaires scolaires et les dictionnaires pour apprenants. En dehors de la planification des dictionnaires dits pédagogiques, la plupart des dictionnaires confectionnés dans les langues gabonaises semblent avoir été produits pour satisfaire les besoins des adultes et des personnes averties et éprises des questions de linguistique. Au lieu d'être des outils précieux dans l'apprentissage des langues locales, la majorité des ouvrages de référence lexicographique en langues gabonaises passerait facilement aux yeux des enfants ou des jeunes gabonais comme des objets inaccessibles, inutiles et rébarbatifs.

La désaffection desdits dictionnaires auprès d'un public jeunes s'expliquerait vraisemblablement par la non prise en compte par les lexicographes des besoins et des aspirations de la jeunesse.

L'émergence de la métalexicographie, étude théorique de la confection des dictionnaires est comme le souligne Gouws (2001: 97), une prise en compte du besoin de meilleurs dictionnaires. C'est dans ce cadre là que nous suggérons la confection de plusieurs versions de dictionnaires de langues locales adaptées aux différents âges des enfants et des jeunes utilisateurs comme cela se fait actuellement en Allemagne, en Angleterre, en Espagne et en France pour ne citer que ces pays là. 
Pour ce faire, nous allons dans une première partie évoquer, dans le cadre de l'éducation en langue maternelle au Gabon, la place et le rôle du dictionnaire de la maternelle jusqu'au premier cycle du secondaire. Tout au long de notre réflexion, le fang ntoumou nous servira de langue d'exemplification. Nous discuterons également des différentes versions de dictionnaire qu'il faut proposer à ces différentes tranches d'âge d'utilisateurs.

Dans une seconde partie, nous étudierons le rôle à assigner aux dictionnaires dans l'enseignement/apprentissage des langues locales au Gabon.

\section{La place et le rôle du dictionnaire de la maternelle jusqu'au premier cycle du secondaire dans l'apprentissage des langues locales du Gabon}

\subsection{Appropriation d'un outil indispensable et d'une activité culturelle}

L'importance de l'usage du dictionnaire à l'école primaire jusqu'au premier cycle du secondaire, en un mot dans le système éducatif, en vue de l'apprentissage d'une langue n'est plus à démontrer. Les auteurs gabonais tels que Mabika Mbokou (2001) et Ella (2011) ont assez explicitement discuté sur le rôle des ouvrages de référence lexicographique dans le système éducatif gabonais en vue de consolider l'enseignement de nos langues locales.

Dans le système éducatif, les ouvrages de référence lexicographique dits pédagogiques (les dictionnaires scolaires notamment) sont très utiles aux enfants parce qu'ils leur permettent de ne point se limiter à l'utilisation d'un seul dictionnaire mais de multiplier les ouvrages de recherche. Dans ce cas, l'objectif est donc de mieux les préparer à l'utilisation des différents dictionnaires pour adultes ou classiques qu'ils vont rencontrer tout au long de leur vie. Cela est possible en leur enseignant (montrant) dès le plus bas âge que quel que soit le dictionnaire, son fonctionnement ne change pas et que le savoir qui y est transmis, même s'il varie quelque peu dans sa formulation, est en réalité le même.

Les retombées de ce contact dès le plus bas âge, entre l'enfant et le dictionnaire sont donc considérables et marquent à jamais son comportement face à cet ouvrage, objet culturel de référence pour toute communauté. Dans les sociétés occidentales, le dictionnaire est érigé au rang d'institution et son usage constitue une activité culturelle (Wiegand 1998, cité dans Gouws 2001: 97). En effet, comme le souligne Nyangone Assam (2001: 190), dans les langues majeures telles que l'anglais, le français, l'espagnol, l'allemand pour ne citer que celles-là, les dictionnaires de tout type sont des ouvrages hautement considérés car ils véhiculent leurs cultures et en font considérablement la promotion.

Il ne sert pas uniquement à l'enfant d'outil pédagogique et didactique sur la langue; il constitue également une ouverture sur le monde, une réponse à ses curiosités de façon ludique et attrayante, une invitation au rêve et à l'imagination, en étant aussi un support commode pour des activités d'observation de la langue. Par ailleurs, le dictionnaire constitue aussi un instrument culturel 
fondamental qui permet à l'enfant d'aller à la rencontre des valeurs et vertus sublimes de sa culture ainsi que celles de la nation.

Aux premiers âges, la place et le rôle du dictionnaire consistent donc essentiellement à ne plus faire de cet ouvrage un mystère pour les enfants. Ils lui donnent la possibilité de se l'approprier et de se familiariser avec pour l'utiliser pleinement et à sa juste valeur lorsqu'ils seront adultes.

C'est la raison pour laquelle au Gabon, on ne peut passer sous silence la planification des dictionnaires pédagogiques (les dictionnaires scolaires notamment) qui sont pratiquement absents du paysage lexicographique gabonais.

À ce jour, il est simplement impossible aux enfants de s'approprier les dictionnaires classiques en langues gabonaises qui leur sont proposés. Cette difficulté se manifeste non seulement au point de vue de l'utilisation à proprement parler desdits ouvrages, mais aussi et surtout au niveau de la maîtrise correcte des langues locales et l'acquisition des valeurs culturelles et fortes de notre pays par les jeunes écoliers gabonais telle que l'a toujours vivement souhaité le Gouvernement gabonais.

Les dictionnaires dans les langues gabonaises doivent être regardés en haute estime par les usagers comme c'est le cas pour les ouvrages de référence en anglais, en français, en espagnol, en allemand, en italien et en portugais pour ne citer que ces langues. Autrement, ces ouvrages se doivent de véhiculer les langues et les cultures des groupes ethnolinguistiques du Gabon: Akélé, Fang, Tsogo, Gisir, Kota, Punu, Myénè, Nzébi, Téké, etc.

\subsection{Les différentes versions de dictionnaire par tranches d'âge d'utilisateurs}

\subsubsection{Généralités}

\subsubsection{Ajustements économique et social}

Comme les chaussures qui deviennent trop petits quand les enfants grandissent, les lexicographes et les maisons d'édition proposent de plus en plus aux parents, différentes versions des dictionnaires adaptés au niveau de développement psychologique et linguistique des enfants. Cette pratique qui obéit souvent à des logiques commerciale, est très sévèrement critiquée par certains observateurs. Les figures 1 et 2 ci-après illustrent le besoin pour les maisons d'édition de produire des dictionnaires adaptés à chaque stade de développement de l'enfant.

Cependant ces personnes oublient ou ignorent peut-être que le dictionnaire est d'abord et un avant tout un produit commercial comme tout autre. Pour cela, il doit ainsi obéir à toutes les lois possibles du marché où règne particulièrement celle de l'offre et de la demande, qui gouverne le monde d'aujourd'hui. Proposer des versions de dictionnaires qui correspondent à la progression intellectuelle et mentale de l'enfant est tout à fait logique. Cette pratique lexicographique démontre une collaboration plus accrue entre lexico- 
graphes et maisons d'édition dans la recherche de la satisfaction des besoins des usagers. En prévoyant des versions de dictionnaires pour chaque tranche d'âge, surtout celles qui sont destinées aux enfants, les lexicographes et éditeurs séduisent les utilisateurs en personnalisant leurs produis. En politique commerciale, personnaliser un produit est un atout de séduction indéniable pour attirer et plaire aux consommateurs. Et c'est de bonne guerre que les lexicographes et éditeurs utilisent cette pratique. Les enfants sont donc attirés par ces dictionnaires qui leur sont spécialement destinés, et se laissent séduire par le fait qu'on s'intéresse spécifiquement à eux.

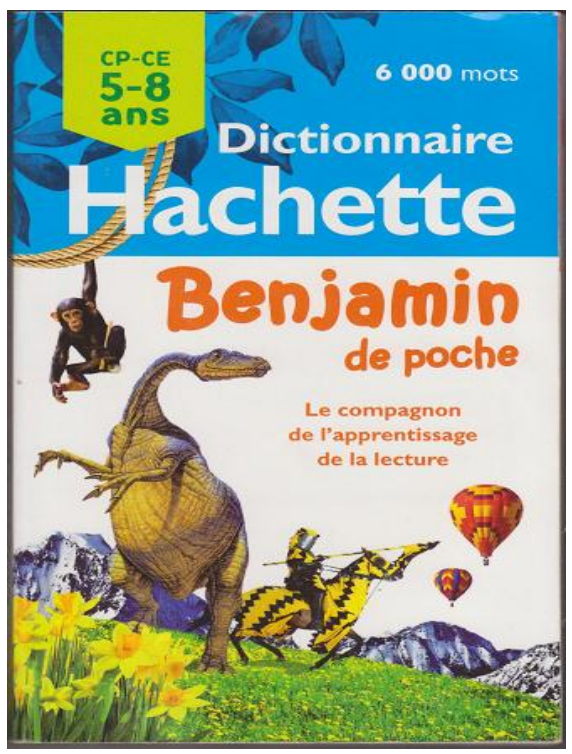

Figure 1: Le Dictionnaire Hachette Benjamin de poche (5-8 ans)

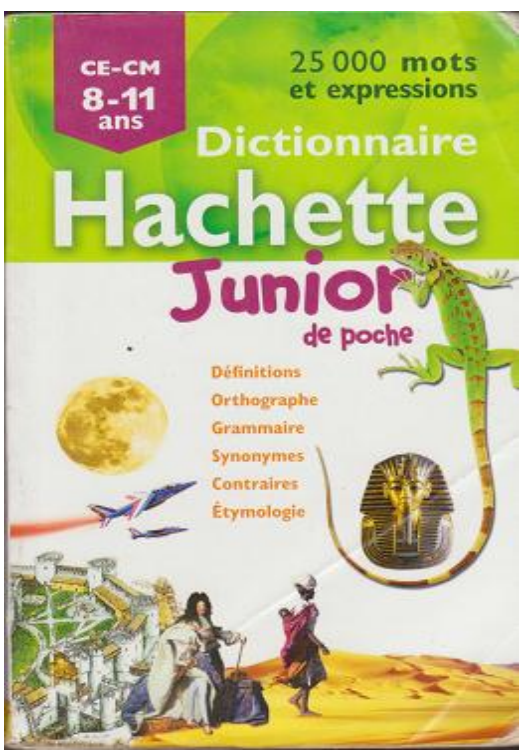

Figure 2: Le Dictionnaire Hachette Junior de poche (8-11 ans)

\subsubsection{Ajustement pratique}

D'un point de vue pratique, les lexicographes proposent des versions de dictionnaires qui siéront à chaque tranche d'âge d'utilisateurs, comme il est normal pour les chaussures que chaque personne trouve pointure à son pied. C'est dans ce sens que Osselton (1983: 13), définit l'utilisation aisée d'un dictionnaire comme l'ajustement de l'activité lexicographique à la communauté, et à la culture du dictionnaire comme l'ajustement de la communauté à l'activité lexicographique. De nombreux enseignants ont en effet souvent constaté que des difficultés de lecture apparaissent lorsque les enfants ne comprennent pas le vocabulaire employé d'un dictionnaire destiné en réalité aux utilisateurs plus âgés, comme des chaussures qui seraient très grandes pour leurs petits pieds. 
Tous les ouvrages pédagogiques et didactiques destinés à l'enseignement des différentes matières que ce soit les langues, les mathématiques, la littérature, l'histoire et la géographie par exemple, sont découpés en fonction des tranches d'âge des élèves ainsi que de leurs niveaux d'études correspondant, de la maternelle jusqu'a la classe de terminale. Qu'on se le dise, le dictionnaire est également un outil pédagogique et didactique au même titre que le livre de mathématiques et de français par exemple. Il revêt peut-être seulement un caractère pluridisciplinaire car il ne sert pas qu'à l'apprentissage des langues. Comme le suggère Dru (1998: 12), il peut également aider l'enfant à comprendre un énoncé de mathématiques, d'histoire, de géographie et de physiques.

Alors, autant il n'y a pas qu'un seul livre de mathématiques ou de français pour tout l'enseignement par exemple, autant les lexicographes et éditeurs ont compris qu'il ne pouvait aussi avoir qu'un seul dictionnaire pour tous les niveaux d'enseignement et tranches d'âge d'utilisateurs. Pour le français et les mathématiques, il y a des livres pour les tranches d'âge et niveaux d'études correspondant à la maternelle, aux $\mathrm{CP}$, aux $\mathrm{CE}$, et aux $\mathrm{CM}$ dans l'enseignement primaire.

Au collège et au lycée, ce découpage est encore plus réduit car à chaque classe correspond pratiquement, sauf à quelques exceptions près, un livre de français, de mathématiques, de physiques, d'histoire et de géographie par exemple. Alors pourquoi s'étonner que pour un meilleur rendement de l'enseignement et de l'apprentissage des langues, que les dictionnaires qui sont aussi des ouvrages jouant exactement le même rôle dans l'enseignement des mathématiques ou de français soient déclinés en plusieurs versions correspondant chacune à un âge ou tranche d'âge et niveau d'étude proprement étudiés?

On pensait qu'arrivés au collège, les élèves pourraient enfin utiliser un dictionnaire classique du type Petit Larousse ou Petit Robert, mais il n'en est rien en réalité. Il faut qu'ils soient préparés pour cela à travers des ouvrages adaptés à chaque stade de leur développement dont ils doivent maîtriser l'utilisation et comprendre l'utilité à travers un apprentissage. C'est en cela que Dru (1998: 12) signale qu'il est nécessaire de fournir aux enfants un apprentissage sur l'utilité et l'utilisation du dictionnaire. Gouws (2001: 97) va encore plus loin en insistant sur le fait qu'en dehors des utilisateurs, les producteurs de dictionnaires et les formateurs ont besoin d'expertise pour former les deux autres groupes. Il estime qu'il est primordialement important que ces trois groupes-cibles suivent une bonne formation pour accompagner les dictionnaires à être bien utilisés comme des réservoirs opérationnels de connaissance.

C'est ainsi que l'évolution du découpage des différentes versions du dictionnaire a donné lieu aujourd'hui aux dictionnaires destinés à des tranches d'âges spécifiques des utilisateurs par rapport à leur niveau d'études. Il y a des versions pour la maternelle de petite et grande section (PS-GS), donc pour les 3 à 5 ans qui sont des syllabaires tels que nous allons le voir plus loin. Les éditions telles que Hachette par exemple, proposent des versions, dont nous présentons les premières de couverture dans cette section, de leurs diction- 
naires confectionnés pour autant de tranches d'âges. Il s'agit de la version des cours préparatoires et élémentaires (CP-CE) pour les 5 à 8 ans appelé Benjamin de poche. La version des deux cours moyens (CM) pour les 8 à 11 ans s'appelle le Junior de poche. Et celle de 10 à 15 ans et le dictionnaire du Collège. Dans l'enseignement des langues comme le signale Nyangone Assam (2001: 190), les diverses versions produites des éditions telles que Larousse, Robert, Oxford, Collins, Longman et Webster ont fait des preuves pour les besoins des utilisateurs toutes catégories confondues. C'est à ce propos que nous avions déjà attiré l'attention sur l'importance des dictionnaires dans le bon déroulement de l'introduction des langues locales dans le système éducatif gabonais, cf. Ella (2011).

La production de ces différentes versions d'un dictionnaire est possible aujourd'hui grâce à l'outil informatique qui comme dans les domaines d'activités est indispensable en lexicographie. Il suffit à partir des supports électroniques disponibles des dictionnaires classiques qui existent déjà de modifier leurs données en s'inspirant des modèles de différentes versions courantes des dictionnaires de français tels que ceux produits par les éditions que nous avons citées plus haut. Pour les nouveaux projets, les personnes en charge devraient se soumettre à proposer toutes les versions de leurs dictionnaires selon les différentes tranches d'âge des utilisateurs.

Il suffit à partir des bases de données des dictionnaires publiés de nos jours en langues gabonaises de ne sélectionner que les données qui ont une pertinence pour le public-cible choisi (5 à 8 ans, 8 à 11 ans, etc.)

La discussion que nous proposons ci-après sur la présentation des versions de dictionnaires des cours préparatoires et élémentaires, des cours moyens et du collège s'appuie énormément sur les données de l'article de Dru (1998).

\subsubsection{Les dictionnaires de la maternelle}

Ces ouvrages ne sont pas des dictionnaires en tant que tels au sens classique du terme, ce sont plutôt des syllabaires. C'est-à-dire, un ensemble de lettres-sons utilisés pour représenter les sons vocalisés ou groupés d'une langue et qui sont illustrés par des images. Les couleurs et les illustrations au fil des pages et les mots utilisant les mêmes lettres-sons donnent envie aux enfants de s'en servir et de connaître la langue enseignée.

La figure 3 ci-après illustre un extrait de la page de la présentation d'un syllabaire du français de la lettre $b$, ainsi que sa combinaison avec d'autres lettres-sons pour former certains mots.

Sur le même principe, les syllabaires en tant que version d'un dictionnaire destinée pour les tous premiers débutants seront déjà très nécessaires aux petits enfants gabonais pour l'apprentissage de leurs langues locales respectives dès leur plus bas âge. Ils le seront tout d'abord par la connaissance dans ces langues des noms des choses et objets représentés. Ensuite, par la reconnaissance des lettres-sons qui permettent de les représenter graphiquement, et qui permettent avec d'autres lettres-sons de former certains mots. 


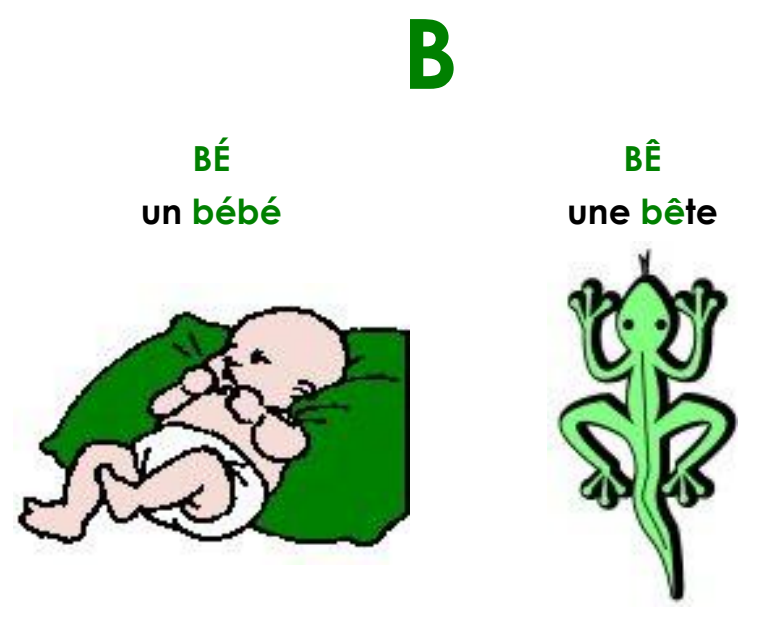

Figure 3: Illustration de la lettre $b$ d'un syllabaire du français

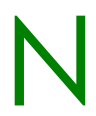

NG

la lune/e ngouane

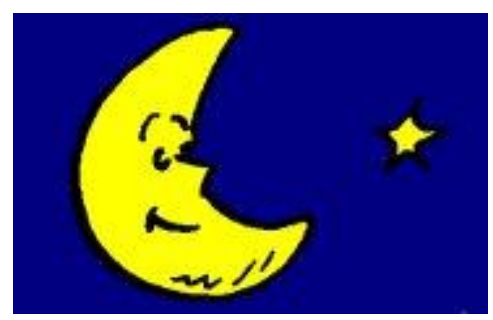

NK

des nuages/mi nkoute

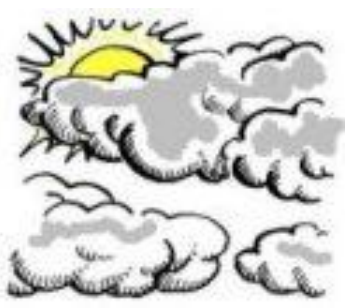

Figure 4: Illustration de la lettre $n$ ainsi que sa combinaison avec d'autres lettres-sons pour former certains mots d'un syllabaire bilingue français-fang ntoumou

La figure 4 ci-dessus illustre un exemple de ce qui pourrait être un extrait de la page de la présentation d'un syllabaire de la langue fang ntoumou de la lettre $n$ ainsi que de sa combinaison avec d'autres lettres-sons pour former certains mots. On notera que cet extrait présente des données bilingues. Nous avons mentionné plus haut que dans le contexte du Gabon où le français est langue officielle et langue maternelle pour de nombreux gabonais, les dictionnaires de 
langues et n'importe quel autre type devrait être bilingues avec le français comme langue source, qui servira de passerelle ainsi que le mentionne Mabika Mbokou (2001: 221) pour accéder aux les langues locales du Gabon comme langues cibles.

\subsubsection{Les dictionnaires des cours préparatoires et élémentaires}

Les versions des dictionnaires de la tranche qui suit celle de la maternelle seront conçues pour être une suite logique de la connaissance dans les langues locales des noms des choses et objets représentés, ainsi que de la reconnaissance des lettres-sons qui permettent de les représenter graphiquement (Voir la figure 5 ci-après). Elles vont assister les jeunes enfants dans la maîtrise de la lecture et de l'alphabet qui seraient déjà en cours d'acquisition grâce aux syllabaires.

Cette version qui vise à initier l'enfant à l'utilisation et à la consultation du dictionnaire, lui facilitera la lecture par l'absence des coupures à l'intérieur des mots que proposent souvent certains dictionnaires classiques de langues locales du Gabon, mais tout en offrant déjà la même structure qu'il rencontrera dans les dictionnaires pour adultes. Cette absence de coupure qui facilite l'initiation à la lecture chez l'enfant et qui sera donc déjà de mise dans les syllabaires, implique alors nécessairement l'utilisation de l'écriture disjonctive au lieu de l'écriture conjonctive.

Dans l'écriture disjonctive, les mots sont lemmatisés sous leur thème sans leurs morphèmes préfixaux. Tandis que dans l'écriture conjonctive, chaque mot est écrit entièrement, c'est-à-dire comme un bloc. En fang ntoumou par exemple, on écrira mbot (homme) et bot (les ou des hommes), bot étant comme une forme irrégulière du pluriel qui adopte donc exceptionnellement avec d'autres mots tels que $d z a$ (village) et maa (les ou des villages) par exemple, une forme d'écriture conjonctive. Alors que la deuxième regroupe les mots selon qu'ils constituent un thème nominal ou verbal auquel s'est adjoint un préfixe nominal ou verbal et nécessite qu'un découpage soit fait pour que les préfixes et thèmes soient présentés et connus de l'utilisateur. Dans ce cas mbot et bot se présentent souvent comme mb.ot et b.ot, $m b$ - et $b$-, désignant respectivement les préfixes nominaux tandis que -ot désigne quant à lui le thème verbal.

Avec l'usage de l'écriture disjonctive, l'enfant trouvera donc des entrées clairement identifiables, qui lui rappelleront celles du français langue officielle qui est dans la plupart des cas sa langue maternelle, et qui seront mises en exergue par une couleur voyante et des illustrations tel que l'extrait du Dictionnaire Hachette Benjamin de poche, cf. Labro (2011a). Comme le propose cette version du dictionnaire, ces entrées seront suivies de leur catégorie grammaticale présentée de façon simplifiée, de vraies définitions en langues locales cernant la signification du mot d'entrée. 


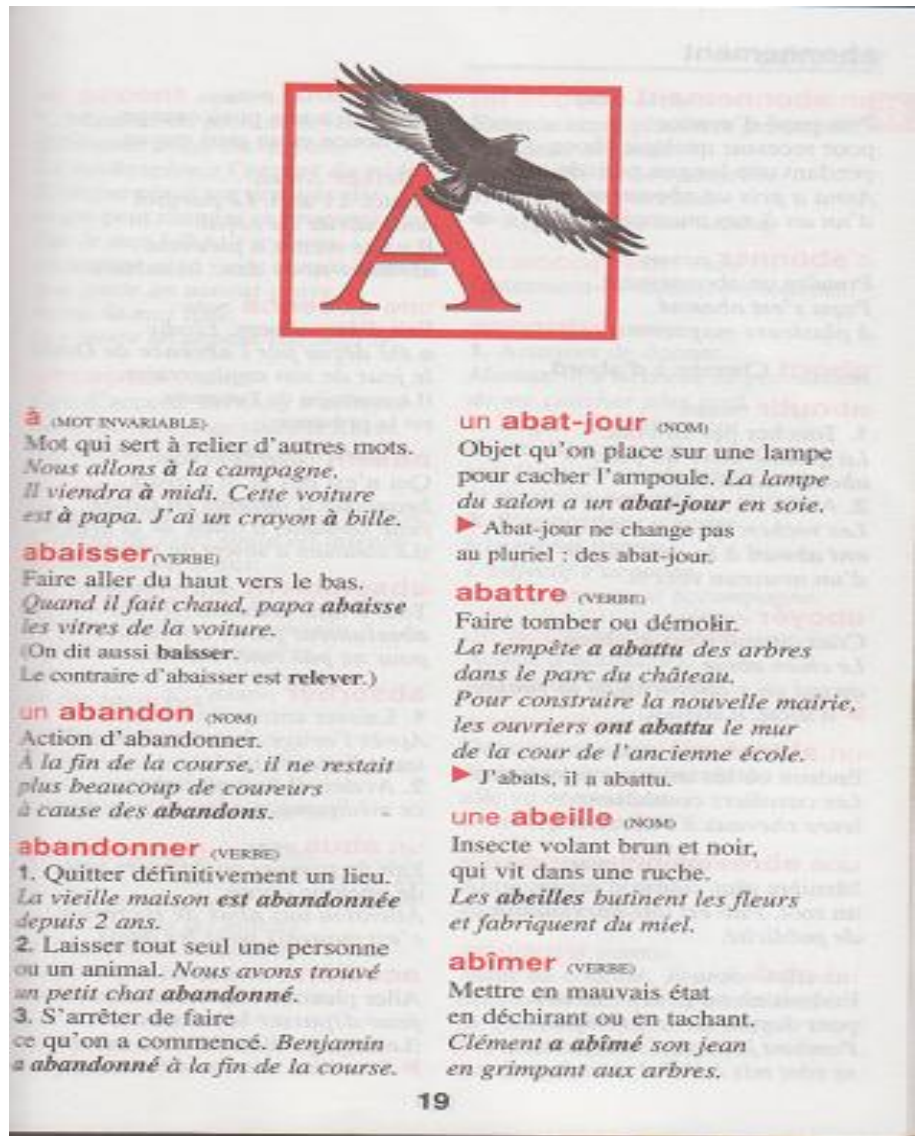

Figure 5: Illustration des noms de choses et objets représentés, ainsi que de la reconnaissance de lettres-sons qui permettent de les représenter graphiquement

Des exemples tout aussi simples, mettant le mot en situation ainsi que la mention des synonymes et contraires et des remarques de grammaire complèteront les atouts de cette version pour en faire un outil offrant avec aisance, plaisir et efficacité qui assistera l'enfant dans l'apprentissage de sa langue locale.

\subsubsection{Les dictionnaires des cours moyens}

Si les mêmes caractéristiques que la version précédente demeurent, avec les images en moins sur la lettre titre des mots à traiter, ainsi qu'une police de caractère réduite, comme cela est présenté dans la figure 6 extraite du Dictionnaire Hachette Junior de poche, cf. Ormal-Grenon (2010), cette version proposera déjà des règles de présentation et de fonctionnement de tout dictionnaire courant. 


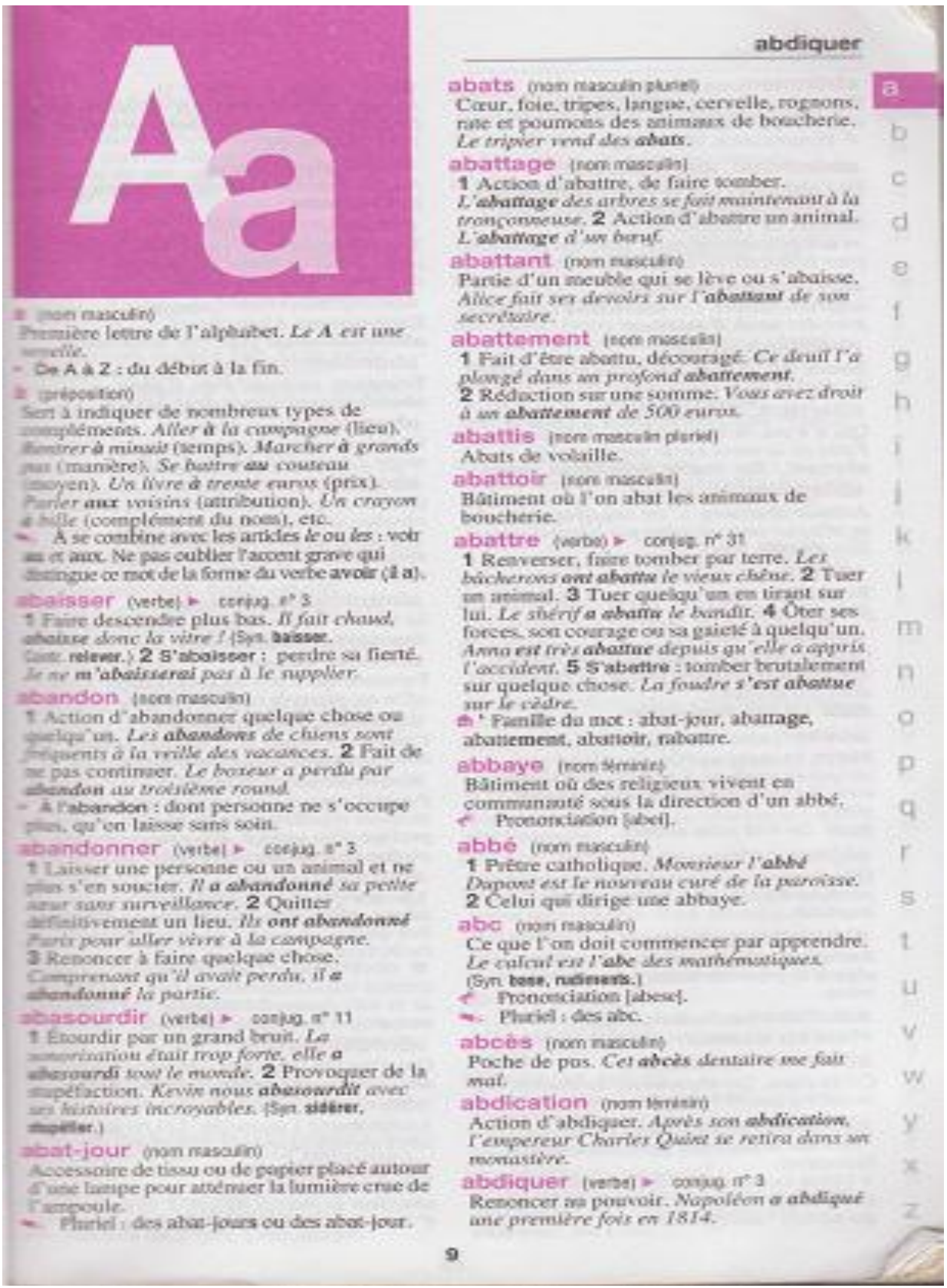

Figure 6: Extrait du Dictionnaire Hachette Junior de poche, cf. Ormal-Grenon (2010) 
Il sera adapté à l'âge et aux capacités de lecture progressivement acquise dans son apprentissage précédent, et il sera fait pour qu'il réponde totalement aux préoccupations sans cesse grandissantes des jeunes utilisateurs qui tendent vers l'adolescence. Cette version va constituer pour les jeunes gabonais de 8 à 11 ans, un outil essentiel dans la maîtrise et la connaissance de l'utilisation du dictionnaire ainsi que de leurs langues locales au seuil de leur entrée au collège. C'est donc une tranche d'âge assez importante pour laquelle les enseignants gabonais devront être très regardant quant aux aptitudes de référence des apprenants.

Si les mêmes caractéristiques que la version précédente demeurent, avec les images en moins sur la lettre titre des mots à traiter, ainsi qu'une police de caractère réduite, comme cela est présenté dans la figure 6 extraite du Dictionnaire Hachette Junior de poche, cf. Ormal-Grenon (2010), cette version proposera déjà des règles de présentation et de fonctionnement de tout dictionnaire courant. Il sera adapté à l'âge et aux capacités de lecture progressivement acquise dans son apprentissage précédent, et il sera fait pour qu'il réponde totalement aux préoccupations sans cesse grandissantes des jeunes utilisateurs qui tendent vers l'adolescence. Cette version va constituer pour les jeunes gabonais de 8 à 11 ans, un outil essentiel dans la maîtrise et la connaissance de l'utilisation du dictionnaire ainsi que de leurs langues locales au seuil de leur entrée au collège. C'est donc une tranche d'âge assez importante pour laquelle les enseignants gabonais devront être très regardant quant aux aptitudes de référence des apprenants.

\subsubsection{Les dictionnaires du collège}

Cette version emmènera les utilisateurs adolescents du Gabon jusqu'au seuil de la maîtrise totale de l'utilisation du dictionnaire, mais aussi et surtout sur la compétence de la lecture, de l'écriture et du parler des langues locales. Spécialement conçu pour assister au quotidien les élèves pendant l'apprentissage de ces langues de la 6e à la 3e, le dictionnaire du collège constitue un formidable levier pour asseoir la maîtrise d'une langue et les bases solides qui permettront la progression de cette maîtrise.

Cependant, cet ouvrage restera toujours un dictionnaire scolaire présentant les mêmes caractéristiques que ses versions précédentes. L'enfant trouvera toujours l'utilisation attrayante et ludique des couleurs pour distinguer les entrées des textes relatifs à leur traitement, la clarté de la langue et des définitions qui sont toujours illustrées qui permettent de voir les mots dans leurs contextes d'utilisation, tel que le montre la figure 7 extraite du Dictionnaire Hachette Collège, cf. Labro (2011b). Il retrouvera aussi les mots synonymes et/ou contraires qui lui seront toujours fournies. 


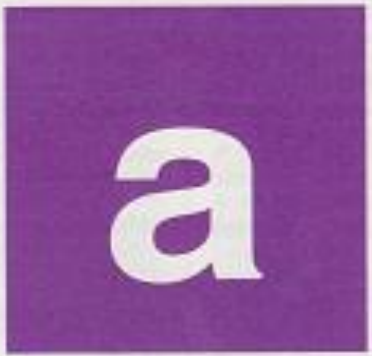

a- Piefice tine do sece qui oprime le manqei, la sappossiontiesempie i nusnh

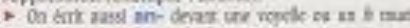

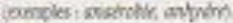

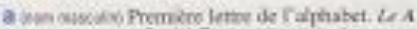

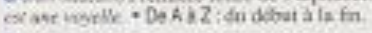

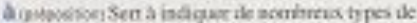

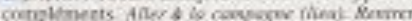

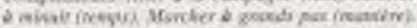

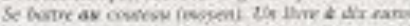

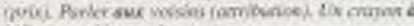

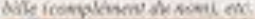

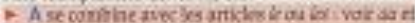

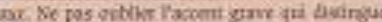
te not de h forre da vecte ante ill any.

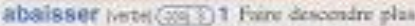

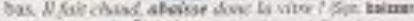

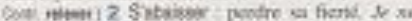

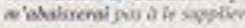

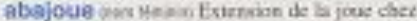
ocerm remmitios an lax sert de riverve

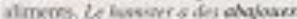

abandon ras raistel 1 Action d'abindome:

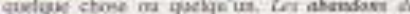

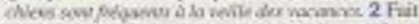

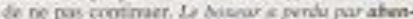

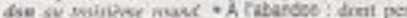
some ne s'eccipe plas, au' en lasoc sans wis.

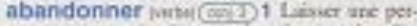

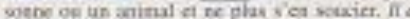

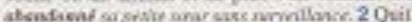

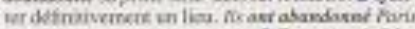

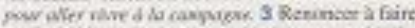

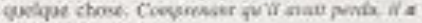
atouscour he porne

abasourdir oetho (colit) 1 Ekoudir por un

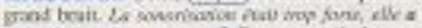

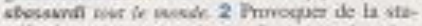

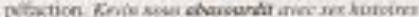

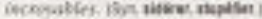

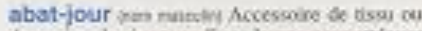
de paper place wasar $\delta$ use limpe pour anteucr bo himikre cre de T'aripoule.

- Ferld ises ahnt-jours zd des ahat-jour.

abats uns mucsis pursi Coer, fole inpos. Layes, servelle, rugrouts, nist et pouncos des

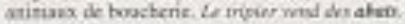

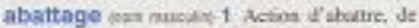

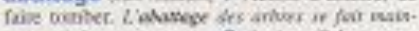

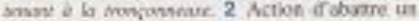
animal. Lebathe d've hiry.

absttant yen rasule, Patie d an neable qui se

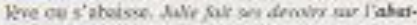
savi do sat shcreisitr

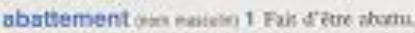

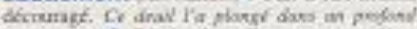

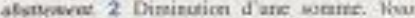

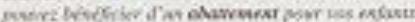
dexaye.

abattis inommusulis phere Abus de velaife.

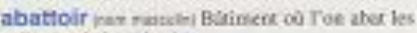
arsirasu de bouthrie

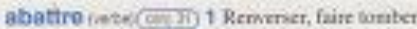

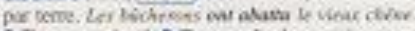
2 Taer ue unimal: 3 Tuer quelyjion en tiram ser

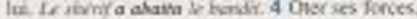

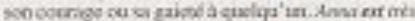

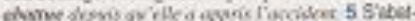
to : Iomber truaderiene ser quelape chose. Co foudexieveateme nir ir criahe.

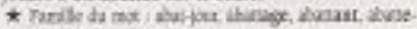
areat. akenoir, nharte

abbatiale coventwin Éplise oune shtoye - mocueriabo labsojail.

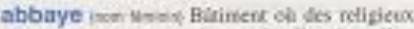
vingai en cromariante wos la dibosion d'ui abe.

- Focooniabon labeil

Figure 7: Extrait du Dictionnaire Hachette Collège, cf. Labro (2011b).

La particularité de cette dernière version du dictionnaire scolaire de nos langues locales tient du fait qu'elle proposera plus d'entrées et des articles synopsis pour un supplément d'informations essentielles sur nos objets, concepts et rites culturels et bien d'autres aspects spécifiques à notre pays ainsi qu'à notre identité. 
Un article synopsis, terminologie proposée par Bergenholtz, Tarp et Wiegand (1999), cités dans Gouws (2001: 101), est une manière innovatrice d'augmenter les possibilités de la distribution microstructurale des données. Ce type d'article, a une zone pour insérer des données additionnelles souvent extralinguistiques, cf. Gouws (2001: 126). C'est à ce propos que nous avions soulevé l'intérêt et l'importance de ces articles dans la confection des dictionnaires au Gabon quel que soit leur type, afin que les utilisateurs s'imprègnent du contenu culturel véhiculé ces ouvrages quel que soit le type, et que dictionnaire remplisse son rôle comme étant un des garants de la langue et de la culture, cf. Saphou-Bivigat et Ella (2006).

C'est le cas d'une entrée telle que bwiti par exemple, qui nécessitera des informations supplémentaires pour informer les jeunes gabonais sur plusieurs aspects de leurs spécificités et de leur identité. Nous présentons ci-après à quoi pourrait ressembler le traitement de cette entrée dans la partie langue localefrançais d'un dictionnaire bilingue bidirectionnel français-langue locale.

bwiti /bwiti/ $n m$.

\section{(i) BWITI}

Initiation aux rites traditionnels destinée à la construction et à la consolidation de l'esprit de l'homme qui est pratiquée essentiellement dans la province de la Ngounié. Elle est réservée uniquement aux hommes. On parle de bwiti lorsque le rituel se fait en consommant le bois sacré. On parle de mwiri lorsque l'initiation se déroule sans la consommation de ce bois.

Le Gabon, comme c'est le cas pour la majorité des pays africains, est fortement multilingue et multiculturel. Dans ce contexte, des instruments aussi importants que les dictionnaires doivent être produits dans le sens de bâtir et unifier ces sociétés considérablement hétéroclites. En métalexicographie, Wiegand (1997) et Gouws (1999), cités dans Gouws (2001: 101), soutiennent que dans ce type de situation, où les dictionnaires ont également une vocation de bâtisseur de la nation et une responsabilité sociale, l'attention doit porter sur l'utilisation des articles synopsis.

Cependant, ces articles seront aussi destinés à fournir des informations concises et précises telles que les situations géographiques et économiques quand c'est nécessaire sur nos régions, villes, départements, cantons et villages. S'il est vrai que le dictionnaire est avant tout un outil au service de la langue, il n'en demeure pas moins qu'il apporte aussi une ouverture sur les pays dont les utilisateurs sont originaires, ainsi que sur le monde. Il apporte également une somme de réponses à toutes nos curiosités, surtout auprès des enfants. 


\section{Les activités d'apprentissage de manipulation et de familiarisation aux dictionnaires pour la maîtrise des langues locales chez les enfants}

\subsection{Généralités}

Il est indispensable d'apprendre aux enfants gabonais à manipuler le dictionnaire de langues locales et à se familiariser avec lui. En effet, on les laisse trop souvent, si ce n'est tout le temps, entrer dans le dictionnaire sans leur expliquer ou leur apprendre son fonctionnement à l'école. Nous ne pouvons logiquement que nous attendre à ce qu'ils le referment tout de suite. Trop souvent, nous oublions que le rôle du dictionnaire c'est d'être un instrument précieux pour son utilisateur en ce qui concerne la maîtrise de la langue tant à l'oral qu'à l'écrit. En effet, une enquête menée par Galisson (1983: 96), a démontré que les utilisateurs interrogés trouvent que la fonction la plus importante d'un dictionnaire est la fonction d'apprentissage. Ce qui fait du dictionnaire un ouvrage indispensable pour l'apprentissage d'une langue.

C'est pour cette raison qu'au Gabon, il est nécessaire qu'à l'école, les élèves reçoivent des instructions quant à l'utilisation du dictionnaire pour qu'il profite de toutes les possibilités qu'offre cet ouvrage. En leur proposant des activités pour lesquelles ils se rendront compte de l'utilité du dictionnaire, les enfants parviendront à bien parler et à écrire en langues locales. Cela est d'autant plus important qu'ils seront évalués dans leurs langues locales en tant que matière d'enseignement et que le dictionnaire leur sera d'une grande nécessité. C'est dans ces conditions que les enfants gabonais ne considéreront plus les dictionnaires existants comme des ouvrages rébarbatifs, compliqués et peu attrayants, mais au contraire comme des outils véritablement indispensables.

Cet apprentissage s'effectuera progressivement à partir du CE (5 ans) jusqu'en classe de 3e (15 ans) si besoin est. Il va essentiellement consister à apprendre aux enfants à se servir de leur dictionnaire de langues locales. Il s'agira d'abord de leur apprendre dans un premier temps à savoir le manipuler et à savoir chercher la définition d'un mot selon son contexte. Il s'agira ensuite de leur apprendre à connaître la structure du dictionnaire et créer des définitions en vue de développer leur imaginaire dans sa langue locale.

\subsection{L'apprentissage de la manipulation et de la recherche de la définition d'un mot selon son contexte}

\subsubsection{L'apprentissage de la manipulation}

Cet apprentissage consistera à habituer les enfants à manipuler le dictionnaire et de vérifier qu'ils maîtrisent l'ordre alphabétique, capacité indéniablement fondamental et indispensable pour se servir de cet ouvrage.

Les enfants seront jugés sur leur capacité à se repérer dans le dictionnaire de leurs langues locales respectives et à s'en servir pour vérifier l'orthographe 
d'un mot. L'objectif visé ici sera de fournir des stratégies de recherche aux enfants afin qu'ils ne soient pas perdus lorsqu'ils se retrouveront seuls face au dictionnaire. Pour ce faire, l'enseignant donnera aux enfants les moyens de rechercher efficacement des mots dans un dictionnaire. Les apprenants pourraient par exemple être amenés à se demander quel est le mot qui vient juste avant et juste après un mot proposé, ou quel est le premier mot commençant par une des lettres alphabétiques.

\subsubsection{L'apprentissage de la recherche de la définition d'un mot selon son contexte}

Cette activité sera le prolongement de la séance ou étape précédente selon la façon dont l'enseignement sur l'apprentissage du dictionnaire sera organisé. Les enfants apprendront à trouver un mot dans le dictionnaire, et il faudra donc par après leur apprendre à lire proprement une définition.

Le but de cette séance sera d'amener les enfants à prendre conscience que comme en français ou en anglais, voire l'espagnol qu'ils étudient aussi, dans leurs langues locales, le sens d'un mot dépend de son contexte et que le dictionnaire de ces langues, pour un même mot, pourra offrir plusieurs définitions. En fang ntoumou, kuègne par exemple, désigne à la fois l'escargot et le singe.

Il faut donc mettre les enfants en garde sur le fait de ne pas se concentrer que sur la recherche d'un mot qu'ils connaissent et qui les conduirait qu'à ne prendre que la première définition qui s'offrira à eux une fois qu'ils auront trouvé ce mot. Ils devront aussi lire la suite du traitement proposé.

En ne prêtant pas attention aux autres sens, les élèves s'arrêtent au premier sens connu alors que l'exercice requiert l'exploration d'un autre sens. Il faudra donc leur apprendre à parcourir attentivement toutes les acceptions du terme traité et ne point s'arrêter au premier sens. Ils apprendront mieux leurs langues en découvrant par exemple que si kuègne désigne le singe (il s'agit de l'acception la plus connue), il n'en demeure pas moins que ce mot est polysémique et désigne aussi l'escargot.

\subsection{L'apprentissage de la structure du dictionnaire et de la création des définitions pour le développement de l'imaginaire de l'enfant gabo- nais dans sa langue locale}

\subsubsection{L'apprentissage de la structure du dictionnaire}

Cette activité fera suite à la précédente, c'est-à-dire, celle qui consiste à amener les enfants à découvrir la structure d'une définition dans leur langues locales et précisément lorsqu'un mot à plusieurs sens. Il faudra maintenant leur proposer d'étudier une définition plus en détail. 
Il s'agira de leur faire comprendre l'organisation d'un article ou d'une définition en des termes courants, c'est-à-dire, leur montrer la nature et la forme des mots (adjectifs qualificatifs, adverbes, conjonctions de coordination, conjonctions de subordination, déterminants, noms propres et communs, prépositions, pronoms et verbes) qui constituent les entrées des dictionnaires de leurs langues locales ainsi que des éléments qui articule la définition du mot choisi comme entrée. Dans cette articulation, il y a le mot lui-même, sa nature, son genre, sa définition et un exemple qui illustre le contexte d'utilisation de ce mot.

Cet aspect spécifique consiste également à montrer aux enfants que cet ouvrage n'est pas constitué uniquement que de définitions, mais qu'il existe aussi des planches thématiques comme celles du corps humain (cf. la figure 8) ou de l'arbre généalogique (cf. la figure 9). La connaissance de ces planches par exemple, constituera une découverte supplémentaire sur les noms des parties du corps humain que ceux des différents membres de la famille.

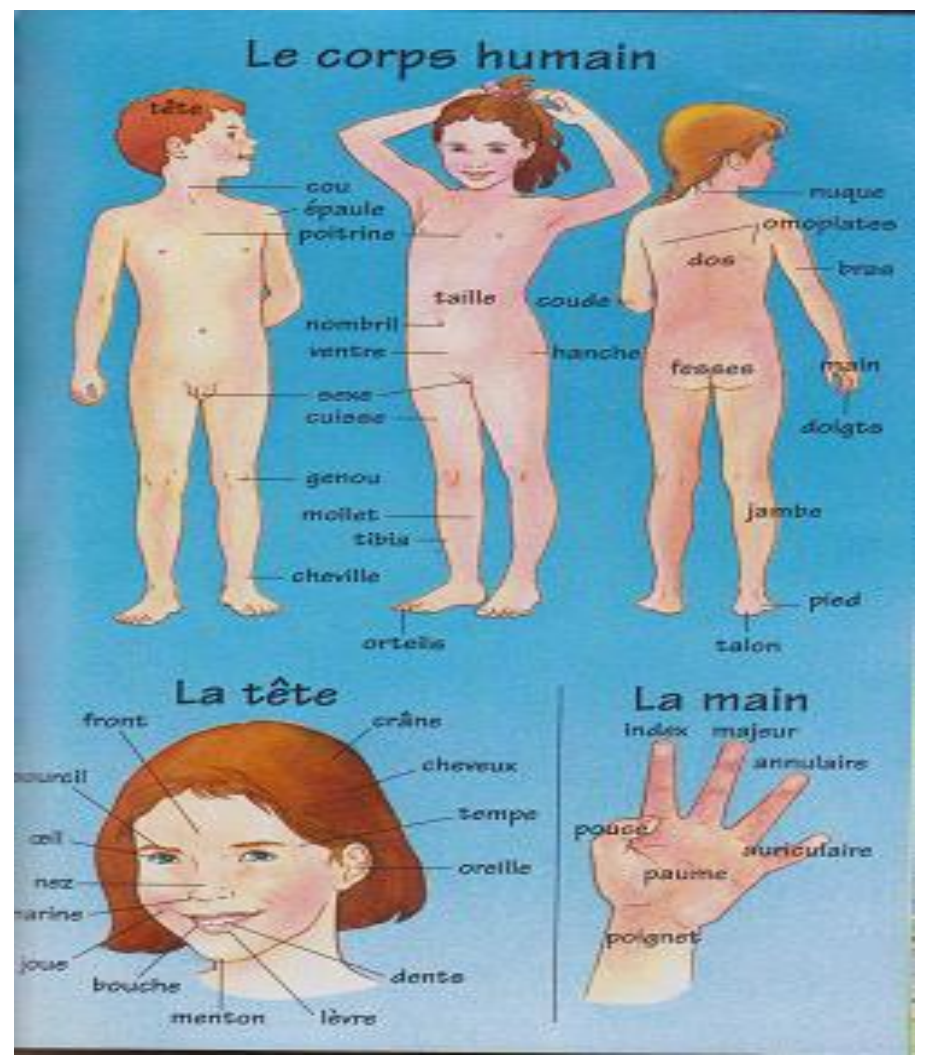

Figure 8: Le corps humain 


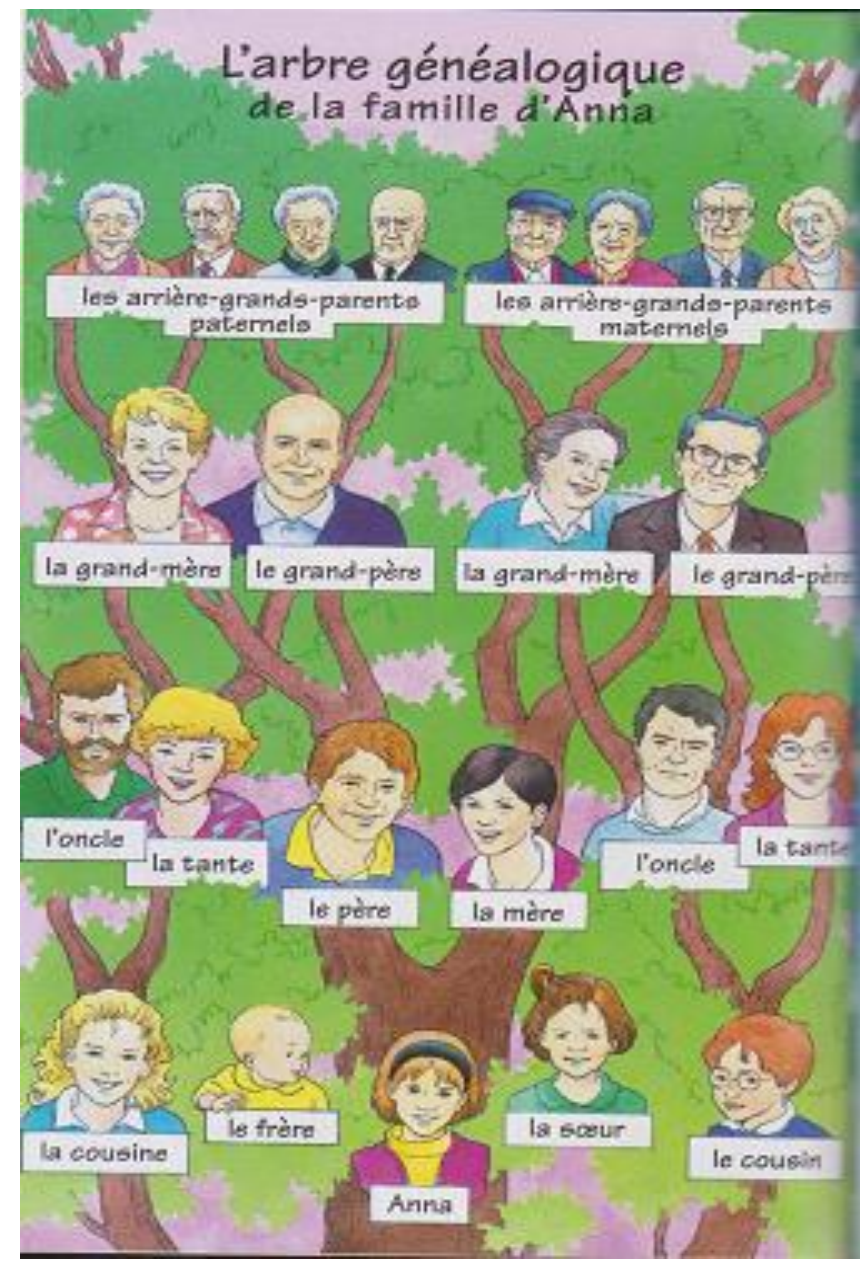

Figure 9: L'arbre généalogique

Nous constatons qu'il est donc important d'expliquer et de montrer aux enfants que les différents démembrements qui constituent la structure du dictionnaire ne sont pas fortuits. Tout au contraire, ils abritent toutes les différentes richesses que contiennent cet ouvrage et dont la connaissance constituera pour eux une ouverture à la maîtrise de sa langue locale. Ils apprendront que dans un dictionnaire on ne découvre pas uniquement que des définitions mais aussi des éléments tels que les cartes géographiques, les tableaux de conjugaison, les drapeaux des différents pays, etc. Les illustrations des planches thématiques leur donneront des renseignements encyclopédiques mais aussi des connaissances linguistiques supplémentaires qui sont tout aussi importantes. 
L'apprentissage de la structure du dictionnaire proprement dite consistera à proposer aux enfants une activité d'observation et de reconnaissance des différentes parties de la structure du dictionnaire, en leur montrant des fragments de pages de différents ouvrages. L'objectif sera de montrer ceux qui correspondent au dictionnaire et de dire quelle sont leur fonction et utilité respectives. Cet exercice se fait naturellement après explications et démonstrations de l'enseignant lors des séances de cours.

\subsubsection{L'apprentissage de la création des définitions pour le développement de l'imaginaire de l'enfant gabonais dans sa langue locale}

Dans cette dernière activité, il s'agira de proposer aux enfants de définir certains mots de la même façon que celle présentée dans le dictionnaire, à partir de toutes les activités précédentes. L'enfant devra avoir retenu en particulier que dans une définition, on trouve le mot, sa nature, son genre, sa définition et un exemple.

En créant leur propre définition, les enfants rentreront plus facilement dans le dictionnaire et cela leur donnera la possibilité de s'approprier la structure de cet ouvrage. Mais plus encore, cela leur donnera parallèlement la possibilité de rentrer plus facilement dans leurs langues locales respectives et de s'en approprier la structure en découvrant des données explicites et complètes sur ces langues. En effet, cet exercice fera appel à la fois à leur capacité de réception, c'est-à-dire, de décodage, ainsi que celle de production, c'est-à-dire, l'encodage.

Pour ce faire, il faudra choisir des mots qui ne poseront a priori aucun problème de signification pour les enfants et qui auront plusieurs sens. En fang ntoumou, il y a par exemple, ngouane qui désigne en même temps la lune et aussi une belle femme. Les enfants sont très imaginatifs et plus observateurs que nous le pensons. Les enseignants seront surpris de s'apercevoir que plusieurs d'entre eux vont proposer des définitions et des exemples très intéressants en pensant aux deux sens des mots qu'ils vont distinguer en les numérotant.

Cette activité se terminera par la comparaison des définitions que les enfants ont proposées avec celles qui sont dans le dictionnaire. Il y aura un sentiment de satisfaction de la part des enfants lorsqu'ils constateront qu'ils auront fait à peu près sinon pour certains aussi bien que le dictionnaire. En présentant correctement le mot défini, la nature, le genre, la définition et l'exemple, ceux-ci se rendront alors compte que le dictionnaire n'est pas un ouvrage si compliqué que cela.

L'objectif est de donner la possibilité aux enfants de se servir du dictionnaire pour des activités ludiques. Ces activités leur permettront de ne se plus se focaliser sur le dictionnaire et se concentrer uniquement que sur leurs activités et ils utiliseront ainsi le dictionnaire, sans se poser de questions. Pour les enfants, ces activités ludiques donneront au dictionnaire une raison d'être comme étant le moyen qui les aidera dans leur travail ainsi que dans leurs différents devoirs de classe ou de maison. Il sera aussi un moyen qui leur per- 
mettra parallèlement de découvrir leurs langues et d'en maîtriser consciemment et inconsciemment les différents aspects du fonctionnement aussi bien à l'écrit qu'à l'oral.

Après ces activités pédagogiques qui feront donc partie des enseignements du CE jusqu'aux CM et voire jusqu'en classe de 3e, les enfants auront moins de problème à rechercher les mots dans le dictionnaire classique de leur langue locale. Ils vont progressivement oublier le nombre de pages de cet ouvrage et son aspect en apparence rébarbatif car ils ne retrouveront plus les couleurs et toutes les images attrayantes de leurs dictionnaires de jeunesse. Ils n'émettront plus aucune objection ou une quelconque répulsion quant à son utilisation en se rendant compte que sans lui plusieurs activités en classe ou à la maison sont difficiles à entreprendre.

\section{Conclusion}

L'introduction des langues locales dans le système éducatif gabonais nécessite l'usage des ouvrages pédagogiques de ces langues comme n'importe quel autre type d'ouvrages, appropriés aux différents niveaux d'études, à savoir, le préprimaire, le primaire et le secondaire. Ce découpage d'ouvrages en fonction des tranches d'âge est pertinent pour les dictionnaires, même si certains pensent que les seules versions classiques sont suffisantes pour servir autant les adultes que les enfants. Le dictionnaire a une place et joue un rôle qui n'est plus à démontrer en tant qu'outil indispensable dans l'apprentissage de la langue, sa promotion, ainsi que de la culture que celle-ci véhicule. Le dictionnaire est également un outil assez complexe. En cela, il constitue un ouvrage pédagogique qui contrairement aux autres, nécessite un apprentissage particulier qui peut être inscrit comme discipline d'enseignement en vue de doter les apprenants d'aptitudes de référence dans l'utilisation des dictionnaires. Ces aptitudes de référence dans l'utilisation de ces ouvrages sont également nécessaires aux lexicographes eux-mêmes et aux enseignements.

À ce jour, l'accent est mis au Gabon sur la confection et la production de dictionnaires classiques de traduction. Les dictionnaires pédagogiques (surtout les dictionnaires scolaires) sont pratiquement absents au paysage lexicographique gabonais. En outre, l'enseignement à l'école d'une composante «aptitudes de référence dans l'utilisation des dictionnaires comme ouvrages de référence» se fait encore attendre. Or, laisser entrer les enfants dans un dictionnaire d'adulte, c'est courir le risque d'une désaffection par les enfants par ce type d'ouvrage non adapté à leur besoins et aptitudes de référence.

Il est donc indispensable d'une part, de confectionner des versions différentes de dictionnaires adaptées chacune aux différentes tranches d'âges et niveaux spécifiques des jeunes utilisateurs, ce qui est aujourd'hui une tâche facilitée par l'outil informatique. D'autre part, il est tout autant indispensable de lui apprendre à se servir du dictionnaire. Ces deux actions combinées accompagneront nécessairement notre gouvernement à atteindre l'objectif de 
son important projet visant l'introduction et la maîtrise des langues locales chez les jeunes gabonais. En effet, si Ilson (1985: 2) souligne que le dictionnaire est le livre le plus réussi sur la langue, nous pensons que les différentes versions d'un dictionnaire correspondant chacune aux différents âges et niveaux d'étude des utilisateurs feront que cet ouvrage le soit encore plus.

\section{Bibliographie}

Bergenholtz, H., S. Tarp et H.E. Wiegand. 1999. Datendistributionsstrukturen, Makro- und Mikrostrukturen in neueren Fachwörterbüchern. Hoffmann, L. et al. (Éds.). 1999. Fachsprachen. Ein internationales Handbuch zur Fachsprachenforschung und Terminologiewissenschaft/Languages for Special Purposes. An International Handbook of Special-Language and Terminology Research. Berlin/New York: Walter de Gruyter.

Dru, Agathe. 1998. La pratique du dictionnaire. Crinon, Jacques et al. (Éds.). 1998. Extrait des mémoires professionnels des stagiaires de deuxième année. http://www.francais.creteil.iufm.fr/mémoires/ dru.htm.

Dubois, J. 1983. Models of the Dictionary: Evolution in Dictionary Design. Applied Linguistics 2(3): 236-249.

Ella, E.M. 2011. Les dictionnaires comme instruments d'appui à l'introduction des langues locales comme activités d'immersion dans l'enseignement. Mikala, G.N. et A. Manfoumbi-Mve (Éds.). 2011. Écritures gabonaises: Histoire, thèmes et langues. Tome II: 344-367. Libreville: Éditions ODEM.

Galisson, R. 1987. De la lexicographie de dépannage à la lexicographie d'apprentissage. Pour une politique de rénovation des dictionnaires monolingues de FLE à l'école. Cahiers de lexicologie 51(2): 95-118.

Gouws, R.H. 1999. Die maatskaplike gerigtheid van die metaleksikografie in 'n meertalige samelewing. Cours d'ouverture. Stellenbosch: Université de Stellenbosch.

Gouws, R.H. 2001. Formation lexicographique: Approches et thèmes. Emejulu, J.D. (Éd.). 2001. Éléments de lexicographie gabonaise. Tome I: 95-134. New York: Jimacs-Hillman Publishers.

Ilson, R. (Éd.). 1985. Dictionaries, Lexicography and Language Teaching. Oxford: Pergamon Press.

Labro, C. 2011a. Dictionnaire Hachette Benjamin de poche. Paris: Hachette Livre.

Labro, C. 2011b. Dictionnaire Hachette Collège. Paris: Hachette Livre.

Mabika Mbokou, Ludwine. 2001. Le rôle du dictionnaire dans le système éducatif. Emejulu, J.D. (Éd.). 2001. Éléments de lexicographie gabonaise. Tome I: 207-222. New York: Jimacs-Hillman Publishers.

Nyangone Assam, Blanche. 2001. La lexicographie dans l'apprentissage des langues gabonaises. Emejulu, J.D. (Éd.). 2001. Éléments de lexicographie gabonaise. Tome I: 189-205. New York: Jimacs-Hillman Publishers.

Ormal-Grenon, J.-B. 2010. Dictionnaire Hachette Junior de poche. Paris: Hachette Livre.

Osselton, N.E. 1983. The History of English Language Dictionaries. Hartmann, R.R.K. (Éd.). 1983. Lexicography. Principles and Practice: 13-21. Londres: Academic Press.

Saphou-Bivigat, Gilles et Edgard Maillard Ella. 2006. De la problématique des articles synopsis dans la compilation des dictionnaires au Gabon. Lexikos 16: 270-279.

Wiegand, H.E. 1997. Die gesellschaftliche Verantwortung der wissenschaftlichen Lexikographie. Hermes, Journal of Linguistics 18: 177-202.

Wiegand, H.E. 1998. Wörterbuchforschung. Untersuchungen zur Wörterbuchbenutzung, zur Theorie, Geschichte, Kritik und Automatisierung der Lexikographie, 1. Teilband. Berlin/New York: Walter de Gruyter. 


\title{
Différentiation systématique des homonymes et des polysèmes en yilumbu (B44) du Gabon
}

\author{
P.A. Mavoungou, Groupe des Recherches en Langues et Culture Orales \\ (GRELACO), Département des Sciences du Langage, \\ Université Omar Bongo, Libreville, République Gabonaise \\ (moudika2@yahoo.com)
}

\begin{abstract}
Résumé: Cette recherche aborde le problème du traitement des homonymes par opposition aux items lexicaux polysémiques en yilumbu, une langue bantoue parlée au Gabon ainsi que dans les pays voisins comme la République du Congo (Congo-Brazzaville) et la République Démocratique du Congo (RDC). Elle identifie plusieurs séries d'homopaires dont la différenciation systématique repose sur l'orthographe ou l'étymologie. Les homonymes reçoivent traditionnellement le statut de lemme ainsi que des nombres en exposant quand ils ont une origine différente. Si ce n'est pas le cas, les mots de mêmes graphies avec une signification différente devraient être traités comme des termes $\mathrm{x}$ fois polysémiques.
\end{abstract}

Mots-clés: HOMONYMES, HOMOPHONES, LEXIQUE, ORTHOGRAPHE, ÉTIMOLOGIE, YILUMBU (B44), DIFFÉRENCIATION, HOMOPAIRES, LEXICOLOGIE, LEXICOGRAPHIE

\section{Summary: Systematic Differentiation of Homonyms and Polysemes in the Yilumbu (B44) of Gabon. This research addresses the problem of the treatment of homo- nyms as opposed to polysemous lexical items in Yilumbu, a Bantu language spoken in Gabon as well as neighbouring countries such as the Republic of the Congo and the Democratic Republic of the Congo (DRC). It identifies several series of homogroups whose systematic differentiation is based on orthography or etymology. Homonyms are traditionally given lemma status as well as superscript numbers when they are of a different origin. If this is not the case, the same words with a different meaning should be treated as terms $x$ times polysemous.}

Keywords: HOMONYMS, HOMOPHONES, LEXICON, ORTHOGRAPHY, ETYMOLOGY, YILUMBU (B44), DIFFERENTIATION, HOMOGROUPS, LEXICOLOGY, LEXICOGRAPHY

\section{Introduction}

L'homonymie, lit-on couramment renvoie à «deux mots de la même prononciation, mais différant dans le sens» (Grevisse 1986: 203). Depuis les débuts de la linguistique moderne, l'homonymie, l'homophonie et la polysémie occupent les spécialistes qui étudient le fonctionnement des langues du monde (Surridge 1994: 155). Hausmann (1989: 641) souligne à ce propos: «L'informa- 
tion portant sur l'homophonie et la paronymie peut être considérée comme sous-développée dans la lexicographie et peu traitée dans la métalexicographie (à l'exception de Rey-Debove 1971: 163)». Jusqu'à présent, à l'exception de Mavoungou (2002, 2005, 2010) et Mavoungou et Plumel (2010), la différentiation systématique des homonymes et des polysèmes dans le contexte de la langue yilumbu (B44, dans la classification de Guthrie 1953) n'a pas été étudiée tant sur le plan synchronique que diachronique. Cette question constitue le centre d'intérêt du présent article, dans lequel je propose de décrire, surtout sur le plan synchronique mais également diachronique (dans une moindre mesure), le fonctionnement des homonymes et des polysèmes du yilumbu.

\section{Quelques considérations théoriques et méthodologiques}

De façon générale, on distingue trois sortes d'homonymes, à savoir: les homonymes homophones et homographes (les mots qui se prononcent et s'écrivent de la même façon); les homonymes hétérophones et homographes (les mots qui s'écrivent de la même façon mais se prononcent différemment); les homonymes homophones et hétérographes (les mots qui se prononcent de la même façon mais s'écrivent différemment). En français, on a par exemple les illustrations suivantes:

moule (mollusque) versus moule (récipient) couvent (du verbe couver) versus couvent (lieu de retraite) verre versus ver (ou vers, vert ou encore vair) homophones et hétérographes homophones et homographes hétérophones et homographes

En yilumbu, nous avons essentiellement une distinction entre homonymes homographes et hétérophones d'une part et homonymes homographes et homophones d'autre part.

\section{Les homonymes homographes et hétérophones du yilumbu}

Dans la catégorie des homographes hétérophones, il convient de distinguer entre le groupe d'homopaires et les séries d'homogroupes de plus de deux membres. Nous entamons l'étude des homographes hétérophones en présentant des séries d'homopaires sous la forme de paires minimales, c'est-à-dire des couples de mots dont les membres se distinguent sur le plan tonal. Les membres des homopaires présentés ci-dessous sont de classe identique ou encore de même genre. En bantouistique, le genre renvoie à l'opposition de deux termes sur la base du singulier et du pluriel (on parle de genre à deux classes ou biclasse) ou alors à l'absence d'une telle opposition (on parle alors de genre à une classe ou monoclasse): 


\begin{tabular}{|l|l|}
\hline bukulu $^{1}$ [búkùlù] & "généalogie" (classe 14, monoclasse) \\
\hline bukulu $^{2}$ [bùkúlù] & $\begin{array}{l}\text { "oseille de guinée ou roselle (Hibiscus sabdariffa)" (classe 14, } \\
\text { monoclasse) }\end{array}$ \\
\hline
\end{tabular}

\begin{tabular}{|c|c|}
\hline dimbunga $^{1}$ [dímbùng̀̀] & "désordre, chaos, anarchie" (classe 5, monoclasse) \\
\hline dimbunga $^{2}$ [dı̀mbúngə̀] & $\begin{array}{l}\text { "variété d'anguille (Protopterus dolloi)" (classe 5, au pluriel } \\
\text { [màbúngə̀] classe 6) }\end{array}$ \\
\hline diyilu $^{1}$ [đıýlilù] & "ciel" (classe 5, monoclasse) \\
\hline diyilu $^{2}$ [díỳ̀lù] & "nez" (classe 5, au pluriel [máyìlù] classe 6) \\
\hline
\end{tabular}

\begin{tabular}{|l|l|}
\hline kuungi $^{1}$ [kú:ngì] & "Justicia extenca" (classe 9) \\
\hline kuungi $^{2}$ [kù:ngi] & $\begin{array}{l}\text { "don, cadeau ou redevance versé au «propriétaire» de la } \\
\text { rivière dans laquelle on a été autorisé de pêcher" (classe 9) }\end{array}$ \\
\hline
\end{tabular}

\begin{tabular}{|c|c|}
\hline musengila $^{1}$ [mùsè्̀ngílà] & $\begin{array}{l}\text { "regroupement (de villages); département" (classe 3, au plu- } \\
\text { riel [mìsę̀ngílà], classe 4) }\end{array}$ \\
\hline musengila $^{2}[1$ & "objet sans manche" (classe 3, au pluriel [mísદ̀ngg̀là] classe 4) \\
\hline
\end{tabular}

\begin{tabular}{|l|l|}
\hline musosu $^{1}$ [mùsósù] & "palabre, problème" (classe 3, au pluriel [mìsósù], classe 4) \\
\hline musosu $^{2}$ [músòsù] & "verge, phallus" (classe 3, au pluriel [mísòsù] classe 4 ) \\
\hline
\end{tabular}

\begin{tabular}{|c|c|}
\hline mwaamba $^{1}$ [mwà̀:mbว̀] & "arbre" (classe 3, monoclasse) \\
\hline mwaamba $^{2}$ [mwǻámbò] & "sauce" (classe 3, au pluriel [myǻ:mbə̀] classe 4) \\
\hline nyuundu $^{1}$ [nú:ndù] & $\begin{array}{l}\text { "marteau masse, enclume, etc." (classe } 9 \text {, au pluriel [tsínùnndù] } \\
\text { classe 10) }\end{array}$ \\
\hline nyuundu $^{2}$ [nú:ndù] & $\begin{array}{l}\text { "loutre du Congo (Aonyx conjicus)" (classe 9, au pluriel } \\
\text { [tsínù:ndù] classe } 10 \text { ) }\end{array}$ \\
\hline
\end{tabular}

\begin{tabular}{|l|l|}
\hline ughaanda $^{1}$ [úyà̀nd̀̀] & $\begin{array}{l}\text { "empêcher la pluie de tomber (rituel)" (classe 15, mono- } \\
\text { classe) }\end{array}$ \\
\hline ughaanda $^{2}$ [ùyaậnd’̀] & "jurer, faire le serment de" (classe 15, monoclasse) \\
\hline
\end{tabular}

\begin{tabular}{|l|l|}
\hline usala $^{1}$ [ùsálə̀] & "travailler, accomplir une tâche" (classe 15, monoclasse) \\
\hline usala $^{2}$ [ùsălò] & "choisir, faire son choix" (classe 15, monoclasse) \\
\hline
\end{tabular}

\begin{tabular}{|l|l|}
\hline $\begin{array}{l}\text { utsiinga }^{1} \text { (mvuunga) [ùtsìngg̀̀ } \\
\text { (mvú:ngà)] }\end{array}$ & $\begin{array}{l}\text { "couvrir (en parlant d'une personne décédée)" (classe 15, } \\
\text { monoclasse) }\end{array}$ \\
\hline utsiinga $^{2}$ [ùtśíngə̀] & "durer" (classe 15, monoclasse) \\
\hline
\end{tabular}

\begin{tabular}{|c|c|}
\hline yibeenga $^{1}$ [yı̀bé્:ingə̀] & "action d'être rouge" (classe 7, monoclasse) \\
\hline yibeenga $^{2}$ [yı̀bè્ે:ngə̀] & "assiette en bois" (classe 7, au pluriel [bìbę̀:ygə̀] classe 8) \\
\hline
\end{tabular}

\begin{tabular}{|l|l|}
\hline yikuumbu ${ }^{1}$ [ỳ̀kú:mbù] & $\begin{array}{l}\text { "panthère (Panthera pardus)" (classe 7, au pluriel [bìkú:mbù] } \\
\text { classe 8) }\end{array}$ \\
\hline yikuumbu $^{2}$ [ýkù:mbù] & $\begin{array}{l}\text { "dédommagement que le mari verse au clan maternel de sa } \\
\text { défunte épouse ou encore dédommagement que le père verse } \\
\text { au clan maternel de son enfant défunt" (classe 7, au pluriel } \\
\text { [bíkù:mbù]) }\end{array}$ \\
\hline
\end{tabular}


Comme déjà souligné plus haut, les membres des homopaires ci-dessus appartiennent à une même classe nominale. Mais ce n'est pas toujours le cas, comme le montre les exemples ci-dessous:

\begin{tabular}{|l|l|}
\hline kuba $^{1}$ [kùbə̀] & $\begin{array}{l}\text { "fruit de l'érable d'Afrique (Poga oleosa)" (classe 10) (au } \\
\text { singulier, on dit dughuba [dùyúßə̀] (classe 11) }\end{array}$ \\
\hline kuba $^{2}$ [kúbə̀] & $\begin{array}{l}\text { "bastonnade, volée de coup de poings, de coups de pied, } \\
\text { etc." (classe 9) }\end{array}$ \\
\hline
\end{tabular}

\begin{tabular}{|l|l|}
\hline $\begin{array}{l}\text { musuunda } \\
\text { [mùsù:ndà (pé:tsù)] }\end{array}$ & "pain (de kaolin)" (classe 3) \\
\hline $\begin{array}{l}\text { musuunda' } \\
\text { (kấ:ndò)] }\end{array}$ & "enùsú:ndòn qui vient au monde par le siège" (classe 1) \\
\hline
\end{tabular}

Dans la catégorie des homographes hétérophones, il existe également des homophones résultant de l'introduction d'un emprunt:

\begin{tabular}{|c|c|}
\hline boolu $^{1}$ [bó:lù] & $\begin{array}{l}\text { "danse du samedi soir qui associe les rythmes traditionnels à } \\
\text { l'accordéon, bal musette, bal populaire; valse" (Emprunt à } \\
\text { l'anglais bal) (classe 9) }\end{array}$ \\
\hline boolu $^{2}$ [bó:lù] & "paresse, fainéantise" (terme non emprunté) (classe 14) \\
\hline mukoondu ${ }^{1}$ [mùkó:ndù] & $\begin{array}{l}\text { "virage; tournant; courbe; détour" (terme non emprunté) } \\
\text { (classe 3, au pluriel [mìkṓndù] classe 4) }\end{array}$ \\
\hline $\begin{array}{l}\text { mukoondu² [múkò̀ndù/ } \\
\text { mùkớndù] }\end{array}$ & $\begin{array}{l}\text { "cotonnier (Gossypium barbadense); coton" (Emprunt au } \\
\text { portugais algodon) (classe 3, au pluriel [mìkóndù]/[míkฏ̀:ndù] } \\
\text { classe 4) }\end{array}$ \\
\hline
\end{tabular}

Dans les groupes d'homopaires ci-dessus, il y a certes une différentiation possible à partir de la classe grammaticale de l'homographe hétérophone considéré, mais c'est surtout l'argument diachronie, en l'occurrence le recourt à l'étymologie, qui permet de distinguer fondamentalement les différents membres des homopaires.

L'orthographe aide également à distinguer certains homonymes. En témoignent les exemples suivants:

\begin{tabular}{|c|c|}
\hline mbe [mbé] & "si" \\
\hline mbe? [mbě] & "n'est-ce pas?" \\
\hline mbe! [mb̂̂ع] & "donne-moi!" \\
\hline
\end{tabular}

\begin{tabular}{|c|c|}
\hline ngebe! [ฤgébè] & "pitié!" \\
\hline ngebe [ךgébé] & "toi-même, toi seul" \\
\hline
\end{tabular}

\begin{tabular}{|l|l|}
\hline yika [ý́k̀̀] & "remplaçante" \\
\hline yikâ [ý́kâ] & "alors; donc" \\
\hline
\end{tabular}


Dans les lexies ci-dessus, la distinction est perceptible dans l'utilisation des points d'interrogation et d'exclamation d'une part. D'autre part, dans la paire yika/yikâ, la distinction est rendue par l'emploi de l'accent circonflexe sur la voyelle $a$.

Dans un premier temps, il m'a paru souhaitable de présenter d'abord les groupes d'homopaires. Passons donc à présent aux séries d'homogroupes de plus de deux membres:

\begin{tabular}{|c|c|}
\hline meenga $^{1}$ [mé̃:ngə̀] & "sang" (classe 6, monoclasse) \\
\hline meenga $^{2}$ [mé̃:'ng̀̀] & "variété de poisson" (classe 9, au pluriel [mę́:ngə̀] classe 10) \\
\hline meenga $^{3}$ [mè̀:ygə̀] & "faïence" (classe 9, au pluriel [mع્:ygə̀] classe 10) \\
\hline
\end{tabular}

\begin{tabular}{|l|l|}
\hline itutu $^{1}$ [itútú] & "rougeole" (classe 7, monoclasse) \\
\hline itutu $^{2}$ [itútù] & $\begin{array}{l}\text { "vin de palme de mauvaise qualité" (Emprunt à l'omyènè } \\
t u t u) \text { (classe 7, monoclasse) }\end{array}$ \\
\hline itutu $^{3}$ [itútù] & $\begin{array}{l}\text { "flambeau confectionné avec des tiges desséchées du faux- } \\
\text { camphrier ou alors avec la nervure médiane de la palme } \\
\text { séchée de bambou; brandon (sorte de torche faite d'un tor- } \\
\text { tillon de paille)" (classe 7, au pluriel [bìtútù] classe 8) }\end{array}$ \\
\hline
\end{tabular}

Dans le premier groupe d'homopaires, meenga ${ }^{1}$ et meeng $a^{3}$ sont de genre identique $(9,10)$ tandis que meeng $a^{2}$ appartient à la classe 6 . Par contre, tous les membres du deuxième groupe d'homopaires appartiennent à la classe 7. Ici, la distinction ne peut être que typographique, en l'occurrence l'utilisation des chiffres en exposant pour distinguer les trois membres du paradigme homonymique.

\section{Les homonymes homographes et homophones du yilumbu}

Comme ce fut le cas pour les homographes hétérophones, il convient aussi de distinguer dans la catégorie des homographes homophones, les groupes d'homopaires ainsi que les séries d'homogroupes de plus de deux membres. Pour ce qui est du groupe d'homopaires considérons les exemples suivants:

\begin{tabular}{|l|l|}
\hline koondu $^{1}$ [kó:ndù] & $\begin{array}{l}\text { "empreinte (chez les animaux)" (classe 9, au pluriel [kó:ndù] } \\
\text { ou [tsikṓndù] classe 10) }\end{array}$ \\
\hline koondu $^{2}$ [kó:ndù] & $\begin{array}{l}\text { "maître des pleureuses" (classe 9, au pluriel [kó:ndù] ou } \\
\text { [tsikón:ndù] classe 10) }\end{array}$ \\
\hline
\end{tabular}

\begin{tabular}{|l|l|}
\hline misoku $^{1}$ [mìsókù] & "poisson (espèce)" (classe 4, monoclasse) \\
\hline misoku $^{2}$ [mìsókù] & "variante du Bwiti considérée comme culte de guérison" \\
& (classe 4, monoclasse). Vraisemblablement, il s'agit d'un \\
& terme d'emprunt. \\
\hline
\end{tabular}

\begin{tabular}{|l|l|}
\hline ufwaana ${ }^{1}$ [ùfwán’̀] & "falloir" (classe 15, monoclasse) \\
\hline ufwaana $^{2}$ [ùfwá:nə̀] & $\begin{array}{l}\text { "suffire, être juste; correspondre, équivaloir; se ressembler" } \\
\text { (classe 15, monoclasse) }\end{array}$ \\
\hline
\end{tabular}




\begin{tabular}{|l|l|}
\hline ughaanga $^{1}$ [ùyậ:yg̀̀] & "frire; griller" (classe 15, monoclasse) \\
\hline ughaanga $^{2}$ [ùyậ:ingə̀] & "attrapper, saisir" (classe 15, monoclasse) \\
\hline
\end{tabular}

\begin{tabular}{|l|l|}
\hline usalila $^{\mathbf{1}}$ [ùsálíl’̀] & $\begin{array}{l}\text { "travailler (pour), être au service de quelqu'un" (classe 15, } \\
\text { monoclasse) }\end{array}$ \\
\hline usalila $^{2}$ [ùsálíl’̀] & $\begin{array}{l}\text { "choisir (pour), faire le choix (pour quelqu'un)" (classe 15, } \\
\text { monoclasse) }\end{array}$ \\
\hline
\end{tabular}

\begin{tabular}{|l|l|}
\hline kuumbu ${ }^{1}[$ kù:mbù] & "fois" (classe 9, monoclasse) \\
\hline kuumbu $^{2}[$ kù:mbù] & $\begin{array}{l}\text { "surnom, nom initiatique" (classe 9, au pluriel [kùmmbù] ou } \\
\text { [tsíkù:mbù] classe 10) }\end{array}$ \\
\hline
\end{tabular}

\begin{tabular}{|l|l|}
\hline moongu $^{1}$ [mó:ygù] & $\begin{array}{l}\text { "patate douce, patate violette (Ipomoa batatas)" (classe 9, au } \\
\text { pluriel [móngù]] ou [tsimóingù] classe 10) }\end{array}$ \\
\hline moongu $^{2}$ [mó:ygù] & $\begin{array}{l}\text { "endroit surélevé, colline; etc." (classe 9, au pluriel [mó:ngù] } \\
\text { ou [tsìmó:ngù] classe 10) }\end{array}$ \\
\hline
\end{tabular}

\begin{tabular}{|l|l|}
\hline toonu $^{1}$ [tònnù] & $\begin{array}{l}\text { "cause, raison; grief" (classe 9, au pluriel [tònnù] ou } \\
\text { [tsítò:nù] classe 10) }\end{array}$ \\
\hline toonu $^{2}$ [tònnù] & "nom de village" (classe 9, monoclasse) \\
\hline
\end{tabular}

\begin{tabular}{|l|l|}
\hline tsaangu $^{1}$ [tsǻ:ingù] & $\begin{array}{l}\text { "nouvelle" (classe 9, au pluriel [tsá:ingù] ou [tsìtsǻángù] } \\
\text { classe 10) }\end{array}$ \\
\hline tsaangu $^{2}$ [tsǻingù] & "semence" (classe 9, monoclasse) \\
\hline
\end{tabular}

\begin{tabular}{|l|l|}
\hline difubu $^{1}$ [dıfúbù] & $\begin{array}{l}\text { "pandanus ou vaquois (Pandanus candelabrum)" (classe 5, } \\
\text { au pluriel [màfúbù] classe 6) }\end{array}$ \\
\hline difubu $^{2}$ [dıfúbù] & $\begin{array}{l}\text { "ananas (Ananas sativus)" (classe 5, au pluriel [màfúbù] } \\
\text { classe 6) }\end{array}$ \\
\hline
\end{tabular}

\begin{tabular}{|l|l|}
\hline diluundu $^{1}$ [dilú:ndù] & "fait d'être réfractaire aux vomitifs" (classe 5, monoclasse) \\
\hline diluundu $^{2}$ [dilúindù] & $\begin{array}{l}\text { "fausse citronnelle (Cymbopogon citratus)" (classe 5, mono- } \\
\text { classe) }\end{array}$ \\
\hline
\end{tabular}

\begin{tabular}{|l|l|}
\hline disosu $^{1}$ [đisósù] & $\begin{array}{l}\text { "citronnelle (Hyparrhenia diplandra)" (classe 5, au pluriel } \\
\text { [màsósù] classe 6) }\end{array}$ \\
\hline disosu $^{2}$ [đisósù] & $\begin{array}{l}\text { "plante herbacée qui aime se répandre dans la plantation" } \\
\text { (classe 5, au pluriel [màsósù] classe 6) }\end{array}$ \\
\hline
\end{tabular}

\begin{tabular}{|l|l|}
\hline dubiindu $^{1}$ [dùbíindù] & $\begin{array}{l}\text { "qui est non négligeable, très important" (classe 11, mono- } \\
\text { classe) }\end{array}$ \\
\hline dubiindu $^{2}$ [dùbíindù] & "falaise; précipice; ravin, etc." (classe 11, monoclasse) \\
\hline
\end{tabular}

\begin{tabular}{|l|l|}
\hline kaba $^{1}[$ káb̀̀] & $\begin{array}{l}\text { "carangue crevalle (Caranx hippos), faux-thon" (classe 9, au } \\
\text { pluriel [kábə̀] ou [tsikábə̀] classe 6) }\end{array}$ \\
\hline kaba $^{2}$ [kábə̀] & $\begin{array}{l}\text { "chêne d'Afrique (Haplormosia monophylla) ou faux chêne" } \\
\text { (classe 9, au pluriel [kábə̀] ou [tsikábə̀] classe 6) }\end{array}$ \\
\hline
\end{tabular}




\begin{tabular}{|c|c|}
\hline kala $^{1}$ [kálə̀] & $\begin{array}{l}\text { "relatif au passé, il y a longtemps, autrefois; déjà" (classe } 9 \text {, } \\
\text { monoclasse) }\end{array}$ \\
\hline kala $^{2}$ [kálə̀] & "crabe" (classe 9, au pluriel [kálə̀] ou [tsíkàl’̀] classe 10) \\
\hline mata $^{1}$ [mát̀̀] & "fusils" (classe 6, monoclasse) \\
\hline mata $^{2}$ [mátə̀] & "fétiche" (classe 6, monoclasse) \\
\hline
\end{tabular}

\begin{tabular}{|l|l|}
\hline mudughu $^{1}$ [mùdúyù] & $\begin{array}{l}\text { "saignement du nez, écoulement de sang par voie nasale" } \\
\text { (classe } 3, \text { monoclasse) }\end{array}$ \\
\hline mudughu ${ }^{2}$ [mùdúyù] & "mercredi" (classe 3, monoclasse) \\
\hline
\end{tabular}

\begin{tabular}{|c|c|}
\hline muloghu ${ }^{1}$ [mùlóyù] & "mauvais sort, malédiction, etc." (classe 3, monoclasse) \\
\hline muloghu' ${ }^{2}$ [mùlóyù] & "cri" (classe 3, au pluriel [mìlóyù] classe 4) \\
\hline
\end{tabular}

\begin{tabular}{|l|l|}
\hline mulughu $^{1}$ [mùlúyù] & $\begin{array}{l}\text { "homonyme, celui ou celle dont on porte le nom" (classe 3, } \\
\text { au pluriel [mìlúyù] classe 4) }\end{array}$ \\
\hline mulughu $^{2}$ [mùlúyù] & "fait d'être insatiable" (classe 3, monoclasse) \\
\hline
\end{tabular}

\begin{tabular}{|l|l|}
\hline musiingi $^{1}$ [mùsíngì] & $\begin{array}{l}\text { "chat sauvage, chat doré (Felis aurata)" (classe 3, au pluriel } \\
\text { [mìsíngì] classe 4) }\end{array}$ \\
\hline musiingi $^{2}$ [mùsíngì] & $\begin{array}{l}\text { "Dabéma, Toum (Piptadenia africana)" (classe 3, au pluriel } \\
\text { [mìsíngì] classe 4) }\end{array}$ \\
\hline
\end{tabular}

\begin{tabular}{|l|l|}
\hline muusu $^{1}$ [mú:sù] & "journée" (classe 3, monoclasse) \\
\hline muusu $^{2}[$ mú:sù] & "pilon" (classe 3, au pluriel [myú:sù] classe 4) \\
\hline
\end{tabular}

\begin{tabular}{|c|c|}
\hline mbaala $^{1}$ [mbá:là] & "mâle" (classe 9, au pluriel [tsìmbá:là] classe 10) \\
\hline mbaala $^{2}$ [mbá:là] & $\begin{array}{l}\text { "nandinie (Nandinia binotata)" (classe 9, au pluriel [tsìmbá:là] } \\
\text { classe 10) }\end{array}$ \\
\hline
\end{tabular}

\begin{tabular}{|l|l|}
\hline ndughu $^{1}$ [ndúyù] & "lagune NDOUGOU" (classe 3, monoclasse) \\
\hline ndughu $^{2}$ [ndúyù] & $\begin{array}{l}\text { "natte de cheveux ..." (classe 9, au pluriel [ndúyù] ou } \\
\text { [tsìndúyù] classe 10) }\end{array}$ \\
\hline
\end{tabular}

\begin{tabular}{|c|c|}
\hline 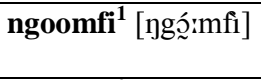 & 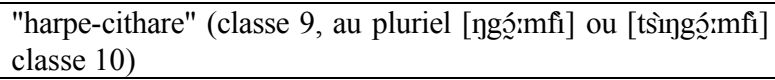 \\
\hline ngoomfi $^{2}$ [ๆgহ́:mfi] & $\begin{array}{l}\text { "guêpe-maçonne" (classe 9, au pluriel [ngórmfi] ou [ts̀ngǵ:mfi] } \\
\text { classe 10) }\end{array}$ \\
\hline
\end{tabular}

\begin{tabular}{|l|l|}
\hline ngulu $^{1}$ [ggúlù] & $\begin{array}{l}\text { "porc domestique" (classe 9, au pluriel [ggúlù] ou [tsìngúlù] } \\
\text { classe 10) }\end{array}$ \\
\hline ngulu $^{2}$ [ggúlù] & "force" (classe 9, monoclasse) \\
\hline
\end{tabular}

\begin{tabular}{|c|c|}
\hline nguungu $^{1}$ [ ggú:ggù] $^{2}$ & $\begin{array}{l}\text { "champignon (Cajanus cajan)" (classe 9, au pluriel [ngú:ngù] } \\
\text { ou [tsìngú:ngù] classe 10) }\end{array}$ \\
\hline nguungu $^{2}$ [ygú:ygù] & $\begin{array}{l}\text { "sarcophrynium (sp)" (classe 9, au pluriel [ygúingù] ou } \\
\text { [tsìngú:ngù] classe 10) }\end{array}$ \\
\hline
\end{tabular}




\begin{tabular}{|c|c|}
\hline nyaanga [nẫingà] & "nom d'un cours d'eau" (classe 9, monoclasse) \\
\hline nyaanga [nẫingə̀] & $\begin{array}{l}\text { "fente naturelle ou artificielle au niveau des dents de la } \\
\text { mâchoire supérieure" (classe 9, au pluriel [nâa:ngə̀] ou } \\
\text { [tsìnâ:ngà] classe 10) }\end{array}$ \\
\hline
\end{tabular}

\begin{tabular}{|l|l|}
\hline nyeentsi $^{1}$ [nغ̀:ts̀̀] & "grillon" (classe 9, au pluriel [tsíṅ̀:ts̀̀] classe 10) \\
\hline nyeentsi ${ }^{2}$ [nغ̀:tsì] & "plaisir, joie" (classe 9, au pluriel [tsínè:ts̀i] classe 10) \\
\hline
\end{tabular}

\begin{tabular}{|c|c|}
\hline nyoombu $^{1}$ [nó:mbù] & "musc" (classe 9, monoclasse) \\
\hline nyoombu ${ }^{2}$ [nó:mbù] & "peau morte" (classe 9, au pluriel [tsìnহ́:mbù] classe 10) \\
\hline
\end{tabular}

\begin{tabular}{|l|l|}
\hline ubala $^{1}$ [ùbálə̀] & "monter (en parlant du soleil)" (classe 15, monoclasse) \\
\hline ubala $^{2}$ [ùbálə̀] & "penser" (classe 15, monoclasse) \\
\hline
\end{tabular}

\begin{tabular}{|l|l|}
\hline ufugha $^{1}$ [ùfúỳ̀] & "coiffer; raser" (classe 15, monoclasse) \\
\hline ufugha $^{2}$ [ùfúyə̀] & $\begin{array}{l}\text { "couvrir (avec une feuille), recouvrir" (classe 15, mono- } \\
\text { classe) }\end{array}$ \\
\hline
\end{tabular}

\begin{tabular}{|l|l|}
\hline ufuta $^{1}$ [ùfúṫ̀] & "cracher" (classe 15, monoclasse) \\
\hline ufuta $^{2}$ [ùfútò] & "payer, régler (facture, dettes, etc.)" (classe 15, monoclasse) \\
\hline
\end{tabular}

\begin{tabular}{|l|l|}
\hline ughoobula $^{1}$ [ùyó:búlà] & $\begin{array}{l}\text { "régurgiter: rendre par régurgitation; recracher" (classe 15, } \\
\text { monoclasse) }\end{array}$ \\
\hline ughoobula $^{2}$ [ùyó:búlà] & "sauver, délivrer" (classe 15, monoclasse) \\
\hline
\end{tabular}

\begin{tabular}{|l|l|}
\hline ukaamba $^{1}$ [ùkáámb̀̀] & $\begin{array}{l}\text { "être acculé, réduit à l'impuissance, avoir le dos au mur, être } \\
\text { accablé, être dépassé" (classe 15, monoclasse) }\end{array}$ \\
\hline ukaamba $^{2}$ [ùkǻ:mb̀̀] & $\begin{array}{l}\text { "annoncer; transmettre, dire, raconter; révéler" (classe 15, } \\
\text { monoclasse) }\end{array}$ \\
\hline
\end{tabular}

\begin{tabular}{|l|l|}
\hline uleenga [ùleć:̣g̀̀] & "se hâter, se dépêcher, se presser" (classe 15, monoclasse) \\
\hline uleenga [ùlẽ्́:ngə̀] & $\begin{array}{l}\text { "être léger, ne pas valoir grand chose" (classe 15, mono- } \\
\text { classe) }\end{array}$ \\
\hline
\end{tabular}

\begin{tabular}{|l|l|}
\hline uleesi $^{1}$ [ùlé:s̀̀] & "faire dormir (en parlant de l'enfant)" \\
\hline uleesi $^{2}$ [ùlé:s̀i] & "montrer, indiquer, enseigner" \\
\hline
\end{tabular}

\begin{tabular}{|c|c|}
\hline usegha $^{1}$ [ùsé yò] & "tirer les vers du nez à quelqu'un" (classe 15, monoclasse) \\
\hline usegha $^{2}$ [ùséyว̀] & "être en état de délabrement" (classe 15, monoclasse) \\
\hline usyeema $^{1}$ [ùsyé:mə̀] & "faire des éclairs" (classe 15, monoclasse) \\
\hline usyeema $^{2}$ [ùsyé:mə̀] & $\begin{array}{l}\text { "faire une préparation médicamenteuse" (classe 15, mono- } \\
\text { classe) }\end{array}$ \\
\hline
\end{tabular}




\begin{tabular}{|l|l|}
\hline uvhola $^{1}$ [ùßólə̀] & "fumer" (classe 15, monoclasse) \\
\hline uvhola $^{2}$ [ùßól̀̀] & "être faible; être fatigué" (classe 15, monoclasse) \\
\hline
\end{tabular}

\begin{tabular}{|l|l|}
\hline uwaala $^{\mathbf{1}}$ [ùwá:l̀̀] & "emplir, être plein, être rempli" (classe 15, monoclasse) \\
\hline uwaala $^{2}$ [ùwáll̀̀] & $\begin{array}{l}\text { "étaler (en parlant de la natte, du tapis, etc.)" (classe 15, } \\
\text { monoclasse) }\end{array}$ \\
\hline
\end{tabular}

\begin{tabular}{|l|l|}
\hline uweela $^{\mathbf{1}}$ [ùwé:l̀̀] & $\begin{array}{l}\text { "épouser, prendre femme, se marier" (classe 15, mono- } \\
\text { classe) }\end{array}$ \\
\hline uweela $^{2}$ [ùwé:l’̀] & "mûrir; être à point" (classe 15, monoclasse) \\
\hline
\end{tabular}

\begin{tabular}{|l|l|}
\hline kali $^{1}[$ kálì] & "nouveau-né, bébé" (classe 9, au pluriel [káli] classe 10) \\
\hline kali $^{2}\left[\mathrm{káli}^{1}\right]$ & "salée" (adjectif) \\
\hline
\end{tabular}

\begin{tabular}{|l|l|}
\hline yina $^{1}$ [yíṅ̀] & "tabou, interdit" (classe 7, au pluriel [bínə̀] classe 8) \\
\hline yina $^{2}$ [yínə̀]. & "quatre" (adjectif numéral cardinal) \\
\hline
\end{tabular}

\begin{tabular}{|l|l|}
\hline yooghu' ${ }^{1}$ [yó:yù]. & "gros champignon noir" (classe 9, monoclasse) \\
\hline yooghu $^{2}$ [yó:yù]. & "ils, eux" (substitutif) \\
\hline
\end{tabular}

Les différents membres des homopaires ci-dessus se différentient essentiellement par la forme du pluriel pour les substantifs. Par contre, pour les verbes et les unités lexicales en emploi absolu (monoclasse), la distinction ne peut être que typographique. Ils devraient recevoir des nombres en exposant, ou alors commencer par un indicateur structurel, reflétant la fréquence d'emploi comme cela est habituellement fait dans les dictionnaires.

La différentiation des homographes hétérophones se fait également au niveau dialectal. On distingue entre le yilumbu parlé dans la province de la Nyanga et le yilumbu parlé dans la province de l'Ogooué-Maritime. Considérons les exemples ci-après:

\begin{tabular}{|l|l|}
\hline wali $^{1}$ [wáli] & $\begin{array}{l}\text { "deux" (dialecte de la province de la Nyanga). Dans la } \\
\text { province de l'Ogooué-Maritime, on utilise le terme bayi } \\
\text { [báyì]. }\end{array}$ \\
\hline wali $^{2}$ [wáli] & $\begin{array}{l}\text { "Garcinia klaineana" (provinces de la Nyanga et de } \\
\text { l'Ogooué-Maritime) }\end{array}$ \\
\hline
\end{tabular}

\begin{tabular}{|l|l|}
\hline dikasa $^{1}$ [đikásə̀]. & $\begin{array}{l}\text { "espèce d'arbuste" (provinces de la Nyanga et de l'Ogooué- } \\
\text { Maritime) }\end{array}$ \\
\hline dikasa $^{2}$ [đikásə̀] & $\begin{array}{l}\text { "marché" (variété du yilumbu parlée dans la province de } \\
\text { l'Ogooué-Maritime). Dans la province de la Nyanga, on } \\
\text { utilise le lexème itanda [itándə̀]. }\end{array}$ \\
\hline
\end{tabular}

\begin{tabular}{|l|l|}
\hline masanyi $^{1}$ [màsájì] & $\begin{array}{l}\text { "gale d'eau" (variété du yilumbu parlée dans la province de } \\
\text { la Nyanga). Dans la province de l'Ogooué-Maritime, on } \\
\text { utilise le terme de matse [máts̀̀]. }\end{array}$ \\
\hline
\end{tabular}




\begin{tabular}{|l|l|}
\hline masanyi $^{2}$ [màsájì] & $\begin{array}{l}\text { "cartouche" (variété du yilumbu parlée dans la province de } \\
\text { l'Ogooué-Maritime). Dans la province de la Nyanga, on } \\
\text { utilise le lexème mayeli [máyèî]. }\end{array}$ \\
\hline
\end{tabular}

\begin{tabular}{|l|l|}
\hline mukuba $^{1}$ [mùkúbə̀] & "bec" (provinces de la Nyanga et de l'Ogooué-Maritime) \\
\hline mukuba $^{2}$ [mùkúbə̀] & "corps" (variété du yilumbu parlée dans la province de \\
& $\begin{array}{l}\text { l'Ogooué-Maritime). Dans la province de la Nyanga, on } \\
\text { utilise le terme dunyuru [dúpùrù]. }\end{array}$ \\
\hline
\end{tabular}

\begin{tabular}{|l|l|}
\hline muluumbu ${ }^{1}$ [mùlú:mbù] & $\begin{array}{l}\text { "locuteur du yilumbu" (provinces de la Nyanga et de } \\
\text { l'Ogooué-Maritime) }\end{array}$ \\
\hline muluumbu $^{2}$ [mùlú:mbù] & $\begin{array}{l}\text { "seau" (variété du yilumbu parlée dans la province de la } \\
\text { Nyanga). Dans la province de l'Ogooué-Maritime, on } \\
\text { utilise l'unité lexicale ipaana [ipá:nò]. }\end{array}$ \\
\hline
\end{tabular}

\begin{tabular}{|l|l|}
\hline mbuunga $^{1}$ [mbû:ng̀̀] & $\begin{array}{l}\text { "odeur" (variété du yilumbu parlée dans la province de la } \\
\text { Nyanga). Dans la province de l'Ogooué-Maritime, on } \\
\text { utilise l'item manaanga [màná:ygə̀]. }\end{array}$ \\
\hline mbuunga $^{2}$ [mbû:ng̀̀] & $\begin{array}{l}\text { "xylopia (espèce)" (provinces de la Nyanga et de } \\
\text { l'Ogooué-Maritime) }\end{array}$ \\
\hline
\end{tabular}

\begin{tabular}{|l|l|}
\hline ubwiila $^{1}$ [ùbwíll̀̀] & $\begin{array}{l}\text { "se laver; se baigner" (variété du yilumbu parlée dans la } \\
\text { province de l'Ogooué-Maritime). Dans la province de la } \\
\text { Nyanga, on utilise le terme uwungula [ùwúngúl’̀]. }\end{array}$ \\
\hline ubwiila $^{2}$ [ùbwíll̀̀] & $\begin{array}{l}\text { "saisir, attraper" (variété du yilumbu parlée dans la } \\
\text { province de la Nyanga). Dans la province de l'Ogooué- } \\
\text { Maritime, on utilise le terme ughaanga [ùyáángè]. }\end{array}$ \\
\hline
\end{tabular}

\begin{tabular}{|l|l|}
\hline yifu $^{1}$ [yífù] & $\begin{array}{l}\text { "mortier" (variété du yilumbu parlée dans la province de la } \\
\text { Nyanga). Dans la province de l'Ogooué-Maritime, on pro- } \\
\text { nonce ghiifu [yí:uù]. }\end{array}$ \\
\hline yifu $^{2}$ [yífù] & $\begin{array}{l}\text { "habitude; défaut, tic (bon ou mauvais)" (provinces de la } \\
\text { Nyanga et de l'Ogooué-Maritime) }\end{array}$ \\
\hline
\end{tabular}

\begin{tabular}{|l|l|}
\hline nduungu $^{1}$ [ndú:ggù] & "arbre" (provinces de la Nyanga et de l'Ogooué-Maritime) \\
\hline nduungu $^{2}$ [ndú:igù] & $\begin{array}{l}\text { "tam-tam" (provinces de la Nyanga et de l'Ogooué-Mari- } \\
\text { time) }\end{array}$ \\
\hline nduungu $^{3}$ [ndú:ngù] & $\begin{array}{l}\text { "pirogue" (variété du yilumbu parlée dans la province de } \\
\text { l'Ogooué-Maritime). Dans la province de la Nyanga, on } \\
\text { utilise le terme bwaatu [bwá:tù]. }\end{array}$ \\
\hline
\end{tabular}

L'orthographe aide également à la distinction entre les membres du groupe d'homopaires:

\begin{tabular}{|c|c|}
\hline mfinyu! [mfínù] & "bien soigné, éclatant" \\
\hline mfinyu [mfínù] & "chiques" (au singulier dumfinyu [dùmfínù] classe 11/10. \\
\hline ngaamba! [ᄁgáámbò] & "dis-moi!" \\
\hline ngaamba [ๆgǻ:mbə̀] & "brouillard" \\
\hline
\end{tabular}


Dans les lexies ci-dessus, la distinction est perceptible dans l'utilisation des points d'exclamation.

Dans la catégorie des homographes homophones, il existe également des homophones résultant de l'introduction d'un emprunt. Il y a, d'une part, le groupe d'homopaires et, d'autre part, les séries d'homogroupes de plus de deux membres. Les séries d'homopaires se présentent comme suit:

\begin{tabular}{|l|l|}
\hline $\operatorname{lotu}^{1}$ [lótù] & $\begin{array}{l}\text { "voiture" (au singulier comme au pluriel; Emprunt au } \\
\text { français l'auto) }\end{array}$ \\
\hline lotu $^{2}$ [lótù] & "cuillère" (au pluriel nyotu ou tsinyotu) \\
\hline
\end{tabular}

\begin{tabular}{|l|l|}
\hline neela $^{1}$ [né:là] & "fenêtre" (Emprunt au portugais janela) classe 9/10 \\
\hline neela $^{2}$ [né:là] & "bague, anneau" (Emprunt au portugais aro) classe 9/10 \\
\hline
\end{tabular}

\begin{tabular}{|l|l|}
\hline payi $^{1}$ [páyì] & "milicien; messager, porte-parole, représentant" \\
\hline payi $^{2}$ [páyì] & "païen" (Emprunt au français païen) \\
\hline
\end{tabular}

\begin{tabular}{|l|l|}
\hline teli $^{1}[$ tèli] & "baleine" (terme non emprunté) classe 9/10 \\
\hline teli $^{2}[$ tèli $]$ & "atelier" (Emprunt au français atelier) classe 9/10 \\
\hline
\end{tabular}

\begin{tabular}{|l|l|}
\hline puungu $^{1}$ [pù:ygù] & "gorille (Gorilla gorilla)" \\
\hline puungu $^{2}$ [pù:ygù] & "Libreville" (Emprunt à l'omyènè o ntshè mpongwè) \\
\hline
\end{tabular}

\begin{tabular}{|l|l|}
\hline boota $^{1}$ [bó:t̀̀] & $\begin{array}{l}\text { "canoë; chaloupe, barque; pirogue (munie de deux rames)" } \\
\text { (Emprunt à l'anglais boat) }\end{array}$ \\
\hline boota $^{2}$ [bó:t̀̀] & "botte" (Emprunt au français botte) \\
\hline \multicolumn{2}{|l|}{} \\
\hline dilaghu $^{1}$ [điláyù] & "fou, folle; malade mental" \\
\hline dilaghu $^{2}$ [đ̊láyù] & "fête, bombance; ..." \\
\hline
\end{tabular}

\begin{tabular}{|l|l|}
\hline dusisu $^{1}$ [dùsísù] & $\begin{array}{l}\text { "ciseaux de tailleur; ciseau de menuisier" (Emprunt au } \\
\text { français ciseau })\end{array}$ \\
\hline dusisu $^{2}$ [dùsísù] & "visage, front" \\
\hline
\end{tabular}

\begin{tabular}{|l|l|}
\hline mukoka $^{1}$ [múk̀̀k̀̀] & "marmite" (Emprunt au français cocotte) \\
\hline mukoka $^{2}$ [múk̀̀k̀̀] & "cocotier" (Emprunt au français coco) \\
\hline
\end{tabular}

\begin{tabular}{|l|l|}
\hline $\begin{array}{l}\text { musuumba } \\
\text { [músùmbò] }\end{array}$ & "nòsû:mb̀̀]/ de clan chez les Baloumbou, Bapounou, Vili, ..." \\
\hline musuumba & \\
\hline
\end{tabular}

\begin{tabular}{|l|l|}
\hline ndogha $^{1}$ [ndóyə̀] & $\begin{array}{l}\text { "homonyme (personne, chose portant le même nom qu'une } \\
\text { autre)" }\end{array}$ \\
\hline ndogha $^{2}$ [ndóyə̀] & $\begin{array}{l}\text { "sauce odika, sauce de chocolat indigène" (Emprunt au } \\
\text { fang ndoc "mangue sauvage") }\end{array}$ \\
\hline
\end{tabular}


Parmi les homographes homophones résultant de l'introduction d'un emprunt, on note la présence d'un seul exemple d'une série d'homogroupes de plus de deux membres:

\begin{tabular}{|l|l|}
\hline mbuungu $^{1}$ [mbû:ngù] & "soin, fait de prendre soin" \\
\hline mbuungu $^{2}$ [mbû:ngù] & "tasse" (Emprunt à l'anglais mug) \\
\hline mbuungu $^{3}$ [mbù:gù̀] & "arête de poisson" \\
\hline
\end{tabular}

Les autres séries d'homogroupes de plus de deux membres ne résultant pas de l'introduction d'un emprunt se présentent comme suit:

\begin{tabular}{|l|l|}
\hline dibula $^{1}$ [dıbúl’̀] & "poche des eaux" \\
\hline dibula $^{2}$ [đıbúlə̀] & "mauvaises paroles; menaces; gloriole" \\
\hline dibula $^{3}$ [dıbúlə̀] & "variété d'arbre" \\
\hline
\end{tabular}

\begin{tabular}{|l|l|}
\hline ibuungu $^{1}$ [ibúiggù] & "carapace, coquille, etc." \\
\hline ibuungu $^{2}$ [1bú:igù] & "repaire de revenants" \\
\hline ibuungu $^{3}$ [1búiggù] & "siège" \\
\hline
\end{tabular}

\begin{tabular}{|c|c|}
\hline ubaanda $^{1}$ [ùbăándò] & "cheviller, clouer" \\
\hline ubaanda $^{2}$ [ùbắnd̀̀] & "commencer, débuter" \\
\hline ubaanda $^{3}$ [ùbắndò] & "maigrir, perdre du poids" \\
\hline
\end{tabular}

\begin{tabular}{|l|l|}
\hline usagha $^{1}$ [ùsâỳ̀] & "mûrir" \\
\hline usagha $^{2}$ [ùsâỳ̀] & "rabattre le poisson dans les filets" \\
\hline usagha $^{3}$ [ùsâỳ̀] & "rincer, remuer un liquide dans la bouche" \\
\hline
\end{tabular}

\section{Du traitement des homonymes et des polysèmes}

S'agissant du traitement de l'homonymie, les dictionnaires procèdent selon deux méthodes. La première méthode est la mise en annexe d'un dictionnaire spécialisé sous forme de listes d'homophones, d'homographes ... (cf. Hausmann 1989: 640). La seconde méthode est le renvoi, à la fin de l'article, aux homonymes. D'un point de vue macro- et microstructurel, les homonymes reçoivent traditionnellement le statut de lemme ainsi que des nombres en exposant quand ils ont une origine différente. On parle en métalexicographie de traitement par dégroupement. Si ce n'est pas le cas, les mots de mêmes graphies avec une signification différente devraient être traités comme des termes $x$ fois polysémiques. Il s'agit ici du traitement unitaire. Dans ce qui suit, je propose des exemples de traitement unitaire (traitement polysémique) versus traitement par dégroupement (traitement homonymique) tels qu'ils apparaissent dans Mavoungou et Plumel (2010).

u-bol-a. Cl. 15. ubola [ùbólà]. Verbe. Voir ibotsi. — 1. Être mouillé, être trempé. Bikutu bitsibola na mvula. L'averse a mouillé le linge. Yoonu, tutsibola na mvula. Hier, on s'est fait mouiller par une averse. Tsusu atsifu na yootsi ibili atsibola na mvula. La poule est morte de froid 
pour s'être fait mouiller par l'averse. 2. Pourrir; tomber en décomposition, être altéré. Mbitsi yina yinabola. Ce poisson est pourri. Bikutu NGOOMBI atsibudama yuutsi mu maamba bikabasigha mbuunga: binabola. Le linge que NGOMBI a laissé à tremper avant-hier dégage une odeur nauséabonde: ça commence à pourrir. NGIIMBI atsisi pweela bilumbu na tsisapaatu o maalu: tsinzala ubola tsikabola. NGUIMBI n'a pas quitté ses chaussures depuis plusieurs jours: ses orteils commencent à pourrir. 3. (fig.) Être serviable, servir ses aînés avec empressement. MBATSHI abola na bakaata. MBATCHI sert ses aînés avec empressement. Note encycl.: En règle générale, les cadets sont au service de leurs aînés. Toutefois, les cadets trop serviables n'arrivent plus à dire non lorsqu'ils ont trop à faire (par exemple, travaux scolaires et loisirs). Dans la sphère scolaire, certains enseignants usent et abusent de la serviabilité des apprenants. Menaane: ubola. Yipunu: ubola. Civili: kubol'.

u-legh-a. Cl. 15. ulegha ${ }^{1}$ [ùléyò]. Verbe. - 1. Jurer (promettre solennellement quelque chose en prêtant serment); invoquer le nom d'un parent en vie ou décédé en cas de mésaventure. Ulegha pesi. Jurer par les siens. Pesi nyumona taata o bibina! Je te jure que je verrai mon père qui est enterré au cimétière! Pesi nyumona maama, mi isadiyaaba! Je te jure sur la tête de ma mère, je n'ai rien fait! Menaane: ulegha. Yipunu: ulegha. Civili: kulef'.

u-legh-a. Cl. 15. ulegha² [ùléyò]. Verbe. Voir ubuligha; ubentsigha. — Se fendre (en parlant de la peau). Ana dunyuru duvalegha. Il a la peau qui se fend. Vho isivhu, mughaanda dunyuru duvaleghaanga, mwa zeeta bavatulaanga. En saison sèche, les plaies sont comme des engelures ou crevasses, il ne faut surtout pas oublier de mettre de la crème. Menaane: urubigha. Yipunu: urubigha. Civili: kulek'.

u-logh-a. Cl. 15. ulogha ${ }^{1}$ [ùlóyə̀]. Verbe. Voir usombugha; udumugha; muyila. - Crier, hurler (de douleur). Bi uvalogha nana? Pourquoi cries-tu ainsi? Batu batsimulogha. On lui a crié dessus. Yemona mwaana avalogha! Mamoosi avaghuulu nzala vho anabola na masuba. $V a$ voir l'enfant qui crie! Peut-être qu'il a faim ou qu'il est mouillé. Mwaana avalogha, avaghuulu nyufu. Mubotula bikutu! L'enfant crie, il a chaud. Découvre-le! Interdit: Il est interdit aux femmes et aux hommes de crier dans la nuit, afin d'éviter le malheur dans la maison. Menaane: ulogha. Yipunu: ulogha. Civili: kulök'.

u-logh-a. Cl. 15. ulogha ${ }^{2}$ [ùlóỳ̀]. Verbe. Voir mulosi. — 1. Jeter un mauvais sort, ensorceler, envoûter. Atsilogha solaami ti iyalaghata. Il a jeté un mauvais sort sur ma plantation afin qu'elle ne brûle pas (agriculture sur brûlis). 2. (par ext.) Maudire (les siens). Atsilogha baana bo. Il a maudit toute sa progéniture. NGIIMBI maambu mootsu nana mutu batsilogha! NGUIMBI se comporte vraiment comme quelqu'un qu'on a maudit! Banalogha baana, basabesi bikoola. Ils ont ensorcelé (= maudire) les enfants, ils n'apprennent plus. Menaane: ulogha. Yipunu: ulogha. Civili: kulok'.

u-ghal-a. Cl. 15. ughala ${ }^{1}$ [ùyál’̀]. Verbe. Voir ughaba. — Nier; renier. Atsighala, ya ti asadituba. Il a nié, il affirme ne pas l'avoir dit. Uyaghala, batu bootsu batsighumona! Ne nie pas, tout le monde t'a vu faire! Mi isaghala dikundu. Je ne nie pas que je suis "vampireux". Upod'ughala vangi uvake ifura nge beeni. Tu peux nier l'évidence, mais tu te mens à toi-même. Maambu mootsu atsighala. Il a nié tout en bloc. KOWU atsighala mwaana nguyi toondu tsimboongu. KOWOU a renié son frère à cause de l'argent. Menaane: ughala. Yipunu: ughala. Civili: kukal'.

u-ghal-a. Cl. 15. ughala ${ }^{2}$ [ùyál’̀]. Verbe. Voir ughoomba. a Ecailler (en parlant du poisson). Yendengalila tsimbitsi! Va m'écailler le poisson! Merye TSHINGOOMBI uyalibana ughala tsimbitsi taata atsinata yoonu! Ecoute TCHINGOMBI, n'oublie pas d'écailler et de vider le poisson que papa a apporté hier! Ana atsisi tsobu nana vho nzila na maamba batsighala tsimbitsi? Tubefu na tsintsi vhavha. Qui a répandu l'eau sale du poisson écaillé si près des habitations? Ça va attirer beaucoup de mouches. Yengala makwaala, tuvaweenda mu uloba! 
Va m'écailler les "makwaala" (esche = appât accroché à l'hameçon), nous allons à la pêche! Menaane: ughala. Yipunu: ughala. Civili: kukömb'.

u-ghal-a. Cl. 15. ughala ${ }^{3}$ [úyálò]. Verbe. Voir ughaba. a Etre dur, durcir. Yevhara maani unaa, avha butoghu bughala! Va planter le maïs là-bas, ici le sol est dur! Usigha dibulu di kabini vho mangala mbot'isalu: butoghu bughala. Il est difficile de creuser des latrines en saison sèche: la terre est dure. Bweela umasi birika vho yilu, sima yikitsighala! Ajoute quelques rangées de briques sur ce mur avant que le ciment ne soit dur! Dimani dina dighala nana butali. Ce rocher est dur comme l'acier. Bavatulaanga biima bavabuumba na butoghu vho mbaatsu kabighala. Les poteries en terre sont durcies par le feu. (Fig. fam.) DUNGUUTU aghale, ana matumuna. DOUNGOUTOU est un dur à cuire, il provoque les gens par la parole. Menaane: ughala. Yipunu: ughala. Civili: kukal'.

ma-anga. Cl. 6. maanga ${ }^{1}$ [máingə̀]. Nom. - Palmier acaule (Sclerosperma manii) croissant en touffes compactes dans les forêts marécageuses. Yileembi yi dibaantsi bavaruunga na maanga. Les branches du palmier acaule servent de tuiles végétales pour l'auvent des corps de garde. Vho mboghu mamosi bavakubighaanga tsintsubu na maghayi ma maanga. Dans les campements, les feuilles du palmier acaule servent souvent à couvrir les huttes de branchage et d'écorces d'arbre. Menaane: maanga. Yipunu: maanga. Civili: mäng'.

ma-anga. Cl. 6. maanga ${ }^{2}$ [máning̀̀]. Nom. — Divination (pendant les veillées initiatiques), visions initiatiques. Ngaanga anatubula maanga. Le devin-guérisseur a révélé la divination. Bo batsyereesi, botunata maanga. Ceux qui sont allés chez le devin-guérisseur vont nous apporter le résultat de la consultation. utubula maanga. (Chez le devin-guérisseur) Révéler la divination. Menaane: maanga. Yipunu: maanga. Civili: mäng'.

ma-anga. Cl. 6. maanga ${ }^{3}$ [má́:ngə̀]. Nom. - Lamantin (Trichechus senegalensis). Maanga mbitsi iboti. Les villageois sont très friands de la viande de lamantin. Bavaboka maanga na nyobu. On tue le lamantin au harpon. Menaane: maanga. Yipunu: maanga. Civili: mäng'.

N-bota. Cl. 15. mbota [mbótว̀]. (Au pluriel) tsimbota. Nom. a 1. Étoile. Mwaana ghuna atsibura na mbotaandi iboti. Cet enfant est né sous une bonne étoile. Bavatuba ti MALOONDA atsiboonga mbota baana ba Kuumba mu uvha baana baandi kabsi bikoola bineni. On raconte que MALONDA aurait pris l'étoile des enfants de Koumba pour le donner aux siens afin qu'ils fassent de grandes études. 2. Milletia (Milletia versicolor). Arbuste de brousse ou petit arbre de forêt généralement buissonnant. Mbota avabugha pweela misoongu! Le milletia soigne nombre de maladies! Bavasiila yifulu na maghayi ma mbota. Les feuilles de milletia sont utilisées dans les bains de vapeur. Usages: Cette essence est fréquemment plantée dans les villages de l'intérieur. Le bois très résistant sert à faire des poteaux de cases et des clôtures. Planté en terre ou simplement couché sur le sol, il repousse rapidement. Le bois est susceptible d'être tourné: il se polit facilement. On en fait aussi des charpentes et des planches (usages cités par Raponda-Walker et Sillans, 1961: 256). Menaane: mbota/mbota; mbwelele. Yipunu: mbota/bambota; mbwelili. Civili: mbot'/simbot'.

u-loong-a. Cl. 15. uloonga ${ }^{1}$ [ùlóngng̀̀]. Verbe. Voir ulongila. a Charger; arranger. Uloonga biima mu poonzi. Charger les affaires dans le panier. Yemuloonga mufuna o mbusa! Aide-la à mettre en place sa charge sur le dos! Menaane: uloonga. Yipunu: uloonga. Civili: kulöng'.

u-loong-a. Cl. 15. uloonga ${ }^{2}$ [ùlóngỳ̀]. Verbe. SYN usina; umonisi. — 1. Porter conseil, conseiller. Uloonga mutu. Conseiller quelqu'un. Nguyi avaloonga mwanaandi mughetu ti afwaana ulutsi diisu. La mère conseille à sa fille d'être prudente. 2. Enseigner. Moniteera avaloonga baana ba yikoola. Le maître enseigne aux écoliers. 3. Indiquer, montrer (le chemin). Ndoongi nzila! Indique-moi le chemin! Maama ndoongi bukulu! "Maman" (oncle maternel) indique-moi ma généalogie! Menaane: uloonga. Yipunu: uloonga. Civili: kulöng'. 
u-luung-a. Cl. 15. uluunga ${ }^{1}$ [ùlúingè]. Verbe. Voir mbaatsu. a Allumer (du feu). Batsibo tsikuni, utabula, uluunga mbaatsu. Ils prirent le bois, le cassèrent, allumèrent du feu (cf. Blanchon, 1984: 12-13). Vho meni, BUSAAMBA atsivhotsi maghala mu uluunga mbaatsu. Ce matin, BOUSSAMBA a ravivé le feu en soufflant sur les braises. Dibindi bavamuluunga mbaatsu. Le croton donne un bon charbon de bois. Menaane: ubaanza. Yipunu: ubaanza. Civili: kulüng'.

u-luung-a. Cl. 15. uluunga ${ }^{2}$ [ùlúingə̀). Verbe. Voir mbaatsu. a 1. Attendre. Nduunga, ivawiitsa! Attends-moi, j'arrive! Atsyeluunga mwaana nguyi o mwiila maamba. Il est allé attendre sa sœu à la rivière (il l'a accompagné). Ufwaana uluunga yaaghu dituura, mu uvhyoogha. Vous devez attendre votre tour pour passer. A ya mi valuunga! C'est lui que j'attends! Yenduunga o meesu! Va m'attendre plus loin! MANGOLU, mwaana mubi: asaluunga koomba ke banabasigha o yikoola. MANGOLO est un mauvais garçon: il n'attend jamais son cadet à la sortie des classes. Tuvaluunga yisivhu mu uweenda o Duumfu. Nous attendrons la saison sèche pour partir à Doumfou. 2. (par ext.) Garder, prendre soin s'occuper de; conserver. Atsyemuluunga na buboti. Il s'est bien occupé de lui. Luunga baana na buboti! Prend bien soin des enfants! MOOMBU avaluunga baana ba MUVAANGI na bungeela! MOMBO prend bien soin des enfants de MOUVANGUI! MAYIINZA avafuta mughetu mu uluunga baana baandi ke ali o bisalu. MAYINTSA a engagé une nounou qui s'occupe de ses enfants lorsqu'elle se rend à son lieu de travail. Menaane: uluunga. Yipunu: ukeela ou uvhivha. Civili: kulüng'.

i-tali. Cl. 7/8. itali ${ }^{1}$ [ítàlì]. (Aussi yitali). (Au pluriel) bitali. Nom. Voir yitali. a La hache. Itali yi MUSAAVHU. La hache de MOUSSAVOU. Menaane: yighuba/bighuba. Yipunu: dyuumbi/muumbi. Civili: tshitali/bitali.

i-tali. Cl. 7/8. itali ${ }^{2}$ [ìtàlì]. (Aussi yitali). (Au pluriel) bitali. Nom. Voir yileemba. a Variété de poisson disque. Menaane: itali. Yipunu: itali (E). Civili: tshitali/bitali.

i-tali. Cl. 7/8. itali ${ }^{3}$ [ítàlì/itàlò]. (Aussi itala). (Au pluriel) bitali. Nom. Voir ibanga. — 1. Endroit surélevé, colline; montagne. Itala mamani. Colline de pierres. 2. (par ext.) Claie au-dessus d'un feu où des denrées sont exposées à la fumée en vue de leur conservation, fumoir. Munginda itali. La suie du fumoir. * Nom de village (toponyme). ITALA bwaala bu TAATI. Le village de TATY c'est ITALA. Menaane: itali. Yipunu: itali (E). Civili: tshitali/bitali.

N-boolu. Cl. 9/10. mboolu [mbó:lù/mbó:là]. (Aussi mboola). (Au pluriel) tsimboolu. Nom. a 1. Sac de sel de traite; sel d'importation. 2. (par analogie de forme) Biscuit, biscotte consommé autrefois par les Baloumbou et les Vili. Mboolu tsisakya, tsitsyemugha kala. Les biscuits appelés "mbolou" ne sont plus commercialisés. Mboolu tsibanga tsivhembugha. Les biscuits appelés "mbolou" étaient de couleur blanche. Menaane: mboolu/mboolu. Yipunu: mboolu/ bamboolu. Civili: mbölu/simbölu.

$\phi$-pili. Cl. 9/10. pili ${ }^{1}$ [pili]. (Au pluriel) tsipili. Nom. a 1. La vipère du Gabon (Bitis gabonica) et la vipère rhinocéros ou vipère cornue (Bitis nasicornis). Batsiboka pili. Ils ont tué une vipère. Mwangala pili. Le venin de vipère. Kaki avateba maki ma pili. Selon une croyance populaire, la foudre ferait éclore les oufs de vipère. 2. (par fig. méton.) Rancune; différent, problème, histoire. Yetu ba naaghu tuna pilye? Quel est le problème entre nous? Pili bi iwuma be yina! Quelles est cette histoire! Prov.: Pili yaanti: mye iliba, mye iliba, mye kaanda. La vipère mord quand on lui marche dessus (Litt.: "Le premier et le deuxième ça passe, au troisième tu te fais mordre"). Interdit: Il est interdit à la femme de consommer la chair de la vipère cornue (car il s'agit d'une viande réservée aux hommes). Pour les femmes enceintes en particulier, la chair de la vipère leur est interdite car le bébé risque d'avoir la peau du reptile. Pour rire: La coloration de la vipère du Gabon la rend quasiment « invisible » lorsqu'elle est tapie dans la litière de la forêt. Quand tu es dans une file en brousse, il ne faut pas être le premier ni le troisième. En effet, si tu es premier, tu marches sur un serpent, si c'est un 
moudouma, il te mord. Si tu es deuxième et que tu marches sur une vipère, tu ne seras pas mordu. Mais si tu es troisième, la vipère te mord. Elle dit: "deux c'est assez". Menaane: pili/ pili. Yipunu: pili/bapili. Civili: mpili/simpili.

$\phi$-pili. Cl. 9. pili ${ }^{2}$ [pìì]. Nom. Voir nduundu. - Soif (désir de boire). Pili maamba avaboka. La soif est mortelle. Dusana maamba vhana, ina pili maamba? N'avez-vous pas un peu d'eau, j'ai soif? Mwaana apasiba na pili maamba, muvhe maamba mali mu biberu vho yilu meetsa. $S i$ l'enfant ressent le désir de boire, il faudra lui donner l'eau qui se trouve dans le biberon posé sur la table. A! Nyufu ma, ika na pili maamba! Oh ma mère quelle chaleur, j'ai la gorge desséchée! Menaane: pili. Yipunu: pili. Civili: pili.

\section{Références}

Blanchon, J.A. 1984. Présentation du Yi-lumbu dans ses rapports avec le Yi-punu et le Ci-vili à travers un conte traditionnel. Pholia: Revue du Laboratoire de Phonétique et Linguistique Africaine 1: 7-35.

Grevisse, M. 1986. Le bon usage: grammaire français avec des remarques sur le langage français d'aujourd'hui. Gembloux: Ducolot.

Guthrie, M. 1953. The Bantu Languages of Western Equatorial Africa. Oxford: Oxford University Press.

Hausmann, F.J. 1989. Les homonyms et les paronymes dans les dictionnaires monolingues. Hausmann, F. J., O. Reichmann, H.E. Wiegand et L. Zgusta. (Éds.). 1989-1991. Wörterbücher. Ein internationales Handbuch zur Lexikographie/Dictionaries. An International Encyclopedia of Lexicography/Dictionnaires. Encyclopédie Internationale de Lexicographie: 640-641. Berlin: Walter de Gruyter.

Mavoungou, P.A. 2002. Metalexicographical Criteria for the Compilation of a Trilingual Dictionary: YilumbuEnglish-French. Thèse de doctorat non-publiée. Stellenbosch: Université de Stellenbosch.

Mavoungou, P.A. 2005. Loanwords in Yilumbu: A Morphological, Semantic and Lexicographic Perspective. South African Journal of African Languages 25(4): 258-272.

Mavoungou, P.A. 2010. A Dictionary Plan of Yilumbu: Metalexicographical Criteria for the Compilation of a Trilingual Dictionary Yilumbu-English-French. Saarbrücken: VDM Verlag.

Mavoungou, P.A. et B. Plumel. 2010. Dictionnaire Yilumbu-Français. Libreville: Les Éditions Raponda Walker.

Raponda-Walker, A. et R. Sillans. 1961. Les plantes utiles du Gabon: essai d'inventaire et de concordance des noms vernaculaires et scientifiques des plantes spontanées et introduits du Gabon. Paris: Lechevalier.

Rey-Debove, J. 1971. Étude linguistique et sémiotique des dictionnaires français contemporains. La Haye: Mouton.

Surridge, M.E. 1994. Différenciation systématique des homophones nominaux non-homonymes en français. Cahiers de lexicologie 64(1): 155-175. 


\title{
LSP Lexicography in the Academic Discourse
}

\author{
Guy-Roger Mihindou, Academic Development and Support, \\ University of Johannesburg, Kingsway Campus, Auckland Park, \\ Johannesburg, South Africa (gmihindou@uj.ac.za)
}

\begin{abstract}
The first dictionaries ever compiled were specialised dictionaries intended to facilitate the comprehension of language for religious purposes. The practice of the compilation of dictionaries of language for special/specific purposes (LSP) constitutes just one aspect of the domain of lexicography as an academic discipline. However, many scholars are still unfamiliar with the status of lexicography as an academic discipline and continue to view it as an applied domain under wellknown disciplines such as linguistics and information technology.

It is therefore important to specify the lexicographic concepts, which have been borrowed from other linguistic and non-linguistic fields, and to note the modifications, which they have undergone within the framework of lexicographic description. In this contribution, the theory and the practice of LSP lexicography are presented and discussed in a contextualised manner, with special attention to a Multilingual Medical Terminology Dictionary Project (MMTDP) as an example of an LSP dictionary.
\end{abstract}

Keywords: LEXICOGRAPHY, LSP, LEXICOGRAPHIC THEORY, SPECIALISED DICTIONARIES, LANGUAGE, ACADEMIC DISCOURSE, SCIENTIFIC DISCIPLINE, LINGUISTICS, SPECIALISED TERM

Opsomming: TSD-leksikografie in die akademiese diskoers. Die eerste woordeboeke wat ooit saamgestel is, was gespesialiseerde woordeboeke bedoel om die verstaan van taal vir godsdienstige doeleindes te vergemaklik. Die praktyk van die samestelling van woordeboeke van taal vir spesiale/spesifieke doeleindes (TSD) maak slegs een aspek uit van die gebied van die leksikografie as 'n akademiese studievak. Baie vakkundiges is egter nog onvertroud met die status van die leksikografie as 'n akademiese studievak en gaan voort om dit te sien as 'n toegepaste vakgebied tussen welbekende studievakke soos die linguistiek en informasietegnologie.

Dit is dus belangrik om die leksikografiese konsepte te spesifiseer wat geleen is van ander linguistiese en nielinguistiese gebiede, en kennis te neem van die aanpassings wat hulle ondergaan het binne die raamwerk van leksikografiese beskrywing. In hierdie bydrae word die teorie en praktyk van TSD-leksikografie op 'n gekontekstualiseerde manier aangebied en bespreek, met spesiale aandag aan 'n Meertalige Mediese Terminologiewoordeboekprojek (MMTWP) as 'n voorbeeld van 'n TSD-woordeboek.

Sleutelwoorde: LEKSIKOGRAFIE, TSD, LEKSIKOGRAFIESE TEORIE, GESPESIALISEERDE WOORDEBOEKE, TAAL, AKADEMIESE DISKOERS, WETENSKAPLIKE DISSIPLINE, LINGUISTIEK, GESPESIALISEERDE TERM 


\section{Introduction}

The discipline known nowadays as lexicography started some five thousand years ago with the compilation of specialised dictionaries and encyclopaedic works intended to facilitate the comprehension of language for religious purposes. The practice of the compilation of language for special/specific purposes (LSP) dictionaries constitutes just one aspect or branch of lexicography as an academic discipline.

Tarp (2010: 451) in an extensive exposé positioned the deep-rooted dispute as to the academic status of lexicography by pointing out two major divisions or camps: the first considers lexicography as an independent scientific discipline, while the second denies lexicography any scientific status, let alone being independent. Tarp presents some subdivisions within the two major camps. The first camp is comprised of the "functionalists" at the Centre for Lexicography in Aarhus, Denmark and the "generalists" represented by the German scholar H.E. Wiegand. The second camp is subdivided into three categories, that is, (1) those who absolutely deny any scientificity to lexicography, (2) those who entertain the idea of lexicographic theory, but refute the independence of lexicography, and (3) those who advocate practical lexicographic work that would need guidance from linguistics.

Without going into details, I would like to establish that this contribution should be viewed as closer to the first division that acknowledges lexicography as an independent and scientific discipline. However, I shall take into consideration the points of view expressed by both camps. In so doing the works of scholars representing both camps will be examined, and lastly, an example of an LSP project will be put forward.

\section{The status of lexicography}

Many scholars within lexicographic circles are unfamiliar with the academic status of the discipline per se. Some still view lexicography as part of general linguistics, or a subdiscipline of information technology. This article argues that the metalexicographical discourse as proposed by Wiegand (1984) on the 'scientificity' of lexicography needs to be contextualised in order to establish a distinctive approach to the object, the method and the content of the discipline. It is also important to specify the concepts, which have been borrowed from other linguistic and non-linguistic fields and note the modifications, which these notions have undergone within the framework of lexicographic description.

Tarp (2010: 457) affirms that no one denies the impressive contribution made by linguists to many excellent dictionaries compiled in the past. However, he refutes the assertion made by Atkins (1992: 5) that "a large proportion of the decisions made by the lexicographer are linguistic decisions". The appropriation of lexicography by linguistics is an exaggeration that does not 
take cognisance of the historical development of lexicography. Tarp (2010) states:

The world has known quite a number of dictionaries and other lexicographical works for the production of which no specialised knowledge of linguistic theory was needed or used. This fact alone indicates that lexicography in general cannot be scientifically categorised as applied linguistics or a sub-discipline of linguistics, and it also makes it pointless to claim that "a new theory of lexicography" should be based on knowledge about pragmatics, discourse, text structure, etc. as claimed by Piotrowski (2009).

Tarp therefore suggests approaching the status of lexicography differently and thinks of two alternative ways. The first one would be to consider lexicography as an ipso-facto subdiscipline of a large number of disciplines of which one is linguistics. The second way is to view lexicography as an autonomous discipline with its own subject field.

With regard to lexicographic practice, Wiegand (1984) explains in his theory what lexicography is not: a science, a craft, part of linguistics, or applied lexicology. Rather, it is: a calculable, analysable, checkable, manageable, testable and teachable practical process aimed at producing dictionaries to satisfy the reference needs of their users (Hartmann 1999: 156). The users' needs, central to lexicographic work, determine the quality of the data, influencing the process of the making and the typology of a given dictionary as well as its full contents. Lexicography of language for specific purposes (LSP) therefore caters mainly for special and restricted target users.

To undertake an academic discourse pertaining to a research field such as lexicography, one should always bear in mind that in essence lexicography presents both practical and theoretical components. In the present case, the metalexicographical theory of Wiegand needs to be modelled and adjusted to the purpose of an LSP dictionary. This implies that the lexicographer should already have a certain type or category of users in mind.

According to Burkhanov (1998: 7), the names of Hausmann, Reichmann, Wiegand and Zgusta cannot be separated from the development of lexicography, especially after the publication of Dictionaries. An International Encyclopaedia of Lexicography. This was an important landmark and a turning-point in the development of this subject field. For him it is most important to specify the concepts and standardise the terminology of metalexicography, i.e. it is not so much about defining lexicographic terminology, but about formulating the basic notions of the field, and then considering the terminological lexical items which seem to be the most appropriate to denote certain concepts.

Burkhanov believes in providing enough information about the basic lexicographic categories in such a way that these publications could be efficiently used as tools in the training of future lexicographers. This is what Wiegand's theory emphatically seems to convey. Smit (1996, 2001 and 2002) presents Wiegand's theory in its essential points along with lexicographic history. Wiegand 
(1996 and 1998) alleges that lexicography as scientific discipline poses its own terminology called "language lexicography" with its proper domain or metadomain known as "special-field lexicography". According to Smit's (2001: 299) translation, Wiegand (1998: 62) expresses his thoughts on terminology as follows:

Language lexicography can either be a self-taught, non-scientific cultural practice, or an independent cultural and scientific practice, consisting of a more or less clearly demarcated self-reflecting component, which can only be mastered, because of its multilayered comprehensiveness, by academically trained staff. ... It forms the central part of the pre-theoretical empirical subject domain out of which the various scientific objects for the different research fields of dictionary research can be extrapolated.

\section{Trends in LSP Lexicography}

There is a trend among scholars such as Pérez Hernández (2002, ch. 3.3 "Terminografia y Lexicografia", translated and cited by Bergenholtz and Tarp 2010: 27) to establish a systematic correspondence between lexicology and lexicography on the one hand, and terminology and terminography on the other hand. If carefully examined, this trend implies that lexicography is for lexicology what terminography is for terminology. In other words, lexicology as the study of the lexicon of a given language is seen as the theory, whereas lexicography, as the study, focusing on the compilation of dictionaries and encyclopaedias, becomes the domain of the applicability of lexicology. In accordance with the same reasoning, terminology would describe "specialised languages" theoretically, while terminography would cater for specialised dictionaries.

It seems that these distinctions between lexicology, terminology, specialised lexicography, and terminography are based on shaky grounds where boundaries are sometimes unclear and theoretical domains often uncertain. As experienced LSP lexicographers, Bergenholtz and Tarp (2010) give their views on a perceived dichotomy between LSP lexicography, also known as specialised lexicography, and terminography. For them there is no need to establish any distinction or dividing line between LSP lexicography and terminography.

They hold the view that there is no real "lexicographical point of view" as far as terminography is concerned, since "the majority of scholars dealing with lexicography fully agree with the majority of terminographers". Thus, in the light of Bergenholtz and Tarp's opinion, one may safely state that specialised lexicography or LSP lexicography and terminography are just different sides of the same coin.

Although one should also keep in mind that the degree of agreement among metalexicographers may present a strong indication of scientific activities upon which they are advancing a particular perspective or expertise, it does however not prevent some divergences between two related disciplines. More often than not the stronger the divergences, the deeper the separation may develop between two fields. 
Much effort has been dedicated to setting up a particular "scientific jargon" and to which extent a "term" should differ from a "word" or a "lexical item". L'Homme et al. (2003) reckons that this trend of demarcation between fields is fruitless nowadays. Even the work on "determinolization" by Meyer and Macintosh (2002) has established that the dividing line between terms and words is blurred, despite the usage of frequency and statistical methods. For Kageura (2002) too, the distinction remains unclear.

According to Fuertes-Olivera (2005: 41), LSP or language for special/specific purposes has been established as a generic term destined for "communication among specialists". It suggests two distinctive tendencies:

1. LPS as a branch of scientific knowledge that displays successfully the need for special training in a specific field.

2. LSP as means through which specialised texts and material production are categorised and/or diversified.

The first tendency typically underlines the need to identify both the purpose of the intended work and the target users for whom an LSP is designed. There is also a need to differentiate LSP from LGP (language for general purposes). Hence the necessity for special training that systematically leads to a categorisation of professionals or academics, at whom the training is aimed: the specialists (experts), would-be specialists (semi-specialists) and the informed laypersons (non-specialists).

The second tendency opens the way in which content material should be processed. One of the major contributions of LSP lexicography is that it stands at the crossroads of many fields/disciplines. As such, it advocates for in-depth interdisciplinary studies. Some scholars view LSP as referring to the applied linguistic discipline, with two focus points: the first a needs-based educational/ training focus, and the second research on language variation across a particular subject field (Wikipedia 2010).

Tarp (2002: 8) argues that even if some people see a relation between linguistics and lexicography, both disciplines are complementary in their object, but differ in the domains of application.

\section{Example of a dictionary project}

The example of a Multilingual Medical Terminology Dictionary Project (MMTDP) may be used as illustration.

The purpose of such a study is to compile a theoretical model for a dictionary of medical terminology that suits both specialists and non-specialists, including laypersons, as target users. The main aim and the nature of this kind of dictionary project are to present a study in which data should be compiled from the point of view of a special or specialised field, in this case, medicine. This comprises that lexicographers will deal with a special vocabulary and a 
special language, according to the purposes of the text, based on the user's needs. Moreover, the classification of this kind of reference work fits in with the so-called language for specific purposes dictionaries (LSPD) with an accent on two distinct forms of medicine: Western and African medicine, further subdivided into modern and traditional medicine. Thus, the term explanatory dictionary is introduced to designate linguistic dictionaries that provide explanations of the lexical meaning of lemmata and sometimes valence in their definitions irrespective of the number of languages involved. This distinction enables the metalexicographer to differentiate monolingual and pluriligual reference works (Burkhanov 1998: 83).

Users expect to retrieve information from dictionaries. Definitions constitute one of the useful tools in a dictionary article to efficiently satisfy the readers' needs for an explanation of meaning. In bilingual dictionaries, for instance, the translation equivalent plays a significant role in the treatment of lexical items. In classical multilingual dictionaries, however, the explanation in terms of definitions is not often expected and also not supposed to be included in the dictionary. But the specificity of such a dictionary project, the MMTDP, requires that it can accommodate terminology of three different languages and cultures. In this case, certain terms from traditional medicine may even need some additional explanations for better understanding, since the concepts may not exist in Western medicine. A controversial lexical item such as witch doctor needs a thorough explanation to avoid unnecessary confusion with, for example, herbalist, also called traditional therapist. For this reason, and the fact the MMTDP allows for both experts and semi-experts, including informed laypersons as target users in one dictionary, the typology of this kind of dictionary is and should be hybrid.

The nature of the explanations in this dictionary will focus on the first meaning of lexical items, that is, denotation, which will have a cultural interest satisfying traditional healers. The particularity of this dictionary is also the equal treatment of the data presenting Western culture and African culture. In this regard two lexicographic notions need to be considered: specialised vocabulary and terminology.

\section{Specialised vocabulary}

A specialised vocabulary is needed because the proposed dictionary will contain specific data in which specialised terms pertaining to the medicinal and healing arena will predominantly be used. Moreover the medical jargon contained in the proposed dictionary is indeed meant for a specialised target group of people familiar with this type of vocabulary.

In lexicography, the distinction between some dictionaries containing data used for general purposes and dictionaries presenting data for special purposes, leads to classifying the MMTDP in the category of dictionaries displaying language for special purposes, with particular attention to the expressions 
and linguistic usages pertaining to the language of medical activities. As a result, compiling a dictionary of medical terms of such a nature is also dealing with specialised lexicographic issues.

\section{Terminology}

Terminology is often defined as an interdisciplinary subject field concerned with activities intended at the systematisation and representation of scientific, technical, and other kinds of expert concepts (Burkhanov 1998: 241). Medical terminology consists of terms or words that are related to medical science. Such words describe the human body, its functions, its normal state, its abnormal state, the diseases and injuries that affect it, and the various means, agents, and procedures employed to prevent, minimise, or cure the effects of disease or injury (Brady 1970).

When one projects the compilation of a lexicographic work such as the MMTDP, one must bear in mind that the terminology has to play a key role in the involvement of specialists and experts to give the proposed dictionary a certain weight and scientific consistency. Smit (2001: 300), quoting Wiegand (1998: 248-256), states regarding the discussion of scientific lexicography and its relationship to other academic disciplines: "It is clear that greater lexicographical projects can nowadays only be undertaken in teams, in most cases also involving experts from other disciplines."

Terminology will be used not only as a tool for medical purposes but also for the understanding of lexicographic mechanisms. These mechanisms are important for the compilation process of the dictionary and the communication between the lexicographer and the user by means of the data.

\section{Remark}

The initiative around a dictionary project such as the MMTDP deserves a sound lexicographic knowledge in order to properly negotiate the issues surrounding the theory and the techniques of dictionary compilation. The understanding of these issues is important for both the compilers, and the clarity of the dictionary planning. The compilation of the dictionary or the dictionary plan encompasses certain considerations that should not be shrouded from reality.

If the kind of self-renaissance among traditional healers to gather themselves under one association of traditional healers is considered, the intention behind such an LSP dictionary is to harmonise and standardise their work, and to propose a different approach to Western medicine. In fact, the objective is to achieve cooperation between the Western and African systems of medicine, and to find a platform in terms of terminology. 
From the example of the MMTDP, one may notice that three distinctive and different fields or academic disciplines are involved in one single dictionary project:

\section{Linguistics, by giving a multilingual dimension to the dictionary project}

By nature the MMDTP should be more concerned about the correctness of the language in order to satisfy its target users, i.e. medical and medicinal experts. It should also concern itself with the use of appropriate words in the correct cotext and context. As conceded by Prinsloo and Gouws (2000: 139), dictionaries should primarily be directed at the communicative needs of the members of the relevant communities and should endeavour to equip the target users with the necessary communicative skills to function successfully in a multilingual and multicultural environment.

Moreover, this work has to be linguistically based and should provide all relevant phonological and morphological diacritics. Dealing with African linguistic realities, for instance, one should always keep in mind that tones are extensively used in the context of natural communication, and the text is conceptualised in such a way that the African language would appear more alive and dynamic than when the tones are ignored. The lexicographer has the liberty to make use of all, or some of the material collected by linguists in order to achieve the genuine purpose of the dictionary: the compilation of a dictionary that successfully meets the needs of the target user of the said dictionary.

\section{Medicine, by means of a medical terminological approach to the dic- tionary project}

This part of the work is likely to influence the lexicographer's decision on the choice and the content of the corpora. Because it deals with a specific field of knowledge, priority will be given to any corpus containing items related to the medical domain. In this sense, the lexicographer needs to be selective in his/her approach.

In the history of mankind, healing has always played an important role. It, together with medicine, seems to be a powerful tool for communities' development. Porter (1997: 7) acknowledges that medicine is moving from strength to strength. Indeed, from the first antibiotics and the first heart transplant to the first test-tube baby, medical science and clinical practice are literally "performing miracles". As a result the life expectancy of people is increasing, especially in Western countries. It should, however, be remembered that besides these miracles of so-called Western medicines, other forms of healing exist as Porter (1997: 7) stresses:

Only the blindest and most bigoted high-tech doctors would now claim that all these traditions have nothing to teach western physicians and western patients. 
Ordinary people have been finding out for themselves, flocking in increasing numbers to practitioners of acupuncture, shiatsu and Zen alongside more western alternative therapies like aromatherapy, Alexander technique, homeopathy, iridology and herbalism.

The proposed dictionary is part of the acknowledgement of terminology from the last mentioned category of healing, herbalism, which predominantly prevails in Africa. Some researchers prefer the terminology of traditional medicine. However, certain medical terms need to be standardised for the purpose of a better understanding in this realm of healing. Hence, translation equivalents between Western and African concepts will make it easier to understand the input of Africa regarding medicine. This will make this dictionary more pertinent and successful.

\section{Anthropological contributions drawn from African medicinal perspec- tives of medicine}

The compilers of the proposed dictionary will not only focus on anthropological considerations but sociolinguistic issues will also be regarded. Introducing notions such as world-view, medical societies and beliefs, as well as integrating parallel healing perspectives, cultural interpretations of diseases, the histories of both traditional African and modern Western medicine will contribute to enhancing the dictionary definitions and presenting a better understanding of the cultures involved in the dictionary plan.

Contributions from scientific specialists such as botanists, ethnobotanists and bioprospectors show the necessity of a genuine partnership in the traditional healing arena as well as the input of traditional therapeutists in modern medicine. It also represents how far the collaboration between modern and traditional medicine has advanced.

An ethnobotanist, for example, works with local people to teach them about the local plants and their medicinal uses. Traditional therapeutists possess knowledge of botanical cures for almost any ailment. However, the ethnobotanist who does not speak the local language needs help in gaining knowledge from and transferring knowledge to the local people. He/She will need to work with a translator if he/she does not speak the language. He/She then needs to negotiate with the local government to secure the cooperation and the permission of the local people to work in the area. The ethnobotanist will then take samples of plants, which the natives will identify as a cure or medication for some or other pain or illness. The ethnobotanist will determine the plants and the chemical composition of the medicine, and check whether they contain pharmaceutical components such as drugs as ingredients.

Bioprospecting (also called biodiversity prospecting), on the other hand, is a pronounced application of what ethnobotanists do. Often working with a drug company to extract natural substances that may form the basis of new pharmaceutical drugs, the bioprospector explores the medicinal and nutritional 
uses not only of local plants in a given area but of microbes and marine organisms as well.

From this example alone, LSP lexicography is shown to be a cross-fields cooperation of three different academic disciplines in which linguistics plays an important role alongside others with which they not necessarily have anything in common. From this angle the question is whether LSP lexicography is a hybrid discipline, for it borrows concepts from various study fields. As mentioned earlier, lexicography did not emerge ex nihilo, it took its form from linguistic works, this trend being reinforced by early lexicographic works, as Gouws and Prinsloo (2005: 3) explain:

Since 1971 varying degrees of proximity has prevailed between lexicography and linguistics with different theories and schools of thought in linguistics having a lesser or a bigger influence on both lexicographic theory and lexicographic practice. Different linguistic theories, cf. Geeraerts (1984; 1986) and Gouws (1989), had an influence on e.g. the explanation of meaning in monolingual dictionaries. Different approaches to lexical semantics, the way in which the influence of structural linguistics led to a distinction between semantic and encyclopaedic data and the much more lenient approach following from cognitive linguistics had an impact on the contents of the lexicographic definition.

According to Gouws and Prinsloo (2005: 4), in the nineteen-seventies and -eighties theoretical lexicography was performed and studied largely within a linguistic context. A significant number of publications in the field of metalexicography focused on linguistic aspects of dictionaries as the result of many leading scholars in metalexicography being linguists by training and attached to university departments of linguistics or languages.

Coming back to the question of whether lexicography is a hybrid discipline, the answer will definitely be negative, for it has its own object, dictionary research, and its own field, metalexicography. Moreover, lexicography is not the first and will not be the last discipline that borrows from other domains of academic reflection. Conversely, one may observe a certain degree of apparent hybrid character within LSP lexicography. The apparent hybridity may result from two aspects: apparent hybridity from an external point of view and apparent hybridity from an internal perspective. The latter emphasises the ambivalent nature of lexicography, whereas the former points toward lexicographic origins.

\section{Internal apparent hybridity owing to its nature}

By nature lexicography is twofold: a theoretical component and a practical component. It is stressed in Gouws and Prinsloo (2005: 1) that the theoretical component focuses on research regarding e.g. the form, contents and functions of dictionaries whereas the practical component leads to the compilation of dictionaries. This double nature of lexicography often gives the impression of a discipline having its object well defined and presenting a clearly distinguished 
theoretical method and terminology, but encompassing within the same term, lexicography, the theory and its practical domain of application. Thus the distinction is made between the practical lexicographer as an agent of dictionary compilation and the metalexicographer as scientific theorist of lexicographic praxis (discourse).

\section{External apparent hybridity owing to its origins}

The other hybridity may be observed from an external viewpoint.

The scientific discourse of the time was more favourable to the study of language approaches and linguistic epistemology; hence philology, grammar, and lexicology just to mention these three disciplines, were already established and well documented. It is not surprising that lexicography in its beginning, and the circumstances surrounding its development created a fertile ground for most scholars and specialists of dictionary compilation, producing lexicographic works in which abundant language treatment is noticeable. Thus Zgusta (1988: vi) says that lexicography is one of the few areas in which linguistic activity has an immediate impact on many people.

\section{Technical considerations of LSP dictionaries and the training of lexi- cographers}

Gläser (2000: 87) raises the question to what extent a specialised dictionary should reflect the social stratification of a LSP so that it also includes words and phrases from the lower stylistic levels (students or informed laypersons).

According to Gläser, the answer to this question depends on a variety of alternatives the lexicographer has to consider. The options are, for example, whether technical vocabulary is limited to terminology and nomenclature as lexical items of written communication that have a clear-cut meaning and are stylistically neutral, or whether technical vocabulary is extended to words and phrases of spoken discourse, in which they occur as professional jargon and occupational slang as popular names for items of nomenclature and also as trade names. Furthermore, it will be fair to ask whether a word from Yipunu, an African language from Central Africa, that does not have any equivalent in modern medicine can be retained as a technical lexical item.

Gläser, who is in favour of the idea of including technical jargon and slang in order to ease the work of translators, interpreters and other users, assesses the factors that may influence the LSPD:

1. The composition of word-stock in a particular domain;

2. The intention of the LSP dictionary: whether it will describe and explain current usage or prescribe and stipulate preferable vocabulary; 
3. The target group of the prospective dictionary users, which may range from specialists on a high theoretical, academic level to technicians, laboratory staff, factory workers and people in the broadest sense of the applied field;

4. The level of abstraction (and cognition) which determines the meaning of technical terms;

5. The degree of the communicative partner's expertise; and

6. The character of work done by those people who work in a special domain, ranging from research and development, to designing and planning and finally to the sphere of production and distribution.

\section{Training of lexicographers}

Lexicography is known as an academic discipline, taught at university level. Gouws (2001: 61) affirms that lexicography is also a specialised career in which people need to be trained to perform the duties of lexicographers. It will therefore be of no use to embark on the compilation of an LSP dictionary without having a fundamental lexicographic training. Gouws (2001: 61-62) considers dictionary projects and the communities that it intends to serve too important to leave the compilation of dictionaries in the hands of untrained or insufficiently trained people. He therefore suggests three main training phases which vary from general to specific:

1. General and metalexicographic training,

2. Training within language families, and

3. Language-specific training.

Despite these three main phases, Gouws (2001: 63) proposes that lexicographers need to further their training by means of short courses and formal university courses, as well as computer training designed primarily for the advancement of the dictionary compilation.

As far as LSP lexicography is concerned, if one has to stop at the above suggestion by Gouws, only LSP dictionaries with special attention to specific language issues will be covered. Other types of LSP dictionaries will require the lexicographer to possess subject-field training with a sound knowledge of the specific domain for which the said dictionary is being compiled. In other words, for a dictionary project such as the MMTDP, in addition to the typical lexicographic training as suggested by Gouws, the lexicographer would have to embark onto a training programme that would ensure that he/she is knowledgeable of Western medicine and traditional African medicine, and/or is well-informed about issues pertaining to the medicinal and wellness sciences.

The new discourse of lexicographic function theory with regard to user perspective may be summarised in the following figure: 


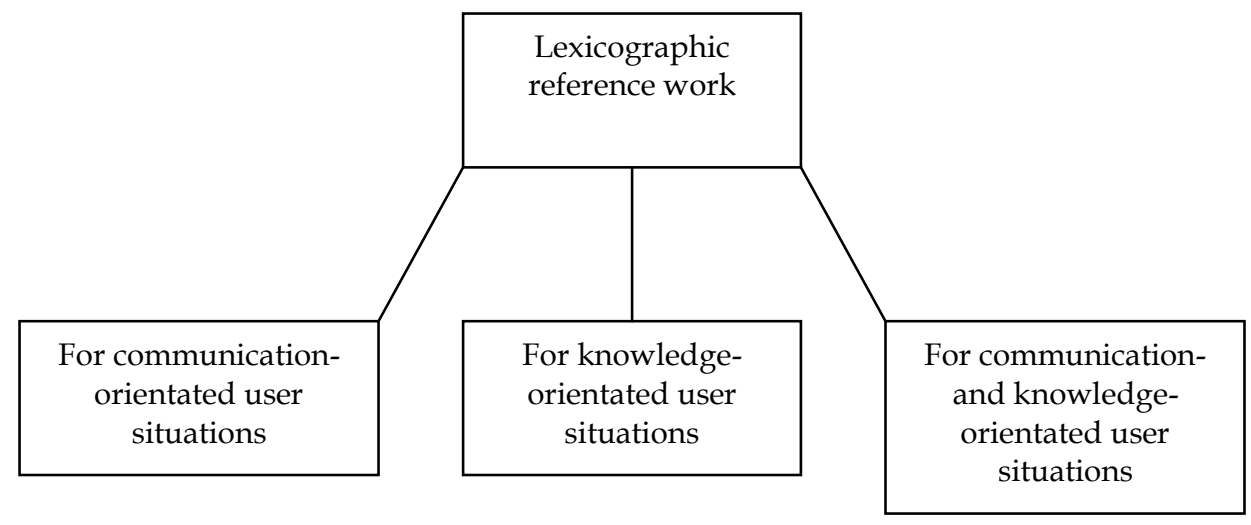

Just as the modern theory of lexicographic functions, Wiegand's "general theory of lexicography" is based upon two main postulates: (a) that lexicographic research is an independent scientific discipline, and (b) that dictionaries are utility products (Wiegand 1998, 2001). By suggesting a "modern theory of lexicographic functions", one may read a sense of furthering discourse in these postulates by other scholars, for example those at the Centre for Lexicography at the Aarhus School of Business in Denmark. Thus the shift from a "phenomenological discourse of lexicography", that is, the study of dictionaries from within presenting a linguistic-philosophical approach, to a more contextualised approach emphasising the user perspective and the user's needs with regard to specific types of user situations.

LSP advocates the contextualised use of specialised terms. Terminological practices have always contributed to widen our perspective on terms and terminology and many have led to new theoretical proposals (L'Homme et al. 2003). Terminological work has undergone several transformations, some of which have been reported in Bowker (2003) and Lutes (1995). Others have proposed new methods for organizing terminological data, i.e. methods based on concepts rather than terms (Sierra and McNaught 2000) or viewing the issue as one of knowledge organisation (Vouros and Eumeridou 2002).

According to L'Homme et al. (2003), language planning continues to remain the centre of interest of several terminological projects. Different methods applied to specific settings have been reported (Antia 2000; 2001; Samuel 1996; Smit 1996). Also, the contribution of terminology to these methods have been thoroughly discussed and even evaluated (Quirion 2003 and 2003a).

Recently new practices have deeply affected terminological work for several reasons. First, an increasing number of specialists are dealing with terms or specialized corpora. While every application is either concerned with lists of terms or text-corpora, it appears that the research efforts of the last decade have increased terminologists' awareness of the contribution to their field of study by other specialists and of the issues raised by different applications. A number of articles published in Terminology for instance show how terminological practices 
are conducted from the point of view of information retrieval (Haas and Hert 2002; Magnigi 1998/1999), science and knowledge transfer (Barona 1998/1999, Sager 1994), machine translation (L'Homme 1994), and even poetry (Avraham 1997). Secondly, new computer-based methods have challenged the way terminologists used to view terminological description.

In conclusion, lexicography is and remains an independent scientific discipline and dictionaries are utility products aimed at real users' needs in specific instances or situations. Through user-friendliness LSP lexicography is furthering the academic discourse by means of specialised terminology that leads to interdisciplinary or multifold domains of expertise. The conflicting dichotomy linguistics versus lexicography should be seen as apparently resulting from the beginnings of theoretical lexicography. The viewpoints expressed by some scholars such as Wiegand, Sinclair, Gouws, Bergenholtz and Tarp contribute to the assertion that lexicography is a calculable, analysable, checkable, manageable, testable and teachable practical process aimed at producing dictionaries to satisfy the reference needs of their users (Hartmann 1999: 156).

Lastly, dealing with the compiling and editing of dictionaries, lexicography certainly has to do with language, but judging by the lack of attention devoted to this practice in linguistics programmes and textbooks, one might be forgiven for concluding that it is a relatively insignificant task or a task of such monumental complexity that it is still beyond our grasp (Connell 2000).

\section{Bibliography}

Antia, B.E. 2000. Terminology and Language Planning: An Alternative Framework of Practice and Discourse. Amsterdam/Philadelphia: John Benjamins.

Antia, B.E. 2001. Terminological Investigations into Specialized Knowledge and Texts: A Case Study of Legislative Discourse. Terminology 7(1): 7-29.

Atkins, B.T.S. 1992. Putting Lexicography on the Professional Map: Training Needs and Qualifications of Career Lexicographers. Alvar Ezquerra, M. (Ed.). 1992. EURALEX '90 Proceedings: 519-526. Barcelona: Vox Biblograf.

Avraham, E.-S. 1997. Ha-Milon He-Hadash. Volume 5. Jerusalem.

Barona, J.L. 1999. Sciences, Language and Social Interaction. Terminology 5(1): 107-119.

Bergenholtz H. and S. Tarp. 2010. LSP Lexicography or Terminography? The Lexicographer's Point of View. Fuertes-Olivera, Pedro A. (Ed.). 2010. Specialised Dictionaries for Learners: 27-37 Berlin/New York: Walter de Gruyter.

Bowker, L. 2003. Specialized Lexicography and Specialized Dictionaries. Van Sterkenburg, Piet (Ed.). 2003. A Practical Guide to Lexicography: 154-164. Amsterdam/Philadelphia: John Benjamins.

Brady, R.J. 1970. Brady's Programmed Orientation to Medical Terminology. Washington D.C.: Robert J. Brady Company.

Burkhanov, I. 1998. Lexicography: A Dictionary of Basic Terminology. Rzeszów: Wydawnictwo Wyższej Szkoły Pedagogicznej. 
Connell, B.A. 2000. The Integrity of Mambiloid. Wolff, E. and O.D. Gensler (Eds.). 2000. Proceedings of the Second World Congress of African Linguistics, Leipzig, 1997: 197-213. Cologne: Rüdiger Köppe.

Fuertes-Olivera, P.A. 2005. Specialised Communication and English Studies: Research Proposals on Specialised Lexicography and English for Specific Purposes. Atlantis 27(2): 41-55.

Geeraerts, D. 1984. Ontwikkelingen in de lexicografische theorievorming. Jaarboek van de Stichting Instituut voor Nederlandse Lexicologie. Overzicht van de jaren 1981 en 1982: 56-65.

Geeraerts, D. 1996. Entfernung, Fortschritt und Unvollständigkeit: Das historische Verhältnis von Lexikologie und Lexikographie. Konerding, K.-P. and A. Lehr (Eds.). 1996. Linguistische Theorie und lexikographische Praxis: 7-15. Tübingen: Max Niemeyer.

Gläser, R. 2000. Should LSP Dictionaries also Include Professional Jargon and Slang? Lexikos 10: 86-98.

Gouws, R.H. 1989. Leksikografie. Cape Town: Academica.

Gouws, R.H. 2001. Lexicographic Training: Approaches and Topics. Emejulu, J.D. (Ed.). 2001. Éléments de lexicographie gabonaise. Tome I: 58-94. New York: Jimacs-Hillman Publishers.

Gouws, R.H. and D.J. Prinsloo. 2005. Principles and Practice of South African Lexicography. Stellenbosch: SUN PReSS.

Haas, S.W. and C.A. Hert. 2002. Finding Information at the US Bureau of Labour Statistics: Overcoming the Barriers of Scope, Concept and Language Mismatch. Terminology 8(1): 31-56.

Hartmann, R.R.K. 1999. What is "Dictionary Research"? Review article of Herbert Ernst Wiegand, Wörterbuchforschung. Untersuchungen zur Wörterbuchbenutzung, zur Theorie, Geschichte, Kritik und Automatisierung der Lexikographie. 1. Teilband. International Journal of Lexicography 12(2): 155-161.

Kageura, K. 2002. The Dynamics of Terminology: A Descriptive Theory of Term Formation and Terminological Growth. Amsterdam/Philadelphia: John Benjamins.

L'Homme, M.-C. 1994. Management of Terminology in a Machine-translation Environment. Terminology 1(1): 121-135.

L'Homme, M.-C., U. Heid and J.C. Sager. 2003. Terminology during the Past Decade (1994-2004). Terminology: International Journal of Theoretical and Applied Issues in Specialized Communication 9(2): 151-161.

Lutes, B. 1995. Using Online Databases for Terminology Searching. Terminology 2(2): 187-217.

Magnigi, B. 1998. Use of Lexical Knowledge based on Information Access Systems. Terminology 5(2): 203-228.

Meyer, I. and K. Mackintosch. 2000. When Terms Move into our Everyday Lives: An Overview of Determinologization. Terminology 6(1): 111-138.

Pérez Hernández, C. 2002. Exploración de los córpora textuales informatizados para la creación de datos terminológicas basadas en el conocimiento. Madrid: Edificio Beronce. http://elies.rediris.es/ elies18/index.html

Piotrowski, T. 2009. Review of Sven Tarp, Lexicography in the Borderland between Knowledge and NonKnowledge. General Lexicographical Theory with Particular Focus on Learner's Lexicography. International Journal of Lexicography 22(4): 480-486.

Porter, R. (Ed.). 1997. Medicine: A History of Healing. New York: The Ivy Press.

Prinsloo, D.J. and R.H. Gouws. 2000. The Use of Examples in Polyfunctional Dictionaries. Lexikos 10: 138-156. 
Quirion, J. 2003. La mesure de l'implantation terminologique: Position d'un protocole. Étude terminologique du domaine des transport au Quebec. Montreal: Office Quebecois de la langue française.

Quirion, J. 2003a. Methodology for the Design of a Standard Research Protocol for Measuring Terminology Usage. Terminology 9(1): 29-49.

Sinclair, J.M. 1984. Lexicography as an Academic Subject. Hartmann, R.R.K. (Ed.). 1984. LEXeter' 83 Proceedings. Papers from the International Conference on Lexicography at Exeter, 9-12 September 1983: 3-12. Tübingen: Max Niemeyer.

Sager, J.C. 1994. Language Engineering and Translation: Consequences of Automation. Amsterdam/ Philadelphia: John Benjamins.

Samuel, J. 1996. La politique terminologique indonesienne: Esquisse d'un bilan. Terminology 3(1): 125-154.

Sierra, G. and J. McNaught. 2000. Extraction of Semantic Clusters for Terminological Information Retrieval from MRDs. Proceedings of the Second International Conference on Language Resources and Evaluation. LREC 2000, May 31-June 2, 2000, Athens, Greece.

Smit, M. 1996. Wiegand's Metalexicography as a Framework for a Multilingual, Multicultural, Explanatory Music Education Dictionary for South Africa. Unpublished D.Litt. Dissertation. Stellenbosch: University of Stellenbosch.

Smit, M. 2001. Herbert Wiegand with a "Metalexicographical Panga" in the Jungle: An Unlocking of Wörterbuchforschung. Lexikos 11: 297-310.

Smit, M. 2002. The Systematic Development of Wiegand's Metalexicography as Demonstrated in Kleine Schiften. Lexikos 12: 290-310.

Tarp, S. 2002. Basic Elements of Lexicographic Theory. Emejulu, J.D. (Ed.). 2002. Éléments de lexicographie gabonaise. Tome II: 7-35. New York: Jimacs-Hillman Publishers.

Tarp, S. 2010. Reflections on the Academic Status of Lexicograpy. Lexikos 20: 450-465.

Vourus, G. and E. Eumeridou. 2002. Simple and EuroWordNet: Towards the Prometheus Ontological Framework. Terminology 8(2): 245-278.

Wiegand, H.E. 1984. On the Structure and Contents of a General Theory of Lexicography. Hartmann, R.R.K. (Ed.). 1984. LEXeter'83 Proceedings. Papers from the International Conference on Lexicography at Exeter, 9-12 September 1983: 13-30. Tübingen: Max Niemeyer.

Wiegand, H.E. 1996. Textual Condensation in Printed Dictionaries: A Theoretical Draft. Lexikos 6: 133-158.

Wiegand, H.E. 1998. Wörterbuchforschung. Untersuchungen zur Wörterbuchbenutzung, zur Theorie, Geschichte, Kritik und Automatisierung der Lexikographie. Band 1. Berlin/New York: Walter de Gruyter.

Wiegand, H.E. 2001. Was eigentlich sind Wörterbuchfunktionen? Kritische Anmerkungen zur neueren und neuesten Wörterbuchforschung. Lexicographica 17: 217-248.

Wikipedia. 2010. http:/en.wikipedia.org/wiki/Languge_for_specific_purposes/2010/09/06.

Zgusta, L. (with the assistance of D.M.T.Cr. Farina). 1988. Lexicography Today: An Annotated Bibliography of the Theory of Lexicography. Tübingen: Max Niemeyer. 


\title{
Bilingual Dictionaries in the South African Context ${ }^{*}$
}

\author{
M.J. Mongwe, Language Service Sub-directorate, Department of Sport, \\ Arts and Culture, Limpopo Province, Polokwane, South Africa \\ (mongwem@sac.limpopo.gov.za)
}

\begin{abstract}
In a multilingual country like South Africa, bilingual dictionaries that can promote effective and active communication among different cultural and speech communities are essential. Many of the existing bilingual dictionaries are often little more than word lists with translation equivalents added to them. In their compilation, thorough lexicographic planning was lacking. It is therefore the reponsibility of the lexicographers of the different South African National Lexicographic Units (NLUs) particularly to compile bidirectional learner's dictionaries of a high quality.

The aim of this article is to present some directives to which bilingual dictionaries must conform to be effective and user-friendly. Such dictionaries must be aimed at specific user groups. Bilingual dictionaries must be structured in such a way that they satisfy the needs of both source language and target language users. The dictionaries must be so designed that users can use them for text reception and text production. For this purpose, aspects of the frame structure such as the front matter, the central list, including the macrostructure and the microstructure, and the back matter require careful planning.
\end{abstract}

Keywords: BILINGUAL DICTIONARY, UNIDIRECTIONAL DICTIONARY, BIDIRECTIONAL DICTIONARY, FRONT MATTER, CENTRAL LIST, MACROSTRUCTURE, MICROSTRUCTURE, SYNONYMY, POLYSEMY, BACK MATTER, TARGET USER, TEXT PRODUCTION, TEXT RECEPTION

Opsomming: Tweetalige woordeboeke in die Suid-Afrikaanse konteks. In 'n veeltalige land soos Suid-Afrika is tweetalige woordeboeke wat 'n doeltreffende en aktiewe kommunikasie tussen verskillende kultuurgroepe en spraakgemeenskappe kan bevorder, noodsaaklik. Baie van die bestaande tweetalige woordeboeke is dikwels nie veel meer as woordelyste met vertalingsekwivalente daarby gevoeg nie. By hul samestelling het deeglike leksikografiese beplanning ontbreek. Dit is derhalwe die verantwoordelikheid van die leksikograwe van die verskillende SuidAfrikaanse Nasionale Leksikografie-eenhede (NLE's) om veral tweerigtingaanleerderswoordeboeke van 'n hoë gehalte saam te stel.

Die doel van hierdie artikel is om ' $n$ aantal riglyne te verskaf waaraan tweetalige woordeboeke moet voldoen om doeltreffend en gebruikersvriendelik te wees. Sulke woordeboeke moet op bepaalde teikengroepe gerig wees. Tweetalige woordeboeke moet op so 'n manier gestruktureer

* This article is based on a chapter from an M.Phil. thesis The Role of the South African National Lexicography Units in the Planning and Compilation of Multifunctional Bilingual Dictionaries accepted by Stellenbosch University, Stellenbosch, South Africa, April 2006. 
wees dat hulle in die behoeftes van sowel brontaal- as doeltaalgebruikers voorsien. Die woordeboeke moet so ontwerp wees dat gebruikers hulle vir teksresepsie en teksproduksie kan benut. Vir hierdie doel verg aspekte van die raamstruktuur soos die voorwerk, die sentrale lys, insluitende die makrostruktuur en die mikrostruktuur, en die agterwerk deeglike beplanning.

Sleutelwoorde: TWEETALIGE WOORDEBOEK, EENRIGTINGWOORDEBOEK, TWEERIGTINGWOORDEBOEK, VOORWERK, SENTRALE LYS, MAKROSTRUKTUUR, MIKROSTRUKTUUR, SINONIMIE, POLISEMIE, AGTERWERK, TEIKENGEBRUIKER, TEKSPRODUKSIE, TEKSRESEPSIE

\section{Introduction}

South Africa as a multilingual country with eleven official languages needs bilingual dictionaries, particularly bidirectional learner's dictionaries, so that the speakers of these languages can learn each other's languages.

Gouws (1996: 103) writes that South African lexicographic practice has also been dominated by a few dictionaries and dictionary types, especially bilingual dictionaries. In a multilingual society, the use of bilingual dictionaries forms an integral part of the daily communication process. Bilingual dictionaries are essential for efficient and active communication between different cultural groups and speech communities. Therefore it is the responsibility of lexicographers of the National Lexicography Units (NLUs) to compile bilingual dictionaries that will aid users in ensuring the success of multilingualism in South Africa. Bilingual dictionaries can be viewed as agents for unifying South Africans and other countries regardless of their geographical areas. They will assist in the translation of documents from one language to another in a way that will enhance the development of South Africa's language diversity.

Marello (2003: 325) defines a bilingual dictionary as "a list of established equivalents between words of different language systems". This means that a lemma from the source language, for example a lemma in Xitsonga, is coordinated with say an English equivalent, English being the target language as in Cuenod's Tsonga-English Dictionary (1982):

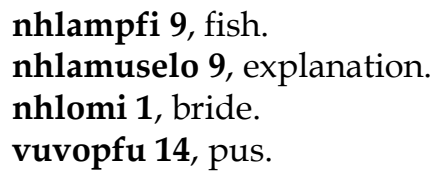

In bilingual dictionaries, according to Marello, the lemmata are translated into the second language. Bilingual dictionaries are therefore also known as translation dictionaries. Gouws (2002: 3) says that in a multilingual society translation dictionaries play important roles in promoting sound communication. Bilingual dictionaries do not give the meaning of the word in the other language, but they provide users with translation equivalents. A translation 
equivalent is defined by Gouws (2002) as "a form in the target language which can be used to substitute the source language form in certain contexts". In simple terms, a bilingual dictionary is a dictionary that involves two languages.

\section{Types of Bilingual Dictionaries}

Most dictionary users do not consider the fact that all dictionaries are compiled for a specific target group, but they consult them for solving problems encountered in any particular usage situation. There are many varieties of bilingual dictionaries, which are subdivided into, among others, unidirectional dictionaries and bidirectional dictionaries.

\section{(a) Unidirectional dictionaries}

Unidirectional dictionaries are also known as monodirectional dictionaries. These dictionaries do not display a switch of source and target language. This can be seen in articles from Cuenod's Tsonga-English Dictionary (1982):

hatima 9, lightning, glittering shiny object.

mudoro 3, (Afr.) prickly pear, jointed cactus (Oputia sp.), an introduced plant, the name is derived from Afr. "turksvye".

nandzu 3, (pl. mil-) fault, offence or debt out of which a court case may arise; guilt.

rhimila 5, (usu. in pl. marh-) nasal mucus.

The English-SiSwati Dictionary (2004) is another example of a unidirectional type of dictionary with one alphabetical ordering of lemmata. There is only one source language, i.e. English; it is treated with SiSwati as the target language throughout the dictionary. This is illustrated by the articles given below:

breakfast $\boldsymbol{n}$. kudla kwasekuseni; (ku) -sukusala

boycott $v$. (ku) -ncamula budlelwane kwesikhashana; kubhikisha; kudvuba, sidvubedvube

investment $\boldsymbol{n}$. kufakwa kwemali emsebentini kute itale

rehabilitation $\boldsymbol{n}$. ku buyisela similo

Van Warmelo's Venda Dictionary: Tshivend $\$ a-E n g l i s h ~(1989)$ is also an example of a unidirectional dictionary with one alphabetical ordering of lemmata, Tshivenda-English, as can be seen below:

kiliniki 9 (Eng.) clinic.

madi-mafhe 6 pure, clear water.

tshitoto 7 (or tshitata) sheaf or bundle, as of arrows, stalks, roots, dried meat, matches.

tungufhadza grieve, distress, pain. 
In most cases, compilers of such dictionaries do it for the benefit of foreigners who need to learn and understand literary texts of another language. They are usually compiled for the benefit of the needs of a specific user group.

\section{(b) Bidirectional dictionaries}

A bidirectional dictionary is a dictionary with two alphabetical components. Dent and Nyembezi's Scholar's Zulu Dictionary English-Zulu/Zulu-English (1987) is an example of a bidirectional dictionary. In these dictionaries there are two alphabetically ordered textual components with each member of the language pair functioning as source language in one component and target language in the other component. This can be seen from the examples of the English-Zulu alphabetical ordering of lemmata below:

truly (adv) iqiniso; isibili; isiminya; impela.

cure (n) ukuphilisa; insindiso; isilapho (remedy). (v) elapha.

sue (v) mangalela; biza; ncenga uxolo (s. for peace); mangalela ukuhlawulwa (s. for damages).

venue (n) inkundla yondlalo; indawo yokuhlanganela; inkundla.

Examples of the Zulu-English alphabetical ordering of lemmata are as follows:

impela (adv) truly ...

-philisa (v) cure.

-mangalela (v) bring a charge against.

-sindisa (v) rescue; save; redeem; heal.

-elapha (v) cure; treat medically.

Another example of a bidirectional dictionary is Bosman et al.'s Tweetalige Skoolwoordeboek Afrikaans-Engels/Engels-Afrikaans (2002). The treatment of the Afrikaans-English alphabetical ordering is as follows:

kommandant, (-e) commandant; commander.

nietig, (-e), insignificant; paltry; trifling; miserable; ...

The English-Afrikaans alphabetical ordering of lemmata has been treated as follows:

commandant, bevelvoerder, kommandant.

insignificant, onbeduidend, niksbeduidend, onbetekenend, gering, nietig, klein.

The English-Tsonga/Tsonga-English Pocket Dictionary (1982) is also a bidirectional dictionary. The following are examples of the English-Tsonga alphabetical ordering of lemmata: 
luggage, mpahla, nhundzu, ndzhwalo.

majority, quantity, vunyingi; age, vukulukumba.

name, vito; - of clan, xivongo; what is your name? vito ra wena u mani?

name, v. -thya vito, -chula vito; -tshula.

noun, vito, riviti.

Examples from the Tsonga-English alphabetical ordering are as follows:

mpahla, baggage, belongings, parcel, luggage, goods.

ndzhwalo, load, burden, luggage.

nhundzu, luggage, belongings, goods.

vito, name, noun; -thya vito or -chula vito, to name.

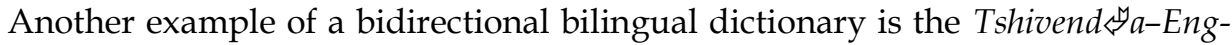
lish/English-Tshivend $\$$ a Dictionary (2004). The following are examples from the Tshivend $\$ a-English section:

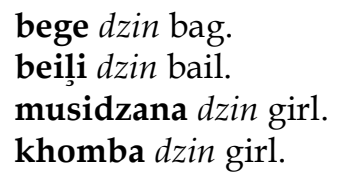

The English-Tshivend $\$$ a alphabetical ordering of lemmata is shown by the following examples:

bag $n$ bege, saga, khedzi; mukwama.

bail $n$ beili.

girl $n$ musidzana, khomba

This presentation, like that of many bilingual dictionaries, is not much more than a word list with a translation equivalent added to it. Therefore, there is an urgent need for lexicographic planning in the South African NLUs. The lack of lexicographic planning was already stressed by Prinsloo (1996: 37) when he quoted Gouws (1990: 55):

The majority of dictionaries for African languages are products of limited lexicographic achievement ... with a few exceptions these dictionaries offer only restricted translation equivalents and reflect a complete lack of lexicographic planning.

Prinsloo (1996: 37) supported his argument further with a quotation from Mbogho (1985: 152):

Bilingual lexicography seems to be developing without any basic theory. ... the basic methodological principles for compiling bilingual dictionaries were largely unknown or overlooked ... African bilingual lexicography is still in its infancy ... one way of promoting African languages is to apply several methodological principles which are tailored to the needs of the users. 
Bidirectional dictionaries are in demand in the South African market as they can fulfil the needs of both the speech communities represented in these dictionaries and those interested in learning the diversity of South African languages. This will eventually promote the prospect of multilingualism in South Africa. If planned and compiled properly, such dictionaries will cater for both groups of users. In principle, all types of dictionaries, whether unidirectional or bidirectional, might as printed dictionaries be compiled for different kinds of users. Lexicographers need to direct their attention to the real needs of a wellidentified user group.

\section{Target Groups}

Dictionaries must be regarded as useful tools compiled for real users. That is the reason why lexicographers should ensure that their target users are able to retrieve information from their dictionaries. Lombard (2000) accentuates this:

It is very important for the lexicographer to know who the target users of his labours are going to be before work on the dictionary can begin. Because the character of a dictionary and the nature of material presented in it should be determined by who the target users are, one of the most important tasks of the compiler of any dictionary is to make the product user-friendly. User-friendliness thus becomes one of the criteria in terms of which a dictionary is assessed.

As the dictionary is intended for dictionary users, it is therefore important for lexicographers to know the needs of their target users before the compilation work can begin. One of the most important tasks for lexicographers of any dictionary unit is to make sure that their dictionaries are user-friendly. This is accomplished by presenting information in such a way that it can easily be found. Li and Bilbow (2001: 214) support this when they state:

In a competitive market, the success rests in shaping the dictionary to meet the needs of its users.

Béjoint (2000: 140) also says:

Lexicographers in many countries have recently felt the need to go beyond empirical observation on the use of the general-purpose dictionaries. Seeking to find out what the users really do, as opposed to what they are believed to do, in order to make sure that the dictionary really corresponds to the needs of the public.

Lexicographers should identify the needs of their target users. Dictionary compilers have to know, and not only to assume what they think users need. The target groups of the different South African NLUs differ. Some of the language groups have been involved in dictionary compilation for decades. The Pan South African Language Board's main objective in its establishment is to ensure that each unit fulfils the needs of the speech communities of each language. 
In a multilingual society, the users of a dictionary are not only restricted to native speakers of the language. Both native and non-native speakers will share in the regular use of the dictionary. The same applies to journalists and language practitioners.

\section{The Frame Structure of Bilingual Dictionaries}

The structure of a dictionary refers to various types of structures as components, for example, the frame structure, macrostructure, microstructure, access structure, etc. The frame structure consists of the front and back matter texts representing the outer texts, and the central list. According to Kammerer and Wiegand (1998), a dictionary with a central text and front and back matter exhibits a frame structure.

Gouws (2004: 70) writes that a typical extended outer text could be found in a dictionary with one or more complex outer texts, i.e. an outer text consisting of a number of subtexts, where it includes its own table of contents as a secondary outer text which enhances the access to the different subtexts.

\section{(a) Complex outer text}

An outer text that contains its own outer text.

\section{(b) Extended complex outer text}

According to Gouws (2001), an extended outer text constitutes a partial frame structure which does not have both a front and back matter but only one of these outer text types. Outer texts directed at the dictionary as a whole and not only at an outer text constitute the primary frame structure.

A bilingual dictionary with a frame structure consists of three components, namely, the front matter, central list and back matter.

\subsection{Front Matter}

Hausmann and Wiegand (1989: 330) argue that the front matter as a whole is not a functional part of a dictionary but rather an arbitrary set of functional text parts. The front matter could be subdivided into the following components:

\section{(a) Table of contents}

It guides the user to both the word lists in the central list and different texts included in the front and back matter sections. 


\section{(b) Foreword}

The foreword is a short introductory essay preceding the text of a book.

\section{(c) Acknowledgements}

This is a note in which the lexicographer acknowledges the contribution of the experts consulted during the process of dictionary compilation.

\section{(d) Users' guidelines}

In any dictionary, this is a compulsory text. Dictionary users are given usage information which guides them in retrieving information without difficulty. In other words, this is used to ensure successful use of the dictionary. This information on usage should be explained clearly to the dictionary users. The dictionary articles contain items representing word class and structural indicators which help the user to identify and interpret the items. Structural indicators are divided into typographical and non-typological indicators.

\subsection{Central List}

The central list can assist the user in various ways depending on the function of the specific dictionary. Each dictionary has a central list covering the article structures from $\mathrm{A}-\mathrm{Z}$. This is the major component of any dictionary. On top of the pages of the central list of a dictionary there are running heads which help users identify the first and last lemmata on each page. These running heads enable dictionary users to find the lemmata without difficulty. The central list is divided into article stretches and each article stretch contains all the articles with lemmata starting with the particular letter. Each article consists of a lemma functioning as the guiding element of the article and entries directed at the treatment of the lemma. All the lemmata form the macrostructure whereas the other entries constitute the microstructure.

\subsubsection{The Macrostructure}

The macrostructure always consists of lemmata in the source language. In the case of the English-Xitsonga list in the unpublished Xitsonga-English/EnglishXitsonga Dictionary (2004), it would mean that the lemmata are in English and their translation equivalents in Xitsonga. The lemmata are given in bold, not capitalized except for proper names, and arranged in alphabetical order. This is typically the case but it is determined by the dictionary-specific arrangements. The role of the macrostructure is to accommodate the lemmata in a dictionary. This can be seen from the examples below from the Xitsonga-English/EnglishXitsonga Dictionary: 
habit $n$. ntolovelo, mukhuva.

kaye $n$. nine.

\subsubsection{The Microstructure}

The microstructure of a dictionary is the addresser of the macrostructure. A dictionary article consists of a comment on form and a comment on semantics. The lemma and entries directed at the form of the lemma, for example, pronunciation and morphology, belong to the comment on form. Translation equivalents and co- and context entries belong to the comment on semantics.

\section{Comment on form}

Lemma form, orthographic variants, pronunciation, morphology, and parts of speech.

\section{Comment on semantics}

Translation equivalents, example structures, pragmatic contrast, and collocations.

Some aspects of comment on form and comment on semantics will be considered in the following paragraphs.

\section{(a) Comment on form}

\section{(i) Pronunciation}

This is the way in which the lemma is pronounced. In the introduction to the Oxford South African Concise Dictionary (2002) it is said:

Pronunciations are not given for ordinary, everyday words.

This depends on the particular dictionary. Pronunciation is given only for lemmata which are likely to cause problems to both the native speakers and other users of a dictionary. Bilingual dictionaries need to give a more comprehensive treatment of pronunciation. Native speakers should be enabled to pronounce the lemmata correctly. Hadebe (2004) writes:

Most dictionaries in African languages mark tone because varying the tone changes the meaning of a particular word.

In the secondary articles of the Reader's Digest's Afrikaans-Engels Woordeboek/ English-Afrikaans Dictionary (1999), the pronunciation is given in brackets, using English sounds for Afrikaans lemmata, and Afrikaans sounds for English lemmata. This is shown in the examples below:

niggie $n$. cousin (ka'zien) dogter van 'n oom of tante.

niece (nies) dogter van 'n broer of suster. 


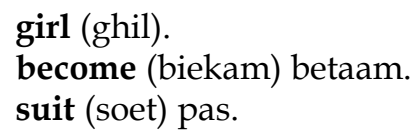

In this dictionary, a full explanation of the symbols is given on how to pronounce both the English and Afrikaans lemmata. It must be remembered that the pronunciation guide is intended merely to help dictionary users pronounce lemmata in the other language. Other examples of pronunciation can be seen from Baillière's Nurses' Dictionary (1995) by Saunders and Tindall below:

friable (fri-abl) Easily crumbled.

fibre (fiber) A thread-like structure.

Pronunciation has not been given in Cuenod's Tsonga-English Dictionary (1982) and Dent and Nyembezi's Scholar's Zulu Dictionary: English-Zulu/Zulu-English (1987) as can be seen from the respective examples below:

musengele 3 , bamboo.

-ntlhantlha, undo, demolish.

orphan (n) intandane; inkedama.

-hlomelana (v) take up arms against one another.

\section{(ii) Noun class}

There are no classes in English and Afrikaans. The African languages are the only languages which have to deal with classes in dictionary making. In Xitsonga, for example, noun classes are indicated by numbers according to Meinhof's classification. This can be seen in Cuenod's Tsonga-English Dictionary (1982) below:

$$
\begin{array}{ll}
\mathbf{1} \text { munhu (person) } & \mathbf{2} \text { vava (father), } 2 \text { vanhu (people) } \\
\mathbf{3} \text { murhi (tree) } & \mathbf{4} \text { mirhi (trees) }
\end{array}
$$

\section{(iii) Parts of speech}

This is one of the grammatical categories of lemmata reflecting their functions in a grammatical context. The following examples are taken from the EnglishTsonga/Tsonga-English Pocket Dictionary (1982):

perjure, v. -xisa, -kanganyisa.

piece, v. -hlanganisa, -nameketa.

This simply tells users that the lemmata piece and perjure are verbs. Compared to the English-Tsonga/Tsonga-English Pocket Dictionary (1982), the Scholar's Zulu Dictionary English-Zulu/Zulu-English (1987) should be given credit for the way it provides lemmata with parts of speech. 


\section{(b) Comment on semantics}

\section{(i) Equivalence relations}

In translation dictionaries, there is a variety of relations that can hold between the lemma and its equivalents. These different relations are caused by the different ways in which meaning is lexicalized in different languages. The relation between the lemma and the translation equivalent has to be evaluated in terms of the nature of the transfer of semantic information. Where the translation equivalent has exactly the same meaning as the lemma, a relation of absolute equivalence exists between the source language and the target language. The most typical relation, however, is one of partial equivalence where a lemma cannot have one translation equivalent with exactly the same meaning. There are three types of equivalence, namely congruence, divergence and zero equivalence. It is important for the lexicographer to ensure successful communication by the way the dictionary is compiled.

Equivalent relation of congruence

This is the relevant equivalent relation in a one-to-one relation between source and target language. This is a specific type of absolute equivalence. Gouws (2003) argues that the equivalent relation of congruence confronts neither the lexicographer nor the dictionary user with serious problems. The reason is that the user does not have to choose between alternative translation equivalents. In such articles, there is little need for additional information to illustrate the correct usage of the translation equivalent.

\section{Equivalent relation of divergence}

Divergence can be defined as the state of moving away in different directions from a common point. In lexicography, divergence exists only when there is a one-to-more-than-one relation between the source and target language.

In dictionary compilation, divergence is a prevailing equivalent relation when one lemma has more than one translation equivalent. Divergence can be divided into two subcategories, namely semantic and lexical divergence. The occurrence of a target language synonym paradigm motivates the existence of a relation of lexical divergence. This can be seen from the following example from the English-Tsonga/Tsonga-English Pocket Dictionary (1982):

diarrhoea, nchuluko; have diarrhoea, -huda, -cheka, -chuluka.

In this example of an equivalent relation of divergence, lexical divergence exists. The three synonyms -huda, -cheka, -chuluka as translation equivalents of the lemma diarrhoea are separated by commas. These commas are not only structural markers indicating the occurrence of a synonym paradigm, but they 
also mark a specific type of equivalent relation, i.e. lexical divergence. The semicolon separating the translation equivalents of the lemma diarrhoea indicates that the lemma not only represents a polysemous lexical item, but also signals that the prevailing equivalent relation is one of semantic divergence.

An equivalent relation does not only exist between a lemma and the translation equivalent paradigm, but also between a lemma and the different subgroupings within the translation equivalent paradigm. Articles do not necessarily have to display relations of mono-equivalence. Mono-equivalence occurs where the translation equivalent paradigm displays either lexical or semantic divergence but not a mixture of these two types. This can be supported by the following examples of a one-to-many correspondence from the English-Tsonga/Tsonga-English Pocket Dictionary (1982):

business, mhaka, ntirho, bindzu, bhisimusi; do business, -pindzula.

ntsuvi, mist, fog; vinegar.

ntwanano, alliance, agreement, treaty, unanimity.

Zero equivalence

The lexicographer responds to a relation of zero equivalence holding between the source and target language by using surrogate equivalence. In a situation where there is zero equivalence, the lexicographer has to offer something else to substitute for the normal translation equivalent.

The absence of a translation equivalent usually indicates the existence of a lexical gap in the target language. The lexicographer will be bound to familiarize him-/herself with certain aspects from the field of lexical semantics. A lexical gap is the absence of a lexical item in a language in a place where the presence of such an item would have been expected.

The most typical examples of surrogate equivalence can be found in the lexicographic treatment of culture-bound items. Where a natural language contact exists between the languages treated in one translation dictionary, the dictionary has to reflect the results of such a language contact situation. The lexicographer indicates existing borrowings from the different languages. Several lemmata in the Oxford South African Concise Dictionary (2002) show existing language borrowing from isiZulu and isiXhosa.

A bilingual dictionary has to give account of the results of language borrowing. Culture-bound items are typical targets for borrowing and can often be included as surrogate equivalents, for example, the source language lemma lobolo in Doke et al.'s English-Zulu Dictionary (1958). The lexicographers have to supply a brief description of the meaning of the source language form. The nature of the lexical gap leads to the inclusion of surrogate equivalents.

A linguistic gap occurs where a given referent is known to the speakers of a language group but where one language has no lexical item to express that particular meaning while the other language does have such an item. HIV/AIDS is known to the speakers of Xitsonga, but Xitsonga has no lexical item to offer as a 
translation equivalent for this form. This constitutes a lexical gap. Where a referential gap exists, the lexicographer will therefore have to include a more comprehensive description as surrogate equivalent, because the users need more information to understand the meaning of the source language item. A referential gap is a situation where target users of a language do not know the object referred to. For example, the word scanner is not known to Xitsonga speakers. This means that they have no knowledge of the object. In case of a linguistic gap, the target language speakers know about the object but they have not established a translation equivalent. For example, the word windscreen is known among the Xitsonga speech communities but they have no fixed term yet.

\section{(ii) Synonyms}

Source language synonyms that qualify for inclusion on account of their usage frequency should be entered as lemmata in their appropriate alphabetical positions. The target language synonyms are entered as translation equivalents and ordered according to frequency of usage. Palmer (1971) defines synonymy in this way:

'Synonymy' is used to mean 'sameness of meaning.' It is obvious that for the dictionary-maker many sets of words have the same meanings; they are synonymous, or are synonyms of one another.

The degree of synonymy that exists between two or more lexical items may not determine whether the lexicographer will indicate synonymy or not. Synonymy is a semantic relation that should be indicated throughout dictionaries. However, not all synonyms will be treated in the same way, and dictionaries should constantly and unambiguously indicate the scope of every synonymic relationship. The lexicographer should determine which member of the synonym paradigm has the highest frequency of usage. If there are more than two members in this paradigm there must be a hierarchical indication on the basis of the frequency of usage. If the synonym paradigm comprises more than one member, the ordering between the various synonyms should be motivated by frequency of usage and not alphabetically. Examples of synonyms are given in the Reader's Digest's Afrikaans-Engels Woordeboek/English-Afrikaans Dictionary (1999) below:

death (die) dood; sterfgeval; (die) afsterwe, oorlyde; after ná die dood; $a t \sim$ by die afsterwe; $b e$ in at the $\sim$ die end meemaak, die slot sien.

uit'trek uitge= pull out (nails); extend (table); draw (out), elicit, educe; unrobe, unclothe, strip; extract (teeth, etc.); abstract; pull off, remove (boots); take off, discard, doff (clothes); withdraw (money); march out, go out, take the field, sally forth; unstop (organ-stop); excerpt; sig undress (o.s); ... 
The translation equivalents in the articles above are separated by semicolons (;) and commas (,). This means that the semicolons separate the equivalents representing the different senses of a single word and the commas are used to separate the equivalents that are similar in meaning.

Lexicographers must give proper treatment of lexical divergence and semantic divergence when compiling dictionaries. Divergence is a situation where synonyms and/or polysemous senses occur in the microstructure. Commas are used for separating synonymous translation equivalents and these synonyms may differ in the sense that some might be partial synonyms while others might be complete or absolute synonyms. The relation of lexical divergence is shown by commas separating synonyms contained in the synonym translation equivalent paradigm.

In semantic divergence, semicolons play a role in the translation equivalent paradigm. There is a difference in meaning, and there is a combination of two aspects of meaning. This means that the microstructure has both commas and semicolons. Commas are used to separate synonyms, while semicolons are used to separate translation equivalents representing different polysemous senses of the lemma. In semantic divergence, lexicographic definitions can be used for surrogate equivalence.

The following example comes from the unpublished Xitsonga-English/ English-Xitsonga Dictionary (2004):

rifu (death), ku fa (to die), ku siya misava (to pass away), ku wisa (to rest), ku etlela (to sleep).

Polysemous source language items have different equivalents for each sense. They are separated by semicolons. Target language synonyms are separated by commas.

\section{(iii) Polysemous translation}

A polysemous lexical item is a single item with more than one related sense. Polysemy could therefore be seen as one word with various semantic distinctions related to each other. Ullmann (1967: 63) defines polysemy as:

The word will $\ldots$ be said to possess 'several meanings', the interrelatedness of which is fully grasped, but which are unserviceable in isolation.

Polysemy implies a word with many senses. These originate from the same basic meaning. Pei (1966) defines polysemy as:

The use of the same word in two or more distinct meanings.

Examples of polysemy can be seen in Cuenod's Tsonga-English Dictionary (1982) for the lemmas -tlhava, nhloko and -dya below: 
-tlhava, stab, pierce; slaughter; be very hot (sun); sprout (maize plants), ngula, make basket (by using awl); moya, walk against wind; swa ndzi timbilu, it grieves me; mhaka, make convincing statement, come out with the truth.

nhloko 9, 1 head. -tirha hi , work following one's silly notions. -tiva $h i \sim$, know by heart, without understanding. munhu wa , a man without commonsense, ya mhaka, the heart of a matter. ya musi, head of pestle. 2 slave.

-dya, eat; devour; consume. ndzhaka, inherit. xikweleti, incur debt, borrow. $\sim$ mbilu, attract irresistibly, have strong influence over. $\sim$ byi, (sc. vuswa) rhelela, be at peace. swo hisa, be in difficulties of any sort, $\sim$ mabulu, converse. U ta na xo, (in game of "touch") you have got "it". hi mahlo, start eating straightaway after long fast. khumbi, be deprived of food. $\sim$ thyaka ra mavoko, live from hand to mouth.

Lexicographers should not treat polysemous words haphazardly in an article. Equivalents representing their different senses should be arranged in a systematic order, i.e. closer related polysemic senses should be placed closer together. By doing so, lexicographers would assist dictionary users in easily retrieving the required information. In dictionary compilation, lexicographers should have a more suitable and user-friendly approach regarding the treatment of polysemy.

Fowler et al.'s Pocket Oxford Dictionary (1984) treats polysemous senses of the word carrier as follows:

carrier 1 person or thing that carries. 2 person or company conveying goods or passengers for payment. 3 part of a bicycle for carrying luggage. 4 person or animal that transmits disease. 5 pigeon trained to carry messages tied to its neck or leg.

Usage frequency is often the determining factor in the ordering of senses. Semantic relatedness can also play a role. In the example above, the polysemic distinctions have been arranged haphazardly. Polysemic distinctions that are connected to human beings are not placed closer to each other. The second polysemic distinction should have been followed by the fourth distinction, because the two refer to a person. A pigeon is a living animal; this means that it should have been put closer to those distinctions dealing with human beings. The polysemic distinctions of the lemma carrier should have been arranged as follows:

carrier 1 person or thing that carries. 2 person or company conveying goods or passengers for payment. 3 person or animal that transmits disease. 4 pigeon trained to carry messages tied to its neck or leg. 5 part of a bicycle for carrying luggage. 
The above given arrangement of the polysemic distinctions would have been acceptable. The lexicographer should at all times try to arrange related senses closer to each other. The users' guidelines text should explain the system of ordering. This also applies to bilingual dictionaries.

Credit should be given to Dent and Nyembezi's Scholar's Zulu Dictionary (1987) in the treatment of the lemma school below:

school (n) isokole; sikholiji; ibandla, ihlelo (sc.); ibhodi yezikole (s. board).

Each sense of a polysemous word should be indicated separately with a sense number or be separated by a semicolon. Undoubtedly in some languages it will be possible to group several of these senses together because they are close in meaning and share a common translation.

\subsection{Back Matter}

The back matter, although regarded as optional and not a compulsory component of a dictionary, is the part of a dictionary that accommodates the following text segments: bibliography, appendix, addendum, explanation of abbreviations, pictures and references associated with the pictures, and relevant literature that can be consulted regarding extra information on the dictionary. The back matter also contains a number of texts with both communication-oriented and knowledge-oriented functions. The knowledge-oriented functions assist the user by providing:
(a) general cultural and encyclopedic data,
(b) specific data about the subject field, and
(c) data about the language.

Communication-oriented functions assist the user to solve problems related to:

(a) text production in both the native and foreign language, and

(b) text reception in both the native and foreign language.

The back matter texts may and should be employed to give a more comprehensive account of this material. Gouws (2004: 84) writes that putting the data exposure structure to proper use could result in the back matter containing texts which guide users to some of the complexities of cultural and encyclopedic data. Some of the information that can be included in bilingual dictionaries are, for example, everyday lexical items like the names of the days of the week such as Ravunthanu (Friday) or the months of a year such as Hukuri (November). Gouws (2004) argues that by giving this data in the outer texts, the lexi- 
cographer ensures that users have a knowledge-enriching experience which falls within the scope of the kind of information users would like to retrieve.

However, the back matter could be very helpful in bilingual dictionaries by giving the names of places, people and provinces. A good example of a dictionary with names of people and place names is the Reader's Digest's Afrikaans-Engels Woordeboek/English-Afrikaans Dictionary (1999).

\section{Purpose of Bilingual Dictionaries}

Average users as members of a specific speech community regard a dictionary as a source of linguistic knowledge. In most cases, if they need to know something about their language, they will consult a dictionary. In a bilingual dictionary, the users want to find a target language item for a given source language item but they will also want to know how and where to use that item.

When a child hears the word corruption read on the media, for example when the Schabir Shaik verdict was given by Judge Hilary Squires on 6 June 2005, the child would like to know what it means. He/She usually asks his/her parents. If the parents consult a bilingual Xitsonga dictionary, they will find the required meaning. The word corruption has manyala as its equivalent in Xitsonga. This could then be communicated to the child.

If a history learner comes across a difficult term, for example, the word freedom in the City Press dated 13 March 2005 in the statement Comrades died for our freedom, the learner can consult a bilingual Xitsonga dictionary and will find that the word freedom has ntshuxeko as its equivalent. By doing so, the learner will understand the word much better and know that Comrades died for our freedom can be translated as Vanghana va hi file leswaku hi kuma ntshuxeko. Thus, after consulting the bilingual dictionary, the learner will be able to proceed with a better understanding of his/her lessons. The same applies to Russel Molefe's (2005: 4) use of the word sacked from the statement Sacked CEO of Limpopo hospital gets his job back in the City Press dated 5 June 2005. The learner will again consult the dictionary and will find that the word sack has as equivalent hlongola. This will help him/her to know that sacked is the past tense of sack and that sacked has hlongoriwile as its equivalent. Ultimately Molefe's statement could be translated in Xitsonga as Mulawurinkulu wa Xibedhlele xa Limpopo loyi a hlongoriwile u thele a vuyiseriwa entirhweni.

Dictionaries have to fulfil a specific purpose. This implies that dictionaries should be regarded as tools to be used by every member of the speech community. Bilingual dictionaries may serve different purposes. A bilingual dictionary is for comprehension, i.e. reading and listening, and for production, i.e. writing and speaking. Text reception helps the user to understand texts. No doubt the user-friendliness of the dictionary goes hand in hand with the skills of users. In text production, the dictionary assists the user to create texts. This is the core area in the lexicographic field. This communication-directed function is one of the primary lexicographic functions. 
It is essential that a bilingual dictionary should be organized so as to help users perform specific tasks. A bilingual dictionary is of fundamental importance in view of solving problems. Basically the role of bilingual dictionaries is to cater for the needs of both source language and target language users. They assist them in reading and understanding what they read or in writing and expressing themselves.

Bilingual dictionaries are also used for translating and interpreting purposes. Both translators and interpreters will from time to time find solutions to their problems. Undoubtedly a bidirectional type of dictionary can serve this purpose. The bidirectional dictionary, the English-Xitsonga/Tsonga-English Pocket Dictionary (1982), as well as the unpublished Ngula ya Xitsonga NLU's Xitsonga-English/English-Xitsonga Dictionary (2004), could play an important role in this regard.

In Africa, lexicographic work started inter alia with the compilation of bilingual dictionaries. The language communities of all the South African official languages need dictionaries, not only to bridge the communication gap between them, but also to document and preserve the rich variety of languages in South Africa. Hendriks (2002) writes that bilingual dictionaries can bring communities together which in the end can empower and educate the new generation, and enable users to appreciate languages and cultures of others in South Africa. She further says that these dictionaries may play a key role in a multilingual society; they can be perceived as important instruments in the communication between different linguistic and cultural groups such as those in South Africa.

Hendriks (2002) quotes Gouws (2003) to support her argument that one of the most important functions of dictionaries is to enable users to achieve a higher degree of communicative competence. The purpose of bilingual dictionaries is to promote effective communication among speakers of different languages and cultures in a multilingual and multicultural society.

Bilingual dictionaries assist source language and target language users in reading with understanding. These dictionaries also help users in writing or expressing themselves so that they in turn will be understood. Hellriegel and Slocum (1982: 583) state that a simple but basic fact is that "effective communication is important to achieve the objectives of [an] organization". Ineffective communication is normally the consequence of poor planning and management, because the planning of communication is a management function. Gouws and Prinsloo (1997: 46) state that dictionaries are instruments of linguistic and communicative empowerment, therefore lexicographers should make sure that their intended target users receive an optimal linguistic presentation.

The role of dictionaries in the communication world is also accentuated by Alberts (1992: 1) when she speaks about the role of bilingualism in "eliminating obstacles in communication". She continues: "The dictionary should nevertheless contain enough information to allow the dictionary user to successfully discover the relevant information." 
The purpose of compiling bilingual dictionaries is to create tools for effective communication among speakers of different language groups. This is supported by Béjoint (1981: 208) when he says:

A dictionary has a two-way function: it can be "a portrait of the vocabulary of a language", or it can be "a tool for effective communication".

The need for compiling bilingual dictionaries is summarised by Al-Kasimi (1977):

As a result of the flourishing increase in international interaction and cooperation, more and more of us are coming to realize that bilingual dictionaries have become a necessary part of our daily economic, intellectual, and cultural activities.

Zgusta (1971: 304) indicates that dictionaries should be significant enough to cater for even the basic needs of tourists or the difficulties of beginners or new learners. He says that if such dictionaries are often used, people will become more educated through being able to fully understand the retrieved information. The end result is that these dictionaries will uplift the sociopolitical, educational and commercial life of the majority of South Africans.

The purpose of bilingual dictionaries is to help the speakers of the various languages spoken in South Africa in learning each others' languages for the promotion of multilingualism. These dictionaries should serve a genuine purpose. Gouws (2001) defines the genuine purpose of a dictionary as follows:

The genuine purpose of a dictionary should ... be to ensure successful dictionary consultation procedures. A successful dictionary consultation procedure depends on the way in which the needed linguistic information can be retrieved.

Lexicographers of the South African NLUs should note that the main objective of a bilingual dictionary is to provide equivalent words in the target language and such words should be easily used in translations from one language to another. To ensure this, the translation equivalents have to be supported by ample content and context entries. Users should be assisted in making the appropriate choice between the equivalents for a given communication situation.

\section{Conclusion}

Dictionaries are important instruments in the teaching of both native and nonnative speakers of the language. These dictionaries can also help to bridge cultural and linguistic gaps and can enhance the communicative competence of the speakers of different speech communities. Each dictionary is compiled to serve a specific purpose for the user. The English-Tsonga/Tsonga-English Pocket Dictionary (1982), for example, is compiled for both the Vatsonga and those who want to learn other languages. South Africans living in a multilingual society with eleven official languages and a diverse society need to know different languages. Louw (1997) writes: 
The current South African metalexicographical literature clearly shows that the contemporary translation dictionaries with Afrikaans and English as a treated language pair do not do enough to facilitate communicative success for speakers of either of these languages.

He continues:

In a multilingual society such as South Africa, translation dictionaries and especially bilingual dictionaries have a very important role to play, because they often function as the primary or even only source of communicative help (and especially of semantic information) for their users.

In a multilingual society, the use of bilingual dictionaries form an integral part of the daily communication process. Reliable dictionaries should educate the future generation to appreciate the languages, customs and cultures of others within South Africa.

\section{References}

Alberts, M. 1992. Behoeftebepaling in die leksikografie. Lexikos 2: 1-27.

Al-Kasimi, A.M. 1977. Linguistics and Bilingual Dictionaries. Leyden: E.J. Brill.

Béjoint, H. 1981. The Foreign Student's Use of Monolingual English Dictionaries: A Study of Language Needs and Reference Skills. Applied Linguistics 2(3): 207-222.

Béjoint, H. 2000. Modern Lexicography: An Introduction. Oxford/New York: Oxford University Press.

Bosman, D.B., I.W. van der Merwe and A.S.V. Barnes. 2002. Tweetalige Skoolwoordeboek AfrikaansEngels/Engels-Afrikaans. Kaapstad: Nasou Bpk.

Cuenod, R. 1982. Tsonga-English Dictionary. Braamfontein: Sasavona.

Dent, G.R. and C.L.S. Nyembezi. 1987. Scholar's Zulu Dictionary English-Zulu/Zulu-English. Pietermaritzburg: Shuter and Shooter.

Dictionary Unit for South African English. 2002. Oxford South African Concise Dictionary. Cape Town: Oxford University Press.

Doke, C.M, D.M. Malcolm and J.M.A. Sikakana. 1958. English-Zulu Dictionary. Johannesburg: Witwatersrand University Press.

Fowler, F.G. and H.W. Fowler. 1984. The Pocket Oxford Dictionary. Oxford Clarendon Press.

Gouws, R.H. 1990. Information Categories in Dictionaries, with Special Reference to Southern Africa. Hartmann, R.R.K. (Ed.). 1990. Lexicography in Africa: 52-65. Exeter: University of Exeter Press.

Gouws, R.H. 1996. A Sequence for Meeting Lexicographic Needs. Lexicography as a Financial Asset in a Multilingual South Africa: 97-110. Pretoria: Department of Arts, Culture, Science and Technology.

Gouws, R.H. 2001. The Use of an Improved Access Structure in Dictionaries. Lexikos 11: 101-111.

Gouws, R.H. 2002. Equivalent Relations in Translation Dictionaries. Unpublished M.Phil Study Guide. Stellenbosch: University of Stellenbosch.

Gouws, R.H. 2003. Using a Frame Structure to Accommodate Cultural Data. Emejulu, J.D. (Ed.). 2003. Éléments de lexicographie gabonaise. Tome 1: 54-69. New York: Jimacs-Hillman Publishers.

Gouws, R.H. 2004. Outer Texts in Bilingual Dictionaries. Lexikos 14: 67-88. 
Gouws, R.H. and D.J. Prinsloo. 1997. Lemmatization of Adjectives in Sepedi. Lexikos 7: 45-57.

Hadebe, S. 2004. Improving Dictionary Skills in Ndebele. Lexikos 14: 89-104.

Hausmann, F.J and H.E. Wiegand. 1989. Component Parts and Structures of General Monolingual Dictionaries: A Survey. Hausmann, F.J. et al. (Eds.). 1989-1991. Wörterbücher. Ein internationales Handbuch zur Lexikographie/Dictionaries. An International Encyclopedia of Lexicography/Dictionnaires. Encyclopédie internationale de lexicographie: 328-360. Berlin: Walter de Gruyter.

Hellriegel, D. and J.W. Slocum Jr. 1982. Management Reading. Reading MA: Addison-Wesley.

Hendriks, K. 2002. The Treatment of Culture-specific Items in Bilingual Dictionaries. Paper presented at the Seventh International Conference of the African Association for Lexicography, Rhodes University, Grahamstown, 8-10 July 2002. Pretoria: (SF)² Press.

Kammerer, M. and H.E. Wiegand. 1998. Über die textuelle Rahmenstruktur von Printwörterbüchern. Präzisierungen und weiterführende Überlegungen. Lexicographica 14: 224-238.

Li, L. and G.T. Bilbow. 2001. From a Business Corpus to a Business Lexicon. Lexikos 11: 209-221.

Lombard, F.J. 2000. Course in General and Computer Lexicography. Unpublished Training Course Notes. Stellenbosch: Bureau of the WAT.

Louw, P.A. 1997. Kriteria vir 'n standaard vertalende woordeboek. Unpublished M.A. Thesis. Stellenbosch: University of Stellenbosch.

Marello, C. 2003. The Bilingual Dictionary: Definition, History, Bidirectionality. London: Routledge.

Mbogho, K. 1985. Observations on Bilingual Lexicography involving Bantu and Indo-European Languages. Babel 31(3): 152-162.

Molefe, R. 2005. Sacked CEO of Limpopo hospital gets his job back. City Press. Johannesburg.

Ngula ya Xitsonga National Lexicography Unit. 2004. Xitsonga-English/English-Xitsonga Dictionary. Unpublished.

Palmer, F. 1971. Grammar. Harmondsworth: Penguin Books.

Pei, M. 1966. Glossary of Linguistic Terminology. New York: Columbia University Press.

Prinsloo, D.J. 1996. The Lexicographic Needs of Pedi. Lexicography as a Financial Asset: 37-45. Pretoria: Department of Arts, Culture, Science and Technology.

Reader's Digest Association. 1999. Afrikaans-Engels Woordeboek/English-Afrikaans Dictionary. Cape Town: The Reader's Digest Association, Southern Africa.

Saunders, W.B. and B. Tindall. 1995. Ballière's Nurses' Dictionary. London: Harcourt Brace Jovanovich.

Silulu SeSiSwati National Lexicography Unit. 2004. English-SiSwati Dictionary. Macmillan Botswana Publishing Co.

Swiss Mission in South Africa. 1982. English-Tsonga/Tsonga-English Pocket Dictionary. Braamfontein: Sasavona.

Tshivend $\$$ a National Lexicography Unit. 2004. Tshivend $\$$ a-English/English-Tshivend $\$ a$ Dictionary. UPrinters.

Ullmann, S. 1967. Principles of Semantics. Oxford: Blackwell.

Van Warmelo, N.J. 1989. Venda Dictionary: Tshivend $\$ a-E n g l i s h$. Pretoria: J.L. van Schaik.

Zgusta, L. 1971. Manual of Lexicography. The Hague: Mouton. 


\title{
What Cultural Information can be taken from Example Sentences in Bilingual Dictionaries, and is it Useful?
}

\author{
Lorna Morris (née Hiles), Cape Town, South Africa \\ (lorna@hiles.co.za)
}

\begin{abstract}
Example sentences provide support for the information provided in a dictionary entry, and in bilingual dictionaries, they show the translation equivalent in natural use. This article sets out to discover whether example sentences in a bilingual dictionary provide any cultural information that could be useful to a learner of a foreign language. To do this, a selection of 100 example sentences is taken from a bilingual Italian-English dictionary aimed at learners of Italian. These sentences are then categorised according to different criteria relating to cultural information. The results are thereupon analysed and discussed. Very few of the categories provide information that is culturally significant, but some of the information is relevant. The conclusion is that while cultural information can be found in this bilingual dictionary, it is not a significant amount of information, and the typical dictionary user would be unlikely to find the information useful.
\end{abstract}

Keywords: DICTIONARY, BILINGUAL DICTIONARY, LEARNER'S DICTIONARY, EXAMPLE SENTENCE, CULTURAL INFORMATION, FOREIGN LANGUAGE, CULTURAL GUIDANCE, GENDER, TABLE OF CATEGORIES

Opsomming: Watter kulturele inligting kan uit voorbeeldsinne in tweetalige woordeboeke verkry word, en is dit nuttig? Voorbeeldsinne verskaf steun vir die inligting gegee in 'n woordeboekinskrywing, en in tweetalige woordeboeke toon hulle die vertalingsekwivalent in natuurlike gebruik. Hierdie artikel wil vasstel of voorbeeldsinne in ' $n$ tweetalige woordeboek enige kulturele inligting verskaf wat nuttig kan wees vir ' $n$ aanleerder van ' $n$ vreemde taal. Daarvoor is 'n keuse van 100 voorbeelde geneem uit 'n tweetalige Italiaans-Engels-woordeboek gerig op aanleerders van Italiaans. Hierdie sinne word dan ingedeel volgens verskillende kriteria met betrekking tot kulturele inligting. Die resultate word vervolgens ontleed en bespreek. Baie min van die kategorieë verskaf inligting wat kultureel belangrik is, maar sommige van die inligting is toepaslik. Die gevolgtrekking is dat, terwyl kulturele inligting in hierdie tweetalige woordeboek gevind kan word, dit nie 'n noemenswaardige hoeveelheid inligting is nie, en dit is onwaarskynlik dat die tipiese woordeboekgebruiker die inligting nuttig sal vind. 
Sleutelwoorde: WOORDEBOEK, TWEETALIGE WOORDEBOEK, AANLEERDERSWOORDEBOEK, VOORBEELDSIN, KULTURELE INLIGTING, VREEMDE TAAL, KULTURELE LEIDING, GESLAG, TABEL VAN KATEGORIË̈

\section{Introduction}

In my thesis on example sentences in South African school dictionaries (Hiles 2009), I suggested that much support can be found in example sentences. I showed that one can find contextual support, grammatical support, as well as additional support. The additional support included figurative language, gender information and cultural information.

I suggested that as further research, the category of additional support is one that can be expanded on. It is my intention in this article to do further research on the category of additional support, and specifically, the cultural information that it provides. I set out to discover how much cultural information, or how many cultural clues I can find in the example sentences of a bilingual dictionary.

My research question is: Can one find useful cultural information in the example sentences in a bilingual dictionary? My hypothesis is that one would be able to find such information.

For the purposes of this research, I have chosen a bilingual Italian-English dictionary. I chose Italian because I do not know the language and have very little pre-existing cultural knowledge, and because it is a language that belongs to a culture other than my own.

When faced with a selection of foreign language dictionaries, I chose the one that appeared to have the most examples per page. The dictionary used is the Collins Easy Learning Italian Dictionary.

I chose the first 100 example sentences from the Italian-English side that I thought had some sort of cultural information in them. This selection was according to my reasoning, but I tried to keep as objective as possible. I did not include example phrases or sentences where I did not find additional information. While choosing the sentences, I also chose the categories to which I could allocate these sentences. The categories I included are: gender, name, politeness, crime/violence, sport, family, entertainment/leisure, health/hygiene, education, employment, economics/consumerism, measurement, Italian geography, other geography.

Each of these categories will be discussed further later.

I checked the English-Italian side of the dictionary to see whether the reversibility principle was followed, and of the 20 entries that were in A in the English-Italian side, four were not treated at all, 12 were treated but with no example and four were treated, with an example sentence, but not the same ones as on the Italian-English side. From this sample, one can conclude that this dictionary does not follow the reversibility principle. 
According to the introduction of the Collins Easy Learning Italian Dictionary, this dictionary is "designed specifically for anyone starting to learn Italian". Incidentally, the dictionary contains a feature that is meant to give cultural guidance, as shown by this sidebar:

Look out for information notes which have this symbol on the lefthand side. They will give you guidance on grammatical points, and tell you about differences between Italian and British life.

These tips include spelling tips and warnings about false friends.

After compiling the table, I analysed it and looked for trends and patterns.

Much of the literature on example sentences examines types of examples, why they are used and what makes a good example. There is also discussion on whether corpus-based examples are better than invented examples, and whether there are different requirements for the example sentences in different dictionaries.

One can ask whether providing cultural information in example sentences is valuable to a user, and Swanepoel (2001: 184) says that "good examples would be those that either illustrate ... or independently contribute information to the mental representation of a lexeme".

Bogaards (1996: 299) is in agreement, saying that "cultural references could be profitable" to learners, but he acknowledges that it is not known whether readers "really use this type of information".

In addition, Yong and Peng (2007: 104) say that examples demonstrate a lemma's "morphological, syntactical, ... and sociocultural features".

Cultural support is discussed in my thesis (Hiles 2009: 9) as "information that may be helpful to the learner. ... These sentences may contain cultural data, which would include racial and gender information. This may be more useful in a bilingual dictionary where the cultures of the different languages are different."

According to Tarp and Gouws (2012: 6) "it is important to stress that vocabulary learning most often - and especially for the younger children goes together with encyclopedic and cultural learning. In this respect, school dictionaries may also assist the school children in a third cognitive situation, i.e. learning about the world, getting world knowledge as a basis for vocabulary learning and interwoven with this."

\section{Discussion of the table}

Taking the 100 example sentences and the 14 categories, I compiled a table that I used to allocate incidences of cultural support to each sentence. 
The table contains columns with the Italian headword, followed by the English translation equivalent, and then the example sentence. Furthermore there is a column showing whether gender is indicated, including a value judgement about whether the sentence indicates a gender bias.

The reason for the gender column is to find out the ratio of male and female pronouns throughout the examples, and to examine whether there are gender stereotypes or sexist attitudes. It was interesting to note that in the 71 sentences that did contain either a male or female pronoun, or a name or another gender indicator, 51 were male and only 20 were female. I then went through the 71 sentences and assigned an "attitude" to each sentence: whether the sentence was neutral or showed a positive or negative attitude. Many of these were difficult to determine, so I used a five point scale: negative (-), possibly negative $(\mathrm{N}-)$, neutral $(\mathrm{N})$, possibly positive $(\mathrm{N}+)$ and positive $(+)$. This made it clear that most of the sentences were neutral, with very few showing any kind of gender bias.

The totals of this column are: neutral: 41; possibly negative: 10; possibly positive: 7; positive: 11 ; negative: 2 . The two negative attitudes are found in the sentences: He finds it difficult to show affection, and He's got bad breath. A sentence such as He spends a lot on clothes could be considered positive or negative, so was kept as neutral. Other neutral sentences include: She lives near here. Did he mention his plan to you? A possibly negative sentence is: She's very difficult to please. A possibly positive sentence is: $\mathrm{He}^{\prime}$ s the right person for the job. A positive sentence is: He said he would help us.

The sample of example sentences taken from this dictionary is too small to be used to determine whether the dictionary exhibits sexist stereotypes, although the high number of male references compared to female references could suggest that Italian culture is more patriarchal.

The name column contains six names. They are all typical Italian names: Paola, Luca, Simona, Roberta, Marisa and Matteo. I needed to do a small amount of research to determine that Luca was a male name. The others were more obvious.

The politeness column contains 11 sentences. These sentences are either polite ways of expressing something, for example, Shall we go to the cinema? Would you mind turning down the volume? or they describe someone being polite, for example, She welcomed me with open arms. He did his best to put me at my ease. This could suggest that Italians do value politeness. The 89 sentences that were not marked in this column are not impolite - they just do not exhibit any polite/impolite characteristics.

The crime/violence column contains seven sentences, for example, He was stabbed in a fight. He only noticed it had been stolen today. Judging whether Italian society is particularly violent or criminal would only be possible if these example sentences were compared with a similar dictionary for another language.

The sport column contains nine sentences. The sports mentioned are aerobics, cycling, running, and gym. Other sentences mention teams and training 
and championships, but do not specify a particular sport. Again, one would need to compare the incidence of sporting sentences with a dictionary for another language in order to come to any conclusion about whether Italian society is particularly sporty. One is more likely able to work this out from one's background knowledge, than with the help of the example sentences in an Italian-English dictionary.

The column for family references contains seven sentences. These include I'm very fond of my aunt, and His parents abandoned him when he was small. This kind of information would be more useful in a language where kinship terminology is different to one's own language. For example, the English word "aunt" would have a different translation equivalent in Zulu depending on whether it is your mother or father's older or younger sister, or older or younger brother's wife.

The entertainment/leisure column contains nine sentences. These sentences refer to leisure activities such as going to the cinema or theatre, listening to the radio or to music, watching TV, or going to the beach. I also included the sentence He mended my bike for me, because I could be using my bike for leisure. One can use this information to find out what Italians do for entertainment, but the list is unlikely to be exhaustive.

In terms of the health/hygiene column, I only found four sentences. These referred to mental health, for example, He seems a bit depressed; illness, for example, He's got Aids; sports injuries, for example, He hurt his arm while training; and He's got bad breath, which could suggest poor hygiene or an illness. It is interesting that all of these sentences refer to "he", which could suggest that Italian men are more prone to illness and injury. (It could suggest this, but probably doesn't.)

The education column contains four sentences. They contain words such as "exam" and "studied" and refer to both college and school. Sentences such as these could indicate to the dictionary user what kind of education system is used in a particular country, and whether tertiary education is available.

The employment column contains eight examples. Apart from the sentence, He's a farmer, these examples all mention "job", "career", "business", "work" and system of reimbursement. They do not indicate different types of jobs or fields of employment.

The economics/consumerism column contains 11 sentences. These sentences all refer to someone paying for something, buying something or owning something. Cars are mentioned a lot, which suggests that people own their own cars. He offered me a good deal and It's a real bargain at that price suggest a free market economy. This column would also show whether a particular society relied on bartering or other economic systems.

The measurement column is a useful one. It only contains three sentences, but these sentences refer to the metric measurement system, indicating that that is what is used in Italy. I bought over a kilo, It's five centimetres high, and I' $m$ one metre seventy all leave the user in no doubt about this. 
The Italian geography column contains two sentences. The first one refers to Bologna and the second one to Florence. Neither sentence contains any quality judgement about the areas: She lives in Bologna and I live in Florence. One would need to look through a lot more of the dictionary to find other locations in Italy, and whether there are any quality judgements about them.

The other geography column contains three sentences, two of which refer to Scotland: She's got a strong Scottish accent, and I stayed with a Scottish family. The other sentence is Have you ever been to New York? Again, there are no values assigned to these areas, but it is interesting to note that two of the three sentences refer to one country. (This could be explained by Collins being a Scottish publisher.)

These categories were the ones that I chose after reading through the example sentences and seeing which themes appeared to be more common, and whether these could be culturally significant. Other categories that could have been used are: character, emotions, home, clothing, pets or transport. At least three sentences in this selection referred to sleep or being in bed, but I could not determine how these were culturally relevant.

Some sentences were difficult to allocate without any other context. For example, He mended my bike for me. This sentence could indicate politeness, if he mended my bike out of the kindness of his heart, or it could have been his job, and he was mending bikes for everyone. It could also fit into the sport category, if I use my bike competitively, or I could use my bike for leisure and not sport. I could even use my bike in my job, or to commute to my job. As such, all the allocations in this table are according to my intuition or reasoning.

\section{Conclusion}

While it can be seen that cultural information can be found in the example sentences of this bilingual dictionary, the value of this information is very limited. A user would need to wade through a huge amount of the dictionary in order to find useful information. These 100 sentences come from the first ten and a half pages of the Italian-English side of the dictionary, which contain 267 example sentences altogether. This means that I found additional or cultural information in only $37 \%$ of the example sentences.

One should also not forget that the typical dictionary user is one who looks words up as they are needed, and does not read through pages and pages of entries, gathering information as he/she goes along.

Perhaps the most useful information found in these sentences is that Italians use the metric system as opposed to the imperial system of measurement. Another useful category would be kinship terms, but it is assumed that in a bilingual dictionary containing two very different systems of kinship terminology, this would be treated somewhere other than simply in the example sentences.

One could go through this dictionary very carefully and note that he is more likely to be sick, depressed or have bad breath, but this does not have any 
cultural relevance that I can see. There is no indication that the gender is allocated in any way other than randomly.

However, a study such as this one would be more valuable if it were used to compare two different cultures in two different bilingual dictionaries. For example, the sport column in this dictionary contains nine sentences. It would be interesting to compare a dictionary in the same series, treating another language, for this information to be of any use.

While cultural information can be found in the example sentences of a bilingual dictionary, one would do better to use this to supplement other sources in order for it to be reliable or useful in any way.

\section{Bibliography}

\section{Dictionary}

Beattie, S. (Ed.). 2012. Collins Easy Learning Italian Dictionary. 3rd edition. Glasgow: HarperCollins Publishers.

\section{Other References}

Bogaards, P. 1996. Dictionaries for Learners of English. International Journal of Lexicography 9(4): 277-320.

Hiles, L. 2009. Examples in South African School Dictionaries: From Theory to Practice. Unpublished Master's Thesis. Stellenbosch: University of Stellenbosch.

Swanepoel, P. 2001. Dictionary Quality and Dictionary Design: A Methodology for Improving the Functional Quality of Dictionaries. Lexikos 11: 160-190.

Tarp, S. and R. Gouws. 2012. School Dictionaries for First Language Learners. Lexikos 22: 333-351.

Yong, H. and J. Peng. 2007. Bilingual Lexicography from a Communicative Perspective. Amsterdam: John Benjamins. 


\title{
The Lemmatisation of Dialectal Forms in a Northern Sotho General Monolingual Dictionary: Is the Language Developed or Polluted?
}

\author{
M.C. Mphahlele, Sesotho sa Leboa National Lexicography Unit, \\ University of Limpopo, Turfloop Campus, Polokwane, South Africa \\ (motlokwe.mphahlele@ul.ac.za)
}

This article is dedicated to an academic who did not only contribute to the establishment of the National Lexicography Units in South Africa, but also to metalexicography in the South African context. Because the lexicographic fraternity in South Africa owes much to him, this article is a way of saying thank you.

\begin{abstract}
Dictionaries are carriers of information, and information presented in dictionaries should reflect the real language use. This article proposes ways in which dialectal forms of a language should be regarded as a source for candidate lemmas in general dictionaries. It is argued that dialectal forms of a language can play an important role in general dictionaries whereby languages can develop through these suggested lemmatisation processes. The notion that dialects are impure forms of a language, is rejected. These natural spoken forms can add value to the written form of the lexicon of a language. Lemmatisation of dialectal forms in general dictionaries could pose a challenging task, because lexicographers have to deal with lexical items that have never been put in writing before. However, given the fact that the lexicographer is someone, who is familiar with the orthography of a given language he/she should be able to write these dialectal words in an orthographically acceptable way.
\end{abstract}

Keywords: GENERAL MONOLINGUAL DICTIONARIES, DIALECTS, DICTIONARY USERS, STANDARD LANGUAGE, STANDARDISATION, METALEXICOGRAPHY, LEXICAL ITEMS

Opsomming: Die lemmatisering van dialektiese vorme in 'n Noord-Sotho algemene eentalige woordeboek: Word die taal ontwikkel of besoedel? Woordeboeke is draers van inligting, en inligting aangebied in woordeboeke behoort die werklike taalgebruik te weerspieël. Hierdie artikel stel maniere voor waarop dialektiese vorme van tale beskou behoort te word as ' $n$ bron vir kandidaatlemmas in algemene woordeboeke. Daar word geredeneer dat dialektiese vorme van ' $n$ taal 'n belangrike rol kan speel in algemene woordeboeke waardeur tale deur hierdie voorgestelde lemmatiseringsprosesse kan ontwikkel. Die opvatting dat dialekte onsuiwer vorme van 'n taal is, word verwerp. Hierdie natuurlik gesproke vorme kan waarde toevoeg tot die geskrewe vorm van die leksikon van 'n taal. Lemmatisering van dialektiese vorme in algemene woordeboeke kan 'n uitdagende taak tot gevolg hê, omdat leksikograwe leksikale items 
moet behandel wat nog nooit voorheen op skrif gestel is nie. Gegewe egter die feit dat die leksikograaf iemand is wat bekend is met die ortografie van 'n gegewe taal, behoort hy/sy hierdie dialektiese woorde in 'n ortografies aanvaarbare manier te kan skryf.

Sleutelwoorde: ALGEMENE EENTALIGE WOORDEBOEKE, DIALEKTE, WOORDEBOEKGEBRUIKERS, STANDAARDTAAL, STANDAARDISERING, METALEKSIKOGRAFIE, LEKSIKALE ITEMS

\section{Introduction}

Non-standard varieties of a language are part of the entire lexicon of a language and are spoken by people of the same language in oral communications. These varieties include dialects, idiolects, slang, registers, vulgar words, etc. This article will concentrate more on the challenges involving the treatment of dialects in general Northern Sotho dictionaries.

A dialect is a regional form of a language spoken specifically by a particular group of people who share the same geographical boundaries. Just like many other languages, Northern Sotho consists of many dialects, amongst others Sepedi, Selobedu, Setlokwa, Sehananwa, Sekopa, Sepulana, Sephalaborwa, Sepai, Sekhutswe, Sekgaga, Setswapo, Setau, Sekone, Sendebele-Sotho, Sekwena, Semamabolo, Semoletši and Semolepo. As these dialects are used by the speakers when they communicate among themselves, they also need to be recorded somewhere in a general dictionary.

Hudson (1980: 32) explains what a standard language is by contrasting it with a dialect:

It is probably fair to say the only kind of variety which would count as a 'proper language' ... is a standard language. Standard languages are interesting in as much as they have a rather special relation to society - one which is quite abnormal when seen against the context of the tens (or hundreds?) of thousands of years during which language has been used. Whereas one thinks of normal language development as taking place in a rather haphazard way, largely below the threshold of consciousness of the speakers, standard languages are the result of a direct and deliberate intervention by society. The intervention, called 'standardisation', produces a standard language where before there were just 'dialects' (... i.e. non-standard varieties).

From Hudson's definition of a standard language, it can be deduced that standard languages are normally produced through human interventions whereas dialects are just natural speech forms spoken as varieties amongst speakers who happen to share geographical boundaries. Natural as they are, dialects are basically the foundation of any standard language.

Questions that could be asked is whether these natural forms of a language are treated by the lexicographers of general dictionaries and whether they adhere to the theoretical conventions put forward by metalexicography, 
i.e. whether dialectal forms are considered to be treatment units in their general dictionaries and, if so, how these non-standard forms are dealt with in the dictionary.

A general dictionary should be an inclusive dictionary that records all the linguistic forms of a language. Because of its nature, it should document the dialectal forms of a language so that the users of the dictionary would know that some lexical items are regionally bound. Regarding the nature of a general dictionary, Gouws (1999: 13) writes:

The comprehensiveness of a comprehensive dictionary, also known as an overall-descriptive dictionary applies to two levels, that is, the selection of lexical items as well as the treatment of these items. A comprehensive dictionary endeavours to include the most representative selection of lexical items. Although no dictionary can include the complete lexicon of a given language, the objective of a lexicographer of a comprehensive dictionary is to represent as many items as possible. Because of its comprehensiveness, this category of dictionary does not only include lexical items from the standard variety of the target language. A prominent feature of comprehensive dictionaries is the inclusion of non-standard forms, dialectical items, items with limited use as well as the vocabulary of different social groups.

There is no doubt that a general dictionary should reflect the vocabulary of the general language by also including other dialectal variations. Gouws and Prinsloo (2005: 49) argue that comprehensive dictionaries are "typically historically oriented and are directed at a lexicographic treatment reflecting the past and the present characteristics of a language". These historical characteristics of a language cannot be successfully documented in general dictionaries if dialects are not considered for treatment in these dictionaries. A detailed record of the history of a language can arguably be found in many dialects of a language as dialects are role players in the process of producing the standard language. The reason for this is that dialects were there even before standard languages evolved.

In taking the arguments of Gouws (1999) further, Mojela (2008: 129) says that it is important to realize that the lemmatisation of the vocabulary of Northern Sotho dialects will not only bridge the gap between the prestige dialects and the stigmatised dialects, but will also guarantee the unity and the stability of the language, because there is still an ongoing debate about the name of the language. This debate emanates from, amongst others, the fact that some dialects are not even represented anywhere in the standard language. Mojela argues further that the lemmatisation of the lexical items from these dialects will increase the size of Northern Sotho. Making these lexical items available, such a comprehensive dictionary will be able to serve speakers of different dialects across a larger geographical area.

After the presentation of Mojela's paper at the 2007 AFRILEX conference, the Sesotho sa Leboa National Lexicography Unit embarked on a pilot project to establish whether Gouws's and Mojela's views could be realised. The purpose of 
this article is therefore to discuss the challenges encountered in dealing with the lexical items from the dialects while compiling a general monolingual dictionary of Northern Sotho. This article further presents suggestions for dealing with the demands of a general dictionary in a multidialectal environment.

\section{Treating Dialects in a General Monolingual Dictionary}

\subsection{Entering the dialectal words as lemmas}

Users consult dictionaries to obtain some information about items from the vocabulary of a specific language (Gouws and Prinsloo 2005). Compiling a general monolingual dictionary may pose a challenge to the lexicographer as this type of dictionary expects the lexicographer to consider lemmatising a full spectrum of lexical items found in a particular language. This becomes a problem because general dictionaries are expected to deal with various forms of a language. They should treat the language as it is without adopting a prescriptive and normative approach. Lexicographers of a general dictionary should move away from this approach and adopt a descriptive, non-selective approach whereby lemmas are treated by virtue of being lexical items of the vocabulary of a language, not as correct, important, fashionable, and/or standard forms of a language.

It is expected that a general monolingual dictionary, with its descriptive and inclusive nature, should treat words from the dialects of the language. This lemmatisation process poses a challenging task because lexicographers have to deal with lexical items that have never been put in writing before. It is expected that the lexicographer as someone who is familiar with the orthography of the language should be able to write these dialectal words in a grammatically acceptable way. This is not an easy task because some of the dialects of Northern Sotho are not related. According to Kosch and Kotzé (1996: 90) these dialects are classified into six dialect clusters which are South Central, Central, NorthWestern, North-Eastern, Eastern and East Central dialects. Their phonological, phonetical, morphological and lexical characteristics are not the same. These differences are also seen between standard Northern Sotho and its dialects whereby some differ from the standard form in many respects. For example, their morphological differences make it difficult to classify them according to the noun class system of Northern Sotho. This means that in order to classify these dialectal words in a dictionary, lexicographers may prefer to include them within a dictionary article. Gouws (2006: 90) argues that one of the valuable insights of modern-day metalexicography is that dictionaries do not necessarily have to display a homogeneous article structure but that a specific article structure needs to be devised to which the default article adheres. This clearly indicates that lexicographers may opt to include the dialectal forms within the article of a standard lemma. If such an approach is adopted as a lexicographic policy, a typical article in a Northern Sotho monolingual dictionary where there 
is dialectal deviation may be necessary. A general monolingual dictionary that only treats dialectal words without specifying the regions of the treated dialects is not comprehensive enough to satisfy the needs and demands of users. Users of such a dictionary would want to know the origins of such dialects.

The following words are dialectal variations in Northern Sotho and may be considered as entries in a Northern Sotho general monolingual dictionary: khumana for humana (get), phikologa for pshikologa (roll), khobe for hlapi (fish), mothate for kota (wood), apa for bolela (speak, talk), kholopana for nona (become fat), naase for lehono (today), boušwa for bogobe (porridge), and lefaru for lewa (boiled grain).

If lexicographers are not conversant with the conventions regarding general monolingual dictionaries, they may sometimes not be sure whether to enter these dialectal words in the dictionary for they are not standardised forms. The reason for this is that they might be afraid that dictionary users may regard such lemmatisations as misleading, because such words are from the dialects. Although lexicographers will record lexical items from other dialects, there is a fear that they may be criticised for polluting the dictionary with unwanted items that do not belong in the dictionary. This also means that for dictionary users to understand the purpose of a particular dictionary, they too need to be familiarised with different lexicographic principles regarding dictionary typologies, failing which they will never be convinced that a general dictionary is performing its function of being an inclusive linguistic instrument. It is therefore imperative that a general dictionary should have a comprehensive front matter text that informs users of its objectives and why such objectives should be achieved.

Regarding the above cases where standard words have their synonyms in the dialects (as in the cases of hlapi and khobe, kota and mothate, nona and kholopana), it has been decided that at least a synonym member from a dialect should be included in the macrostructure of the dictionary as a lemma and such a dialectal lemma should receive a limited lexicographic treatment. In other words, a full lexicographic treatment is given at the standard word while a dialectal form receives a cross-reference. The only exception is when there is a relation of partial synonymy between such synonyms. In such cases, both the lemmas receive complete treatment with at least a reference marker linking the two articles.

These dialectal lemmas are also distinguished from the standard ones by a system of labelling. As such, geographical labels are used to indicate deviation from the standard language to mark the distribution of lemmas in specific areas where the language is spoken. In doing this, it has been decided not to label a lemma as a dialect but indicate the areas of its distribution. In the case of khobe, for example, the label Selobedu is added to indicate that it is used by the Balobedu people. This labelling assists dictionary users to know the areas where these words are used before acquiring their meanings. According to 
Feinauer (1999: 37), this kind of labelling is important as it leads to interaction between the label and the rest of the article.

Sometimes it is also not easy to know whether a particular word is dialectal or not, because some of the dialects of Northern Sotho are nearer to the standardised form. This means that most of the words from these dialects were codified and accepted as standard. This becomes evident from some of the words used in the Sepedi, Sekgaga, Semolepo and Semoletši dialects. For example, lexicographers do not know whether words such as itia (beat), itea (beat), fao (there), ntshe (there), bapala (play), nankhono (until today) and ntsogošo (left) are dialectal or not. And given the fact that these are used by speakers of the dialects prominent in standard Northern Sotho, these words might not be regarded as dialectal by many users of Northern Sotho. In these cases, a lexicographic decision has to be taken whether to label such a lexical item or not. Such a decision has to be influenced by the type of dictionary that is being compiled and as such these words are labelled as dialectal. This is, for example, because not all words from the Sepedi dialects are standardised. Amongst these are words such as mmane (my wife), itea (beat), ntshe (there), ahwi! (exclamation), and gadia (glance briefly at). Such word deviations are also labelled as dialectal even though they come from the prestige dialects of Northern Sotho.

Feinauer (1999: 20) defines semantic depletion as a case whereby the meaning of some lexical item has faded due to the high frequency of usage of the specific lexical item in a broad diversity of contexts. According to Feinauer, these lexical items are seen as semantic supports.

The true meanings of some of the lexical items from the dialects of Northern Sotho have faded to such an extent that they could be used as replacements for many other verbs in the same dialect. For example, in the Sepulana dialect, the verb tšhela is used to refer to many assimilated meanings such as pour, make, do, put and drive. In such cases, it was decided not to include occurrences of semantic depletion in the dictionary, because it is known that semantic depletion is an assimilated meaning that is obtained from the context and does not form part of the lexical meaning of a lemma. Therefore, a printed general dictionary cannot afford such inclusion because of space-saving considerations.

\subsection{Definitions and usage examples}

Gouws (1999: 14) says that a prominent feature of comprehensive dictionaries is the inclusion of non-standard forms, dialectal items, items with limited use as well as the vocabulary of different social groups. After lemmatising a dialectal word, there is the problem of deciding what language should be used in defining it. It is uncertain whether to use standard Northern Sotho or whether to use a dialect to define these items. In the current Northern Sotho monolingual dictionary, a dialect is not used to define such dialectal lemmas. Unfortunately many users, who speak some of the Northern Sotho dialects do not understand some of these given definitions, because they are not speakers of 
the standard language used in the dictionary. It is still to be established whether dialectal lemmas should be defined in the same dialect.

Although the use of standard Northern Sotho in defining and supplying usage examples as microstructural elements was continued, it is uncertain whether such a decision is doing justice to the dialects claimed to be represented in the dictionary. Although a general dictionary should be descriptive in nature, it is also undecided whether lexicographic conventions permit the use of dialects in treating dialectal items in a general dictionary.

A question to metalexicographers is that if standard language is used to define dialectal lemmas, is real language use really represented in the dictionary? It is said that the comprehensive approach of a general dictionary implies that it should include a substantial amount of encyclopaedic information regarding the dialectal forms. Will it be possible to represent the encyclopedic information of these dialectal lexical items in a comprehensive way if a language different from such dialectal information is used? The opinions of the speakers of these dialects were also tested, and their response was that they would prefer dialectal words treated with terms from the same dialect. Their argument was that if their dialects are treated in this way, they will have a sense of ownership of such a dictionary. This proves that a general dictionary can become a form of identity to all the speakers of a language. Gouws (1999: 16) says that the user and his needs have acquired a central position in lexicographic discussions and that the increased importance of the userperspective within the field of metalexicography emphasises again that dictionaries are practical instruments and that information transfer has to be determined by practical demands. This means that a successful dictionary is one that addresses the needs of the target users. If this is what the users of a general dictionary need, then ignoring their needs would render a dictionary unsuccessful. The dictionary is unable to use the dialects to define a dialectal lemma, because at the moment, as mentioned earlier, some of the dialects are difficult to put to writing. An attempt was made to involve some of the speakers of these dialects to assist in writing these words and their definitions, but it was discovered that some of the dialects have never been written before. What should be done now? Are they to be excluded from the dictionary because of this? Should the orthography of these dialectal words be developed before including them in a dictionary or is this the task of the Language Boards?

When the inclusion of usage examples regarding these dialectal forms was considered, a similar challenging situation was encountered. Feinauer (1999: 30) says that the most important task of examples is to explicate the syntactic performance of the lemma by placing it into a syntactic context. It is also a problem when the standard language is used to show the performance of a dialectal lexical item in real language use, because such a dialectal form does not function in Northern Sotho but in a dialect. Using Northern Sotho to show how such a word performs linguistically cannot satisfactorily inform the dic- 
tionary user about its contextual use. It is better to present such an example in its dialectal form, because the purpose of a usage example is to illustrate how a lemma is used in a communication context. Such a presentation can be supported by means of voice recordings on additional media.

Some of the translation dictionaries that tried to confine themselves to the general vocabulary of Northern Sotho are Ziervogel and Mokgokong's Groot Noord-Sotho Woordebook/Comprehensive Northern Sotho Dictionary of 1975 and Endemann's Wörterbuch der Sotho Sprache of 1911. These dictionaries record a large number of lexical items from some of the dialects of Northern Sotho and it is unfortunate that they are no longer widely used as they are out of circulation. The Preface to Ziervogel and Mokgokong's (1975: 87) Groot Noord-Sotho Woordebook/Comprehensive Northern Sotho Dictionary, which clearly indicates the nature of this dictionary reads as follows:

We began compiling this Dictionary in 1960 with a view to collect the vocabulary of Northern Sotho. We started with the written language, the two main elements of which are Pedi and the dialects of the Pietersburg-Potgietersrus area. This has been supplemented with the entries from the spoken language. ... All entries have first been checked with recognized authorities on the Northern Sotho language. As far as dialectical forms are concerned, only (own emphasis) those found in written sources and known as such by the average Northern Sotho speaker have been entered. Such dialectical forms are, of course, written in the official Northern Sotho orthography.

It is evident that Ziervogel and Mokgokong relied heavily on written language and not on spoken language when dealing with the dialects in their dictionary. Although this dictionary has represented some of the dialectal forms, its scientific nature (that is, lemmatising words according to their stems) has unfortunately deprived the users from finding the desired meaning of the dialectal words as quickly as possible. Sometimes users do not even succeed in finding the intended lemma.

Northern Sotho consists of words related to each other as synonyms and polysemes. The nature of a general bilingual dictionary requires that dialectal synonyms and polysemes are entered in the translation equivalent paradigm as members of the translation equivalents. Presented in this way, this meaning relationship would reflect the vocabulary of the language.

\section{Conclusion}

- General dictionaries should reflect real language by giving a valid account of the spoken language.

- In the case where a language distinguishes different dialects, dictionary units should have field workers for recording the spoken language to be treated in a general dictionary. By doing this, lexicographers will also be 
able to present pronunciation information regarding dialectal words in an accurate way with the assistance of their voice recordings.

- $\quad$ The Boards of Directors of the National Lexicography Units (NLUs) need to familiarise themselves with some aspects of metalexicography so that they may understand the nature and characteristics of different dictionaries compliled by the NLUs. In this way, what is contained in general dictionaries will have the approval of the Boards of Directors.

- The NLUs compiling general dictionaries should have a strict lexicographic manual which explains in detail why non-standard words should be included in the dictionary. This manual should be followed by the compilers right from the beginning of a lexicographic project until the end. It is the duty of the Editors-in-Chief to defend the validity and relevance of these manuals and they should also try to update them in cases when such needs arise.

- If the Oxford English Dictionary can include thousands of regionalisms encountered in standard contexts in the different English-speaking areas of the world, why can the dialects used by speakers from the neighbouring areas who also regard Northern Sotho as their first language not also be included in a general monolingual Northern Sotho dictionary?

- In treating the language as it is, lexicographers should include anatomical words and vulgarisms from the dialects. These words should be labelled so that the user is able to see the difference between them and the standard form.

- General dictionaries should be seen as all-inclusive dictionaries attempting to record all varieties of a language. Their scope should be designed in such a way that some of the lexical items are not omitted.

- A growing language should be reflected in a general dictionary. New lexical items that are technically, geographically, stylistically and temporally restricted should be seen as part of the macrostructural elements.

- Given the above, lexicographers need to familiarise themselves with the conventions to be followed when compiling general dictionaries.

From this discussion it is now easy to answer the question posed by this article: whether lemmatising dialectal forms in our general dictionaries is a way of developing or polluting the language? Dialectal forms are an integral part of the language and considering them as a source for possible candidate lemmas could develop the language and make the processes of "standardisation" even easier. 


\section{Bibliography}

Endemann, K. 1911. Wörterbuch der Sotho Sprache. Hamburg: L. Friedrichsen.

Feinauer, A.E. 1999. The Treatment of Semantic Information in Dictionaries. M.Phil. Study Guide. Stellenbosch: University of Stellenbosch.

Gouws, R.H. 1999. General Theory of Lexicography. M.Phil. Study Guide. Stellenbosch: University of Stellenbosch.

Gouws, R.H. 2006. Discipline, Dilemmas, Decisions and Data Distribution in the Planning and Compilation of Monolingual Dictionaries. Lexikos 16: 84-94.

Gouws, R.H and D.J. Prinsloo. 2005. Principles and Practice of South African Lexicography. Stellenbosch: SUN PReSS.

Hudson, R.A. 1980. Sociolinguistics. Cambridge: Cambridge University Press.

Kosch, I.M. and A.E. Kotzé. 1996. Northern Sotho Sound System. Study Guide for NSE301-3. Pretoria: University of South Africa.

Mojela, M.V. 2008. Standardization or Stigmatization? Challenges Confronting Lexicography and Terminography in Sesotho sa Leboa. Lexikos 18: 119-130.

Ziervogel, D. and P.C. Mokgokong. 1975. Groot Noord-Sotho Woordeboek/Comprehensive Northern Sotho Dictionary. Pretoria: J.L. van Schaik. 


\title{
Towards Internally-motivated English School Dictionaries for Zimbabwe*
}

\author{
Dion Nkomo, School of Languages - African Languages Studies Section, \\ Rhodes University, Grahamstown and Department of Afrikaans and Dutch, \\ Stellenbosch University, Stellenbosch, South Africa \\ (d.nkomo@ru.ac.za/deeouf@yahoo.co.uk)
}

\begin{abstract}
This article elaborates on the dichotomy of externally-motivated and internally-motivated dictionaries, introduced by Gouws (2005), and applies it in an analysis of the historical development of Zimbabwean lexicography. It shows that the applicability of this notion is not restricted to the analysis of dictionaries in indigenous African languages, but can also be expanded to dictionaries in languages of foreign origin which are now official languages in many African communities. With English being one of the official languages in Zimbabwe, this article argues that the production of English school dictionaries should be another growth point for Zimbabwean lexicography, whose recent rapid development occurred thanks to the production of mother-tongue dictionaries in the two main languages, Shona and Ndebele. Despite problems of a very ambiguous dictionaryusing policy in the education system, Zimbabwean learners continue to rely on imported English dictionaries. The appropriateness of these dictionaries is not considered when Zimbabweans buy or consult dictionaries. Quite often, learners use any readily available dictionary, regardless of whether or not it is appropriate, resulting in many learners using dictionaries that are too advanced for their levels. According to this article, one of the major problems with these dictionaries is not just that they are foreign, but that they are also externally-motivated since their user profiles are not compatible with the user profile of Zimbabwean learners.
\end{abstract}

Keywords: INTERNALLY-MOTIVATED DICTIONARIES, EXTERNALLY-MOTIVATED DICTIONARIES, SCHOOL DICTIONARIES, ZIMBABWEAN LEXICOGRAPHY, DICTIONARY CULTURE

Opsomming: Op weg na intern-gemotiveerde skoolwoordeboeke in Zimbabwe. Hierdie artikel ontgin die tweeledigheid van ekstern-gemotiveerde en intern-gemotiveerde woordeboeke, voorgestel deur Gouws (2005), en gebruik dit in 'n ontleding van die historiese ontwikkeling van die Zimbabwiese leksikografie. Dit toon dat die toepasbaarheid van hierdie

This article is based on a chapter from a Ph.D. dissertation (Nkomo 2012) accepted by Stellenbosch University, Stellenbosch, South Africa. Acknowledgements are due to Prof. R.H. Gouws and Stellenbosch University, Stellenbosch, for support towards the successful completion of the research, and Rhodes University, Grahamstown, for financially supporting the writing-up of this article. 
opvatting nie beperk is tot die ontleding van woordeboeke in die inheemse Afrikatale nie, maar ook uitgebrei kan word tot woordeboeke in tale van vreemde herkoms wat nou amptelike tale in baie Afrikagemeenskappe is. Met Engels as een van die amptelike tale in Zimbabwe, voer hierdie artikel aan dat die produksie van Engelse skoolwoordeboeke 'n groeipunt vir die Zimbabwiese leksikografie behoort te wees, waarvan die onlangse vinnige ontwikkeling plaasgevind het danksy die produksie van moedertaalwoordeboeke in die twee hooftale Sjona en Ndebele. Ten spyte van probleme van 'n baie dubbelsinnige beleid betreffende woordeboekgebruik in die opvoedingstelsel, hou Zimbabwiese leerders vol om hulle te verlaat op ingevoerde Engelse woordeboeke. Die geskiktheid van hierdie woordeboeke word nie in aanmerking geneem wanneer Zimbabwiërs woordeboeke koop of raadpleeg nie. Heel dikwels gebruik leerders enige maklik beskikbare woordeboek, ongeag of dit geskik is of nie, met die gevolg dat baie leerders woordeboeke gebruik wat te gevorderd is vir hul vlakke. Volgens hierdie artikel is een van die hoofprobleme met hierdie woordeboeke nie slegs dat hulle vreemd is nie, maar dat hulle ook ekstern-gemotiveerd is aangesien hulle gebruikersprofiele nie verenigbaar is met die gebruikersprofiele van Zimbabwiese leerders nie.

Sleutelwoorde: INTERN-GEMOTIVEERDE WOORDEBOEKE, EKSTERN-GEMOTIVEERDE WOORDEBOEKE, SKOOLWOORDEBOEKE, ZIMBABWIESE LEKSIKOGRAFIE, WOORDEBOEKKULTUUR

\section{Introduction}

The turn of the 21st century saw the emergence and exponential growth of scholarship on Zimbabwean lexicography. This scholarship has been closely linked to the African Languages Lexical (ALLEX) Project. Although Zimbabwean lexicography is now over a century old, the ALLEX Project represents its momentous period as it resulted in the publication of several dictionaries in the country's two languages, Shona and Ndebele. The dictionaries published during this period marked a break in the established lexicographical tradition in the country, with mother-tongue lexicographers producing dictionaries for the Zimbabwean community.

Although Zimbabwean lexicography has begun producing dictionaries for the local community, it still remains uncertain if the needed dictionary culture has been sufficiently established. Hartmann and James (1998: 41) define dictionary culture as "the critical awareness of the value and limitations of dictionaries and other reference works in a particular community". During the ALLEX Project, lack of a dictionary culture posed a challenge for lexicographers (Hadebe 2004, Maphosa and Nkomo 2009). Hadebe (2004: 89) writes about improving dictionary-using skills as "the long aim of developing a dictionary culture amongst the Ndebele". He argues that "user-friendliness is difficult to attain ... in a community where ... dictionary culture is non-existent" (Hadebe 2004: 90). An analysis of dictionary use, skills and ownership, among other aspects, by Maphosa and Nkomo (2009) confirms "the infancy of a dictionary-using culture in the Ndebele community" (Maphosa and Nkomo 2009: 45). It may be noted that these two studies were undertaken from a largely language-specific lexico- 
graphical perspective, i.e. evaluating the first monolingual Ndebele dictionary with a view of developing the culture in order to improve both future practical lexicography and dictionary use in the language. However, Maphosa and Nkomo (2009: 45) observe:

Although the ... community is not accustomed to Ndebele dictionaries, it has nevertheless used English dictionaries. Secondary school students could even name some English dictionaries they have consulted. The ... need for ... information ... from English dictionaries ... is part of the dictionary culture of the Ndebele community.

While their research was done from the perspective of Ndebele lexicography, they observe that "English dictionaries seem to be an integral part of the dictionary-using culture in the Ndebele community" (Maphosa and Nkomo 2009: 42). As long as dictionary culture remains investigated from languagespecific perspectives, certain facts about it may be difficult to uncover. Similarly, practical lexicography may be compelled to determine certain priorities in cognisance of certain linguistic, communication and educational realities, as Zimbabwean lexicography during the ALLEX Project has done, but lexicographical scholarship may need to be broader and more visionary in order to cater for certain areas which may be taken for granted. English dictionaries in African communities represent one such area.

This article presents and develops some ideas from Nkomo (2012), research that considers a lexicographical intervention in the study and use of English in Zimbabwe. It affirms the use of English dictionaries as part of Zimbabwean lexicography to which metalexicography should pay attention. English dictionaries used in the country are therefore located in the historical development of Zimbabwean lexicography and are consequently subjected to scholarly criticism. Specifically, the notion of externally-motivated versus internally-motivated dictionaries (Gouws 2005) is used to characterise English dictionaries used in the country's schools and to argue for internally-motivated English school dictionaries which may respond to the immediate needs of Zimbabwean learners.

\section{The distinction between externally-motivated and internally-moti- vated dictionaries}

The distinction between externally-motivated and internally-motivated dictionaries was introduced by Gouws (2005). He employs this distinction to indicate that the earliest dictionaries in African languages were not produced for the use of the speakers of African languages. Gouws (2005: 96) characterises externally-motivated dictionaries as follows:

Although they have been compiled and published in Africa the motivation for their compilation had been to assist users from outside Africa in their attempts to communicate with members of the local speech communities. 
On the contrary, internally-motivated dictionaries would be those produced to assist local users in a speech community (cf. Gouws 2005). This means that internally-motivated dictionaries in Africa are those that have been produced to assist members of African speech communities. This distinction provides a useful apparatus for the historical analysis of lexicographical developments in Africa. However, this dichotomy needs to be explored further to analyse the features of dictionaries that motivate their classification as internally-motivated or externally-motivated.

One of the facts that emerge from this undertaking is that the relevance of the distinction also applies to dictionaries in languages of foreign origin which are now official languages in most African communities. This means that internally-motivated dictionaries may be conceived in languages such as English, French and Portuguese for speech communities in countries like Zimbabwe, Gabon and Mozambique respectively. For this to happen, African lexicographers should not focus exclusively on dictionaries in indigenous African languages as this may leave all the responsibility of producing dictionaries in languages of foreign origin in the hands of foreign lexicographers. There might be justification in this if the foreign lexicographers are mother-tongue speakers of the concerned languages with a wealth of experience in practical lexicography. However, determining the needs related to that particular language in a different country may be quite challenging for foreign lexicographers, especially if it is not done in collaboration with linguists and teachers of the concerned languages in the target communities.

Furthermore, it will be indicated that whereas externally-motivated dictionaries have been compiled and published in Africa, internally-motivated dictionaries may also be compiled and be published for a specific speech community externally. In addressing the challenge cited in the preceding paragraph, foreign lexicographers may successfully compile internally-motivated dictionaries for a different speech community, provided the compilation process is preceded by a user-research in the relevant community. This may be done by working closely with linguists and teachers of the concerned languages in the target communities. The dictionaries may even be published in a different country but eventually prove to be useful and user-friendly for the target users.

\section{Externally-motivated dictionaries in Zimbabwe}

It may no longer be easy to determine the first dictionary to be used in Zimbabwe, let alone the purpose for which it was used, as well as when and by whom it was used. What may be assumed is that, as they were coming from Europe which had established literary and lexicographical traditions, missionaries and explorers might have equipped themselves with dictionaries, among other works of reference such as atlases and encyclopaedias. However, local Africans could not benefit from such reference works as they were not yet liter- 
ate and conversant in European languages. What may therefore be effectively analysed as elements of the history of Zimbabwean lexicography are those earliest dictionaries that were produced for use within the Zimbabwean borders. Those dictionaries formed the lexicographical foundations of the practice that continued until the second half of the 20th century. They include the following:

- Dictionary of the Tebele and Shona Languages (Elliot 1897);

- Matebele and Makalaka Vocabulary: Intended for the Use of Prospectors and Farmers in Mashonaland (Weale 1903);

- Notes for a SiNdebele Dictionary and Grammar (Elliot 1910);

- A Shona Dictionary with an Outline of Shona Grammar (Biehler 1950);

- Standard Shona Dictionary: Compiled for the Southern Rhodesia Native Affairs Department (Hannan 1959);

- A Practical Ndebele Dictionary (Pelling 1966);

- $\quad$ A Basic English-Shona Dictionary (Dale 1975).

These dictionaries have much in common. Firstly, they were all compiled during the colonial era. Secondly, the dictionaries are interlingual, mainly covering local languages as subject of lexicographical treatment and English as the metalanguage. Thirdly, the dictionaries were all compiled by foreigners of European origin. Finally, and most crucially, Chabata (2007: 280) observes that the dictionaries were meant for the use of missionaries or colonial administrators trying to learn the indigenous languages, but not Zimbabweans learning either their native languages or English. Weale's (1903) dictionary, according to its self-telling subtitle, attests to this fact. Similar observations have been made regarding bilingual dictionaries produced in other African countries during the colonial period (Awak 1990: 10; Busane 1990: 20). It was too early for the production of monolingual dictionaries in the indigenous Zimbabwean languages. All this is consistent with the remarks made by Gallardo (1980) regarding bilingual dictionaries. He (Gallardo 1980: 61) writes:

Only fully standardized languages have their lexicon organized in monolingual dictionaries. ... In non-standardized language situations, dictionaries do not exist or, at best, are bilingual dictionaries, that is, compiled in function of a different language. ... apart from being always bilingual, [the dictionaries] are usually not compiled by members of the speech community involved, who are not even able to use them.

The foregoing would suggest that the dictionaries under discussion have been of no absolute value to indigenous Zimbabweans. This would be an overstatement. One aspect of their use is in connection with English by native speakers of indigenous languages. Professor George Fortune foresaw the use of the Standard Shona Dictionary in connection with problems regarding English when, 
in the preface of the second edition, he recommended that the dictionary's "enlarged English-Shona Index ... must serve until a proper English-Shona dictionary is compiled" (Hannan 1978: vi). Hannan (1978: 758) was equally honest enough to advise that the index would be limited as far as English is concerned when he wrote:

It must be emphasised that this is not an English-Shona dictionary. The Shona words listed in an index entry are not presented as the only Shona words that have this particular English meaning; they are presented as Shona words in whose definitions, in the Shona-English dictionary, this particular English word occurs which leads to the index entry.

Hadebe (2005: 266) confirms the use of the earliest bilingual dictionaries in connection with English needs. The use of the dictionaries for translation from English to African languages is one of the primary functions for which they were compiled. This assumes a high level of competence in English from the users. The use of the dictionaries by users who want to acquire English vocabulary and meaning via the indigenous languages is a nonconsequential function which confronts the user with problems of sense discrimination in these dictionaries. Loyal to their primary target users, the dictionaries provide introductory and grammatical information in the front matter texts using English. The limited grammatical data in the form of word-class indication is given using English codes in both sections of the biscopal Standard Shona Dictionary and A Practical Ndebele Dictionary. This clearly requires a high level of English competence and experience of using English dictionaries which could not be guaranteed among many Zimbabweans at the time the dictionaries were produced. At the moment, their use, especially by users who want to learn English vocabulary and meaning, is a clear indicator of a lexicographical hiatus in the country's inventory of reference works. New dictionaries which prioritise the speakers of indigenous languages as deserving learners of English are needed. Such dictionaries need to take into account recent metalexicographical developments in bilingual and learners' lexicography.

At a certain point, monolingual English dictionaries produced mainly in Britain entered the Zimbabwean lexicographical scene. There is no doubt that the latter used to play an important role in the education sector during and after the colonial period. Zimbabweans used monolingual English dictionaries as they studied further in local and foreign institutions where English was, and still remains, the dominant language of education. It will appear in Section 5 that despite an unfavourable dictionary-using policy in Zimbabwean education and a number of challenges that they present, imported monolingual dictionaries continue to be used in Zimbabwean schools, unfortunately not to optimal success levels.

There is, however, only one English dictionary that appeared in Zimbabwe, i.e. the Ventures Student's Dictionary (VSD) published by College Press in 1984. The introduction of this dictionary, quoted here in full, states: 
This dictionary is written for students with a basic knowledge of the English language but who have not yet reached an advanced level of ability. It has been prepared with two particular groups of users in mind: students for whom English is a Second Language, that is those who are taught school subjects such as geography, mathematics, physics, and literature in English; and students studying for examinations at the intermediate level. The choice of entries and meanings reflects the needs of both such groups: for example, greater attention has been paid to 'study language' - than is usual in dictionaries of a similar size.

Students sometimes use a learner's dictionary that is too advanced for their real needs. It is hoped that this medium-sized dictionary will indeed be a useful reference book and will be found to develop the knowledge and abilities of the intermediate learner of English.

Although there seems to have been some thought towards the production of the VSD, e.g. that students "sometimes use a learner's dictionary that is too advanced for their needs" (Manser 1984: i), the VSD has itself not been the best solution. Firstly, as will be seen in section 6.1, a lexicographically-informed characterisation of Zimbabweans as English learners indicates that the intermediate level, starting at Grade 4 and ending at Form 4, is too broad. The VSD, which College Press sells as a primary school dictionary, may also be too advanced for most intermediate learners. The second part of its user guide states that pronunciation is indicated using the spelling of the International Phonetic Association (IPA). Not only intermediate Zimbabwean learners of English will find this difficult, but also many advanced learners without the relevant training. This part of the user guide states further that "the form of speech shown is the kind of British English spoken by educated native speakers in England" (Manser 1984: v). When the dictionary is considered as a whole, including its back matter texts, it becomes clear that the VSD was compiled like other English learners' dictionaries whereby the target user is only known for being an additional learner of English but not a specifically Zimbabwean one. The only Zimbabwean feature this dictionary possesses is that it was published in Zimbabwe, for it could be one of the Macmillan learners' dictionaries which College Press, an associate company of Macmillan, renamed according to a Zimbabwean textbook series for a Zimbabwean market. Otherwise the only English dictionary published in Zimbabwe is not even an internally-motivated dictionary, because its target users are not compatible with the user profile and characterisation of Zimbabweans as learners of English.

\section{Internally-motivated Zimbabwean mother-tongue dictionaries}

What remained missing from the Zimbabwean lexicographical scene for a long time are internally-motivated monolingual dictionaries in the indigenous languages. There were several efforts in compiling such dictionaries which were, however, unsuccessful (Hadebe 2006: 59). This remained the case until the 
advent of the ALLEX Project in 1992. The ALLEX Project was a joint research endeavour between the University of Zimbabwe's Department of African Languages and Literature and partner departments at two Scandinavian universities, the University of Oslo in Norway and the University of Gothenburg in Sweden. Its focus was on the lexicography of African languages, mainly Shona and Ndebele. Spanning over 15 years, it ended in 2007, having been institutionalised into the African Languages Research Institute (ALRI) in 2001. At its various stages until the present, it has been hailed as "a milestone in the development of Zimbabwean languages" (Chabata 2007, 2008). To a very large extent, this is due credit since seven dictionaries were completed. These include:

- Duramazwi reChiShona, a Shona general monolingual dictionary (Chimhundu 1996);

- Isichazamazwi SesiNdebele, a Ndebele general monolingual dictionary (Hadebe et al. 2001);

- Duramazwi Guru reChiShona, an advanced Shona monolingual dictionary (Chimhundu et al. 2001);

- Duramazwi reUrapi neUtano, a Shona biomedical terms dictionary (Mpofu et al. 2004);

- Duramazwi reMimhanzi, a Shona dictionary of music terms (Mheta 2005);

- Isichazamazwi SezoMculo, a Ndebele dictionary of music terms (Nkomo and Moyo 2006);

- Duramazwi reDudziramutauro neUvaranomwe, a Shona dictionary of linguistic and literary terms (Chimhundu and Chabata 2007).

What makes the ALLEX Project a success story as far as African lexicography is concerned is mainly the fact that it pioneered mother-tongue lexicography in Zimbabwe. Furthermore, the end of the ALLEX Project has seen some of the Zimbabwean lexicographers taking their capabilities further in both lexicographical practice and research. The Cross Border Languages (CROBOL) Project which involves Zimbabwean and Mozambican languages is the brainchild of some former ALLEX Project lexicographers. Despite challenges related to funding, the legacy of the ALLEX Project gives hope that a long meagre spell in Zimbabwean lexicography may not be experienced again.

\section{English dictionaries in Zimbabwean schools}

The policy regarding the role of dictionaries in the Zimbabwean education system seems to be very ambiguous. The 'O' Level English syllabus states that pupils should be able to: 
understand and use the different types of reading materials they are likely to meet both inside and outside school, including fiction, poetry, drama, non-fiction, textbooks, reference books (especially dictionaries), magazines, newspapers, instruction manuals and reports (ZIMSEC 2008-2012: 13).

The mention of dictionaries in this quotation is problematic, not only because it is given in brackets, but for at least two reasons. Firstly, dictionaries should not be placed in one basket with all those 'reading materials' because they are meant to be consulted but not to be read (Béjoint 2000: 10; Tarp 2008: 46). Secondly, while the other materials may be read or used to learn something from them, the use of dictionaries is normally motivated by problems encountered while reading other texts like textbooks or novels. Finally, and related to the second reason, while understanding all the different types of reading materials listed above, perhaps with the exception of manuals, which may be the ultimate goal in the learning process, using dictionaries will normally be a means towards understanding the other materials.

Lack of clarity regarding dictionary use in the Zimbabwean education and lack of scholarly attention to this specific issue and the issue of English dictionaries in general has resulted in a situation whereby it is assumed that only lexicography in the African languages has problems while everything is well with English lexicography. Nkomo (2012: 22) argues that because of this, the following has been unknown regarding English dictionaries in Zimbabwe:

- Whether dictionaries are used in the teaching/learning of English;

- Whether dictionaries are available in the market which can support the teaching/learning of English;

- Whether the dictionaries that are either used or available for use are suitable for the learners.

Trying to fill this knowledge hiatus, Nkomo (2012: 251) found that, as a consequence of an ambiguous dictionary-using policy, the following problems prevail with regard to the use of English dictionaries in the Zimbabwean education system:

(a) Few teachers and learners in public schools own dictionaries;

(b) Many teachers prohibit learners from using dictionaries, regarding dictionary use as a form of dependency which impedes creative language acquisition;

(c) Some of the learners who own dictionaries do not bring them to school as they are prohibited while others use them regardless of the teachers' policy;

(d) Dictionary typology is not an issue for schools who own dictionaries, with advanced learners' dictionaries even found at primary schools; 
(e) Teachers, Curriculum Development Unit officials and Zimbabwe School Examinations Council officials are themselves unclear about the policy which discourages dictionary use;

(f) Dictionaries are not a priority in public schools where textbooks are in acute shortage.

In the light of these findings, it is clear that Zimbabwe requires dictionary pedagogy, not only for learners but also for teachers and other stakeholders in the education system. It is a problem both for lexicography in the African languages and for lexicography in general. Yet dictionary pedagogy alone will not thrive without appropriate dictionaries whereby the immediately available dictionary is consulted or bought. The fact that Zimbabwean lexicography excludes the production of English dictionaries means that they have to be imported. English school dictionaries are currently being produced in abundance in England, America, South Africa and other countries where English lexicography is part of the main lexicographical processes. Although these dictionaries are produced by mother-tongue speakers of English and published by lexicographical powerhouses like Oxford University Press, Longman and Macmillan Publishers, they sometimes have certain limitations when it comes to certain users. This problem applies to different types of English dictionaries. Firstly, some of the dictionaries are produced for mother-tongue speakers of English whose needs do not correspond to those of a variety of additional English learners such as Zimbabweans. Secondly, there are then English learners' dictionaries which are produced for additional English learners in general. The only consideration that is taken into account in their production is normally that the target users are additional English learners, disregarding the diversity of these additional English learners to such an extent that the linguistic, cultural, historical and educational backgrounds influencing the diverse learner needs are not catered for. As indicated earlier on, despite being published in Zimbabwe, the VSD belongs in this category. Finally, there is also what Benson (2001) terms the ethnocentrism of the English dictionary whereby certain prejudices tend to affect the formulation of explanations of meaning and choice of illustrative examples. Consider the following treatment of the word hedgehog in the 7th edition of the Oxford Advanced Learner's Dictionary (OALD):

a small brown European animal with stiff parts like needles (called SPINES) covering its back. Hedgehogs are NOCTURNAL (= active mostly at night) and can roll into a ball to defend themselves when they are attacked.

While it might be relevant to mention that hedgehogs are found in Europe, it is incorrect that they are European animals. Hedgehogs, known as inhloni in Zimbabwean Ndebele (Pelling 1975), inhloli in isiZulu (De Schryver et al. 2010) and intloni in isiXhosa (Fischer et al. 1985) are also found in other continents of the world. Defining hedgehog as a European animal is therefore misleading, because Zimbabwean learners who know a hedgehog and its name in their 
native language may think that the dictionary refers to something else, not the animal that they may have seen in their rural homes in Lupane or Nkayi. In this regard, Tomaszczyk (1983), referred to in Tarp (2008), criticises definitions in English learners' dictionaries for being too British. Benson (2001: i) finds it unsurprising when he writes:

Since most of English dictionaries are published in Britain or the United States, this has led to an ethnocentric representation of the language, in which knowledge is filtered through Anglo-American perspectives on English in the world.

When it comes to children's dictionaries or school dictionaries, lexicographers tend to rely on the curriculum material in their formulation of dictionary bases or lexicographical corpora. Consultations with curriculum developers and teachers are advisedly made. This is the case with a number of English dictionaries such as the Oxford Junior Dictionary, the Oxford Children's Dictionary and the Oxford Primary Dictionary. On the cover of the Oxford Primary Dictionary it is indicated that the dictionary has been "tested in schools", indicating that the production of the dictionaries took into account the needs of the target users. However, the explicit statement that the Oxford Junior Dictionary "fulfils the Primary National Strategy requirements for KS2-YR2" in the UK and the "Scottish guidelines P3, 4 and 5" will leave one wondering what it fulfils in other educational and linguistic contexts like South Africa where it is also sold. On this account, when marketed all over the English-speaking world, these dictionaries will not even be externally-motivated in the target communities but they will fail the local users as products meant for a foreign market. Thus the decision by Oxford University Press (South Africa) and Maskew Miller Longman to produce the First Bilingual Dictionary series and the Foundation Phase Dictionary series respectively is a commendable move for providing learners with internally-motivated and user-friendly school dictionaries. In section 6, some steps are outlined to propose a similar undertaking for Zimbabwean English learners.

\section{Steps towards internally-motivated English school dictionaries for Zimbabwe}

In line with the lexicographical function theory (cf. Bergenholtz and Tarp 1995, 2003; Tarp 2000, 2004, 2004a, 2008), it is proposed that the first step towards the production of internally-motivated English school dictionaries for Zimbabwe should be the characterisation of Zimbabweans as English learners and the situations in which they learn and use the language. After this a model can be formulated for the production of the dictionaries and the implementation of such a model in view of the user profiles, their situations and lexicographical needs. The purpose of the following subsections is to illustrate these suggestions by means of detail. 
As learners and users of English, Zimbabweans may be divided following the language learning levels generally used in language teaching to obtain the categories of Zimbabwean English beginners, intermediate English learners and advanced English learners. However, these language-learning levels need to be re-interpreted for lexicographical purposes, especially in accordance with the theory of learners' lexicography (Tarp 2004, 2004a, 2008). Both the inner and outer criteria should then be considered to characterise the learners (Tarp 2008: 137). For example, whereas the Zimbabwean learners may share common mother-tongue languages, they may be distinguished in terms of their educational levels as follows:

(a) English beginners as learners between Grade 0 and Grade 3 within which, according to the language-in-education policy, the learners should learn English as a subject but learn other subjects using the mother tongue.

(b) Intermediate English learners as learners between Grade 4 and Form 4 within which English is a compulsory subject and English medium is compulsory for teaching all subjects. With this level being the broadest, both quantitative and qualitative changes associated with the learning and use of English result in further sublevels of lower-intermediate learners (Grade 4 to Grade 7), middle-intermediate learners (Form 1 to Form 2) and upper-intermediate learners (Form 3 to Form 4).

(c) Advanced English learners as those Zimbabweans who have passed the English General Certificate of Education Ordinary Level (GCE 'O' Level/ 'O' Level) examinations which qualifies them for admission to the advanced level and tertiary education as well as employment in various professions where the 'O' Level English pass is essential. After this they will continue learning English as part of lifelong learning outside the school programme.

Finer and elaborated details with regard to the categorisation and subcategorisation of Zimbabweans as English learners and users are made in Nkomo (2012), taking into account the expected levels of comprehension, production and thinking in English in the contexts of learning English as a subject and using it as a medium of instruction. When this is considered together with various learner characteristics and problems which the learners may experience and solve by consulting dictionaries, a model is formulated for a lexicographical intervention in the acquisition of English in Zimbabwe.

\subsection{A model for internally-motivated English school dictionaries}

The proposed model for the lexicographical support in the acquisition of English by Zimbabwean learners comprises dictionaries that are typologised according to the English learners characterised in section 6 above. The model is presented in figure 1. 


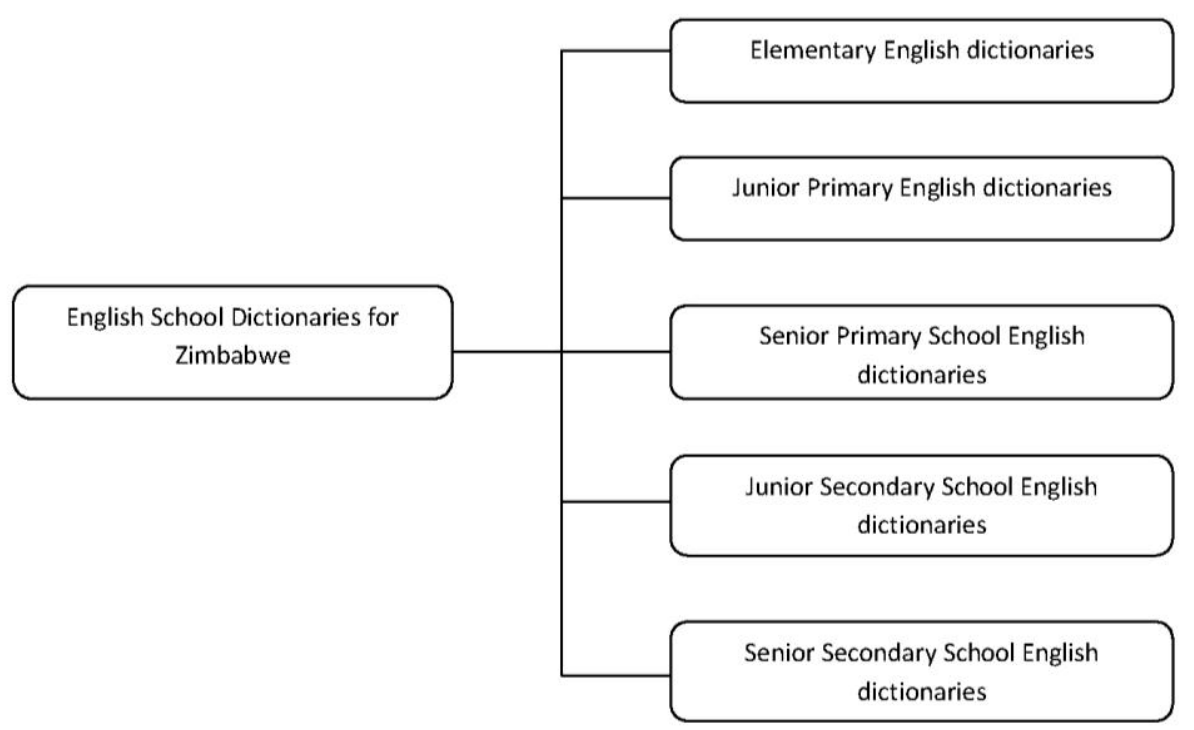

Figure 1: A proposed model for internally-motivated English school dictionaries for Zimbabwe (Adapted from Nkomo 2012: 214)

Since the proposed model is based on the characterisation of the English learners in the Zimbabwean school system, it will be important that their compilation takes into account the changing situations and subsequent needs of the learners regarding English as a subject and a medium of instruction. This will have implications for lexicographical tasks such as lemma selection, explanations of meaning, choice and formulation of examples and the utilisation of outer texts. Therefore, instead of discussing the dictionaries that comprise the proposed model, lexicographical tasks are defined with examples being made in relation to the dictionaries proposed for different levels.

\subsubsection{Lemma selection}

Tarp (2000: 198) states:

The only way to reach a scientific conclusion of what should be included in a dictionary is to base this conclusion on an analysis of the user, the user characteristics, the user situations, the user needs and the corresponding lexicographic functions.

This statement is of utmost importance at the lemma selection stage, but it applies also to the inclusion of other types of lexicographical data. Writing specifically on lemma selection, Gouws and Prinsloo (2005: 86) assert: 
The lemma selection of a dictionary should be done in accordance with the functions and type of that dictionary. It should be done in such a way that the selection of the lexicon falling within the scope of the dictionary is adequately reflected in the dictionary.

Practising lexicographers are fully aware of the far-reaching consequences of lemma selection on their final work. This is indicated by statements that have been made regarding the selection of the lexicon covered in many published dictionaries. However, some of the information that is supplied in this regard is of little help. It seems to be either motivated by commercial reasons or an act of common practice. For example, the use of corpora and the textbooks used in schools are commonly employed justifications for the lemmatic scope of a number of school dictionaries. Yet the mere fact that most of those corpora, textbooks and schools are confined to Britain for dictionaries that are then marketed as international products smacks of hypocrisy on the part of the publishers. What is unfortunate is giving an impression that a dictionary whose lemma selection was localised would still remain equally useful even in other different contexts. Otherwise the localisation of lemma selection especially for school dictionaries is the best way of covering vocabulary needs and other information needs associated with the vocabulary scope that certain learners will encounter or use on a regular basis in their learning. In that case, dedicated corpora such as the one reported by Louw and Jordan (1993) would be useful for Zimbabwean secondary school dictionaries, because it draws its material from Zimbabwean textbooks and other educational materials.

Localisation of lemma selection will ensure that the underlying principles for the process, such as those cited from Tarp (2000) as well as Gouws and Prinsloo (2005) above, are adhered to. In implementing the proposed model, localisation will afford the learners at the beginner level, for instance, an opportunity to learn words that are peculiarly Zimbabwean, having originated from other Zimbabwean languages, but thus far not included in existing English school dictionaries. It will also be possible to capture a balanced representation of urban and rural life through the lemmatic scope of dictionaries, something which is missing from beginner's dictionaries imported from Britain. Even at higher levels, the learners will get to learn words, which they will also need to use, that have developed as products of the local culture, history and religion within the mainstream of English communication in the country.

It has to be emphasised that localised lemma selection does not imply that the proposed school dictionaries have to include only those words that are of local origin in Zimbabwe. A more general lexical selection may still be used as the point of departure. However, certain words will need to be pruned from the existing English dictionaries and be replaced by those that are relevant in the local learning and communication of the target users.

On another level, localised lemma selection will ensure that Zimbabweans have access to all the relevant vocabulary and information pertaining to that vocabulary regardless of being part of either British or American English. At 
lower levels, British school dictionaries consciously exclude American forms, a favour that is reciprocated by American lexicographers. While British English used to provide standards for Zimbabwe, the American influence has now been embraced in education. English examiners no longer penalise learners for using American spelling in favour of British forms. Rather, the learners are advised to use whatever choices they make consistently. This means that labor is now acceptable as long as it will not be used interchangeably with labour in the same script. Lemma selection for locally-motivated English school dictionaries in Zimbabwe will have to include both British and American forms, be it in terms of vocabulary or spelling. This is what will make Zimbabwean English school dictionaries different from both those that are imported from Britain and America.

\subsubsection{Explanations of meaning}

When it comes to the localisation of meanings, the proposed dictionaries should ensure that the explanations of meaning (definitions) are relevant to the target users' worldview and where polisemy exists, this should also apply to sense ordering. Following Nakao (1989), Tarp (2008: 187) gives bathroom as a good example of a word whose meaning varies with countries and cultures. His observation may apply to Zimbabwe where the idea of a bathroom even varies according to whether one stays in a township or a low density suburb, i.e. the issue of social class. The bathroom would be the same room as the toilet in the former but in the later there is the luxury of having them separately. For rural children the idea may even be alien, and the word toilet may even have to be learnt for the first time at school. Therefore, a localised explanation will need to ensure that learners, especially at beginners and lower-intermediate levels get optimum meaning information that is not blind to other realities.

The word ice is another good example. Ice is generally frozen water. However, owing to climatic differences, the idea of frozen water in Europe is much broader than it is to Zimbabweans. For learners at a younger age, it would be irrelevant to provide details that refer to ice that forms outside as a result of freezing temperatures. Thus, before exposing them to that kind of ice, it would be much better to tell them of ice that is found in the fridge or freezer. This means that the ice that is used to preserve food becomes the primary sense. Space permitting, the sense of ice covering the ground or mountains will have to be given as a secondary sense or perhaps a primary sense in dictionaries for older learners. This is not the case in the existing dictionaries which have been published in a different environment. Therefore, for locally-motivated English school dictionaries, explanations of meanings should enhance the relevance of the supplied information and ensure that the dictionaries do not project an ethnocentric worldview such as the OALD definition of hedgehog cited earlier. 


\subsubsection{Illustrative examples}

Just like explanations of meaning, examples in dictionaries need to be relevant. They need to depict typical contextual usage. Again, let us take ice as an example of a lemma whose explanation of meaning needs to be supplemented by an example. An illustrative example which refers to children playing on ice or ice covering the water would be irrelevant in Zimbabwe, but the one referring to buying ice in preparation for a party would be more relevant. However, this will depend on the specificity of the paraphrase of meaning. If it is general as in the sense of frozen water, a localised example will certainly have to refer to that frozen water which keeps food or drinks cold.

Related to the same word ice would be Christmas. While the explanation may be unproblematic for this word, exemplification may need greater care. For example, a sentence relating to going for ice skating on Christmas would be spot-on for European target users. On the contrary, for Zimbabweans and Africans in general, Christmas comes in summer. Therefore, an unlocalised example may cause cognitive disturbances to the learner who will find it unusual to go for ice skating, not only on Christmas but even in winter.

A seemingly simple word like food will even require great caution when it comes to exemplification, which may be compulsory in elementary dictionaries. Whatever foodstuffs are mentioned in the example sentence, they need to be those that are known to the users. European or Chinese food would estrange young Zimbabwean learners if it was used as part of a sentence exemplifying the lemma food in the same way as foreign food tends to estrange people when they get exposed to it for the first time.

Accordingly, corpus-based examples may play an important role in the internally-motivated English school dictionaries. Local usage of the language should be reflected and the examples should be relevant to the users. This can contribute to the accomplishment of both cognitive and communication functions of dictionaries. Therefore, while British school dictionaries may provide good models for a lexicographical intervention in the acquisition and use of English in Zimbabwe, examples as data categories are one area that may make them less appealing.

\subsubsection{Bilingual and multilingual solutions}

The Oxford first bilingual dictionaries in South Africa may be regarded as bilingual versions of the Oxford Very First Dictionary (OVFD) or the Oxford First Dictionary (OFD). With Oxford University Press being the publisher of the monolingual dictionaries in Britain and the bilingual ones in South Africa, there is no doubt that the dictionary concepts of the OVFD and OFD were adopted in the conception of the South African bilingual dictionaries. However, one characteristic that makes the dictionaries South African is the fact that they have been made bilingual, pairing English with the indigenous South African 
languages. Of course, more localisation other than making the dictionaries bilingual took place, especially on the level of lemmatisation the dictionaries were made more relevant to South African learners.

Providing bilingual lexicographical data could be another practical approach to producing internally-motivated English school dictionaries for Zimbabwe. In this case, this means that further to pruning irrelevant words in the lemma stock, redrafting and rearranging paraphrases of meaning as well as examples, including such data categories as translation equivalents, translated paraphrases of meanings and examples in Shona, Ndebele and other Zimbabwean languages, depending on the level of language learning for which each dictionary will be used, will be a major step. The learners will have at their disposal dictionaries which facilitate the acquisition and use of English by means of local languages. This may be effected in some of the monolingual school dictionaries produced in England or the South African bilingual school dictionaries falling under the Oxford First Bilingual Dictionary series or the Maskew Miller Longman Foundation Phase Dictionary series. By making Zimbabwean indigenous languages members of the language pairs/sets through bilingual or multilingual solutions, the existing English dictionaries would be significantly turned from being foreign or externally-motivated dictionaries into being internally-motivated dictionaries.

\subsubsection{Outer texts}

The debate of relevance, which has been discussed with respect to explanations of meaning and examples may also be extended to the data contained in the outer texts of school dictionaries. English school dictionaries published in Britain and South Africa clearly reflect the respective countries as the environment with which dictionary users should be familiar. The middle matter text guiding dictionary users in letter writing in the Oxford Primary Dictionary uses London addresses. The Macmillan School Dictionary has a text entitled "Telephone numbers" whereby area codes for London and Cambridge as well as the international dialling code for the UK are given in the examples. Because of using examples that are relevant to Britain in their outer texts, these dictionaries immediately become relevant to users in that locality. This is a case where something that is good for the British is bad for Zimbabweans, and it is characteristic of several other British dictionaries, including the OALD. In the OALD, a very long list of abbreviations is given in the back matter. Besides what would be standard universal abbreviations such as CV for curriculum vitae, D.O.B. for date of birth and NGO for non-governmental organisation, most abbreviations are specifically British or American. Observing this, one may conclude that the OALD endeavours to assist learners not only with English but also with a knowledge of Britain and America. Given that Zimbabwean English learners primarily learn the language to use it within their country where it is an official language, 
it becomes clear that the language they learn from this dictionary is distanced from local cultures which also contribute towards the development of English.

The study of outer texts in the South African school dictionaries indicates that an effort was made to localise the contents. For instance, immediately after giving an account of the origins of the English language, the Longman South African School Dictionary gives a history of South African English in its back matter. Local addresses are used in guides to letter-writing while a section on weights and measures uses an example relating to the fact that the Kruger National Park covers 20000 square kilometres. The Oxford South African Secondary School Dictionary gives in its back matter a list of South Africa's languages, describes the National Curriculum Statement, phases of education in South Africa and the constituents of the National Senior Certificate. All these features indicate that lexicographers set out to make the school dictionaries internally-motivated.

Internally-motivated English school dictionaries for Zimbabwean learners may be produced by emulating the South African dictionaries in terms of the localisation of the contents of outer texts. The VSD once again comes off badly. The only Zimbabwean word or concept that is used in the dictionary is Zimbabwe, firstly in the imprint giving bibliographical details and in the back matter text listing names of countries and continents. Besides this, its long list of abbreviations contains nothing Zimbabwean at all. If the dictionary was truly Zimbabwean, it should have given the learners an opportunity to learn, among others, what ZANU (PF), ZAPU or ZBC stands for. Outer texts listing Zimbabwean cities, languages, tourist attractions (since Zimbabwe is endowed with several of them, including the Victoria Falls which is among the "seven wonders of the world") and abbreviations, and giving a historical outline of the English language or education system in the country would have been relevant to the target users. The Oxford First Bilingual Dictionary series also make use of dictionary stories in the reference section (middle matter and back matter texts) and characters whose names are typically South African are used. If the publisher undertakes to produce similar dictionaries for Zimbabwe, as it aspires to cover Southern Africa, personal names like Shafiek and forms of address like Oom need to be replaced with typically Zimbabwean names and forms in order for the users to identify closely with the dictionaries.

As the initial steps of establishing and developing a dictionary culture for specialised lexicography, some outer texts in the school dictionaries have to list the terms and registers used in specific school subjects. The school dictionaries should not be restricted to the communicative and cognitive situations associated with the use of English. Where possible, the cognitive dimension of learning other subjects should also be catered for, although that is primarily the task of LSP lexicography, since English is also learnt and used even in situations of learning different subjects. 


\subsection{Practical implementation of the model}

In order to produce English school dictionaries whose endeavour is to assist Zimbabwean learners, those dictionaries ideally need to be Zimbabwean in every sense, i.e. produced in Zimbabwe for Zimbabwean users. This would make the dictionaries completely internally-motivated. Having the dictionaries published locally would not only facilitate the localisation procedures discussed earlier, it would also help the users develop a bonding relationship with the dictionaries and provide the necessary ingredients for the establishment of a dictionary culture in the country.

However, it would be important in this regard to consider the lexicographical experience of Zimbabwean publishers and their potential regarding the kinds of dictionaries proposed here. The question may be asked why those publishers have not taken an active role in the production of English dictionaries for Zimbabweans and whether their reasons do not pose a huge impediment in the implementation of the proposed model. Three publishers, namely College Press, Mambo Press and Longman Zimbabwe have each played a role in Zimbabwean lexicographical history. Besides publishing a number of dictionaries before and for the ALLEX Project, College Press and Longman Zimbabwe are the local distributors of English dictionaries for the international lexicographical powerhouses to which they are affiliated, i.e. Macmillan Publishers and Longman International/Pearson Education respectively. Mambo Press was also the publisher of a number of bilingual dictionaries before the ALLEX Project and the LSP dictionaries produced under the ALLEX Project. Nkomo (2012: 230) found that College Press and Longman Zimbabwe have the capacity, through collaboration with their mother companies, to produce internally-motivated English dictionaries for Zimbabwe rather than merely distributing the imported dictionaries whose target users are not compatible with the user profiles of local English learners. Besides these publishers, Oxford University Press in South Africa has recently started to spread its wings over Southern African countries like Botswana and Namibia where it has started producing localised dictionaries similar to those produced in South Africa and they have already started to engage with Zimbabwean English teachers and other stakeholders with possibilities of extending their dictionaries series.

The presence of Oxford University Press in South Africa, and its rivals Longman and Macmillan, has definitely enhanced the localisation of English lexicography in South Africa. If one compares the South African and Zimbabwean situations, it becomes apparent that the infrastructural presence of these powerhouses of English lexicography is not enough. The host country has to make its lexicographical needs known and convince the publishers that what they are offering in terms of externally-produced dictionaries is inadequate. The discussion in this article should be considered the beginning of such a dialogue. Of course, that can only be possible in an environment of a developed dictionary culture where not only the lexicographical needs will be acknowledged, but where efforts will also be made to address these needs by 
consulting the available dictionaries, no matter how insufficient their assistance might be. This presupposes a dictionary culture, or clear efforts of establishing such a culture as the acknowledgement in South Africa that dictionaries have a role in the implementation of the national language policy that is enshrined in the country's constitution adopted on the brink of Apartheid (Gouws 2003). Should such collaborative efforts be initiated, it would not ultimately matter where the dictionaries are published, as long as the user profiles, dictionary bases or dictionary corpora are established by taking account of Zimbabweans as English learners and their user situations established in the context of language learning and use within the Zimbabwean education system. Therefore, as indicated earlier, internally-motivated English dictionaries do not necessarily have to be produced within the local community where the dictionaries have to be used, in as much as externally-motivated dictionaries have been produced within the target communities.

\section{Conclusion}

This article has applied Gouws's (2005) distinction between externally-motivated and internally-motivated dictionaries. While externally-motivated dictionaries may be associated with the lexicography of the missionary period in African communities, this article has indicated that Zimbabwe, and indeed many other African countries, continue to rely on imported dictionaries with regard to languages of foreign origin like English which are now official languages. In the case of Zimbabwe, it has been argued that the English dictionaries that are used, especially within the education system, can be characterised as externally-motivated, because, although they are generally prepared with additional English language learners in mind, they do not pay sufficient attention to local user profiles.

Accordingly, an argument has been made for internally-motivated English school dictionaries for Zimbabwe. These dictionaries will have to take into account Zimbabwean learners as target users and consider the country's education system as the broad context within which to identify user situations. This will inform lexicographical tasks such as the formulation of dictionary bases or lexicographical corpora, lemma selection, defining, choice and formulation of illustrative examples as well as the utilisation of outer texts. If all these tasks are performed with Zimbabwean learners in mind, then it would not matter much whether the dictionaries are published in Zimbabwe or externally. For example, internally-motivated English school dictionaries may be published by Oxford University Press in South Africa as long as collaboration with relevant stakeholders in Zimbabwe results in productive user research. However, Zimbabwean publishers also need to play a more active role besides the distribution of imported dictionaries compiled by their mother companies.

However, as far as school dictionaries are concerned in Zimbabwe, dictionary culture is another area of concern. The dictionary using policy within 
the education system deserves attention which means that lexicographical pedagogy is needed not only for the learners, but also for teachers and other educational stakeholders like curriculum developers. Such an endeavour should not be language-specific but has to be informative about the role of dictionaries in the learning of English, indigenous languages and other school subjects.

\section{References}

\section{Cited dictionaries}

A Basic Shona Dictionary. Dale, D. 1975. Gwelo: Mambo Press.

A Practical Ndebele Dictionary. Pelling, J.N. 1966. Harare: Longman Zimbabwe.

A Shona Dictionary with an Outline of Shona Grammar. Biehler, E. 1950. Salisbury: Jesuit Fathers.

Dictionary of Lexicography. Hartmann, R.R.K. and G. James (Eds.). 1998. London/New York: Routledge.

Dictionary of the Tebele and Shona Languages. Elliot, W.A. 1897. London: David Nutt.

Duramazwi Guru reChiShona. Chimhundu, H. et al. (Eds.). 2001. Harare: College Press.

Duramazwi reChiShona. Chimhundu, H. (Ed.). 1996. Harare: College Press.

Duramazwi reDudziramutauro neUvaranomwe. Chimhundu, H. and E. Chabata. 2007. Gweru: Mambo

Press.

Duramazwi reMimhanzi. Mheta, G. 2005. Gweru: Mambo Press.

Duramazwi reUrapi neUtano. Mpofu, N. et al. (Eds.). 2004. Gweru: Mambo Press.

Isichazamazwi SesiNdebele. Hadebe, H. et al. (Eds.). 2001. Harare: College Press.

Isichazamazwi SezoMculo. Nkomo, D. and N. Moyo (Eds.). 2006. Gweru: Mambo Press.

Longman South African School Dictionary. Adrian-Vallance, E. et al. (Eds.). 2008. Harlow: Pearson Education.

Macmillan School Dictionary. Rundell, M. 2001. Oxford: Macmillan Education.

Matebele and Malaka Vocabulary: Intended for the Use of Prospectors and Farmers in Mashonaland. Weale,

M.E. 1903. Cape Town: Murray and St. Leger.

Notes for a SiNdebele Dictionary and Grammar. Elliot, W.A. 1910. Bristol: The Sindebele Publishing Company.

Oxford Advanced Learner's Dictionary. Wehmeier, S. et al. (Eds.). 2009. Oxford: Oxford University Press.

Oxford Children's Dictionary. Allen, R. 2003. Oxford: Oxford University Press.

Oxford English-Xhosa Dictionary. Fischer, A. et al. 1985. Cape Town: Oxford University Press.

Oxford First Dictionary. Goldsmith, E. and A. Delahunty (Eds.). 2007. Oxford: Oxford University Press.

Oxford Junior Dictionary. Dignen, S. 2007. Oxford: Oxford University Press.

Oxford Primary Dictionary. Allen, R. and R. Delahunty (Eds.). 2006. Oxford: Oxford University Press.

Oxford South African Secondary School Dictionary. Reynolds, M. (Ed.). 2009. Cape Town: Oxford University Press.

Oxford Very First Dictionary. Kirtely, C. 2007. Oxford: Oxford University Press.

Standard Shona Dictionary: Compiled for the Southern Rhodesia Native Affairs Department. Hannan, M. 1959. London: Macmillan.

Standard Shona Dictionary. Hannan, M. 1974². Salisbury: The Literature Bureau.

Ventures Student's Dictionary. Manser, M.H. (Ed.). 1984. Harare: College Press. 


\section{Other literature}

Awak, M.K. 1990. Historical Background, with Special Reference to Western Africa. Hartmann, R.R.K. (Ed.). 1990: 8-18.

Béjoint, H. 2000. Modern Lexicography: An Introduction. Oxford/New York: Oxford University Press. Benson, P. 2001. Ethnocentrism and the English Dictionary. New York: Routledge.

Bergenholtz, H. and S. Tarp. 2003. Two Opposing Theories: On H.E. Wiegand's Recent Discovery of Lexicographic Functions. Hermes, Journal of Linguistics 31: 171-196.

Bergenholtz, H. and S. Tarp (Eds.). 1995. Manual of Specialised Lexicography. The Preparation of Specialised Dictionaries. Amsterdam/Philadelphia: John Benjamins.

Busane, M. 1990. Lexicography in Central Africa: The User Perspective, with Special Reference to Zaïre. Hartmann, R.R.K. (Ed.). 1990: 19-35.

Chabata, E. 2007. The African Languages Research Institute: A Milestone in the Development of African Languages. Lexikos 17: 278-291.

Chabata, E. 2008. Language Development: Progress and Challenges in a Multilingual Zimbabwe. Southern African Linguistics and Applied Language Studies 26(1): 13-26.

Gallardo, A. 1980. Dictionaries and the Standardization Process. Zgusta, L. (Ed.). 1980. Theory and Method in Lexicography: Western and Non-Western Perspectives: 59-69. Columbia: Hornbeam Press.

Gouws, R.H. 2003. Towards the Formulation of a Theoretically Motivated Model for the National Lexicography Units in South Africa. Hartmann, R.R.K. (Ed.). 2003. Lexicography: Critical Concepts: 218-246. London/New York: Routledge.

Gouws, R.H. 2005. Lexicography of Africa. Brown, K. (Ed.). 2005 Encyclopedia of Language and Linguistics: 95-101. Second edition. Oxford: Elsevier.

Gouws, R.H. and D.J. Prinsloo. 2005. Principles and Practice of South African Lexicography. Stellenbosch: SUN PReSS.

Hadebe, S. 2004. Improving Dictionary Skills in Ndebele. Lexikos 14: 89-104.

Hadebe, S. 2005. Reflections on the Proposed Ndebele-Shona/Shona-Ndebele Dictionary. Lexikos 15: 265-275.

Hadebe, S. 2006. The Standardisation of the Ndebele Language through Dictionary-Making. Harare/ Oslo: The ALLEX Project.

Hartmann, R.R.K. (Ed.). 1990. Lexicography in Africa. Progress Reports from the Dictionary Research Centre Workshop at Exeter, 24-26 March 1989. Exeter: University of Exeter Press.

Louw, W.E. and J. Jordan. 1993. Corpus of Zimbabwean English at the University of Zimbabwe Computer Centre. Zambezia 20(2): 131-138.

Maphosa, M. and D. Nkomo. 2009. The Microstructure of Isichazamazwi SesiNdebele. Lexikos 19 Supplement: $38-50$.

Nakao, K. 2003. English-Japanese Learners' Dictionaries. International Journal of Lexicography 2(4): 295-314.

Nkomo, D. 2012. Towards a Lexicographical Intervention in the Acquisition and Use of English in Zimbabwe. Unpublished D.Litt. Dissertation. Stellenbosch: Stellenbosch University.

Tarp, S. 2000. Theoretical Challenges to Practical Specialised Lexicography. Lexikos 10: 189-208.

Tarp, S. 2004. Basic Problems of Learners' Lexicography. Lexikos 14: 222-252. 
Tarp, S. 2004a. Reflections on Dictionaries Designed to Assist Users with Text Production in a Foreign Language. Lexikos 14: 299-325.

Tarp, S. 2008. Lexicography in the Borderland between Knowledge and Non-Knowledge: General Lexicographical Theory with Particular Focus on Learner's Lexicography. Tübingen: Max Niemeyer.

Tomaszczyk, J. 1983. The Case for Bilingual Dictionaries for Foreign Language Learners. Hartmann, R.R.K. (Ed.). 1983. Lexicography: Principles and Practice: 41-51. London: Academic Press.

ZIMSEC. 2008-2012. Zimbabwe General Certificate of Education (ZGCE) For Examination in November 2008-2012 'O' Level Syllabus English Language (1122). 


\title{
'n Kritiese waardering van die hantering van kollokasies en idiome in die HAT (2005)
}

\author{
Anna N. Otto, Departement Taal- en Literatuurstudie, \\ Nelson Mandela Metropolitaanse Universiteit, Port Elizabeth, Suid-Afrika \\ (anna.otto@nmmu.ac.za)
}

Opsomming: Odendal en Gouws het die HAT gevestig as waarskynlik dié gewildste Afrikaanse verklarende woordeboek in Suid-Afrika. In die vyfde uitgawe van die HAT (2005) kom 'n groot aantal kollokasies en idiome voor, maar die argument in hierdie artikel is dat ' $n$ reeds puik woordeboek verder ten opsigte van die bogenoemde twee datakategorieë verbeter kan word deur: (a) die skrapping van verouderde woorde, kollokasies en idiome te oorweeg ten einde ruimte te bespaar vir meer eietydse leksikale items, (b) die benutting van Media24 as gebalanseerde datakorpus, (c) die aanwending van teoretiese insigte van onder andere Melčuk om te verseker dat belangrike leksikale funksies in dié woordeboek in kollokasies weerspieël word, en (d) 'n konsekwente hantering wat kan lei tot groter gebruikersvriendelikheid. Die opnamebeleid, soos in die gebruikersgids aangedui, moet konsekwent toegepas word sodat kitsherwinning van inligting verseker kan word. Eweneens moet etikette, waar nodig, konsekwent aangebied word ten einde waardevolle gebruiksleiding te verskaf. Data uit die spreektaal kan verseker dat veral situasionele vaste uitdrukkings in dié woordeboek tot hulle reg kom.

Sleutelwoorde: IDIOOM, KOLLOKASIE, SELEKSIEBEPERKINGS, BASIS, KOLLOKATOR, MIKROSTRUKTUUR, ETIKET, KORPUSMATERIAAL, VERGELYKING, VOORBEELD, VERKLARENDE WOORDEBOEK, DISKOERSFUNKSIE

\footnotetext{
Abstract: A Critical Appreciation of the Treatment of Collocations and Idioms in the HAT (2005). Odendal and Gouws established the HAT as probably the most popular Afrikaans explanatory dictionary in South Africa. In the fifth edition of the HAT (2005), a large number of collocations and idioms appear, however, the argument in this article is that an already excellent dictionary can be further improved with regard to the above-mentioned two data categories by: (a) considering the removal of archaic words, collocations and idioms in order to save space for more contemporary lexical items; (b) using Media24 as a balanced data corpus; (c) utilising theoretical insights from inter alia Melčuk to ensure that important lexical functions are reflected in collocations in this dictionary and (d) a consistent treatment which can lead to greater user-friendliness. The treatment policy, as indicated in the usage guide, should be applied consistently in order to ensure rapid access to information. Likewise, labels should, where necessary, be consistently included to provide valuable usage guidance. Data from the spoken language can ensure that especially situational fixed expressions are recognised in this dictionary.
} 
Keywords: IDIOM, COLLOCATION, SELECTION RESTRICTIONS, BASE, COLLOCATE, MICROSTRUCTURE, LABEL, CORPUS MATERIAL, COMPARISON, EXAMPLE, EXPLANATORY DICTIONARY, DISCOURSE FUNCTION

\section{Inleiding}

In Lexikos 16 wys Odendal (2006: 287) op die feit dat hy Perskor in die jare neëntig genader het om 'n tweede, jonger redakteur aan te stel met die oog op 'n vierde en verdere uitgawes van die Verklarende Handwoordeboek van die Afrikaanse Taal (voortaan HAT), en hy sê dan verder dat hy Rufus Gouws voorgestel het. Dié uitstekende keuse motiveer hy soos volg: "Sy status as teoretiese en praktiese leksikograaf maak hom 'n onbetwiste leier as woordeboekkundige." Hierdie kundigheid van Gouws (en Odendal) blyk onder andere uit die groot aantal idiome en kollokasies in die HAT (2005). Voorstelle ter verdere uitbreiding en moontlike verbetering van hierdie datakategorieë sal in hierdie artikel aan die hand gedoen word. Die voorbeelde wat gebruik word, kom uit die Media24 Argief, asook Otto (s.j.).

\section{Terminologieverklaring}

\subsection{Kollokasies}

Oor die term kollokasie is daar beslis nie eenstemmigheid nie. Hartmann en James (1998: 22) definieer dit as "die semantiese verenigbaarheid van grammaties nabygeleë woorde" (my vertaling). Verder word uitgewys dat sekere patrone tussen woorde soos adjektief - selfstandige naamwoord, byvoorbeeld blonde hare, selfstandige naamwoord - werkwoord, byvoorbeeld moord pleeg, of werkwoord - setsel, byvoorbeeld berus op (feite) positief beskou kan word as "solidariteitsrelasies" (my vertaling) of negatief as "seleksiebeperkings" (* geel hare, "moord doen, *berus in (feite)). Ongeag van hoe hulle beskou word, bly die feit staan dat kollokasies vaster verbindings is as vrye kombinasies en minder vas as idiome. Aangesien kollokeerbaarheid moeilik vir aanleerders is, behoort woordeboeke hierdie patrone te spesifiseer, veral waar vertaalekwivalensie onvoorspelbaar is. Dit is verder nie duidelik watter lid van die kollokasie meer "basies" as die ander lid is nie en onder watter een van die twee lede die kollokasie in die woordeboek moet verskyn nie (Hartmann en James 1998: 23).

Die vraag kan tereg gestel word of kollokasies ook belangrik is in woordeboeke vir moedertaalsprekers. Standaardwoordeboeke vir moedertaalsprekers kan weens 'n ruimteprobleem nie te veel kollokasies afsonderlik opneem nie (vergelyk Bergenholtz en Gouws 2010: 46), maar baie jong moedertaalsprekers in Suid-Afrika sukkel deesdae selfs met hulle moedertaal as gevolg van die gebrek aan 'n leeskultuur en daarmee saam ook soms gebrekkige onderwys. Bergenholtz en Gouws (2010: 44) wys daarop dat 'n woordeboekgebruiker wat 
'n woordeboek raadpleeg vir teksproduksie veral inligting nodig het oor produktiewe gebruik. Gebruiksfrekwente woorde mag onvoorspelbare gebruike of kollokasies vir 'n polisemiese onderskeiding hê wat nie so bekend is nie. Ten einde die gebruiker bewus te maak van hierdie kollokasies of voorbeeldsinne, behoort selfs hoogs frekwente woorde soms as lemmas in hierdie tipe woordeboek te kwalifiseer. Indien 'n mens in die gids vir die woordeboekgebruiker lees dat die HAT se lemmas daarop gerig is om belangrike taalkundige en gebruiksleiding oor te dra, kry mens die idee dat die HAT wel 'n woordeboek is wat ook op teksproduksie gerig is. Dit sou dus wenslik wees om soveel as moontlik kollokasies in die HAT op te neem ten einde moedertaalsprekers te help om hulself beter uit te druk. Probleme met kollokasiegebruik deur moedertaalsprekers is nie beperk tot Suid-Afrika nie, hoewel dit hier waarskynlik 'n baie groter probleem is as byvoorbeeld in Europa. Howarth (1998: 171) wys op die feit dat moedertaalsprekers se afwykings verband hou met grammatikale wysigings en leksikale vervanging. Vergelyk ook Svensén (1993: 101) wat bevestig dat kollokasies belangrik is in beide eentalige en aktiewe tweetalige woordeboeke, aangesien die leksikograaf nie van die gebruiker kan verwag om te weet watter woorde gewoonlik saam optree nie.

Fontenelle (2008: 173) wys op die tipe vrae wat gebruikers byvoorbeeld oor die woord arrow kan vra: "What can one do to arrows? (= which verbs can take arrow as direct object?); What can arrows do? (= which verbs can take arrow as subject?); What can arrows be like? (= which adjectives can modify arrow?)" Die semantiese verhouding tussen die basis en die kollokator kan (veral in 'n masjienleesbare woordeboek) aangedui word deur die "MeaningText Theory", soos deur Mel'čuk en andere ontwikkel (vergelyk Fontenelle se beskrywing hiervan in Cowie (1998: 197), waardeur die meeste sistematiese en herhaaldelik voorkomende leksikaal-semantiese verhoudings in 'n algemenetaal-leksikon geformaliseer kan word in terme van 'n stel van ongeveer 60 funksies. Een van hierdie funksies is byvoorbeeld Magn wat soos volg deur Fontenelle (1998: 200) verduidelik word:

$\mathrm{Q}$ Which adjective can express an intense form of enthusiasm?

A Magn $($ enthusiasm $)=$ devouring, intense, unequalled, unflagging, wild

'n Verdere vraag vir die leksikograaf sou wees: Waar behoort kollokasies in die mikrostruktuur tereg te kom? Gouws (1996: 5) verskaf die volgende oplossing:

Belonging to separate information categories the collocations and idioms ... should be accommodated in different article positions which will leave the user with different search areas allocated to each information category. By using different typefaces or structural markers the user could be lead to a clear distinction between these two information categories.

In hierdie verband dui Gouws (1989: 227) meer spesifiek aan dat kollokasies in die mikrostruktuur as koteksinskrywings voorkom om die tipiese mikrosintaktiese konteks van die lemma te illustreer. 


\subsubsection{Die hantering van kollokasies in die HAT (2005)}

In die volgende bespreking sal voorstelle aan die hand gedoen word met betrekking tot enersyds die moontlike uitbreiding van kollokasies en andersyds die skrapping van verouderde kollokasies.

Die HAT (2005) dui die letterlike gebruik van baai saam met die vaste setsel in aan, maar gee nie 'n voorbeeld van die figuurlike gebruik, soos in die volgende voorbeeld nie: "Ons baai heerlik in die glorie wat op ons afbons." By baklei word net die grammatiese kollokator met aangedui en nie die hoogs frekwente teen en vir nie, soos blyk uit die onderstaande voorbeelde: baklei teen: Teen wie moet hy baklei? Daar is geen ander bulle in die wildtuin waarteen hy sy staal kan wys nie. Terloops, die sinoniemdefinisies is onvolledig, want hulle maak byvoorbeeld nie voorsiening vir "veg" (soos by diere in die voorafgaande voorbeeld nie). baklei vir: Hulle baklei vir reg en geregtigheid. In plaas daarvan om twee voorbeeldsinne te hê met tydswoorde in, kon tipiese grammatiese kollokasies soos baklei teen en baklei vir geillustreer gewees het. Vergelyk die voorbeeldsinne in HAT: Die susters baklei heeldag. 'n Man en vrou wat gedurig baklei.

By baar word tereg, in figuurlike sin, kollokators soos kommer en probleme aangedui, maar nie ander frekwente kollokators soos onrus, opsien en sorg nie, soos blyk uit die volgende voorbeelde: Sodanige statistiek sal onrus baar by die breë publiek en daartoe lei dat niemand meer die produk wil koop nie. PB het opsien gebaar deur aan te kondig dat hy ook nou ' $n$ nuwe party wil stig. en Die toenemende misbruik van wapens deur skoliere baar groot sorg.

Frekwente kollokators soos aflaai en laai ontbreek by bagasie, maar 'n tipiese voorbepaling te veel kom wel in die HAT (2005) by bagasie voor.

In die HAT (2005) ontbreek die tipiese kollokasie bande smee, soos in die volgende voorbeeld: Dit sal geweldig baie vir die land beteken - vir sy toerisme, buitelandse valuta en nuwe bande wat gesmee sal word. Tog word bande verbreek twee keer opgeneem, een keer onder band 2 (fig.) as Ou bande verbreek en aan die einde van die artikel onder die uitdrukkings by Bande verbreek, "jou losmaak van". Hierbenewens is verouderde of minstens verouderende uitdrukkings soos die volgende opgeneem: iemand se band aandraai, almal se band wees, bo iemand se band en uit die band spring.

Baie ruimte kan in die HAT bespaar word deur heelwat van die verouderde woorde en nederlandismes te verwyder en die ruimte wat so verkry word, te vervang met neologismes, moderne kollokasies en idiome wat meer algemeen gebruik word. Die skrapping van die volgende woorde kan byvoorbeeld ernstig oorweeg word: aan 1 ... 5, aanbel, aanblaf 2, aandien, aandrang 3, viewerig (tans sonder enige etiket), aanfluiting. Daar is nog baie meer verouderde woorde wat vir skrapping in aanmerking sou kon kom, want Zgusta (1989: 72) se opmerking is veral waar ten opsigte van Afrikaans: "Constant change of lexicon is observable in each language." 


\section{$2.2 \quad$ Idiome}

Net soos daar nie eenstemmigheid is oor wat kollokasies is nie, is daar eweneens verskillende menings oor wat 'n idioom is. Hartmann en James (1998: 71) definieer ' $n$ idioom as ' $n$ vaste uitdrukking waarvan die geheelbetekenis nie altyd afgelei kan word van die kombinasie van die betekenisse van die konstituerende woorde nie, byvoorbeeld go to the country "announce a general election" teenoor sy letterlike teenhanger go to the country "travel to the countryside".

\subsection{1 'n Bespreking van die hantering van idiome in die HAT (2005)}

\subsubsection{Verteenwoordigendheid}

Prinsloo (2009: 225-226) beskryf die HAT (2005) as 'n uitstekende, groot omvattende algemene enkelvolumewoordeboek wat nie tradisioneel op korpusmateriaal gebaseer is nie en wat baie baat kan vind by die gebruik van 'n gebalanseerde korpus, naamlik die Media24 Argief. Vervolgens sal aangetoon word dat die HAT (2005) inderdaad aangevul behoort te word deur korpusse.

In die HAT (2005) verskyn daar onder baadjie verskillende idiome, maar 'n idioom wat dikwels voorkom, ontbreek hier, naamlik (in 'n) nuwe baadjie, soos blyk uit die volgende voorbeelde: Vandeesmaand, met ons nuwe baadjie ook reeds gevestig, bied ons u opnuut 'n keur van prikkelende leesstof. en Hierdie idee is nie noodwendig rewolusionêr van aard nie, maar meestal ou idees wat net in 'n nuwe baadjie angebied word.

In die HAT (2005) word die idioom eers baas en dan Klaas onder baas ${ }^{\mathbf{1}}$ gegee, maar die idiomatiese uitdrukking baas en Klaas wees is nie opgeneem nie. Laasgenoemde is aangetref in die volgende voorbeeld: Hulle beland saam in Boston, aangewese op mekaar, maar sy is baas en hy Klaas, en hulle pes mekaar. Onder Klaas is Klaas wees, "'n dienskneg, 'n mindere wees" wel as uitdrukking opgeneem en verklaar.

Die bekende vergelyking slaap soos ' $n \mathbf{b a b a}$ is nie in die HAT (2005) opgeneem nie. In my eie databasis kom die volgende voorbeeld voor, maar daar is ook heelwat voorbeelde op die internet: Snags slaap ek soos ' $n$ baba. Ook my man ... wat gewoonlik in die nanag wakker geskrik het, slaap soos ' $n$ klip.

Die idioom bak staan is nie in die HAT (2005) opgeneem nie. Dit kom geredelik voor in die geselstaal. Vergelyk die volgende voorbeelde: Dit het net lelik bak staan gekos toe die helfte van ons werkers nie opgedaag het nie! Ons het omtrent bak gestaan by die basaar.

Ook ontbreek die idioom vir elke bakatel wat voorkom in 'n voorbeeld soos die volgende: Nog ene huil vir elke bakatel dat die trane spat.

Die Groot Vyf, soos in die volgende voorbeeld, word ook nie vermeld nie: Nes die huidige reeks note word die Groot Vyf steeds op die nuwe note uitgebeeld, maar die diere verskyn nou op die agterkant. 
Binne die Suid-Afrikaanse konteks het aangewese groepe 'n baie spesifieke betekenis en behoort derhalwe ook verklaar te word, soos blyk uit die volgende sitaat: Om dié rede is sommige poste, waar daar onderverteenwoordiging is, vir aangewese groepe.

Eweneens ontbreek twee en twee bymekaarsit (< Engels), soos blyk uit die volgende voorbeeld: ' $n$ Dierehawe wat hulle gebel het om blyplek vir die honde te $k r y$, het ... twee en twee bymekaargesit en vir Shelley gebel.

Onder spore ontbreek die uitdrukking diep spore trap, soos in die volgende voorbeeld: "Ernst het oral diep spore getrap," het sy suster ... vertel.

'n Informele idioom kom nie onder hart voor nie, naamlik jou hart klop tjoklits (< Engels): Ek beveel die blog aan ... as mooi kiekies jou hart tjoklits laat klop.

Nog 'n ontbrekende idioom is aan die agterspeen suig wat nie in die HAT (2005) onder agterspeen opgeneem is nie. Vergelyk: Ons is moeg om aan die agterspeen te suig.

\subsubsection{Volledigheid/korrektheid van idioomaanbieding}

Gouws (1990: 269) wys daarop dat Afrikaanse verklarende woordeboeke se hantering van variasie by idiome nie konsekwent is nie. In hierdie verband sê hy: "By leksikale lemmas word die aangawe van wisselvorme as deel van die aanvaarde leksikografiese praktyk beskou. Dit behoort ook ten opsigte van multileksikale lemmas toegepas te word en by vaste uitdrukkings moet die optrede van opsionele elemente beskou word as wisselvormvariante van die betrokke leksikale item."

Botha (1991: 32) beskryf die vorm waarin vaste uitdrukkings opgeneem word. Hy sê onder andere dat, indien 'n uitdrukking in die positiewe en negatiewe vorm kan optree, word dit in die mees tipiese vorm gegee (bv. nie weet waar jy an of af is nie en die kool is die sous nie werd nie) met voorbeeldmateriaal van die positiewe en die negatiewe vorm. Indien die uitdrukking slegs negatief gebruik word, word dit uitsluitlik in dié vorm opgeneem en (a) normaalweg in die neutraalste vorm, dus met nie ... nie, bv. nie 'n vlieg kwaad doen nie maar (b) vaste negatiefvorme word slegs in die betrokke vorm gegee (bv. van geen sout of water weet nie; geen nuus is goeie nuus; niks nuuts onder die son nie; so nooit as te nimmer).

In die HAT (2005) kom die idioom iemand op sy baadjie takseer onder baadjie voor. Hierdie idioom word dikwels in die negatiewe vorm gebruik en die opsionele dubbele nie behoort dus as deel van die idioom, tussen hakies, aangedui te word indien daar nie genoeg korpusinligting is om aan te dui of die positiewe al dan die negatiewe gebruik die voorkeurvorm is nie, dit wil sê: (Nie) iemand op sy baadjie takseer (nie). Vergelyk byvoorbeeld: Ma sê jy takseer nie ' $n$ mens op sy baadjie nie.

Aan die ander kant moet idiome volledig wees in dié sin dat al die vaste elemente wel daar moet wees. By die vyfde betekenisonderskeiding van aan ${ }^{\mathbf{1}}$ b.nw. word die idioom hoog aan wees as 'n betekenisonderskeiding aangedui, en nie as 'n idioom wat voorafgegaan word deur die merker UITDR., korrek en 
volledig gegee en verklaar is en van die etiket verouderend/verouderd voorsien is nie. Vergelyk: ... 5 Aangeklam, dronk: Hy was (hoog, goed) aan na die partytjie.

Vergelyk ook: die bal aan die rol sit teenoor die bal is (vinnig) aan die rol wat nie in die HAT (2005) opgeneem is nie: Ondersoek (sal) ingestel ... word na die moontlikheid om ons reikwydte te vergroot. Die bal is aan die rol. en Die bal was vinnig aan die rol. Beyers het reeds vroeër die jaar ... uit die BB bedank.

Idiome het dikwels belangrike diskoersfunksies. Volgens Moon (1998: 217) het vaste uitdrukkings verskeie teksfunksies: Hulle tree informatief, evaluerend, situasioneel, modaliserend of organiserend op. In die HAT word onder voet byvoorbeeld aangedui dat jou voet! ' $n$ uitroep is om iemand af te jak, maar se voet, wat ook algemeen gebruik word om te toon dat die spreker glad nie met iets saamstem of van iets hou nie, is nie opgeneem nie. Spreektaaltekste behoort ondersoek te word ten einde veral situasionele vaste uitdrukkings in 'n woordeboekkorpus op te neem.

Dit is belangrik dat die korrekte gebruik van idiome verseker word deur alle idiome wat nie neutraal gebruik word nie van etikette te voorsien. (Vergelyk byvoorbeeld Potgieter 2006: 188) wie se kriterium vir tweetalige woordeboeke ewe geldig is vir eentalige verklarende handwoordeboeke.) Die oorgrote meerderheid idiome in die HAT (2005) word korrek geëtiketteer, maar daar is tog uitsonderings. Daar word byvoorbeeld nie aangedui dat op die bakoond sit 'n verouderde idioom is nie. Dieselfde probleem kom by die bed hou voor. Verder word laasgenoemde uitdrukking soms as 'n kollokasie met 'n verklaring (by bed 1) hanteer, maar onder hou' ${ }^{\mathbf{1}}$ word dit as 'n uitdrukking onder die merker UITDR. gegee en verklaar. Indien 'n mens wel hierdie verouderde uitdrukking in die HAT wil behou, behoort dit onder bed hanteer te word, aangesien dit idiomaties is en die HAT se konvensie is om uitdrukkings onder die eerste selfstandige naamwoord op te neem. Die rede vir hierdie inkonsekwentheid lê waarskynlik daarin dat die grense tussen verskillende tipes uitdrukkings soms baie vaag is. Vergelyk in hierdie verband Moon (1998: 2) se opmerking: "Different terms are sometimes used to describe identical or very similar kinds of unit; at the same time, a single term may be used to denote very different phenomena."

Volgens Botha (1991: 33) word vergelykings, bv. so rooi soos bloed onder idiomatiese uitdrukkings opgeneem. Dit is belangrik dat die gekose merker, UITDR., deurgaans voor idiome of ander vaste uitdrukkings gebruik word. Enkele uitsonderings, waar hierdie merker ontbreek, is by aal: So glad soos ' $n$ aal, baie geslepe.

\section{Slot}

Hoewel die HAT (2005) ongetwyfeld 'n rykdom aan kollokasies en vaste verbindings, waaronder idiome, bevat, kan hierdie woordeboek baat by 'n hersiening wat betref hierdie twee datakategorieë deur verouderde leksikale items te vervang met hedendaagse items, deur 'n gebalanseerde datakorpus soos 
Media24 te gebruik, deur teoretiese insigte uit die leksikografie aan te wend en deur die hanteringsbeleid met betrekking tot idiome en kollokasies konsekwent toe te pas.

\section{Bibliografie}

Bergenholtz, Henning en Rufus H. Gouws. 2010. A Functional Approach to the Choice between Descriptive, Prescriptive and Proscriptive Lexicography. Lexikos 20: 26-51.

Botha, W.F. 1991. Die lemmatisering van uitdrukkings in verklarende Afrikaanse woordeboeke. Lexikos 1: 20-36.

Cowie, A.P. (Red.). 1998. Phraseology: Theory, Analysis, and Applications. Oxford: Clarendon Press.

Fontenelle, Thierry. 1998. Discovering Significant Functions in Dictionary Entries. Cowie, A.P. (Red.). 1998: 189-208.

Fontenelle, Thierry. 2008. Using a Bilingual Dictionary to Create Semantic Networks. Fontenelle, Thierry (Red.). 2008: 169-189.

Fontenelle, Thierry (Red.). 2008. Practical Lexicography: A Reader. Oxford: Oxford University Press.

Gouws, R.H. 1989. Leksikografie. Pretoria/Kaapstad: Academica.

Gouws, R.H. 1990. Vaste uitdrukkings as multileksikale lemmas in verklarende Afrikaanse woordeboeke. Tydskrif vir Geesteswetenskappe 30(4): 265-283.

Gouws, R.H. 1996. Idioms and Collocations in Bilingual Dictionaries and their Afrikaans Translation Equivalents. Lexicographica 12: 54-88.

Hartmann, R.R.K. en G. James. 1998. Dictionary of Lexicography. Londen: Routledge.

Hausmann, F.J., O. Reichman, H.E. Wiegand en L. Zgusta (Reds.). 1989-1991. Wörterbücher. Ein internationales Handbuch zur Lexikographie/Dictionaries. An International Encyclopedia of Lexicography/Dictionnaires. Encyclopédie internationale de lexicographie. Berlyn: Walter de Gruyter.

Howarth, Peter. 1998. The Phraseology of Learners' Academic Writing. Cowie, A.P. (Red.). 1998: 161-186.

Moon, Rosamund. 1998. Fixed Expressions and Idioms in English: A Corpus-Based Approach. Oxford: Clarendon Press.

Odendal, F.F. 2006. HAT veertig jaar - 'n persoonlike oorsig. Lexikos 16: 280-289.

Odendal, F.F. en R.H. Gouws (Reds.). 2005. HAT Verklarende Handwoordeboek van die Afrikaanse Taal. Kaapstad: Pearson Education South Africa.

Otto, A.N. s.j. Kollokasiewoordeboek van Afrikaans. Ongepubliseerde woordeboek op CD-Rom.

Potgieter, Liezl. 2006. Die bewerking van idiome in tweetalige woordeboeke. Lexikos 16: 180-192.

Prinsloo, D.J. 2009. A Perspective on the Lexicographic Value of Mega Newspaper Corpora - The Case of Afrikaans in South Africa. Lexikos 19: 225-241.

Svensén, Bo. 1993. Practical Lexicography: Principles and Methods of Dictionary-Making. Oxford/New York: Oxford University Press.

Zgusta, L. 1989. The Role of Dictionaries in the Genesis and Development of the Standard. Hausmann, F.J. et al. (Reds.). 1989-1991: 70-79. 


\title{
Leksikografiese seleksie as deel van die samestellingsproses van 'n vakwoordeboek vir vertalers*
}

\author{
Liezl Potgieter, Paarl, Suid-Afrika \\ (liezlpotgieter@gmail.com)
}

Opsomming: Leksikografiese seleksie is een van die belangrike stappe wat die samestelling van enige woordeboek behoort vooraf te gaan. Ook by die beplanning en samestelling van vakwoordeboeke vir vertalers, speel leksikografiese seleksie 'n belangrike rol om te verseker dat die eindproduk so gebruikersvriendelik en bruikbaar moontlik is vir vertalers. In hierdie artikel word die vyf stappe van leksikografiese seleksie eers bespreek waarna daar kortliks aandag gegee word aan die bewerking van vertaalekwivalente in 'n tweerigting- vertalende vakwoordeboek met vertalers as teikengebruikers.

Sleutelwoorde: LEKSIKOGRAFIESE SELEKSIE, SELEKSIE VAN METODE, SELEKSIE VAN VAKGEBIED, SELEKSIE VAN DATA, SELEKSIE VAN LEMMAS, SELEKSIE VAN EKWIVALENTE, VERTAALEKWIVALENTE, ABSOLUTE EKWIVALENSIE, DIVERGENSIE, ZEROEKWIVALENSIE， SURROGAATEKWIVALENSIE， SKYNEKWIVALENSIE， OMKEERBAARHEIDSBEGINSEL

\begin{abstract}
Lexicographic Selection as Part of the Compilation Process of a Specialist Dictionary for Translators. Lexicographic selection is one of the important steps that should precede the compilation of any dictionary. Also in the planning and compiling of specialist dictionaries for translators, lexicographic selection plays an important role in order to ensure that the final product is as user-friendly and usable as possible for translators. In this article, the five steps of lexicographic selection are firstly discussed after which the treatment of translation equivalents in a bidirectional translational specialist dictionary with translators as target users is briefly looked at.
\end{abstract}

Keywords: LEXICOGRAPHIC SELECTION, SELECTION OF METHOD, SELECTION OF SUBJECT FIELD, SELECTION OF DATA, SELECTION OF LEMMAS, SELECTION OF EQUIVALENTS, TRANSLATION EQUIVALENTS, ABSOLUTE EQUIVALENCE, DIVERGENCE, ZERO-EQUIVALENCE, SURROGATE EQUIVALENCE, FALSE FRIENDS, REVERSIBILITY PRINCIPLE

* Hierdie artikel is 'n uittreksel uit 'n ongepubliseerde doktorale proefskrif Die ontwerp van vertalende vakwoordeboeke met vertalers as teikengebruikers: ' $n$ Teoretiese model wat in Maart 2011 aan die Universiteit van Stellenbosch, Stellenbosch voltooi is. 
It is true that lexicographic selection is widely used in its narrow sense to describe the process of choosing the lexical units to be entered into a dictionary as lemmata. This is, however, only one of several kinds of interrelated lexicographic procedures. (Nielsen 1994: 129)

Leksikografiese seleksie is een van die belangrike stappe wat die samestelling van enige woordeboek voorafgaan. Ook by die beplanning en samestelling van vakwoordeboeke vir vertalers, speel leksikografiese seleksie 'n belangrike rol om te verseker dat die eindproduk so gebruikersvriendelik en bruikbaar moontlik is vir vertalers. Wanneer daar na leksikografiese seleksie verwys word, dink die meeste mense gewoonlik dat dit slegs na lemmaseleksie verwys, maar leksikografiese seleksie sluit baie meer in as net die seleksie van lemmas (Nielsen 1994: 129). Volgens Nielsen bestaan leksikografiese seleksie uit vyf stappe wat een na die ander op mekaar volg. Die stappe is soos volg:

(a) seleksie van metode

(b) seleksie van vakgebied

(c) seleksie van data (Taal 1 en Taal 2)

(d) seleksie van lemmas (uit brontaaldata)

(e) seleksie van ekwivalente (uit doeltaaldata)

Ek wil egter van Nielsen verskil wat betref die volgorde van die stappe. Na my mening is stap (b), die seleksie van die veld, die eerste stap wat in die praktyk toegepas word en word die metode eers daarna bepaal. Die seleksie van vakgebied word na my mening voorafgegaan deur die seleksie van die taalpaar wat in die woordeboek aan bod sal kom. Ek gaan dus die onderskeie stappe in hierdie volgorde behandel.

\section{Seleksie van taalpaar en vakgebied}

Die eerste stap in die leksikografiese seleksieproses is die seleksie van die taalpaar sowel as die vakgebied(e) of veld(e) wat in die woordeboek behandel gaan word. Hier kies die leksikograaf watter vakgebied se terminologie in die woordeboek bewerk gaan word en watter tale in die woordeboek aan bod gaan kom. Verder kies die leksikograaf ook of die woordeboek 'n eenrigting- of ' $n$ tweerigting- vertalende woordeboek gaan wees. Die keuse van vakgebied kan geskied op grond van die leksikograaf se kennis van 'n betrokke vak of as gevolg van 'n leemte wat bestaan weens 'n gebrek aan 'n geskikte woordeboek vir 'n vakgebied. Na hierdie seleksie afgehandel is, kan daar dan aanbeweeg word na die volgende stap waar die metode ten opsigte van die seleksie van lemmas bepaal word. ${ }^{1}$ 


\section{Seleksie van metode}

Die seleksie van metode verwys na die proses waartydens besluit word watter metode toegepas gaan word ten opsigte van die seleksie van lemmas en vertaalekwivalente. Die seleksie van 'n metode wat die basis vorm van die seleksieproses, kan een van 'n paar vorme aanneem. Alhoewel die leksikograaf se linguistiese en ensiklopediese bevoegdheid 'n nodige voorvereiste is, sal dit alleen nie lei tot gebalanseerde en gegronde lemmaseleksie nie (Bergenholtz en Tarp 1995: 100). Een metode waarop die lemmaseleksie gedoen kan word, is deur 'n lemmalys saam te stel gebaseer op die leksikograaf se eie kennis - 'n metode bekend as introspeksie (Bergenholtz en Tarp 1995: 105). 'n Verdere metode is deur lemmas te inkorporeer uit ander woordeboeke, woordelyste en privaat "versamelings" van TSD-terme ${ }^{2}$ en -uitdrukkings, en volgens Svensén (2009: 55) is dit die metode wat tot onlangs toe meestal by die samestelling van vertalende woordeboeke gebruik is. Nielsen (1994: 131) noem hierdie seleksiemetode die woordeboekkopieermetode. Dikwels word lemmaseleksie van stapel gestuur deur 'n aantal lekseme te kies wat resepsie-, produksie- en vertaalprobleme oplewer. Hierdie lys word dan aangevul met lemmas uit ander TSDvakwoordeboeke oor dieselfde vakgebied. Nie een van hierdie metodes is egter baie betroubaar nie. Indien die leksikograaf te min kennis van die vakgebied het, kan dit tot leemtes in die woordeboek lei, en alhoewel die gebruik van ander woordeboeke baie tyd kan bespaar, kan dié metode nie as betroubaar beskou word nie tensy die woordelys in die bestaande woordeboek gekontroleer word teen sowel die huidige ontwikkeling in die vakgebied as die omvang van die beoogde woordeboek. Bergenholtz en Tarp (1995: 100) voel daarom dat eerder as om van die leksikograaf se eie kennis en 'n bestaande woordeboek se woordelys gebruik te maak, dit die moeite werd is om 'n onafhanklike seleksieproses te gebruik met die spesifieke woordeboek in gedagte. Een sodanige metode waarvan leksikograwe gebruik kan maak, is om die indekse agterin TSD-handboeke te raadpleeg, mits sodanige indekse betroubaar en omvattend is. Aangesien dit egter dikwels nie die geval is nie, word daar eerder aanbeveel dat leksikograwe 'n TSD-tekskorpus gebruik. Die tekskorpus kan dan 'n alfabetiese indeks genereer waarin alle enkelwoorde opgeneem sal word. In die geval van multiwoorditems, gaan dit egter wel 'n bietjie meer werk van die leksikograwe vereis, aangesien hulle met behulp van die korpusontsluitprogram se soekfunksie sodanige multiwoorditems sal moet identifiseer en opspoor (Bergenholtz en Tarp 1995: 100-101).

'n Volgende metode wat gebruik kan word, is een wat deur Al-Kasimi (1977: 105) soos volg beskryf word:

The principle criteria for the selection of entries and meanings are (a) frequency, based on both frequency count and semantic count, (b) usefulness, and (c) restriction to the regional and social dialects which the dictionary purports to record. 
Die metode vir leksikografiese seleksie wat deur Al-Kasimi voorgestaan word, is ' $\mathrm{n}$ frekwensieteorie met die addisionele gebruik van 'n "bruikbaarheidskriterium". Hierdie kriterium kan verstaan word om alle, of ten minste soveel moontlike, terme en uitdrukkings in te sluit wat nuttig is vir die woordeboek se doel, funksie en teikengroep, maar wat nie ingesluit is by die frekwensielys nie omdat dit nie voorkom in tekste wat vir die opstel van die frekwensielys gebruik is nie (Nielsen 1994: 131).

Wanneer 'n mens 'n woordeboek met behulp van die frekwensiemetode saamstel, is dit nodig om 'n onderliggende korpus te hê waaruit die data op 'n frekwensiebasis geselekteer word. 'n Tekskorpus kan gedefinieer word as 'n versameling linguistiese data wat volgens sekere kriteria geselekteer word, óf in die vorm van geskrewe tekste óf transkripsies van spraakopnames, en wat as basis gebruik word vir leksikografiese projekte (Svensén 2009: 43; Nielsen 1994: 133). Dit is egter belangrik om te besef dat die keuse/seleksie van die individuele tekste waaruit die tekskorpus opgemaak word, 'n beduidende invloed op die seleksie van lemmas het, aangesien slegs die terme en uitdrukkings wat in die tekskorpus gevind word, die primêre basis van die woordeboek se lemmalys sal vorm.

Die frekwensie-gebaseerde metode het heelwat voordele. Eerstens kan 'n frekwensielys leksikograwe help om kollokasies en vaste uitdrukkings op te spoor wat in die woordeboek opgeneem behoort te word. En indien die korpus gerekenariseer is, is dit baie maklik om die onderskeie kollokasies op te spoor. Indien die frekwensielys alfabeties georden is, is dit 'n gerieflike hulpmiddel vir die woordeboeksamestellers indien die woordeboek ook alfabeties georden gaan word. Derdens behoort die frekwensielys ook alle woorde te bevat wat in die onderliggende korpus aangetref word en nie net die frekwentste terme nie. Dit beteken dat die moontlikheid dat terme uit die woordeboek weggelaat word, tot 'n minimum beperk word. Laastens maak 'n tekskorpus dit ook makliker om voorbeeldmateriaal van die TSD-terme te vind. Dít is veral nuttig indien die beoogde woordeboek nie net linguistiese data nie, maar ook ensiklopediese data bevat (Nielsen 1994: 133-134).

\section{Seleksie van data}

By 'n korpusgebaseerde woordeboek is dataseleksie of korpussamestelling die proses waar tekste of dataeenhede gekies word om as basis vir die leksikografiese projek gebruik te word. Wanneer 'n korpus saamgestel word, is daar 'n hele aantal faktore wat in ag geneem en besluite wat geneem moet word. Die eerste vraag wat die leksikograwe hulle moet afvra, is waarom daar 'n behoefte aan ' $n$ korpus is en vir watter doel dit gebruik gaan word, aangesien dit 'n invloed sal hê op die samestelling van die korpus. Nog 'n belangrike besluit wat geneem moet word, is die besluit rakende die seleksie van tekste wat in die korpus ingesluit moet word. Tekstipes en teksgenres moet met sorg gekies word: die daaglikse pers dek 'n groot aantal vakgebiede, terwyl vaktydskrifte 
meer gespesialiseerd is en meer tegniese terme bevat. Die materiaal kan bestaan uit volledige tekste en/of uittreksels uit tekste. In die geval van 'n vakwoordeboek sal daar by die samestelling van die korpus hoofsaaklik (of selfs uitsluitlik) vaktekste gebruik word, en dit is belangrik dat die korpus so groot moontlik sal wees. By leksikografiese projekte waar die inhoud tot korpusdata beperk word, kan egter geargumenteer word dat die korpus niks meer as 'n beperkte monster van die geheel kan wees nie. Gevolglik kan dit gebeur dat terme en uitdrukkings wat in werklike TSD-kommunikasie bestaan, nie in die woordeboek ingesluit word nie omdat hulle nie in die teks voorkom waaruit die korpus opgebou is nie, en die waarde van die woordeboek dus ingeperk word (Nielsen 1994: 137). In 'n poging om hierdie probleem te oorkom, is dit belangrik dat korpusse aangevul moet kan word en verkies leksikograwe om gebruik te maak van 'n korpus-gebaseerde benadering, eerder as 'n korpusbeperkte benadering (Nielsen 1994: 137). Dit gee aan leksikograwe die vryheid om terme en uitdrukkings in die woordeboek in te voeg wat nie in die korpus voorkom nie, maar tog deel van die vakterminologie uitmaak, aangesien minder bekende terme juis belangrike inskrywings in 'n vakwoordeboek gerig op vertalers is. Hier moet die leksikograaf ook vir kultuurgebonde variante voorsiening maak. In 'n woordeboek gerig op mediese en gesondheidsterme sal informele kultuurgebonde terme, byvoorbeeld uit die tradisionele geneeskunde, as kandidate oorweeg moet word. 'n Metode moet gevind word om dié dataseleksie moontlik te maak.

Nadat die korpusdata vir sowel die brontaal as die doeltaal versamel is, word dit in 'n rekenaar ingevoer en die nodige data, lemmas en kollokasies kan dan met behulp van een van 'n verskeidenheid korpusontsluitprogramme (byvoorbeeld Wordsmith Tools) aan die onderskeie korpusse (vir sowel die brontaal as die doeltaal) onttrek en gebruik word.

\section{Seleksie van lemmas}

Dit is vanselfsprekend dat die bruikbaarheid van 'n vertalende vakwoordeboek wat slegs uit 'n woordelys met lemmas en vertaalekwivalente bestaan, nie baie hoog kan wees nie. Terselfdertyd noem Bergenholtz en Tarp (1995: 98) dat dit ook nie korrek is om 'n vakwoordeboek te beoordeel bloot op grond van watter lemmas in die lemmalys ingesluit is, al dan nie. Dit beteken egter nie dat die seleksie van lemmas en vertaalekwivalente nie van die uiterste belang is nie. Die seleksie van sowel die lemmas as die vertaalekwivalente is ' $n$ baie belangrike deel van die woordeboeksamestellingsproses, maar nogtans is daar tot dusver binne die praktiese leksikografie veels te min aandag aan hierdie twee prosesse geskenk (Bergenholtz en Tarp 1995: 98).

Die vierde stap in die leksikografiese seleksieproses is die seleksie van lemmas uit die korpusse. Die doel van lemmaseleksie is om te bepaal hoeveel van die bestaande woorde en frases binne die gekose vakgebied in die woordeboek opgeneem moet word. Hier moet leksikograwe gebruik maak van pro- 
grammatuur soos WordSmith Tools se WordList- en KeyWords-funksies. Die WordList-funksie word eers gebruik om 'n frekwensielys van woorde (sowel TAD-woorde as TSD-terme) wat in die korpus voorkom, saam te stel. Daarna word die KeyWords-funksie gebruik om die terme wat in die korpus en frekwensielys voorkom, van die algemene woorde te skei, dit uit die korpus te onttrek en te lys (Taljard et al. 2007: 160). Hierna behoort die leksikograaf 'n voorlopige lemmalys te hê, gebaseer op die frekwensie van woorde in die korpus. Die voorlopige lemmalys kan dan aangevul word met TSD-terme wat nie in die lemmalys aangetref word nie, of nie aan die minimum vereistes voldoen nie, maar wat die woordeboeksamestellers weet problematies is. Die ideaal is natuurlik dat sodanige seleksie van addisionele terme geskied in samewerking met vakspesialiste wat die terminologie ken (Nielsen 1994: 147).

Hierdie aanvullende lemmaseleksie moet eerstens gedoen word uit dié terme in die frekwensielyste wat nie weens hulle lae frekwensietelling ingesluit is nie. Tweedens moet die aanvullende lemmas geselekteer word uit dié groep terme wat "nuttig" kan wees vir die woordeboek se teikengebruikers, maar wat nie in die onderliggende korpus aangetref word nie as gevolg van leemtes in die korpus (Nielsen 1994: 147).

In die vertalende leksikografie speel multiwoorditems 'n belangrike rol en dis daarom nodig dat hulle ook in die woordeboek ingesluit sal word, veral as die vertaalekwivalent ' $n$ enkelwoord of ' $n$ enkelwoorditem is, of in gevalle waar die vertaalekwivalent nie woord vir woord identies is aan die lemma nie. Verder is dit ook belangrik dat die leksikograaf sal let op die insluiting van kollokasies en vaste uitdrukkings, aangesien dit veral die vertaling van hierdie items is wat problematies kan wees vir vertalers. Dit is belangrik dat kollokasies as sekondêre bewerkingseenhede ingesluit en bewerk sal word.

'n Laaste aspek wat tydens lemmaseleksie in ag geneem moet word, is die insluiting van afkortings omdat afkortings 'n groot deel van die TSD-woordeskat uitmaak. Aangesien daar nie van gebruikers verwag kan word om te weet na watter volvorm en gelemmatiseerde term die afkorting verwys nie, moet sowel die afkorting as die uitgeskryfde term gelemmatiseer word, selfs al word die afkortings slegs gelys met 'n kruisverwysing na die volvormlemma (Bergenholtz en Tarp 1995: 104). Dit kan verder van nut wees indien die leksikograaf, buiten die insluiting van afkortings in die sentrale woordelys, die afkortings ook in 'n aparte buiteteks sal lys. Sodoende kan vertalers wat weet dat die betrokke term ' $n$ afkorting is, direk na die afkortinglys gaan en hoef hulle nie te gaan soek of die afkorting wel in die sentrale lys opgeneem is, al dan nie.

Indien al hierdie aspekte in ag geneem word, behoort die leksikograaf nou 'n volledige lemmalys te hê wat die tipes leksikale items weerspieël. Die lemmalys sal dus nie net woordlemmas nie, maar ook subleksikale lemmas, byvoorbeeld affikse en veral tegnostamme (bv. elektro- of tweerigting- uit Kuberwoordeboek), asook meerwoordlemmas bevat.

Vervolgens moet daar ook aandag gegee word aan die lemmatiseringsproses. Die leksikograwe moet dus besluit of hulle slegs gebruik gaan maak 
van hooflemmas en of hulle ook sublemmas gaan insluit. Indien daar sublemmas ingesluit gaan word, moet daar verder besluit word hoe sodanige sublemmas aangebied en bewerk gaan word - gaan daar van nislemmatisering of neslemmatisering gebruik gemaak word? Laastens is dit ook belangrik dat die leksikograwe sal besluit oor die insluiting en bewerking van rudimentêre artikels. ${ }^{3}$

Nadat daar oor al die voorafgaande kwessies besluit is, kan daar voortgegaan word met die seleksie en bewerking van vertaalekwivalente.

\section{Seleksie en bewerking van vertaalekwivalente}

Die seleksie van vertaalekwivalente speel 'n belangrike rol in die samestelling van vertalende vakwoordeboeke, en dit is veral die vlak van die gebruikers wat by sodanige seleksie van groot belang is. Indien die voorgestelde gebruikers kenners van die vakgebied is, sal die seleksie van vertaalekwivalente verskil van gevalle waar die voorgestelde gebruikers byvoorbeeld semideskundiges of leke is. Aangesien vertalers met 'n verskeidenheid vaktekste kan werk wat deur persone met verskillende vlakke van vakkennis geskryf en/of gelees word, word daar aanbeveel dat daar nie net die vakkundige terme waarmee deskundiges bekend is in die woordeboek opgeneem sal word nie, maar ook dat daar terme en vertaalekwivalente ingesluit sal word wat deur semideskundiges en leke gebruik word. 'n Voorbeeld van sodanige vertaalekwivalent is Klein Wa (uit Sterrekundewoordeboek) wat vertaal kan word as "Little Bear", "Little Dipper" of "Ursa Minor". Terwyl "Little Bear" en "Little Dipper" vertaalekwivalente is wat meer deur leke en semideskundiges gebruik word, is "Ursa Minor" die Latynse naam wat algemener deur deskundiges binne die sterrekundeveld gebruik word.

Die bewerking van vertaalekwivalente wissel na gelang van die ekwivalentverhoudings tot die lemma waarin die vertaalekwivalente staan. In die geval van vertalende woordeboeke, val daar baie klem op die vertaalekwivalente. Dit is daarom noodsaaklik dat die leksikograwe 'n betroubare, bygewerkte, sistematies saamgestelde en toeganklike hulpmiddel tot hulle beskikking het om met die seleksie van vertaalekwivalente te help. 'n Tekskorpus wat vir die doel van ekwivalentseleksie saamgestel is, is so 'n hulpmiddel (Bergenholtz en Tarp 1995: 104), aangesien die leksikograaf in oorleg met 'n vakkundige die tekskorpus kan opstel deur gebruik te maak van relevante, betroubare en feitelik korrekte vaktekste wat dan die basis van die tekskorpus kan vorm.

Die bewerking van sodanige vertaalekwivalente speel ook ' $\mathrm{n}$ belangrike rol in die gebruikersvriendelikheid van vakwoordeboeke vir vertalers. In die volgende gedeelte sal gekyk word na verskeie moontlike oplossings vir die aanbieding van vertaalekwivalente en hulle bewerkings in vertalende vakwoordeboeke. Gebruikers raadpleeg meestal vertalende woordeboeke op soek na 'n vertaalekwivalent om 'n woord of term in die brontaal in die doeltaal mee te vervang. Vertalers raadpleeg dus nie net 'n woordeboek om hulle te help met 
teksresepsie nie, maar wel ook om hulle te help met teksproduksie. Tog word daar in die meerderheid van die geraadpleegde woordeboeke weinig konteksen koteksleiding verskaf sodat vertalers kan weet watter vertaalekwivalent binne watter konteks of situasie gebruik kan word, en hierdie tekort aan konteks- en koteksleiding maak dit vir gebruikers baie moeilik om kommunikatiewe ekwivalensie te bereik (Gouws 2006: 85).

Wanneer vertalers vertalende vakwoordeboeke tydens die vertaling van vaktekste gebruik, is dit meestal omdat hulle op soek is na 'n korrekte vertaalekwivalent vir 'n betrokke vakterm. Daarom is dit belangrik dat leksikograwe nie net aandag sal gee aan die verskaf van vertaalekwivalente nie, maar ook die verskaf van genoegsame konteks- en koteksleiding om die vertalers te help om die korrekte vertaalekwivalent vinnig en maklik op te spoor en reg te gebruik.

In gevalle waar daar ' $n$ verhouding van absolute ekwivalensie tussen die brontaalitem en die doeltaalitem bestaan, bestaan daar dus sowel semantiese as kommunikatiewe ekwivalensie tussen die brontaal- en doeltaalterm en die term kan maklik en probleemloos vertaal word. Dit is egter die gevalle waar daar nie 'n verhouding van absolute ekwivalensie en kongruensie bestaan nie, waar vertalers probleme ondervind tydens die vertaling van vakterme. In die volgende gedeelte sal daar voorstelle gemaak word vir maniere waarop hierdie probleem gehanteer kan word en die bewerking van vertaalekwivalente verbeter kan word om vertalers genoegsaam te help om die korrekte vertaalekwivalent vir die betrokke term binne 'n betrokke konteks op te spoor.

\subsection{Divergensie}

Dit gebeur dikwels dat daar vir 'n brontaalterm meer as een vertaalekwivalent in die doeltaal bestaan, maar dat die onderskeie vertaalekwivalente slegs gedeeltelike sinonieme is of selfs verskillende polisemiese waardes van die brontaalterm verteenwoordig. In hierdie gevalle is dit belangrik dat die leksikograwe die vertalers genoegsaam sal help om te verseker dat die korrekte vertaalekwivalent binne die korrekte konteks gebruik sal word. Indien die bronen doeltaalterme slegs gedeeltelik ekwivalent is, is dit nodig dat die leksikograaf die verskille aan die gebruikers sal uitwys en die nodige konteks- en/of koteksleiding sal verskaf sodat die gebruikers sal weet watter vertaalekwivalent binne watter konteks gebruik moet word, al dan nie. In die onderstaande artikel (artikel 1) kan gesien word hoe 'n gebrek aan koteks- en konteksleiding dit vir die gebruikers baie moeilik maak om die korrekte vertaalekwivalent vir 'n betrokke konteks te kies.

uitdeelware public domain software, shareware

Artikel 1: uitdeelware uit Kuberwoordeboek 
Indien die leksikograaf egter die vertaalekwivalente van konteks- en/of koteksleiding voorsien het, sou dit die vertalers se soektog aansienlik vergemaklik het, soos in artikel 2 gesien kan word.

uitdeelware \{free software\} public domain software, \{software that is free to try before buying it\} shareware

Artikel 2: uitdeelware aangepas uit Kuberwoordeboek

Belangriker nog as die verskaf van konteks- en/of koteksleiding in gevalle van leksikale divergensie, is die verskaf van genoegsame leiding in gevalle van semantiese divergensie (met ander woorde in gevalle waar die brontaalitem polisemies is). In baie vakwoordeboeke (insluitend Kuberwoordeboek) word polisemiese waardes in baie gevalle slegs aangedui met behulp van 'n kommapunt (sien artikel 3 en 4) en word daar aan die gebruikers min of geen addisionele data verskaf om te help om die korrekte vertaalekwivalent vir die betrokke teks of konteks te kies nie.

masjinaal mechanical; automatic

Artikel 3: masjinaal uit Kuberwoordeboek

herroep recall; undo

Artikel 4: herroep uit Kuberwoordeboek

Artikel 3 en 4 is voorbeelde van artikels waar daar semantiese divergensie voorkom, maar daar aan die gebruikers geen leiding verskaf word om te weet watter vertaalekwivalent binne watter tipe teks of konteks gebruik moet word nie. Dit is daarom noodsaaklik dat die leksikograwe aan die woordeboekgebruikers die nodige konteks- en koteksleiding sal verskaf en die gebruikers op die verskillende betekenisonderskeidinge attent sal maak. Dit kan gedoen word met behulp van aanvullende data in die vorm van glosse en/of voorbeeldmateriaal soos gesien kan word in artikel 5 en 6. Sodanige konteks- en koteksleiding is ook van groot waarde in gevalle waar woordeboeke 'n teksresepsiefunksie het.

masjinaal \{referring to machines\} mechanical; \{works by itself\} automatic

Artikel 5: masjinaal aangepas uit Kuberwoordeboek

herroep recall $\sim$ text/files from store; undo $\sim$ the previous action

Artikel 6: herroep aangepas uit Kuberwoordeboek 
Dit is voorts ook belangrik dat die leksikograwe konsekwent te werk sal gaan met die invoeg van glosse en dit nie net lukraak ingevoeg sal word nie. Dit is noodsaaklik dat al die vertaalekwivalente waarvan die konteks of betekenis by die gebruikers onduidelikheid kan veroorsaak, van koteks- en/of konteksleiding voorsien sal word. Hier mag die leksikograwe hulle nie op die gebruikers se intuïsie beroep nie en moet daar eerder te veel as te min leiding gegee word. Slegs in gevalle waar daar geen onduidelikheid bestaan ten opsigte van die betekenis of konteks nie, kan die glos of konteksleiding weggelaat word. Vanuit 'n vertalersoogpunt is die invoeg van hierdie addisionele inskrywings veral belangrik omdat vertalers gewoonlik onder tyddruk werk en so vinnig moontlik by die korrekte vertaalekwivalent moet uitkom - dit dien dus as kitstoegang tot die nodige data. Deur konteksleiding in te voeg, word die vertalers se soektog beperk tot net een woordeboek en hoef hulle nie nog ander bronne te raadpleeg om vas te stel binne watter teks en konteks die onderskeie vertaalekwivalente gebruik moet word nie (Gouws 2006: 88).

Ook in gevalle waar daar polidivergensie in die artikel voorkom, is dit belangrik dat daar genoegsame leiding aan die gebruikers verskaf sal word sodat hulle die korrekte vertaalekwivalent vinnig en maklik kan identifiseer. In artikel 7 kan gesien word hoe verwarrend die vertaalekwivalentparadigma kan wees indien daar geen konteksleiding aan die gebruikers verskaf word nie.

fout error, fault; mistake, bug

Artikel 7: fout uit Kuberwoordeboek

Wat nog meer verwarring in die artikel veroorsaak, is die feit dat, alhoewel sommige van die vertaalekwivalente as sinonieme en ander as ekwivalente van bepaalde polisemiese waardes van die term wat deur die lemma voorgestel word, aangedui word, dit wil voorkom asof die leksikograwe 'n fout in die artikel gemaak het. Wanneer daar na die onderstaande definisies vir elk van die vertaalekwivalente gekyk word, lyk dit asof "error" en "fault" wel doeltaalsinonieme is wat dieselfde polisemiese waarde van die leksikale item wat deur die lemma voorgestel word, verteenwoordig, maar "mistake" en "bug" ekwivalente van verskillende polisemiese waardes is en nie doeltaalsinonieme soos dit in die artikel aangegee word nie.

Tabel 1: Definisies van onderskeie vertaalekwivalente vir fout

\begin{tabular}{|l|l|}
\hline Term & \multicolumn{1}{|c|}{ Definisie } \\
\hline Error & $\begin{array}{l}\text { Mistake due to an operator; mistake caused by hardware or software } \\
\text { fault; mistake in a program that prevents a program or system running } \\
\text { correctly [DOC]. }\end{array}$ \\
\cline { 2 - 2 } & The amount by which the result is incorrect [www.Blurtit.com]. \\
\hline
\end{tabular}




\begin{tabular}{|c|c|}
\hline Term & Definisie \\
\hline \multirow[t]{3}{*}{ Fault } & $\begin{array}{l}\text { An error or failure. A software fault is when the program directs the } \\
\text { computer to go outside of its restricted memory boundary. A hardware } \\
\text { fault is a failure in one of the circuits [CDE]. }\end{array}$ \\
\hline & $\begin{array}{l}\text { Situation where something has gone wrong with software or hardware, } \\
\text { causing it to malfunction [DOC]. }\end{array}$ \\
\hline & $\begin{array}{l}\text { An incorrect step, process or data definition computer program. This is } \\
\text { the out growth of a mistake [sic] [www.Blurtit.com]. }\end{array}$ \\
\hline Mistake & A human action that produces an incorrect result [www.BIurtit.com]. \\
\hline \multirow[t]{2}{*}{ Bug } & $\begin{array}{l}\text { A programming error in a software program and usually having unde- } \\
\text { sirable effects [WNWHD]. }\end{array}$ \\
\hline & $\begin{array}{l}\text { (Informal) Error in a computer program which makes it run incorrectly } \\
\text { [DOC]. }\end{array}$ \\
\hline
\end{tabular}

$\mathrm{Na}$ aanleiding van die definisies hierbo, blyk dit dat die bewerking van fout eerder as volg daar moet uitsien:

fout error, fault; mistake; bug

Artikel 8: fout aangepas uit Kuberwoordeboek

En in 'n poging om die artikel nog gebruikersvriendeliker te maak, sou dit ook voordelig wees om die onderskeie vertaalekwivalente van glosse te voorsien. Soos gesien kan word in die aangepaste artikel hieronder (artikel 9), maak die invoeg van konteksleiding die gebruikers se soektog soveel makliker en help dit hulle om die korrekte vertaalekwivalent probleemloos op te spoor.

fout \{prevents program from running correctly\} error, fault; \{incorrect result caused by human action\} mistake; \{programming error\} bug

Artikel 9: fout aangepas uit Kuberwoordeboek

\subsection{Zero-ekwivalensie en surrogaatekwivalensie}

Net soos by taal vir algemene doeleindes (TAD), kom daar ook by vaktaal (TSD) gevalle voor waar daar vir 'n brontaalterm geen vertaalekwivalente in die doeltaal bestaan nie. Vanuit 'n vertaal- en teksproduksie-oogpunt is dit egter belangrik dat sodanige terme nie net uit die woordelys weggelaat sal word nie, maar wel in die woordeboek opgeneem en bewerk sal word, aangesien dit juis dié terme is wat vir vertalers problematies is.

In gevalle waar leksikograwe gekonfronteer word met terme waarvoor daar geen vertaalekwivalente in die doeltaal bestaan nie, moet sodanige terme 
dan van 'n betekenisomskrywing of 'n surrogaatekwivalent ${ }^{4}$ voorsien word, alhoewel leksikograwe binne die vakleksikografie oor die algemeen eerder terme skep as om lemmas net van betekenisomskrywings te voorsien. Die volgende artikels (artikel 10 en 11) is voorbeelde van terme uit Kuberwoordeboek waarvoor daar nie Afrikaanse vertaalekwivalente bestaan het nie en die skrywer surrogaatekwivalente vir die terme geskep het (Viljoen 2001).

$$
\text { blur ontskerp (sien ook sharpen) }
$$

Artikel 10: blur uit Kuberwoordeboek

swirl werwel

Artikel 11: swirl uit Kuberwoordeboek

Alhoewel dit nuttig is dat leksikograwe terme sonder vertaalekwivalente van surrogaatekwivalente voorsien, moet die uiteindelike lesers van die vertaalde tekste ook in gedagte gehou word. Baie van die nuutskeppings is knap en treffend, maar dit beteken nie dat hulle in die vaktaal gaan inslag vind nie. Wanneer vertalers dus met 'n surrogaatekwivalent (nuutskepping) gekonfronteer word, moet hulle hulle afvra of die leser van die vertaalde teks uit die nuutskepping sal kan aflei waarna daar verwys word, en of dit nie dalk beter is om ' $n$ betekenisomskrywing te gebruik nie. Juis om hierdie rede is dit belangrik dat leksikograwe nie net terme van surrogaatekwivalente sal voorsien nie, maar ook betekenisomskrywings en/of konteksleiding sal verskaf om die vertalers te help om die teks op so 'n wyse te vertaal dat die gebruikers die term sal herken en verstaan. Dit is daarom aan te beveel dat die leksikograaf, in gevalle waar terme van surrogaatekwivalente voorsien word, eerstens die woordeboekgebruikers daarop attent sal maak dat die vertaalekwivalent nie 'n bestaande ekwivalent is nie, maar 'n surrogaatekwivalent wat deur die leksikograaf geskep is. Dit kan gedoen word met behulp van eenvoudige struktuurmerkers (byvoorbeeld 'n asterisk of iets soortgelyks) waarmee surrogaatekwivalente gemerk kan word, soos blyk uit artikel 12 en 13. Tweedens is dit ook vanuit ' $n$ vertalersoogpunt belangrik dat leksikograwe in die geval van zeroekwivalensie die vakterm nie net van 'n surrogaatekwivalent nie, maar ook van 'n betekenisomskrywing sal voorsien, soos gesien kan word in artikel 14 .

blur ontskerp (sien ook sharpen)

Artikel 12: blur aangepas uit Kuberwoordeboek

swirl werwel*

Artikel 13: swirl aangepas uit Kuberwoordeboek 
swirl (in kolkbeweging smeer) werwel*

Artikel 14: swirl aangepas uit Kuberwoordeboek

Deur gevalle van zero-ekwivalensie op hierdie wyse te bewerk, help dit vertalers om nie net die term vinnig en maklik te vertaal nie, maar ook te verseker dat die lesers van die vertaalde teks die term sal herken en/of verstaan.

\subsection{Skynekwivalensie (faux amis)}

Nog 'n moontlike slaggat waarvan leksikograwe die woordeboekgebruikers bewus moet maak, is die geval van skynekwivalensie (ook bekend as vals vriende of faux amis). Skynekwivalensie kom voor wanneer dit lyk asof daar op grond van sekere ooreenkomste 'n ekwivalentverhouding tussen twee woorde of terme bestaan, terwyl die twee woorde inderwaarheid nie aan mekaar ekwivalent is nie. ${ }^{5}$ Hayward en Moulin (1984: 190) beskryf skynekwivalensie soos volg:

Confusion arises because word A (which belongs to the foreign language ...) looks or sounds exactly or nearly like word B, which belongs to the ... mother tongue. The user then establishes an unwarranted interlingual equivalence on the basis of this total or partial similarity.

In gevalle van skynekwivalensie is dit belangrik dat dit vir die gebruikers aangedui word (soos in artikel 15 en 16) om te verseker dat vertalers nie die skynekwivalent as vertaalekwivalent aanwend nie, maar die korrekte vertaalekwivalent in die korrekte konteks gebruik.

fee $[n]$ geld(e), vergoeding (nie fooi(e) nie)

Artikel 15: fee uit Kuberwoordeboek

toll fee tolgeld, tolheffing (nie tolfooi nie)

Artikel 16: toll fee uit Kuberwoordeboek

\subsection{Die omkeerbaarheidsbeginsel}

'n Tweerigting- vertalende woordeboek moet 'n aanduiding gee van die wedersydse ekwivalentverhouding tussen die twee tale se leksikale items deur te probeer om al die leksikale items wat in die X-Y-afdeling verskyn, ook in die Y-Xafdeling as onderskeidelike lemmas en vertaalekwivalente te lys. ${ }^{6}$ Sodoende word daar verseker dat die vertalers bewus gemaak word van al die moontlike sinonieme en vertaalekwivalente en kan hulle die korrekte term of vertaalekwivalent makliker identifiseer. Hier speel lemmaseleksie dus 'n bepalende rol. 
Soos gesien kan word in die onderstaande artikels, word daar in Kuberwoordeboek talle voorbeelde aangetref van lemmas/vertaalekwivalente wat in een afdeling van die woordeboek voorkom, maar nie in die ander nie. By artikel 17 word daar twee vertaalekwivalente (sinonieme) en geen sinonieme vir die lemma (herstelinstandhouding) gelys nie. Tog word daar in die artikel vir corrective maintenance (artikel 18) wel 'n sinoniem vir "herstelinstandhouding" gelys (naamlik "korrektiewe instandhouding"). Hierdie sinoniem word egter nie as vertaalekwivalent vir "remedial maintenance" verskaf nie (alhoewel "corrective maintenance" en "remedial maintenance" volgens artikel 17 sinonieme is), en voorts word "korrektiewe instandhouding" ook glad nie as artikel in die Afrikaans-Engels kant van die woordeboek opgeneem nie.

herstelinstandhouding corrective maintenance, remedial maintenance

Artikel 17: herstelinstandhouding uit Kuberwoordeboek

corrective maintenance (remedial maintenance) herstelinstandhouding, korrektiewe instandhouding

Artikel 18: corrective maintenance uit Kuberwoordeboek

remedial maintenance (corrective maintenance) herstelinstandhouding

Artikel 19: remedial maintenance uit Kuberwoordeboek

Hierdie tipe inkonsekwenthede veroorsaak dat die vertalers nie voldoende bewus gemaak word van al die moontlike vertaalekwivalente/sinonieme nie. Vanuit 'n gebruikersoogpunt is dit dus noodsaaklik dat die omkeerbaarheidsbeginsel in vertalende woordeboeke toegepas sal word om te verseker dat alle items wat in die een afdeling gelys word, ook in die ander afdeling gelys sal word (buiten in die geval van surrogaatekwivalente).

\section{Ten slotte}

Soos gesien kan word, speel leksikografiese seleksie en die bewerking van vertaalekwivalente 'n belangrike rol in die samestelling van 'n tweerigting- vertalende vakwoordeboek vir vertalers. Indien leksikograwe hiervan bewus is en al die nodige stappe in die leksikografiese seleksieproses volg en die verskillende tipes bewerkings van verskillende tipes vertaalekwivalente in ag neem, is daar 'n beter kans dat die eindproduk 'n gebruikersvriendelike en bruikbare hulpmiddel vir vertalers sal wees. 


\section{Notas}

1. Sien Nielsen 1994: 134-137 vir meer oor die vakgebiedseleksieproses.

2. $\mathrm{TSD}=$ Taal vir Spesiale Doeleindes; $\mathrm{TAD}=$ Taal vir Algemene Doeleindes

3. Rudimentêre artikels wat hier veral na kruisverwysingslemmas verwys, is artikels waar die lemmas nie uitvoerig bewerk word nie, maar die gebruiker slegs met 'n kruisverwysing na 'n ander lemma gestuur word.

4. 'n Surrogaatekwivalent is 'n plaasvervanger (dikwels 'n neologisme) wat vir die konvensionele vertaalekwivalent geskep word.

5. Sien Gouws et al. 2004: 797-806 vir meer oor skynekwivalensie.

6. Dit is egter belangrik om te besef dat die omkeerbaarheidsbeginsel nie altyd absoluut toegepas kan word nie. In gevalle waar 'n lemma aan die X-Y-kant van 'n surrogaatekwivalent voorsien word, sal die surrogaat dikwels nie as 'n lemma in die Y-X-kant opgeneem word nie.

\section{Bronnelys}

\section{Woordeboeke}

CDE = Computer Language Company Inc. 2009. Computer Desktop Encyclopedia. [Intyds] Beskikbaar www.yourdictionary.com [2010, 15 Februarie].

De Klerk, J.H. (Red.). 1990. Sterrekundewoordeboek, met aanvullende inligting en bylaes/Dictionary of Astronomy, with Supplementary Information and Appendices. English-Afrikaans/Afrikaans-Engels. Nasionale Vakterminologiediens.

DOC $=$ Dictionary of Computing. 1994. Teddington: Peter Collins Publishing.

Viljoen, H.C. (Red.). 2006. Kuberwoordeboek Afrikaans-Engels, Engels-Afrikaans/Cyber Dictionary Afrikaans-English, English-Afrikaans. Pretoria: Protea Boekhuis.

WNWHD = Schell, B. en C. Martin. 2006. Webster's New World Hacker Dictionary. [Intyds] Beskikbaar www.yourdictionary.com [2010, 15 Februarie].

\section{Ander bronne}

Al-Kasimi, A.M. 1977. Linguistics and Bilingual Dictionaries. Leiden: E.J. Brill.

Bergenholtz, H. en S. Tarp. 1995. Manual of Specialised Lexicography: ThePreparation of Specialised Dictionaries. Amsterdam: John Benjamins.

Gouws, L. 2006. Die bewerking van idiome in tweetalige woordeboeke: 'n Hulp vir vertalers? Ongepubliseerde M.A.-skripsie. Stellenbosch: Universiteit van Stellenbosch.

Gouws, R.H., D.J. Prinsloo en G.M. de Schryver. 2004. Friends will be Friends - True or False. Lexicographic Approaches to the Treatment of False Friends. Williams, G. en S. Vessier (Reds.). Proceedings of the Eleventh EURALEX Congress, EURALEX 2004, Lorient, France, July 6-10, 2004: 797-806. Lorient: Faculté des Lettres et des Sciences Humaines, Université de Bretagne-Sud.

Hayward, T. en A. Moulin. 1984. False Friends Invigorated. Hartmann, R.R.K. (Red.). 1984. LEXeter '83 Proceedings. Papers from the International Conference on Lexicography at Exeter, 9-12 September 1983: 190-198. Tübingen: Max Niemeyer.

Nielsen, S. 1994. The Bilingual LSP Dictionary. Principles and Practice for Legal Language. Tübingen: Narr. 
Svensén, B. 2009. A Handbook of Lexicography: The Theory and Practice of Dictionary-making. Cambridge: Cambridge University Press.

Taljard, E., R. Gauton en L.A. Gauton. 2007. Issues in the Planning and Design of a Bilingual (English-Northern Sotho) Explanatory Dictionary for Industrial Electronics. Lexikos 17: 152-169.

Viljoen, H.C. 2001. RE: [rekenaarterme] EN > AF: grafikaterme (lank). Rekenaarterme. Werkgroep vir Afrikaanse IT-terme. [Intyds]. Beskikbaar: http://tech.groups.yahoo.com/group/rekenaarterme/message/1595 [2010, 17 Februarie]. 


\title{
The Role and Function of Illustrative Material in the Planning of an Encyclopaedic Dictionary of Yilumbu*
}

\author{
Gilles Saphou-Bivigat, Institut des Recherches en Sciences Humaines \\ (IRSH-CENAREST) et Département de Littérature des Sciences du \\ Langage et de la Communication (GERC), Libreville, Republic of Gabon \\ (saphoubivigat@yahoo.fr)
}

\begin{abstract}
Illustrative material has been described (cf. Heinz 2005: 5-8) as lexicographic units that give a specific dictionary its character and soul. It should always be used in dictionaries for specific purposes and not merely for decoration. It can take many forms (e.g. authentic examples, constructed examples, quotations, sentences, syntagms, pictures, etc.). These lexicographic elements are reviewed and addressed in this article from the user perspective with special reference to the planning of an encyclopaedic dictionary of Yilumbu. In this proposed dictionary, illustrative material has been planned to serve two main functions for the target users of the dictionary, namely the Balumba speakers: a production or encoding function enabling them to construct Yilumbu texts, and a reception or decoding function enabling them to understand Yilumbu texts.
\end{abstract}

Keywords: ILLUSTRATIVE MATERIAL, ENCYCLOPAEDIC DICTIONARY, COGNITIVE FUNCTION, COMMUNICATIVE FUNCTION, TEXT PRODUCTION, TEXT RECEPTION

Résumé: Le rôle et la fonction du matériel d'illustration dans la planification d'un dictionnaire encyclopédique du yilumbu. Le matériel d'illustration été décrite (cf. Heinz 2005: 5-8) comme des unités lexicographiques qui donnent à un dictionnaire spécifique son caractère et son âme. Il doit toujours être utilisé dans les dictionnaires à des fins spécifiques et pas seulement pour la décoration. Il peut prendre des nombreuses formes (par ex., des exemples authentiques, des exemples construits, des citations, des phrases, des syntagmes, des photos, etc.). Ces éléments lexicographiques sont examinés et traités dans cet article du point de vue de l'utilisateur avec une référence particulière à la planification d'un dictionnaire encyclopédique du yilumbu. Dans ce dictionnaire en proposition, le matériel d'illustration a été prévu pour remplir deux fonctions principales pour le public cible du dictionnaire, c'est-à-dire les Balumbu:

* This article is based on part of a chapter from an unpublished D.Litt. Dissertation A Theoretical Model for an Encyclopaedic Dictionary for the Gabonese Languages with Reference to Yilumbu, completed in 2010 at the University of Stellenbosch, Stellenbosch, South Africa. 
une fonction de production ou d'encodage leur permettant de construire des textes en yilumbu, et une fonction de réception ou de décodage leur permettant de comprendre des textes en yilumbu.

Mots-clés: MATÉRIEL D'ILLUSTRATION, DICTIONNAIRE ENCYCLOPÉDIQUE, FONCTION COGNITIVE, FONCTION COMMUNICATIVE, PRODUCTION DE TEXTES, RÉCEPTION DE TEXTES

\section{The purpose, functions, nature, target users and typology of the planned dictionary}

The lexicographer of any new dictionary project has to be familiar with the target user and the linguistic needs and reference skills of the intended user group. The research of Saphou-Bivigat (2010) was an attempt to design a theoretical model for an encyclopaedic dictionary for the Gabonese languages with specific reference to Yilumbu (B44), an African language of the Bantu phylum spoken in Gabon and in the Republic of the Congo (Brazzaville). As far as the nature of the planned dictionary is concerned, it will be a monolingual encyclopaedic dictionary with a bilingual dimension, because Yilumbu will be the source language and the target language will be French. Generally an encyclopaedic dictionary presents a single word list within which the treatment is either exclusively linguistic or mixed. In the proposed dictionary, Yilumbu will constitute the main language. However, the bilingual dimension will be introduced by the insertion of French equivalents. French will only be used in providing translation equivalents of the lemmas. The treatment will be provided in Yilumbu. The intended user group and purpose will have a significant impact on the contents of the dictionary. As a matter of fact, the dictionary is meant for both adults and children and will also fulfil a pedagogical function. The potential users of the dictionary thus represent a culturally homogeneous community, the Balumba. This community is made up of Yilumbu mother-tongue speakers, but the language consists of two main mutually intelligible dialectal variants (cf. Mavoungou 2002 and 2006).

With regard to functions, the dictionary should have a cognitive function as main function. In this regard, it should be noted that an encyclopaedic dictionary differs from linguistic dictionaries in that it contributes significantly to building the general knowledge of the user. Thus, the cognitive function is regarded as the primary function of the proposed encyclopaedic dictionary. More specifically, it should meet the cognitive, cultural and scientific needs of the potential users. Apart from the cognitive function, the planned encyclopaedic dictionary should also fulfil a communicative function in terms of the following specifications:

(a) To help users in understanding Yilumbu texts.

(b) To help users in producing and receiving Yilumbu texts.

(c) To give translation equivalents from Yilumbu to French. 
Moreover, the communicative function of the planned encyclopaedic dictionary is only relevant in a situation where the users will also show the need for producing or reproducing the knowledge acquired from the dictionary.

\section{The role and function of illustrative material in the planning of an encyclopaedic dictionary of Yilumbu}

\subsection{The use of illustrative examples}

An illustrative example is any phrase or sentence that illustrates the use of the item defined or translated. The objective of the planned dictionary is to provide different types of data, including verbal illustrations, quotations, citations and encyclopaedic notes. The first purpose of examples is to show concretely that lexical units with particular meanings exist in the language.

The situation presented above is more applicable to linguistic dictionaries, because illustrative examples help to present sentences that a Yilumbu speaker would spontaneously produce upon hearing a given word, its typical collocations, the sense discrimination of polysemous words and the differentiation of synonyms. Moreover, illustrative examples help knowing the grammatical categories and the stylistic peculiarities of a given lexical unit. Consider the following example in this regard:

dikuumbi/makuumbi cl. 5/6 [dikú:mbì]. $n$. 1. Bateau; navire. BIBAAMBA biteti bayitsaanga na makuumbi. Les premiers occidentaux abordèrent les côtes africaines en bateaux. MUSAAVHU atsyeboonga dikuumbi o Port-Mikaandi mu uweenda o Lambarini. Moussavou a embarqué à Port-Gentil sur le bateau devant le conduire à Lambaréné. DIKUUMBI divavhyoogha bwaatu utola. Un bateau est plus grand qu'une pirogue. Ali mu dikuumbi. Il est sur le bateau. 2. (Par ext.) Avion. DIKUUMBI difunobotugha o Mayumba. L'avion vient de décoller de Mayumba. DIKUUMBI di maamba ditsivhyoogha dikuumbi di yilu utola na utsira. Un bateau est plus large et plus lourd qu'un avion. DIKUUMBI difunovhyoogha o yilu. Un avion vient de passer au dessus de nos têtes. 3. (Par ext.) Véhicule (terme générique). VHAVHA Puungu ke usana dikuumbi pasi. À Libreville, si tu n'a pas de véhicule il est difficile de se déplacer.

Text example 1: Article dikuumbi

dikuumbi/makuumbi cl. 5/6 [dikú:mbì] n. 1. Boat; vessel. BIBAAMBA biteti bayitsaanga na makuumbi. The first Westerners approached the African coast by boats. MUSAAVHU atsyeboonga dikuumbi o PortMikaandi mu uweenda o Lambarini. Moussavou embarked in Port-Gentil on the boat that must take him to Lambaréné. DIKUUMBI divavhyoogha bwaatu utola. A boat is bigger than a dugout. AlI mu dikuumbi. He is on 
the boat. 2. (By ext.) Airplane. DIKUUMBI difunobotugha o Mayumba. The plane has just taken off from Mayumba. DIKUUMBI di maamba ditsivhyoogha dikuumbi di yilu utola na utsira. A boat is wider and heavier than an airplane. DIKUUMBI difunovhyoogha o yilu. A plane has just passed above our heads. 3. (By ext.) Vehicle (generic term). VHAVHA Puungu ke usana dikuumbi pasi. If you do not own a car in Libreville, it is difficult to move around.

\section{English translation of text example 1: Article dikuumbi}

In this article of the lemma sign dikuumbi, representing a polysemous lexical item, the different distinctions in meaning are presented on historical and frequency grounds. Sense 1 (ship) is the primary sense used in Yilumba; therefore, it is placed first in the article. Sense 2 (airplane) is the second sense that the lemma developed in the course of time and is the most used nowadays, and sense 3 (car) is used by extension.

Some basic questions are to be considered while dealing with illustrative examples in an encyclopaedic dictionary:

- Which words (if any) are to be given without examples?

- Which lexical units require more illustrative examples?

- What should the length of examples be?

- Should the lexicographer give constructed examples or quotations from written texts only?

- Should quotations be given with citations or without citations?

Most importantly (cf. Heinz 2005: 5) the question of knowing the following will be dealt with:

- What is a good example?

- What is a useful example?

- How can exampling in dictionaries be improved?

Answers to these questions depend on the type of dictionary and the type of lexical unit. A good and useful example is one that best illustrates the specific context to which the lemma refers. The first step in finding ways to improve exampling in dictionaries is to make provision for the inclusion of examples for every lemma sign. As a matter of fact, no lexical unit should be given without illustrative examples.

With regard to the extent of a sentence, it is always better to keep examples as simple and concise as possible. However, the lexicographer may use relatively long sentences, especially when they are meant to help in a certain way to capture the sense(s) and the context of the usage of the lexical item. 
Examples should enable users to become familiar with authentic spoken language. Yilumbu is not a language with a strong written tradition. Whenever possible, the lexicographer should use existing citations in Yilumbu literature, especially when they better illustrate the use of the lexical item represented by the lemma sign. The following are examples taken from Blanchon (1984), illustrating the use of the lexical item ngwaamba (the absence of meat in homes):

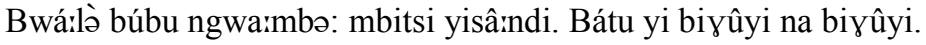

Translation: Here in the village there is a lack of meat. People are eating food without any meat.

Ha: dibáyəlá ti: mînu ngana yíbulu. Mî yébókə ngê:le:ngi áyi. Yétu, ngwaamba tuvâ:fu na yífu:mbə.

Translation: "Ah," said the man, "I found my game. I will kill this squirrel. We are starving at home."

Nyúmfu. Úba:nga:ngə nyúmfu ayénə́ro:mbə tsímbitsi. Nzala. Ngwa:mbə.

Translation: A vulture. There was a vulture that was looking for food. It was starving.

In these (authentically spoken Yilumbu) examples taken from Blanchon (1984), users have both decoding and encoding language material in order to improve their knowledge of the language. Users will perform well in both the communicative-oriented function and the cognitive function, depending on the situation in which the lexical item is needed and applied. The illustrations provided by Blanchon (1984) are good examples, because they best illustrate the use of the word ngwaamba, both in terms of content and situation.

With regard to the question, "What makes a good lexicographic example?", the answer is that it is one that clearly conveys the different contexts in which a lexical item is used in order to help in sense disambiguation. It is also one that is concise and simple. Illustrative examples should be chosen according to the following criteria, designed by Chun and Plass (1997), Hupka (1989), Mayer (1999) and Schriver (1997):

- They should be used systematically and consistently. Each separate sense of every article should be illustrated by at least one citation.

- $\quad$ They should be translated into the user's native language. Otherwise they will be of little use or waste much time, because they very probably will contain some other words whose meaning is unknown to the user.

- $\quad$ They should be selected to reflect the culture of the speakers of the target language.

- $\quad$ They should be brief and informative. 
As in the case of lexicographic examples, however, the following are still needed:

- Theoretically motivated analyses of how the data provided in illustrations relate to and are linked to the information provided in lexicographic definitions.

- Experimental evidence on what constitutes a good lexicographic illustration (for what aspects of the meaning of lexemes and for what word classes).

Illustrative material may interact with the encyclopaedic dictionary text in different ways:

- $\quad$ They stand alone, speaking for themselves.

- $\quad$ They may elucidate the data provided in the dictionary articles, the text being structured as supplementary encyclopaedic data that can be useful to students during their language-using process.

- An explanation of the illustration may be given.

- An illustration may also serve to clarify and further the encyclopaedic note.

- $\quad$ There may be an overlap between text and illustration, the encyclopaedic information being provided in both linguistic and visual form.

All the above-mentioned elements and criteria can to some extent be applied to encyclopaedic dictionaries. However, encyclopaedic dictionaries differ in principle from linguistic dictionaries in the cognitive function that they aim to fulfil in order to better satisfy the needs of different potential target users of such dictionaries. The examples used in encyclopaedic dictionaries are not meant to illustrate the usage of a lexical item or assist the user in the text production situation. They rather help the lexicographer to convey the denotations of the lexical items, in other words things to which concepts, names and abbreviations refer when spoken about. In this regard the illustrative examples in the planned encyclopaedic dictionary should be used to:

- Contextualize the concept, in other words give the historical picture of when the event took place or the object was used and how it developed.

- Indicate the cultural environment and context in which a given action is performed.

- $\quad$ Refer to a historical event in which certain famous people took part.

- $\quad$ Refer to a different area where a given concept can be applied.

These criteria will help the lexicographer to provide the users with the needed information on a specific lemma in the dictionary article of an encyclopaedic 
dictionary. The data types provided will differ from one dictionary article to another, depending on the material available. Some lemmas will display a cross-reference article in which the treatment of the item will be cross-referred to another item in the dictionary where the concept has already been fully treated.

This will be supported when possible with a well-selected pictorial illustration in order for the user better to understand the concept or the lexical item in context. Text examples 2, 3 and 4 below show illustrative examples of each lemma as well as how encyclopaedic notes look like. Each illustrative example is given in both Yilumbu and French (and in both Yilumbu and English for the Yilumbu-English translation needed in these articles).

ifumu/bifumu cl. 7/8 [ífúmù]. n. 1. Ventre, abdomen. MuSAAVHU ana ifumu yi neni. Moussavou a un gros ventre. 2. (Ext.) Grossesse. MWAANA mughetu ali mu ifumu. La jeune fille est en grossesse. 3. (Ext.) Estomac. IfUMU ina funzugha. Litt. L'estomac s'est troublé.

Text example 2: Article ifumu

ifumu/bifumu cl. 7/8 [ífúmù]. $n$. 1. Belly, womb. MUSAAVHU ana ifumu yi neni. Moussavou has a big belly. 2. (By ext.) Pregnancy. MwAAnA mughetu ali mu ifumu. The young girl is pregnant. 3. (By ext.) Stomach. IFUMU ina funzugha. Litt. The stomach is upset.

\section{English translation of text example 2: Article ifumu}

mangumba cl. 6 [màngúmbə̀]. $n$. Variété de danse exécutée lors des cérémonies de levées de terre. MUSAAVHU aba na nuumba mu ndoonga baghetu bawimbilaanga mangumba ilumbu be yina. Moussavou avait une petite amie parmi les femmes qui dansèrent les Mangoumba ce jour-là. Note encyclopédique: Mangumba est une danse organisée par la famille de la personne disparue, deux semaines après le décès en guise de levée de terre et pour éventuellement annoncer le port de deuil. La particularité de cette cérémonie réside dans le caractère obscène des chants et danses exécutés en la circonstance. En temps normal, les Balumbu sont extrêmement pudiques. Les parties honteuses du corps sont tabous et on n'en parle qu'à travers l'usage de métaphores, euphémismes et autres figures de style. Il semble que cette cérémonie est célébrée pour obtenir la pacification de l'esprit du défunt (ou de la défunte).

Text example 3: Article mangumba

mangumba cl. 6 [màngúmbə̀]. $n$. Type of dance that is performed during the ceremony called "rising from the ground". MUSAAVHU aba na nuumba mu ndoonga baghetu bawimbilaanga mangumba ilumbu be 
yina. Moussavou had a girlfriend among the women who danced the Mangumba that day. Encyclopaedic note: Mangumba is a dance that is organized by the family of the deceased, two weeks after the burial in order to serve as a rising from the ground and it eventually announces the bearing of the mourning. The particular characteristic of this ceremony lies in the obscene character of the songs and dances performed in this case. Usually, the Balumbu are extremely decent. The private parts of the body are taboo and one speaks about them only by the use of metaphors, euphemisms and other stylistic devices. It seems that this ceremony is arranged in order to pacify the spirit of the deceased.

English translation of text example 3: Article mangumba

mutulitsi/batulitsi cl. 1/2. [mùtúlítsi] . $n$. Personne qui forge, le forgeron; l'artisan. Vho teemu ighulu, batulitsi batulaanga moonga, tsipalu na tsinyobu. Autrefois, les forgerons fabriquaient traditionnellement des lances, des sagaies et des harpons. Note encyclopédique: Autrefois, la forge était associée au pouvoir, à la médecine traditionnelle et à la magie. Les forgerons étaient très souvent des rois, des chefs traditionnels et des devins-guérisseurs.

\section{Text example 4: Article mutulitsi}

mutulitsi/batulitsi cl. 1/2. [mùtúlítsì]. $n$. Blacksmith, artisan. Vho teemu ighulu, batulitsi batulaanga moonga, tsipalu na tsinyobu. In the past, blacksmiths traditionally manufactured lances, spears and harpoons. Encyclopaedic note: In the past, metallurgy was associated with power, traditional medicine and magic. Blacksmiths were often kings, chiefs and traditional healers.

\section{English translation of text example 4: Article mutulitsi}

Of importance in the article of the lemma mangumba (a type of dance in the Yilumbu culture) given as text example 3, the lexicographer using this model must undertake exhaustive surveys in order to obtain the full cultural content of the lexical item. As a matter of fact, this dance is only performed during funerals after the burial. In the same line of argumentation, the lexical item mutulitsi (blacksmith) obviously has something to do with butali (iron) but most importantly metallurgy is associated with power, traditional medicine and magic. It is obvious that the presentation and the treatment of such data by the lexicographer in the dictionary articles can help potential users not only in the retrieval of the information but also in the clear and objective understanding of the culture of the source language speech community. In the treatment of lexical items such as the ones presented above, users will have to be informed about what mutulitsi and butali refer to, the way the activity is carried out, the purpose of doing it, the different stages of the development of the activity, who 
is qualified to execute the job and the different functions that the tool and the executor play in the cultural activities of the community. The treatment provided in text example 4 above is not exhaustive; the lexicographer will have to make use of the maximum data available to him/her and make good use of it in order to facilitate the users' consultation process. Furthermore, the way in which this data will be distributed within the article is of great importance to the level of retrievability of the data.

The use of pictorial illustrations should be planned in accordance with the needs and reference skills of the target users of the proposed encyclopaedic dictionary. However, because of the great semantic importance of pictorial illustrations in modern dictionaries and the explicitness that can be achieved by using pictorial illustrations, thus enhancing the retrieval of information, a new approach to pictorial illustrations in the proposed encyclopaedic dictionary is necessary.

\subsection{The use of pictorial illustrations}

Stein (1991: 106) distinguishes four main types of pictorial illustration in dictionaries:

- Illustrations showing common animals, objects and plants.

- Illustrations showing things that are not easily explained in words, such as shapes, complex actions or small differences between words that are similar but not the same.

- Illustrations depicting groups of related objects with a view to explaining the differences between similar objects, showing the range of shapes and forms covered by a particular word and serving as an important aid to vocabulary expansion.

- Illustrations showing the basic or physical meaning of words commonly used in an abstract or figurative way.

To a certain extent the above classification of pictorial illustrations can be applied to encyclopaedic dictionaries as long as they are essentially used to help the target users. They should assist users to form an idea of the image the lexical item represents. For the encyclopaedic dictionary as such the picture will be used based on a specific lemma, the cognitive function of the dictionary and the reference skills of the target users. It is clear that not all the lemmas will need pictorial illustrations, or rather pictorial illustrations will be used when they are available. Since encyclopaedic dictionaries and other dictionaries contain different data types, encyclopaedic dictionaries in particular will provide pictorial illustrations as a supportive element, as suggested by Singh (1982: 144-145). 
With regard to illustrations showing common animals, objects and plants, the green parrot of Gabon (see picture below) is an icon in almost all Gabonese cultures.

\section{Illustrative picture 1}

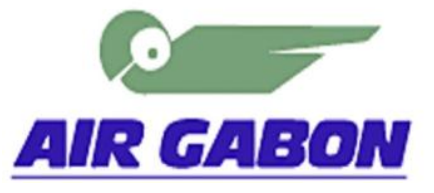

Source: Magazine Mbolo d'Air Gabon

The green parrot was the emblem of the former Gabonese national airline Air Gabon. As far as the lexicographic treatment with an encyclopaedic function is concerned, it should be noted that the Gabonese African green parrot (Psittacus erithacus) is a very talkative, intelligent and sensitive bird. It may be the best talker of all birds, easily learning hundreds of words and other sounds. The green parrot can easily be tamed as a pet.

According to Smit (1996), pictorial illustrations help dictionary users to understand and remember the content of an accompanying verbal equivalent (in particular), because they motivate them, reinforce what is read and symbolically enhance and deepen the meaning of the verbal equivalent. The chosen illustrations have to be considered in the light of this dual requirement: Where pictures or diagrams more easily explain things than words, illustrations should be used to help in understanding the definition of the lemma in question.

Verbal input represents the symbolic structures of a language and it is processed sequentially to form, first of all, prepositional mental representations of the meaning of the lexicographic input. The prepositional representations are then mapped onto a mental model of the presented information. Visual input, on the other hand, conveys information by means of visio-spatial structure (i.e. spatial arrangements of the components of an image) and the information is encoded in parallel or simultaneously. The comprehension of an image requires establishing an analogy between the picture and a corresponding mental model. Image comprehension thus bypasses the prepositional representation of information and is therefore assumed to be language independent (cf. Svensén 1993: 167).

The general purpose encyclopaedic dictionary is much more than an instrument for providing answers to linguistic questions. As far as this point is concerned, a number of scholars have mentioned the following:

(a) Illustrative pictures are given along with the verbal definitions, examples and so on to further clarify the meanings of the lexical units. 
(b) Zgusta (1988) states that since the dictionary is a text couched in natural language, it possesses pragmatic aspects itself.

(c) Fleming (1967: 247) defines pictorial illustrations as those configurations of line, dot or area and any combination of these three resembling events or objects (persons, places and/or things) either as perceived or as generally conceived.

(d) Al-Kasimi (1977: 77) comments that the definition should be expanded to include such borderline cases as number lines, geometric figures, structural chemical formulas, curves, graphs and time lines.

(e) Putter (1999: 51) regards the use of illustrations in dictionaries as a type of definition that is known in lexicography as ostensive definition. It is normally a type of definition that is used to augment and to elucidate a verbal definition.

As in the case of illustrative examples, some basic questions are to be considered while giving pictorial examples: How many pictures can be given per article? What are the lexical units that require pictures for definitions?

Owing to the limited space in a dictionary, the answer to this question should be determined by the target user profile. It is also worth noting that pictorial illustrations (in colour) are expensive to print. Given the encyclopaedic nature of the planned dictionary, a reasonable number of pictorial illustrations should be presented.

It is easily understandable that no general dictionary can give pictures for all its lexical units. Moreover, cultural data are a type of data that merits the inclusion of illustrations in encyclopaedic dictionaries. In itself it may be regarded as a type of encyclopaedic data. Illustrations may serve as vehicles to clarify and/or disambiguate the meanings of culture-specific words. Lexicographers also came to realize that the criteria for the inclusion of illustrations in different types of dictionary might differ on the basis of the cultural differences between encyclopaedic dictionary users and the culture in which the target language is embedded. However, only a few objects can be illustrated by pictures.

With regard to the use of pictorial illustrations, it could also be asked: What are the lexical units that require pictures for definitions?

The defining of flora and fauna is a big problem. In spite of all the verbal description of this class of words, the user of the encyclopaedic dictionary may not be able to form a clear and concrete picture of the object defined. It is useful to give a picture of the object along with the definitions. This will reinforce the image created by the verbal definition and help the reader to understand the object more clearly.

In addition, cultural objects require pictures. For example, different types of net are used for fishing. Any verbal description may not be adequate to describe all of these. If pictures are given, the reader may clearly understand 
the object. Pictures could also be given for unfamiliar objects in the culture of the language community, in other words objects pertaining to Balumbu history. Newly introduced objects in the culture such as scientific and technical items may also be accompanied by pictures to enable the reader to form a concrete picture of these. Furthermore, pictures can help in understanding lexical units whose definitions may not be adequate to describe them. Different articles of daily use, words related to sports, clothing, household goods and various other materials and articles might therefore be accompanied by pictorial illustrations.

Pictorial illustrations or ostensive definitions can be utilized fruitfully in the defining process, especially in cases where it is difficult clearly to explain the meaning of a lemma by means of a descriptive definition. Pictorial illustrations will also complement or expand the semantic value in the Yilumbu culture: for example, the use of pictures saves words and long explanations. These pictures reinforce learning, and a picture may often, quite differently from a definition, appeal to the readers' previous experience of the world and enable them to achieve fresh insights. Anyone who has turned the pages of an illustrated encyclopaedic dictionary has probably noticed that it is mainly nouns, and in particular those denoting concrete objects, that are described by means of illustrations. Consider the following in this regard:

\section{Illustrative picture 2}

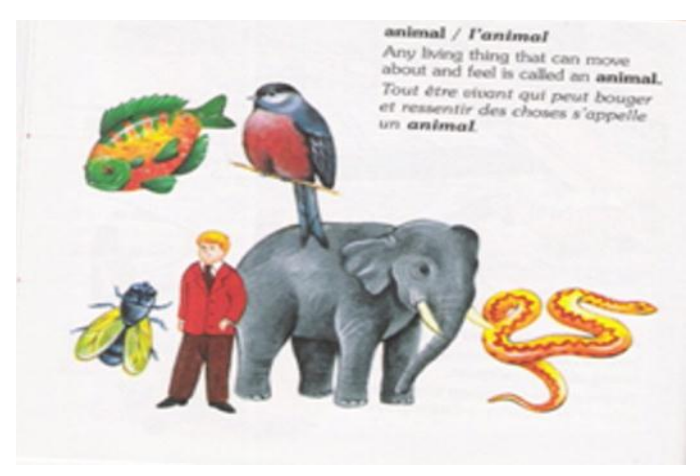

Source: Larousse Children's Dictionary French (2005)

The pictorial illustration above may portray the kind of animals and birds that are found in Gabonese forests. It is part of the editorial policy of the planned dictionary to attach significant importance to pictorial illustrations, because they have the capacity to complement the meaning of any given lexical item. In the Yilumbu situation, pictorial illustrations will help to represent specific animals and plants, as well as newly introduced objects in particular. These pictures could be individually chosen for inclusion in the central list of the dictionary to illustrate a relevant lemma. Consider the following picture in this regard: 


\section{Illustrative picture 3}

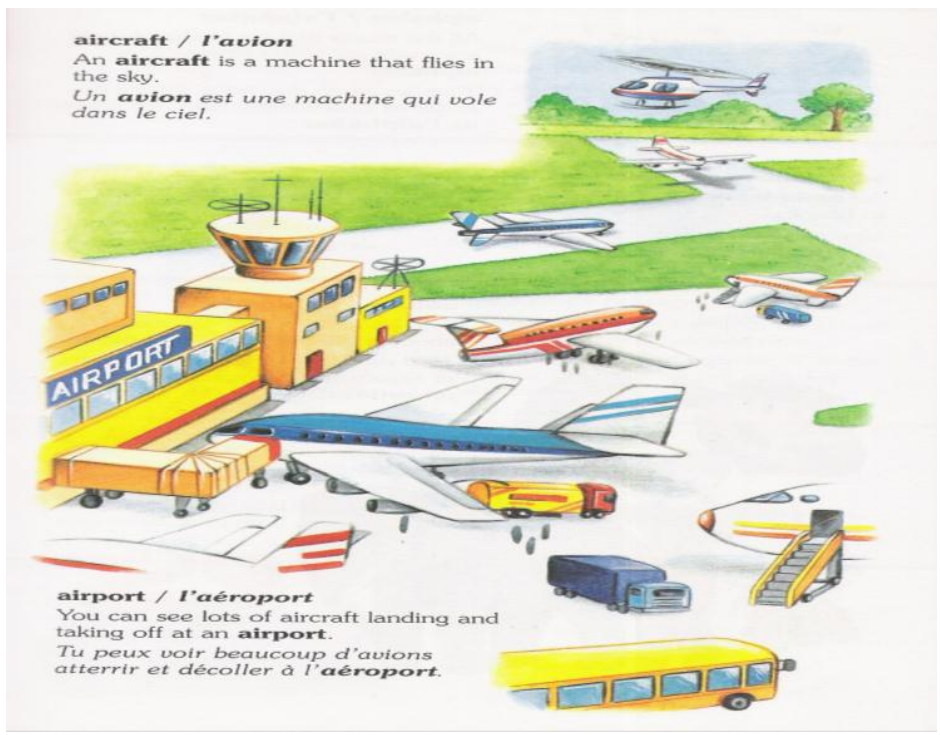

Source: Scholastic Children's Dictionary

The pictorial illustration above displays the aircraft side of an airport. It can be used to illustrate airport activities as well as various types of aircraft.

With regard to the positioning of ostensive illustrations, large pictures will be employed in the back matter; small pictures will be included as microstructural items addressed at selected lemmas. In the proposed dictionary, the pictorial illustrations will be placed in the dictionary article next to the lemma sign when possible. Following the items giving the illustrative examples, the items presenting the ostensive illustrations will be provided. The use of pictorial illustrations has to be planned in accordance with the needs and reference skills of the target users of the proposed dictionary.

\subsection{The of etymological notes}

The proposed encyclopaedic dictionary with the planned microstructural programme will also include etymological notes as microstructural items in fixed article positions, usually at the end of the article or at the end of the specific sense to which the etymological notes applies.

This will mainly concern loanwords. General guidelines concerning the need for etymological notes are uniform when a dictionary is at the same time intended for text reception and for introducing the dictionary subject matter. The function of etymological notes is to assist users with the origin of the word in their search for lemmas or choice of equivalents. 
Etymological notes should always be prepared with the intended user in mind, in terms of both contents and scope as well as of style.

Kakamoëka cl. 9 [kák̇̀mwè:k̀̀] $n$. comp. Nom d'un village situé sur la rive droite du fleuve Kouilou (Congo). Kakamweeka bwala bu ke ku Kongu. Kakamoëka est un village du Congo. Note étymologique: Le toponyme Kakamoëka est d'origine vili. La traduction littérale de ce toponyme vili qui signifie « aïeul commun », suggère un lieu de rencontre et surtout de départ des émigrants vers différentes directions (Mabiala 1992: 139-149).

Text example 5: Article Kakamoëka

Kakamoëka cl. 9 [kákə̀mwè:kə̀] comp. $n$. Name of a village located on the right bank of the river Kwilu (Congo). Kakamweeka bwala bu ke ku Kongu. Kakamoëka is a town in the Congo. Etymological note: Kakamoëka is a Vili place name. The literal translation of this Vili place name, meaning "common grandfather", suggests a meeting place, especially a stopover for emigrants on their way in various directions (Mabiala 1992: 139-149).

English translation of text example 4: Article Kakamoëka

Of interest in this article given as text example 4 is the etymological note presented as a strategy of explication. In fact, the lemma sign, decomposed into the monomorphemic units Kaka (aïule) and Moeka (unique, seul, même), clearly shows the meaning of the toponym.

\section{Conclusion}

On the basis of the research described above, it can be concluded that the proposed encyclopaedic dictionary should include a wide range of illustrative material, namely: authentic examples, constructed examples, quotations, sentences, syntagms, pictorial illustrations, etc. Authentic spoken language material is of paramount importance in a lexicographic reference work. Whenever possible, existing citations in Yilumbu literature should be used by the lexicographer, especially when they better illustrate the use of the lexical item represented by the lemma sign. On the basis of this study, it can be said that pictorial illustrations will add to the communicative value of the intended encyclopaedic dictionary. Pictorial illustrations should never be used in dictionaries only for decoration purposes. Instead, they should save space which would otherwise be taken up by long descriptions of a lemma (cf. Gangla-Birir 2005: 47-48). 


\section{References}

Al-Kasimi, A.M. 1977. Linguistics and Bilingual Dictionaries. Leyden: E.J. Brill.

Blanchon, J.A. 1984. Présentation du yilumbu dans ses rapports avec le yipunu et le civili à travers un conte traditionnel. Pholia. Revue du Laboratoire de Phonétique et Linguistique Africaine 1: 7-35.

Chun, D.M. and J.L. Plass. 1997. Research on Text Comprehension in Multimedia Environments. Language Learning and Technology 1(1): 60-81.

Fleming, M. 1967. Classification and Analysis of Instructional Illustrations. AV Communication Review 15: 246-258.

Gangla-Birir, L. 2005. The Use of Pictorial Illustrations in African Language Dictionaries. Lexikos 15: 38-51.

Heinz, M. (Ed.). 2005. L'exemple lexicographique dans les dictionnaires français contemporains. Actes des «Premières Journées Allemandes des Dictionnaires» (Klingenberg am Main, 25-27 juin 2004). Tübingen: Max Niemeyer.

Hupka, W. 1989. Die Bebilderung und sonstige Formen der Veranschaulichung im allgemeinen einsprachigen Wörterbücher. Hausmann, F.J., O. Reichmann, H.E. Wiegand and L. Zgusta (Eds.). 1989-1991. Wörterbücher. Ein internationales Handbuch zur Lexikographie/Dictionaries. An International Encyclopedia of Lexicography/Dictionnaires. Encyclopédie internationale de lexicographie: 704-726. Berlin/New York: Walter de Gruyter.

Larousse. 2005. Larousse Children's Dictionary French. Paris: Larousse.

Mabiala, J.-N. 1992. La situation linguistique de la r: La situation linguistique de la région du Kouilou (Congo). Pholia. Revue du Laboratoire de Phonétique et Linguistique Africaine 7: 139-149.

Mavoungou, P.A. 2002. Metalexicographical Criteria for the Compilation of a Trilingual Dictionary: YilumbuEnglish-French. Unpublished D.Litt. Dissertation. Stellenbosch: University of Stellenbosch.

Mavoungou, P.A. 2006. A Trilingual Dictionary Yilumbu-French-English: An Ongoing Project. Lexikos 16: 121-144.

Mayer, R. 1999. Research-based Principles for the Design of Instructional Messages: The Case of Multimedia Explanations. Document Design (1): 7-20.

Putter, A.M. 1999. Verklaringsmeganismes in kinderwoordeboeke. Unpublished M.A. Thesis. Potchefstroom: University of Potchefstroom.

Saphou-Bivigat, G. 2010. A Theoretical Model for an Encyclopaedic Dictionary for Gabonese Languages with Reference to Yilumbu. Unpublished D.Litt. Dissertation. Stellenbosch: Stellenbosch University.

Scholastic. Scholastic Children's Dictionary. New York: Scholastic Inc.

Schriver, K. 1997. Dynamics in Document Design: Creating Text for Readers. New York: John Wiley.

Singh, R.A. 1982. An Introduction to Lexicography. Mysore: Central Institute of Indian Languages.

Smit, M. 1996. Wiegand's Metalexicography as a Framework for a Multilingual, Multicultural, Explanatory Music Dictionary for South Africa. Unpublished D.Litt. Thesis. Stellenbosch: University of Stellenbosch.

Stein, G. 1991. Illustrations in Dictionaries. International Journal of Lexicography 4(2): 99-127.

Svensén, B. 1993. Practical Lexicography: Principles and Methods of Dictionary-Making. Translated from the Swedish by John Sykes and Kerstin Schofield. Oxford/New York: Oxford University Press.

Zgusta, L. (with the assistance of D.M.T.Cr. Farina). 1988. Lexicography Today: An Annotated Bibliography of the Theory of Lexicography. Tübingen: Max Niemeyer. 


\title{
Troeteltaal in taalkundige en leksikografiese verband ${ }^{*}$
}

\author{
Gerda Simpson, Stellenbosch, Suid-Afrika
}

Opsomming: In hierdie artikel word 'n kort oorsig van troeteltaal gegee: die oorsprong en toepassing daarvan, die beskouing daarvan as 'n taalvariëteit, die herleiding daarvan na naamgewing, die leksikografiese behandeling daarvan, die etikettering daarvan in woordeboeke, die betekenisaspekte daarvan en die kennis daarvan in die gebruikstaal. Troeteltaal wat meestal met 'n ondertoon van liefde gepaard gaan, kan gebruikstaal positief beïnvloed. Leksikograwe behoort meer aandag aan die behandeling van troetelwoorde in woordeboeke te gee.

Sleutelwoorde: TROETELTAAL, TAALVARIËTEIT, NAAMGEWING, ETIKETTERING, BETEKENISOMSKRYWING

\begin{abstract}
Language of Endearment in Linguistic and Lexicographic Context. In this article, a short overview of language of endearment is given: its origin and application, its consideration as a language variety, its deduction to name-giving, its lexicographic treatment, its labelling in dictionaries, its aspects of meaning and its acquaintance in ordinary language. Language of endearment, which is mostly accompanied by an undertone of love can influence ordinary language positively. Lexicographers should pay more attention to the treatment of words of endearment in dictionaries.
\end{abstract}

Keywords: LANGUAGE OF ENDEARMENT, LANGUAGE VARIETY, NAME-GIVING, LABELLING, PARAPHRASE OF MEANING

\section{Inleiding}

Woordeboekverklarings vir die woord troetel sluit onder meer in "met liefde behandel", "liefkoos", "streel" en "versorg". Hierdie besonder positiewe konnotasie het gelei tot 'n soekroete om die ontstaan, bekendheid en gebruik van hierdie woord in Afrikaans te probeer vasstel en sodoende ook die krag daarin opgesluit by leksikograwe te laat herlewe. Om die herlewing van troetelwoorde by die algemene taalgebruiker aan te moedig, behoort hulle dus meer prominensie in woordeboeke te geniet, aangesien 'n woordeboek 'n data-aanbod daarstel wat verteenwoordigend is van die gewone omgangstaal in die

* Hierdie artikel is gebaseer op 'n ongepubliseerde M.Phil.-skripsie getitel 'n Taalkundige en leksikografiese perspektief op troeteltaal in Afrikaans wat in 2012 by die Universiteit van Stellenbosch, Stellenbosch, Suid-Afrika voltooi is. 
tydsgewrig van die samestelling daarvan. Woordeboeke dien ook as interessante inligtingsbronne van data in die gebruikstaal, en betreffende troeteltaal, is hierdie aspek van kardinale belang, aangesien dit uit navorsing blyk dat troeteltaal onder oud en jonk in onbruik verval het.

Troeteltaal wat meestal met 'n ondertoon van liefde gepaardgaan, het die potensiaal om gebruikstaal positief te beïnvloed. Deur die eeue word liefde in verskeie gelowe as basis van suksesvolle menseverhoudinge aanbeveel en uitgeleef, en daarom is die mag van troeteltaal tot op hede deur leksikograwe asook algemene taalgebruikers onderskat. In die opbou van verhoudinge tussen mense van verskillende taalgroepe, asook die eerste gesprekke tussen moeder en pasgebore baba neem eenwoordkommunikasie 'n uiters belangrike plek in. Behalwe hul gewone gebruiksbetekenis in 'n sekere verband, kan alle woorde ook 'n emotiewe waarde insluit. In die vestiging van kommunikasie is hierdie eenwoord-kommunikasiemedium, soos troeteltaal, met die emotiewe komponent daaraan verbonde, van uiterste belang.

Sou ' $n$ mens troeteltaal by alle ouderdomsgroepe aan 'n norm wou meet, wat 'n balans kon bied tussen formele taal in opvoedkundige instellings en informele gebruikstaal, waarby troeteltaal inskakel, is die siening van Zgusta (1971: 60) baie raak en toepasbaar:

The norm is that part of the possibilities of the system which is considered good ... There is always a strong element of tradition in the norm. The norm must be functionally adequate to all levels of functions of written and spoken language ... The outstanding properties of lexical meaning draw a line between generality which can be perceived in different dimensions.

Sekere troetelname is reeds taalkundig aanvaarbaar gevind en kom so algemeen voor in gewone gebruikstaal dat die gebruikers nie meer werklik bewus is van die semantiese aspek daarin aanwesig nie. 'n Mens kan argumenteer dat aandag aan taalkundige toetsing van meer voorbeelde van troetelwoorde en hul bewerking daartoe kan lei dat hulle ook erkenning sal vind in algemene woordeboeke, onderrigsituasies en gevolglik in alledaagse gebruik. Die gebruiksfrekwensie van minder bekende troetelwoorde mag juis nie hulle waarde en betekenis bepaal nie.

In die bespreking van troeteltaal word geprobeer om meer insig te bring in die niestandaardstatus, ten spyte van die soms algemene gebruik, gebiedsgebondenheid en wisseling onder gebruikersgroepe van troeteltaal as taalvariëteit. 'n Mens sou selfs na troetelvorme kon verwys as 'n deel van taalgroei met 'n saamsnoerende substansie: van kombuistaal tot kunstaal.

\section{Oorsprong en toepassing van troeteltaal}

'n Linguistiese bespreking van troeteltaalvorme as 'n variëteit van Afrikaans vind aansluiting by die siening dat mense se taal 'n prent skilder van die hele lewe van en sosiale omgang tussen die lede van afsonderlike gemeenskappe. 
Omdat Afrikaans 'n groeiende taal is wat eers in 1925 na 'n lang stryd amptelike erkenning gekry het, is besluit om dieper in sommige van die oudste tale te delf om 'n oortuigender aanknoping tussen die gegewe betekenisse van troetel en liefde vas te stel.

In hierdie soekproses is as verdere wegwyser in verklarings van verklarende Afrikaanse woordeboeke die volgende gevind: "met liefde behandel, liefkoos", waaruit 'n volgende riglyn gespruit het, naamlik 'n konnotasie met 'n geestelike komponent en die rol daarvan in mense se bestaan, en dus ook onvermydelik met hul aangepaste taalgebruik in hierdie verband. Hieruit het 'n logiese skakel met gelowe, van watter denominasie en in welke land of indiwidu se leefstyl ook al, 'n rasionele moontlikheid geblyk te wees. Voorts kan dan ook 'n verband met liefde, 'n sleutelterm in gelowe, ongeag uiteenlopende interpretasies, beoefening en skriftuurlike voorskrifte en wenke in handleidings, as vertrekpunt vir hierdie benadering tot die bespreking gevind word. Vandaar het navorsing, volgens aantekeninge in gesaghebbende publikasies in die antieke tale sinvol geblyk te wees. Ook daaglikse beriggewing van menings deur die gewone publiek en denkers op akademiese vlak in dié verband lei tot die gevolgtrekking dat 'n oortuigende definisie en resep vir liefde (troetel) maar net 'n soeke sal bly. Daar is nog nie eenstemmigheid oor 'n oorkoepelende samevatting bereik nie. Die moontlikheid van sinonieme in die toepassing van troeteltaalvorme sal nog ontgin moet word.

In studies, ook in Afrikaans, oor die semantiek deur 'n verskeidenheid taalgeleerdes blyk dit dat eenstemmigheid bestaan oor die siening dat volkome sinonimie tussen woordpare hoogs uitsonderlik is. Verwysings na "Moeder Theresa" en "my moeder" kan geensins sinoniem wees nie, al is die woorde identies in spelling, klem en uitspraak. Die emotiewe betekenis verwys na heeltemal verskillende velde, en hulle is nie in konteks vervangbaar nie. Volgens De Stadler (1989: 77) kan daar wel "losser" (naby-)sinonimie wat sekere semantiese parameters insluit, in taalgebruik voorkom. Hy noem dit die polisemantiese aard van woordbetekenis. Hierdie verwante betekenisse kom in 'n ruim mate in troetelname soos byvoorbeeld Poppie en Poppelol voor. Die losser vorm van sinonimie kan ook sowel kognitiewe as emotiewe betekenis hê en is dikwels soos in troeteltaal konteksgebonde. Die semantiek van 'n troetelnaam wat soms 'n geruime tyd lank as 'n eienaam gebruik word en dit later selfs word, steun egter op die verband waarin die naam vir die spreker en hoorder sin maak. In die verklaring van die woord troetel en samestellings daarmee begin die meeste verklarende woorde met lief-, byvoorbeeld "liefkoos, liefkosende naam of woord". Dit dien as regverdiging om liefdestaal as 'n nabysinoniem van troeteltaal te aanvaar en te bespreek, en die oeroorsprong in die oudste antieke tale van Afrikaanse denominasies te gaan navors en te probeer bepaal in watter semantiese verband troetel (liefde) met 'n betekenis aansluitend by die verklarende woorde daarvoor in Afrikaans voorkom. Die feit dat nuanses van liefde in menseverhoudinge 'n sleutelelement in gelowe verteenwoordig, sluit nou hierby aan. 
Alles in die heelal het iewers 'n begin gehad, 'n onvoorspelbare wisselende verloop, gekoppel aan 'n wye verskeidenheid van uiteenlopende faktore, situasies en ervaringe vir alle indiwidue, groepe en gemeenskappe. So dan ook troeteltaal en terme vir liefdesuitinge, wat seker as taalelemente, die naaste aan die woord se begin beskou kan word. Die gee en uitspreek van troetelwoorde soos liefling, liefste en skat het aanvanklik meestal kort na die geboorte, die begin van 'n nuwe lewe, hul oorsprong gehad. Die toepassing het met verloop van tyd wel veranderinge ondergaan. Dit is heel dikwels uitgebrei na volwassenes, manlik en vroulik. ' $n$ Verskuiwing van betekenisnuanses, selfs as negatief interpreteerbaar, is ook soms ter sprake, soos in die bespreking van die betekenis van troetelname.

Dit is welbekend dat taal in sy ontstaan en ontwikkeling en in reeds gebruiklike vormgewing van gedagtes in woorde oor en weer deur volke by mekaar geleen is. Volgens eie behoeftes, belangstellings en omgewingsfaktore is aanpassings gemaak en besluite oor elke taalgroep se besondere keuse van 'n eie taalsisteem geneem en deur gebruike gevestig. Moontlik as gevolg van die veelvolkigheid van die inheemse gemeenskap, die probleem van die aanvanklike bou van 'n nasie en groot verskille tussen etniese groepe het die eerste deelnemers aan die Afrikaanse taalskepping besef dat eenvoud en erkenning van variëteite 'n primêre uitgangspunt sal moet wees. Insluiting van oorspronklike segswyses moes uit die gewone omgangstaal kom, verstaanbaar in konteks wees en met die daaglikse doen en late verband hou. Die gevolg is dat oorspronklike woorde, idiome en uitdrukkings spontaan ontstaan het en ' $n$ weerspieëling van die saamwerk en saambou aan 'n oorspronklike nuwe taal was wat gedurig bly uitbrei. Hierdie oorspronklikheid vind ook neerslag in troeteltaal as een van die variëteite van Afrikaans. Hierdeur vind Afrikaans aansluiting by van die oudste tale, soos Hebreeus, Grieks en Latyn. Daar is hierop voortgebou en vandag het Afrikaans 'n wye versameling leksikale items wat tot die troeteltaalvariëteit behoort.

Ook daaglikse beriggewing van menings deur die gewone publiek en denkers op akademiese vlak in dié verband lei tot die gevolgtrekking dat 'n oortuigende definisie en resep vir troetel (liefde) maar net 'n soeke sal bly. Daar is dus nog nie eenstemmigheid oor 'n oorkoepelende samevatting bereik nie. ' $n$ Moontlikheid van sinonieme in die toepassing van troeteltaalvorme sal nog ontgin moet word.

\section{Troeteltaal as taalvariëteit van Afrikaans}

Inleidend word verwys na aspekte van die bewerking van die lemmas variant en variasie in die volgende standaard algemene sinchroniese woordeboeke, naamlik Pharos 1: Afrikaans-Engels/English-Afrikaans Woordeboek/Dictionary (2005) en HAT: Handwoordeboek van die AfrikaanseTaal (2005). In eersgenoemde kom variant nie in die alfabetiese lys van die Afrikaanse deel voor nie. In die Engelse afdeling kom variant wel voor as selfstandige naamwoord met die ver- 
taalekwivalente wisselvorm, byvorm en variant. In HAT (2005) is die verduideliking: "Afwyking; verandering; verskillende lesing, vorm van 'n teks of ander gegewe." Hierdie bespreking van troeteltaalvorme bewys dat die meeste van die genoemde verklarings duidelik toepaslik is op die voorbeelde van troetelwoorde. Volgens hierdie verklarings sal troeteltaalvorme onder vrye variante kon ressorteer, omdat hulle spontaan deur veral ouers, maar ook deur ander volwassenes, goeie vriende en soms selfs deur kinders self geskep word en heel dikwels tot in die volwasse stadium bly voortbestaan. By troetelvorme is daar taalkundig die geval van afwykings van oorspronklike vorme, byvoorbeeld harta in plaas van hartjie en gebruik van 'n noemtroetelnaam in plaas van ' $\mathrm{n}$ doopnaam in 'n geval soos Kobie in plaas van Jakoba.

Sommige taalkundiges glo aan spontane taalontwikkeling, terwyl ander meen dat Afrikaans ontstaan het uit spontane ontwikkeling plus vreemde invloede. Louw (1948: 53) is van mening dat die spontane ontwikkelingsteorie as 'n logiese ontwikkeling van taalkontinuïteit beskou moet word. Van der Merwe $(1970: 33,88)$ meen dat Afrikaans wat sy huidige vorm betref, reeds tussen 1656 en 1658 beslag gekry het en variant- en variasievorme dus tot so ver teruggevoer kan word.

Troeteltaalvorme verwoord taalgevoeligheid wat een van die prioriteitsmikpunte in gebruikstaal is, want hulle is spontaan en bevorder die vloei van gemoedelike gesprekke. As volwaardige items van die leksikon behoort hulle in sekere tipes Afrikaanse woordeboeke opgeneem en bewerk te word. Die meeste troetelvorme is selfstandige naamwoorde wat slegs 'n etiket of bondige verduideliking benodig om hulle troeteltaalstatus aan te dui. Wanneer die lemma wat 'n troetelnaam verteenwoordig ietwat vreemd voorkom, byvoorbeeld Kanoes, mag die verduideliking belangstelling prikkel en woordeboekgebruik bevorder. Uitbreiding en aanvulling vorm in elk geval deel van enige woordeboek se inhoud en afwykende vorme kan per etiket gemerk word.

Lombard (1993: 140) beweer: "'n Etiket help ... om die gebruik van 'n sekere woord binne 'n sekere gebied van die taalgebruik te plaas." Hy sluit hiermee aan by Gouws (1988: 14) se stelling dat 'n etiket 'n verband tussen 'n woord en sy gebruik aandui. Lemmas sonder standaardstatus, soos die meeste troetelwoorde, word met etikette gemerk om bepaalde sosiolinguistiese waardes te illustreer. Dit geld ook, volgens Claassen (2008: 28) woorde wat in 'n bepaalde sosiale sfeer gebruik word, maar nie as dialekte gereken word nie.

In 'n mindere of meerdere mate lê die gebruik van troetelname 'n verband van liefde en vriendskap tussen mense en kan dus in dié verband toegepas word. In ooreenstemming met die leksikografiese vereistes vir die gebruik van etikette, kan troetelname geëtiketteer in woordeboeke ingesluit word Die gepastheid, al dan nie, van 'n andersoortige troetelwoord soos boelie in ' $n$ gespreksituasie sal vir insluiting met 'n etiket die bepalende faktor hier wees. Die gebruik van etikette moet aan voorgeskrewe leksikografiese vereistes voldoen. Die ingesluite troetelwoord moet reeds in die taal se leksikon opgeneem wees. Die troetelwoord val dan volgens Lombard (1993: 102) in die geselstaal 
net onder die neutrale vlak van Standaardafrikaans en kan gevolglik in woordeboeke as troetelvorm aangedui word.

Variasies en variëteite, ook in die kader van niestandaardvorme soos troeteltaal, dra by tot taalverryking en taalvriendelikheid. In die Afrikaanse taalkunde kom taalvariasie, waartoe troeteltaalvorme behoort, al van die taal se ontstaan op 'n opmerklike skaal voor. Aangesien die vorme nog steeds as niestandaard beskou word, word hulle meestal gekoppel aan 'n spesifieke streek of gemeenskap en kry so 'n plaaslike gebondenheid, wat moontlik as 'n oortuigende argument vir die ondergeskikte status van hierdie "taaluitbreiding" met die oog op opname en behandeling in woordeboeke beskou moet word.

Volgens Ponelis (1989: 11) kan taalverandering óf van binne en van buite óf van onder en van bo voorkom. Wanneer van onder af, begin die proses op informele stylvlak in die gewone omgangstaal, soos dit die geval met troeteltaal is. So 'n tipe taalgebruik kan maklik algemeen raak, en dan selfs later by kultuur- en skryftaal 'n vaste gewoonte word. Volgens Webb (1989: 429-430) kan taalverandering of taalvariasie as 'n soort styl, wat formeel of informeel kan wees, geklassifiseer word. Na sy mening pas die styletiket wanneer taalgebruik met ' $n$ bepaalde situasie saamhang of 'n sekere aktiwiteit beskryf of in die verbeelding oproep. 'n Mens sou hierdie taalsiening dus ook met troeteltaal kon assosieer, en in die volgende gevalle toepas. Wat 'n spesifieke situasie betref, kan verwys word na die geboorte van 'n baba of die dood van 'n eersteling en trooswoorde aan byvoorbeeld 'n jongmens wat ledemate in 'n ongeluk verloor het. In die geval van 'n aktiwiteit kan troeteltaal ook geluk en vriendskap vergestalt in woorde soos liefde, liefkoos en vertroetel.

Allerlei tipes variasies dra in taal by tot taalverandering, insluitende sintaktiese, fonologiese en leksikale aspekte. Ander faktore soos gebruiksuitbreiding, veralgemening, stigmatisering en standaardisering vervul verder ook belangrike funksies. Die lys van troetelnaamverwante noemname wat semanties in 'n soortgelyke gees as dié van vertroeteling gebruik word, is wel reeds in Afrikaans omvangryk, hoewel die woord troetel en sy begrip by die huidige jonger geslag onbekend skyn te wees.

Ponelis (1989: 9) stel sy siening oor Afrikaans soos volg: "Studie van Afrikaans is gerig op geledinge, konteks, die ontwikkeling en klassifikasie van Afrikaans binne die perspektief van die taalkunde as wetenskap." Onder konteks ressorteer die mikrososiolinguistiek wat een van die hoofdissiplines is waaronder variasietaalkunde val. Troetelvorme wat volgens hul semantiese aard en verklaring in die definiens in woordeboeke tot Ponelis se studie-omskrywing van taalkunde behoort en dus aan bestaande taalkundige voorskrifte voldoen, pas dan by die gestelde perspektief in.

\section{Naamgewing}

Troeteltaal kan herlei word na naamgewing van 'n mens, dier of ding om 'n spesiale rede in 'n besondere situasie of omstandighede. Die verste terugwer- 
kende oorsprong kan volgens die antieke tale, Hebreeus en Grieks, gevind word in veral moeder-kind-verhoudinge maar verder hoofsaaklik in ouer-kindverhoudinge. 'n Moontlike verdere uitvloeisel hieruit van troetelname vir volwassenes is nie onmoontlik nie. Daar kom selfs gevalle voor waar meer as een troetelnaam vir 'n kind gebruik word, toepaslik op verskillende situasies. Die doel van naamgewing is juis dat 'n mens sal weet wie hy/sy is, 'n kenteken van identiteit aan jou toegeken, saam met 'n plig en verantwoordelikheid wat jy alleen sal moet handhaaf.

Woordeboeke as betroubare bronne van taalvernuwing en taaluitbreiding is semanties baie direk gekoppel aan naamgewing. Aangesien troeteltaal in hoofsaak met naamgewing gemoeid is, probeer ' $n$ mens om ' $n$ leksikale betekenisbenadering by implikasie toe te pas, waaroor daar uiteraard verskil van mening sou kon wees. Interpretasie van betekenis van leksikale items verskil en regverdig persoonlik-eie benaderings. Volgens interpretasie van indiwidue sal daar voorbeelde voorkom van, onder andere, skertsende en oorspronklike skeppings, maar ook van benamings gebaseer op besonder intense liefde en toegeneentheid saam met jammerte, lojale vriendskap en verwysings na persoonlike eienskappe van indiwidue, byvoorbeeld slegte humeur of onverwagte emosie.

Naamgewing behoort egter in ooreenstemming te wees met taalreëls sodat 'n nuwe benaming verstaanbaar binne die situasie waarop dit betrekking het, ontleed kan word. Die woordvorm is egter nie altyd 'n maatstaf vir die bepaling van betekenis nie. Volgens Meiring (1979: 30) is 'n mens se kennis van die gebruik van woorde die bepalende faktor vir die insluiting daarvan in 'n woordeboek. 'n Troetelnaam kan byvoorbeeld tot op 'n stadium 'n meervoudige draer (byvoorbeeld van nuanses) wees, maar elke situasie moet 'n konstante referent hê. Daar mag nie van 'n veronderstelling uitgegaan word nie, want dit kan in 'n gespreksituasie tot wanindrukke en verkeerde afleidings aanleiding gee. Voordat 'n troetelnaam gebruik word, moet daar sekerheid wees dat die naam deur die spreker in 'n gepaste konteks toegepas word. Die eerste taak van die kommunikatiewe linguistiek is om die teiken van die linguistiese aktiwiteite te verplaas van die struktuur van die taal na die funksie van die taal in 'n sosiale konteks.

\section{5. 'n Leksikografiese omgewing vir troeteltaal}

Die ontoereikende opname en bewerking van troetelvorme in Afrikaanse woordeboeke dwing 'n mens om na 'n beter leksikografiese aanbod daarvan te soek. Een van die beste definisies van 'n woordeboek is dié van Zgusta (1971: 197):

A dictionary is a systematically arranged list of socialized linguistic forms compiled from the speech-habits of a given speech-community and commented on by the author in such a way that the qualified reader understands the meaning ... 
of each separate form, and is informed of the relevant facts concerning the function of thát form in its community.

Zgusta (1971: 182) deel sy siening van die doel en samestelling van woordeboeke soos volg: "Dictionaries offer various pictures of language, which is in its turn with whole of society and life; therefore the topic of dictionaries is an inexhaustible one." Hy voeg hierby: "The real life of a language, however, is in its use."

Daar moet egter altyd rekening gehou word met die gebruiker se behoeftes wat vooraf deur die leksikograaf by sy teikengehoor vir sy tipe woordeboek vasgestel moet word. Gouws (1989) deel ook Zgusta se mening dat "'n woordeboek ... die neerslagplek vir werklike taalgebruik (is)", en sy verdere beklemtoning hiervan (1989: 13) deur te sê dat woordeboeke as bron van inligting en oplossings van taalkwessies vir die taalgebruiker die belangrikste boek behoort te wees wat oor taal geskep is.

Die keuse uit die woordeskat van 'n betrokke taal moet linguisties en leksikografies gemotiveer kan word wat betref die lemmas wat opgeneem word, asook die vorm waarin hulle ingesluit word. Troeteltaal het vaste vorme, waarvan sommige met verloop van tyd gewysig word, byvoorbeeld skat en skattebol. Die wysiging dui normaalweg op intensivering van gevoel, maar kan ook groter klem aandui om vinniger aandag te kry of te flikflooi om 'n guns. As hulle egter eers in woordeboeke as deel van die bestaande standaardtaal erken is, word hulle as sodanig gevestig. Dit sal 'n wye veld in Afrikaans dek.

Volgens Zgusta se benadering moet die inhoud van 'n woordeboek volgens 'n sisteem aangebied word. Daar moet vaste kriteria bestaan waarvolgens woordeskat in 'n woordeboek as betroubare inligtingsbron opgeneem word. Daar moet dus duidelikheid wees oor die manier waarop verskillende leksikale items gelemmatiseer word. Troeteltaalvorme wat ook deel is van die leksikale verskeidenheid se opname en bewerking, moet volgens dieselfde reëls gehanteer word.

In aansluiting by Zgusta se benadering, algemeen deur leksikograwe erken en toegepas, kan verwys word na die uitsprake deur prof. N.S. Kabuta van Sentraal-Afrika by 'n leksikografiese kongres te Stellenbosch in 2008 oor sy doelstellinge vir sy Tsjiluba-Franse woordeboek (mondelinge mededeling): "to try to teach young people that they have an identity, to create thinking in their colloquial language, also to improve their vocabulary through a dictionary and to change and become proud of their identity". Dit sal hulle selfs in staat stel om artikels en boeke oor ander onderwerpe te lees en sodoende self dan artikels en boeke te kan skryf. Hy wil hulle oortuig dat hulle ten goede kan verander en so interessanter mense word deur bewus te raak van hierdie interessante boek, die woordeboek, 'n bron van inligting. Hy het reeds ver met sy aanbevelenswaardige doelwit in die opvoeding van die jeug gevorder, nie net op akademiese vlak nie, maar ook op sosiale vlak. Ander potensiële woordeboek- 
samestellers kan baie uit sy wenke en ervaring put, en sodoende volgens hulle eie behoeftes aanpas.

Woordeboeke van wisselende omvang en inhoud in die Afrikatale is vanselfsprekend, 'n noodsaaklikheid vir die toekomstige sosiale en akademiese ontwikkeling en handhawing van die onderskeie inheemse tale. Sodoende word die identiteitsbesef aangesterk en gevestig in Afrika, 'n voorbeeld van 'n multikulturele samelewing in die meeste van sy lande. Hierdie rol wat woordeboeke kan speel, is van die uiterste belang in die bevordering van wedersydse respek en begrip onder die onderskeie taalgebruikers van Afrika. Die woordeboekspektrum van Afrikaans moet van sodanige aard wees dat vorme uit alle variëteite leksikografies aan bod kom. Dit geld ook troeteltaal as 'n variëteit van Afrikaans.

\section{Etikette}

Aangesien troeteltaalvorme nog slegs tot ' $n$ geringe mate as standaard beskou en in die sentrale lys van woordeboeke ingesluit word, het dit tyd geword om meer aandag aan die uitbreiding van hierdie komponent te gee en die voordele daarvan te bespreek. 'n Uitbreiding van die woordeskat is in tale 'n noodsaaklikheid omdat daar gedurig vernuwings op vele terreine aan die orde van die dag is. Daar bestaan dus nie 'n rede waarom heelwat meer as die bekende voorbeelde van troeteltaalvorme, naamlik sus (-sie) en boet (-ie, $-a)$ nie ook deel van woordeskatuitbreiding kan wees nie. In die navorsing is interessante nuwe skeppinge soos dingetjie, omi, moekie, soppie en veel meer gevind. Sulke vorme kan wel opgeneem word in sekere woordeboeke en so deel word van almal se woordeboek- en omgangstaalgebruik. Belangriker is egter dat hierdie vorme per etiket gemerk moet word as behorende tot die troetelvariëteit.

In die data van woordeboeke is daar 'n netwerk van paradigmatiese leksikale items wat sekere semantiese verbande verteenwoordig. As gevolg hiervan is baie woorde as 't ware familie van mekaar. Deur middel van etikette by sodanige verwante lemmas word die aandag van die gebruiker vroegtydig gevestig op moontlike verskille en ooreenkomste sodat alternatiewe oorweeg en getoets kan word voordat 'n gedagte neergeskryf of geuiter word. Taalverleentheid kan so subtiel uitgeskakel word, soos byvoorbeeld in die geval van die gebruik om na iemand se gesig as sy bakkies te verwys.

Volgens Gouws (1988: 4) dui die term etiket op daardie inskrywings in woordeboekartikels wat as merkers optree om 'n ander inskrywing in die artikel se beperkinge ten opsigte van byvoorbeeld sy stylaard, sfeer en geografiese voorkoms aan te dui. Etikette help verder gebruikers om die gepastheid, al dan nie, van verskillende lemmas vir 'n verskeidenheid gespreksituasies uit te lig. Vergelyk die gebruik van aai vir "troetel", aanlê vir "vry" of kru taal soos moers in 'n normale meningsverskil. Die gebruik van etikette moet egter vir die gebruiker verstaanbaar en onkontensieus wees, want hulle vervul 'n belangrike toeligtende rol van 'n gemoedelike of 'n onvriendelike gesindheid. 
Volgens Gouws (1989) kan etikette 'n onmiddellike inligtingsoordragfunksie hê. Kommunikasiesukses kan dus bevorder word. As 'n etiket aandui dat na 'n troetelnaam, byvoorbeeld Slimmie of Goggie, verwys word, sal die begrip daarvan in 'n gesprek of 'n tydskrifverhaal heelwat anders geïnterpreteer word. Nuuskierigheid sal moontlik verdere navrae tot gevolg hê of die leeslus prikkel of selfs die leser laat besluit dat die skrywer se skryftalent maar skraal is. Die besoeker sou moontlik wou weet waarop die naam wat intelligensie impliseer, gebaseer is, en of dit dalk as aansporing vir 'n lui leerder beproef word. Sou die kind se intelligensie deur ' $n$ kundige reeds getoets wees om vir die ouers 'n riglyn vir sy/haar verdere opvoeding te bied?

Waar troeteltaalvorme in woordeboeke opgeneem word, kan hulle per etiket gemerk word. Naas die bestaande etikette wat gebruik kan word, sou daar ook nuwe etikette, spesifiek gerig op troeteltaalvorme, ingevoer kan word.

Etikette behoort saam met ander struktuurmerkers in 'n verklarende buiteteks verduidelik te word. Die gebruiker moet daaruit die korrekte objektiewe afleiding kan maak. 'n Volledige betroubare lys van merkers, gewoonlik verskillend vir spesifieke soorte woordeboeke, is noodsaaklik en so 'n buiteteks by alle soorte woordeboeke, soos in die verklarende handwoordeboek HAT (2005), sal vir gebruikers interessant en 'n betroubare bron en handleiding wees. Dit kan belangstelling in en die gebruik van woordeboeke, wanneer benodig as inligtingsbronne, stimuleer en woordeboeke vir sommige navorsingsprojekte en -take noodsaaklik maak. Die verfyning van merkers is hier dus ter sake. Vir die gebruiker moet dit duidelik wees wat die presiese implikasie van die optrede van 'n spesifieke etiket is. Waar die etiket 'n negatiewe waarde merk soos by die troetelvorme laspos en boelie, kan 'n blokkie met 'n minusmerkie [-] en by 'n positiewe waarde 'n blokkie met 'n plusmerkie [+] gekoppel word.

Hierdie addisionele inligting sal woordeboekgebruikers moontlik meer bedag maak op gepaste woordkeuses in indiwiduele asook groepsgesprekke. Die hoofdoel van troeteltaalgebruik is juis om op die krag opgesluit in taal te fokus. Die vestigingsrol wat etikette hierin kan speel, kan nie misken word nie, en verdien pertinente klem in algemene woordeboeke.

\section{Betekenisaspekte van troeteltaalvorme}

'n Omvattende beskrywing van betekenis is in werklikheid onmoontlik, want elke mens is met ' $n$ indiwiduele ingesteldheid in hierdie verband gebore. De Stadler (1989: 15) wys op hierdie diversiteit van die begrip van semantiek met sy beskouing dat 'n mens sou kon onderskei tussen uitingsbetekenis, maar verder ook tussen deskriptiewe, preskriptiewe, sosiale en emosionele betekenis. Troetelvorme skakel hoofsaaklik met deskriptiewe emosionele indiwiduele interpretasies wat nie noodwendig logies gefundeer is nie. Hoe bring ' $n$ mens byvoorbeeld die kloutjie by die oor in die volgende voorbeelde: turksvy, gevoelens opkrop en hoei-haai, wanneer 'n mens die verklarende betekenisse in 'n algemene 
woordeboek lees en Afrikaans nie ken nie? Wat troeteltaal betref, sou 'n mens die verhouding tussen buitetalige werklikheid en gebruikstaal kon ondersoek.

'n Konseptuele betekenisbenadering is veral relevant in kontrei- en troeteltaal wat intern van aard is. Betekeniskomponente van leksikale items bepaal dikwels die semantiese velde waarin leksikale items ingedeel is. Volgens Lyons (1968: 443) berus leksikale items se funksie op 'n sinchroniese benadering van leksikale betrekkinge wat op grond van hul betekenisse met 'n wye verskeidenheid onderskeidinge gefundeer is. In die geval van troetelvorme en -name val die taalgebruik wat dikwels in onderskeidende nuanses voorkom, meestal in die betekenisdomein van liefde. Die aanleiding tot spesifieke keuses berus op persoonlike waarneming van kinders se nabootsing, reaksies op gebeure, voorkeure vir kossoorte of lekkernye, voorkoms, vlei of prys, tugtiging en skertsende spot, maar veral op liefde in verskillende grade geuiter. Meer aandag aan troeteltaalvorme en hul betekenis in algemene woordeboeke kan 'n interessante taalbewuste belangstelling tot gevolg hê, veral as dit in skoolleerplanne ingevoer word.

Volgens Botha (2006: 130) word die begrip van betekenis die raakste beskryf in die samevatting van Encarta World English Dictionary (1999): "make understand by experience; to bring understanding to somebody, especially through experience". Hierby sluit die Woordeboek van die Afrikaanse Taal Deel I (1950) se definisie van betekenis aan: "die begrip of sin wat deur die taal uitgedruk of oorgedra word ... die bedoelde betekenis van die spreker en begrepe betekenis van die hoorder is nie altyd identiek nie". Die frase "'n man van aansien" kan verstaan word as 'n aantreklike persoon of 'n agtenswaardige persoon. Hierdie verskynsel van polisemie kom ook in troeteltaal voor by byvoorbeeld troepie as troetelnaam of met die betekenisonderskeiding van 'n klein groepie soldate. Hierdie geval van polisemie wys dat 'n bepaalde leksikale item een betekenisonderskeiding kan hê wat tot die domein van troeteltaal behoort, terwyl die ander betekenisonderskeidinge nie deel van troeteltaal is nie. In hulle hantering van betekenis moet woordeboeke ook hiervan verslag doen.

'n Konseptuele betekenisbenadering is veral relevant in kontrei- en troeteltaal wat intern van aard is en kan verwys na, onder andere, sekere tipiese of eienaardige gewoontes van 'n persoon se handgebare of gesigsuitdrukkings wat dikwels tot 'n bynaam aanleiding gee. Botha (2006: 133) verwys hierby na Taylor (2002) wie se siening dit is dat dit die taal-wêreld-betekenisrelasie in sekere situasies betrek. Hierdie standpunt toon 'n verband met Lyons (1977: 177) se "referring expression" soos in die geval van troeteltaal wat na liefde en toegeneentheid, ' $n$ besondere verhouding in 'n spesifieke situasie, verwys. Taylor (1995) interpreteer taalinterne situasies waarin persoonlike verhoudings setel, as "symptomatic of meaning, not as meaning itself". Vergelyk die opvatting oor interpretasies in hierdie bespreking waar na menings oor troetelnuanses verwys word. Volgens Mües (1967: 15) kon niemand nog tot dusver die werklik omvattende sfeer van betekenis aanvaarbaar verklaar nie, veral omdat dit ten nouste verband hou met onvoorspelbare menslike situasies en hul reak- 
sies in taaluitinge. In troeteltaal is daar ook sprake van uiterlike vorm plus interne gedagte (gevoel) in een woord sigbaar en hoorbaar: "Wesentlich ist, daß es hier nur um zwei Aspekte ein und derselbe Sache handelt, daß das eine nicht um das andere ist" (Mües 1967: 20). Die een betekenis is dus nie afhanklik van 'n ander moontlike interpretasie nie. Antal (1972) en Droste (1985) glo weer dat sekere semantiese onderskeidinge binne een betekenis saamhang met die sake waarna verwys word, met ander woorde die sake waarvoor die betekenis gebruik word. Dit geld dan ook troetelname met verwysing na sekere mense, want hier is die betekenis in besondere mate aan indiwiduele waarneming en ervaring gekoppel. 'n Rol kan ook hier gespeel word deur die invloed van buitestaanders en ander se menings naamlik in spotprente, foto's van ongelukke en beskrywings deur joernaliste en nuuslesers, besprekings deur paneellede by vergaderings asook voorlesings uit eie werke by woordfeeste. Hieruit vloei dikwels besprekings van wisselende indrukke, bruikbare wenke en wysiginge in persoonlike reaksies, faktore ter sprake by troeteltaal. Besprekings deur woordeboeksamestellers waarin troeteltaal as onderwerp ingesluit sou kon word, kan dalk 'n bydrae lewer om te help met die vestiging van troeteltaal as volwaardige variëteit waarvan die items 'n eie en unieke betekenis het. Konteks en situasies speel ' $\mathrm{n}$ buitengewone rol in die gee en gebruik van troetelname en -aksies in gesinsverband.

Begrip saam met kennis moet altyd by woordkeuse en taalgebruik, veral ook in troeteltaal, 'n sleutelrol speel.

Woordeboeke is juis hier die sleutel tot almal se taalontwikkeling en taalgroei wat betekenisse van hul woordeskat betref. Namate veral kinders, maar ook alle taalgebruikers se waarnemingsvermoë uit nuuskierigheid of noodsaak as gevolg van werksomstandighede ontwikkel en toeneem, speel taalvaardigheid en woordkennis ' $n$ besonder belangrike rol. Troeteltaalvorme word algemeen gebruik, maar hulle betekenis is nog selde verklaar. Woordeboeke wat troeteltaalvorme as lemmas opneem, moet kriteria ter sake in die beskrywing van ander woorde se betekenis ook toepas op hierdie weinig behandelde taalvariëteit.

\section{Kennis van troeteltaal}

In 'n informele opname gedoen onder leerders gedurende 2011, het dit aan die lig gekom dat slegs 3\% van die respondente die woord troetel ken. Dit was interessant om daarop te let dat die gebruik van troeteltaal meestal voorkom waar 'n besondere ernstige verhouding tussen twee volwasse betrokkenes bestaan. Alhoewel die woord troetel grootliks onbekend is, is troetelname waarna verwys is, en blykbaar in geselstaal algemeen voorkom, gekoppel aan 'n positiewe gevoelswaarde. Eufemistiese taalgebruik met die verkleiningsuitgang in noemname, byvoorbeeld Bokkie, Katryntiie, Apie en Boetie is vry algemeen.

Troetelvorme in gebruikstaal is geensins gevestig nie, maar het nog nie heeltemal verdwyn nie en kom hoofsaaklik lukraak voor. Die leerders was van 
mening dat hulle wel van 'n troetelnaam sou hou, want dit laat hulle spesiaal voel. Troetel is wel nie met byname geassosieer nie.

Troetel hang ten nouste saam met liefde. As regverdiging vir hierdie standpunt is tot voorchristelike tye teruggegaan en bewyse gevind. In die opname is bewyse van die interpretasie van troetel deur 'n veel jonger geslag gesoek. Liefde en omgee deur ouers en vriende was hier nog steeds die fokuspunt. Met verloop van tyd en weens veranderde leefwyse is dit logies dat die basiese patroon van die raamwerk van mense se lewens, taal en gewoontes in die algemeen wysiginge sou ondergaan. Hierdie informele opname skep die indruk dat troeteling deur middel van troetelname nie meer in die babastadium algemeen is nie, maar na gebruiksname verskuif het. Die hoofindruk van nader aan die oppervlak in hegte verhoudinge is afleibaar.

Die keuse van die woord troetel het wel geblyk 'n raak besluit te wees omdat bevordering van ' $n$ nuwe bewustheid en gebruik daarvan beter menseverhoudinge kan help skep, veral in 'n era van groot verandering in lewensbeskouinge in die saambestaan van wyduiteenlopende kulture se waardebepalings.

Die woord troetel was vir die jonger geslag leerkragte en vir $90 \%$ van die kinders heeltemal vreemd, maar na 'n aantal vrae, is ' $n$ algemene assosiasie met liefde deur hulle aangedui. 'n Poging om 'n verklaring hiervoor te vind, kon nie van die kinders verkry word nie behalwe dat die woord by hulle 'n gevoel van toegeneentheid geskep het. Die meeste het die woord egter met hul ma of ouma, ' $n$ nabygeliefde, of, in mindere mate, met beste maats verbind. Hulle sou egter tevrede wees met die koppeling van 'n troetelvorm soos veral skat, liefie en hartjie, byvoorbeeld Bettie hartjie. 'n Moontlike verklaring hiervoor sou dalk kon wees ' $n$ behoefte aan aandag en 'n sterker versekering van intense gevoel. Hulle vind dit moeilik om die begrip van betekenis regtig te snap en tog "praat" troetel met hulle.

Die vraag ontstaan: "Waarom sou troeteltaalvorme in woordeboeke as gesaghebbende inligtingsbronne, soos deur taalkundiges aangevoer, belangrik geag kon word? Waarom is dit nie die geval nie, as hierdie navraag in gesprekke met mense in gemeenskappe geopper word?" Tog is dit 'n lewensfeit dat troeteltaalwoorde soos doedoe, mamma, moeder, liefie, skattie en baba in Afrikaans die heel eerste taalitems is waaraan kinders blootgestel word. Ook by kennismaking met vreemdes bied woorde die ideale aanknopingspunt vir 'n verdere gesprek. Afhangende van die situasie en persoonlikhede van aangespreektes en luisteraars, kan troetelwoorde reeds hier voorkom wanneer verrassing en blydskap ter sprake is. Hierby kan gevoeg word dat eerste taal- en selfs gebareskakeling tussen verskillende kulture en taalgroepe ook moontlik troetelwoorde en troetelbelaaide tekens kan insluit, afhangende van die konteks soos van ontmoetings op sosiale en romantiese vlak. In ander tale na aan Afrikaans is troetelwoorde, volgens ons veelvolkige gemeenskappe, welbekend in sosiale omgang. Dit geld ook vir skriftelike skakeling. Voorbeelde sluit in lovey, sweet (Engels); Schatz (Duits); bello (Italiaans) en sithandwa (Xhosa). 'n Verdere vraag wat hieruit voortvloei, is die onsekerheid waarom woordeboekma- 
kers nog nie meer troeteltaalvorme as die enkeles, soos boet en sussie saam met ousie en liefie/liefling, as standaard en aanvaarbaar vir insluiting beskou het nie.

'n Mens kan die gevolgtrekking maak dat die gebruik van die woord troetel en begrip daarvan hoogs uitsonderlik is. Omdat indiwidue hierdie woord nie ken nie, is hulle ook nie vertroud met die begrip nie. Hulle het die woorde liefie en skat gehoor, maar assosieer die woorde nie met die begrip van liefde en sorg nie.

Uit die navorsing is die indruk ook gelaat dat taalvariante met hul leksikale waarde wisselend in streke en in gebruiksfrekwensie, in woordeboekformaat kan meehelp om troeteltaal te vestig. Soos reeds in die voorafgaande bespreking aangedui, lei die verskeidenheid van betekenisse wat aan dieselfde woord geheg kan word, daartoe dat die verskynsel algemeen in verskillende gemeenskappe voorkom en 'n invloed op onderlinge verhoudinge het, soos in die geval van kaffer wat as troetelnaam voorgekom het of as rassisties en beledigend beskou kan word. Nou voel 'n mens geneig om te wil weet waarom kragwoorde soos bliksem, donner (donder) en moer wat vir die gemiddelde Afrikaanssprekende as taboetaal beskou kan word, tog (saam met 'n etiketteken) in gewilde woordeboeke opgeneem is. Die feit dat troetel die medium is waarmee liefde oorgedra word op verskillende vlakke en terreine, soos binne families en vriendekringe, romanties by alle ouderdomsgroepe, in gewoontespraak en in die werksomgewing, dien as genoegsame bewys dat troeteltaal op dieselfde aandag as kragwoorde in ons woordeboeke geregtig is, mits hul gebruiksfrekwensie dit regverdig.

In die Suid-Afrikaanse Grondwet word respek en waardigheid vir alle Suid-Afrikaners as basis gebruik. Al die multikulturele gemeenskappe in sogenaamde kultuurgroepe word verteenwoordig. Geen taal wat as diskriminerend ten opsigte van 'n persoon se integriteit beskou kan word, word verdra nie. Dit is die dilemma. In een gemeenskap is ' $n$ woord troeteltaal en in ' $n$ ander ' $n$ growwe belediging. Dis verder 'n onbeheerbare lewensfeit, want geen mens het 'n keuse van sy geboorteplek en opgroeitaal en -omgewing nie.

Die erkenning van veel meer troeteltaalvorme en die persepsies daarvan as voorbeelde van gebruiksvriendelike taal en gereelde gebruik en propagering daarvan in gewone geselstaal is aanbevelenswaardig. Daarmee speel hulle dan 'n belangrike rol om gemeenskappe te verenig in 'n breër samelewing.

Die waarneembare veroudering en gevolglike gebrekkige kennis en toepassing van troetelvorme, veral by ouers, kan dalk 'n gevolg wees van die vinniger en veeleisender tempo van lewe vandag.

'n Tipe oplossing kan moontlik gevind word in buitetekste as aanvulling in standaardwoordeboeke oor die volgende:

- meer inligting oor die woorde wat in werklikheid troetelwoorde is, byvoorbeeld afkortings van noemname, en

- $\quad$ betekenisse in kontekste. 
Troeteltaalvorme pas boonop perfek in by die voorgeskrewe reëls vir die samestelling van 'n woordeboek, waar die insameling van data oor 'n wye area prioriteit is. Die ingesamelde data moet gekoppel wees aan ' $n$ duidelike betekenis, soos in die geval van troetelname wat uitsluitlik vir 'n spesifieke persoon om 'n definitiewe rede gegee word - feitlik altyd uit liefde of besorgdheid, maar soms ook in luimige sin, en baie selde negatief bedoel. Dit is bevind dat troetel as kwalifiseerder in verskillende woorde optree, onder andere, troetelplant, -dier en -speelgoed. Dit verbreed dan eintlik die betekenisomvang van die begrip waarmee die waarde daarvan as variëteit verhoog word.

Die gebruik, hoewel meestal onbewustelik, is so algemeen dat 'n mens wonder of gebruikers besef dat hulle eintlik 'n troetelvorm gebruik, soos in die geval van oudste, en verskeie name deur respondente ingedien. Semantiese parameters, soos sinonimiese en etimologiese verwysings of byvoorbeeld ' $n$ oorgeërfde naamgewing, is beslis in troeteltaalvorme relevant en dit regverdig meer aandag in algemene twee- en eentalige woordeboeke. In buitetekste is hierdie aanvulling by die sentrale teks gewis aan te beveel, hoofsaaklik om die positiewe krag daarvan. Basies is die hele mensdom se bestaan gekoppel aan en beheers deur een of ander element van gevoel.

Troetelname en -taal was vanaf die heel vroegste ontstaan van Afrikaans algemeen 'n aktiewe deel van geselstaal. Dit het van meet af aan tot vandag toe veral onder jong liedjiemakers as inspirasie gedien en sowel aanvaarding as navolging ontvang. Die semantiese waarde van omgee en sorgsaamheid, soos in woordeboeke verduidelik, skemer altyd deur. Miskien kan die intrinsieke nuanses van liefde, toegeneentheid, sorgsaamheid, behoefte aan saamwees, vriendskap met al sy skakeringe en selfs speelsheid en lughartigheid vergestalt in troetelwoorde en -taal taalvriendelikheid beduidend begunstig.

\section{Slot}

Blaai 'n mens deur woordeboeke, kan dit jou opval, by enige letter van die alfabet, hoe dikwels lemmas in die woordeskat as troeteltaal beskou sou kon word, as hulle toegelig word met voorbeelde wat empiries voorsien is, veral dié wat op -ie en -ies, soos in troeteltaal, eindig. Hulle kan, onder andere, die volgende insluit: Boepie, Bakkies, Dollie, Ertjie, Fasie, Haantjie en Hasie wat voorkom in lyste wat van respondente ontvang is. Troeteltaalvorme kan nou wel nie altyd as logies beskou word nie, omdat dit in troeteltaal hoofsaaklik om verhoudinge gaan. Sonder kennis van die oorspronklike konteks is dit moeilik om die logika te bepaal. Die filosofies-etiese aspek wat 'n onvermydelike opeenvolging van oorsaak en gevolg, 'n beredenering, impliseer, speel nie in troeteltaal 'n rol nie. Troetelvorme vloei spontaan uit die spreker se gevoel. 'n Verband tussen linguistiek en etiek is van belang. Wat as onlogies in troeteltaal beskou kan word, kom ter sprake in die "onvermydelike opeenvolging", terwyl die linguistiese wat troeteltaal betref, verskuil is in "met tere liefde behandel", "liefkoos" en "streel". 
By vergelyking van bogenoemde moontlike troeteltaalvorme word 'n mens bewus van verskille in perspektiewe na aanleiding van kontekste wat ter sprake kon wees by die aanvanklike toepassing. Na 'n studie van die breë verskeidenheid taalelemente wat troeteltaal verteenwoordig, is dit vreemd dat hierdie faktore nog nie woordeboeksamestellers genoegsaam geïnteresseer het om troeteltaal onder gebruiksaandag in woordeboeke te vestig nie. Duidelike verwysings na die leksikon moet egter in 'n addendum deur die betrokke leksikograaf gegee word. 'n Positiewe resultaat in aansluiting by die inleiding van hierdie bespreking kan in opvolging van gegewe wenke tot sukses in toepassing en 'n nuwe ingesteldheid van 'n besef van die krag in troeteltaalvorme lei. Beter menseverhoudinge op alle vlakke sal 'n gelukkige samehorige resultaat kon help bestendig.

Op die hipotese in die inleiding gestel, dat troeteltaalvorme as volwaardige taalvariante van Afrikaans beskou en gevolglik in algemene woordeboeke ingesluit moet word, kan bevestigend gereageer word. Aangesien woordeboeke as inligtingsbronne hulle teikengehoor, die breë publiek, behoort te dien, moet daar tred gehou word met veranderinge en uitbreiding in taalgebruik, soos in die geval van troetelvorme.

\section{Bibliografie}

\section{A. Woordeboeke}

Du Plessis, M. (Hoofred./Chief Ed.). 2005. Pharos 1: Afrikaans-Engels/English-Afrikaans Woordeboek/ Dictionary. Kaapstad: Pharos Woordeboeke.

Rooney, K. (Ed.-in-Chief). 1999. Encarta World English Dictionary. Londen: Bloomsbury.

Odendal, F.F. en R.H. Gouws (Reds.). 2005. HAT: Verklarende Handwoordeboek van die Afrikaanse Taal. Kaapstad: Pearson Education South Africa.

Schoonees, P.C. (Hoofred.). 1950-1961. Woordeboek van die Afrikaanse Taal. Deel I-IV. Pretoria: Die Staatsdrukker.

\section{B. Ander bronne}

Antal, L. 1972. Aspekte der Semantik zu ihrer Theorie und Geschichte. Frankfurt am Main: Athenaum.

Botha, W.J. 2006. Betekeniservaring en die betekenisgesag van die woordeboek. Johannesburg: Randse Afrikaanse Universiteit.

Botha, T.J.R. et al. (Reds.). 1989. Inleiding tot die Afrikaanse taalkunde. Pretoria: Academica.

Claassen, V. 2008. Die vertaling van dialekte: knelpunte en verklaring van die volkseie. Ongepubliseerde M.Phil.-skripsie. Stellenbosch: Universiteit van Stellenbosch.

De Stadler, L.G. 1989. Afrikaanse semantiek. Johannesburg: Southern Boekuitgewers.

Droste, F.G. 1985. Stromingen in de hedendaagse linguistiek. Leuven: Universitaire Pers.

Gouws, R.H. 1988. Die gebruik van etikette as leksikografiese hulpmiddel. Suid-Afrikaanse Tydskrif vir Taalkunde. Geleentheidsuitgawe 6. 
Gouws, R.H. 1989. Leksikografie. Pretoria: Academica.

Lombard, F.J. 1993. Etikette in sinchronies verklarende woordeboeke. Lexikos 3: 140-151.

Louw, S.A. 1948. Dialekvermenging en taalontwikkeling: Proewe van Afrikaanse taalgeografie. Kaapstad/ Amsterdam: A.A. Balkema.

Lyons, J. 1968. Introduction to Theoretical Linguistics. Cambridge: Cambridge University Press.

Lyons, J. 1977. Semantics. Cambridge: Cambridge University Press.

Meiring, B. 1979. Die semantiek van eiename. Ongepubliseerde M.A.-skripsie. Pretoria: Universiteit van Suid-Afrika.

Mües, W. 1967. Sprache: Was ist das? München: Hueber.

Ponelis, F.A. 1989. Die aard en bestudering van die Afrikaanse taal. Botha, T.J.R. et al. (Reds.). 1989: 9-37.

Taylor, J.R. 1995. Linguistic Categorization: Prototypes in Linguistic Theory. Oxford: Clarendon Press.

Van der Merwe, H.J.J.M. 1970. Inleiding tot die taalkunde. Pretoria: J.L. van Schaik.

Webb, V.N. 1989. Die Afrikaanse variasietaalkunde. Botha, T.J.R. et al. (Reds.). 1989: 412-435.

Zgusta, L. 1971. Manual of Lexicography. Den Haag: Mouton. 


\title{
Rufus Gouws se rol in die bekendstelling van H.E. Wiegand se metaleksikografie en terminologie in die Suider-Afrikaanse konteks
}

\author{
Maria Smit, Stellenbosch, Suid-Afrika (ria.eden@gmail.com)
}

Opsomming: Hierdie artikel bring hulde aan Rufus H. Gouws se bydrae tot die standaardisering en ontwikkeling van die leksikografiese vakterminologie in Afrikaans. Deur sy volgehoue betrokkenheid by die teoretiese leksikografie en by internasionale projekte soos die Wörterbuch zur Lexikographie und Wörterbuchforschung (WLWF) het hy reeds sedert die 1980's die grondslag gelê om die leksikografie as 'n onafhanklike vakgebied met die nodige gepaardgaande terminologie in Suid-Afrika te vestig. Hierby het hy onder andere gebruik gemaak van die ryk metaleksikografiese insigte van Herbert Ernst Wiegand uit Duitsland. Die artikel bied eerstens 'n oorsig oor die ontwikkeling van leksikografiese terminologie, ook by Wiegand. Daarna beskryf dit die ontwikkeling van leksikografiese terminologie in Suid-Afrika en die bydrae deur Gouws gelewer. Die artikel sluit af met ' $n$ bespreking van 'n paar terme wat toegangsroetes aanwys aan die hand van drie spesifieke tipes wat Wiegand identifiseer. Hierdie terme verskyn in die eerste deel van die WLWF waar Gouws Afrikaanse vertaalekwivalente daarvoor verskaf het.

Sleutelwoorde: AFRIKAANSE LEKSIKOGRAFIESE TERMINOLOGIE, BINNEGERIGTE EKSTERNE TOEGANGSROETES, EKSTERNE TOEGANGSROETE WAT NA 'N ARTIKEL LEI, HERBERT ERNST WIEGAND, LEKSIKOGRAFIESE VAKTERMINOLOGIE, LEMMATIESGERIGTE TOEGANGSROETE WAT UIT 'N ARTIKEL LEI, ONTWIKKELING VAN LEKSIKOGRAFIESE TERMINOLOGIE, TOEGANGSROETES, TOEGANGSROETE WAT UIT EN NA 'N ARTIKEL LEI, WIEGANDSE TERMINOLOGIE

\footnotetext{
Abstract: Rufus Gouws's Role in the Introduction of H.E. Wiegand's Metalexicography and Terminology in the Southern African Context. This article pays tribute to Rufus H. Gouws's contribution to the standardisation and development of lexicographical terminology in Afrikaans. Because of his continued involvement in theoretical lexicography and international projects such as the Wörterbuch zur Lexikographie und Wörterbuchforschung (WLWF), he laid the basis in South Africa since the 1980s for establishing lexicography as an independent discipline with the necessary accompanying terminology. In this, he drew, amongst others, on the rich metalexicographical insights of Herbert Ernst Wiegand from Germany. This article firstly gives an overview of the development of lexicographical terminology, also by Wiegand. Then it describes the development of lexicographical terminology in South Africa, and the contribution made by
} 
Gouws. The article concludes with a discussion of a couple of terms denoting access routes on the basis of three specific types identified by Wiegand. These terms appear in the first volume of the WLWF, where Gouws provided Afrikaans translation equivalents for them.

Keywords: ACCESS ROUTE LEADING OUT OF AND TO AN ARTICLE, ACCESS ROUTES, AFRIKAANS LEXICOGRAPHICAL TERMINOLOGY, DEVELOPMENT OF LEXICOGRAPHICAL TERMINOLOGY, HERBERT ERNST WIEGAND, INTERNALLY-DIRECTED OUTER ACCESS ROUTE, LEMMATICALLY-DIRECTED ACCESS ROUTE LEADING OUT OF AN ARTICLE, LEXICOGRAPHICAL SPECIAL-FIELD TERMINOLOGY, OUTER ACCESS ROUTE LEADING TO AN ARTICLE, TERMINOLOGY BY WIEGAND

\section{Inleiding}

In 1988, terwyl ek met my Meestersgraad in Algemene Taalwetenskap oor vertalingswoordeboeke besig was, het ek toevallig vir Rufus Gouws, 'n klasmaat uit my voorgraadse Afrikaans-Nederlandsdae, vertel dat my man en ek vir sabbatsverlof na Heidelberg, Duitsland sou gaan. Rufus het dadelik voorgestel dat ek kontak maak met prof. Herbert Ernst Wiegand wat destyds 'n leerstoel in die Germanistiek, en meer spesifiek die Leksikografie, aan die Universiteit van Heidelberg beklee het. Wiegand het op my skrywe gereageer deur my uit te nooi om sy weeklikse doktorale kollokwium en ook ander voorlesings by te woon. Dit is hoe ek, via Rufus, aan die wonderwêreld van Wiegand se metaleksikografie voorgestel is, en wat uiteindelik gelei het tot my doktorale studie, onder Rufus, oor Wiegand se leksikografiese teorie en die toepassing daarvan op die beplanning van ' $n$ ensiklopediese musiekwoordeboek vir Suider-Afrika.

Deur die jare het Rufus sy kontak met Wiegand behou en uitgebrei, en was Wiegand self by verskeie geleenthede op Stellenbosch, as gas van die Universiteit Stellenbosch en ook as gas van die Stellenbosch Institute for Advanced Study (STIAS). Die vanselfsprekendheid waarmee ons vandag Afrikaanse leksikografiese terminologie hanteer, kan grotendeels aan hierdie kontak toegeskryf word - en aan Rufus se onvermoeide skep en gebruik van die nodige Afrikaanse, en in talle gevalle, ook Engelse terminologie. Sy betrokkenheid by die Wörterbuch für Lexikographie und Wörterbuchforschung/Dictionary of Lexicography and Dictionary Research (WLWF = Wiegand et al. 2010) moet nie onderskat word nie.

In hierdie bydrae wil ek Rufus Gouws graag huldig vir die werk wat hy in sy loopbaan gedoen het om leksikografie as akademiese vak in Suid-Afrika en die res van Afrika te bevorder, en gevolglik ook vir sy rol in die vorming van 'n geskikte vaktaal, onder andere ook binne die raamwerk van die Wiegandse leksikografiese vakterminologie. Hierdie artikel fokus op 'n aantal terme wat ontstaan het deur Gouws se belangstelling in en betrokkenheid by Wiegand se steeds groter wordende arsenaal van leksikografiese terme. Eerstens is daar 'n kort oorsig oor hoe leksikografiese terminologie in die algemeen ontwikkel het, 
ook deur Wiegand se toedoen. Dan word daar kortliks gekyk na hoe leksikografiese terme in Afrikaans ontwikkel het en die bydrae wat Gouws daartoe gelewer het. Die laaste deel van die artikel konsentreer dan op meer onlangse terme wat met Wiegand se nuutste ontwikkelings in sy teksteoretiese benadering tot woordeboeke (oftewel sy belangstelling in woordeboekstrukture) verband hou, en hoe Gouws se bydrae tot hierdie kategorie terme lyk. Daar word spesifiek na drie tipes gekyk wat Wiegand by toegangstrukture identifiseer.

\section{Die ontwikkeling van Wiegand se leksikografiese terminologie}

Dit is natuurlik nie waar dat leksikografiese vakterme eers tydens Wiegand se loopbaan ontstaan het nie. Voordat hy ernstig begin publiseer het oor die leksikografiese teorie, was daar immers reeds 'n kanon oor teoretiese leksikografie in die vorm van byvoorbeeld Zgusta (1971) en Al-Kasimi (1977). Ook in ander dele van die akademiese wêreld was mense aan die werk in die veld van die teoretiese leksikografie, en hulle het natuurlik ook reeds gevestigde terme gebruik. Hier dink ons byvoorbeeld aan Hartmann (1983) in Engeland, Barnhart (1978) in die V.S.A., Hausmann (1985) in Duitsland, Geeraerts (1984a) in Nederland en Bergenholtz (1983) in Denemarke, om maar slegs enkele voorbeelde te noem. Maar daar kan met sekerheid vasgestel word dat die enkele navorser wat die grootste aantal vakterme vir leksikografie uitgedink en in werking gestel het, Herbert Ernst Wiegand was. ${ }^{1}$

Wiegand het feitlik 'n dekade lank oor die leksikologie en allerlei kwessies in woordeboeke gepubliseer voordat hy vorendag gekom het met sy "algemene leksikografiese teorie" (Wiegand 1983, 1984): 'n sistematiese uiteensetting van hoe hy gereken het woordeboeke op 'n teoretiese manier bestudeer sou kon word om in die praktyk beter produkte te lewer. Hierdie teorie het bestaan uit verskeie gebiede, soos (a) navorsing oor woordeboekgebruik; (b) woordeboekkritiek; (c) die geskiedenis van woordeboeke en (d) die algemene teorie van taalleksikografie. Laasgenoemde veld het hy weer verder onderverdeel in (i) 'n algemene seksie, wat bestaan uit aspekte soos die doelstellings van woordeboeke, leksikografiese teorie se verwantskappe met ander teorieë, en beginsels van die geskiedenis van die leksikografie; (ii) die organisasieteorie, wat hom besig hou met die opstel van 'n woordeboekplan, 'n woordeboekbasis en 'n leksikografiese lêer (dit is 'n lys lemmas wat uit die woordeboekbasis geselekteer is vir opname in ' $n$ bepaalde woordeboek), asook die eintlike skryf van woordeboektekste; (iii) die teorie van leksikografiese taalnavorsing, wat die teorie van dataversameling, dataprosessering en rekenaargesteunde leksikografie insluit, en (iv) die teorie van leksikografiese taalbeskrywing. Laasgenoemde afdeling sluit sake in soos woordeboektipologie en 'n teksteorie vir leksikografiese tekste. Hierdie laaste onderafdeling, die teksteorie, het oor die jare heen taamlik verander en veral baie sterk uitgebrei, veral ten opsigte van die moontlikhede om teksteorie aan te wend in elektroniese stelsels vir die skep 
van nuwe woordeboeke, hetsy gedruk of elektronies. Die nuutste weergawe van Wiegand se teksteoretiese werk kan in die sistematiese inleiding van die WLWF (2010: 123-242) nagegaan word.

Soos wat Wiegand al hoe meer woordeboeke bestudeer het - hy is 'n selferkende versamelaar van omtrent alle woordeboeke wat ooit in die wêreld verskyn het, selfs in tale wat hy nie noodwendig kan lees nie - het hy al hoe meer begin konsentreer op die tekstuele strukture in woordeboekartikels: die komponente waaruit woordeboekartikels bestaan, hulle funksies en onderlinge relasies tot mekaar en tot ander tekste binne en buite 'n bepaalde woordeboek. Die vernaamste rede daarvoor is dat Wiegand dit vir woordeboekmakers wil moontlik maak om vooraf sjablone op te stel waarmee hulle baie noukeurig kan beplan wat die inhoud van 'n bepaalde woordeboek moet wees om aan die behoeftes van hulle beoogde gebruikers te voldoen. Wiegand gaan dus uit van die praktyk van bestaande woordeboeke om die teorie van woordeboekmaak te voed. In die laaste paar jaar het die Wiegandse teksteorie geweldig uitgebrei, maar omdat die oorgrote meerderheid van sy geskrifte in Duits is, is baie van sy besprekings en verduidelikings ontoeganklik vir mense wat nie Duits magtig is nie. Die terme self, waarmee Wiegand die teksstrukture in woordeboeke benoem, is ook tipies Duits, in die sin dat hulle meestal uit samestellings bestaan wat moeilik in ' $n$ taal soos Engels omgesit kan word. Daarom is die Engelse vertaalekwivalente van Wiegand se Duitse terme in baie gevalle eerder kort frases as komposita.

Dit is wat die publikasie van die WLWF (2010) (waarvan nog slegs die eerste van drie dele in 2010 verskyn het) so nuttig maak. Hierdie omvattende werk sal uiteindelik ongeveer 6000 Duitse vakleksikografiese lemmas bevat wat ook boonop van vertaalekwivalente in nege ander tale voorsien sal word. Gouws is verantwoordelik vir die skep van sowel die Afrikaanse as die Engelse vertaalekwivalente asook die skryf van die kort Engelse definisie by elke lemma.

Die nuutste ontwikkelings ten opsigte van leksikografiese terminologie, ook by Wiegand, weerspieël dus die stelling van Bergenholtz en Gouws (2010: 107): "Terms are not merely introduced for the sake of terms but the introduction of new terms reflects the dynamic nature of the underlying theory." Dit beteken dat leksikografiese teorie nie 'n stagnante wetenskap is nie, maar dat dit steeds groei en uitbrei namate nuwe woordeboeke verskyn en nuwe verskynsels benoem moet word. Praktyk voed teorie, en andersom.

\section{Vestiging van leksikografiese vakterme in Suid-Afrika}

Ook in Suid-Afrika was daar natuurlik reeds in die 1970's en vroeër 'n aantal publikasies wat oor teoriese aspekte van die leksikografie gehandel het. Voorbeelde hiervan is Odendal $(1961,1978)$ en Louw (1985). Gouws het egter reeds in van sy vroegste werk begin om gebruik te maak van terminologie wat deur Wiegand aangewend is en waaraan laasgenoemde ' $n$ baie spesifieke betekenis 
gekoppel het. Dit geld vir terme wat Wiegand van andere oorgeneem het, en dié wat hy self uitgedink het. Ons sien byvoorbeeld dat, wanneer hy oor die gebruik van etikette as leksikografiese hulpmiddel skryf, Gouws (1988: 4) pleit vir 'n eenvormige vakterminologie in Afrikaans. Hy (1988: 40-42, 48) gebruik byvoorbeeld reeds daar die term mikrostruktuur en gee 'n kort verduideliking daarvan. Hoewel die term volgens Gouws (1988: 40) aanvanklik deur Geeraerts (1984b) ingevoer is, is hierdie term deur Wiegand ontgin en is dit tot vandag toe ' $n$ baie belangrike element in sy metaleksikografie.

In sy boek Leksikografie bespreek Gouws (1989a: 34-41) die destydse gebrek aan 'n gestandaardiseerde leksikografiese terminologie in Afrikaans. Terme soos lemma, woordeboekartikel, tekssegment, tekselement, teksbousteen, makro- en mikrostruktuur kry aandag in uiteensettings oor betekenis en gebruik. Nie alleen gebruik Gouws dus terminologie wat deur Wiegand bekendgestel word nie, maar hy steun ook reeds sedert die laat 1980's op die teoretiese insigte wat Wiegand se metaleksikografie bied - selfs al stem hy nie altyd honderd persent met Wiegand saam nie. ${ }^{2}$

Baie van Gouws se akademiese artikels ${ }^{3}$ en hoofstukke het deur die jare in Engels verskyn. Hoewel baie van sy werk in buitelandse publikasies verskyn het (meestal in Engels, maar ook soms in Duits), het hy onder andere ook baie in die tydskrif Lexikos gepubliseer. ${ }^{4}$ By die Engelstalige Lexikos-artikels het hy egter telkens aan die begin van elke artikel Afrikaanse sleutelwoorde verskaf, wat ook baie daartoe bygedra het om die teoretiese terminologie te vestig.

Leksikografiese terminologie en begripsvelde wat Gouws deur die jare in sy artikels, hoofstukke en boeke gebruik het in aansluiting by die Wiegandse betekenisse, en waarvoor hy in baie gevalle Afrikaanse vertaalekwivalente gevestig het, sluit onder andere in: makrostruktuur (Gouws 1989b, 1992, 1993a, 1995, Gouws en Prinsloo 1997), mikrostruktuur (Gouws 1993a, 1995, 2003b), nes- en nisstrukture (Gouws 2002), buitetekste (voor- en agtertekste) (Gouws 2004a, 2007b), toegangstrukture (Gouws 1993a, 1996, 2001b, 2006, Bergenholtz en Gouws 2010), soekareastrukture (Gouws 2003b), adressering (Gouws 1993a, 1994, 1996, 2000, 2003b), verryking (Gouws 2010), woordeboektipologie (Gouws 1993b, Gouws en Ponelis 1992), aanleerderwoordeboeke (Gouws 2004b, 2009a), links-uitgebreide artikelstrukture (Gouws en Prinsloo 2005a) en nog talle meer.

Dit is belangrik om te noem dat die Lexikos-reeks deur die jare baie daartoe bygedra het om Afrikaanse leksikografiese terminologie te vestig. Selfs al het artikels in Engels verskyn (wat te verstane is, as 'n mens in gedagte hou dat baie nagraadse studente in die leksikografie uit ander Afrikalande kom en nie Afrikaans magtig is nie), word die Engelse artikels altyd van 'n Afrikaanse opsomming met Afrikaanse sleutelwoorde voorsien. Dit is hierdie sleutelwoorde wat die Afrikaanse leksikografiese vakterminologie help vestig het.

Omdat dit sinloos en onmoontlik is om bloot al die Wiegandse terme wat deur Gouws in Afrikaans ingevoer is, hier te lys, kan net nog twee voorbeelde van artikels gegee word waarin Gouws met gemak terme van Wiegand gebruik: Wanneer Gouws (2002) die beginsel van nisting verduidelik, kom terme soos 
die volgende aan die bod: eerstevlaknesting, enkelnisting, heterogene nisting, hibridiese nisting, homogene nisting, nesting, teksverdigting, veelvuldige nisting en verwyderde nisting.

Selfs wanneer daar in Engels geskryf word, word terme uit die Wiegandse stal met gemak gebruik. Terme wat verband hou met woordeboeke as draers van tekstipes word in Gouws en Prinsloo (2005b) bespreek, en dit sluit terme in soos: buitetekste (voor- en agterteks), datadistribusiestruktuur, geïntegreerde en niegeïntegreerde buitetekste, toegangstruktuur, soekareastruktuur, adresseringstruktuur, mediostruktuur, artikeltrajekte, interne en eksterne kruisverwysingsadresse en woordeboek-eksterne kruisverwysingsadresse, met verskillende onderafdelings en terminologiese netwerke.

Die res van hierdie artikel fokus op 'n paar leksikografiese terme wat te doen het met toegangsroetes wat nog nie op groot skaal in die Afrikaanse vakliteratuur oor woordeboeke aangewend is nie. Die Afrikaanse vertaalekwivalente verskyn egter reeds in die eerste deel van die WLWF (2010), en is deur Gouws geskep.

\section{Enkele voorbeelde van leksikografiese vakterme}

Die woordeboekartikels wat Gouws deur die jare in sy geskrifte ontleed, kom baie dikwels uit Suid-Afrikaanse woordeboeke. Dit sluit veral Afrikaanse woordeboeke, tweetalige woordeboeke met Afrikaans en Engels, en woordeboeke met Suid-Afrikaanse Afrikatale in. 'n Voorbeeld hiervan kan gesien word in Gouws (2009b), waar artikels uit die Groot Woordeboek (Eksteen 1997) en die Verklarende Handwoordeboek van die Afrikaanse Taal (= HAT; Odendal en Gouws 2005) gebruik word om die beginsels van nisting en nesting onderskeidelik te illustreer. Ook dele van die Woordeboek van die Afrikaanse Taal (WAT) word bespreek en aspekte van die mikrostrukture word ontleed, soos in Gouws (1997 en 1999).

Omdat baie Suid-Afrikaanse woordeboeke 'n heelwat eenvoudiger struktuur het as byvoorbeeld Duitse woordeboeke, kan die groot voorraad terme wat Wiegand geskep het in sy jarelange ondersoeke van bestaande woordeboeke nie naastenby toegepas word op die eenvoudiger mikrostrukturele argitekture van die plaaslike eweknieë nie. In die WLWF is dus 'n groot aantal terme vir Afrikaans geskep wat nog nie noodwendig neerslag vind in die praktyk van Afrikaanse woordeboeke wat onlangs verskyn het nie: die strukture van Afrikaanse woordeboeke weerspieël nog oor die algemeen nie Wiegand se nuutste toevoegings tot die leksikografiese terminologie nie. Hierdie terme is hoofsaaklik deur Wiegand gevorm op grond van sy studie van veral Duitse woordeboeke, en Gouws het Afrikaanse vertaalekwivalente vir hierdie terme geskep.

Die terme wat gekies is vir hierdie bespreking, benoem 'n aantal toegangsroetes wat Wiegand (2007: 180-211) beskryf en verduidelik. Wiegand maak 'n 
basiese onderskeid tussen eksterne en interne toegangsroetes. Ons bepaal hier ons aandag by die eerste soort.

Dit is volgens Wiegand moontlik om op verskillende maniere toegang te kry tot tekselemente in woordeboeke en hulle buitetekste. Hy (2007: 182) gebruik die Latynse werkwoord currere (= loop) om verskeie vorme van toegangsprosedures tot verskillende woordeboektekste te benoem. Hy betrek ook ander vorme van die werkwoord, soos incurrere (= inloop), excurrere (= uitloop) en adcurrere (= tot by 'n bepaalde punt loop). Op grond van hierdie werkwoorde bou hy die volgende adjektiewe in Duits: binnenkurrent (= letterlik: na binne gerig), inkurrent (= letterlik: wat binnetoe lei), exkurrent (= letterlik: wat buitentoe lei) en adkurrent (= letterlik: wat na iets lei). In die eerste deel van die WLWF, wat terme van A tot $C$ insluit, verskyn 'n aantal samestellings met die Duitse stam -kurrent, waarvan slegs 'n paar hieronder bespreek word.

'n Eksterne toegangsroete kry die naam nie soseer omdat 'n gebruiker van buite af in die woordeboek inkom nie, maar eerder omdat die roete wat die gebruiker volg na en deur sekere stappe van eksterne toegangstrukture gaan (Wiegand 2007: 187). Wiegand onderskei ook tussen verskillende soorte eksterne toegangstrukture; alfabetiese rangskikking is een van hulle - en die een wat verreweg die meeste in woordeboeke gebruik word (sien ook WLWF: 621-622, Wiegand 1989). Natuurlik onderskei Wiegand ook weer tussen verskillende soorte alfabetiese rangskikking, maar laat ons as voorbeeld die streng alfabetiese rangskikking neem.

Die eenvoudigste toegangsroete is 'n enkelvoudige toegangsroete (Wiegand 2007: 187) wat van buite 'n woordeboek af na die woordeboek kan lei, of wat van binne ' $n$ woordeboek kan lei na iets binne-in of iets buitekant die woordeboek. Daar is ook nog saamgestelde toegangsroetes, waaroor daar nie nou gepraat gaan word nie.

Enkelvoudige eksterne toegangsroetes is die soort wat die heel meeste gebruik word wanneer woordeboeke geraadpleeg word. So 'n enkelvoudige eksterne toegangsroete het ' $n$ begin en 'n einde. Die begin van die roete kan buite die woordeboek wees, of dit kan gebeur as 'n gebruiker reeds besig is om die woordeboek te raadpleeg en dan 'n soekvraag kry of in 'n konflik raak, byvoorbeeld as gevolg van ' $n$ versteuring by teksresepsie. Die einde van die toegangsroete is altyd 'n eksterne toegangstekselement soos byvoorbeeld 'n lemma (Wiegand 2007: 189). Dit is daarom dat dit "ekstern" genoem word - omdat die einde altyd na 'n eksterne toegangselement (via die lemma na 'n artikel) lei.

\section{(a) Eksterne toegangsroete wat na 'n artikel lei}

Wiegand (2007: 189-191) bespreek die Duitse begrip artikeladkurrenter äußerer Zugriffspfad en Gouws vertaal dit in die WLWF (2010: 559) as eksterne toegangsroete wat na ' $n$ artikel lei.

Laat ons kyk na 'n geval waar die soektog buite die woordeboek begin aan die hand van die volgende taamlik voor die hand liggende voorbeeld: ${ }^{5}$ Simon, ' $n$ 
Graad IV-leerder, kom op die woord makietie af in 'n teks. Hy weet nie wat hierdie woord beteken nie, en slaan dit in sy nuwe alfabetiese woordeboek, die Oxford Afrikaanse Skoolwoordeboek (OAS = Louw 2012), na. Dit word gedoen deur 'n eksterne toegangshandeling uit te voer en met behulp van die gidselement | makietie |, wat die begin van die roete is, en die lemma makietie te vind, wat die einde van die roete (soektog) is. Hierdie eksterne toegangsroete het Simon na die gewenste artikel gelei. Hoe meer bedrewe Simon is, hoe makliker en korter sal sy soekpad wees en hoe gouer sal sy toegangshandeling voltooi wees.

Simon se toegangshandeling kan soos in figuur 1 skematies uitgebeeld word.

UITTREKSEL UIT 'N ALFABETIESE

MAKROSTRUKTURELE EKSTERNE

TOEGANGSTRUKTUUR

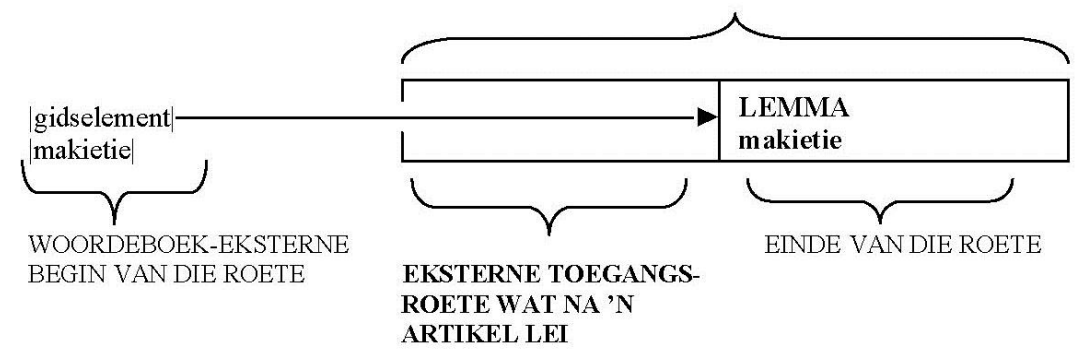

Figuur 1: Voorstelling van 'n algemene eksterne toegangsroete wat na 'n artikel lei.

Die eksterne toegangsroete wat na ' $n$ artikel lei is een van die soorte nie-mediostrukturele eksterne toegangsroetes wat 'n mens kry. Wiegand (2007: 190) identifiseer ook nog ander, naamlik 'n eksterne toegangsroete wat na 'n binneteks lei, 'n eksterne toegangsroete wat na 'n buiteteks lei, 'n eksterne toegangsroete wat na ' $n$ invoeging lei, en 'n eksterne toegangsroete wat na die register lei. "Nie-mediostruktureel" beteken dat die mediostruktuur van die betrokke woordeboek nie benut hoef te word nie; by hierdie soort toegangsroetes hoef 'n mens dus nie van kruisverwysings en dergelike soektegnieke gebruik te maak nie.

\section{(b) Toegangsroete wat uit en na 'n artikel lei}

Nog 'n soort nie-mediostrukturele eksterne toegangsroete is wat Wiegand (2007: 200-201) in Duits beskryf as artikelexkurrenter und artikeladkurrenter äußerer Zugriffspfad. Gouws vertaal dit in die WLWF (2010: 565) as toegangsroete wat uit en na ' $n$ artikel lei. Dit kom veral voor wanneer daar 'n spesifieke versteuring plaasvind by teksresepsie. Hierdie toegangsroete ontstaan egter binnein die een artikel, en is dus volgens Wiegand (2007: 200) binnegerig - en ver- 
trek dan uit die eerste artikel na 'n tweede artikel om die roete te kan voltooi. Die volgende voorbeeld verduidelik hierdie begrip: Simon, die Graad IV-leerder, soek weer in sy nuwe OAS na die betekenis van "likwidateur". Die inskrywing lyk soos volg:

likwidateur [lik wi da teur] naamwoord (likwidateurs) die persoon of instelling wat die likwidasie van 'n maatskappy behartig, of wat ' $\mathrm{n}$ insolvente boedel afhandel: Die bank het 'n likwidateur aangestel om die insolvente boedel af te handel.

Simon kry die artikel met die lemma likwidateur, maar as hy die betekenisomskrywing deurlees, verstaan hy nie wat die woord "insolvent" beteken nie. Nou voer hy met die gidselement |insolvent| 'n eksterne toegangshandeling uit, wat hom na die lemma insolvent neem. Hierdie toegangsroete neem hom uit die een artikel na 'n ander artikel. Die toegangshandeling kan soos in figuur 2 uitgebeeld word.

UITTREKSEL UIT 'N ALFABETIESE MAKROSTRUKTURELE EKSTERNE

TOEGANGSTRUKTUUR

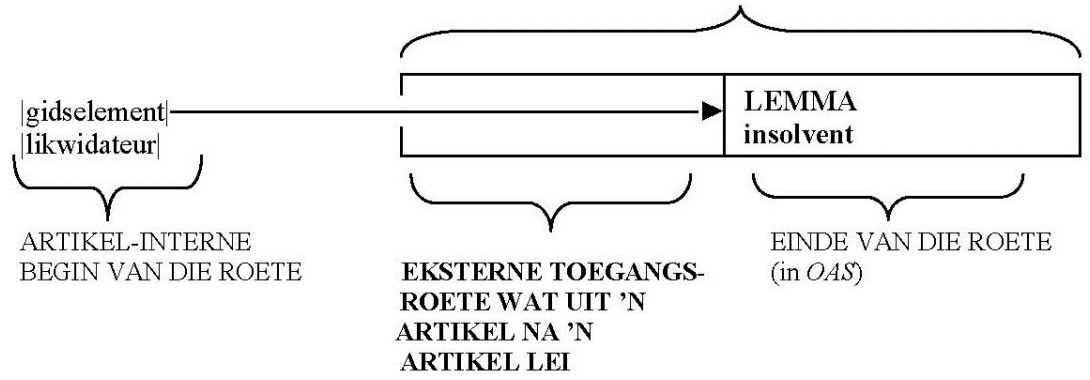

Figuur 2: Voorstelling van 'n algemene eksterne toegangsroete wat uit 'n artikel na 'n artikel lei.

Daar is nog heelwat ander soorte nie-mediostrukturele eksterne toegangsroetes, aangesien die roete ook in die binneteks, die buitetekste, en in die invoeging sou kon begin, vanwaar dit dan na 'n artikel kan lei.

\section{(c) Binnegerigte eksterne toegangsroete}

Naas nie-mediostrukturele eksterne toegangsroetes waarvan voorbeelde in (a) en (b) hierbo bespreek is, identifiseer Wiegand (2007: 191) mediostrukturele 
eksterne toegangsroetes wat ook enkelvoudige eksterne toegangsroetes is. Soos die naam reeds te kenne gee, is die mediostruktuur van 'n woordeboek betrokke by hierdie soort toegangsroetes, wat beteken 'n kruisverwysingsopvolghandeling moet uitgevoer word. Hoewel daar 'n hele paar soorte is, bepaal ons ons nou slegs by wat Wiegand (2007: 191) in Duits tipeer as binnenkurrente äußere Zugangspfade (Gouws vertaal dit in die WLWF (2010: 707) as binnegerigte eksterne toegangsroetes). Daar is volgens Wiegand nog ander soorte mediostrukturele eksterne toegangsroetes, maar hulle is nie nou ter sake nie.

'n Binnegerigte eksterne toegangsroete se begin en einde is albei binne-in die woordeboek geleë. In teenstelling tot eksterne toegangsroetes wat na iets lei, word by binnegerigte eksterne toegangsroetes die woordeboek-interne posisie van die roete, die mediostrukturele oriëntasie van die roete en die tekstuele posisie van die einde van die roete in ag geneem (Wiegand 2007: 191). Dit beteken dat die begin van die roete ' $n$ tekssegment is wat 'n kruisverwysing moontlik maak, en die einde van die roete is 'n eksterne toegangselement (of lemma) wat binne-in die woordeboek geleë is.

Daar is heelwat tipes mediostrukturele binnegerigte eksterne toegangsroetes, maar ons kyk net na een soort in die volgende voorbeeld: Simon is besig om 'n wetenskaptaak te doen. Hy soek na die betekenis van "swael" in sy OAS, waarvan daar die volgende inskrywings verskyn:

swael $^{1}$ naamwoord (swaels, swaeltjie) (Biologie)

'n klein voëltjie met lang gepunte vlerke en

'n stert met twee punte, wat die somer hier

vertoef, maar in die winter na die noordelike

halfrond trek: Die goue aandlug is deurspikkel

van derduisende dartelende klein swaeltjies.

swael $^{2}$ naamwoord (geen meervoud) (Wetenskap) $\rightarrow$ SIEN swawel.

Simon besef dadelik dat dit om hierdie tweede swael gaan, en hy voer 'n kruisverwysingsopvolghandeling uit na swawel. Die roete wat hier gevolg word, word deur Wiegand (2007: 192-193) in Duits beskryf as 'n artikelexkurrenter artikelinkurrente orientierter Zugriffspfad. Dit beteken die roete loop uit 'n artikel uit en is dan gerig aan 'n ander artikel (of aan die lemma van daardie artikel). In die WLWF (2010: 563-564) word hierdie soort toegangsroete aangedui as 'n subtipe binnegerigte eksterne toegangsroete van wat Wiegand in Duits noem die artikelexkurrenter lemmatisch orientierter Zugriffspfad - die sogenaamde lemmatiesgerigte toegangsroete wat uit ' $n$ artikel uitlei (Gouws se vertaling, WLWF 2010: 563564). Hierdie toegangsroetes se eindes lê nog steeds in eksterne toegangstekselemente oftewel lemmas, en daarom is hulle steeds eksterne toegangsroetes. Hierdie tipe toegangsroete kan soos in figuur 3 skematies uitgebeeld word. 


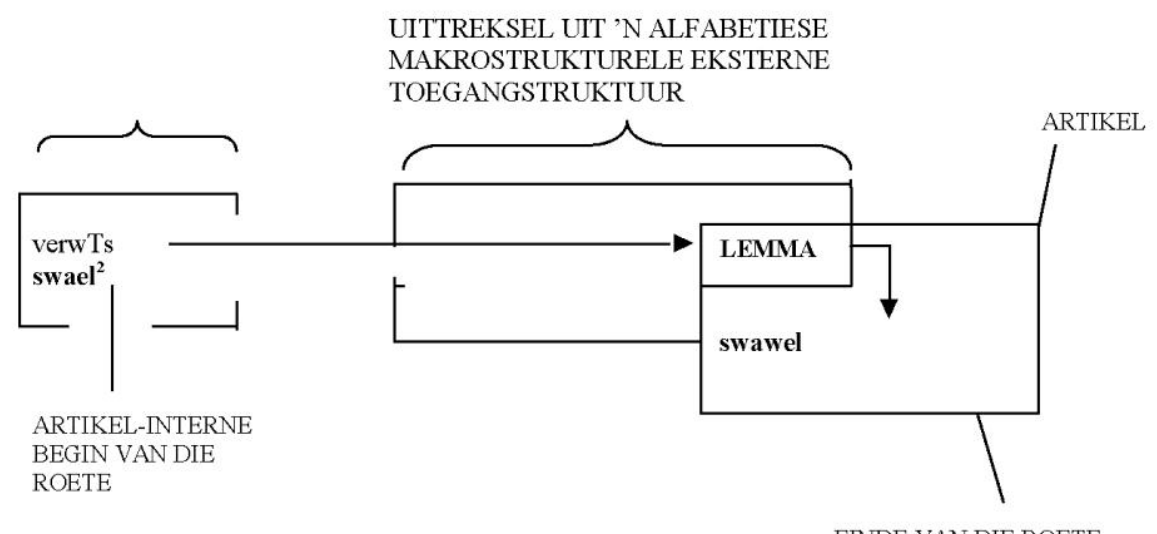

Figuur 3: Lemmatiesgerigte eksterne toegangsroete wat uit 'n artikel uitlei; Afkorting: verwTs = tekssegment wat 'n verwysing moontlik maak.

\section{Slotsom}

In hierdie artikel is gekyk na Rufus Gouws se jarelange bydrae tot die vorming en vestiging van Afrikaanse leksikografiese terminologie. ' $\mathrm{n}$ Paar voorbeelde van sy mees onlangse bydraes wat opgeneem is in die WLWF, waarvan Deel 1 in 2010 verskyn het, is kortliks bespreek aan die hand van eenvoudige voorbeelde.

Die vraag sou kon ontstaan of dit werklik nodig is dat daar soveel terme in Afrikaans geskep word vir verskynsels wat dalk nog nie eens by ons bestaan nie. Selfs Wiegand (2007: 196) erken dat daar kritici is wat wonder of dit nodig is om tipes toegangsroetes te identifiseer waarby daar nie rekening gehou word met die mediostrukturele oriëntasie (dit wil sê met kruisverwysingsmeganismes) van woordeboeke nie. Hy (2007: 196) regverdig egter sy uitgebreide tipologie van toegangsroetes deur te beweer dat hierdie onderskeidings dit moontlik maak om die kwalitatiewe en kwantitatiewe mediostrukturele profiele van vakwetenskaplike aanleer- of raadplegingswoordeboeke (in die sin van Wiegand 2006) te bepaal. In die Duitssprekende wêreld bestaan immers reeds vakwoordeboeke waar daar van talle verskillende tipes toegangstrukture gebruik gemaak word. By ons is die struktuur van woordeboeke, selfs vakwoordeboeke, oor die algemeen minder kompleks. Nietemin is dit vir opstellers van woordeboeke nuttig om kennis te neem van die moontlikhede wat uitgespel word in die teoretiese leksikografie, en om terminologie byderhand te hê wat insig kan aanhelp in die implikasies van die gebruik van spesifieke verskynsels.

'n Laaste vraag is of die nuutste vertaalekwivalente wat Gouws geskep het, inslag sal vind in die Afrikaanse leksikografiese teorie en praktyk. Wiegand se benamings vir verskynsels het deur die jare al hoe komplekser en digter geword: selfs hy het soms nou al twee of meer Duitse samestellings nodig 
om subtipes mee te kan benoem. As ons byvoorbeeld kyk na die bogenoemde terme artikeladkurrenter äußerer Zugriffspfad, artikelexkurrenter und artikeladkurrenter äußerer Zugriffspfad, binnenkurrente äußere Zugriffspfade en artikelexkurrenter lemmatisch orientierter Zugriffspfad wat Wiegand gebruik om (eintlik) doodgewone en eenvoudige stappe tydens woordeboekgebruik te beskryf, kan 'n mens verstaan as daar mense is wat beswaard voel oor sy komplekse terminologiesisteme. Vir 'n vlietende oomblik sou 'n mens kon wonder of Gouws nie liewer ook die stam -kurrent moes gebruik het toe hy vertaalekwivalente geskep het nie: dalk iets soos artikeladkurrente eksterne toegangsroete (in plaas van eksterne toegangsroete wat na 'n artikel lei); artikelekskurrente en artikeladkurrente eksterne toegangsroete (in plaas van toegangsroete wat uit en na 'n artikel lei); binnekurrente eksterne toegangsroetes (hoewel die huidige binnegerigte eksterne toegangsroetes volgens my 'n raak en bondige vertaalekwivalent daarstel) en artikelekskurrente lemmatiesgerigte toegangsroete (in plaas van lemmatiesgerigte toegangsroete wat uit ' $n$ artikel lei). Hierdie bondiger (hoewel steeds lomp) vertaalekwivalente sou dalk makliker gebruik kon word en minder verwarrend kon wees as die huidige vertaalekwivalente wat eintlik parafrases is. Afrikaans leen hom immers ook tot samestellings, soos wat suksesvol geblyk het in ander leksikografiese terme deur Gouws geskep, soos soekareastrukture, links-uitgebreide artikelstrukture, datadistribusiestruktuur, kruisverwysingsopvolghandeling en dies meer. Een oorweging van Gouws kon natuurlik gewees het dat ons in Afrikaans steeds voorkeur gee aan Germaanse woordvorme, en dat Wiegand hier van Latynse vorme gebruik maak. 'n Ander oorweging is dat Gouws voorkeur sou wou gee aan eenvoudiger taalgebruik (in Engels "plain language" wat ook in SuidAfrika 'n prioriteit is). Wat Gouws se beweegredes ook al was: die skep van vertaalekwivalente vir terme wat Wiegand uitgedink het, bly 'n groot uitdaging. Net die tyd sal leer of die huidige terme inslag sal vind. Intussen is ons dankbaar vir die groot werk wat Gouws verrig het om ons instrumente te verskaf waarmee ons ons vak in teorie en praktyk kan beoefen.

\section{Endnote}

1. In 'n taamlik ongelukkige voorval het Pálfi en Kristiansen (2010) die eerste volume van die WLWF wat verskyn het, gekritiseer op grond van die feit dat hierdie publikasie hoofsaaklik uit "Wiegandse" terme bestaan en dat ander vakwoordeboeke oor die leksikografie wat onlangs verskyn het (soos die NLO (1997) en Hartmann en James (2006)), nie eintlik hierdie "Wiegandse" terminologie opgeneem het nie. Vir die doel van hierdie artikel is hierdie kritiek nie relevant nie - die gebruik van terminologie wat deur Wiegand ingevoer is, en soos dit deur Gouws in Afrikaans (en Engels) vertaal en aangewend is, is steeds van groot hulp in die Suider-Afrikaanse konteks.

2. Hoewel Gouws (1989: 25-26) hier beweer dat hy van Wiegand verskil oor die vraag of die leksikografie 'n selfstandige dissipline in eie reg is, en of dit 'n onderafdeling van die leksikologie is, het hy later skynbaar tog Wiegand se siening aanvaar (sien byvoorbeeld in Gouws 
2007a: 322). Wiegand het reeds baie vroeg al die stelling gemaak dat die leksikografie 'n dissipline in eie reg is.

3. Gouws bedryf nie net teoretiese leksikografie nie. In die woordeboeke waaraan hy meewerk of wat hy self skryf, gebruik hy egter nie teoretiese leksikografiese terminologie wat moontlik sy lesers kan verwar of ontstel nie. In die voortekste van byvoorbeeld Gouws, Feinauer en Ponelis (1994), Gouws, Stark en Gouws (2004) en Odendal en Gouws (2005) verskyn duidelike en baie bruikbare gidse vir die woordeboekgebruiker, maar sonder allerlei teoretiese begrippe. Veral die insiggewende artikeluitleg in laasgenoemde woordeboek (Odendal en Gouws 2005: xx-xxi) is baie gebruikersvriendelik sonder om potensiële lesers met vreemde begrippe en terme te verwar.

4. Dit is ook belangrik om te onthou dat Rufus Gouws nie net akademiese werk gelewer het en prakties by die opstel van woordeboeke betrokke was nie. In 'n raadgewende hoedanigheid het hy ook 'n uiters groot bydrae gelewer by talle woordeboekprojekte in al die offisiële tale dwarsoor Suid-Afrika en in ander Afrikalande deur onder andere slypskole en seminare. Sien byvoorbeeld sy artikels (Gouws 2001a en 2003a) oor die beplanning van modelle vir die woordeboekeenhede in Suid-Afrika. Sy nagraadse studieleiding aan talle Magister- en doktorale studente uit alle oorde is uiteraard ook baie belangrik vir die vestiging van die leksikografie as vakgebied en as gesonde praktyk.

5. Die drie voorbeelde wat ek gekies het om die Wiegandse konsepte mee te verduidelik, kom uit 'n nuwe Afrikaanse woordeboek, die Oxford Afrikaanse Skoolwoordeboek (OAS = Louw 2012). Ek het met opset baie eenvoudige voorbeelde gekies sodat selfs Simon, my fiktiewe woordeboekgebruiker, hulle sou kon verstaan.

\section{Bronnelys}

Al-Kasimi, A.M. 1977. Linguistics and Bilingual Dictionaries. Leiden: E.J. Brill.

Barnhart, C.L. 1978. American Lexicography 1945-1973. American Speech 53: 83-140.

Bergenholtz, H. 1983. Grammatik im Wörterbuch. Zur Terminologie und zur empirischen Basis. Kopenhagener Beiträge zur germanistischen Linguistik 21: 70-92.

Bergenholtz, H. en R.H. Gouws. 2010. A New Perspective on the Access Process. Hermes: Journal of Language and Communication Studies 44: 103-127.

Eksteen, L.C. (Red.). 199714. Groot Woordeboek Afrikaans-Engels/Engels-Afrikaans/Major Dictionary Afrikaans-English/English-Afrikaans. Kaapstad: Pharos.

Geeraerts, D. 1984a. Ontwikkelingen in de lexicografische theorievorming. Jaarboek van de Stichting Instituut voor Nederlandse Lexicologie. Overzicht van de jaren 1981 en 1982: 56-65.

Geeraerts, D. 1984b. Dictionary Classification and the Foundations of Lexicography. ITL: Review of Applied Linguistics 63: 37-63.

Gouws, R.H. 1988. Die gebruik van etikette as leksikografiese hulpmiddel. Suid-Afrikaanse Tydskrif vir Taalkunde. Geleentheidsuitgawe 6.

Gouws, R.H. 1989a. Leksikografie. Pretoria/Kaapstad: Academica.

Gouws, R.H. 1989b. Setsels as makrostruktuurelemente van Afrikaanse woordeboeke. Suid-Afrikaanse Tydskrif vir Taalkunde 7(2): 59-67.

Gouws, R.H. 1992. Die leksikografiese bewerking van neweskikkers. Tydskrif vir Geesteswetenskappe 32(2): 91-103. 
Gouws, R.H. 1993a. Afrikaans Learner's Dictionaries for a Multilingual South Africa. Lexikos 3: 29-48.

Gouws, R.H. 1993b. Aspekte van die Suid-Afrikaanse leksikografiepraktyk. Tydskrif vir Geesteswetenskappe 33(2): 79-95.

Gouws, R.H. 1994. Ostensiewe adressering in vertalende woordeboeke. Lexikos 4: 61-85.

Gouws, R.H. 1995. Woordeboeke met Afrikaans en Duits as taalpaar: 'n metaleksikografiese situering binne die Afrikaanse vertalende leksikografie. Suid-Afrikaanse Tydskrifvir Taalkunde. Supplement 25.

Gouws, R.H. 1996. Bilingual Dictionaries and Communicative Equivalence for a Multilingual Society. Lexikos 6: 14-31.

Gouws, R.H. 1997. Linguistische Theorie, lexikographische Praxis und das Woordeboek van die Afrikaanse Taal. Konerding, K.-P. en A. Lehr (Reds.). 1997. Linguistische Theorie und lexikographische Praxis: 17-31. Lexicographica Series Maior 82. Tübingen: Max Niemeyer.

Gouws, R.H. 1999. Mediostructural Representation, Textual Condensation and User-orientation in the WAT X. Lexicographica: International Annual for Lexicography 15: 4-37.

Gouws, R.H. 2000. Doeltaalgerigtheid teenoor lemmagerigtheid in vertalende woordeboeke. Tydskrif vir Geesteswetenskappe 40(1): 39-47.

Gouws, R.H. 2001a. Der Einfluß der neueren Wörterbuchforschung auf einen neuen lexikographischen Gesamtprozeß und den lexikographischen Herstellungsprozeß. Lehr, A., M. Kammerer, K.-P. Konerding, A. Storrer, C. Thimm en W. Wolski (Reds.). 2001. Sprache im Alltag: Beiträge zu neuen Perspektiven in der Linguistik: 521-531. Berlyn/New York: Walter de Gruyter.

Gouws, R.H. 2001b. The Use of an Improved Access Structure in Dictionaries. Lexikos 11: 101-111.

Gouws, R.H. 2002. Niching as a Macrostructural Procedure. Lexikos 12: 133-158.

Gouws, R.H. 2003a. Towards the Formulation of a Metalexicographically Motivated Model for the National Lexicography Units in South Africa. Hartmann, R.R.K. (Red.). 2003. Lexicography: Critical Concepts. Volume I: Reference Works across Time, Space and Languages: 218-245. Londen/ New York: Routledge.

Gouws, R.H. 2003b. Aspekte van mikrostrukturele verskeidenheid en inkonsekwentheid in woordeboeke. Lexikos 13: 92-110.

Gouws, R.H. 2004a. Outer Texts in Bilingual Dictionaries. Lexikos 14: 67-88.

Gouws, R.H. 2004b. Monolingual and Bilingual Learners' Dictionaries. Lexikos 14: 264-274.

Gouws, R.H. 2006. Discipline, Dilemmas, Decisions and Data Distribution in the Planning and Compilation of Monolingual Dictionaries. Lexikos 16: 84-94.

Gouws, R.H. 2007a. Op pad na 'n nuwe woordeboektipologie. Southern African Linguistics and Applied Language Studies 25(3): 319-331.

Gouws, R.H. 2007b. A Transtextual Approach to Lexicographic Functions. Lexikos 17: 77-87.

Gouws, R.H. 2009a. Geïntegreerde woordeboekgebruik van vakwoordeboeke vir aanleerders. Lexikos 19: 72-93.

Gouws, R.H. 2009b. Sinuous Lemma Files in Printed Dictionaries: Access and Lexicographic Functions. Nielsen, S. en S. Tarp (Reds.). 2009. Lexicography in the 21st Century: In Honour of Henning Bergenholtz: 3-21. Amsterdam/Philadelphia: John Benjamins.

Gouws, R.H. 2010. Verryking as 'n leksikografiese prosedure. Stellenbosch Papers in Linguistics PLUS 40: 27-37.

Gouws, R.H., I. Feinauer en F. Ponelis. 1994. Basiswoordeboek van Afrikaans. Pretoria: J.L.van Schaik.

Gouws, R.H. en F.A. Ponelis. 1992. Issues in the Development of Afrikaans Lexicography. SuidAfrikaanse Tydskrifvir Taalkunde. Supplement 12. 
Gouws, R.H. en D.J. Prinsloo. 1997. Lemmatisation of Adjectives in Sepedi. Lexikos 7: 45-57.

Gouws, R.H. en D.J. Prinsloo. 2005a. Left-expanded Article Structures in Bantu with Special Reference to isiZulu and Sepedi. International Journal of Lexicography 18: 25-46.

Gouws, R.H. en D.J. Prinsloo. 2005b. Principles and Practice of South African Lexicography. Stellenbosch: SUN PReSS.

Gouws, R.H., M. Stark en L. Gouws. 2004. Nuwe woordeboek sonder grense. Kaapstad: Maskew Miller Longman.

Hartmann, R.R.K. 1983. Lexicography: Principles and Practice. Londen: Academic Press.

Hartmann, R.R.K. en G. James. 2006². Dictionary of Lexicography. Londen/New York: Routledge.

Hausmann, F.J. 1985. Lexikographie. Schwarze, C. en D. Wunderlich (Reds.). 1985. Handbuch der Lexikologie: 367-411. Königstein: Atheneum.

Louw, J.P. 1985. Lexicography and Translation. Kaapstad: Bybelvereniging van Suid-Afrika.

Louw, P. 2012. Oxford Afrikaanse Skoolwoordeboek. Kaapstad: Oxford University Press Southern Africa.

NLO = Bergenholtz, H., I. Cantell, R.V. Fjeld, D. Gundersen, J. Hilmar Jónsson en B. Svensén (Reds.). 1997. Nordisk leksikografisk ordbok. Oslo: Universitetsforlaget.

Odendal, F.F. 1961. Leksikografiese probleme II. Standpunte 15(1): 49-55.

Odendal, F.F. 1978. Die gesag van die woordeboek. Snyman, H. (Red.). 1978. Uit vier windstreke: 65-77. Kaapstad: Nasou.

Odendal, F.F. en R.H. Gouws. 20055. HAT: Verklarende Handwoordeboek van die Afrikaanse Taal. Kaapstad: Maskew Miller Longman.

Pálfi, L.-L. en B. Kristiansen. 2010. Review. International Journal of Lexicography 23(4): 491-502.

Wiegand, H.E. 1983. Ansätze zu einer allgemeinen Theorie der Lexikographie. Schildt, J. en D. Viehweger (Reds.).1983. Die Lexikographie von heute und das Wörterbuch von morgen: AnalysenProbleme-Vorschläge: 92-127. Linguistische Studien, Reihe A. Arbeitsberichte 109. Berlyn: Akademie der Wissenschaften der DDR, Zentralinstitut für Sprachwissenschaft.

Wiegand, H.E. 1984. On the Structure and Contents of a General Theory of Lexicography. Hartmann, R.R.K. (Red.). 1984. LEXeter '83 Proceedings. Papers from the International Conference on Lexicography at Exeter, 9-12 September 1983: 13-30. Lexicographica Series Maior 1. Tübingen: Max Niemeyer.

Wiegand, H.E. 1989. Aspekte der Makrostruktur im allgemeinen einsprachigen Wörterbuch: Alphabetische Anordnungsformen und ihre Probleme. Hausmann, F.J., O. Reichmann, H.E. Wiegand en L. Zgusta (Reds.). 1989. Wörterbücher. Ein internationales Handbuch zur Lexikographie/ Dictionaries. An International Encyclopedia of Lexicography/Dictionnaires. Encyclopédie internationale de lexicographie. Deel 1: 371-409. Handbücher zur Sprach- und Kommunikationswissenschaft 5.1. Berlyn/New York: De Gruyter.

Wiegand, H.E. 2006. Das Lern- und Konsultationswörterbuch. Ein neuer Fachwörterbuchtyp am Beispiel der Wörterbücher zur Sprach- und Kommunikationswissenschaft (WSK). Lexikos 16: 205-221.

Wiegand, H.E. 2007. Über Zugriffspfade in Printwörterbüchern. Ein Beitrag zur Schnittstelle von Benutzungshandlungen und Wörterbuchform. Lexikos 17: 180-211.

$\boldsymbol{W L} \boldsymbol{W} \boldsymbol{F}=$ Wiegand, H.E., M. Beißwenger, R.H. Gouws, M. Kammerer, A. Storrer en W. Wolski (Reds.). 2010. Wörterbuch zur Lexikographie und Wörterbuchforschung/Dictionary of Lexicography and Dictionary Research. Deel 1: A-C. Berlyn/New York: De Gruyter.

Zgusta, L. 1971. Manual of Lexicography. Janua Linguarum Series Maior 39. Den Haag/Parys: Mouton. 


\title{
Aperçu critique sur \\ Petit Dictionnaire Français-Gisira- Ngosi et éléments de verbes de Sœur Gabriel-Marie Lemoine
}

\author{
Fatima Tomba Moussavou ép. Ekwa Ebanéga, \\ Département des Sciences du Langage, Université Omar Bongo, \\ Libreville, Gabon (fatytm@hotmail.com.fr)
}

Résumé: Le Petit Dictionnaire Français-Gisira-Ngosi et éléments de verbes, compilé par la Sour Gabriel-Marie Lemoine, constitue un apport considérable dans la recherche en langue gisir. Ce travail présente quelques faiblesses sur le plan lexicographique. Le but de cet article consiste à identifier ces manquements et à proposer des voies qui pourraient améliorer la qualité de ce dictionnaire dans une édition future révisée. Des aspects tels que les pré-textes, la nomenclature (la macrostructure, la microstructure, la structure d'accès et la médiostructure) et les posttextes y sont discutés.

Mots-clés: GISIR, DICTIONNAIRE BILINGUE MONOSCOPAL, LANGUE BANTU, LEMMATISATION, ITEMS LEXICAUX, CRITIQUE DICTIONNAIRE, LEXICOGRAPHIE, PRÉ-TEXTES, NOMENCLATURE, MACROSTRUCTURE, MICROSTRUCTURE, STRUCTURE D'ACCES, MEDIOSTRUCTURE

\begin{abstract}
Critical Overview of Petit Dictionnaire Français-Gisira-Ngosi et éléments de verbes by Sister Gabriel-Marie Lemoine. The Dictionnaire Français-GisiraNgosi et éléments de verbes compiled by Sister Gabriel-Marie Lemoine is a significant contribution to the research on the Gisira language. This work shows some deficiencies in the lexicographic plan. The aim of this article is to identify these shortcomings and to propose ways which could improve the quality of this dictionary in a future revised edition. Aspects such as the front matter texts, the central list (the macrostructure, the microstructure, the access structure and the mediostructure) and the back matter texts are discussed.
\end{abstract}

Keywords: GISIRA, MONOSCOPAL BILINGUAL DICTIONARY, BANTU LANGUAGE, LEMMATISATION, LEXICAL ITEMS, DICTIONARY CRITICISM, LEXICOGRAPHY, PRE-TEXTS, NOMENCLATURE, MACROSTRUCTURE, MICROSTRUCTURE, ACCESS STRUCTURE, MEDIOSTRUCTURE

\section{Introduction}

Le gisir (ou gisira) ${ }^{1}$ est l'une des composante du groupe sira-punu (B40) de la branche linguistique bantu. Selon la classification de Guthrie (1953), la langue 
gisir est désignée sous le sigle B41. Les autres langues faisant partie du groupe B40 sont le yisangu (B42), le yipunu (B43), et le yilumbu (B44).

Selon Idiata (2007: 77-78), la langue gisir est parlée essentiellement au Gabon par les Bisir qui sont localisés dans la province de la Ngounié, principalement à Fougamou et à Mouila (la capitale de la province). On les rencontre aussi dans d'autres provinces de l'Ogooué Maritime, du Moyen Ogooué et de l'Estuaire à cause de la dynamique des populations. Démographiquement, le chiffre des locuteurs Bisir est approximativement de 30.000 à 40.000 individus. La langue gisir est constituée de deux dialectes: le gisir de Ngosi parlé à MandjiNdolu et dans ses environs et le gisir de Kamba parlé à Fougamou et le long de la route menant à Mouila. ${ }^{2}$

La langue gisir, toujours selon Idiata (2007: 78-79), dispose des travaux linguistiques sur le plan documentaire des travaux linguistiques principalement sur la phonologie et la tonologie (Blanchon 1988, 1990, 1999a, 1999b et 2000; Blanchon et Mouguiama 1997, Mouguiama 1993, Dodo-Bounguendza 1992; Koumba 1990; Mamfoumbi, Koumba et Ondo-Mébiame 1990), la morphosyntaxe (Mouguiama 1991), les glissements sémantiques du Proto-Bantu aux langues du groupe B40 (Mouguiama 1993 et 1998), l'ethnolinguistique (Mbou'l Monombi 2004; Mouguiama 1994). On peut aussi mentionner des travaux dans le domaine de la grammaire (Raponda-Walker 1936, 1998, 2008) et de la lexicographie (Lemoine 1994).

Le travail lexicographique intitulé Petit Dictionnaire Français-Gisira-Ngosi et éléments de verbes de Sœur Gabriel Lemoine (que nous abrégerons PDFGN), objet de notre étude, est un dictionnaire bilingue monoscopal dont la langue source est le français et la langue-cible l'un des dialectes du gisir mentionné cidessus le gisir de Ngosi. L'auteur du PDFGN, Sœur Gabriel-Marie Lemoine est une missionnaire catholique au Gabon. Elle appartient à la Congrégation Notre Dame de l'Immaculée-Conception (sœurs bleues) de Castres en France et a travaillé près de vingt-cinq ans en pays Ngosi. Le PDFGN est édité aux Éditions Multipress de Libreville en 1994 avec le Concours de la Mission de Coopération et d'Action Culturelle près de l'Ambassade de France au Gabon. Sœur Gabriel Lemoine a le mérite, comme la plupart des missionnaires de l'époque coloniale (cf. Nyangone Assam et Mavoungou 2000: 252-274, Mihindou 2001: 7-37, Tomba Moussavou 2011: 253, Ekwa Ebanéga 2007: 27-31), d'être la première à produire un dictionnaire en gisir de Ngosi 34 ans après l'indépendance du Gabon.

À l'instar des dictionnaires bilingues produits par les missionnaires, il a été conçu premièrement à des fins communicatives et évangéliques. Lemoine (1994: 2) déclare dans l'avant-propos de son ouvrage: «À la mission de MandjiNdolou ... j'aimais tout le monde, alors aidée de l'un de l'autre, je me suis intéressée à la langue gisira, j'ai traduit les 600 lectures et Évangiles des trois années liturgiques, puisque étant seule, sans prêtre, j'y faisais les célébrations ... Je me suis fait ce petit dictionnaire Français-Gisira-Ngosi ...» Aussi, le PDFGN-t-il est destiné aux jeunes élèves Bisir et autres locuteurs du gisir. Toujours dans l'avant-propos, Lemoine (1994: 2) affirme que: «Beaucoup de jeunes et anciens élèves m'ont dit: Ah! 
Ma sœur, fais - le imprimer ton dictionnaire, on en a besoin ... J'espère qu'il pourra servir et faire plaisir à tous mes nombreux amis gisira que je porte dans mon cour et dans ma prière.»

Le PDFGN compte 135 pages et contient \pm 2.382 entrées, il peut être divisé en trois parties: les pré-textes, la nomenclature et les posttextes. Selon Gouws (2001: 121) «les dictionnaires sont considérés comme des porteurs de textes qui contiennent une variété de textes ou des textes composés présentés dans les différentes sections. Pour faire face à cette variété de textes, les dictionnaires modernes affichent d'une manière particulière une architecture comprenant la nomenclature, c'est-à-dire le dictionnaire proprement parlé, les pré-textes et les posttextes. Les pré-textes constituent les textes précédant la nomenclature, les posttextes sont composés des textes suivant la nomenclature. Les pré-textes et les posttextes constituent les textes externes.» Le PDFGN est une production bilingue intéressante dans la mesure où il a l'avantage de respecter les normes de la lexicographie moderne concernant les composantes d'un dictionnaire. Toutefois l'on se demande si les textes de ces trois sections du PDFGN respectent aussi les principes de lexicographique moderne ou ils sont confinés dans l'approche traditionnelle des dictionnaires. Lemoine (1994: 2) elle-même atteste dans l'avant-propos de son ouvrage qu'on peut y trouver des «fautes». Quelles sont donc les carences lexicographiques du PDFGN?

L'intérêt de cet article est de proposer une critique du contenu des prétextes, de la nomenclature et ceux des posttextes pour découvrir si ces derniers répondent aux exigences de lexicographie moderne. Cette critique est utile dans la mesure où elle pourra servir à une révision du PDFGN. Landau (2001: 397) fait une distinction entre une réédition et une révision. Une réédition implique une mise à jour des données ou des entrées du dictionnaire en substituant les anciennes par les nouvelles, cet exercice se fait quelques années après la publication du dictionnaire alors qu'une révision consiste à un examen complet des précédentes éditions qui est nécessaire lorsqu'un dictionnaire a plus de dix ou quinze ans.

La critique investiguera respectivement les pré-textes, la nomenclature, autres structures du dictionnaire à savoir la structure d'accès, la médiostructure et les posttextes du PDFGN.

\section{Les pré-textes}

D'après Gouws (2001) les pré-textes constituent la section introductive du dictionnaire. Leur rôle est de fournir aux usagers du dictionnaire des informations et des explications concernant la structure du dictionnaire, l'organisation et les types de données du dictionnaire, les conventions et symboles utilisés dans le dictionnaire, etc. Al-Ajmi (2001: 61) propose une classification des types d'informations que l'on rencontre dans les pré-textes d'un dictionnaire bilingue. Il s'agit de: 
(a) Les usagers-cibles;

(b) Les raisons de la publication du dictionnaire;

(c) Les sources du dictionnaire;

(d) Le nombre des entrées (ou mots);

(e) Le plan du dictionnaire;

(f) Un mode d'emploi ou un guide de l'usager, texte obligatoire qui contient les instructions aux utilisateurs.

Cette liste n'est pas exhaustive, d'autres informations peuvent figurer dans les pré-textes. Par exemple, dans le Dictionnaire Yilumbu-Français de Mavoungou et Plumel (2010), on trouve un texte de remerciements exprimant la gratitude des auteurs à l'endroit des personnes et institutions qui les ont assistés dans la réalisation de travail faisant partie des pré-textes de ce dictionnaire. Gouws (2001, 2004) mentionne également qu'un sommaire peut également faire partie des pré-textes afin de permettre aux usagers d'accéder rapidement et facilement aux textes et sections composant le dictionnaire.

\subsection{Les pré-textes du PDFGN}

Pour ce qui est des pré-textes du PDFGN, ils comprennent trois textes:

(1) Un texte indiquant le titre de l'ouvrage Petit Dictionnaire Français-GisiraNgosi et éléments de verbes, la précision de l'aire géographique MandjiNdolu du dialecte gisir de Ngosi, le nom de l'auteur (Sœur Gabriel-Marie Lemoine), la congrégation ecclésiastique à laquelle l'auteur appartient en France (Congrégation Notre Dame de l'Immaculée-Conception (sœur bleues) de Castres (Tarn)), l'adresse de ladite congrégation à Libreville (Boîte postale 340), l'initiateur de la publication (la Mission de Coopération et d'Action Culturelle près de l'Ambassade de France au Gabon) (la page 1).

(2) Un avant-propos (page 3) et une photographie de l'auteur.

(3) Un texte de l'alphabet de la langue gisir (page 5).

(4) Des photographies illustrant la Mission Sainte-Croix et une vue générale de l'école construite en 1978 (page 4), la fabrication d'une pirogue dans la région de Mandji (page 6).

(1) Le texte indiquant le titre de l'ouvrage fournit des informations additives précises qui font référence à l'appartenance ecclésiastique de l'auteur et la localisation géographique du dialecte gisir de Ngosi à Mandji-Ndolu. Cette page scelle le PDFGN d'un sceau catholique et donne une colora- 
tion religieuse à l'ouvrage de Lemoine. Le texte (1) mentionne également l'assistance de la Mission de Coopération et d'Action Culturelle près de l'Ambassade de France au Gabon pour l'édition du PDFGN.

concerne l'avant-propos du PDFGN. Nous pouvons évaluer les informations contenues dans l'avant-propos du PDFGN à l'aide de la liste des informations d'Al-Ajmi (2001: 61) mentionnée ci-dessus.

(a) les usagers-cibles:

Ces derniers ne sont pas précisément spécifiés dans les pré-textes du PDFGN. Cependant, en parcourant soigneusement l'avant-propos de l'auteur, nous pouvons les citer. L'auteur déclare à ce titre: "Je connaissais presque chacun par son nom, enseignais la catéchèse à tous les enfants, environ 600 par an, soignant les plaies, les malades ... enseignant, soignant aussi les adultes, procurant à certains la joie du Baptême... J'aimais tout le monde, alors aidée de l'un et l'autre, je me suis intéressée à la langue gisira." Ses déclarations nous invitent à penser que le PDFGN est destiné à satisfaire les besoins des élèves, des adultes et à tous ceux qui veulent apprendre la langue gisir.

(b) les raisons ou les motivations qui ont poussé l'auteur à confectionner le PDFGN:

Ces raisons ou motivations sont d'abord d'ordre évangélique et communicatif. Ce dictionnaire a été conçu d'abord pour aider la missionnaire Sœur Gabriel-Marie Lemoine à communiquer avec les Bisir pour transmettre l'Évangile. Secondairement ce dictionnaire a été publié pour aider les jeunes Bisir à apprendre leur langue.

(c) les sources:

Selon Wiegand (1984: 140), tel que cité par Gouws (2001: 106), un dictionnaire peut se confectionner à partir de trois sources particulières: les sources primaires, les sources secondaires et les sources tertiaires. Les sources primaires sont tous les matériaux écrits reflétant des situations types de la communication. Les enregistrements de la langue orale font aussi partie des sources primaires. Les sources secondaires sont tous les dictionnaires consultés pendant la confection du dictionnaire.

Les sources primaires du PDFGN ne sont pas indiquées dans les pré-textes de l'ouvrage. Nous nous contenterons de l'allusion de l'auteur faite dans l'avant-propos, en ce qui concerne l'utilisation des documents. Nous imaginons simplement que l'ensemble des lectures et Évangiles consultés pour la réalisation de ce travail pourraient faire partie de ces documents que nous rangerions parmi les sources primaires.

Les sources secondaires et tertiaires ne sont pas présentées dans les pré-textes du PDFGN. L'auteur ne fait aucune mention de tous les dictionnaires (sources secondaires) utilisés pour la confection du diction- 
naire. Les sources tertiaires, constituées des monographies, des articles et des grammaires, ne sont pas prises en compte par l'auteur.

(d) le nombre d'entrées:

Aucune indication du nombre d'entrées n'est mentionnée dans la section introductive du PDFGN. Nous avons dû compter les entrées dans la nomenclature pour en déterminer le nombre approximatif de 2.382 entrées.

(e) le guide de l'usager:

Le texte obligatoire du guide de l'usager ne figure pas dans les pré-textes du PDFGN. Lemoine n'a pas pourvu pour les usagers un texte instructif les guidant pour une consultation des textes contenus dans son dictionnaire. Elle a manqué d'expliquer le système éditorial de son dictionnaire, ainsi que le traitement lexicographique des données incluses dans le dictionnaire. N'étant pas familier du système éditorial du dictionnaire, l'usager doit fournir un effort pour déchiffrer les données du PDFGN.

Selon Ondo-Mébiame et Ekwa Ebanéga (2011: 341), l'absence d'un guide de l'usager est l'un des points faibles relevé par certains auteurs sur les dictionnaires qui ont porté sur les langues gabonaises, et qui ont été produits par les missionnaires et les administrateurs coloniaux.

(3) Le texte relatif à l'alphabet offre des données sur l'orthographe du gisir ainsi que les données sur la prononciation. L'alphabet du gisir proposé par Lemoine (1994: 5) est composé de 10 voyelles, 14 consonnes et 5 lettres combinées. Nous présentons ci-dessous un tableau de l'alphabet du gisir:

\begin{tabular}{|c|c|}
\hline $\begin{array}{l}\text { Voyelles: tous les mots de la langue gisir } \\
\text { se terminent par une voyelle }\end{array}$ & Consonnes \\
\hline $\begin{array}{l}\text { a à la fin des mots se prononce à peine } \\
\text { e fermé comme bonté - jamais muet } \\
\text { è ouvert, comme dans le mot français mère } \\
\text { i ne forme jamais une syllabe distincte } \\
\text { î comme en français seulement à la fin } \\
\text { des mots dans le mot gisir bü̈ «miel» } \\
\text { o comme dans le mot français coco } \\
\text { ö ouvert comme dans le mot français } \\
\text { fort } \\
\text { u comme le latin ou } \\
\text { y comme dans le mot français yeux } \\
\text { w comme dans le mot français oui }\end{array}$ & $\begin{array}{l}\text { b comme dans le mot français bébé } \\
\mathbf{d} \text { comme dans le mot français dent } \\
\mathbf{j} \text { comme dans le mot français jeune } \\
\mathbf{g} \text { comme dans le mot français guerre } \\
\mathbf{k} \text { remplace la lettre } c \text { du français comme } \\
\text { dans le mot capitaine } \\
\mathbf{1} \text { dans le mot français long } \\
\mathbf{m} \text { devant la consonne } b \text {, } f \text {, est un son } \\
\text { atténué par exemple dans le mot gisir } \\
\text { mbumba «arc-en-ciel» } \\
\mathbf{n} \text { a se prononce plus ou moins atténué } \\
\text { devant } d, t, g \text {, par exemple dans le mot } \\
\text { gisir ndagu «maison» } \\
\mathbf{n} \text { se prononce comme dans le mot } \\
\text { français agneau }\end{array}$ \\
\hline
\end{tabular}




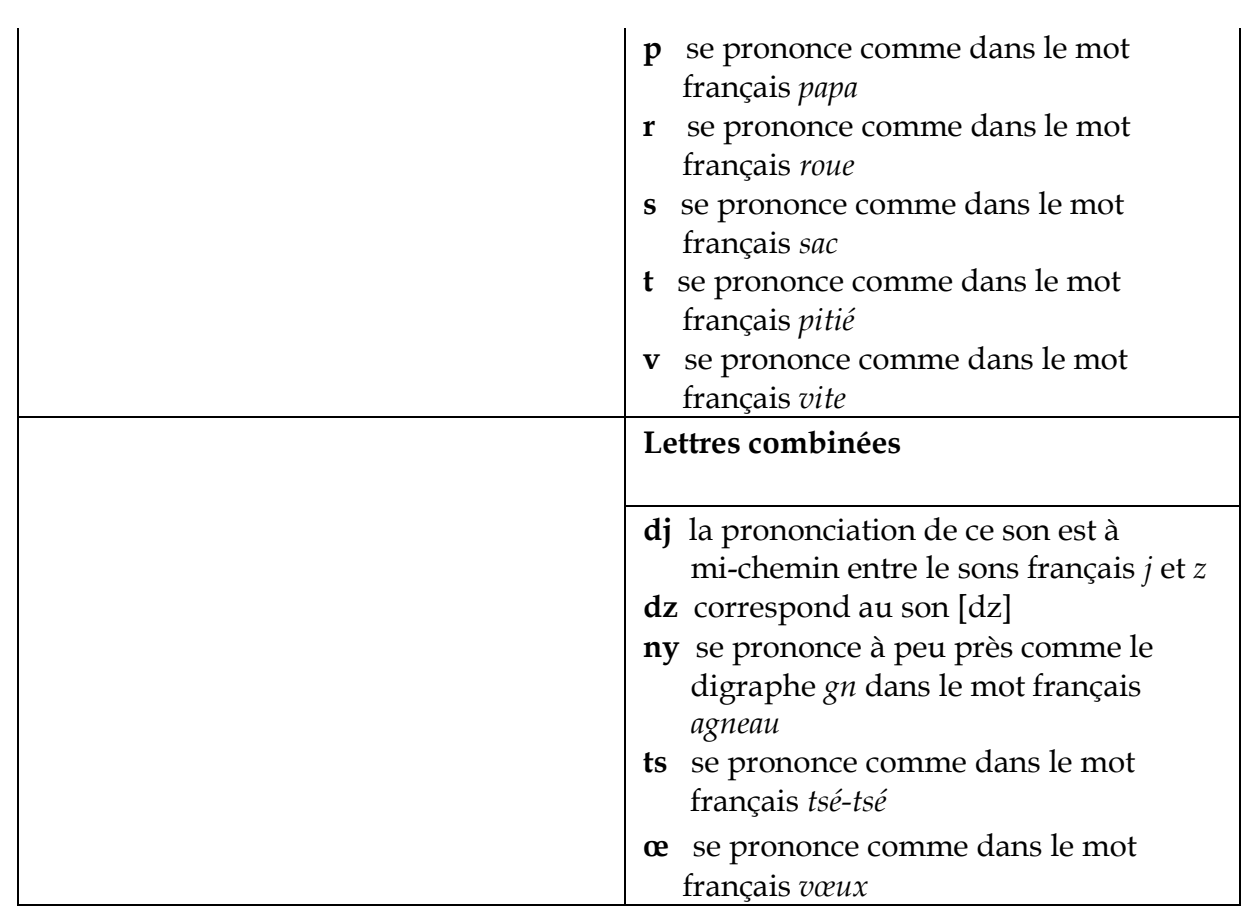

L'alphabet du PDFGN qui a l'avantage d'etre simple et accessible aux usagers emprunte néanmoins les caractères latins. Cet alphabet est calqué sur celui du français comme ceux proposés par les autres missionnaires catholiques français à l'exemple de Galley (1964: 561-562) et Bonneau (1956) respectivement pour la langue fang (A 75) et pour la langue yipunu (B 43).

(4) concerne les photographies des pré-textes; ils illustrent les lieux où l'auteur a exercé comme missionnaire.

\section{La nomenclature}

La nomenclature se compose d'une série de schèmes d'articles et chaque schème d'articles inclut une variété d'articles qui fonctionnent comme des textes autonomes (Gouws 1999: 41). La nomenclature est également appelée la liste centrale en ce sens qu'elle constitue la principale composante du dictionnaire. C'est à l'intérieur de celle-ci qu'a lieu le traitement lexicographique. De même, la nomenclature est constituée de deux principales composantes, à savoir: la macrostructure et la microstructure. La macrostructure est la principale composante structurale de la nomenclature. Elle regroupe l'ensemble des items lexicaux retenus comme lemmes du dictionnaire. La microstructure, quant à elle, est la somme ordonnée de manière linéaire, des types d'informations apparaissant à la suite du lemme (Hausmann et Wiegand 1989: 340). 


\subsection{La macrostructure du PDFGN}

\subsubsection{Lemmatisation des items lexicaux}

En examinant l'avant-propos du PDFGN, nous imaginons que la majorité des mots français traduits en gisir est produite par les élèves, les jeunes et les adultes qui aimeraient apprendre leur langue.

Les lemmes (ou mots) sont présentés dans l'ordre alphabétique (de A à Y).

Cependant, nous relevons l'absence des items commençant par K, X, Y, Z et W. Dans les pré-textes du PDFGN, l'auteur ne fait aucune mention de la raison qui justifie cette insuffisance; ce qui laisse l'usager perplexe et pourrait se demander si ces manquements sont dus au niveau de la collecte des mots du français (ou du gisir) ou à l'absence des termes commençant par les lettres $K, X$, $\mathrm{Y}, \mathrm{Z}$ et $\mathrm{W}$ (ou qui n'ont pas d'équivalents en gisir).

En outre, l'auteur a manqué de mentionner dans les pré-textes du PDFGN, les critères à partir desquels, les items lexicaux ont été lemmatisés. Les verbes par exemple se présentent sous leur forme infinitive. Cette présentation relève de la tradition française de lemmatisation des verbes. Nous remarquons cependant que la lemmatisation des verbes pronominaux du PDFGN n'est pas régulière. Parfois, cette dernière rompt l'arrangement alphabétique des lemmes. À titre d'illustration, considérons les listes des lemmes suivants sous les lettres A et P:

\begin{tabular}{|l|}
\hline A \\
s'abaisser \\
abattre \\
abriter \\
s'abriter \\
$\ldots$. \\
âgé \\
s'agenouiller \\
P \\
promettre \\
prononcer \\
prophète \\
proposer (se)
\end{tabular}

Les verbes s'abaisser, abattre, abriter, s'abriter, ... s'agenouiller et l'adjectif âgé brisent l'arrangement alphabétique des lemmes; par contre les lemmes promettre, prononcer, prophète, proposer (se) respectent l'ordre alphabétique. Le verbe proposer est suivi du pronom réfléchi (se). C'est l'arrangement le plus utilisé dans les dictionnaires de langue française.

L'auteur suit également la tradition française de lemmatisation des noms. Celle-ci consiste à inclure les noms selon le genre et le nombre (masculin- 
singulier). L'auteur du PDFGN choisit de traiter non seulement les noms simples mais aussi les noms composés.

\subsubsection{Lemmatisation des noms composés}

L'auteur a choisi de traiter les noms composés comme lemmes. Béjoint (1999: 82) fait une distinction entre les noms composés de types " $X Y$ ", "X Y"ou "X-Y". L'auteur présente les noms composés de type "X Y" (foulard de tête, page 52) et "X-Y" (pique-bœuf, page 83). Ces observations nous invitent à penser que le traitement des noms composés n'est pas appliqué de façon systématique dans le PDFGN. L'usager pourrait aussi se demander comment les groupes de mots sont inclus dans le PDFGN? Les groupes de mots sont également traités dans l'ouvrage comme lemmes.

\subsubsection{Lemmatisation des groupes de mots}

L'auteur a choisi de traiter les groupes de mots comme lemmes. Cette stratégie de lemmatisation n'est pas inconnue. Elle est similaire à celle utilisée par certains dictionnaires comme le South African Dictionary Junior Secondary et le South African Oxford School Dictionary qui leur donnent un statut sous-lemmatique. Prenons par exemple les cas de supporter la faim et surpasser la dose (page 102).

L'auteur aurait mieux fait de les lemmatiser sous supporter et surpasser, comme dans les deux dictionnaires précités. Dans l'exemple qui suit, nous présentons le traitement modifié des lemmes supporter la faim et surpasser la dose. Ce traitement est fait à partir des lemmes supporter et surpasser:

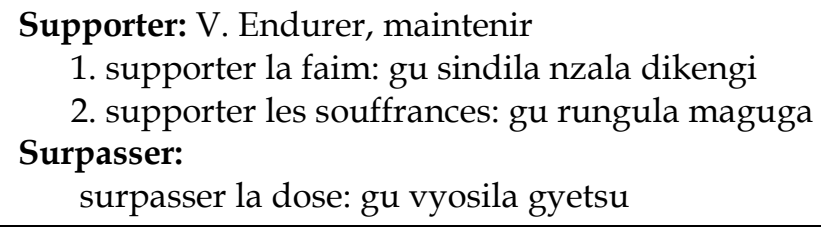

Dans les exemples mentionnés précédemment, les articles modifiés des entrées supporter et surpasser sont considérés comme des lemmes principaux. Ils donnent accès à d'autres types d'entrées qui sont des sous-lemmes.

\subsubsection{Lemmatisation des phrases}

L'auteur a également choisi d'inclure les phrases comme lemmes, le reproche fait à l'auteur concernant le traitement des groupes de mots est aussi valable pour le traitement des phrases. L'auteur aurait fait mieux de sous-lemmatiser des phrases sous des lemmes principaux. Prenons le cas de l'article modifié quoique tu fasses, je serai là (page 89) présenté comme suit: 
quoique: bien que, encore que.

quoique tu fasses, je serai là.

Dans l'article modifié du lemme quoique tu fasses, je serai là ci-dessus, le lemme quoique est traité comme lemme principal et donne accès au souslemme quoique tu fasses, je serai là plutôt que constituer deux lemmes distincts.

\subsection{La microstructure du PDFGN}

La microstructure est la somme ordonnée de manière linéaire, des types d'informations apparaissant à la suite du lemme (Hausmann et Wiegand 1989: 340). Elle constitue la deuxième composante structurale de la nomenclature. Un élément macrostructurel combiné avec son traitement microstructurel constitue un article de dictionnaire (Gouws 2001: 123).

Les données contenues dans la microstructure peuvent se subdiviser en commentaire sur la forme et en commentaire sur le sens. Le commentaire sur la forme selon Gouws et Prinsloo (2005: 119) renvoie à l'orthographe, la prononciation, les données morphologiques, les parties du discours. Le commentaire sur le sens renvoie à ce qui est dit à propos de la signification du lemme. Par exemple les définitions, les équivalents, les exemples sont du domaine du commentaire du sens. Avant de parler des différents types de données qui constituent la microstructure, nous discuterons d'abord les entrées que l'on trouve dans le PDFGN.

\subsubsection{Types d'entrées}

Quand on examine attentivement la microstructure ou lorsqu'on programme la microstructure du dictionnaire, il est important de connaître les types d'entrées incluses comme des éléments microstructurels. Le terme entrée désigne tout constituant d'un article de dictionnaire. Nous en montrons quelques aspects dans le PDFGN. Considérons l'article suivant du lemme éclair (page 43):

$$
\begin{aligned}
& \text { éclair: dusyèmu-tsyèmu } \\
& \text { il y a des éclairs: gu koe tsyèmu } \\
& \text { l'orage fait des éclairs: kaki a ka va tsyèmu }
\end{aligned}
$$

L'article du lemme éclair nous montre que dusyèmu-tsyèmu est une entrée; c'est l'équivalent du mot éclair. Il y a des éclairs et l'orage fait des éclairs sont également des entrées; c'est le contexte d'utilisation du mot éclair.

Parmi les types d'entrées utilisées dans le PDFGN, l'auteur utilise les marqueurs structurels pour indiquer un item ou rendre compte des différents types de données contenues dans l'article de l'ouvrage. Il utilise deux types de marqueurs structurels: 
- les marqueurs structurels typographiques; et

- les marqueurs structurels non-typographiques.

Les marqueurs structurels du PDFGN feront l'objet d'une discussion plus approfondie dans la section 3 ci-dessous concernant la structure d'accès.

\subsubsection{Le commentaire sur la forme du PDFGN}

Le commentaire sur la forme selon Gouws et Prinsloo (2005: 119) renvoie à l'orthographe, à la prononciation et aux parties du discours.

\subsubsection{Les données orthographiques}

Les données orthographiques sont fournies dans le texte faisant référence à l'alphabet du gisir. Nous rappelons pour mémoire que ce texte a été exposé dans la section consacrée aux pré-textes du PDFGN (voir section 2.1 de cet arti-

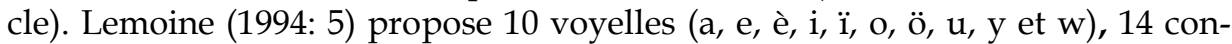
sonnes (b, d, j, g, k, l, m, n, n, p, r, s, t et v) et 5 lettres combinées (dj, dz, ny, ts et $œ)$ pour la langue gisir. Aussi elle indique que tous les mots du gisir se terminent par une voyelle.

L'alphabet du PDFGN qui a l'avantage d'être simple et accessible aux usagers, emprunte néanmoins les caractères latins. Raponda-Walker (1998: 7) trouve une explication à cet emprunt dans le fait suivant: «les idiomes gabonais n'ayant jamais été écrits, n'ont pas d'alphabets propres. C'est pourquoi, dès le début de la colonisation, tous ceux qui ont voulu les écrire ont eu recours à l'alphabet de leur pays d'origine ... les missionnaires catholiques français ... ont employé l'alphabet français. Mais dans ces alphabets européens, certaines lettres représentent des sons que l'on ne rencontre point en langage africain. D'autre part, les idiomes africains ont quelquefois des sons qu'il n'est pas possible de rendre avec les seules lettres d'un alphabet européen.»

\subsubsection{Les données sur la prononciation}

Les données sur la prononciation ne font pas partie du traitement microstructurel dans le PDFGN. Toutefois, on note que les données sur la prononciation figurent dans les pré-textes du PDFGN. Ces données figurent dans le texte de l'alphabet du gisir. Tout comme les données sur l'orthographe, ces indications sur la prononciation ont déjà été énoncées dans la section des prétextes (voir section 2.1 de cet article).

Le texte de l'alphabet donne des indications sur la prononciation des voyelles, des consonnes et des lettres combinées du gisir mentionnés en supra. Chaque lettre du gisir est suivie d'une indication sur la prononciation et du son similaire français. Ces prononciations sont également illustrées par des exem- 
ples de mots français. Ces derniers sont présentés en écriture orthographique du français.

\subsubsection{Les données morphologiques}

Dans le PDFGN, le traitement des données morphologiques n'est pas appliqué de façon systématique. On relève en parcourant le texte certaines abréviations (m., f., inv.). L'auteur a d'ailleurs manqué d'expliquer les quelques abréviations traitées dans les pré-textes du PDFGN. L'usager doit simplement imaginer que les données morphologiques en question pourraient être respectivement le masculin, le féminin, et l'invariable. L'auteur aurait gagné en traitant toutes les données morphologiques (nom, verbe, adjectif, adverbe, singulier, pluriel, etc.) et en les représentant par leurs abréviations respectives (n., v., adj., adv., sg., pl., etc.). Prenons le cas des articles modifiés des lemmes champ, chant (page 27) et couverture (page 34).

Chant: n., (sg) dwimbu, (pl) nymbu

Champ: n., (sg) gyamba, (pl) byamba

Couverture: n., (sg) gifu, (pl) bifu

Une fois de plus, l'auteur a manqué d'indiquer et d'expliquer des données morphologiques dans les pré-textes. Le gisir est une langue bantu, par conséquent une langue à préfixes. Dans tout substantif (nom) on distingue un radical invariable et un préfixe variable.

Par exemple les mots comme mu-kongu: montagne, colline; mikongu: montagnes, collines sont formés de $m u$ qui est le préfixe du singulier, mi le préfixe du pluriel et le radical -kongu.

De telles données morphologiques devraient être présentées dans les prétextes du PDFGN. Pour plus de détails sur les données morphologiques en gisir, voir Raponda-Walker (2008: 183-236).

\subsubsection{Le commentaire sur le sens du PDFGN}

Selon Gouws et Prinsloo (2005: 125), le commentaire sur la forme renvoie à la sémantique et la pragmatique.

\subsubsection{Les données sémantiques du PDFGN}

L'ouvrage PDFGN contient des données sémantiques à l'exemple des équivalents (en caractère roman normal), les exemples ou contextes d'utilisation du mot (en italique), mais elles ne sont pas présentées de façon systématique. À l'observation, nous notons l'absence des marqueurs structurels (chiffres) indiquant les exemples ou les différents contextes d'utilisation du mot. Ce qui 
aurait pu aider l'usager à avoir un accès à ces données. Considérons l'article modifié du lemme debout:

\section{debout: matèli \\ 1. être debout: gu ba matèli \\ 2. mettre debout: gu rétsema}

Dans l'article du lemme ci-dessus, les marqueurs structurels (chiffres) $(1,2)$ indiquent les différents exemples ou contextes d'utilisation du mot, suivis de leurs équivalents respectifs. Une discussion relative aux marqueurs structurels indiquant les données sémantiques sera donnée dans la section 4 ci-dessous consacrée à la structure d'accès.

\subsubsection{Les données pragmatiques du PDFGN}

Les données pragmatiques renvoient aux données extralinguistiques contenues dans la microstructure. L'auteur du PDFGN inclut les illustrations dans la nomenclature.

Pour ce qui est des illustrations dans la nomenclature du PDFGN, nous notons des insuffisances dans le traitement de celle-ci. Prenons le cas de l'illustration de la page 109.

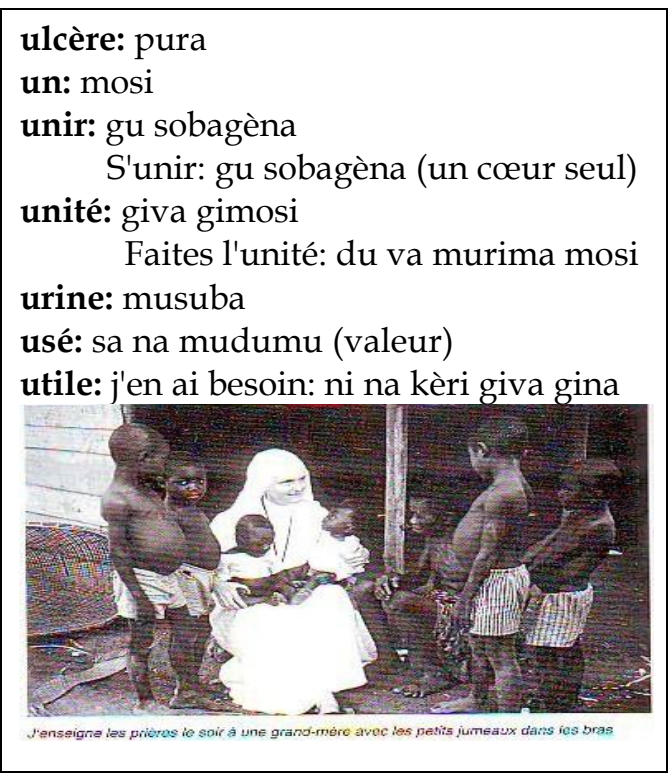

À l'examen, l'illustration n'est pas adressée à aucun des lemmes (mots) qu'elle suit. Le but de l'illustration est de compléter les informations quand l'intelligibilité du mot pose problème. Cependant, l'illustration ci-dessus n'a pas sa place 
dans le PDFGN. L'on se demande quel est le rôle de celle-ci dans ce dictionnaire. Le but du dictionnaire (y compris les informations qu'il contient) est de satisfaire les besoins des usagers-cibles. L'illustration en question manque son objectif, elle exprime la vie de l'auteur et ses aménités avec la population.

\section{La structure d'accès du PDFGN}

La structure d'accès est le chemin de recherche suivi par un utilisateur pour accéder à un lemme déterminé ou une catégorie des données. Une distinction est faite entre la structure d'accès externe et la structure d'accès interne (cf. Gouws 2001: 122-123).

Dans la section 3.2.1 précédente consacrée aux entrées, il a été dit que l'auteur utilise les marqueurs structurels pour spécifier différents types de données contenues dans l'article de l'ouvrage. Dans le PDFGN, nous distinguons deux types:

- la structure d'accès externe; et

- la structure d'accès interne.

La structure d'accès externe est le chemin de recherche guidant l'utilisateur vers le lemme approprié. La structure d'accès interne est le chemin interne de recherche d'articles guidant l'usager vers l'entrée spécifique des données (cf. Gouws 2001: 122-123).

À l'observation, la structure d'accès externe du PDFGN est constituée par: les entrées situées sur la couverture dont le titre de l'ouvrage, un dessin illustrant la mission Sainte Croix de Mandji-Ndolu catholique de la Congrégation, la désinence de l'éditeur (Multipress de Libreville) et la nomenclature alphabétique de $\mathrm{A}$ à $\mathrm{Y}$.

La structure d'accès interne se caractérise par l'utilisation des conventions lexicographiques qui guident l'usager à travers le chemin de sa recherche. Ces conventions comprennent deux types de marqueurs structurels:

- les marqueurs structurels typographiques; et

- les marqueurs structurels non-typographiques.

Les marqueurs structurels typographiques sont les suivants:

- le gras pour exposer la représentation du lemme;

- la police de caractère roman normal pour indiquer l'équivalent du mot, les synonymes, l'étiquette dans l'article du lemme fertile pris dans le PDFGN: [fertile: (terre) ...], où terre est l'étiquette en italique;

- $\quad$ l'italique pour exposer les exemples ou contextes d'utilisation du mot. 
Ensuite, l'auteur utilise les marqueurs structurels non-typographiques:

- les parenthèses ( ) indiquent la partie du discours [cf. fatiguer (se) ...], les synonymes [cf. doctrine (enseignement) ...], les étiquettes, le genre du mot [cf. foi (la), ...], le suffixe du mot [cf. facile(ment) ...], l'auxiliaire [cf. fâché (être) ...];

- le signe (:) placé immédiatement après le lemme indique le traitement microstructurel du mot [cf. espoir: gitu];

- $\quad$ le signe (-) sert à indiquer le mot composé [cf. épine: dusyendi-tsyendi], les synonymes du mot [cf. s'enfuir: gu rina-gu guenda mbangu-gu bomba].

Ce que l'on remarque des marqueurs structurels, c'est que l'auteur use d'une multiple utilisation de la police de caractère roman normal pour indiquer l'équivalent du mot, les synonymes et l'étiquette. Nous notons les exemples de ce type en ce qui concerne l'utilisation des parenthèses ( ) pour la partie du discours, les étiquettes, le genre du mot, le suffixe du mot et l'auxiliaire et l'emploi du signe (-) pour le mot composé, les synonymes du mot. L'auteur aurait gagné en ayant recours à un seul signe ou principe de présentation spécifique à chaque donnée du PDFGN.

\section{La médiostructure du PDFGN}

Gouws (1999: 43) définit la médiostructure comme le système de renvoi qui guide l'usager à partir d'une position de référence vers une adresse. Une distinction est faite entre renvoi interne et renvoi externe.

Dans un renvoi interne, le lexicographe guide l'usager vers une autre donnée à l'intérieur de l'article traité afin d'y trouver des informations supplémentaires. Par contre, dans un renvoi externe, l'usager est orienté vers un autre article, ou alors, vers un autre texte du dictionnaire (pré-textes et posttextes) où il est susceptible de trouver un complément d'informations.

Dans PDFGN, les renvois ne sont pas appliqués assurément. Prenons le cas du traitement du lemme voir [cf. voir: ... gulaba ... (page 112) ]; il reçoit un traitement lexicographique supplémentaire dans l'un des textes des posttextes du PDFGN consacré à la conjugaison du verbe voir. Il en est de même pour les traitements des lemmes voir, parler, aimer, manger, boire, entendre. Considérons les articles modifiés des lemmes parler, aimer, manger, entendre:

$$
\begin{aligned}
& \text { parler: v.3. guambila ... } \\
& \text { aimer: v.4. guronda ... } \\
& \text { manger: v.5. gulamba ... } \\
& \text { entendre: v.6. gulu ... }
\end{aligned}
$$


Dans les exemples ci-dessus, nous notons la forme abrégée du verbe (v.) et les chiffres $(1,2, \ldots 6)$ indiquent les différentes conjugaisons des verbes. L'auteur aurait donc mieux fait d'utiliser un marqueur de renvoi et les entrées $(1,2, \ldots 6)$ indiquant la conjugaison du verbe dans les posttextes pour que ces données soient plus accessibles à l'usager.

\section{Les posttextes}

Les posttextes constituent la section suivant la nomenclature du dictionnaire. C'est dans celle-ci que les rédacteurs indiquent les données additives telles les abréviations, les symboles, les unités de mesure, les noms géographiques.

Dans un environnement multilingue, Gouws (2002: 72) considère que les dictionnaires sont non seulement des réservoirs de connaissance linguistique, mais également des sources de données pragmatiques et culturelles. De ce fait les données culturelles peuvent être traitées dans les textes externes.

\subsection{Les posttextes du DFGN}

Les posttextes du DFGN comprennent six textes:

(1) la monnaie et les nombres des choses et personnes en gisir de la page 115 à la page 117 .

(2) les verbes en gisir de la page 119 à la page 128.

(3) les danses des Bisir à la page 129 à la page 130.

(4) un texte des prières en gisir.

(5) un chant du Collège pour les élèves de 6e, 5e et 4e du collège de Mandji de 1986 à 1992 à la page 133.

(6) l'histoire de la Mission à la page 135.

Le texte (1) qui décrit la numération pour compter principalement l'argent et secondairement les choses et les personnes en gisir peut être considéré comme un texte à la fois linguistique et culturel parce qu'il propose des données intéressantes de la numération de la langue gisir, et aussi parce qu'il fournit des données d'un aspect de la culture économique des Bisir.

Le texte (2) est un texte linguistique qui présente des informations grammaticales de la conjugaison des verbes en gisir. Des données grammaticales des auxiliaires français être et avoir, des verbes simples (parler, aimer, manger, boire, préparer à manger, entendre, et mourir), des verbes pronominaux (se soigner, se reposer), des verbes qui se construisent avec un pronom ou complément (mentir à quelqu'un, appeler quelqu'un) sont fournies. Ces verbes sont conjugués en gisir au temps et modes de l'indicatif, le subjonctif et l'impératif, aux formes affirmatives et négatives. 
Ce texte est non intégré à la nomenclature du PDFGN, c'est-a-dire qu'il complète la nomenclature et l'on n'en a pas besoin pour accéder à l'information présentée dans les articles de la nomenclature. Selon Gouws (2001: 123) un texte externe est dit intégré lorsqu'il fonctionne en liaison avec la nomenclature et l'on en a besoin pour assurer une récupération optimale et complète des informations.

Un système de renvois peut mettre en relation les posttextes et la nomenclature d'un dictionnaire. Un tel système de renvoi qui lie la nomenclature et les posttextes du PDFGN a été proposé dans la section consacrée à la médiostructure du PDFGN (voir section 5 de cet article).

Le texte (3) est un texte culturel qui présente les différents types de danses des Bisir. Lemoine en dénombre onze: Bwiti, Mwiri, Nyemba, Mugulu, Mabandzi, Girina, Bilumbu, Mavassa, Divanda-Mavanda, Mukwèlengi et Ntsimba.

À l'observation, nous remarquons que seul le terme Bwiti a été inclus dans la liste centrale du PDFGN. Pourquoi l'auteur a-t-elle choisi d'inclure le terme Bwiti dans la liste centrale et pas les autres termes culturels? À cette question, nous ne trouvons aucune explication. L'auteur aurait mieux fait d'inclure dans la liste centrale tous les termes des danses des Bisir.

Enfin les textes (4), (5) et (6) des posttextes sont des textes d'ordre religieux. Comme dans les pré-textes, ces textes montrent l'empreinte catholique de l'auteur du PDFGN. Le texte (4) est un texte religieux des prières en gisir nous laisse entrevoir que le PDFGN est un dictionnaire pour les usagers catholiques, car la compréhension de ce texte nécessite une connaissance préalable des prières catholiques. Les textes (5) et (6) sont respectivement des archives religieuses concernant un chant des élèves du Collège de la Mission SainteCroix et de l'histoire de la Mission.

\section{Conclusion}

Le PDFGN est une production bilingue monoscopale mettant en jeu le français et le gisir Ngosi. L'auteur du PDFGN qui n'est pas lexicographe mérite bien d'être félicité pour avoir mis à la disposition des Bisir cet outil pratique et facile d'utilisation. Le PDFGN qui est composé des pré-textes, d'une nomenclature et des posttextes, fournit aux usagers des informations utiles sur la langue et la culture des Bisir Ngosi. Cependant, les textes du PDFGN présentent des lacunes qui méritent d'être améliorées dans le cadre d'une révision vu que le dit dictionnaire a déjà plus de dix ans. Cette révision n'adoptera non plus l'approche traditionnelle des dictionnaires, mais aura plutôt pour fondement les principes de lexicographique moderne.

$\mathrm{Au}$ niveau des pré-textes, le PDFGN révisé doit pouvoir présenter des informations précises concernant le nombre d'entrées, les motivations sous-tendant la production du dictionnaire, les utilisateurs-cible. Le texte obligatoire du guide de l'usager jusque-là inexistant, doit nécessairement faire partie des prétextes du PDFGN révisé. 


\section{Aperçu graphique du DFGN}

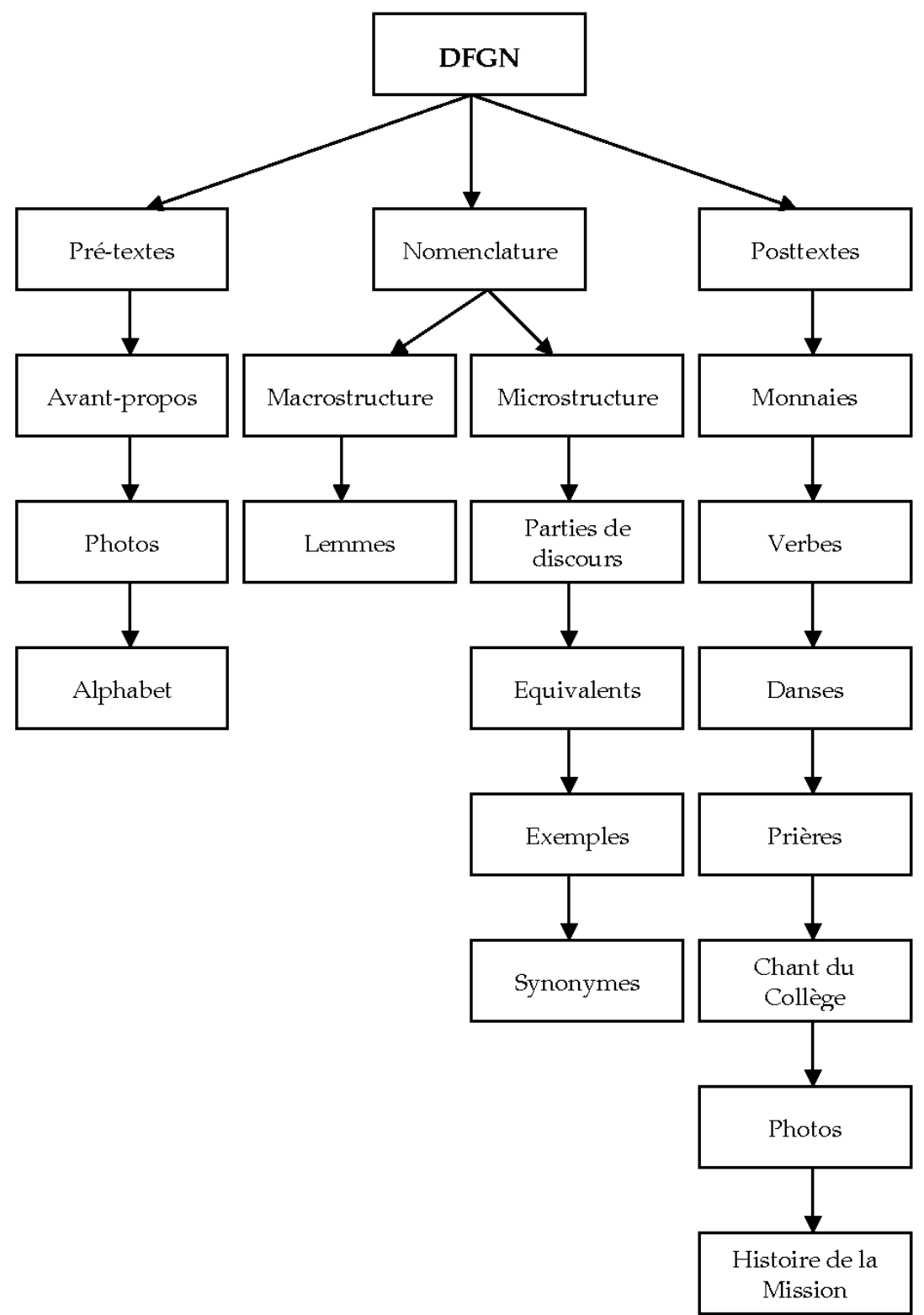

Les pré-textes doivent pouvoir offrir aux usagers des données additives sur la langue gisir. Des textes linguistiques sur l'orthographe, la prononciation, la morphologie et la grammaire du gisir seront nécessaire pour la compréhension des textes gisir. Le texte sur l'orthographe présentera un alphabet propre au 
gisir. Ce dernier qui ne sera plus calqué sur celui du français. L'alphabet orthographique du gisir proposé tiendra compte de deux principes: la simplicité et la bi-univocité (un son distinctif doit comprendre à un seul symbole et réciproquement).

La macrostructure du PDFGN révisée devra inclure non seulement les lemmes, mais également les sous-lemmes. La microstructure devra fournir des données morphologiques, syntaxiques, sémantiques et pragmatiques. Les données sur la prononciation devront aussi être présentées. La structure et l'ordre établi dans lesquels son présentés ces données microstructurales seront clairement élucidées dans les pré-textes du PDFGN révisé. Le PDFGN révisé devra également prévoir un système de renvois qui mettra en liaison les données de la microstructure et les posttextes.

Au niveau des posttextes, l'ajout d'une table de matière indiquant les différents textes du dictionnaire et les pages correspondantes sera d'une grande utilité pour la consultation et l'accès rapide du PDFGN. L'intégration d'un petit lexique Gisira-Ngosi-Français dans les posttextes pourrait également élever le PDFGN révisé au rang de dictionnaire bilingue biscopal et polyaccessible.

\section{Notes}

1. Selon Raponda-Walker (2008: 175) la langue gisir est appelée improprement eshira.

2. Les points de vue divergent quant au nombre de dialectes de la langue gisir. Si Mouguiama (1993) et Idiata (2007) s'accordent pour en dénombrer deux: le gisir de Ngosi parlé à MandjiNdolu et dans ses environs et le gisir de Kamba parlé à Fougamou et le long de la route menant à Mouila; Malékou (2007: 4) quant à lui, s'éloigne de cette proposition et souligne que le gisir de Ngosi et le gisir de Kamba sont plutôt deux sous-dialectes ou sous-variantes d'un dialecte gisir de Banda en aval du fleuve Ngounié. Selon Malekou (2007: 4) la langue gisir serait également constituée de deux autres dialectes: le gisir de Tandu, le gisir du canton tandou, en amont du fleuve Ngounié et le gisir de Ngubi de la lagune Iguéla dans l'OgoouéMaritime.

Les variantes dialectales suivantes le gisir de Kamba, le gisir de Tandu et le gisir de Ngosi et leurs localisations géographiques respectives avaient déjà été identifiées par Lémoine (1994) sous le traitement lexicographique du lemme race (page 91) ci-dessous:

Race: dilongu-ma
Gisira:
Gisira kamba: Mouila
Gisira gi tandu: Fougamou
Gisira gi ngosi: Mandji




\section{Références bibliographiques}

\section{Dictionnaires}

Bonneau, J. 1956. Grammaire pounoue et lexique pounou-français. Mémoires de l'Institut d'Études Centrafricaines. Brazzaville (A.E.F): Montpellier.

Galley, S. 1964. Dictionnaire Fang-Français et Français-Fang, suivi d'une grammaire Fang. Neuchâtel: Henri Messeiller.

Hawkins, J.M. 1996. The South African Oxford School Dictionary. Cape Town: Oxford University Press.

Lemoine, G.-M. 1994. Petit Dictionnaire Français-Gisira-Ngosi et éléments de verbes. Libreville: Multipress-Gabon.

Mavoungou, P.A et B. Plumel. 2010. Dictionnaire Yilumbu-Français. Libreville: Raponda-Walker.

Nesbitt, R. 1996. Chambers-Macmillan South African Dictionary Junior Secondary. Manzini: Macmillan Boleswa Publishers.

\section{Autres littératures}

Al-Ajmi, H. 2001. The Role of the Introductory Matter in Bilingual Dictionaries of English and Arabic. Lexikos 11: 60-70.

Béjoint, H. 1999. Compound Nouns in Learners' Dictionaries. Herbst, T. et K. Popp (Éds.). The Perfect Learners' Dictionary (?): 81-99. Lexicographica Series Maior 95. Tübingen: Max Niemeyer.

Blanchon, J.A. 1988. Relèvement tonals en eshira et en massago: première approche d'une tonologie comparée du groupe B40. Pholia 3: 71-86.

Blanchon, J.A. 1990. The Great *HL Split in Bantu Group B40. Pholia 5: 17-30.

Blanchon, J.A. 1999a. Douze études sur les langues du Gabon et du Congo-Brazzaville. Munich: Lincom Europa.

Blanchon, J.A. 1999b. Tone Cases in Bantu Group B40. Creissels, D. et J.A. Blanchon. 1999. Issues in Bantu Tonology: 37-82. Cologne: Rüdiger Köppe.

Blanchon, J.A. 2000. Bipartition des noms syllabiques réflexes du type tonal *BH dans la zone B40 et H12. Journal of African Languages 21 (2): 123-134.

Blanchon, J.A. et L. Mouguiama. 1997. Les thèmes à initiale vocalique et la tonalité du verbe conjugué en eshira de Mandji (Gabon). Linguistique africaine 18: 5-49.

Dodo-Bounguendza, E. 1992. Esquisse phonologique et morphologique du gisira, langue bantoue (B 41) du Gabon. Thèse de doctorat. Bruxelles: Université Libre de Bruxelles.

Ekwa Ebanéga, G.-M. 2007. Microstructural Programme for Dictionaries in Fang. Thèse de doctorat non publiée. Stellenbosch: Université de Stellenbosch.

Gouws, R.H. 1999. Towards the Formulation of a Theoretical Model for the Compilation of Dictionaries for the National Lexicography Units of South Africa. Report Submitted to the Pan South African Language Board. Stellenbosch: Université de Stellenbosch.

Gouws, R.H. 2001. Lexicographic Training: Approaches and Topics/Formation lexicographique: approches et thèmes. Emejulu, J.D. (Éd.). 2001: Éléments de lexicographie gabonaise. Tome I: 58134. New York: Jimacs-Hillman Publishers.

Gouws, R.H. 2002. Using a Frame Structure to Accommodate Cultural Data/L'utilisation d'un cadre structurel pour le traitement des données culturelles. Emejulu J.D. (Éd.). 2001: Éléments de lexicographie gabonaise. Tome II: 54-87. New York: Jimacs-Hillman Publishers. 
Gouws, R.H. 2004. The Outer Texts in Bilingual Dictionaries. Lexikos 14: 67-88.

Gouws, R.H. et D.J. Prinsloo. 2005. Principles and Practice of South African Lexicography. Stellenbosch: SUN PReSS.

Guthrie, M. 1953. The Bantu Languages of Western Equatorial Africa. Oxford: Oxford University Press.

Hausmann, F.J. et H.E. Wiegand. 1989. Component Parts and Structures of General Monolingual Dictionaries: A Survey. Hausmann, F.J. et al. (Éds.). 1989-1991. Wörterbücher. Ein Internationales Handbuch zur Lexikographie/Dictionaries. An International Encyclopedia of Lexicography/Dictionnaires. Encyclopédie internationale de lexicographie: 328-360. Berlin: Walter de Gruyter.

Idiata, F.D. 2007. Les langues du Gabon: 77-79. Paris: L'Harmattan.

Koumba, V. 1990. Essai de phonologie du gisir (langue bantu du Gabon B41). Mémoire de maîtrise. Libreville: Université Omar Bongo.

Landau, S.I. 2001. Dictionaries: The Art and Craft of Lexicography. Cambridge: Cambridge University Press.

Malékou, P.E. 2007. Les anthroponymes et les toponymes gisir: Proposition d'un modèle de dictionnaire. Mémoire de maîtrise. Libreville: Université Omar Bongo.

Mamfoumbi, M., V. Koumba et P. Ondo-Mébiame. 1990. Gisira. Revue Gabonaise des Sciences de l'Homme 2: 203-209.

Mbou'l Monombi, N.C. 2004. Étude ethnolinguistique des devises gisir. Mémoire de maîtrise. Libreville: Université Omar Bongo.

Mihindou, G.-R. 2001. Apports des missionnaires à la lexicographie gabonaise: dictionnaires bilingues Fang-Français/Français-Fang; Français-Yipounou/Yipounou-Français; Français-Mpongwé. Emejulu, J.D. (Éd.). 2001. Éléments de lexicographie gabonaise. Tome I: 26-35. New York: JimacsHillman Publishers.

Mouguiama, L. 1991. Étude morphosyntaxique du constituant nominal en ngosi, dialecte du gisira. Mémoire de maîtrise. Libreville: Université Omar Bongo.

Mouguiama, L. 1993. Éléments de phonologie diachronique du gisir, correspondances Proto-Bantu-gisir et lexiques spécialisés. Mémoire de D.E.A. Lyon: Université Lyon 2.

Mouguiama, L. 1994. Perception de la maladie chez les eshira (Gabon). Pholia 9: 121-130.

Mouguiama, L. 1998. Description des mécanismes de glissement sémantique en bantou du nord-ouest. Thèse de doctorat. Lyon: Université Lumière Lyon 2.

Nyangone Assam, B. et P.A. Mavoungou. 2000. Lexicography in Gabon: A Survey. Lexikos 10: 252-274.

Ondo-Mébiame, P. et G.-M. Ekwa Ebanéga. 2011. Regard critique sur On Est Ensemble: 852 mots pour comprendre le français du Gabon. Lexikos 21: 337-358.

Raponda-Walker, A. 1936. Éléments de grammaire gisira. Libreville: Mission Sainte Marie.

Raponda-Walker, A. 1998 Éléments de grammaire gisira. Libreville: Éditions Raponda-Walker.

Raponda-Walker, A. 2008. Éléments de grammaire gisira. Raponda-Walker, A. 2008. Éléments de Grammaire des Langues Gabonaises (Ghetsogho, Ebongwé, Fang, Gisira): 180-238. Libreville: Éditions Raponda-Walker.

Tomba Moussavou, F. 2011. Early Lexicographic Works in Gabon: The Grammaire Pounoue et Lexique pounou-français as Case Study. ALAC. (Afrique, Langues et Cultures). Revue Scientique Internationale de la Chaire UNESCO Interculturalité: 253-271. Libreville: CUI-Gabon.

Wiegand, H.E. 1984. On the Structure and Contents of a General Theory of Lexicography. Hartmann, R.R.K. (Éd.). 1984. LEXeter '83 Proceedings: Papers from the International Conference on Lexicography at Exeter, 9-12 September 1983: 13-28. Tübingen: Max Niemeyer. 


\title{
Kriteria vir woordeboek- werkboeke in Afrikaans
}

\author{
Michele F. van der Merwe, Departement Kurrikulumstudies, \\ Universiteit Stellenbosch, Stellenbosch, Suid-Afrika \\ (michelevdm@sun.ac.za)
}

Opsomming: Hierdie artikel is ' $n$ kritiese evaluering van woordeboekwerkboeke in Afrikaans. Die woordeboekwerkboeke word gekategoriseer en hul teikengebruikers word geïdentifiseer en beskryf. Die artikel probeer om op 'n sistematiese wyse die verskillende werkboeke van die grootste skoolwoordeboekuitgewers in Suid-Afrika, naamlik Maskew Miller Longman, Oxford, Pearson Education en Pharos te ondersoek en die inligting wat hulle aanbied, te kategoriseer, te analiseer en te vergelyk. Stark (1990: 1) het sekere riglyne vir woordeboekwerkboeke binne die teorie van woordeboekstrukture opgestel en hulle word ondersoek. Die teorie van woordeboekfunksies word op woordeboekwerkboeke in hierdie artikel toegepas. Die inhoud van woordeboekwerkboeke word beskryf in die konteks van leksikografiese funksies van woordeboeke en op grond hiervan word aangevoer dat 'n nuwer indeling van die inhoud van woordeboekwerkboeke gebruik kan word.

Sleutelwoorde: AFRIKAANSE OPVOEDKUNDIGE LEKSIKOGRAFIE, SKOOLWOORDEBOEKE, AANLEERDERSWOORDEBOEKE, WOORDEBOEKWERKBOEKE, WOORDEBOEKFUNKSIES, KOGNITIEFGERIGTE FUNKSIES, KOMMUNIKATIEFGERIGTE FUNKSIES, ALFABETISERING, NASLAANVAARDIGHEDE, TEIKENGEBRUIKER, DIDAKTIESE LEIDING

\begin{abstract}
Criteria for Dictionary Workbooks in Afrikaans. This article is a critical evaluation of dictionary workbooks in Afrikaans. The dictionary workbooks are categorized and their target users are identified and described. The article tries to examine in a systematic way the different workbooks of the biggest school dictionary publishers in South Africa, namely Maskew Miller Longman, Oxford, Pearson Education and Pharos and to categorize, analyze and compare the information they provide. Stark (1990: 1) compiled certain guidelines for dictionary workbooks within the theory of dictionary structures and they are investigated. The theory of dictionary functions are applied with regard to dictionary workbooks in this article. The content of dictionary workbooks is described in the context of lexicographical functions of dictionaries and on this ground it is argued that a newer classification of the contents of dictionary workbooks could be made.
\end{abstract}

Keywords: AFRIKAANS PEDAGOGICAL LEXICOGRAPHY, SCHOOL DICTIONARIES, LEARNER'S DICTIONARIES, DICTIONARY WORKBOOKS, DICTIONARY FUNCTIONS, COGNITIVE FUNCTIONS, COMMUNICATIVE FUNCTIONS, ALPHABETIZATION, REFERENCE SKILLS, TARGET USER, DIDACTIC GUIDANCE 


\section{Inleiding}

Skoolwoordeboeke en aanleerderswoordeboeke maak deel uit van die opvoedkundige leksikografie. Verskeie werkboeke of aktiwiteitsboeke vir die gebruik by woordeboeke is in Afrikaans gepubliseer. Woordeboekwerkboeke het 'n belangrike opvoedkundige rol te speel in sowel skole as in die samelewing, aangesien hulle oor probleemoplossende potensiaal beskik. Werkboeke vir die gebruik by woordeboeke kan as 'n belangrike hulpmiddel vir die onderwyser in die taalkundeklas beskou word. Dit kan as opvoedkundige hulpmiddel vir die ontsluiting van inligting in woordeboeke en woordeboekterminologie gebruik word.

Dit is noodsaaklik dat teikengebruikers van woordeboekwerkboeke gespesifiseer word ten einde hulp en leiding aan ouers en onderwysers te verskaf. Teikengebruikers se vaardighede kan verhoog word met behulp van woordeboekwerkboeke indien voldoende didaktiese leiding in die werkboeke verskaf word. Dit het ook 'n belangrike ondersteuningsrol in die verhoging van leerders se taalvlakke te vervul.

Die doel van die artikel is om teikengebruikers van woordeboekwerkboeke te identifiseer en te beskryf. Die inhoud van woordeboekwerkboeke word uiteengesit en geanaliseer. Met 'n literatuurstudie kon die skrywer vasstel dat daar nie resente internasionale navorsing beskikbaar is met woordeboekwerkboeke as onderwerp nie en allermins in die Suid-Afrikaanse en Afrikaanse konteks. Daar word geprobeer om 'n nuwer en relevanter indeling vir woordeboekwerkboeke te vind. Dit word binne die teorie van leksikografiese funksies beskryf. 'n Skematiese vergelyking van die inhoud van woordeboekwerkboeke in terme van woordeboekfunksies word aangebied.

\section{Terminologiese kwessies}

Stark (1990: 1) gebruik die allesomvattende term woordeboekwerkboek om na handboeke, handleidings en gebruikersgidse te verwys wat daarop aanspraak maak dat hulle instruksies of aanwysings aan aanleerders van ' $\mathrm{n}$ taal bied om woordeboeke te gebruik. In die artikel word die term werkboek gebruik, soos in die titels van die nagevorste materiaal gereflekteer, byvoorbeeld Nuwe Woordeboek sonder grense Werkboek, Senior fase Graad 7-9 (voortaan afgekort as WSGW), Pharos Leerderboek by die Aanleerderswoordeboek (voortaan afgekort as PLA), HAT Aktiwiteite en Speletjies, bedoel om gebruikers vertroud te maak met die HAT Afrikaanse Skoolwoordeboek (voortaan afgekort as HATS), Pharos Leerderboek by die Skoolwoordeboek (voortaan afgekort as PLS) en Oxford Tweetalige Skoolwoordeboek Werkboek (voortaan afgekort as OTSW).

Die WSGW-reeks bestaan uit werkboeke vir graad 4, graad 5, graad 6, en graad 7-9, maar vir die doel van die artikel word op laasgenoemde, naamlik die werkboek vir die senior fase gefokus. HATS het werkbladsye, blokkiesraaisels en woordsoekraaisels beskikbaar wat ook gratis by www.hat-longman.co.za afgelaai 
kan word en waaroor die gebruiker op die titelblad van HATS ingelig word. PLA en PLS verskyn as aparte boeke om onderskeidelik saam met Aanleerderswoordeboek en Skoolwoordeboek te gebruik. Hulle bevat aktiwiteite in Afrikaans en Engels wat as taalpaar in die woordeboeke figureer. OTSW verskyn as werkboek om saam met Oxford Afrikaans-Engels Skoolwoordeboek te gebruik, maar daar is ook 'n klein gedeelte met woordeboekaktiwiteite binne die Oxford Afrikaans-Engels Skoolwoordeboek. Aktiwiteite in Afrikaans en Engels word verskaf.

Volgens Stark (1990: 1) kan die meeste werkboeke, opgestel om saam met woordeboeke gebruik te word, in drie algemene kategorieë ingedeel word, naamlik (1) eentalige aanleerderswoordeboeke; (2) eentalige woordeboeke vir moedertaalsprekers en (3) tweetalige woordeboeke. Vanweë die groter rol wat gebruikersbehoeftes in die leksikografie speel, vind daar ontwikkeling in woordeboektipologie plaas wat implikasies vir Stark se indeling het. Gouws en Tarp (2008: 66) wys daarop dat daar terminologieverwarring in Suid-Afrika, maar ook in ander lande ten opsigte van die terme skoolwoordeboek en aanleerderswoordeboek is. Die term aanleerderswoordeboek verwys gewoonlik na 'n woordeboek wat gebruikers ondersteun in die aanleer van 'n taal wat nie die verwagte gebruiker se eerste taal is nie, terwyl die term skoolwoordeboek verwys na 'n woordeboek wat in die skool gebruik word, gewoonlik om die gebruikaanwending en verbetering van skoolkinders se eerste taal (of moedertaal) te bevorder (Sien Gouws 2001). Gevolglik word dus verwag dat skoolwoordeboeke eentalige woordeboeke sal wees. Dit is egter nie die geval met Oxford AfrikaansEngels Skoolwoordeboek en Pharos Skoolwoordeboek nie. Beide woordeboeke is tweetalige woordeboeke met Afrikaans en Engels as taalpaar. Gouws en Tarp (2008: 66) beskou Oxford Afrikaans-Engels Skoolwoordeboek vanweë die tweetalige aard daarvan as 'n aanleerderswoordeboek, en dus by implikasie ook Pharos Skoolwoordeboek. Beide kwalifiseer as aanleerderswoordeboeke op grond daarvan dat hulle gerig is op die verbetering van die niehuistaal van gebruikers. Gouws (2006: 73) argumenteer dat woordeboeke eerder volgens funksie as volgens die tradisionele indeling benoem moet word. Dit val nie binne die bestek van dié artikel om die tradisionele tipologiese indeling van die woordeboeke te beredeneer nie, aangesien die artikel gerig is op die woordeboeke se werkboeke. Die implikasie is egter dat Stark se indeling nie sonder meer so aanvaar en gebruik kan word nie. Werkboeke kan ook eerder volgens funksie as volgens die tradisionele indeling benoem word.

Pharos gebruik die term leerderboek en dit dra by tot terminologieverwarring, want in die Suid-Afrikaanse skoolkonteks verwys die term leerder/learner na 'n leerling of 'n skolier en nie noodwendig na 'n aanleerder van 'n taal nie. 'n Leerder/learner kan dus ook na 'n moedertaalspreker verwys wat 'n woordeboek raadpleeg om meer oor sy moedertaal/huistaal uit te vind. Ook is dit moeilik om Aanleerderswoordeboek volgens die tradisionele woordeboektipologie te klassifiseer, aangesien dit 'n tweetalige aanleerderswoordeboek is met Afrikaans en Engels as taalpaar. 
'n Nuwer en funksioneler indeling van werkboeke kan daarin bestaan om slegs twee kategorieë werkboeke te onderskei, en hulle op grond van die taalvaardigheidsvlakke van die teikengroepe te kategoriseer. Hiervolgens word tussen 'n werkboek vir moedertaalsprekers (huistaalsprekers) en 'n werkboek vir taalaanleerders onderskei. Eersgenoemde fokus dan op die verbetering van moedertaalsprekers se taalvlakke en laasgenoemde op die ondersteuning van aanleerders se taalvlakke.

Die bestek van die werkboeke wat vir die doel van die artikel ondersoek word, ressorteer dus onder die volgende twee kategorieë:

'n Werkboek vir taalaanleerders: Nuwe Woordeboek sonder grense is 'n eentalige woordeboek vir aanleerders van Afrikaans. Pharos Aanleerderswoordeboek is 'n tweetalige woordeboek vir aanleerders van Afrikaans en Engels. Oxford Afrikaans-Engels Skoolwoordeboek en Pharos Skoolwoordeboek is tweetalige skoolwoordeboeke, maar kwalifiseer as aanleerderswoordeboeke.

'n Werkboek vir moedertaalsprekers: HAT Afrikaanse Skoolwoordeboek is 'n eentalige woordeboek vir moedertaalsprekers van Afrikaans.

\section{Die teikengebruikers van werkboeke}

Volgens Gouws (2006: 73) word daar in gebruikersgedrewe leksikografie van die standpunt uitgegaan dat die gebruiker, die gebruikersbehoeftes, die gebruikersituasie en die gebruiksituasie bepalend is vir die leksikografiese aanbod. Dit sluit aan by die funksieteorie, vgl. Gouws en Prinsloo (2005: 6, 7).

Werkboeke word opgestel om saam met sekere woordeboeke gebruik te word, maar die vraag kan tereg gevra word wie die teikengebruikers van die betrokke boeke is. In 'n gebruikersgedrewe leksikografie word die gebruiker en sy behoeftes vooropgestel en woordeboeke word volgens die behoeftes van die gebruiker opgestel. In 'n gebruikersgedrewe leksikografiese omgewing behoort werkboeke ook teikengebruikers se behoeftes voorop te stel. Word werkboeke opgestel met 'n spesifieke teikengroep in gedagte en word dit so in die werkboek gespesifiseer? Is die werkboek byvoorbeeld op die kind of die onderwyser gerig? Is die werkboek saamgestel om in die klas gebruik te word of is dit vir selfstudie deur die gebruiker?

Vervolgens word die teikengebruikers van die verskillende werkboeke geïdentifiseer, soos deur die betrokke werkboek omskryf:

Volgens die omskrywing van die teikengebruiker in WSGW is dit duidelik dat die woordeboek gerig is op die aanleerders van Afrikaans. Vergelyk die aanhaling uit Nuwe Woordeboek sonder grense (Voorwoord vir die onderwyser): "Die woordeboek is saamgestel vir leerders in graad 4 tot 12 wat addisioneletaalsprekers van Afrikaans is. Leerders van die Eerste en Tweede Addisionele Taal kan hierdie woordeboek met vrug regdeur al die skoolfases gebruik. Die Nuwe Woordeboek sonder grense en die gepaardgaande Nuwe Woordeboek sonder grense Werkboek is ontwikkel vir leerders van Afrikaans as Eerste en Tweede 
Addisionele Taal. Dit is geskoei op die HNKV vir Tale, en kan saam met die Nuwe Afrikaans sonder grense-handboekreeks gebruik word."

'n Teikengebruiker word nie vir OTSW gespesifiseer nie. Die woordeboek is baie vaag daaroor en die uitgewers vermeld onder Woordeboekkenmerke, p. iv: "Hierdie woordeboek is ontwerp om jou te help om beter Afrikaans, indien jy 'n leerder van Afrikaans is, of beter Engels, indien jy 'n leerder van Engels is, te skryf en praat." Die afleiding kan gemaak word dat die woordeboek geskik is vir aanleerders van beide Afrikaans en Engels, maar die gebruiker weet nie of dit vir hoër- of laerskoolleerders of dalk beide is nie.

PLS se teikengebruikers word gedefinieer deurdat in die Voorwoord genoem word dat die werkboek vir hoërskoolleerders is, nl. "Leerderboek is spesiaal opgestel om saam met Pharos se Skoolwoordeboek gebruik te word, wat geskik is vir leerders in graad 8 tot 12." Aangesien Skoolwoordeboek, alhoewel tweetalig, 'n skoolwoordeboek is, kan die afleiding gemaak word dat die teikengroep leerders is met Afrikaans Huistaal wat na Engels vertaal en leerders met Engels Huistaal wat na Afrikaans vertaal.

Volgens PLA is die Afrikaanse aktiwiteite veral gemik op Engelse leerders wat Afrikaans as eerste addisionele taal moet aanleer. Daarom word leeruitkomste en assesseringstandaarde vir die Afrikaanse aktiwiteite vir graad 5, 6, 7 en 8 ten opsigte van Afrikaans Eerste Addisionele Taal en Engels Huistaal verskaf. Die Engelse aktiwiteite, daarenteen, is toegespits op Afrikaanse leerders wat Engels as eerste addisionele taal aanleer. Om dié rede word leeruitkomste en assesseringstandaarde vir die Engelse aktiwiteite vir graad 5, 6, 7 en 8 ten opsigte van Afrikaans Huistaal en Engels Eerste Addisionele Taal gegee.

By die aktiwiteite van HATS op die internet word geen melding van teikengebruikers gemaak nie. In die voorwoord van HATS word die volgende egter genoem: "Die HAT Afrikaanse Skoolwoordeboek is in die eerste plek vir Afrikaans Huistaal- en Afrikaans Eerste Addisionele Taalleerders geskryf. Die woordeboek voldoen aan die vereistes van die Nasionale Kurrikulum, maar hoewel die keuse van trefwoorde, die formulering van definisies en die seleksie van voorbeeldsinne en -frases op die skool- en leefwêreld van tieners afgestem is, is oormatige vereenvoudiging vermy sodat elke gebruiker van Afrikaans, nie net leerders nie, die woordeboek met vrug kan gebruik." Die afleiding kan dus gemaak word dat die aktiwiteite vir gebruikers van HATS opgestel is.

\section{Die inhoud van werkboeke}

Stark (1990: 34, 35) beskryf die inhoud van verskeie werkboeke, eerder as om voor te stel hoe die inhoud daarvan verbeter kan word. Alhoewel die meeste werkboeke taal- of taalkundig-georiënteerd is, word van verskillende organisatoriese beginsels ten opsigte van die inhoud gebruik gemaak. Stark (1990: 35) verdeel die inhoudsanalise in ses gebiede, naamlik: (1) die woordeboekmakrostruktuur en formele aspekte van woordeboekkonsultasie, (2) die woordeboek 
en skryf, (3) die woordeboek en praat, (4) die woordeboek en grammatikale inligting, (5) die woordeboek en semantiese inligting, (6) ander woordeboekverbandhoudende werkboekaktiwiteite en -voorstelle, (6.1) studentgeoriënteerde temas en (6.2) onderwysergeoriënteerde temas.

Geen van die werkboeke wat vir hierdie artikel ondersoek is, verwys na (3) die woordeboek en praat of na (6.1) studentgeoriënteerde temas en (6.2) onderwysergeoriënteerde temas nie. Afdeling (6) (ander woordeboekverbandhoudende werkboekaktiwiteite en -voorstelle) is baie vaag en word as ' $n$ algemene kategorie beskou waar inligting wat nêrens anders inpas nie, bloot geberg kan word. Stark werk binne die teorie van woordeboekstrukture en nie volgens die teorie van leksikografiese funksies nie.

Binne die teorie van leksikografiese funksies onderskei Gouws (2006: 75) tussen twee hooftipes leksikografiese funksies, naamlik kognitiefgerigte en kommunikatiefgerigte funksies. Die doel van kognitiefgerigte funksies is om die gebruiker ondersteuning te verleen met algemene kulturele en ensiklopediese data, data oor spesifieke vakgebiede en data oor taal. Kommunikatiefgerigte funksies ondersteun gebruikers met die probleemoplossing aangaande teksproduksie in die moeder- en vreemde taal, teksresepsie in die moeder- en vreemde taal, asook die vertaling van tekste uit die moeder- in die vreemde taal en omgekeerd. Tarp (2008) voeg 'n verdere woordeboekfunksie by, naamlik 'n operasionele wat na 'n addisionele, onderliggende funksie van woordeboeke verwys om gebruikers te help om woordeboeke te gebruik en om woordeboekvaardighede te ontwikkel.

'n Taalgerigte aktiwiteit, byvoorbeeld praat, lees en vertaling, is gewoonlik die motivering vir die gebruik van 'n woordeboek. Tarp en Gouws (2010: 470) onderskei sewe woordeboekfunksies noodsaaklik in skoolwoordeboeke vir huistaalleerders: kommunikatiewe funksies relevant vir taalkunde, naamlik om leerders met teksresepsie (geskrewe of mondeling) en met teksproduksie (geskrewe of mondeling) te help; kognitiewe funksies relevant vir taalkunde, byvoorbeeld om leerders met grammatika en woordeskat te help, en om hulle meer oor die wêreld te leer; kognitiewe funksies nie relevant vir taalkunde nie, naamlik om leerders meer oor die etimologie van woorde te leer; en operasionele funksies nie relevant vir taalkunde nie, byvoorbeeld om leerders te help om woordeboekvaardighede aan te leer.

Die teorie van leksikografiese funksies het 'n groot rol te speel in die kategorisering en analise van inligting in werkboeke, soos in die volgende afdeling geïllustreer word.

\section{5. 'n Analise van werkboeke}

Vervolgens word 'n analise van die aktiwiteite en die gepastheid al dan nie daarvan vir die sogenaamde teikengebruiker van die werkboek gedoen. Daar word deurgaans na die funksies van woordeboeke verwys. 


\subsection{Alfabetisering}

Alfabetisering, d.w.s kennis van die alfabet en alfabetiese volgorde, is 'n voorvereiste vir 'n woordeboekgebruiker, hetsy 'n leerder of 'n aanleerder om suksesvolle toegang tot 'n woordeboekartikel te bewerkstellig. Dit verwys na die operasionele funksie van woordeboeke, naamlik om leerders te help om woordeboekvaardighede te ontwikkel. Alfabetisering kan as 'n pre-operasionele funksie beskou word, aangesien kennis van die alfabet die gebruiker toegang tot die ontsluiting van 'n woordeboek se funksies gee.

NWSG beskik oor drie take om alfabetisering te oefen. In die eerste taak word die alfabet as geheel geoefen, waar aanleerders instruksies verskaf word om letters alfabeties te rangskik. In twee verdere take word aanleerders geleer om ag te slaan op onderskeidelik die tweede, derde, vierde en vyfde letter van woorde indien die vorige letters dieselfde is. Hulle word byvoorbeeld gevra om $g$-woorde, $k l$-woorde en str-woorde alfabeties te rangskik. Daar is 'n groot sprong tussen die moeilikheidsgraad van die take en aanleerders kan dit moeilik vind om die tweede en derde take uit te voer, aangesien dit in 'n taal is wat aangeleer word. Dit word wel van seniorfase-leerders verwag om alfabetiese ordening volledig te bemeester het. Twee metodes word gebruik om die take meer kindervriendelik en interessant te maak, naamlik om 'n afdruk van 'n rekenaartoetsbord te verskaf en te vra dat die letters alfabeties gerangskik word. Daar word ook van enkele illustrasies gebruik gemaak waarvan die woorde alfabeties rangskik moet word. Die illustrasie van die skilpad wat deurgaans in die woordeboek aangewend word om addisionele inligting te verskaf, word ook in die werkboek gebruik wat kontinuïteit tussen die werkboek en woordeboek bewerkstellig. Vir 'n taalaanleerder is dit 'n toepaslike gebruik.

OTSW bevat twee oefeninge oor alfabetisering. Die benadering wat gevolg word, is meer kreatief en kindervriendelik, aangesien leerders nie slegs instruksies ontvang om woorde alfabeties te rangskik nie. Denkbeeldige leerders word byvoorbeeld in twee spanne verdeel, naamlik die A-M-span en die N-Z-span en gebruikers moet hulle name in alfabetiese volgorde verskaf. Daar is illustrasies van die denkbeeldige leerders waarmee gebruikers hulle dus kan identifiseer. ' $n$ Tweede en baie kreatiewe oefening word verskaf wanneer leerders ' $n$ alfabetkode moet voltooi met alfabetletters wat 'n sekere numeriese waarde het. Indien die alfabetkode voltooi is, kan dit gebruik word om 'n geheime boodskap te ontsyfer. Die oefening pas by senior laerskoolleerders se kognitiewe ontwikkelingsvaardighede en bied geleentheid vir stimulerende denke. Vir taalaanleerders van Afrikaans en Engels kan die oefening egter problematies wees. ' $n$ Variasie op die algemene oefening van alfabetisering vind plaas wanneer leerders gevra word om vanne wat met die letter $\mathrm{D}$ begin, alfabeties te rangskik. Die ses vanne wat verskaf word, het telkens 'n klinker as tweede letter en leerders word daarop gewys om spesifiek die klinkers in ag te neem. Voorletters word by vanne gevoeg om die moeilikheidsgraad van die oefening 
te verhoog. Die oefening besit opvoedkundige waarde, aangesien dit 'n praktiese toepassing is soortgelyk aan dié waar leerders 'n nommer in 'n telefoongids moet opsoek. Sodoende word aan leerders gedemonstreer dat naslaanvaardighede nie net beperk is tot die gebruik van 'n woordeboek nie.

'n Verdere voorbeeld van praktiese toepassing van naslaanvaardighede is die gebruik van die indeks van ' $n$ atlas met die opdrag om name van Suid-Afrikaanse dorpe te soek en in alfabetiese volgorde te plaas. Leerders kan so besef dat die kennis van alfabetiese volgorde 'n voorvereiste vir effektiewe naslaan is, ook by die gebruik van ander naslaanbronne as woordeboeke.

PLA bevat twee aktiwiteite rakende alfabetisering waarvan die eerste ' $n$ voorbereidende aktiwiteit vir die daaropvolgende is. Aanleerders moet die antwoorde op vrae verskaf en dan telkens die eerste letter van elk van die antwoorde neerskryf. Dié letters moet dan gealfabetiseer word. So 'n oefening wat hoërorde-denke van die gebruiker verg, is ' $n$ interessanter manier as om net bloot te versoek dat letters gealfabetiseer word. Daarna word die gealfabetiseerde letters gebruik om 'n tekening te maak wat in 'n diagram verskuil is. Dit getuig van ' $\mathrm{n}$ interessante en kreatiewe manier om met die alfabet om te gaan. So 'n visuele voorstelling is gepas vir graad 5-8-aanleerders se ontwikkelingsvlak.

PLS beskik oor twee alfabetiseringsaktiwiteite. In die eerste aktiwiteit word 20 trefwoorde wat met die letters $m, n$ en $o$ begin, verskaf en leerders word versoek om hulle alfabeties te rangskik, soortgelyk aan 'n aktiwiteit in HATS. Leerders word daarop gewys dat 'n mens ook na die derde en vierde letters van 'n woord moet kyk om vas te stel waar 'n woord alfabeties inpas. Dit is meer uitdagend as die HATS-aktiwiteit, aangesien trefwoorde met hoofletters en selfs twee homonieme, naamlik muil ${ }^{1}$ en muil $^{2}$ verskaf word. Dit is die enigste werkboek wat aan homonimiese ordening aandag gee. Dit is baie sinvol, aangesien leerders daarmee gekonfronteer gaan word tydens die naslaanproses in 'n woordeboek.

Die tweede aktiwiteit is ook uniek in vergelyking met ander werkboeke, aangesien dit oor alfabetiese ordening van samestellings handel. Leerders word versoek om 'n trefwoord in die woordeboek na te slaan en na die vertalings van 31 samestellings waarin die woord voorkom, te soek. Nadat aan hulle gedemonstreer is hoe die proses van alfabetiese ordening van samestellings werk, word hulle versoek om die nodige samestellings met 'n trefwoord in die korrekte plek in 'n woordeboekartikel in te vul. Dit is 'n oefening wat hoërordedenke verg en 'n voorbeeld van 'n baie goeie aktiwiteit vir leerders om die alfabetiseringsbeginsel van samestellings te begryp.

HATS verskaf twee aktiwiteite rakende alfabetisering. In die eerste aktiwiteit moet woorde soos kuns, golf, pas, diep en optel alfabeties rangskik word en in die tweede aktwiteit moet woorde wat met dieselfde alfabetletter begin, gealfabetiseer word. Die grootste uitdaging vir leerders is om woorde waarvan die eerste vyf letters identies is, bv. trompie en trompet, te rangskik. Bogenoemde aktiwiteite bied egter nie veel uitdaging aan 'n hoërskoolleerder nie, aangesien 
alfabetiese ordening ' $n$ vaardigheid is wat reeds in die laerskool, en spesifiek in die Grondslagfase, bemeester moet word.

\subsection{Operasionele funksie}

Die operasionele funksie van woordeboeke verwys na die funksie om leerders woordeboekvaardighede aan te leer vir die gebruik van 'n woordeboek ten einde inligting suksesvol te ontsluit. Aktiwiteite in werkboeke wat daarop gemik is om aan die gebruiker hulp te verskaf om die toegangstruktuur van woordeboeke te begryp, sluit in verwysings na gidswoorde, inhoudsopgawe en gebruikerstoeligting. Dié funksie word deur al die werkboeke as baie belangrik beskou, aangesien aktiwiteite daaroor in al die werkboeke voorkom.

Drie werkboeke, naamlik NWSG, HATS en OTSW, bevat aktiwiteite rakende gidswoorde. Die doel van gidswoorde, naamlik om die gebruiker te help om woorde vinniger op 'n bladsy te kry, word in OTSW verduidelik. Hier word 'n spesifieke woordeboekbladsy in die werkboek gewys en die gebruiker word sodoende baie goed bewus gemaak wat 'n gidswoord is en hoe dit in die woordeboek funksioneer. Gebruikers kry opdrag om gidswoorde te soek en dan die vertaling daarvan in Engels neer te skryf (d.w.s. 'n kommunikatiewe funksie). NWSG verwys spesifiek na die woordeboek en gee die opdrag om gidswoorde in die woordeboek na te slaan. Ander aktwiteite sluit 'n lysie woorde in en aanleerders moet besluit of die woorde tussen twee gegewe gidswoorde voorkom. Dit is 'n goeie aktiwiteit wat opgevolg word met 'n verdere aktiwiteit waar gidswoorde en alfabetiese ordening geïntegreer word. HATS verwys die gebruiker ook na die woordeboek om te kontroleer of sekere woorde op 'n lys binne gegewe gidswoorde val. Deurdat dit terselfdertyd kennis van alfabetiese ordening toets, is dit 'n sinvolle aktiwiteit.

Slegs OTSW verwys na die funksie van 'n inhoudsopgawe en verskaf ook 'n verduideliking daaroor. Leerders kry die geleentheid met behulp van vyf vrae om inligting in die inhoudsopgawe van die woordeboek op te soek. Dit is funksioneel om woordeboekgebruikers bewus te maak van die feit dat daar 'n inhoudsopgawe in 'n woordeboek kan wees.

NWSG verwys na die skematiese toeligtende aantekeninge in die woordeboek en aanleerders kan 'n aktiwiteit voltooi deur weggelate woorde daarvoor in te vul. Die weggelate woorde sluit begrippe in soos voorbeeldsin, definisie en trefwoord om dele van 'n woordeboekartikel te benoem.

OTSW verwys ook na 'n woordeboekartikel en vra vrae oor dele van die artikel met verwysing na trefwoorde, vertalings en voorbeeldsinne. Verdere aktiwiteite is daarop gerig om die leerder 'n woordeboekartikel te laat soeklees vir verskillende inskrywings om te verseker dat die leerder die artikel verstaan. Leerders word ook verwys na die gebruik van etikette, en in die aktiwiteit moet die korrekte etiket vir die doel van die inskrywings verskaf word.

PLS en PLA bevat beide 'n skematiese voorstelling van woordeboekartikels, asook 'n breedvoerige verduideliking van leksikografiese terme. Dit is 
nuttige inligting wat die gebruiker nie net help om terme aan te leer nie, maar ook om die tipes inligting wat in die woordeboeke aangebied word, te ontsluit. Daar word na terme soos trefwoord en etiket verwys en 'n benoeming van tipiese punktuasie wat in woordeboeke gebruik word, byvoorbeeld die tilde en skuinsstreep, vind plaas.

$\mathrm{Al}$ die werkboeke wat ondersoek is, verwys na leksikografiese terme soos trefwoord, gidswoord, inskrywing, etiket, kruisverwysing en voorbeeldsin. Ongelukkig word daar terminologie gebruik wat met toepasliker terme vervang kan word. Werkboeke kan eerder verwys na lemma in plaas van trefwoord, na artikel eerder as inskrywing, en na ingevoegde tekste eerder as notas. Die verwysing na leksikografiese terme is 'n gebruikersgesentreerde funksie om die woordeboekgebruiker toe te rus om leksikografiese verskynsels te benoem, te leer ken en te gebruik tydens woordeboekkonsultasie. Dit kan die gebruiker help om sogenaamd "woordeboekgeletterd" te word.

\subsection{Kognitiewe funksie}

Die kognitiewe funksie van woordeboeke verwys na data oor taal en sluit onder andere inligting oor spelling, leestekens, uitspraak, woordsoorte, woordvorme, asook semantiese inligting in. In hierdie afdeling word inligtingstipes slegs bespreek indien drie werkboeke daarna verwys.

HATS, OTSW en PLS bevat aktiwiteite rakende spelling van woorde. In HATS is drie aktiwiteite wat ten doel het om leerders korrek te leer spel en hulle te leer hoe om 'n woordeboek te gebruik om spelling te kontroleer. In 'n oefening word leerders gevra om 'n ontbrekende letter te verskaf ten einde 'n woord korrek te spel, byvoorbeeld in die geval van *onmiddelik waar die letter $l$ ingevoeg moet word. In 'n volgende aktiwiteit word leerders daarvan bewus gemaak dat woorde in die meervouds- of in die verkleiningsvorm verbuig, d.w.s. die spelling daarvan verander. 'n Derde aktiwiteit is ook baie kreatief opgestel waar leerders moet leer dat letters dikwels dieselfde kan klink, maar nie noodwendig korrek gespel word nie, bv. *vrons teenoor frons.

OTSW bevat twee redigeeraktiwiteite waar leerders spelling en leestekens kan korrigeer. Hulle word ook na die afdeling oor leestekens en spelreëls in die woordeboek verwys. Die redigeeraktiwiteite bevat tipiese foute wat deur Engelssprekendes in Afrikaans gemaak word, byvoorbeeld die verdubbeling van letters wat in 'n lang klank soos in *heele voorkom. Dit is nie vanselfsprekend dat leerders die antwoorde van die aktiwiteite sonder leiding sal vind nie en dit is nie geskik vir aanleerders van 'n taal nie. Dit geld ook 'n derde aktiwiteit, naamlik 'n keuse van twee woorde wat dikwels verwar en verkeerd gespel word en wat korrek in 'n sin gebruik moet word, bv. ly en lui.

PLS verwys na Engelse woorde wat dikwels verwar word, bv. retch en wretch. Leerders moet eerstens die woorde se spelling en betekenis in die woordeboek naslaan en dan die korrekte woord gebruik om 'n gegewe sin te voltooi. Met behulp van dié aktiwiteit vind naslaanwerk in die woordeboek plaas. So 
word leerders se kognitiewe vaardighede gestimuleer om die verskil tussen die betrokke woorde se spelling en betekenis te onthou.

Inligting in verband met woordsoorte verwys na sintaktiese of grammatikale inligting oor woorde. NWSG, HATS en PLA beskik oor aktiwiteite waarin woordsoorte bepaal kan word. NWSG begin elke aktiwiteit met 'n begripsverklaring en 'n voorbeeld uit die woordeboek. Dit is didakties baie goed, aangesien dit aan die aanleerder gedemonstreer word. NWSG verwys na die manier waarop woordsoorte in die woordeboek aangedui word, voorbeelde van woordsoorte word verskaf en aanleerders word gevra om definisies van sekere woordsoorte na te slaan. As aktiwiteit word van aanleerders verwag om woordsoorte van losstaande woorde in die woordeboek na te slaan en neer te skryf. Woorde word in isolasie verskaf en die funksie van die woord word ongelukkig nie in 'n sin gedemonstreer nie.

HATS beskik oor drie aktiwiteite rakende woordsoorte. Leerders kry opdrag om die woordsoorte van sekere woorde te identifiseer en daarna in 'n woordeboek na te slaan en te kontroleer of dit korrek is. Tydens 'n tweede aktiwiteit word leerders daarvan bewus gemaak dat 'n woord tot meer as een woordsoort kan behoort en leerders moet die woordsoortgroepe aandui voordat dit in 'n woordeboek nageslaan word. As 'n derde aktiwiteit word sinne verskaf en 'n geïdentifiseerde woord se woordsoort moet benoem word. Dié metode verteenwoordig die korrekte didaktiese hanteringswyse van woorde se grammatikale funksie, aangesien woorde nooit in isolasie beoordeel kan word nie, maar altyd as deel van 'n sin waarin die woord se grammatikale funksie duidelik blyk.

PLA se hantering van woordsoorte vereis meer kognitiewe vaardighede van die aanleerder. Byvoeglike naamwoorde is in 'n rooster versteek en aanleerders moet hulle eerstens identifiseer en dan in die woordeboek kontroleer of hulle wel byvoeglike naamwoorde is. Daarna moet die woorde alfabeties gerangskik word. Die grammatikale funksie van byvoeglike naamwoorde word ongelukkig nie aan aanleerders geillustreer nie en die aktiwiteite bly slegs oefeninge in naslaanvaardighede en alfabetisering.

Woordvorming verwys na meervoude, verkleinwoorde, verledetydsvorme, attributiewe vorme en trappe van vergelyking. NWSG illustreer die woordeboek se hantering van meervoude en verkleinwoorde deur na 'n artikel in die woordeboek te verwys. In die aktiwiteit moet aanleerders die meervouds- en verkleiningsvorm van woorde naslaan en dit neerskryf. Daar is ook 'n aktiwiteit waar meervouds- en verkleiningsvorme verskaf moet word en aanleerders die korrekte agtervoegsel by 'n woord moet voeg. Die werkboek bevat 'n oefening oor trappe van vergelyking waar leerders die antwoorde in die woordeboek moet naslaan en HATS bevat aktiwiteite waar al bogenoemde woordvorme gevind kan word. Leerders word gevra om byvoorbeeld meervouds- en verkleiningsvorme in te vul.

OTSW bevat 'n gekombineerde aktiwiteit waar aanleerders die meervouds- en verkleiningsvorm van dieselfde woord moet gee. 'n Oefening oor 
trappe van vergelyking is voorsien waar aanleerders die vergrotende en oortreffende trappe in die woordeboek moet naslaan en dan moet gebruik om sinne te voltooi. Daar is verder 'n aktiwiteit oor deeltjiewerkwoorde, wat dikwels problematies is vir aanleerders van Afrikaans. Aanleerders word versoek om deeltjiewerkwoorde ook na die verlede tyd te verander.

Inligting oor die semantiese waarde of betekenis van woorde sluit in inligting in verband met illustrasies, definisies, homonimiese vorme, polisemiese onderskeidinge, sinonimiese en antonimiese betrekkinge, asook voorbeeldsinne. Alhoewel HAT Skoolwoordeboek en Oxford Skoolwoordeboek beide illustrasies in die woordeboek gebruik, is dit slegs NWSG wat enige verwysing na die gebruik van illustrasies bevat. Leerders word sodoende bewus gemaak van die betekeniswaarde wat illustrasies kan inhou.

Inligting oor die semantiese inhoud van woorde is baie belangrik vir die woordeboekgebruiker, maar slegs twee werkboeke, naamlik NWSG en HATS, bevat inligting oor die leerder se verstaan van die definisie van 'n woord. NWSG bevat sewe aktiwiteite en HATS twee oor die verstaan van definisies. Die begrip van polisemiese onderskeidinge blyk die belangrikste begrippe ten opsigte van semantiese inhoud vir die opstellers van die werkboeke te wees, aangesien drie werkboeke aktiwiteite daaroor bevat. NWSG, HATS en OTSW bevat aktiwiteite rakende polisemiese onderskeidinge van woorde. NWSG verduidelik dat woorde meer as een betekenis kan hê en dat dit met behulp van syfers in die woordeboek aangedui word. Woorde met polisemiese onderskeidinge word in verskillende sinne gebruik en leerders moet dit in die woordeboek naslaan om te besluit watter Engelse vertaling die beste by die betekenisonderskeiding pas. Dit is ' $n$ uitdagende oefening, maar met behulp van die woordeboek sal leerders die korrekte antwoorde bekom.

HATS verduidelik dat woorde meer as een betekenis kan hê en dan word leerders gevra om die aantal betekenisse van sekere woorde te verskaf nadat die woorde in die woordeboek nageslaan is. OTS bevat slegs een vraag rakende polisemiese onderskeidinge en leerders moet verskillende betekenisse van 'n woord uit 'n gegewe woordeboekartikel neerskryf.

Sinonimie word slegs deur twee werkboeke, naamlik NWSG en PLS behandel. Soos deurgaans die geval in die werkboek, verskaf NWSG eers 'n verklaring van die betrokke begrip en dan word 'n woordeboekartikel gebruik om die voorkoms van sinonimie in die artikel te illustreer. As opdrag moet aanleerders die sinonieme van sekere woorde naslaan en neerskryf. NWSG is die enigste werkboek wat die gebruik van antonieme en voorbeeldsinne illustreer deur aktiwiteite daaroor te verskaf. PLS verduidelik ook wat die begrip sinonimie behels en verskaf ' $n$ lys van 24 woorde waarvan leerders die sinonieme moet neerskryf. Die woordeboek kan gebruik word om antwoorde te kontroleer.

HATS bespreek die onderskeid tussen homofone en homonieme, asook die verskil tussen formele en informele, en letterlike en figuurlike taalgebruik. In die algemeen word die hantering van semantiese inhoud in die werkboeke 
afgeskeep en beter hantering daarvan sou kon verseker dat leerders en aanleerders die maksimum inligtingsoordrag uit die woordeboeke kan bekom.

\subsection{Kommunikatiewe funksie}

Die kommunikatiewe funksie van woordeboeke verwys onder andere na vertaling van tekste uit die moedertaal na die vreemde taal en omgekeerd. Slegs OTSW en PLA bevat kommunikatiefgerigte aktiwiteite. OTSW bevat twee oefeninge in vertaling waar leerders sinne moet vertaal. Dit is kort sinne en leerders word die instruksie gegee om sleutelwoorde in die woordeboek na te slaan. Vir 'n oefening in redigering word 'n paragraaf met spelfoute verskaf en leerders word versoek om dit te redigeer. Op die agterblad van die werkboek word die aanname gemaak dat die werkboek leerders sal help om die regte vertaling te kies. Dit is te betwyfel of dié doelwit bereik sal word, gesien in die lig van die weinig didaktiese leiding wat in terme van vertaling verskaf word.

PLA bevat ' $n$ aktiwiteit vir vertaling en redigering. Vir die vertaling word 'n teks (uittreksel uit 'n kortverhaal) verskaf met die opdrag om die woordeboek te gebruik om dit uit Afrikaans in Engels te vertaal. Geen leiding of wenke word verskaf hoe om 'n vertaling aan te pak of hoe om 'n woordeboek as hulpmiddel daarvoor te gebruik nie. Vir die aktiwiteit in redigering word ' $n$ teks gegee met die mededeling dat daarin "48 spel- en leestekenfoute" is, en aanleerders word versoek om dit te korrigeer. Dit kan opvoedkundig sinvol wees indien dit met behulp van 'n onderwyser se leiding aangepak word.

OTSW en PLS verleen hulp met teksproduksie in die moeder- en vreemde taal met behulp van aktiwiteite oor die skryf van briewe en informele kommunikasie. OTSW help met die skryf van briewe, e-posse en sms'e met behulp van bondige oefeninge. PLS beskik oor 'n hele afdeling oor hoe om formele en informele briewe te skryf, asook hoe om 'n projek saam te stel. In die subafdeling van formele briewe word daar voorbeelde van briewe verskaf, met verduidelikende kantaantekeninge daarby om leiding aan die leerder te gee. Kriteria waarvolgens briewe geassesseer word, word verskaf wat baie nuttige inligting vir die gebruiker is. Goeie didaktiese leiding word sodoende gegee.

Tabel 1: Skematiese vergelyking van die inhoud van werkboeke na aanleiding van woordeboekfunksies

\begin{tabular}{|l|l|l|l|l|l|}
\hline & NWSG & HATS & OTSW & PLS & PLA \\
\hline Woordeboekfunksie & & & & & \\
\hline Alfabetisering & 3 & 2 & 2 & 2 & 2 \\
\hline Operasionele funksies & & & & & \\
\hline 1 Gidswoorde & 1 & 1 & 1 & & \\
\hline 2 Inhoudsopgawe & & & 1 & & \\
\hline Verduideliking van woordeboekartikel & 1 & & 3 & 1 & 1 \\
\hline
\end{tabular}




\begin{tabular}{|l|l|l|l|l|l|}
\hline & NWSG & HATS & OTSW & PLS & PLA \\
\hline Kognitiewe funksies & & & & & \\
\hline 1 Spelling & & 3 & 1 & 1 & \\
\hline 2 Leestekens & & & 1 & & \\
\hline 3 Uitspraak (klem) & 1 & & & & \\
\hline $\begin{array}{c}\text { 4 Grammatikale inligting (woord- } \\
\text { soorte) }\end{array}$ & 1 & 3 & & & 3 \\
\hline 5 Morfologiese inligting & & & & & \\
\hline a meervoude & 2 & 1 & & & \\
\hline b verkleinwoorde & 2 & 1 & 1 & & \\
\hline c verledetydsvorme & 2 & 1 & 1 & & \\
\hline d attributiewe vorme & & 1 & & & \\
\hline e intensiewe vorme & & 1 & & & \\
\hline f trappe van vergelyking & 2 & 1 & 1 & & \\
\hline g voor- en agtervoegsels & & & 3 & & \\
\hline Semantiese inligting & & & & & \\
\hline 1 Visuele inligting (illustrasies) & 2 & & & & \\
\hline 2 Definisies (semantiese inligting) & 7 & 1 & & & \\
\hline 3 Homonieme & 1 & 1 & & & \\
\hline 4 Polisemiese onderskeidinge & 1 & 1 & 1 & & \\
\hline 5 Sinonieme & 2 & & & 1 & \\
\hline 6 Voorbeeldsinne (sintaktiese inlig- \\
ting) & 2 & & & & \\
\hline 7 Antonieme & 2 & & & & \\
\hline 8 Homofone & & 1 & & & \\
\hline Kommunikatiewe funksies & & & & & \\
\hline 1 Vertalings & & & & & \\
\hline 2 Redigering & & & & 1 & \\
\hline Formele en informele kommunikasie & & & & & \\
\hline Samestelling van 'n projek & & & & & \\
\hline
\end{tabular}

\section{Slot}

In hierdie artikel is die teikengebruikers van werkboeke bepaal met behulp van omskrywings deur die betrokke werkboeke, asook die inhoud van die werkboeke. ' $n$ Bespreking van die gepastheid al dan nie van die inhoud na aanleiding van die betrokke teikengebruiker is gedoen.

'n Nuwer indeling vir die inhoud van werkboeke, naamlik 'n indeling volgens die funksieteorie, word voorgestel. Dit is duidelik uit die skematiese vergelyking dat die inhoudstemas van werkboeke oorvleuel, byvoorbeeld betreffende die operasionele funksie. Vergelyk die klem wat op alfabetisering gelê word, gidswoorde, asook die verduideliking van woordeboekartikels. By die kognitiewe funksie is daar oorvleueling ten opsigte van spelling, gramma- 
tikale inligting, morfologiese inligting, asook semantiese inligting. Wat betref die kommunikatiewe funksie bestaan daar oorvleueling ten opsigte van vertaling en formele teenoor informele kommunikasie. Dit is dus funksies wat as belangrik beskou word deur werkboekopstellers en aandag moet geniet in die opstel van nuwe werkboeke.

\section{Bibliografie}

Du Plessis, M. 1998. Tweetalige Aanleerderswoordeboek/Bilingual Learner's Dictionary AfrikaansEngels/English-Afrikaans. Kaapstad: Pharos Woordeboeke.

Gouws, R.H. 2001. Lexicographic Training: Approaches and Topics. Emejulu, J.D. (Red.). 2001. Éléments de Lexicographie Gabonaise, Tome I: 58-94. New York: Jimacs-Hillmann Publishers.

Gouws, R.H. 2006. Leerdergedrewe leksikografie. Tydskrif vir Taalonderrig 40(1): 72-84.

Gouws, R.H. en D.J. Prinsloo. 2005. Principles and Practice of South African Lexicography. Stellenbosch: SUN PReSS.

Gouws, R.H., M. Stark en L. Gouws. 2004. Nuwe Woordeboek sonder grense. Kaapstad: Maskew Miller Longman.

Gouws, R.H. en S. Tarp. 2008. A New Step Forward for South African Learners' Lexicography: The Oxford Afrikaans-Engels/English-Afrikaans Skoolwoordeboek/School Dictionary. Tydskrif vir Taalonderrig 42(1): 65-79.

Gouws, S. en M. Lätti. 2005. Nuwe Woordeboek sonder grense Werkboek, Senior fase Graad 7-9. Kaapstad: Maskew Miller Longman.

HAT Aktiwiteite en Speletjies. 2010. Kaapstad: Pearson Education S.A. Ook aanlyn beskikbaar op http://www.longman-hat.co.za.

Kromhout, J. 2004. Skoolwoordeboek Afrikaans-Engels/School Dictionary English-Afrikaans. Kaapstad: Pharos Woordeboeke.

Louw, P. (Red.). 2007. Oxford Afrikaans-Engels/English-Afrikaans Skoolwoordeboek/School Dictionary. Kaapstad: Oxford University Press, South Africa.

Luther, J. 2009. HAT Afrikaanse Skoolwoordeboek. Kaapstad: Maskew Miller Longman.

Paizee, D. en M.L. Kriel. 2006. Oxford Tweetalige Skoolwoordeboek Werkboek. Kaapstad: Oxford University Press.

Smith-Müller, W. 2006. Pharos Leerderboek by die Aanleerderswoordeboek. Kaapstad: Pharos Woordeboeke.

Smith-Müller, W. 2007. Pharos Leerderboek by die Skoolwoordeboek. Kaapstad: Pharos Woordeboeke.

Stark, M.P. 1990. Dictionary Workbooks: A Critical Evaluation of Dictionary Workbooks for the Foreign Language Learner. Exeter: University of Exeter Press.

Tarp, S. 2008. The Third Leg of Two-legged Lexicography. Hermes. Journal of Linguistics 40: 117-131.

Tarp, S. en R.H. Gouws. 2010. Skoolwoordeboeke vir huistaalleerders van Afrikaans. Lexikos 20: 466-494. 


\section{Magister- en doktorale studente van / Master's and Doctoral Students of Rufus H. Gouws 1986 tot / to 2012}

Magisterstudente / Master's Students

1986

De Klerk (tans Otto), Anna Nel

Die Afrikaanse arbeiderstaal van die Richmond-omgewing

1989

Van Niekerk (tans Cloete), Aletta Elizabeth

Die leksikografiese hantering van komposita

1990

Fouché (tans Van der Merwe), Michele

' $n$ Evaluering van die semantiese inligting in die Verklarende Handwoordeboek van die Afrikaanse Taal

1992

Rademeyer, Liza

Die funksies van verbale voorbeeldmateriaal in eentalige woordeboeke

Trautmann, Christelle

Ekwivalensieverhoudinge in Afrikaanse vertalende woordeboeke

Vos, Ina Louise

Semantiese norme in Afrikaanse verklarende woordeboeke

1994

Harteveld, Pieter

Die invloed van rekenarisering op die leksikografiese praktyk in die Buro van die WAT

1995

Beuke (tans Beuke-Muir), Christina Maria

Aspekte van die leksikografiese hantering van variante met spesifieke verwysing na Namibiese Afrikaans 


\section{Beyer, Herman Louis}

Die leksikografiese hantering van morfologies gemerkte geslagsopposisiepare in Afrikaanse woordeboeke, met spesifieke verwysing na die Verklarende Handwoordeboek van die Afrikaanse Taal

1996

\section{Mallo, Anna Margaretha}

Die hantering van leksikale gapings in Afrikaanse vertalende woordeboeke

1997

\section{De Wet, Gertruida}

Die opname en bewerking van subleksikale lemmas in Afrikaanse vertalende woordeboeke

\section{Hill, Branwell Rohan}

Die hantering van polisemie (en die oorvleueling daarvan met homonimie) in die verklarende handwoordeboeke van die Afrikaanse taal en die Verklarende Afrikaanse Woordeboek

\section{Louw, Phillipus Adriaan}

Kriteria vir ' $n$ standaard vertalende woordeboek

\section{Muller, Laurentius}

Kommunikatiewe ekwivalensie in Afrikaanse verklarende woordeboeke met spesifieke verwysing na Groot Woordeboek/Major Dictionary

\section{8}

\section{Schoonheim, Frederike}

Een studie naar aspecten van de invloed van de Nederlandse lexicografie op Afrikaanse woordenboeken

2000

\section{Brand, Johanna Elizabeth}

Lexicographic Inconsistency in the Central List of Major Dictionary/Groot Woordeboek

2001

\section{Mphahlele, Motlokwe Clifford}

A Model to Achieve Communicative Equivalence in Translation Dictionaries

Stark (tans Steyn), Mariza

Die toegangstuktuur in verklarende aanleerderwoordeboeke

2002

\section{Müller, Annake}

Divergensie as ekwivalentverhouding: 'n Vergelykende studie tussen Tweetalige Woordeboek/Bilingual Dictionary en Groot Woordeboek/Major Dictionary 
2003

Hendriks, Karen

The Treatment of Culture-bound Lexical Items in Bilingual Dictionaries Intended for a Multilingual Environment

Keyser, Helane

Ondersoek na ' $n$ model vir die opleiding van leksikograwe vir verklarende woordeboeke

2006

Gouws (tans Potgieter), Liezl

Die bewerking van idiome in tweetalige woordeboeke: ' $n$ Hulp vir vertalers?

Mongwe, Mkomati John

The Role of the South African National Lexicography Units in the Planning and Compilation of Multifunctional Bilingual Dictionaries

2008

Nkomo, Dion

Towards a Theoretical Model for LSP Lexicography in Ndebele with Special Reference to a Dictionary of Linguistic and Literary Terms

2009

\section{Hiles (now Morris), Lorna}

Examples in South African School Dictionaries: From Theory to Practice

2012

Simpson, Gerda

Taalkundige en leksikografiese perspektief op troeteltaal in Afrikaans 


\section{Doktorale studente / Doctoral Students}

1989

Otto, Anna Nel

Kriteria vir ' $n$ Afrikaanse aanleerderwoordeboek

1990

Lombard, Frederik Johannes

' $n$ Metaleksikografiese fundering van Afrikaanse skoolwoordeboeke

1996

\section{Smit, Maria}

Wiegand's Metalexicography as a Framework for a Multilingual, Multicultural, Explanatory Music Education Dictionary for South Africa

1998

Bosman, Hendrina Johanna

Die meerwoordige leksikale item in Afrikaans

1999

Fouché-Van der Merwe, Michele

Gebruikersperspektief in die Afrikaanse leksikografie

2000

Mavoungou, Paul Achille

Metalexicographical Criteria for the Compilation of a Trilingual Dictionary: YilumbuEnglish-French

2003

\section{Botha, Willem Frederik}

Die impak van die leksikografieteorie op die samestelling van die Woordeboek van die Afrikaanse Taal

2004

Afane Otsaga, Thierry

The Standard Translation Dictionary as an Instrument in the Standardization of Fang Louw, Phillipus Adriaan

Criteria for a Multifunctional, Monolingual Dictionary in Junior Secondary Education

2006

Beyer, Herman Louis

' $n$ Metaleksikografiese ondersoek na kontekstualisering in Afrikaanse vertalende woordeboeke 
Mabika Mbokou (now Mbindi), Ludwine

A Model for the Macro- and Microstructure of a Yipunu-French School Dictionary

Mihindou, Guy-Roger

A Theoretical Model for a Yipunu-English-French Explanatory Dictionary of Medical Terms

Nyangone Assam, Blanche

Dictionaries as Teaching Instruments for Mother-tongue Education: The Case of Fang in Gabon

2007

Ekwa Ebanéga, Guy-Modeste

A Microstructural Programme for Dictionaries in Fang

Ella, Edgard Maillard

A Theoretical Model for a Fang-French-English Specialized Multi-volume School Dictionary

Tomba Moussavou (now Ekwa Ebanéga), Fatima

Metalexicographic Criteria for a Monolingual Descriptive Dictionary Presenting the Standard Variety of Yipunu

2010

\section{Saphou-Bivigat, Gilles}

A Theoretical Model for an Encyclopaedic Dictionary for the Gabonese Languages with Reference to Yilumbu

\section{Soami, Léandre Serge}

Towards the Development and Application of Representative Lexicographic Corpora for the Gabonese Languages

\section{1}

\section{Potgieter, Liezl}

Die ontwerp van vertalende vakwoordeboeke met vertalers as teikengebruikers: 'n Teoretiese model

2012

\section{Nkomo, Dion}

Towards a Lexicographical Intervention in the Acquisition and Use of English in Zimbabwe 